\title{
AGILITY and RESILIENCE: \\ THE ADAPTIVE CAPACITY OF \\ FRIENDS OF THE EARTH INTERNATIONAL \\ AND GREENPEACE
}

by

VANESSA TIMMER

B.A.H., Queen's University, 1996

M.Sc., Oxford University, 1997

A THESIS SUBMITTED IN PARTIAL FULFILLMENT OF

THE REQUIREMENTS FOR THE DEGREE OF

DOCTOR OF PHILOSOPHY

in

THE FACULTY OF GRADUATE STUDIES

(Resource Management and Environmental Studies)

THE UNIVERSITY OF BRITISH COLUMBIA

February 2007

(C) Vanessa Timmer, 2007 


\begin{abstract}
As environmental issues, politics and economic activity have become increasingly global in character, transnational social movement organizations (TSMOs) have emerged to exert their influence on decision-making across scales and to catalyze social change towards a sustainable future. The underlying assumption of this dissertation is that TSMOs face complex and dynamic internal and external pressures, which test their organizational viability over time. In order to maintain their viability, TSMOs have to build adaptive capacity, the ability to repeatedly and reliably develop strategic responses to change. I challenge the emerging consensus in the social movement and organizational literatures that a decentralized and informal structure provides an adaptive advantage for TSMOs. Instead, I propose that different structural configurations can result in distinct and equally viable approaches to building adaptive capacity.

I focus on two TSMOs, Friends of the Earth International (FoEI) and Greenpeace. Whereas FoEI has a decentralized and informal structure, Greenpeace has a relatively more centralized and formalized structure. However, FoEI and Greenpeace both exhibit organizational viability based on evidence including their income level and membership. Therefore, I assume that FoEI and Greenpeace have built adaptive capacity, which can be analyzed by exploring their typical strategic responses to four key organizational challenges: 1) tactical innovation, the challenge of creatively adjusting tactics to disrupt the status quo; 2) managing external relations, the challenge of partnering with other actors or remaining independent; 3 ) organizational maintenance, the challenge of securing resources in order to survive; and 4) managing internal relations, the challenge of resolving internal conflict.
\end{abstract}

FoEI, as a 'global grassroots movement,' continuously expands its tactical repertoire; develops collaborative partnerships; depends on a mass voluntary base; and resolves conflict through participatory dialogue; which I label the Agility Model of building adaptive capacity. In contrast, Greenpeace, as a 'global campaigning organization,' specializes in high profile, nonviolent, direct action tactics; predominately operates independently; secures financial support; and resolves conflict through managing for coherence; which I label the Resilience Model. I analyze these models, and conclude that FoEI and Greenpeace are hybrid systems and that other unique adaptive capacity models at the organizational and movement levels are possible. 


\section{TABLE OF CONTENTS}

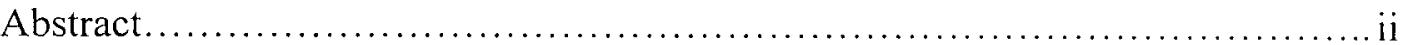

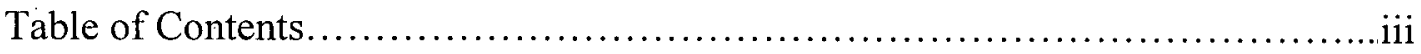

List of Tables.........................................................

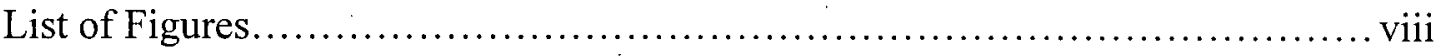

List of Abbreviations.......................................................

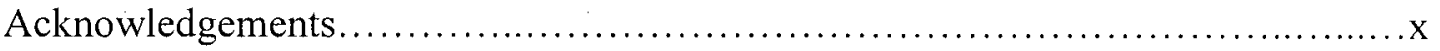

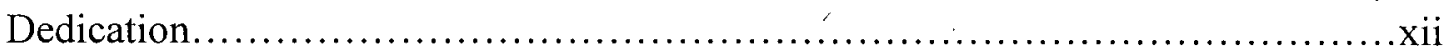

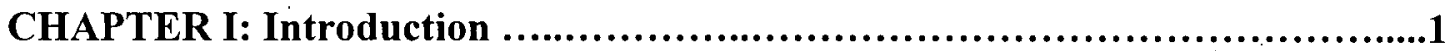

1.1 Overview of the Central Argument....................................... 1

1.2 Introduction to the Case Study Organizations...............................

1.2.1 Friends of the Earth International......................................

1.2 .2 Greenpeace................................................ 10

1.2.3 The Organizational Viability of FoEI and Greenpeace...............12

1.2.4 Similarities and Differences between FoEI and Greenpeace..........24

1.3 Social Movements and Organizational Theory................................ 26

1.4 Open Systems Perspective............................................. 30

1.5 Organizational Effectiveness, Output Goals and Support Goals..................35

1.6 Organizational Effectiveness in a Complex and Dynamic Environment........45

1.7 Research Methods..................................................... 51

1.8 Organization of the Thesis............................................ 56

CHAPTER II: TSMOs in a Complex, Dynamic Political Environment ..........58

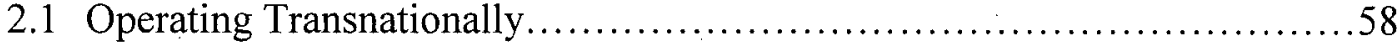

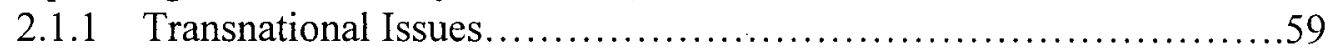

2.1.2 Transnational Organization Field................................60

2.1.3 Transnational Political Opportunity Structures.....................66 63

2.1.4 Transnational Social Movement Sector..............................65

2.2 Interpretive Frames..................................................... 70

2.3 Action Repertoires................................................. 76

2.4 Dynamics of Protest................................................. 86 


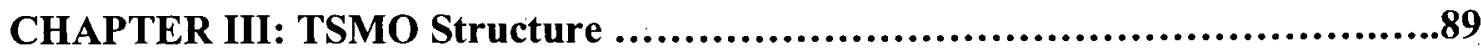

3.1 Resource Mobilization Theory and SMOs.....................................89

3.2 Organizational Structure .................................................... 90

3.3 Formalization and Centralization...........................................99

3.4 Organizational Structure of Friends of the Earth International..................97

3.4.1 FoEI Decision-Making Processes.................................. 100

3.4.2 FoEI Division of Labour. ............................................ 103

3.4.3 FoEI Membership............................................... 108

3.5 Organizational Structure of Greenpeace..................................111

3.5.1 Greenpeace Decision-Making Processes...........................113

3.5.2 Greenpeace Division of Labour...................................118

3.5.3 Greenpeace Membership........................................ 122

3.6 Transnational Organizational Forms...................................... 124

CHAPTER IV: Adaptive Capacity .............................................132

4.1 The Transformation of Social Movement Organizations.......................132

4.2 Structure and Adaptability.................................................. 139

4.3 Organizational Challenges and Strategic Dilemmas.......................... 146

4.3.1 Tactical Innovation................................................ 155

4.3.2 Managing External Relations.......................................157

4.3.3 Organizational Maintenance.......................................... 161

4.3.4 Managing Internal Relations ..................................... 165

4.4 Adaptive Capacity: Agility and Resilience.................................168

4.4.1 Organizational Change and Adaptation...............................172

4.4.2 Dynamics of Organizational Change in Agility and Resilience...........173

CHAPTER V: Tactical Innovation..............................................181

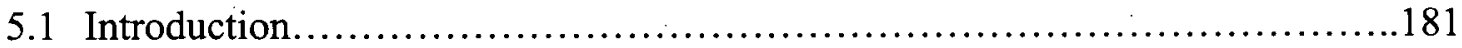

5.2 From Theory to Empirical Data......................................... 184

5.3 Tactical Innovation.................................................... 187

5.3.1 Short-term Campaign Episodes and Tactical Innovation.................190

5.3.2 Longer-term Campaign Strategies and Tactical Innovation...............194

5.3.3 Long-term Organizational Strategy and Tactical Innovation..............196

5.4 Working Globally: An Analytical Comparison of FoEI and Greenpeace.........199

5.4.1 Historical Overview of FoEI.....................................201

5.4.2 Historical Overview of Greenpeace..................................204

5.4.3 North-South Links and International Campaign Strategies.............207

5.4.4 Single, loud, global voice with National variation.....................218 
CHAPTER VI: FoEI and Tactical Expansion...................................224

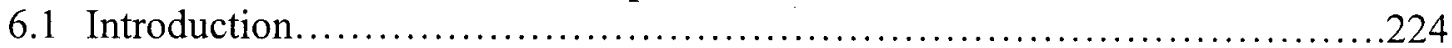

6.2 National Level Tactical Innovation.........................................229

6.3 FoEI International Activity in the 1970s and 1980s.........................232

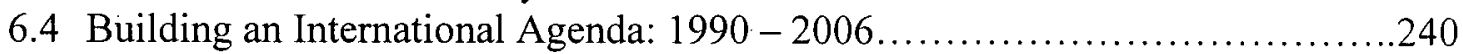

6.5 North-South Links and Social Justice........................................244

6.6 FoEI Member Groups, Social Sustainability, and the International Agenda....249

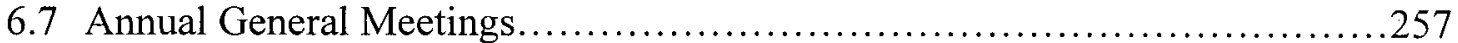

6.8 Global Grassroots Movement...........................................260

CHAPTER VII: Greenpeace and Tactical Specialization ........................265

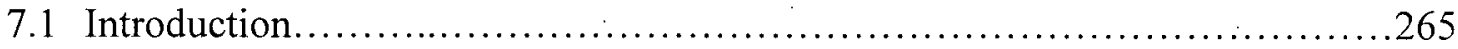

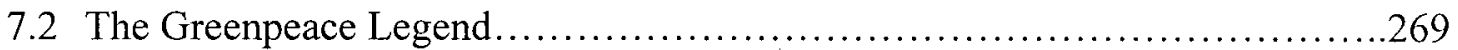

7.3 Direct Action as a Political Act of Resistance................................2271

7.4 Mindbombs, the Greenpeace Message and the Mass Media...................275

7.5 Quiet Diplomacy and Double Pincer Moves.................................2282

7.6 Greenpeace Science and Technological Innovations.........................28

7.7 North-South Tactics and Issues within Greenpeace........................290

7.8 One Greenpeace: Working Globally to Create an Ecological Sensibility.........296

CHAPTER VIII: External \& Internal Relations \& Organizational Maintenance..303

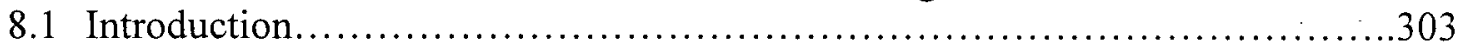

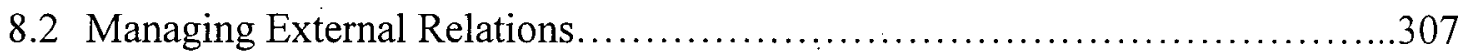

8.2.1 FoEI, Civil Society and Local and Indigenous Peoples...................309

8.2.2 Greenpeace, Civil Society and Local and Indigenous Peoples...........314

8.2.3 Managing Relations with Governments and Corporations...............321

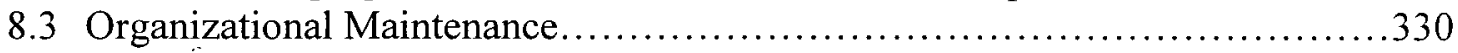

8.3.1 Radical Protest Organization or Conservative Interest Group............332

8.3.2 Connection with the Grassroots and Flexibility.........................338

8.4 Managing Internal Relations ............................................. 348

CHAPTER IX: Conclusion .............................................................357

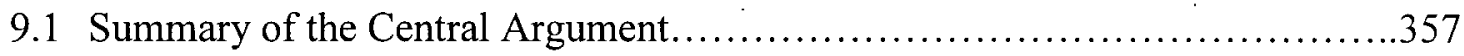

9.2 The Adaptive Capacity of FoEI and Greenpeace...............................359

9.3 TSMOs as Hybrid and Dynamic Open Systems...............................370

9.4 Implications for Theory and Recommendations for Further Research...........373

9.5 Adaptive Capacity and the Sustainability Transition..........................379

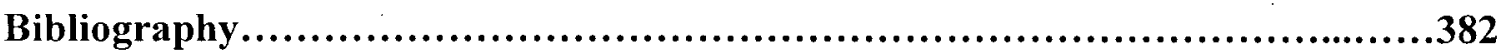

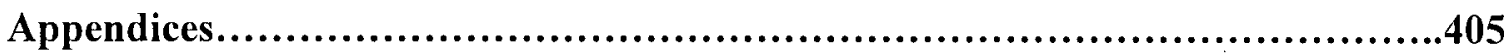

Appendix A: FoEI Campaigns................................................... 405

Appendix B: Greenpeace Campaigns.......................................... 424

Appendix C: The Evolution of FoEI Mission Statements................................439

Appendix D: FoEI and Greenpeace Empirical Data...............................443

Appendix E: List of Dissertation Related Publications and Presentations.............446

Appendix F: UBC Research Ethics Board's Certificates of Approval................447 


\section{LIST OF TABLES}

page

Table 1.1: Comparison between FoEI and Greenpeace International Income.

Table 1.2: Comparison between membership numbers in FoEI and Greenpeace.

Table 1.3: Number of FoEI National Member Groups as compared with Greenpeace National and Regional Offices.

Table 1.4: Comparable Campaigns in FoEI and Greenpeace.

Table 2.1: Growth and Issue Focus of Transnational Social Movement Organizations.......

Table 3.1: Friends of the Earth International Members and Year of Admission.

Table 3.2: Greenpeace National and Regional Offices and Year of Origin

Table 3.3: Comparison of FoEI and Greenpeace Structures.

Table 3.4: Organizational Structures of TSMOs.

Table 4.1: Summary of Challenges and Strategic Dilemmas.

$147-8$

Table 4.2: Comparison of two ideal type Adaptive Capacity models.....

Table 5.1: FoEI and Greenpeace Interviews Conducted for this Dissertation.

Table 5.2: Key Events in FoEI Evolution towards Working Globally

Table 5.3: Key Events in Greenpeace Evolution towards Working Globally.

Table 5.4: Comparison between FoEI and Greenpeace on international campaigns and North-South linkages.

Table 5.5: Comparison between FoEI and Greenpeace's Similar and Distinct International

Campaign Areas

Table 5.6: Comparison between FoEI and Greenpeace on national variations and single, loud, global voice.

Table 6.1: Select Events in Friends of the Earth International History

Table 6.2: Friends of the Earth International Annual General Meetings.

Table 7.1: Select Events in Greenpeace History.

Table 8.1: Overview of the Organizational Challenges

Table 8.2: FoEI and Greenpeace's Typical Strategic Responses to the Four 
Table 8.3: Comparison between FoEI and Greenpeace on Managing External Relations..... 309

Table 8.4: Comparison between FoEI and Greenpeace on Organizational Maintenance..... 331

Table 8.5: Comparison between FoEI and Greenpeace on Managing Internal Relations..... 348

Table 9.1: Comparison between the Strategic Responses of FoEI and Greenpeace......... 360

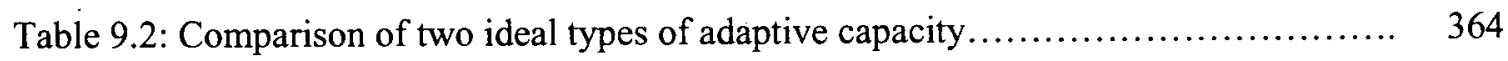




\section{LIST OF FIGURES}

Figure 1.1: Income of Friends of the Earth International Secretariat: $1990-2005$.

Figure 1.2: Comparison between income of FoEI Secretariat and Greenpeace

International: $1990-2005$.

Figure 1.3: Income of Greenpeace International: $1990-2005 \ldots \ldots \ldots \ldots \ldots \ldots \ldots \ldots \ldots \ldots \ldots$

Figure 1.4: Membership numbers for FoEI: 1990 - 2005........................ 17

Figure 1.5: Membership numbers for Greenpeace: $1990-2005 \ldots \ldots \ldots \ldots \ldots \ldots \ldots \ldots \ldots \ldots \ldots$

Figure 1.6: Comparison of FoEI National Member Groups and Greenpeace National and Regional Offices.

Figure 1.7: Media Profile of FoEI and Greenpeace in Major Papers.

Figure 1.8: Internet web access comparison between FoEI and Greenpeace.

Figure 1.9: Visitors to www.foei.org.

Figure 1.10: Output and Support Goals for Organizational Effectiveness.

Figure 1.11: Organizational Effectiveness and Adaptive Capacity. 50

Figure 1.12: Key Concepts within this Dissertation 56

Figure 2.1: Transnational Dimensions of the Environment. 58

Figure 2.2: Interpretive Frames and Action Repertoires. 70

Figure 3.1: TSMO Structure.. 90

Figure 4.1: Adaptive Capacity and Organizational Challenges ...

Figure 4.2: Patterns of Adaptation for Agility and Resilience.

Figure 5.1: Historical Evolution of Working Globally in FoEI and Greenpeace.

Figure 6.1: Reference Timeline for Chapter 6.

Figure 6.1: Reference Timeline for Chapter 7 268

Figure 8.1: Comparing the number of FoEI National Members and Greenpeace National and Regional offices over time. 


\section{LIST OF ABBREVIATIONS}

AGM

CEAT

FoEI

GMOs

IFIs

IUCN

IWC

MNC

NRO

SGC

SMO

TNC

TSMO

UN

UNCED

UNESCO

UNEP

WBCSD

WSSD

WTO

WWF
Annual General Meeting

Coordination Européanne des Amis de la Terre

Friends of the Earth International

Genetically modified organisms

International financial institutions

World Conservation Union

International Whaling Commission

Multi-national corporation

National and Regional Office (Greenpeace)

Stichting Greenpeace Council

Social movement organization

Transnational corporation

Transnational social movement organization

United Nations

United Nations Conference on Environment and Development

United Nations Economic and Social Commission

United Nations Environment Program

World Business Council on Sustainable Development

World Summit on Sustainable Development

World Trade Organization

World Wide Fund for Nature 


\section{ACKNOWLEDGEMENTS}

I am grateful for the financial grants I was fortunate to receive during my $\mathrm{PhD}$. This generous support was provided by the University of British Columbia's University Graduate Fellowship, Green College, the Canadian Forest Service Award, the Social Sciences and Humanities Research Doctoral Fellowship, the Canada-US Fulbright Award, Harvard University's Initiative on Science and Technology for Sustainability (ISTS), and the Packard Foundation. In addition to supporting my basic living costs, these grants enabled me to travel in order to conduct interviews and research at the central offices of Friends of the Earth International and Greenpeace in Amsterdam, The Netherlands; to conduct interviews and research during the preparatory meetings (New York) and the official conference (Johannesburg, South Africa) of the United Nations World Summit on Sustainable Development; and to attend scholarly, civil society and United Nations conferences. The Fulbright Award and funding from Harvard's ISTS and the Packard Foundation provided me with the opportunity to study at Harvard University (2002 2003). I was a Pre-doctoral Research Fellow with the ISTS at Harvard's Kennedy School of Government within the Belfer Center on Science and International Affairs and the Center for International Development.

I was privileged to be guided through the dissertation process by my committee members. Dr. Peter Nemetz, my supervisor, was an anchor of support from our first meeting, remained entirely available for meetings and feedback on drafts, and encouraged my intellectual journey. He has an incredible gift for clarity and, through our discussions and his impeccable and insightful editing, he greatly assisted my thinking and writing. Dr. Kathryn Harrison provided a thorough and interesting perspective, and enthusiastically offered support even in her busiest times. On more than one occasion, she distilled my argument into a coherent sequence, which formed the backbone for future drafts. 'Dr. Les Lavkulich generously welcomed me into the program, provided thoughtful guidance, and served as the inspiration for this dissertation research. Through our many lively and intellectually stimulating discussions, he introduced me to systems theory, had an unrelenting faith in my abilities, and persuaded me to chart my own intellectual path. Dr. Terre Satterfield has been a mentor, who provided excellent guidance based on her expertise in social science research. She motivated me to hone my analytical and qualitative skills, encouraged me to refine my academic rigor and delighted when I found my own voice.

In addition, I received welcome scholarly guidance from the late Dr. Ivan Head, who placed the emergence of global civil society in a historical context. Outside of UBC, I am grateful for insights and advice from Dr. Timothy O'Riordan from the University of East Anglia, and Dr. Calestous Juma, Dr. Bill Clark, Nancy Dickson, and Dr. Dave Brown at Harvard University. I look forward to the insights and feedback from my external examiner, university examiners and Chair. I would also like to acknowledge the support of the faculty, staff and students of the Institute for Resources, Environment and Sustainability at the University of British Columbia, particularly the cheerful and helpful assistance of Nancy Dick and Lisa Belanger. I have been fortunate to share my PhD years with an exciting group of student colleagues at UBC, Green College, the Santa Fe 
Complex Systems Summer School, Harvard University and Cambridge, and at international conferences. We shared our excitement of ideas and encouraged each other to pursue academic excellence. Thank you to Clive Goodinson for producing the Agility and Resilience diagram that underpins my research.

This dissertation would not have been possible without the generous time and contributions of staff and campaigners at Friends of the Earth International and Greenpeace. Ann Doherty and Mae Ocampo at the International Secretariat of Friends of the Earth International spent many hours with me, sharing their thoughts and enthusiasm about my research, as well as providing critical FoEI public documents. I am also indebted to Mike Childs, Kevin Dunion, John Hontelez, Tony Juniper, Daniel Mittler, Beatrice Olivastri, Meena Raman and Marijke Torfs for sharing their insights about the evolution of Friends of the Earth International. At Greenpeace, Omer Elaniem and Jenny Stunnard gladly arranged interviews, offered valuable internal and public Greenpeace documents, and provided their own insights about Greenpeace. I am thankful to Gerd Leipold, Brian Fitzgerald, Marcelo Furtado, Josselien Janssens, Michael M'Gonigle, T. Mohan, Rémi Parmentier, Steve Sawyer, Jenny Stannard, Guido Verbist, and Rex Weyler for speaking with me about the history and development of Greenpeace.

I want to thank my friends and family for their support, love and commitment. Particularly in the past three years, I have depended on their encouragement to lift my spirits and renew my energy. I feel blessed to have such wonderful friends to share laughter, ideas, dancing, singing, incredible adventures, music, debates, quiet contemplation, large-scale theatrical endeavours, CRTII interventions, road trips, intellectual journeys, admiration of animals (especially Cecil), improvised scenes, difficult times, heart-to-heart conversation, wacky banter, and real life experiences. To those I have known since childhood and to those who I feel like I have known since childhood, thank you.

I am grateful to my brother-in-law, Andrew, for offering continuous encouragement and cheering me onward. My sister, Dagmar, has been invaluable in her excitement and deep interest in my research, her incredible support in editing, and her belief in my abilities. My parents, Jan and Doeshka, have showed me the meaning of dedication and kindness by celebrating eureka moments and small achievements, sharing my joy and dismay, brainstorming theoretical ideas, providing everyday support and companionship, and being the source of my regeneration and adaptability. It is to my family that I dedicate this dissertation. 
This dissertation is dedicated

to Dagmar and Andrew, my sister and brother, who travel with me towards a sustainable future; and

to Doeshka and Jan, my parents, who taught me to see the beauty and mystery of our Earth 


\section{CHAPTER ONE: Introduction}

\subsection{Overview of the Central Argument}

The failure of national governments to adequately address global environmental problems, such as climate change and biological diversity loss, has stimulated the emergence of non-governmental actors as new prominent and critical players at the transnational level (Smith et al. 1997: xiii; Keck and Sikkink 1998: 1; Florini 2000:3; Clark 2003a: 3). With the support of modern communication technologies and affordable international transport, a number of nongovernmental actors have chosen to operate transnationally in order to multiply channels of access to international policy arenas, challenge environmentally harmful global economic activity, and catalyze social change towards a sustainable future. There remains considerable scholarly debate as to the legitimacy of nongovernmental actors in contributing to global problem-solving, or the actual impact that these actors have on government and corporate decisions and behavior (Florini 2000; Edwards 2001); however; there is little doubt that nongovernmental actors have organized across national borders in order to engage in international advocacy work (Clark 2003b). With this global focus, nongovernmental actors are faced with new challenges including determining the most effective organizational structure for advancing their goals over time within a transnational political environment.

Friends of the Earth International (FoEI) and Greenpeace are two of the largest and most prominent international environmental organizations. They have survived through a range of internal and external pressures and, as I will argue in Section 1.2.1 below, have remained viable over the three decades since their founding. This is a significant accomplishment given the shifting nature of their political environment, the complexity of their subject area, hostile confrontations with actors they target in their campaigns, and rising demands to prove their legitimacy. The political environment within which they operate can be considered complex and dynamic not least because FoEI and Greenpeace are actively working to influence and change this environment. Greenpeace and FoEI are social movement organizations (SMOs) which "are associations of people making idealistic and moralistic claims about how human personal or group life ought to be organized" (Lofland 1996: 3). SMOs seek to alter the status quo and to "change some 
element of the social structure or reward distribution, or both, of a society" (McCarthy and Zald 1977: 1218). Greenpeace and FoEI are also transnational social movement organizations (TSMOs). They are transnational because they organize across national boundaries to include participants from more than one country and engage in "global level contentious politics" (Smith 2005: 229).

This international focus and multi-country span results in "additional environmental and organizational complexity" (Ghoshal and Westney 2005: 5). As social movement organizations, Friends of the Earth International and Greenpeace respond to multiple "internal and external pressures that affect their viability, their internal structures and processes, and their ultimate success in attaining their goals" (Zald and Ash 1966: 327). External demands include the pressure to partner with other actors and to continuously innovate their tactics in order to maintain leverage over powerful societal actors such as governments, international organizations and corporations. In addition, TSMOs are faced with internal demands to satisfy organizational requirements such as securing resources for their survival and managing their cultural and political diversity as they expand into different countries.

Even though Friends of the Earth International and Greenpeace are subject to a range of similar pressures (see Chapter Two), they have developed different structural arrangements. Greenpeace has adopted a relatively more formalized and centralized organizational structure than FoEI (Rucht 1999; Clark 2003b: 4). This raises the question of whether there is "one best way" of organizing under complex and dynamic conditions. In a recent survey of changes in transnational social movement organization forms, Smith (2005: 247) provides a possible answer to this question. Smith writes that "over the past several decades, the form of transnational SMOs has become more decentralized and adaptive, indicating that these organizations are responding to a changing and uncertain global environment." According to Smith (2005: 236), a more decentralized and informal form "accelerates decision making and therefore adaptability of groups by decentralizing authority within the organization," and, "in a rapidly changing and uncertain political context, such flexibility is essential." In making this argument, Smith 
joins a broad literature focused on both social movement and business organizations that trace the rise of decentralized and informal organizational forms in response to complex and dynamic conditions (Fowler 2000; Anheier and Themudo 2001; Sklair 2001; Staber and Sydow 2002; Pal and Pantaleo 2005).

This literature adopts the following line of analysis: As organizations are subjected to increasingly complex and turbulent internal and external pressures, they adopt an internal organizational arrangement that is more decentralized and informal in order to respond to these conditions and to adapt to change. The structure of Friends of the Earth International aligns with this depiction of a decentralized, informal structure, but what does this mean for Greenpeace? Greenpeace is relatively more centralized and formalized, and yet it continues to survive within a complex and dynamic political environment.

This puzzle serves as the motivation for my dissertation.

\section{I seek to clarify the relationship between organizational structure and adaptability. I} propose that Greenpeace's more centralized and formalized structure is not simply an exception to the general trend of decentralized and informal structures but is in itself a viable way of organizing for adaptability. These structural configurations are tied to decision-making processes and strategy formation within TSMOs. For the purposes of this dissertation, I define organizational strategy as the pattern or plan developed by individuals within an organization to integrate the organization's goals, policies and activities in a cohesive whole (Mintzberg et al. 1998). I propose that adaptability can arise from some but not all combinations of structure and strategy.

I will argue in Section 1.2.1 below that Greenpeace has not only survived but has maintained organizational viability. Moreover, both FoEI and Greenpeace exhibit organizational viability. I measure organizational viability through empirical data including FoEI and Greenpeace's income levels, membership numbers, and media profile over time. The underlying assumption of this dissertation is that both Friends of the 
Earth International and Greenpeace are long-term successful organizations. The purpose of this dissertation is not to determine which organization secures long-term organizational viability more effectively by analyzing an objective measure of organizational viability. The purpose is rather to determine how these two organizations have remained viable within complex and dynamic conditions. Organizational viability serves as a surrogate measure for measuring the impact, or output effectiveness, of FoEI and Greenpeace as it indicates their continued capacity to have an impact rather than their actual impact. Organizational viability is not equal to success but is a precondition for success, and not all viable organizations are equally effective in terms of outcomes and impact. In addition, viable TSMOs do not necessarily follow a linear positive trajectory and experience periods of growth and decline and of more or less influence. Although organizational viability is a necessary but not sufficient measure of their effectiveness, I propose that an analysis of the organizational viability of FoEI and Greenpeace sheds light on their ability to advance their goals and adapt to change. Assuming that TSMOs play a critical role in the long-term challenge of managing global environmental change (Wapner 1996; Doherty 2002), I am interested in FoEI and Greenpeace's approach to maintaining their viability over time.

My central research question is: does the prevailing assumption hold that a decentralized and informal structure is the only way for transnational social movement organizations to maximize adaptability in complex and dynamic conditions? I define formalization as "the degree to which an SMO has an explicitly (e.g., written) scheme of organization - division of labor - that it strives to enact in its routine activities" (Lofland 1996: 142-3). Centralization refers to "the degree to which an SMO's activities are devised and directed by a well-identified SMO-wide leadership as opposed to activities originating and pursued by multiple, relatively independent SMO subgroupings" (Lofland 1996: 143). Analytically, these variables represent two dimensions of organizational structure - the level of centralization and the degree of formalization; empirically, they are often combined (Staggenborg1989; Gamson 1990; Lofland 1996). Chapter Three will explore the connections between centralization and formalization and the distinctions between them. I will analyze these two dimensions in 
parallel and compare the decentralized, informal structure of Friends of the Earth International with the relatively more centralized and formal structure of Greenpeace. In Chapter Nine, I discuss how these organizations are, in fact, hybrid systems which tend towards this characterization while also being more complex than this structural description suggests. I explore other possible structural combinations, including a decentralized and formalized structural configuration, that warrant further research.

Variations in formalization and centralization have traditionally been explained as related to a range of variables including the pursuit of organizational efficiency (McCarthy and Zald 1977), the institutionalization and conservatism of organizations (Van der Heijden 1997; Doherty 2002), and the level of commitment to organizational democracy (Rothschild-Whitt 1979; Rothschild and Whitt 1986). Building on these insights, I align with scholars who are interested in the influence of formalization and centralization on an organization's ability to adapt within complex and dynamic environments (e.g., Letts et al. 1999; Fowler 2000); however, I depart from the current trend of equating decentralized, informal organizational forms with adaptability. I argue that any organizational structure has both strengths and weaknesses. As Greenpeace demonstrates, centralized and more formalized organizational forms do not always fail to adapt to uncertain and turbulent conditions, and, in fact, can succeed where others fail. I aim to make a theoretical contribution in two ways: (1) by challenging the emerging scholarly consensus that decentralized, informal organizational structures are the only way of organizing to maximize adaptability in a complex and dynamic environment, and (2) by presenting two models of adaptability that are feasible within such an environment. These models represent extremes on a continuum. In my conclusion, I propose that other variations on these models, and other unique models, are possible; however in this dissertation, I focus on these two proposed models in order to explore the relationship between adaptability and structure.

For the purposes of this thesis, I define the ability of an organization to create a strategic response to internal and external change as an organization's adaptive capacity. The term "adaptive capacity" is used, in addition to adaptability, in order to highlight the fact 
that, over time, organizations elaborate and refine those strategic responses that are deemed to provide workable solutions to key organizational challenges. Individuals within an organization typically develop a pattern of adopting those strategic responses that reliably and repeatedly solve these challenges and support long-term organizational viability. This pattern becomes embedded in an organization's strategies and structures - often as a result of intentional choices by individuals within the organization - and subsequently, partially constrains future responses.

I propose that the viability of a transnational social movement organization and its adaptive capacity can be evaluated based on its ability to devise organization-wide strategic responses to four key organizational challenges: 1) tactical innovation: the challenge of creatively adjusting tactics and of devising new tactics in order to repeatedly respond to changing external conditions; 2) managing external relations: the challenge of negotiating partnerships with external actors; 3 ) organizational maintenance: the challenge of mobilizing resources in order to survive and remain viable; and 4) managing internal relations: the challenge of facilitating internal cohesion and managing internal conflict within the social movement organization. Although both Greenpeace and Friends of the Earth International are faced with similar organizational challenges, I aim to illustrate that they have adopted different and equally viable strategic responses to these challenges. I will explore how each strategic response represents both a workable solution to an organizational challenge and a strategic dilemma, as each response embodies strengths and deficiencies. Because of the advantages and disadvantages of each approach, I will also explore how campaigners within FoEI and Greenpeace, on occasion, step outside of these patterned responses to creatively respond to change and opportunistically adopt different approaches in order to advance their goals.

Grounded in the empirical analysis of Friends of the Earth International and Greenpeace as well as in a unique synthesis of the organizational literature, I propose two models of adaptive capacity: the Agility Model, defined as organizing for continuous adaptation; and the Resilience Model, defined as organizing for episodic adaptation. Adaptation is 
defined as organizational change. The models are inspired by the works of Miles and Snow (1978), Holling (1979), Lofland (1996), Mintzberg et al. (1998), Mintzberg and Quinn (1998), Weick and Quinn (1999), Letts et al. (1999), and Fowler (2000). As I will discuss in Chapter Four, the Agility Model is aligned with a decentralized and informal organizational structure, whereas the Resilience Model is tied to a relatively more centralized and formal structure. By presenting the existence and viability of a Resilience Model and by highlighting the disadvantages and deficiencies of the Agility Model, I challenge the scholarly consensus that TSMOs with a decentralized, informal structure are the only structural arrangement for maximizing adaptability in complex and dynamic conditions. Neither Agility nor Resilience exists in a pure form in reality, in part because of the internal organizational complexity of transnational social movement organizations; however, I construct these two models as "ideal types" that enable the classification of organizations along a continuum. I conclude by recommending further research on variations on these models and on other unique adaptive capacity models derived from combining empirical and theoretical analysis. The Agility Model and Resilience Model serve as heuristics in understanding the patterns and dynamics of organizational change and adaptation in FoEI and Greenpeace. They represent extreme ends of a continuum of adaptive capacity approaches and, therefore, assist in identifying the strategic dilemmas that social movement organizations face in finding workable solutions and responses to internal and external organizational challenges.

\subsection{Introduction to the Case Study Organizations}

The comparison between Greenpeace and Friends of the Earth International is instructive because these two transnational social movement organizations share many similarities and a few key differences. These organizations were both founded in the late 1960s in North America as part of the modern environmental movement, experienced organizational growth and expansion to offices around the world, developed within a similar transnational political environment, and undertake political campaigns in many of the same issue areas. However, FoEI and Greenpeace have adopted different interpretations of environmental issues and the effectiveness of particular courses of action, different organizational strategies and tactics in pursuing their mission, and 
different structural configurations. In this dissertation, I seek to explore how these differences affect their adaptive capacity, meaning their distinct patterned response to internal and external pressures.

\subsubsection{Friends of the Earth International}

Friends of the Earth was founded in 1969 by David Brower following his resignation as Executive Director of the Sierra Club of the United States. Disagreements between Brower and the Board of the Sierra Club resulted from disputes over issues (e.g., their position on nuclear power), managerial style and budgeting (e.g., the spending of club funds), organizational structure and decision-making process (e.g., the bureaucratic and hierarchical structure of the Sierra Club), the national focus of the club, and decisions on club activities (e.g., the Club's focus on recreational and educational activities as opposed to lobbying and publishing of environmental books) (McCormick 1989: 144; Wapner 1996: 121; Carmin and Balser 2002: 373). For Brower, Friends of the Earth would rectify many of the shortcomings that he perceived in the Sierra Club. FOE would be international, decentralized, political and anti-nuclear. It would focus on legislative lobbying, litigation and political campaigning, as well as publishing books for awarenessraising on environmental issues. Reflecting on the origins and growth of FoEI, David Brower wrote the following in the 1984-1985 Annual Report of Friends of the Earth International.

Realizing it was time to stop working toward a Moon-like Earth, I started a new organization. We fished around for a name and came up with Friends of the Earth. It was essential that it be international in scope. With meetings in London, Paris and Stockholm, we were able to convince environmental people in three more countries to let the FOE idea migrate. Other countries now in the FOE network were courted, or courted us, and in no time the sun was rising, somewhere on a FOE group. We made it a point not to be clearly organized or directed by some tired old formula from the top. Find good people with the right idea and let them move ahead their way (David Brower, August $9^{\text {th }} 1985$ in FoEI 1984-5: 4).

The initial Friends of the Earth office opened in San Francisco, California in 1969. In 1971, Brower gathered with "environmental people" from France, Germany, Italy, Switzerland, the United Kingdom, Sweden and the United States for a meeting in Paris, 
France. In the same year, at a meeting in Roslagen (Sweden), environmental activists from France, Sweden, England and the USA, including Brower, founded Friends of the Earth International. FoEI gave primacy to the autonomy and "self-determination" of national members while employing "consensus decision-making" and operating under the mission "to promote...the conservation, restoration and rational use of the natural resources and beauty of the Earth" (Burke 1982: 107).

David Brower's wife, Ann, suggested the name "Friends of the Earth" and the idea that the earth needs friends resonated outside of the United States. In the 1980s, environmental groups in Asia, Latin America and Africa joined the federation and expanded the organization outside its original northern country members (Burke 1982). These new member groups brought a more integrated perspective on environmental issues as interconnected with issues of ecological and cultural diversity, human and peoples' rights, sovereignty, equity and social, economic and gender justice. The first annual meeting hosted by a member organization from the South was in 1986 and it was held in Malaysia. Participatory, democratic decision-making and national group autonomy are core values of FoEI and, although southern offices supported the decentralized structure, they called for joint international campaigning in order to tackle issues that span national borders. In 1981, a small secretariat was established in order to assist in international coordination and information exchange. By 1983, the FoEI members elected an Executive Committee to oversee international activities between the annual, and later biannual, general meetings. Friends of the Earth Europe was created in 1985 in order to coordinate activities amongst the European branches of FoEI, and in 2001 a similar regional coordinating body was established amongst Latin American and Caribbean groups.

FoEI member groups describe themselves as a "worldwide grassroots environmental network campaigning for an ecologically sustainable, just and peaceful world." Building on this description, I label FoEI a 'global grassroots movement' whose uniqueness lies

\footnotetext{
${ }^{1}$ Turner, Tom (1986) Friends of the Earth: The First Sixteen Years. San Francisco, USA, Earth Island Institute.
} 
in its ability to operate across scales from the grassroots to the global level. Based on their local and national experiences and campaigns, FoEI member groups have agreed on an international agenda and collaborate on international campaigns, while embracing their internal cultural and political diversity.

\subsubsection{Greenpeace}

The origins of Greenpeace date back to 1969 in Vancouver, Canada. A group of Canadians and recently immigrated Americans launched a protest against US nuclear bomb testing at Alaska's Amchitka Island, citing concern about possible earthquake and tidal wave effects, atmospheric pollution, and ecological devastation to the refuge of sea otters, eagles and other wildlife on and around the island. The 1969 demonstration along the Canada-US border did not halt the initial test; however, it raised significant public concern about nuclear testing. The demonstration inspired a small group of environmentalists and peace activists to organize further in order to capitalize on this momentum. In an interesting parallel to the origin of Friends of the Earth, one of the original Greenpeace activists was the head of the Sierra Club of British Columbia, which he suggested could support the protest; however the head office of the Sierra Club in San Francisco refused to offer consent for an anti-nuclear testing campaign (Carmin and Balser 2002: 377). This led the protestors to start their own group to host the campaign: the "Don't Make a Wave Committee."

In 1971, this committee officially incorporated as Greenpeace. According to Greenpeace legend, the name was coined by Bill Darnell at one of the early organizing meetings and captured the protestors concern about the "two great issues of our time: the survival of the environment and the peace of the world" (Weyler 2004: 67, 95). Drawing inspiration from the Quaker tradition of "bearing witness," a small team of activists set sail in a fishing boat, the Phyllis Cormack, with the intent of placing themselves within the test zone in Amchitka in an act of "calculated law-breaking" (Rucht 1995). The boat was intercepted before it reached the testing area, but the combined work of the activists on board and the support group in Vancouver to publicize the voyage changed the public consciousness on nuclear testing. The media attention succeeded in creating "a mind 
bomb sailing àcross an electronic sea into the minds of the masses" (Hunter 1979: 61). The term 'mind bomb' was coined by one of the Greenpeace founders, Bob Hunter, a journalist with an interest in media theory and the writings of Marshall McLuhan (Hunter 1971). According to Hunter, mindbombs are "consciousness-changing sounds and images to blast around the world in the guise of news." ${ }^{, 2}$ With the advent of television and the mass media, Hunter argued that social change could be catalyzed through "powerful new images delivered via the media" with the power to "change mass consciousness" (Hunter 1979: 61).

The "Don't Make a Wave Committee" was founded for a specific campaign on nuclear testing; however, after this campaign, the founders dissolved the committee and changed its name to the Greenpeace Foundation with the intention of creating "an all-purpose ecological 'strike force' rather than a one-issue ad hoc committee" (Hunter 1979: 114). Greenpeace rapidly expanded its reach by applying its signature high-profile direct action tactics to other peace and environmental campaigns. The Quaker principles of "bearing witness" and "nonviolence" remained central to the organization as it began new campaigns against whaling and seal hunting.

Greenpeace campaigns emphasize the transnational nature of environmental issues and their root causes in the misuse of power of corporations and governments. Notably, its organizational strategy for challenging these powerful actors is in creating 'mindbombs,' symbolic actions such as activists steering inflatable boats between whaling ships and whales which employ the power of the media to change global consciousness on environmental issues (Rucht 1995; Wapner 1996; Doherty 2002). The image of activists placing their lives in danger to protect other species and humans from ecological disasters resonated strongly, and within the first few years, groups bearing the Greenpeace name were emerging around the world. In 1979, Greenpeace offices were brought together under an umbrella organization, Greenpeace International, to control the use of the 'Greenpeace' name, resolve internal conflicts and increase coordination. Unlike in FoEI, the international growth of the organization was unanticipated. Bob Hunter, who joined

\footnotetext{
${ }^{2}$ http://www.greenpeace.org/usa/news/bob-hunter\#
} 
the initial voyage of Greenpeace as a journalist, writes about the Amchitka campaign "which none of us imagined would have a sequel, let alone lead to the formation of an eco-navy, complete with a bureaucracy and a political arm, capable (sometimes) of stopping whole megaprojects, fighting such post-space-age nightmares as ozone depletion, genetically modified food and climate change" (Hunter 2004: 16).

As I discuss in Chapters 5 and 7, Greenpeace developed a relatively centralized and formalized structure in order to support its delivery of direct action campaigns; therefore, I label Greenpeace as a 'global campaigning organization' whose uniqueness lies in its ability to repeatedly engage in creative confrontations against urgent ecological abuse, with the aim of stimulating public debate and inspiring activism.

\subsubsection{The Organizational Viability of FoEI and Greenpeace}

An underlying assumption of this dissertation is that both Friends of the Earth International and Greenpeace have maintained their organizational viability over time. In this section, I draw on empirical data in order to substantiate this claim. Specifically, I analyze their reported income levels, their membership numbers, and the rate of increase in national and regional members and offices. As TSMOs seek media coverage in order to increase the effectiveness of their campaigns, I analyze the media profile of FoEI and Greenpeace over the thirty-five years of their existence as an indicator of their viability. Moreover, TSMOs aim to trigger social change through providing information on issues and on their campaigns. I analyze their web access statistics, which provides data on visitor numbers to their websites as an indicator of the degree to which FoEI and Greenpeace information is used as an online resource. Finally, I review FoEI and Greenpeace's campaign issue areas, and note their reported campaign victories.

A key indicator of the organizational viability of FoEI and Greenpeace is their income. Table 1.1 provides a comparison of the income of Friends of the Earth International and Greenpeace International from 1990 until 2004. 
Table 1.1 Comparison between FoEI and Greenpeace International Income (in Euros) - (Source: FoEI and Greenpeace Annual Reports)

\begin{tabular}{|c|c|c|}
\hline Year & $\begin{array}{c}\text { Friends of the Earth } \\
\text { International }\end{array}$ & Greenpeace International \\
\hline 1990 & - & $27,103,734$ \\
\hline 1991 & 304,508 & $31,681,395$ \\
\hline 1992 & 390,935 & $31,785,685$ \\
\hline 1993 & 271,257 & $27,344,957$ \\
\hline 1994 & 262,228 & $24,213,836$ \\
\hline 1995 & 426,795 & $29,043,866$ \\
\hline 1996 & 613,697 & $24,373,856$ \\
\hline 1997 & 536,792 & $25,408,805$ \\
\hline 1998 & 587,698 & $28,832,000$ \\
\hline 1999 & 592,567 & $30,683,000$ \\
\hline 2000 & 948,563 & $34,503,000$ \\
\hline 2001 & $1,165,890$ & $39,269,000$ \\
\hline 2002 & $1,515,990$ & $37,224,000$ \\
\hline 2003 & $1,782,035$ & $36,015,000$ \\
\hline 2004 & $1,671,204$ & $39,933,000$ \\
\hline
\end{tabular}

As is apparent from both columns of this table, the income of FoEI and Greenpeace International has increased over time. It is important to note that Table 1.1 describes the income of the International Secretariats of FoEI and Greenpeace and not of the organizations in their entirety including Greenpeace national and regional offices and FoEI national member groups; however, I argue that the income level of both the International Secretariat of FoEI and Greenpeace International provides insight into the viability of the organization as a whole.

At the international level, Friends of the Earth International has an income of 1.671 million euros. This income increased substantially over the fifteen years due to increased fundraising efforts at the international level and a slight increase in membership dues. Recently, FoEI's income has remained relatively stable. Figure 1.1 presents the income changes in FoEI over time as a line graph. 
Figure 1.1 Income of Friends of the Earth International Secretariat: 1990 - 2005 (Source: FoEI Annual Reports)

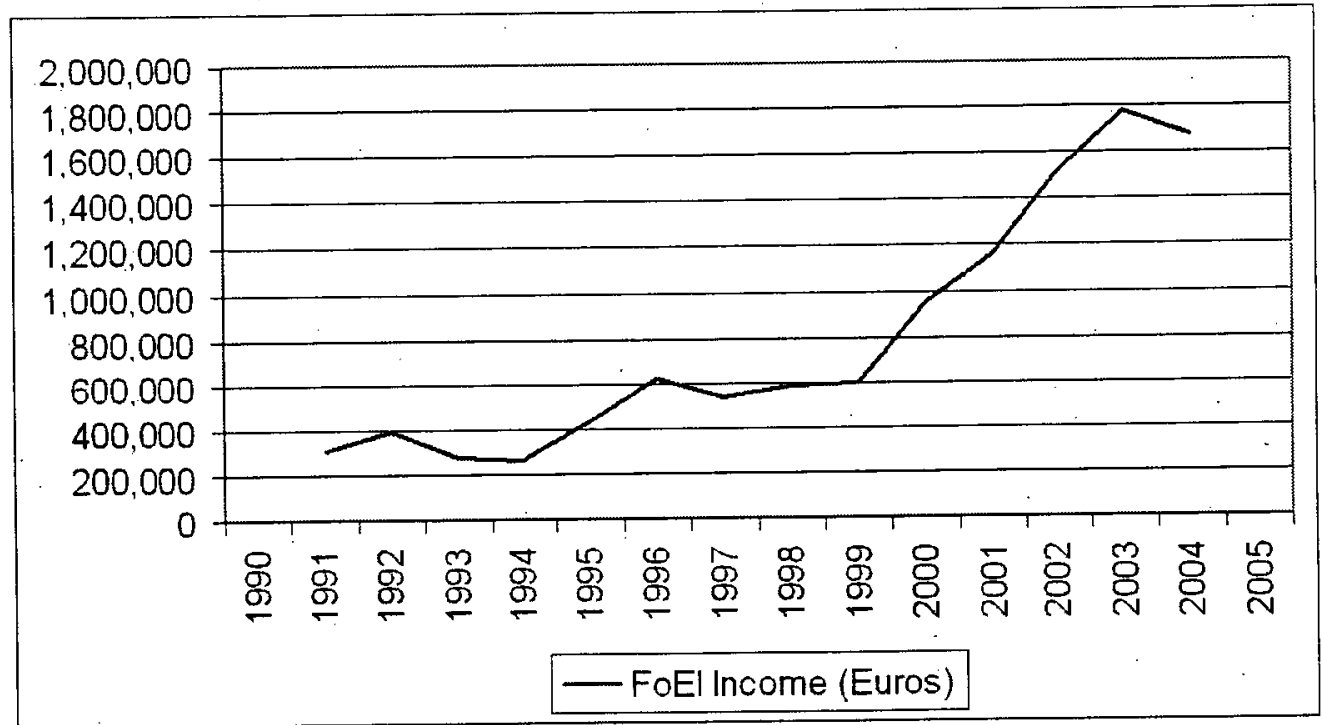

There is a marked difference in the level of income between FoEI and Greenpeace International, with Greenpeace International reporting an income that is twenty-five times the size of FoEl's International Secretariat (see Figure 1.2). This income difference is due to the relative centralization of Greenpeace as well as its broad base of financial supporters. Greenpeace International has a substantial income of 40 million euros.

Figure 1.2 Comparison between income of FoEI Secretariat and Greenpeace International: $1990-\mathbf{2 0 0 5}$

(Source: FoEI and Greenpeace Annual Reports)

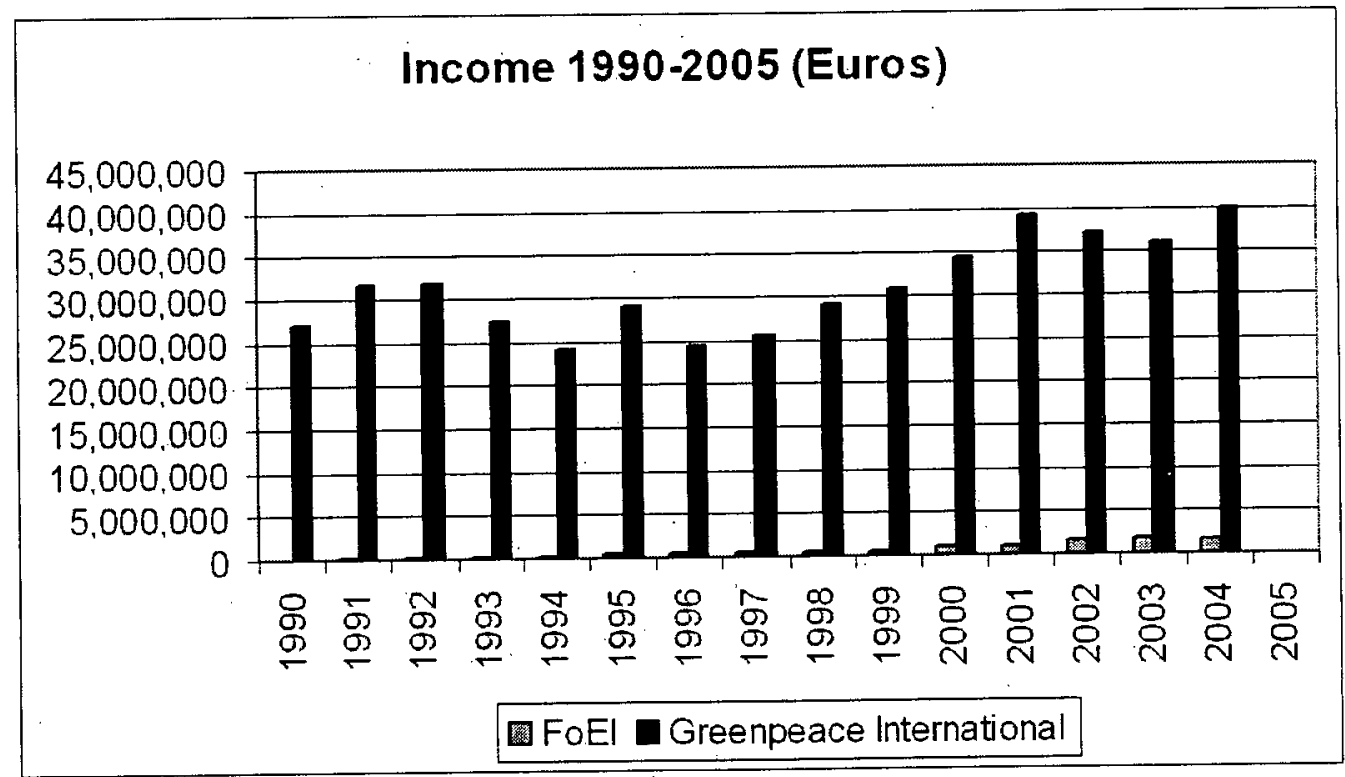


As there is no information on FoEI worldwide income, I have not included it here; however, Greenpeace does reports on its worldwide income, which currently stands at 162 million euros. Figure 1.3 presents the change in income in Greenpeace International as a line graph.

\section{Figure 1.3 Income of Greenpeace International: 1990 - 2005}

(Source: Greenpeace Annual Reports)

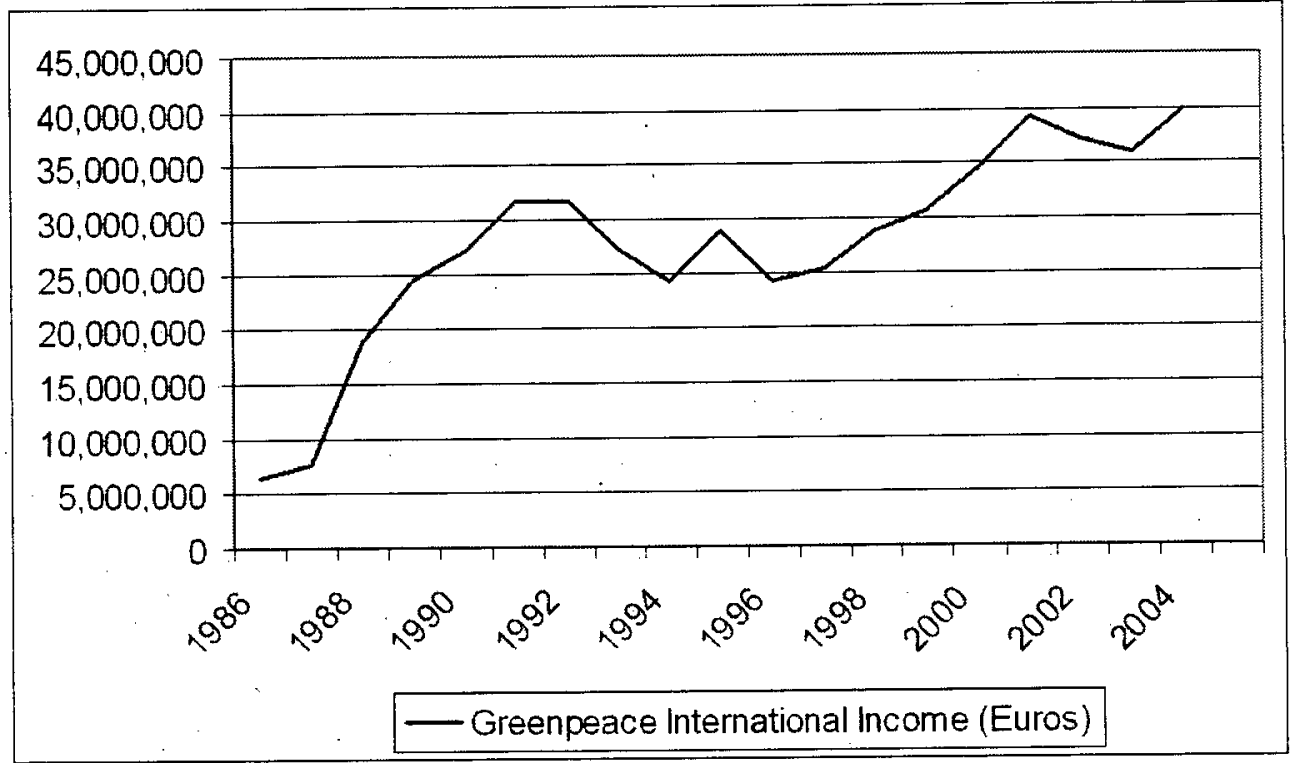

The empirical data on income outlined above suggests that both FoEI and Greenpeace are not organizations in decline but continue to accrue substantial financial resources for their organizations and campaigns. Both FoEI and Greenpeace have also experienced an increase in membership over time. FoEI and Greenpeace use the term 'member' to refer to different things. FoEI refers to its national groups as "member groups;" however, for this empirical data set, the FoEI "membership" number is tabulated based on the reported memberships within national FoEI-groups. In some countries, this refers to the voting membership of a FoEI national group or its individual financial supporters. In other countries, the membership includes the grassroots volunteer base that supports a FoEI member group. ${ }^{3}$ In contrast, Greenpeace 'members' are its individual financial supporters that contribute to Greenpeace in order to support the work of its professional campaigners. The membership numbers do not include Greenpeace volunteers or the direct action activists that engage in Greenpeace campaigns. Table 1.2 displays a

\footnotetext{
${ }^{3}$ Interview with Ann Doherty, FoEI Communications Coordinator, August 2006
} 
comparison between the membership numbers in FoEI and Greenpeace from 1990 to 2005.

Table 1.2 Comparison between membership numbers in FoEI and Greenpeace (Source: FoEI and Greenpeace Annual Reports)

\begin{tabular}{|c|c|c|}
\hline Year & $\begin{array}{c}\text { Friends of the Earth } \\
\text { International }\end{array}$ & Greenpeace \\
\hline 1990 & 500,000 & $5,000,000$ \\
\hline 1991 & 500,000 & $5,100,000$ \\
\hline 1992 & 500,000 & $5,000,000$ \\
\hline 1993 & 600,000 & $4,100,000$ \\
\hline 1994 & 700,000 & $4,000,000$ \\
\hline 1995 & 800,000 & $2,900,000$ \\
\hline 1996 & 900,000 & $2,900,000$ \\
\hline 1997 & 900,000 & $2,400,000$ \\
\hline 1998 & 950,000 & $2,400,000$ \\
\hline 1999 & 975,000 & $2,500,000$ \\
\hline 2000 & $1,000,000$ & $2,650,000$ \\
\hline 2001 & $1,200,000$ & $2,800,000$ \\
\hline 2002 & $1,300,000$ & $2,800,000$ \\
\hline 2003 & $1,400,000$ & $2,800,000$ \\
\hline 2004 & $1,500,000$ & $2,700,000$ \\
\hline 2005 & $1,600,000$ & $2,700,000$ \\
\hline
\end{tabular}

The table demonstrates that FoEI and Greenpeace have a significant membership base; however, FoEI has experienced a steady increase in membership, whereas Greenpeace experienced a decline in the early to mid-1990s. FoEl's increase in membership can be partly explained by its approach to global expansion. The new national groups that apply to join or are recruited to FoEI are frequently organizations that were already in existence and active prior to their involvement in FoEI. When they join the FoEI network, they bring their existing membership base and increase the membership numbers of the FoEI network. As Table 1.3 and Figure 1.6 describe, FoEI has steadily increased its federation from 44 national groups in 1990 to 71 groups in 2005 . This increase has resulted in a corresponding increase in membership numbers over that time. Figure 1.4 displays this increase as a line graph. 


\section{Figure 1.4 Membership numbers for FoEI: 1990 - 2005}

(Source: FoEI Annual Reports)

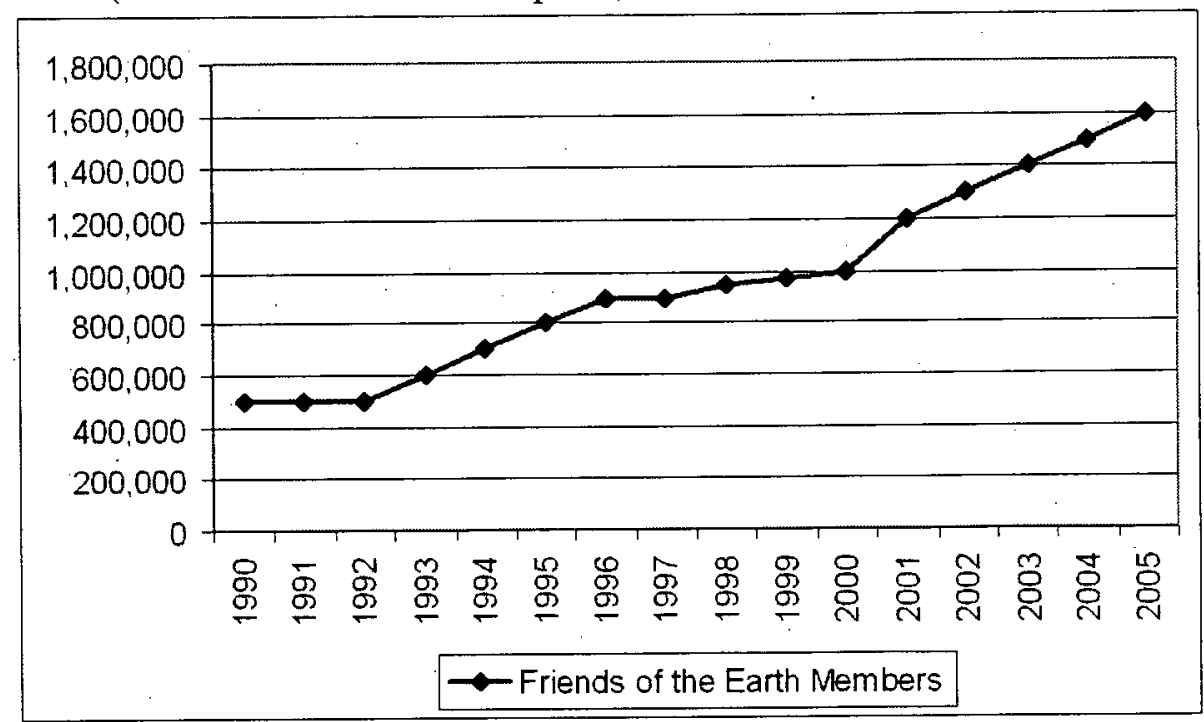

In contrast, Greenpeace has experienced both decline and relatively stability in its membership - its financial supporters - over the past fifteen years. Individual contributions increased to reach a record high in 1991, partly due to public outcry and support following the 1985 French bombing of the Greenpeace ship, the Rainbow Warrior (Brown and May 1989: 125). The rapid decline in membership numbers in the early to mid-1990s is largely attributable to the drop in financial supporters to the US Greenpeace office, due to alleged mismanagement of resources, the emergence of an environmentally-friendly political climate, and a movement away from Greenpeace's signature nonviolent direct action tactics within the US office (Warkentin 2001: 68). Since the mid-1990s, Greenpeace membership has remained relatively steady. As the current Greenpeace International Executive Director notes, "organization stable: the environment is not." ${ }^{, 4}$ Figure 1.5 displays the change in membership numbers for Greenpeace as a line graph.

\footnotetext{
${ }^{4}$ Greenpeace (2005) Annual Report. Greenpeace International, Amsterdam, The Netherlands
} 
Figure 1.5 Membership numbers for Greenpeace: $1990-2005$ (Source: Greenpeace Annual Reports)

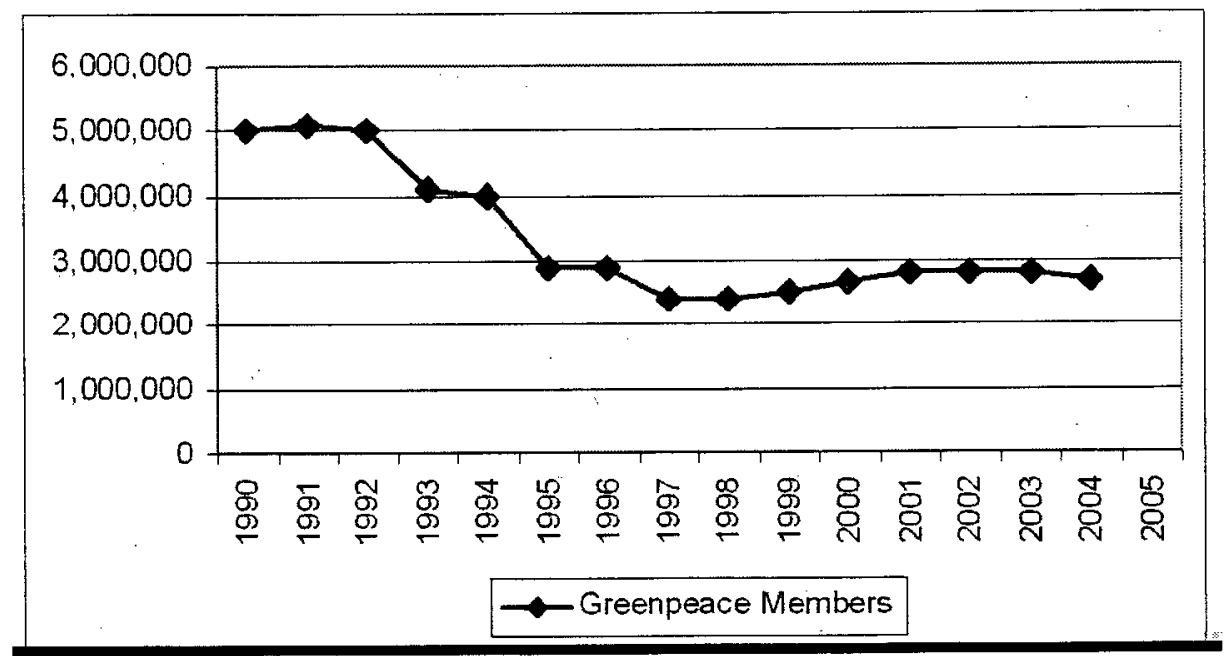

Unlike FoEI, Greenpeace national and regional offices are not recruited from existing organizations but are founded as Greenpeace entities. Often Greenpeace representatives coordinate the establishment of well-functioning offices in partnership with environmental activists recruited from the country (Wapner 1996: 123). Initially, the global expansion of Greenpeace offices took place in an ad hoc manner; however, since the mid-1980s, new national and regional offices have been established or closed down according to deliberate plans for a global presence. ${ }^{5}$ Table 1.3 compares the expansion of Greenpeace offices with that of Friends of the Earth International.

\footnotetext{
${ }^{5}$ Bode, T. (1999) Greenpeace Global Presence. Submitted to Executive Directors Meeting of Sept/October of 1999 by Greenpeace International for discussion.
} 
Table 1.3 Number of FoEI National Member Groups as compared with Greenpeace National and Regional Offices

(Source: FoEI and Greenpeace Annual Reports)

\begin{tabular}{|c|c|c|}
\hline Year & $\begin{array}{c}\text { Friends of the Earth } \\
\text { International }\end{array}$ & Greenpeace \\
\hline 1990 & 44 & 28 \\
\hline 1991 & 47 & 28 \\
\hline 1992 & 51 & 30 \\
\hline 1993 & 52 & 31 \\
\hline 1994 & 52 & 32 \\
\hline 1995 & 54 & 32 \\
\hline 1996 & 56 & 33 \\
\hline 1997 & 58 & 41 \\
\hline 1998 & 59 & 41 \\
\hline 1999 & 61 & 41 \\
\hline 2000 & 66 & 39 \\
\hline 2001 & 66 & 38 \\
\hline 2002 & 68 & 38 \\
\hline 2003 & 68 & 38 \\
\hline 2004 & 71 & 38 \\
\hline 2005 & 71 & 38 \\
\hline
\end{tabular}

As the table displays, both FoEI and Greenpeace have expanded their operations globally over time; however, there is a notable differences in this trend after 1997 with FoEI continuing to expand, while the number of national and regional offices of Greenpeace declines and then remains steady. As I will discuss in detail in Chapter Eight, FoEI has continued to accept and recruit new FoEI member groups to its network, whereas Greenpeace has consolidated its operations and actively chosen to retain a constant number of national and regional offices in order to deliver efficient, focused, global campaigns. Figure 1.6 displays this comparison as a graph, which traces both the steady growth of FoEI and the recent "steady state" strategy of Greenpeace. 
Figure 1.6 Comparison of FoEI National Member Groups and

Greenpeace National and Regional Offices

(Source: FoEI and Greenpeace Annual Reports)

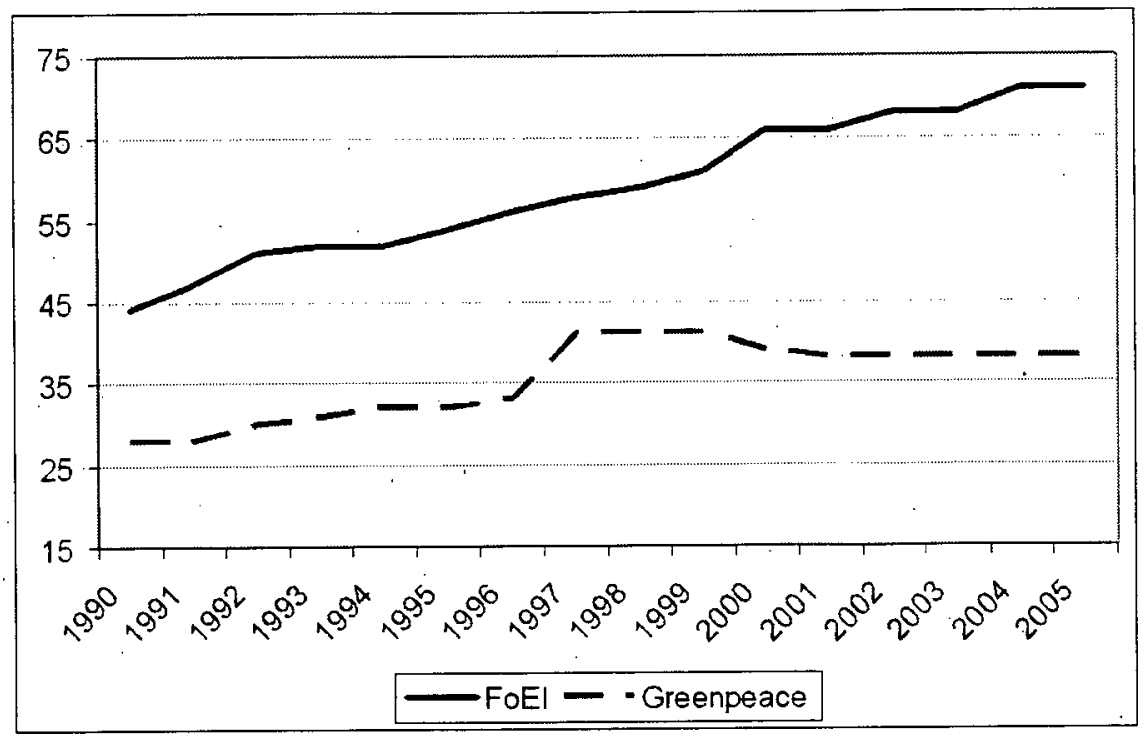

As an additional indicator of their viability, both FoEI and Greenpeace report that they could expand their number of offices or member groups much more rapidly than they do. In 2003, FoEI reported that "an average of 30 groups request membership information from the International Secretariat each month." Greenpeace reports "we receive many requests every day to open offices all over the world. ${ }^{7}$ As I will discuss in Chapters Six and Seven, FoEI and Greenpeace campaigners choose to limit this expansion in order to adjust to new members and offices and to operate effectively across their existing organizational structure. Part of their effectiveness is determined by the media profile they receive. In Figure 1.7, I compare the media profile of FoEI and Greenpeace over their thirty-five years of existence across a large number of major papers.

\footnotetext{
${ }^{6}$ FoEI (2003) Annual Report. FoEI, Amsterdam, The Netherlands, p. 14

${ }^{7} \mathrm{http} / / / \mathrm{www}$.greenpeace.org
} 
Figure 1.7 Media Profile of FoEI and Greenpeace in Major Papers

including the New York Times, Washington Post, the Financial Times (London), The Guardian (London), and the Christian Science Monitor (Boston) (Source: Lexis Nexus Academic)

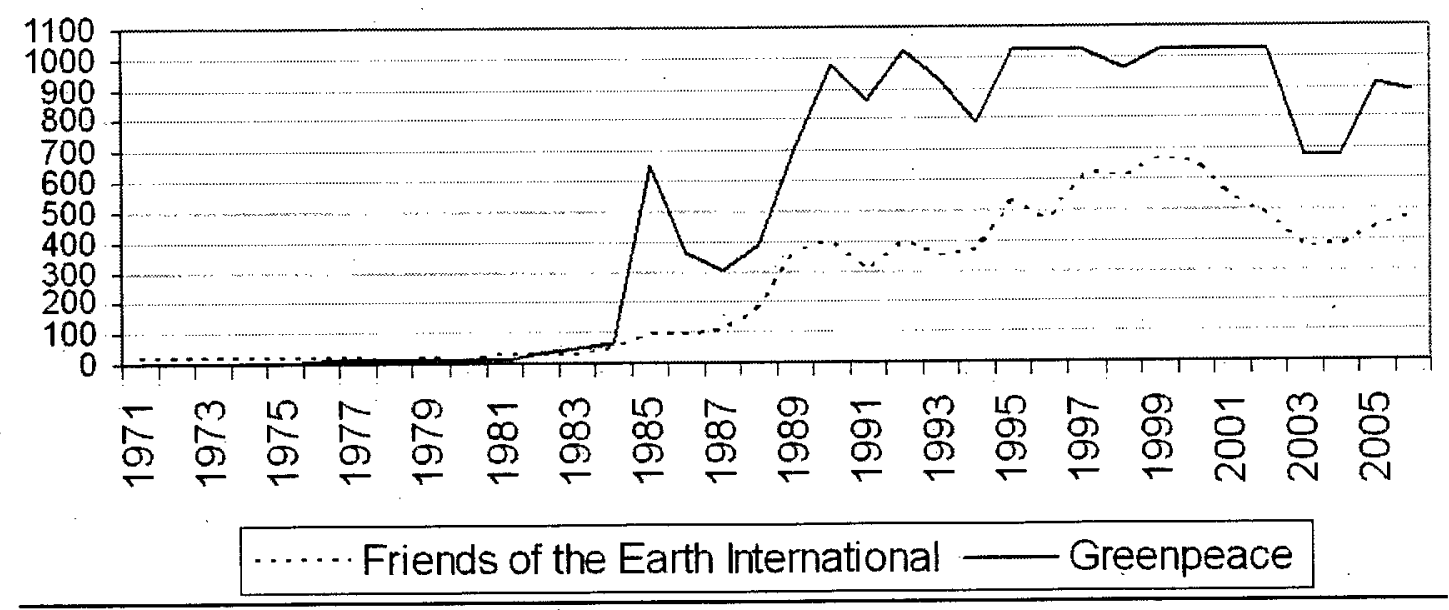

As the graph demonstrates, media coverage of FoEI and Greenpeace increased substantially for both organizations in the 1980 s as a result of their increased capacity and campaign work. These TSMOs can also be considered to be viable organizations because they have continued to receive significant media coverage in recent years. The difference between FoEI and Greenpeace in terms of media coverage is largely due to the fact that Greenpeace campaigns are specifically targeted at garnering media attention. Similarly, Greenpeace has a history of using new media, including the Internet, as part of its campaigns and public engagement tactics (Warkentin 2001: 77; Eden 2004). An analysis of Greenpeace's website access statistics provides an indication as to the degree to which Internet users perceive Greenpeace as an online resource on their campaign issues.

Figure 1.8 compares the number of visitors to Greenpeace's website with the web access statistics of Friends of the Earth International. 
Figure 1.8 Internet web access comparison between FoEI and Greenpeace (Source: http://www.alexaholic.com)

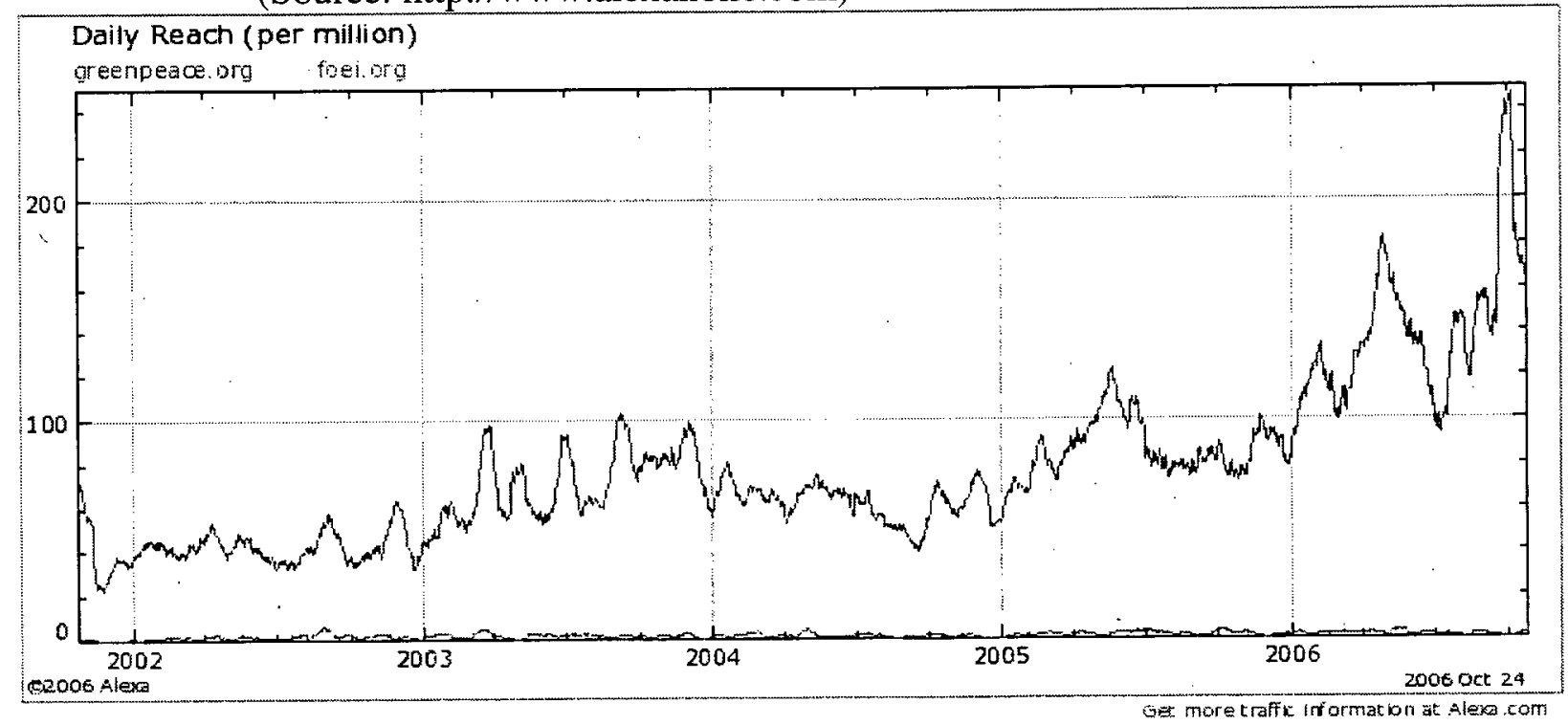

In this Figure, the visitors to greenpeace.org are displayed as the top line of the graph, and the visitors to foei.org are displayed as the bottom line of the graph. The number of Greenpeace visitors has increased significantly in the past four years from under 100 million visitors to a peak of over 200 million visitors earlier this year. In contrast, the website access of www.foei.org appears insignificant; however, as Figure 1.9 displays, there has been a marked increase in FoEI online visitors as well. The FoEI website has experienced more than a doubling of visitors from just over 200,000 in 2002 to over 500,000 visitors in 2004 , due to its launch of a new FoEI website and an increase in activity at the international level. ${ }^{8}$

\footnotetext{
${ }^{8}$ Entering "Greenpeace" into Google.com results in 21,200,000 hits and "Friends of the Earth" results in $2,840,000$ hits.
} 
Figure 1.9 Visitors to www.foei.org (Source: Friends of the Earth International's Annual Reports)

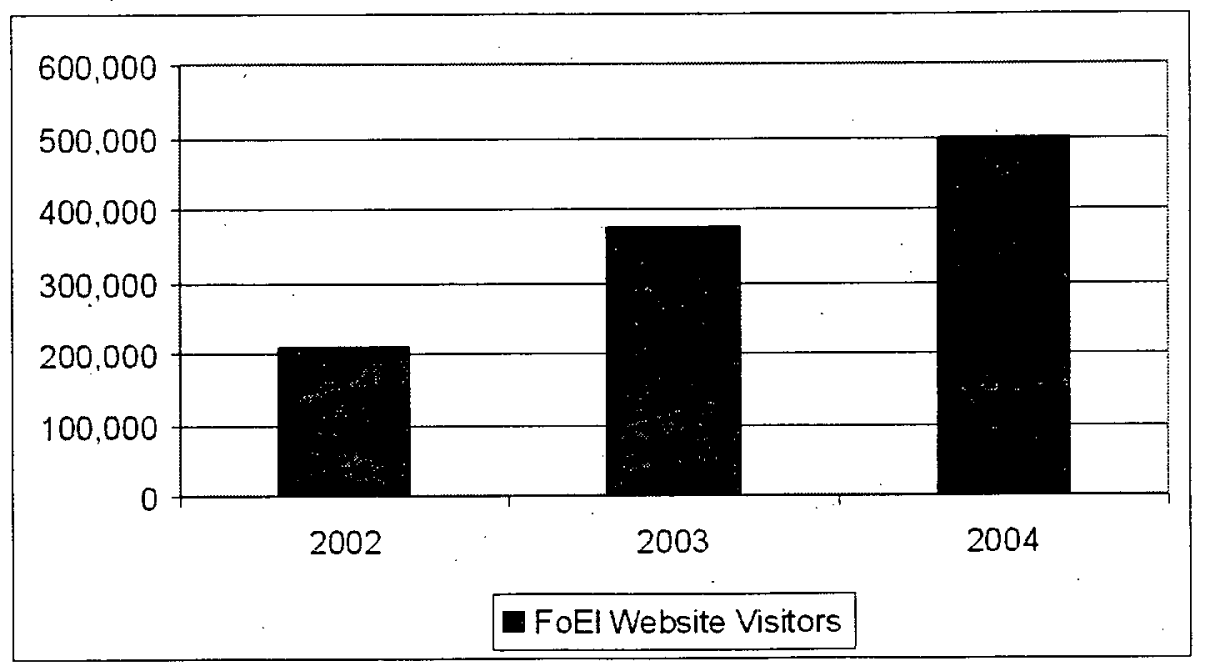

FoEI and Greenpeace exhibit organizational viability in terms of income numbers, membership, media profile, and online presence. Another measure of their viability is their reported campaign activities. Early FoEI campaigns focused on nuclear, whaling and environmental issues such as tropical rainforest protection. Since the 1970s, FoEI campaigns have significantly broadened their scope. In addition to numerous national and local level campaigns on issues including desertification, maritime issues and Antarctica, Friends of the Earth International works on "today's most urgent environmental and social issues" including campaigns on:

- Climate change,

- Corporate accountability,

- Genetically-Modified Organisms,

- Forests,

- International Financial Institutions,

- Trade,

- Human and Environmental Rights,

- Biodiversity, and

- Ecological debt ${ }^{9}$

A selection of the "international campaign victories" that FoEI lists in its 2004 Annual Report includes their reported success in halting of gold exploration by the US mining company Newmont in the Peruvian Mountains, opening consultation processes in the

\footnotetext{
${ }^{9}$ FoEI (2004) Annual Report. FoEI, Amsterdam, The Netherlands
} 
World Bank and US Overseas Private Investment Corporation, and securing the recognition of indigenous rights within the United Nations Conference on Biological Diversity. Currently, Greenpeace organizes public campaigns for:

- The protection of oceans and ancient forests,

- The phase out of fossil fuels and the promotion of renewable energy to stop climate change,

- The elimination of toxic chemicals,

- The prevention of genetically modified organisms being released into nature,

- An end to the nuclear threat and nuclear contamination, and

- Safe and sustainable trade.

In its 2005 Annual Report, Greenpeace documents a series of global and national victories including its reported success in stimulating policies by Samsung electronics to phase out hazardous chemicals, halting the Stuart Shale Oil Project in Australia, overturning the prosecution of Greenpeace by both ESSO and the US government, and playing a role in the establishment of international environmental law on eliminating hazardous chemicals in the form of The Stockholm Convention. Appendix A and Appendix B detail a selection of campaign activities and reported victories of FoEI and Greenpeace from 1971 until 2006. The high level of campaign activity also provides an indication as to the organizational viability of FoEI and Greenpeace.

\subsubsection{Similarities and Differences between FoEI and Greenpeace}

Friends of the Earth International and Greenpeace have played a significant role in the transnational environmental movement. Since their origins in the late 1960, they have interacted with a similar complex and dynamic political environment (see Chapter Two). They share a common concern with the misuse of power by corporations and governments resulting in environmental and social problems. They both employ confrontational promotional campaigning tactics supported by research and institutional tactics (e.g., lobbying). They are also similar in the transnational nature of their organizational structures, with corresponding challenges of managing internal diversity and conflict. As Table 1.4 documents, FoEI and Greenpeace are active in some of the same campaigns. This campaigning overlap is evident in their list of victories for 2004, in which both FoEI and Greenpeace reported their role in effectively pressuring for the 
ratification of Kyoto Protocol on climate change by the Russian government and in influencing the withdrawal of Monsanto's genetically modified Roundup Ready Wheat. ${ }^{10}$

\section{Table 1.4 Comparable Campaigns in FoEI and Greenpeace} (Source: FoEI Annual Report 2004; GPI Annual Report 2005)

\begin{tabular}{|c|c|}
\hline Friends of the Earth International & Greenpeace \\
\hline $\begin{array}{l}\text { - Climate change } \\
\text { - Genetically-modified organisms } \\
\text { - Forests } \\
\text { - Trade } \\
\text { - Maritime } \\
\text { - Corporate accountability } \\
\text { - Core theme: biodiversity }\end{array}$ & 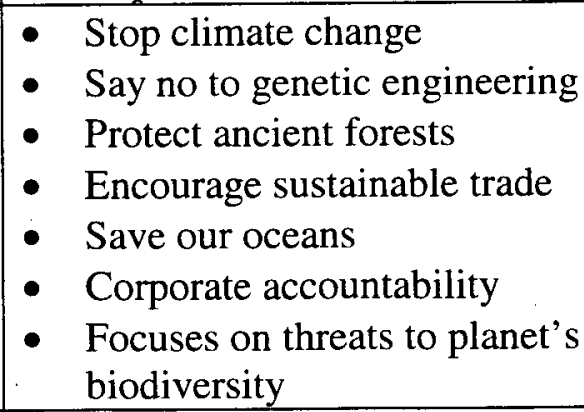 \\
\hline
\end{tabular}

As will become apparent, differences between these two organizations are differences of degree. Both Greenpeace and FoEI are environmental movement organizations but Friends of the Earth integrates social issues relatively more into its mission and activities than Greenpeace. The strategies and tactics adopted by both organizations are a combination of confrontational activities (e.g., direct action and protests) and nonconfrontational actions (e.g., lobbying and litigation); however, Greenpeace is relatively more renowned for its media friendly direct action tactics, in which Greenpeace activists "bear witness" to environmental crimes, "expose environmental criminals," and engage in "high-profile, non-violent conflict." "Friends of the Earth International, in contrast, is relatively more focused on building a global grassroots movement organized in a decentralized, participatory democratic way in order to "liv[e] the change [they] wish to see and to work... together in solidarity." ${ }^{12}$ FoEI uses relatively more institutionalized tactics (e.g., research and lobbying) to "challenge the current model of economic and corporate globalization, and promote solutions that will help to create environmentally sustainable and socially just societies." ${ }^{13}$ Most importantly for this dissertation, in their organizational structures, Greenpeace is relatively more centralized and formalized than

\footnotetext{
${ }^{10}$ FoEI (2004) Annual Report. FoEI, Amsterdam, The Netherlands; Greenpeace (2005) Annual Report. Greenpeace, Amsterdam, The Netherlands

${ }^{11} \mathrm{http}: / / \mathrm{www}$.greenpeace.org/about

${ }^{12}$ FoEI (2005) Annual Report. FoEI, Amsterdam, The Netherlands

${ }^{13}$ FoEI (2004) Annual Report. FoEI, Amsterdam, The Netherlands
} 
Friends of the Earth International. It is this difference that inspired the research question for my dissertation: does the prevailing assumption hold that a decentralized and informal structure is the only way to maximize adaptability in response to complex and dynamic internal and external changes?

\subsection{Social Movements and Organizational Theory}

In order to answer the research question, I draw predominately on two academic literatures: social movement theory and organizational studies. Recently, top scholars in these two areas of sociology have come together to emphasize the areas of overlap and to identify the complementarities between these two fields (Davis et al. 2005). The resulting common frameworks developed by the authors stem from the cross-fertilization of organizational studies and social movement theory and provide rich insights that inform this thesis. In developing my contribution to social movement research, I draw heavily from organizational studies and, in doing so, join a thirty-year history of social movement scholars that have similarly bridged these two areas (e.g., Zald and Ash 1966; McCarthy and Zald 1973; 1977). McAdam and Scott (2005: 5) note that the intersections between these two fields have been predominately "unidirectional" to date with social movement scholars "productively borrow[ing] and adapt[ing] organizational ideas to their own uses." This borrowing and adapting was primarily done by a group of scholars - known as the resource mobilization school - who focus their attention on social movement organizations (SMOs). It is these scholars that form the primary audience for this thesis.

Social movement theory has its historical basis in collective action theory, social psychology and the study of individual behavior within groups. In the 1960s, scholars challenged the then dominant view of protest and collective reform activities, which depicted protest as irrational behavior based in common grievances (e.g., Turner and. Killian $1957,3^{\text {rd }}$ ed.). Instead, protest and social unrest were conceived of as instrumental activities that led to "collective action," "social movements" and "social movement organizations" (Gamson 1968, 1975; Tilly and Rule 1965; Zald and Ash 1966). Social movements can be defined as "collective challenges to existing arrangements of power and distribution by people with common purposes and solidarity 
in sustained interaction with elites, opponents and authorities" (Meyer and Tarrow 1998: 4). Examples of social movements include the labour movement, the civil rights movement, the women's movement, the peace movement, the human rights movement, the environmental movement, and the anti-globalization or "protest" movement focused on the effects of economic globalization (Clark 2003a: 157).

Social movement theorists focus on a variety of areas of research (Diani 1992) including group and individual activist identities (New Social Movement Theory e.g.; Cohen 1985; Melucci 1989), the process by which excluded interests gain access to an established polity (Policy Process Perspective e.g., Tilly 1978), the shared interpretations of the world that groups construct to "legitimate and motivate collective action" (Framing e.g., Snow et al. 1986; Snow and Benford 1988), and the tactics routinely used to pursue the goals of a social movement (Repertoires of Contention e.g., McCarthy et al. 1996; Carmin and Balser 2002). In addition, social movement theorists recognize the importance of "the more or less formally organized everyday life patterns upon which movements build collective action," defined as mobilizing structures (McCarthy 1997: 249). Social movements are also shaped by and influence political opportunity structures, defined as "the relative openness or closure of the institutionalized political environment, the stability of that broad set of elite arrangements that typically undergird a polity, the presence of elite allies, [and] the state's capacity and propensity of repression" (McAdam et al. 1996: 10).

I specifically explore the analytical approach adopted by the resource mobilization school, which concentrates on organizational structure and process (e.g., McCarthy and Zald 1977; Zald and McCarthy 1987). It is within this school of social movement literature that the emerging consensus on the adaptability of decentralized and informal structures is evident (e.g., Smith 2005). Unlike the dominant approach of theorists who studied collective behavior earlier in the $21^{\text {st }}$ century, resource mobilization theory (RMT) scholars were influenced directly by the movements of the sixties and seventies and were sympathetic to these movements. They depicted movement participation as a rational choice to achieve specific goals (Freeman and Johnson 1999: 4). Resource 
mobilization theorists argued that, in order to create an enduring structure, movements need a degree of organization including leadership, administration, participation incentives, and access to resources and support. RMT drew on organizational theory to define the internal characteristics of social movement organizations (SMOs) and to analyze the effect of variations in these characteristics on the organization's ability to solve key problems, which I refer to as organizational challenges. These problems include the maintenance of organizational viability, the management of internal conflict and external relations, and development and continuous adaptation of strategies and tactics in pursuit of their goals (Staggenborg 1988; 1989).

As I define in Section 1.1, social movement organizations "are associations of people making idealistic and moralistic claims about how human personal or group life ought to be organized" (Lofland 1996: 3). SMOs seek to "change some element of social structure or reward distribution, or both, of a society" (McCarthy and Zald 1977: 1218). SMOs can be situated in the context of a variety of social movement actors who adopt positions that "are marginal to or excluded from mainstream society" (Lofland 1996:3) at the time they are made. These actors range in scale, continuity and organizational form from individuals who are proponents of marginalized, moralistic claims; to crowds and insurgencies; to large-scale loosely bounded social movements (Lofland 1996: 7). Social movement organizations have a greater degree of formalization and continuity than crowds, insurgencies and social movements and are smaller in scale than the social movements of which they are a part (Lofland 1996: 11). Social movement organizations often emerge as a social movement matures and can be seen as the "carriers" and "building blocks" as they create more enduring structures to further the aims and objectives of a broader social movement (Gamson 1987; McAdam et al. 1988: 716-717; Smith 2005: 228) and enable the movement to "mobilize and combine resources for social change" (Zald and McCarthy 1987: 3).

Friends of the Earth International and Greenpeace are social movement organizations that emerged out of the environmental movement in the late 1960s (see also Doherty 2002). Similar to Smith et al. (1997), I distinguish social movement organizations from the more 
general category of nongovernmental organizations (NGOs). NGỌs are defined as formalized groups that are private, voluntary and nonprofit but not necessarily seeking change in the status quo (Kriesberg 1997: 12). Social movement organizations are a subset of the larger category of NGOs, and can be distinguished as NGOs with a social change orientation. Organizations pursuing a value-oriented / social change agenda have also been called civil society organizations to indicate their role in civil society, defined as the domain of human interaction and associational life that exists above the individual, below the state, and outside market interactions (Anheier et al. 2001; Kaldor 2003).

The values of civil society organizations are not always progressive. As Brown et al. (2000: 278) note, "not all civil society actors are equally serious about achieving social missions or public purposes, nor do all subscribe to the values of tolerance, reciprocity and nonviolence that some argue are central to the definition of civil society" with the "transnational group Aryan Nations... as much a part of it as Greenpeace" (Wapner 1997: 76). Often there is an "arbitrary division between 'good' westernized civil society and 'bad' traditional uncivil society" (Kaldor 2003: 10). Kaldor notes that this conceptualization excludes international criminal networks and neo-traditional organizations, based on kinship and religion - such as revolutionary groups, terrorist networks and fundamentalist religious networks - that "offer alternative sites of power or autonomous spaces" (2003: 10; see also Adamson 2002). The distinction amongst these groups is difficult to maintain given the excluded, marginalized and deeply contested perspectives of social movements and social movement organizations and their confrontation of dominant power holders in society, often in disruptive ways. There is a significant overlap between the terms 'social movement organization' and 'civil society organization'; however, for the purposes of this dissertation, I have grounded my analysis within social movement theory and, therefore, adopt the term 'social movement organization.'

Social movement organization research has a significant overlap with investigations into pressure groups and interests groups within political science, and nonprofit organizations and voluntary associations within economics and sociology. Jordan and 
Maloney (1997: 54) suggest that analysis of social movement organizations may be better understood as "a variant on the interest group theme" under "conventional pressure group" theory. Although insights can be drawn from interest group theory, Doherty (2002: 19-20) disagrees with the notion that this theory offers an equivalent or superior analytical lens. He argues that social movement theory adopts a distinct and useful perspective, which includes "attention to the cultural and sociological dimensions" and the forms and scale of collective action, the mobilization of support and "network relationships between different groups within a social movement." I agree with Doherty and primarily adopt a social movement theory lens to analyze Greenpeace and Friends of the Earth International, while drawing on a number of other disciplines that have investigated these environmental groups (e.g., International Relations theory - Risse 2003).

The diverse disciplinary approaches to organizations such as FoEI and Greenpeace are reflected in the array of terms used to describe them, including transnational advocacy groups (Khagram et al. 2002: 3), international civil society organizations (Clark 2003b: 4), institutionalized interest groups (Bryner 2001: 14), campaign groups (Jordan and Maloney 1997), specific-issue promotional pressure groups (Willetts 1982: 8) and international nongovernmental social change organizations (Keck and Sikkink 1998). Common to many of these terms is the inclusion of either "international" or "transnational" to indicate both the multinational operations of groups such as Greenpeace and Friends of the Earth International and their activity on global issues and across national borders. I adopt the term "transnational social movement organization" (TSMO) to align with the emerging social movement research that explores collective action and organizations spanning a wide geographic reach, operating in an international political environment, and adopting a focus on transnational issues (Smith et al. 1997; Smith 2005).

\subsection{Open Systems Perspective}

Social movement theory and, specifically, the resource mobilization school embrace two insights from organizational studies that are also central to this thesis: an open systems 
perspective (discussed in this section) and a multi-faceted conception of organizational effectiveness (discussed in sections 1.4 and 1.5 below) (e.g., Zald and Ash 1966). An open systems perspective emphasizes the relationships between an organization and its environment (Scott 2003: 82-101). Instead of focusing on "relations between goals, structures and efficiency," the shift towards an open system model of organizations subsumes these issues below concerns about "survival, organization-environment relations, and organizational effectiveness" (Morgan 1997: 34). Inspired by the work of a theoretical biologist, Ludwig von Bertalanffy (1973), open systems theorists adopt a systems approach to understanding organizations, defined as "a way of thinking in terms of connectedness, relationships and context" (Gallopin and Christianson 2000). Organizations, like other systems (e.g., a cell, a complex organism) are in constant interaction with their environment and require a continuous flow of inputs to translate into outputs in order to maintain the internal functioning of the organization (Morgan 1997: 40). This interchange with the environment "is an essential factor underlying the system's viability" (Buckley 1967).

Open systems have boundaries; however, these boundaries are porous and can shift. Organizations as open systems expend energy on both spanning boundaries as well as maintaining them. These boundaries are blurred by the fact that "all systems are made up of subsystems that are themselves subsumed in larger systems - an arrangement that creates linkages across systems and confounds attempts to erect clear boundaries around them" (Scott 2003: 90). The 'environment' could be defined as anything outside of the boundaries of the organization; however, even as an open system, an organization is shaped by and influences a subset of this wider environment. An open systems approach proposes that organizations design themselves with the environment in mind. Accordingly, various scholars have suggested definitions of the specific "task environment" and the "social, political and economic environment" that directly affects an organization as well as the "general environment" or "context" to which the organization should be attuned (Morgan 1997: 41-42). For organizations and their participants, this approach stresses "the importance of being able to scan and sense changes in the task and conceptual environments, of being able to bridge and manage 
critical boundaries and areas of interdependence, and of being able to develop appropriate operational and strategic responses" (Morgan 1997: 42).

As part of the open systems approach to organizations, the institutional school within organizational studies focuses on the interactions among organizations within a particular historical period and on competitive interactions among organizations vying for scarce resources (e.g., Meyer and Rowan 1977; Perrow 1986; Scott 2001). According to institutional theorists, organizational interactions occur within the context of an environment that provides symbolic resources (e.g., legitimacy and prestige) and economic resources (e.g., money and technology) essential for the survival and effectiveness of the organization. Over time, the interactions amongst organizations operating in a resource constrained environment produce a set of norms to which organizations must adhere in order to have access to resources. These norms adopt a "rule-like, social fact quality" and are "not tied to a particular actor or situation" but require an organization to become "cloaked in an institutionally acceptable rhetoric" (Aldrich 1999: 48; see also Meyer and Rowan 1977). As interactions within the context of these norms continue, organizations tend to imitate each other and adopt similar structures and practices in order to meet and master these norms. This imitation process has been termed 'institutional isomorphism' and institutional theorists argue that this imitation strategy provides legitimacy and continued support for the organization (Meyer and Rowan 1977).

Research on social movement organizations and nongovernmental organizations has similarly attempted to define the critical aspects of the external environment to which an organization should be attuned. For resource mobilization theorists, the environment is perceived as a source of critical political, social and economic resources (McCarthy and Zald 1977). These include the political opportunity structures discussed above, which are the "consistent - but not necessarily formal or permanent - dimensions of the political environment that provide incentives for collective action" (Tarrow 1998: 77; see also McCarthy and Zald 1977). Pre-existing social arrangements are the mobilizing structures (e.g., membership in a church, participation in a social network) that can 
become the "seedbed of collective action" when new political opportunities enable members to use these networks and social settings to mobilize for action (Tilly 1978; Tilly et al. 1975). Critical resources also include financial support, which enable a social movement organization to sustain its activities. In organizational studies, resource dependency theorists have similarly examined the acquisition of resources by organizations for survival and effectiveness, and particularly the organizational strategies adopted by organizations to minimize external dependencies on the providers of those resources (Pfeffer and Salancik 1978).

The "Strategic Triangle" model proposed by Brown and Moore (2001) is a useful conceptual tool for defining critical elements of the environment for international nongovernmental organizations and transnational social movement organizations. Originally developed for public agency managers in government, Brown and Moore (2001) apply this strategic tool to international nongovernmental organization, and, by extension, to transnational social movement organizations (TSMOs) (Heymann 1987: 1224; Lax and Sebenius 1986: 264-267; Moore 1995; Moore 2000; Brown and Moore 2001).

The strategic triangle represents "three crucial calculations that leaders [of-TSMOs] must make if their organizations are to survive, produce socially valuable results, and successfully adapt to changing circumstances" (Brown and Moore 2001). The three points of the triangle - value creation, legitimacy and support, and operational capacity indicate the critical areas that require attention by a TSMO in developing and adjusting its strategy and its position in the environment. First, by highlighting value creation, Brown and Moore emphasize that a TSMO "exists to accomplish some public purpose", and requires an organization to make "substantial judgments of what would be valuable and effective" to.pursue in its activities, to focus attention on assessing the outcomes and impacts of these activities, and to ensure that resources are being efficiently deployed for value creating efforts (Moore 1995). Second, with the legitimacy and support point of the triangle, Brown and Moore suggest that TSMOs consider whether their organizational purpose and activities are perceived to be legitimate and whether they are politically, 
legally, and financially supported. The legitimacy of a TSMO is defined as the right to exist, operate and influence other actors (Edwards 2000) and can be based on its value claims (moral legitimacy), its expertise in a topic area (technical or performance legitimacy), its compliance with legal requirements (legal legitimacy) and by its internal democracy, transparency and accountability (political legitimacy) (Brown and Moore 2001). Finally, by including operational capacity, Brown and Moore focus on the administrative and operational feasibility of a TSMO's activities, the capacities necessary to deploy available financial, material and political resources to produce desired outcomes, and the partnerships required in order for the TSMO to perform and advance its mission. TSMOs often seek large-scale and broad changes in individuals and society, which requires TSMOs to build and participate in networks around their particular issue area so that their activities can be "“co-produced' with partners" (Brown and Moore 2001).

The partners with whom a TSMO aligns in its activities are only one set of the external constituencies, often referred to as stakeholders, to whom the TSMO is accountable. The accountability of an organization is the extent to which the organization can be held to its promises. Accountability can be usefully conceived of as a relationship between the TSMO and its stakeholders wherein duties, responsibilities and obligations are owed to particular actors (Kearns 1996; Brown and Moore 2001; Brown et al. 2003; Ebrahim 2003; Scholte 2004; Lloyd 2005). The private sector is primarily accountable to shareholders and democratic public agencies are answerable to their elected representatives and voters. Unlike these actors, TSMOs typically do not have one primary stakeholder to whom they are accountable. They usually have multiple stakeholders that offer different forms of support and place various, and often conflicting, expectations on TSMOs (Brown and Moore 2001). A TSMO's stakeholders can include donors and supporters that provide funding, regulators that process certification, clients or beneficiaries that receive and use TSMO services, partners that cooperate on programs and campaigns, targets of their campaigns that can question the legitimacy of their claims, the TSMO staff, volunteers and Board that dedicate themselves to the 
organization, and members who have joined the TSMO in order to participate, to be represented or to support the TSMO's activities (Brown et al. 2003).

For institutional theorists within organizational studies, this accountability system (Brown and Moore 2001) or accountability environment (Kearns 1996) is the organization field within which an organization operates. The concept of an organization field leads scholars to analyze the context within which an organization operates by defining the "arena - system of actors, actions and relations - whose participants take one another into account as they carry out interrelated activities" (McAdam and Scott 2005: 10). Traditionally, social movement theorists have adopted the concept of an organization field to examine social movement industries, defined as "all SMOs that have as their goal the attainment of the broadest preferences of a social movement" (McCarthy and Zald 1977: 1219). They use this to analyze the effects of "other, alternative or rival social movements on a focal movement organization and population" (McAdam and Scott 2005: 9). For the purposes of this dissertation, I adopt the term 'social movement sector' rather than 'social movement industry' as I am not tracing the activities of rival SMOs. Recent collaborative efforts between organizational theorists and social movement theorists have replaced "the individual organization or social movement with the organization field as the fundamental unit of analysis" in order to contextualize their analysis of social movements and social movement organizations (McAdam and Scott 2005: 17 - emphasis in original). Although I focus specifically on social movement organizations as the unit of analysis within this thesis, I analyze these organizations in the context of their organization field and the diverse actors with whom these SMOs interact. Drawing on the common framework developed by McAdam and Scott (2005: 17), I identify the wider social and political environment within which the SMOs operate and the key actors in the organization field.

\subsection{Organizational Effectiveness, Output Goals and Support Goals}

Conceptualizing Greenpeace and Friends of the Earth International as social movement organizations interacting with their environment also raises a second critical insight from organizational studies: the multi-faceted conceptualization of organizational goals and 
organizational effectiveness, and the various strategic dilemmas that an organization faces as it simultaneously seeks to achieve its multiple goals. Early social movement theorists (e.g., Zald and Denton 1963) drew on the work of Philip Selznick (1957), an organizational scholar who explored how strategic dilemmas shape the development of an organization. Social movement organizations pursue multiple goals including achieving their social change objectives and maintaining organizational viability, and need to adapt in order to respond to internal and external pressures.

An organization's effectiveness in achieving these goals can be measured by different criteria assessing the performance of an organization relative to a standard (Edwards and Hulme 1996; Forbes 1998; Davis 2000; Sowa et al. 2004). By arguing that decentralized, informal organizational structures maximize adaptability within a complex, dynamic environment, scholars such as Smith (2005) and Fowler (2000) are aligning themselves with contingency theorists within organizational studies who proposed that certain types of structures are more effective within certain environments (Lawrence and Lorsch 1967). But as Scott (2003: 350) notes, this theoretical assumption of contingency theorists have stimulated other scholars to ask the question "better suited in what sense?" and to explore different effectiveness criteria that may lead an organization with a specific organizational form to be "good in one context or under one criteria... [and] bad under another" (Ashby 1968 in Scott 2003: 350).

Rather than determine whether Friends of the Earth International (FoEI) and Greenpeace are effective or not in some general sense, I align with the approach proposed by Scott (2003) to "examine what types of effectiveness criteria are suggested by what constituencies and what type of indicators of effectiveness are proposed with what implications for organizational assessment." In other words, I adopt a multi-faceted conception of organizational effectiveness and argue that FoEI and Greenpeace are both effective in their own way. I propose that these organizations are effective because they have remained viable, based on the empirical data outlined in Section 1.2.1 above. Their ability to remain viable over time is a surrogate measure of success that indicates their continued capacity to pursue their goals. I argue that the organizational viability of 
FoEI and Greenpeace stem from their adaptive capacity, their ability to develop typical strategic responses to complex and dynamic internal and external pressures.

Multiple indicators of effectiveness arise in part because of the diverse stakeholders and actors in the organization field of social movement organizations - including donors, staff, regulators, allies - who formulate different assessments, based on their interests, as to the performance of an SMO (Brown et al. 2003). It is possible that a number of stakeholders could reach similar conclusions as to the criteria for evaluating effectiveness. This would lend weight to the argument that it is possible to define independent and "objective" criteria of effectiveness (Herman and Renz 1999: 119). However, more often, there are different and even conflicting judgments by various stakeholders that require SMOs to negotiate tradeoffs in fulfilling their expectations (Brown et al. 2003). This suggests that setting universal standards for effectiveness and defining effectiveness indicators in objective terms can be misleading and even inappropriate if, in fact, there are multiple stakeholders assessing an organization in multiple ways (Coates and David 2002). It would also support the view that effectiveness can best be defined as a social construct, in that "some parts of reality do not exist independent of the beliefs and actions of people," and, therefore, "effectiveness is a stakeholder judgment, formed and changed in an ongoing process of sense making and negotiation" (Herman and Renz 1999: 118). Fulfilling the different demands and expectations made by diverse stakeholders upon the SMO is a difficult task, particularly because SMO stakeholders do not necessarily conceive of their demands as a social construct but, more likely "will state their aims so that they appear to be universalistic and objective" (Scott 2003: 355).

As stated above, I argue that Greenpeace and Friends of the Earth International are both effective social movement organizations based on their continued organizational viability. I draw on the historical analysis of organizational theory by Scott (2003) and a complementary work on organizational metaphors by Morgan (1997) in order to place the analysis of this thesis within the context of other analyses of organizational effectiveness. According to early organizational theorists such as Karl Marx, Max Weber, Frederick 
Taylor and Herbert Simon, organizations were considered closed and rational systems wherein organizations were perceived as being internally focused, ordered and controlled in order to achieve specific formally agreed goals (Scott 2003: 33-55). For Morgan (1997), this approach to organizations and management aligns with the metaphor of the organization as a machine. Morgan notes that classical management theory and scientific management were initially proposed as being a generic "one best way" to organize, and applicable across all types of organizations. However, there are widely recognized limitations to this model as it "tends to underplay the human aspects of organization and to overlook the fact that the tasks facing organizations are often much more complex, uncertain and difficult than those that can be performed by most machines" (Morgan 1997: 27).

Within the rational approach to organizations, "organizations are viewed as instruments for the attainment of goals," which generates effectiveness criteria based on the specific goals of the organization and on the number, efficiency, productivity and quality of its activities and outputs - its output effectiveness (Scott 2003: 351). Organizations make decisions as to their activities and programs based on their assessment of how the inputs they receive - funding, information, staff, allies - can be translated into value (Brown et al. 2003: 35). By tracing their activities through a value chain, it becomes apparent that their outputs need to be assessed at two levels of effectiveness: outcomes and impacts. Measuring outcomes of an activity places the focus on changes in the behavior of actors that are the target of that activity. Gauging impact requires an assessment of the broader social, economic and political results of the activity. Output effectiveness can also be assessed through process measures that analyze the quantity or quality of organizational activities to "assess effort rather than effect" (Scott 2003: 366). Process measures are one step removed from output assessments that evaluate achievements. These measures are based on the assumption that the organization has correctly calculated which activities will deliver results. If this assumption is not accurate, there can be a disconnect between output goals and means. Process measures have the advantage of directly evaluating organizational characteristics and internal activities, rather than assessing external performance which can be difficult to ascertain. 
The natural system perspective on organizations emerged in the early to mid- $20^{\text {th }}$ Century as a reaction to the closed, rational system approach to organizations and management and its emphasis on output goals (Scott.2003: 56-81). Although the focus remained on internal functioning of organizations, this approach depicted organizations as a social collectivity working for the viability of the organization through developing shared systems of meaning, nurturing social and human relations, fostering loyalty and commitment, and creating informal systems of engagement. Natural systems theorists accepted the view from earlier rational theorists that organizations pursued a set of instrumental goals, but added that organizations also seek to maintain themselves, and therefore have a set of support goals to ensure their survival (Gross 1968; Perrow 1970: 135). As Scott (2003: 57) notes, "no organization can devote its full resources to producing products or services; each must expend energies maintaining itself." Organizational maintenance can simply refer to survival and receiving "adequate" funding (Herman and Renz 1998) for persistence; however, organizations frequently seek a more "thriving" approach to organizational maintenance and pursue "financial sustainability" (Moore 2000) or a continuous input of resources to increase organizational viability, ensure legitimacy and support (Brown and Moore 2001), grow (Van der Hiejden 1997), and remain relevant and regenerate (Fowler 2000). Survival can simply refer to the existence of a skeletal structure of an organization in decline; whereas, terms such as viability and thriving indicate healthier and more vibrant indicators of organizational maintenance.

As will become evident in Section 1.5 below, a focus on organizational maintenance and support goals brings in a temporal dimension and evaluates the viability of an organization over time. An organization can build structures and capacities as it evolves - including adaptive capacity - that support its organizational performance. Of course, the maintenance of an organization for its own sake is not the same as external performance and the effectiveness of an organization in achieving outcomes and impacts. As Fowler (2000: 133) states, it is not simply about maintaining the viability of an organization and facilitating its regeneration, but also posing the question "regenerate for 
what?" Fowler argues that organizational maintenance is aimed at enhancing the performance, public trust, reputation, quality and relevance of an organization. The alignment between output effectiveness and internal organizational effectiveness is not always achieved, and it has long been the concern of organizational theorists that organizational maintenance and external value creation can be in tension (Gouldner 1959: 405; Jordan and Maloney 1997; Galaskiewicz and Bielefeld 1998; Doherty 2002). Within organizational studies, theorists adopting an organizational ecology perspective focus specifically on organizational survival, particularly at the level of populations of organizations, because of their skepticism of tracing direct and accurate linkages between external performance and survival (Aldrich 1979; Hannan and Freeman 1977). In their analysis of "permanently failing organizations," Meyer and Zucker (1989) similarly assert that, as an organization ages, it contains multiple constituencies that have an interest in maintaining its existence even if it is failing to achieve its official goals. Natural systems theorists would argue that this persistence can still be conceived as serving a purpose even if it is not achieving "official" goals; however, a more holistic approach to defining the effectiveness of an organization is based on its ability to both maintain itself internally - its support goals - while also achieving outcomes - its output goals. 


\section{Figure 1.10 Output and Support Goals for Organizational Effectiveness}

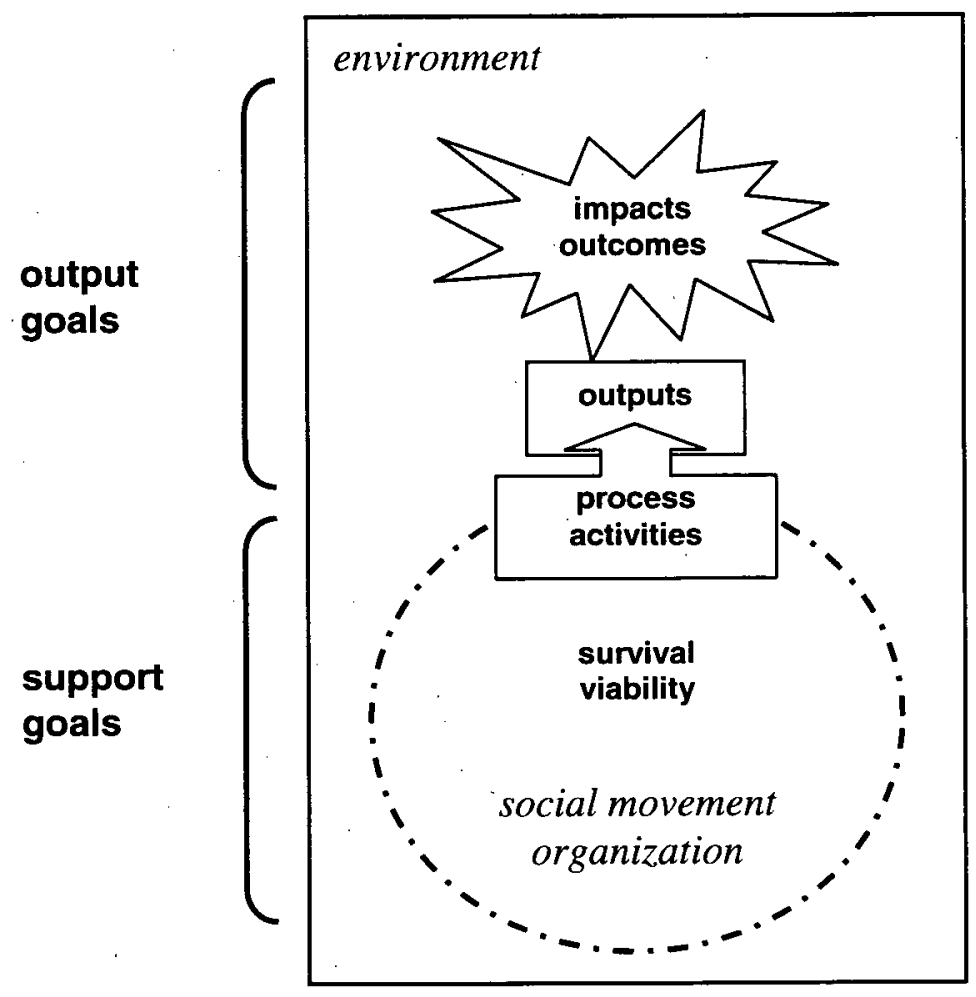

Figure 1.10 distinguishes between output goals and support goals. It depicts a social movement organization that is fulfilling its support or maintenance goals by surviving and remaining viable within the environment. The social movement organization is also engaging in activities and processes that produce outputs in order to advance its output goals of creating outcomes and impacts in the environment. Scholars often portray the task of achieving support and output goals simultaneously as a more complex task for social movement organizations than for private sector organizations (Brown et al. 2003). The straightforward bottom-line measurement of financial performance used to assess the value produced by private sector organizations is contrasted with the strategic dilemma facing social movement organizations (Moore 2000). Social movement organizations are perceived as being caught in a tension between "achieving mission" and "sustaining adequate funding" (Herman and Renz 1998). As such, they are striving to satisfy two bottom lines of "mission effectiveness and financial sustainability" (Moore 2000). Although ultimately private sector organizations are accountable to their shareholders and customers, it is not clear whether this tension between "social" and "financial" measure 
of performance (Siciliano 1997) is solely experienced by nongovernmental organizations and social movement organizations. With the rise in demands for corporate responsibility and the "triple bottom line" of economic, social and environmental criteria, private sector organizations are compelled to identify a broader stakeholder group (e.g., legislators, the public, and communities affected by their activities) as being important for achieving future financial performance, maintaining their social license to operate, and establishing continued legitimacy (Hoffman 2001). With this recent trend, there is some convergence in effectiveness measures between the two sectors, and substantial sharing of analytical tools, such as the "Balanced Scorecard" for assisting the development of organizational performance measures (Kaplan 2001). That said, the tension is more pronounced for social movement organizations due to the fact that the value of their activities is "not particularly well measured by financial performance" (Moore 2000). In the private sector, there is direct feedback from customers, in terms of financial input, if the product produced by a company is considered to be of value; whereas in social movement organizations, there is often a distinction between the beneficiaries (the people and communities benefiting from the SMO's activities (e.g., marginalized communities, future generations, other species) and the benefactors (the donors and supporters providing financial resources, partnership and other support) (Moore 2000).

Measuring performance in achieving outcomes by social movement organizations is a challenging task since "outcomes such as improved services, enhanced capacity or policy reform can be difficult to measure, distant in time, and subject to a variety of influences" outside of the SMO (Brown et al. 2003: 39). These factors combine to makes effectiveness measures "inherently ambiguous" (Brown et al. 2003: 39). It is even more difficult to assess the effectiveness of social movement organizations in "expanding successful programs so they can create large-scale social impact" through, for example, replicating successful programs in new geographical areas or adding new topic areas or new activities to an existing campaign scope (Letts et al. 1999:2). For some social movement organizations, a shift towards assessing impacts in addition to outcomes requires a focus on "mission success" (Sawhill and Williamson 2001a: 371) and 
"measurable impact" (Beckwith et al. 2002: 409) that evaluates the organization's contribution to the ultimate mission and goals (e.g., conserving biodiversity or reducing poverty) (see, for example, Sawhill and Williamson 2002a; Sawhill and Williamson $2001 \mathrm{~b}$ on The Nature Conservancy and biodiversity conservation; and Beckwith et al. 2002 on Care International and poverty reduction). An evaluation of impact requires setting a "strategic target" that explicitly outlines these ultimate impacts.

For social movement organizations that aim to alter the status quo within society, the mission and impact goals of the organization are necessarily "larger" than the SMO's practical campaign goals, regardless of the effectiveness of its processes, programs and activities (Brown and Moore 2001; Beckwith et al. 2002). These points suggest that building alliances and creating coalitions and partnerships to achieve the broader impact goals are critical to "mak[ing] lasting and positive impacts" (Beckwith et al. 2002: 416; see also Moore 2000). Because the outputs of the programs of a social movement organization are frequently created in partnership with allies in formal coalitions or in informal networks (Uvin et al. 2000), tracing specific contributions to individual organizations becomes even more problematic (Brown et al. 2003: 36). In addition, information about long-term impacts is not accessible for assessing performance in the short-term and, even in the long-term, cannot be easily traced as being causally affected by the campaigns and actions of a particular SMO. Demonstrating impact can lead an organization to "risk taking credit inappropriately or shouldering the blame for indicators beyond their control" (Campbell 2002: 243). Brown and his colleagues (2003) suggest that a "combination of easy-to-get, immediate information about processes and outputs, and more ambiguous information about longer-term outcomes and impacts" may be most appropriate in determining social movement organization effectiveness. They recommend that SMOs should be careful not to overemphasize short-term campaigns and easily quantifiable indicators in efforts to demonstrate output effectiveness.

As this discussion suggests, measuring the effectiveness of specific outputs on achieving outcomes and impact is not easy. By creating a more enduring structure, social movement organizations shift their focus to building the organizational viability and 
capacity to produce programs and outputs over time, and to learn and adapt from experience in order to increase their odds of having an effective impact. Letts et al. (1999: 3 - emphasis in original) argue that an emphasis on expanding programs does not by itself increase impact but requires a focus on "building effective organizations that can sustain and improve those programs." According to Letts et al., a focus on internal organizational effectiveness and capacity-building - the support goals - rather than only on program or output effectiveness is essential for achieving social impact and overall effectiveness over time. Letts et al. focus on nonprofit organizations but this analysis holds equally for social movement organizations. The following quote illustrates their central argument.

Traditionally, nonprofit organizations have relied on programs to create impact, and on expanding those programs to increase the reach of organizations and missions. Both funders and nonprofit organizations are increasingly recognizing that sometimes even the best programs do not survive, much less grow.... Although a variety of forces threaten success in the nonprofit world, one fact is clear: Programs cannot stand alone. Even innovative programs alone are a weak foundation for large-scale social impact. The missing ingredient in the prevalent, program-centred conception of social impact is organizational capacity. Programs need solid organizations behind them - organizations focused on fulfilling mission in a changing environment. Organizations not only develop programs, but also operate, sustain, improve and grow them - eventually replacing them with new approaches. It is the capacity for strong performance in organizations the ability to develop, sustain, and improve the delivery of mission - that provides the foundation for lasting social benefits (Letts et al. 1999: 3-4).

Letts and her colleagues define this shift as a change in focus from program delivery and program expansion - output goals - to organizational performance and capacity - a combination of output goals and support goals. They focus specifically on those organizational capacities that enable an organization to operate in a changing environment. Letts et al. determine that this is based on an organization's "adaptive capacity", which they define as the ability of an organization to learn, to be responsive, to innovate repeatedly, to motivate staff, to deliver quality products and services, and to collaborate with allies to attain output goals. Adaptive capacity is presented as a critical component of organizational effectiveness and it is this notion that guides the analysis of this thesis. 


\subsection{Organizational Effectiveness in a Complex and Dynamic Environment}

The previous section on organizational effectiveness built on the perspectives of rational and natural systems organizational theorists (Scott 2003). Rational systems theorists argued that effectiveness could be determined by the achievement of output goals. Natural systems theorists added that support or maintenance goals were also critical as they ensured organizational survival and viability. A number of rational and natural system theorists had anticipated the importance of organization - environment relations; however, it was only after the 1960s that an open system approach to organizations became dominant and an additional set of criteria for evaluating effectiveness was introduced (Scott 2003: 82-101). As outlined in Section 1.3 above, open systems theorists perceive organizations as being highly interdependent and interactive with their environment and "engaged in system-elaborating [output goal] as well as systemmaintaining [support goal] activities" (Scott 2003: 352). As an open system, organizations require critical information acquisition, processing and organizational adaptation mechanisms "since an organization's long-term well-being is dependent on its ability to detect and respond to subtle changes in its environment" (Scott 2003: 352). Individuals within these organizations intentionally scan their environment for change and creatively adjust their organizations to respond to these changes.

Open systems theorists added adaptability as a new criterion of organizational effectiveness measuring the extent to which an organization's output goals and organizational maintenance remain relevant and responsive to environmental changes and internal organizational shifts. In this thesis, I focus on this final effectiveness measure: adaptability. In doing so, I am selecting a support goal and structural indicator, which assesses the capacity of an organization for effective performance by analyzing organizational features, rather than assessing the outcomes of their activities and processes (output goals). This is a surrogate measure of effectiveness because this measure "index[es] not the work performed by structures but their capacity to perform work" (Scott 2003: 367). 
In this thesis, I am interested in how individuals within a social movement organization repeatedly respond to changing internal and external pressures, rather than analyzing an SMO's response to a particular episode of change. Although I draw on analyzes of specific Friends of the Earth International and Greenpeace campaigns and actions, it is important to note that the assessment of their output effectiveness is not the primary focus of this thesis. I argue that Greenpeace and Friends of the Earth International have operated successfully within conditions of complex and dynamic external and internal pressures over the four decades of their existence. Under these conditions, I propose that these social movement organizations have developed a typical patterned response - a capacity - to respond to the requirement for adaptability within these conditions. As mentioned in the Section 1.1, I define this patterned response as the adaptive capacity of a social movement organization. I propose that adaptive capacity is a characteristic that arises from certain combinations of structure and strategy, and that, over time, individuals within organizations elaborate and refine those strategic responses that are deemed to provide workable solutions to key organizational challenges.

Why is the ability to create adaptive capacity an important index of the effectiveness of social movement organizations such as FoEI and Greenpeace? Building on the insights of open systems theorists, I argue that it is important for measuring organizational effectiveness over time. Analyzing change over time is critical to understanding the organizational evolution of an SMO and its interactions with the environment. SMOs are defined as the "more organized, enduring and long-lived" parts of a social movement, which have a "collective, continuing, and organized character" (Lofland 1996: 10-11). Analyzing the effectiveness of a SMO over time and over a longer time frame may be appropriate in assessing their capacity to be "enduring" and "long-lived" while remaining relevant and furthering the goals of the social movement within which they are embedded. In Chapter Five, I argue that adaptability is critical for organizations seeking to influence long-term social change beyond individual campaigns. In order to advance fundamental changes in the power structures, economic activities, policies and resource distribution systems of society, SMOs need to remain active for decades, particularly as actors benefiting from the status quo actively suppress such change. 
Given the nature of a social movement organization and the individuals participating in its activities, it is remarkable that SMOs continue to survive for a significant period of time. Unlike most private sector organizations, many SMOs are "accidental" in the sense that the organization was established in direct response to an emergency or cause, or set up as a small-scale experiment assumed to have an uncertain future (Smillie and Hailey 2001: 14). Few SMOs begin by developing such things as formally declared missions, clear strategies and work plans, or established governance, structures and systems. Neither do they anticipate transforming into large influential organizations.

Organizational growth has been proposed as a dimension of organizational effectiveness, particularly as growth in resources can provide opportunities for organizational development (Van der Heijden 1997: 35-40; Smillie and Hailey 2001: 4; Sowa et al. 2004: 719); however, even during periods of decline in resources, SMOs can remain effective in advancing their output goals. I propose that a focus on adaptability over the time of organizational development provides additional insights into the conditions under which effectiveness occurs by exploring the creative and strategic approach individuals within SMOs adopt to respond to change over time.

The continued viability of social movement organizations such as Greenpeace and Friends of the Earth International is also remarkable given the types of individuals that a SMO mobilizes, the expectations of supporters, and the culture of activism within a social movement organization. As Chapters Five and Six will demonstrate, Friends of the Earth International and Greenpeace have survived through periods of internal organizational conflict and crisis - triggered by such things as politics, passion, and different interpretations of environmental change and appropriate responses. Dobbin (2001: 75) notes that social movement organizations may use the language of strategic management, entrepreneurialism and remuneration in descriptions of their activities or organizational manuals; however, strategic and "inward-looking description still often assume[s] the language of emotion and commitment." Even when social movement organizations establish rules, processes and structures, the individuals and groups within these social movement organizations - often even those who created the rules, processes 
and structures - are independent, passionate, driven people that will spontaneously circumvent structural arrangements if they find that these arrangements hamper campaigning and efforts for social change. According to Freeman and Johnson (1999), it is this combination of spontaneity and structure that defines social movements.

It is difficult to identify the exact amount of structure necessary to distinguish a social movement from a crowd or trend, and often harder to distinguish a social movement organization from an interest group, but those distinctions are crucial. It is the tension between spontaneity and structure that gives a social movement its peculiar flavor. When one significantly dominates the other, what may one day be, or may once have been, a social movement is something else.... Regardless of whether structure or spontaneity comes first, or if they appear simultaneously, the important point is that both must exist (Freeman and Johnson 1999: 1).

Social movement organizations pride themselves on their focus on action and campaigning. Some of this campaigning requires quick decision-making within the context of shifting interests and actions of campaign targets (McAdam 1983; Batliwala 2002). The effect is that resources used to build organizational structure and processes can be seen as luxuries or distractions, rather than necessary for building long-term organizational capacity. In fact, "programs and organizational capacity are almost seen as competitors in a zero-sum struggle for limited resources" (Letts et al. 1999: 32). Donors and supporters can also hold expectations of efficiency and low administrative overhead in delivering campaigns and programs. Some activists perceive strategic planning as a private sector technique, and have a bias against adopting private sector approaches to organizing because private sector organizations are frequently the targets of their campaigns (Letts et al. 1999). Anheier (2000: 2) argues that until recently, social movement organizations viewed "management" as a "bad word" that did not fit with the characteristics of their organization that some regarded as focused on "voluntarism, philanthropy, compassion and a concern for the public good." Anheier notes that SMOs are increasingly adopting private sector models for capacity building to deal with their growing prominence and influence and with their uncertainty of how to operate in turbulent conditions. 
I argue above that a time dimension becomes important in understanding the evolution of Greenpeace and Friends of the Earth International as organizations that have thrived for 35 years. It becomes even more important when we consider that these social movement organizations are interacting with a complex and dynamic transnational environment. As Chapter Two will describe, the environment within which Friends of the Earth International (FoEI) and Greenpeace operate has changed substantially over the decades, and some of these changes can be attributed in part to the efforts of these social movement organizations to trigger societal and personal change. I argue that these changes can be traced across several key dimensions: the nature of the environmental and sustainability challenge, the complexity and multi-faceted nature of the issues being addressed, and the interests and activities of the diverse actions with whom these organizations interact. Greenpeace and Friends of the Earth International have been affected by and have influenced the incremental evolution of their issue areas and political environment, and have also experienced episodes of abrupt change including unpredictable crises resulting from hostile backlash to their activities or unanticipated windows of opportunity for exerting influence. 


\section{Figure 1.11: Organizational Effectiveness and Adaptive Capacity}

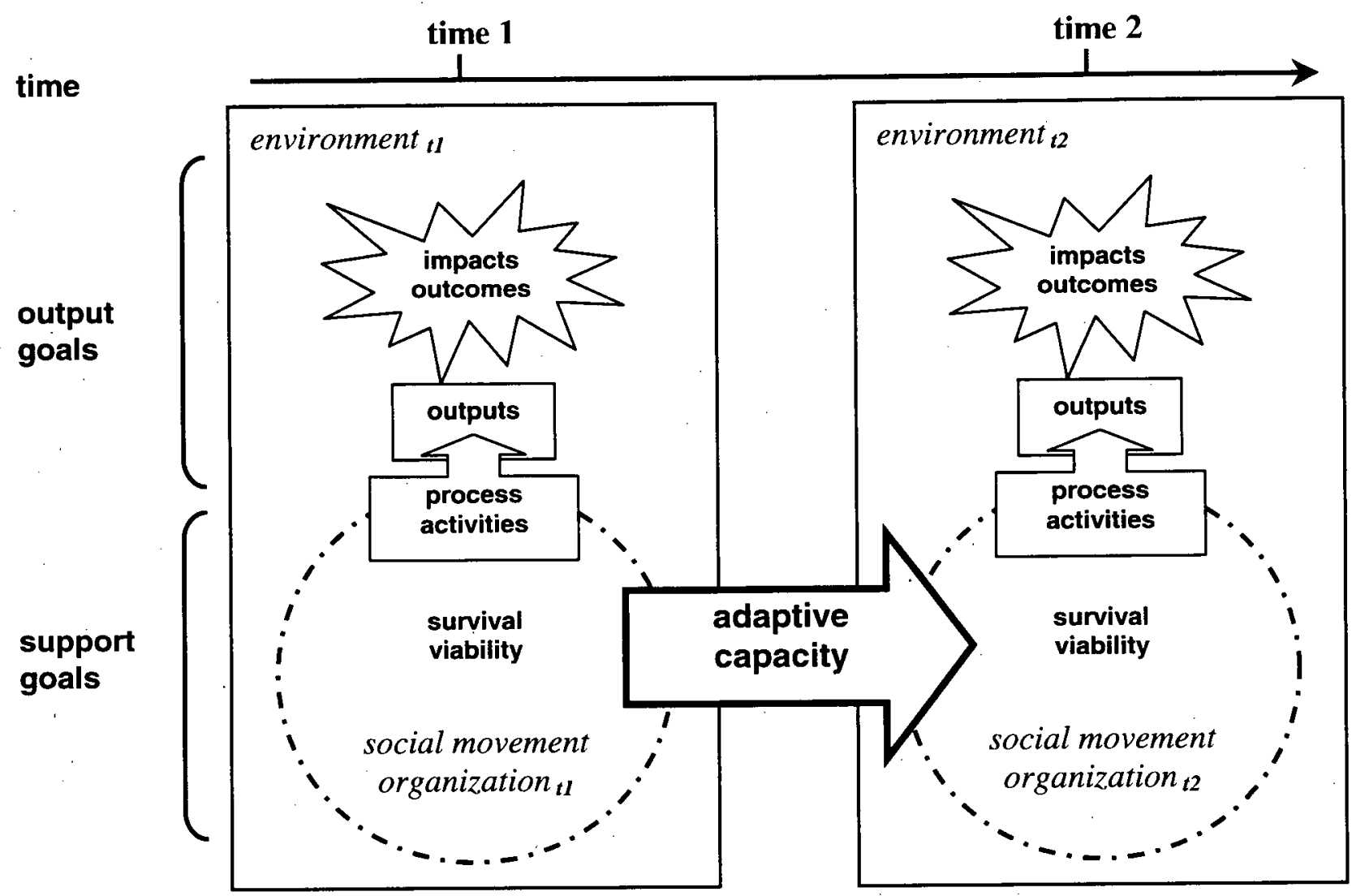

As Figure 1.11 displays, adaptive capacity is the organizational ability to build a patterned response to complex and dynamic internal and external pressures over time, depicted in the figure as a change from 'time 1' to 'time 2'. Complexity and turbulence in internal and external pressures is not a condition unique to social movement organizations. Accordingly, there is a recent surge in scholarly and practitioner interest in how organizations in all sectors - private, governmental, intergovernmental and nongovernmental - can organize effectively in an increasingly multifaceted, varied and rapidly changing environment (e.g., Davidow and Malone 1992; D’Aveni 1994;

Galbraith 1994; Hamel and Prahalad 1994; Hamel 1996; Brown and Eisenhardt 1998; Letts et al. 1999; Wheatley 1999; Christianson and Overdorf 2000; Fowler 2000; Moore 2000; Morgan 1999; Smillie and Hailey 2001; Warkentin 2001; Ashkenas et al. 2002; Ebrahim 2003). Weick and Quinn (1999) argue that in the context of a dynamic environment, an effective organization can be defined as one that is continuously able to adapt and builds adaptive capacity. In fact, Young et al. (1999) propose that it is this 
capacity to adapt - which they define as the ability of organizations "to find creative and flexible ways to organize and manage themselves in order to survive and work effectively" - that is a distinguishing feature of nongovernmental organizations.

I propose that the strategies SMOs develop in response to complex and dynamic conditions are developed over time based on the iterative relationship between an organization's core beliefs and values, tactics, activities, structural formation and experiences. Although this routine response can be called into question in situations of discontinuous and dramatic change in the environment, I argue that the patterned response is remarkably robust. In social movement organizations, some of this robustness can be attributed to the fact that members of the organization predominately focus on action in pursuit of social change rather than on reassessing the functionality of past response routines. These routines also remain robust because there are many factors that determine the complexity and turbulence of the environment; accordingly, there are also a number of viable ways of organizing to operate in this environment (Young et al. 1999). The purpose of this thesis is to illuminate two such unique and viable routine responses to organizing within complex and dynamic conditions.

\subsection{Research Methods}

In this thesis, I challenge the assumption of "one best way" of organizing to maximize adaptability in complex and dynamic conditions by analyzing the relationship between the degree of centralization and formalization of social movement organizations and the effect of organizational structure on adaptive capacity. I employ two research methodologies to conduct this analysis: a comparative case study approach and a grounded theory approach (Lofland and Lofland 1984; Lofland 1996: 24; Yin 2003). In Section 1.2 above, I introduce the two case study organizations - Friends of the Earth International and Greenpeace - which inspired this dissertation and note the similarities and important differences in their mission, activities, and structures. Both organizations were established in the late 1960 s as part of the modern environmental movement and are considered to be part of the same "social movement industry" (Doherty 2002). Brown and Iverson (2004: 397) recommend case study research that "is focused within an 
industry classification or market" in order to "allow for a more refined understanding... by controlling the potential influences". on the central variable which in this dissertation is "adaptive capacity." The relatively more centralized and formalized structure of Greenpeace in comparison with Friends of the Earth International lend these two organizations to a comparison that can bring the effects of their different structural configurations and corresponding strategic responses into sharper relief. As Jasanoff (2005: 29) writes, "the comparative method works best when the entities to be compared are different enough to present interesting contrasts, yet similar enough for the variations to be disciplined."

In analyzing the adaptability of Greenpeace and Friends of the Earth International, I define these transnational social movement organizations as open systems interacting with the political environment. Yin (2003) recommends a case study approach when the investigation is taking place in a real-life context and the contextual conditions are influential, when the boundaries between the phenomenon being analyzed and the context are blurred, and when the situation is complex with multiple sources of evidence that require triangulation in order to compare data for analysis. I have collected predominately qualitative data, supported by pertinent quantitative data, for tracing the organizational development of FoEI and Greenpeace. The case study analysis includes the following sources of data (Lofland 1996: 26-27):

- Scholarly literature on Greenpeace and Friends of the Earth International. Both of these organizations have been subject to a number of detailed studies on their organizational history (e.g., Burke 1982; Wilson 1984; Lamb 1996 on FoEI; Hunter 1979; Bohlen 2001; Weyler 2004 on Greenpeace), on their specific tactics such as the use of the media and the Internet for activism (e.g., Dale 1996; Warkentin 2001; Pickerill 2003) and on their campaigns (e.g., Stoett 1997; Florini 2000; Newell 2000; Purdue 2000; Arts et al. 2001; Bloodgood 2002). I also reviewed scholarly contributions that present critical analyses of these organizations (e.g., Chatterjee and Finger 1994; Dowie 1995; Jordan and Maloney 1997). I draw heavily on scholars that explicitly compare Friends of the Earth International and Greenpeace (e.g., 
Dalton 1994; Wapner 1996; Diani and Donati 1999; Carmin and Balser 2002;

Doherty 2002).

- Popular literature. FoEI and Greenpeace are extensively represented in "articles of a journalistic or even sensationalistic cast that appear in mass circulation magazines and newspapers," not least because of their pursuit of news coverage of events and issues (Lofland 1996: 26). In this dissertation, I draw on popular literature to identify positive and negative stereotypical perspectives of Greenpeace and FoEI.

- Internal organizational documents. I collected data from archival sources in formally maintained collections and libraries within FoEI and Greenpeace, as well as documents from private collections of individuals associated with these TSMOs. Documents reviewed from both of these organizations included annual reports, conference reports, public statements, governance documents, constitutions, bylaws, Board Manuals, organizational handbooks, official campaign publications, strategy documents, and publicly available internal correspondence, committee reports and meeting minutes. These documents were essential in the analysis of the mission statements, membership, finances, budgets, governance and structure, campaigns and other internal characteristics. The data was collected over three site visits to the international office / secretariat of these organizations. The staff at both organizations was extremely generous with their time and assistance in arranging interviews and gathering data. In both organizations, I was provided with access to formal and informal documents and allowed to make copies or received copies of these files for reference. For the period following the site visits, I have remained in regular contact with key staff in the organization and have been provided with additional assistance, the lateșt organizational news and organizational documents.

- Serial publication. Friends of the Earth International produces a serial publication that serve as an information clearinghouse for internal organizational members and as a communication tool for supporters, LINK magazine. I reviewed both recent and archival copies of this serial publication.

- Biographies. There are a number of biographies and autobiographies of past leaders and key participants in FoEI and Greenpeace that are useful sources of information 
about their experiences and the organizational development of these two TSMOs (e.g., Hunter 1979; Brower 1990).

- Interviews. I undertook a series of in-depth semi-structured interviews with past and present representatives of Friends of the Earth International and Greenpeace. I conducted 10 FoEI interviews and 11 Greenpeace interviews including campaigners and Board members (see Table 5.1 for a complete list). Participants from within Greenpeace and FoEI, or who were connected with these TSMOs in the past, were selected based on their level and length of involvement in the SMOs and their role and position in the organization. Each interview was conducted in English and ranged in length from three-quarters of an hour to two hours. The participants signed a consent form and the interviews addressed a range of areas including: the participant's history or relationship with the organization, their role in the organization, retrospective perspectives on organizational responses to internal and external pressures including their role in these responses, and the relationship of the organization to the political environment and actors in the organizational field.

As the sources of data listed above suggest, I employ interview and document analysis as my primary research techniques in this dissertation. I supplement this analysis with observations that $I$ have made of these organizations in action at the United Nations Commission on Sustainable Development 2001-2002 and at the 2002 UN World Summit on Sustainable Development in Johannesburg, South Africa. By combining multiple sources of evidence, I am able to develop "converging lines of inquiry" and establish whether there is congruence amongst the multiple data sources (Yin 2003: 92-93). This triangulation of data - "asking the same question of different sources of evidence" (Yin 2003: 83) - is particularly important in my dissertation as it increases the likelihood that the account of organizational development and responses to internal and external pressures is as accurate as possible and captures different perspectives on organizational development, internal conflicts and goal attainment (Hartley 1994).

The exploratory nature of this study also suggests that a case study orientation is fitting (Yin 2003). I immersed myself in the case study data, and through iterative consultations 
with scholarly literature and my intuitions and insights about the data, I inducted the proposition that Greenpeace represents a viable approach to maximizing adaptability within complex and dynamic conditions. This approach to data analysis is also referred to as a "grounded theory" approach in which a theoretical model or "theory is 'developed that is grounded in data from the field" (Creswell 1998: 63). Lofland (1996: 86) writes the following summary of a grounded theory approach to social movement organizations (SMOs):

Researchers begin with an open-ended and open-minded desire to know an SMO and they are guided by the data and themselves as agents of induction in the task of emergently formulating one or more generic propositions (Strauss and Corbin 1990; Lofland and Lofland 1995). This immersion-induction or "grounded theory" perspective means that researchers approach the existing literature on SMOs and social movements as sources of flexible and variable consultation that stimulate their quest rather than as materials to be mastered in some strictly memorized fashion and applied in a mechanical manner (emphasis in original).

In this way, Lofland argues that researchers move from formulating questions about social movement organizations to developing propositions as to possible answers. As I iteratively analyzed the case study data and social movement theory, I found that I needed to search outside of the social movement literature in order to answer my central research question: does the prevailing assumption hold that a decentralized and informal structure is the only way for transnational social movement organizations to maximize adaptability in complex and dynamic conditions?

I develop my answer to this research question by drawing on a combination of social movement theory, international relations literature, organizational theory, and systems theory. The result of this interdisciplinary analysis is the models of adaptive capacity detailed in Chapter Four, and the analysis of adaptability and structure. 


\subsection{Organization of the Thesis}

In Figure 1.12, I build on Figure 1.11 in order to introduce the key concepts that I employ within this dissertation. This figure also serves as a guide to the organization of the thesis.

Figure 1.12 Key Concepts within this Dissertation

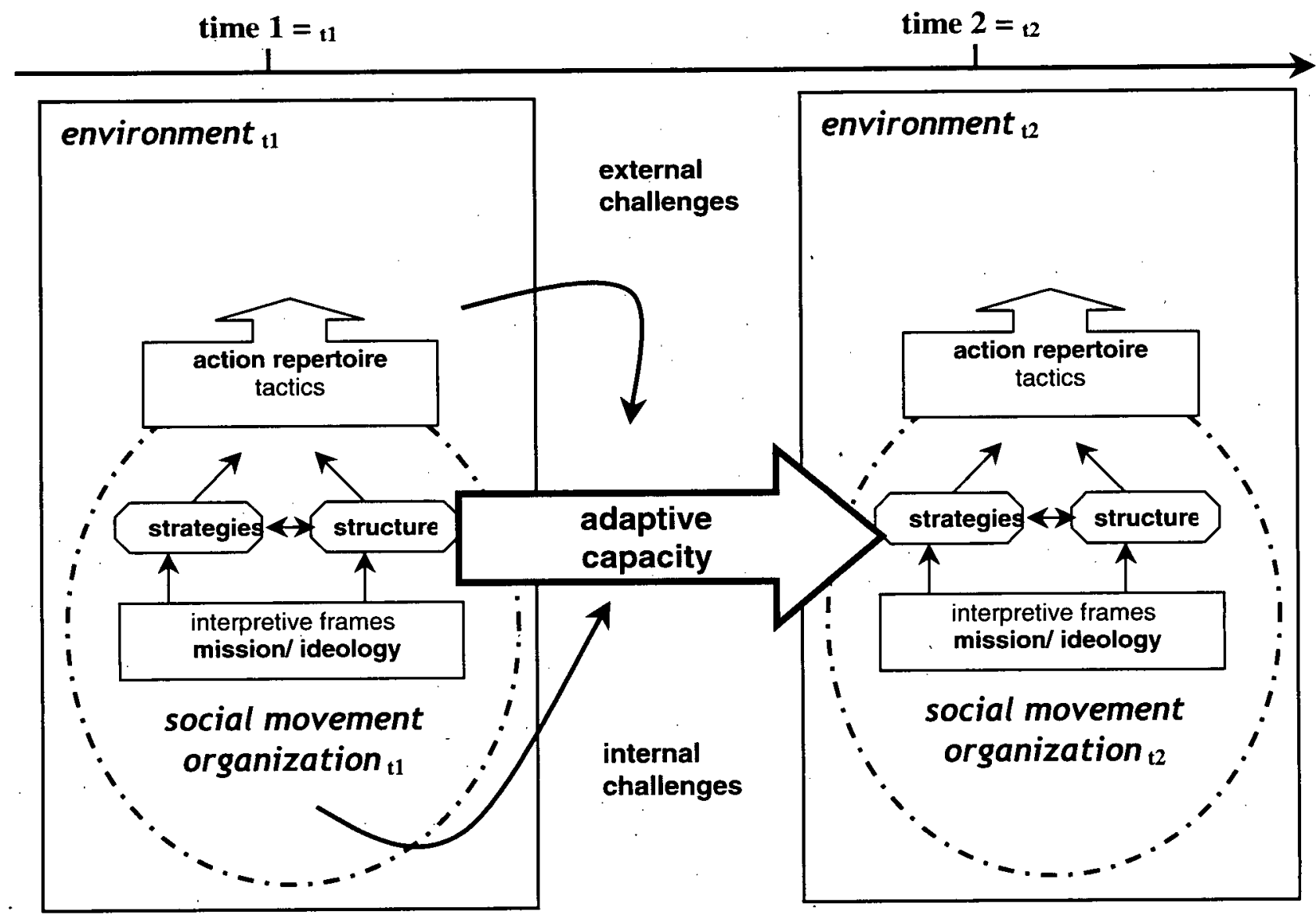

In Chapter Two, I examine the complex and dynamic political environment within which Friends of the Earth International and Greenpeace operate by exploring dimensions of this environment, including the field of actors with whom these TSMOs interact. I then outline the internal complexity of social movement organizations by discussing their interpretive frames, defined as the process by which individuals within SMOs actively assign meaning to and interpret the world around them (Snow et al. 1986; Snow and Benford 1988). Based on these interpretive frames, an SMO adopts an action 
repertoire, the routine forms of activities and clusters of tactics that an organization uses in a given historical period (Tilly 1978).

In Chapter Three, I substantiate my claim that Friends of the Earth International and Greenpeace have developed distinct organizational structures, by analyzing the degree of formalization and centralization of these two TSMOs. In Chapter Four, I present my main scholarly contribution, the Adaptive Capacity theoretical construct. I propose that TSMOs evolve strategies to respond to key organizational challenges. Over time, strategic responses that are deemed to repeatedly and reliably resolve these internal and external challenges become intentionally embedded in the TSMOs structure and decision-making processes and, subsequently, constrain future strategic responses. I argue that certain combinations of strategies and structures facilitate the building of adaptive capacity and support the continued viability of the TSMO. In Chapters Five through Eight, I compare two organizations that exhibit organizational viability, Friends of the Earth International and Greenpeace, in order to shed light on their distinct and successful approaches to building adaptive capacity.

In Chapter Nine, I analyze the strengths and deficiencies associated with FoEI and Greenpeace's approaches to adaptability. I highlight insights from this dissertation that may be of use to SMO practitioners and, specifically, members of Greenpeace and Friends of the Earth International. I present concluding insights that are relevant to my primary audience, the scholarly community investigating the adaptability of organizations and, specifically, resource mobilization theorists. I aim to contribute to this community by challenging the assumption that decentralized and informal structures are the only structures that maximize adaptability in complex and turbulent conditions, and by proposing an alternative approach to building adaptive capacity within transnational social movement organizations, as exemplified by Greenpeace, that is equally viable under these conditions. I also propose that other adaptive capacity models are possible at the organizational and movement level. 


\section{CHAPTER TWO: TSMOs in a Complex, Dynamic Political Environment}

\subsection{Operating Transnationally}

Friends of the Earth International and Greenpeace are transnational social movement organizations operating in a political environment and an organization field that spans local to global scales. The transnational nature of their operations and activities are part of a broader shift from national to transnational social movement activity that is analogous to the change from local to national social movement activity over the past centuries (Tilly 1984; Tarrow 1996). There are at least four main dimensions to this shift: (1) the issues are transnational in scope; (2) the actors they engage with are transnational, (3) the political opportunity structures they encounter at the national and international level, and (4) the transnational character of their social movement sector. Figure 2.1 depicts the TSMO as embedded within its environment, and lists the dimensions that I will explore in the sections below.

Figure 2.1 Transnational Dimensions of the Environment

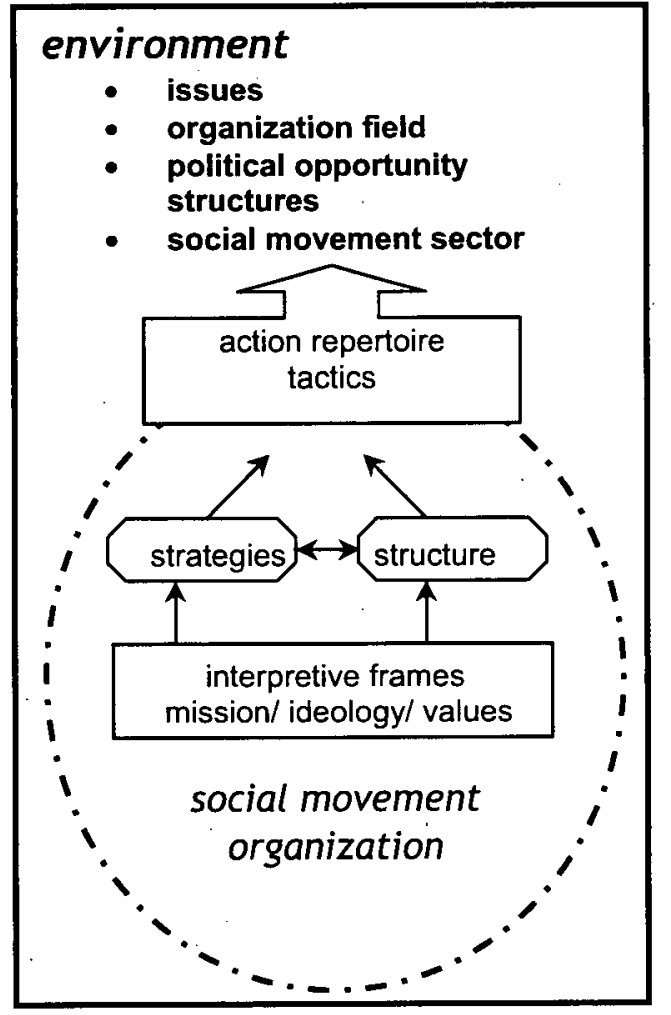




\subsubsection{Transnational Issues}

First, the issues that Greenpeace and FoEI are engaged with are transnational in nature. As McCormick (1989: 143) notes, organizations such as Friends of the Earth and Greenpeace draw attention to "international questions." Greenpeace's first campaign on US nuclear testing drew strength from operating outside of the United States in Canada (Hunter 2004: 16), in part because it focused attention on the trans-boundary nature of issues such as peace, nuclear disarmament, and environmental destruction. As section 1.2.1 described, David Brower, the founder of Friends of the Earth, actively sought to create an international organization in order to address what he considered to be an inherently international issue of "the preservation, restoration and rational use of the earth" (FoE Letterhead as quoted in Carmin and Balser 2002:373). FoEI and Greenpeace, as part of the modern environmental movement, emerged in response to problems of unsustainable human interactions with the natural environment, including extensive ecosystems degradation and pollution, and of resulting detrimental impacts on human and ecosystem health and quality of life (McCormick 1989; Newell 2000; Doherty 2002). Today, the campaigns of Greenpeace and Friends of the Earth International remain focused on transnational issues including climate change, deforestation, ocean pollution, overfishing, whaling, genetically modified organisms, trade, hazardous chemicals and the activities of multinational corporations and international financial institutions.

Environmental problems that occur or are tackled at a global scale are a relatively new phenomenon (Turner et al. 1990). Currently, environmental changes across scales are happening in complex ways, with unexpected dynamics and at an unprecedented pace (Berkes and Folke 1998; Clark et al. 2001; Kates et al. 2001; Turner et al. 2003: 8085). Some environmental problems "reach a global magnitude in character... by affecting a realm of the environment that operates as a fluid global system" including climatic change and the depletion of the ozone layer; whereas other environmental problems stem from "globally cumulative changes... that reach a global magnitude by either occurring so widely across the Earth's surface as to attain a worldwide character or by significantly affecting the total stock of some resources, however spatially concentrated it may be" 
(Myers 2001: 608). Examples of globally cumulative changes include habitat and species loss that accumulates into a global biodiversity crisis, and rapid and widespread deforestation that accumulates into a problem of global forest loss and degradation. A report commissioned by the US National Research Council (1999). indicates that the growing interconnectedness of human and natural systems will result, in the medium term, in "environmental threats [that arise] from multiple, cumulative, and interactive stresśes, driven by a variety of human activities" and these threats will become "difficult to untangle from one another and complex to manage." To add to the complexity, environmental problems that are global in magnitude can have different impacts in different regions and places (Yearley 1996). There are also important distinctions in the extent to which countries are sources of global environmental problems, such as industrialized countries contributing the largest percentage of greenhouse gases that lead to climate change. Greenpeace and FoEI join other actors in raising awareness about global environmental issues, and pursuing an international response to this "era of global environmental change and interdependence" by emphasizing the complex interactions amongst ecological, social, political and economic systems across scales and time (Clark et al. 2001: 3). As the next two sections highlight, FoEI and Greenpeace have developed different interpretations of the transnational environmental problem and of potential solutions which, in turn, influence their strategies and tactics, their organizational structure and their outcomes and impact (Carmin and Balser 2002).

\subsubsection{Transnational Organization Field}

A second dimension of the transnational shift in social movement activity is the transnational nature of the organization field within which Greenpeace and Friends of the Earth International operate. FoEI and Greenpeace seek to influence a transnational organization field of actors. who are interconnected through processes of political, economic, and cultural globalization. In past centuries, communities and societies have interacted across borders through trade and cultural exchanges. However, this relatively "thin" interdependence can be contrasted with "globalization" which Keohane and Nye (2000), building on Held (1999), describe as being the process by which these interconnections are becoming increasingly "thick." Greenpeace and FoEI pursue their 
interests within a dense web of international actors many of whom are joined together in historically unprecedented ways by communications and transportation technology (Tarrow 1996: 9).

Global interdependence is shaping the way that national governments function. There is a rapid rise in the number of international, regional and bilateral agreements and treaties on such issues as international trade, transboundary air pollution and nuclear nonproliferation that has resulted from the interactions amongst national governments (Young 1997). These "international decision-making webs" (Smith et al. 1997: 67) on different issues have been defined as international regimes - the legal and political "social institutions composed of agreed-upon principles, norms, rules and decisionmaking procedures that govern the interaction of actors in specific issue areas" (Levy et al. 1995). International regimes place constraints on national decision-making as domestic and international interests of nation-states are defined in relationship to each other (Putnam 1988; Keck and Sikkink 1998: 4; Risse 2003). Scholars have documented the influential role that Greenpeace and Friends of the Earth International have played in shaping international regimes on such issues as climate change, ozone depletion, whaling, toxic chemicals, and the transboundary movement of hazardous wastes, as well as analyzing the regimes in which Greenpeace and FoEI have struggled to have an impact including nuclear proliferation and trade (e.g., Benedick 1991; Stoett 1997; Fox and Brown 1998; Florini 2000; Newell 2000; Purdue 2000; Arts et al. 2001; Bloodgood 2002).

Smith (2005) writes that "as national markets dissolve into a growing global marketplace, national governments have turned increasingly to international organizations to negotiate new rules about the boundaries of state authority." In addition to targeting nation-states with their activities, Greenpeace and FoEI focus their efforts on influencing the international agencies that national governments have established, including international organizations (e.g., the World Trade Organizations and United Nations agencies), economic institutions (e.g., the World Bank and International Monetary Fund), and regional bodies (e.g., the European Union and the Organization of African Unions) 
(della Porta et al. 1999; Guidry et al. 2000). International and regional gatherings of these agencies also serve as arenas for transnational social movement activity (Florini 2000); for example, Greenpeace and Friends of the Earth International are active at a range of international meetings including those of the UN Convention on Biological Diversity, the International Whaling Commission, the UN Framework Convention on Climate Change, and the World Trade Organization.

Traditionally, scholarly analysis of actors operating at the transnational scale has been the domain of International Relations scholars (e.g., Mathews 1997; Risse 2003). International Relations literature emerged to analyze the role of nation-state governments within global governance processes; however, it became widely acknowledged that governance at the transnational level involves and is shaped by both states and non-state actors. Non-state actors include international organizations, multinational corporations and civil society actors (Risse 2003). Some scholars maintain that the influence of nonstate actors is minimal compared with the interactions amongst nation-states in determining world politics (e.g., Waltz 1993). Other scholars herald non-state actor involvement as a "power shift" wherein national governments are both "losing autonomy in a globalizing economy" and sharing power with non-state actors (Mathews 1997). Reinicke (1998: 219) argues for a combined approach by acknowledging that global governance without governments "is not an option;" and that, equally, the success of global governance processes requires "enlist[ing] the active cooperation of non-state actors." Greenpeace and Friends of the Earth International have adopted strategies to operate effectively within this expanded transnational organization field. In addition to campaigns aimed at nation-states and international organizations, they target companies with their campaigns. Both Friends of the Earth International and Greenpeace protest against Monsanto for its production of genetically modified organisms. FoEI reports successful protests against the activities of British Petroleum in Georgia and the US mining company, Newmont in Indonesia. ${ }^{14}$ Greenpeace campaigns against Exxon/Mobil Corporation because of its perceived disregard of climate change and its lack of

\footnotetext{
${ }^{14}$ FoEI (2004) Annual Report. FoEI, Amsterdam, The Netherlands.
} 
development of renewable energy. ${ }^{15}$ Greenpeace also reports a successful campaign in which Samsung electronics corporation "announced plans to phase hazardous chemicals out of its products, after they were graded 'red' on the Greenpeace website" (GPI 2005).

FoEI and Greenpeace respond to the increased capacity of multinational corporations "to mix and match flows of minerals, raw materials, manufactured goods, information and services from many sites worldwide [which] has outstripped the capacity of local or national social movements to contest their plans" (Cohen and Rai 2000: 8). Campaigns of collective action against the behavior of corporations often adopt a transnational character as local and national social movement actors in countries impacted by corporate activity gain from making claims alongside activists in the country where a corporation is headquartered (Tarrow 1996: 22). There are also possibilities of Northern activists assisting social movement activists in places negatively affected by corporate activities by lending their voice, votes, consumer power, ability to demonstrate, and access to privileged information about the countries and companies in a campaign (Clark 2003a: 182). Different companies and industries require different strategies and tactics depending on their visibility as a target (e.g., many small to medium sized businesses as compared to a multinational corporation), their vulnerability to disruptive protest (e.g., susceptibility of a business to boycotts and damage to their brand), and their interest in being perceived as proactive in social and environmental corporate citizenship.

\subsubsection{Transnational Political Opportunity Structures}

As a third dimension, the transnational shift in social movement activity is also due to the variety of "factors that facilitate or constrain social change efforts" at the transnational level. Social movement theorists label these factors as the "political opportunity structures" within the transnational organizational field (McCarthy 1997: 254), which include the level of democracy and freedom of political expression in diverse nationstates, tax laws and fundraising possibilities both national and internationally, established norms amongst actors in the field, and rules of access and participatory procedures that govern decision-making by governmental, intergovernmental and transnational actors

${ }^{15}$ Greenpeace (2005) Annual Report. Greenpeace International, Amsterdam, The Netherlands. 
(Smith et al. 1997: 66; Martens 2001): Political opportunity structures vary from country to country and from actor to actor, and even vary within the multiple layers of complex organizations and agencies. Dryzek and his colleagues (2003) identify differences in the influence of environmental movements across the United States, United Kingdom, Germany and Norway that derive from the level of inclusiveness of social movement actors into the decision-making process of the nation-states. These differences are equally pronounced between social movements operating in countries in the 'North' and in the 'South'; for example, southern social movements seeking to influence authoritarian regimes are not able to use the same tactics as social movements operating within democratic regimes (e.g., lobbying, petitioning, influencing voters). For each issue campaign, groups like Greenpeace and FoEI must strategically select the level of engagement within the layered transnational organization field that "provides them with the greatest opportunities and imposes the weakest constraints" (Tarrow 1996: 12). As Klandermans (1997) notes, "with the increasing number of political layers involved in the definition and implementation of a policy, the choice of one's adversaries [and the choice of one's allies] becomes less obvious and therefore more of a matter of social construction."

At the international level, the openness of political opportunity structures within global governance processes is influenced by the possibilities for engagement by social movement actors. For example, the United Nations (UN) "Conference Decade" of the 1990 s... affirm[ed] the right of nongovernmental actors to participate in shaping national and global policies on the environment, population, human rights, economic development, and women" (Batliwala 2002: 394). The possibility of acquiring accreditation and "consultation status" by transnational and, more recently, by local and national social movement organizations in certain transnational decision-making arenas including the United Nations, has facilitated the involvement of and greater access for social movement actors (Smith 2005: 234). Friends of the Earth International and Greenpeace have accredited consultative status to the United Nations Economic and Social Council (ECOSOC), which provides them with access to certain intergovernmental negotiations at the United Nations. FoEI also has observer status at 
international organizations such as the Food and Agriculture Organization (FAO), the International Whaling Commission, and the International Tropical Timber Agreement (ITTA). Greenpeace is accredited to more than 30 international and regional organizations dealing with environmental issues. In other global governance arenas, such as the World Bank and World Trade Organization, access to decision-making is more restricted and limited; however, there are still opportunities to influence their agendas through, for example, building ties with staff inside the organization who is sympathetic to the social movement's cause (Fox and Brown 2000).

There are thousands of international, national and local social movement actors, including Greenpeace and FoEI, which are officially accredited to intergovernmental agencies; however, access provided by accreditation does not guarantee access to decision-makers. Amongst accredited social movement activists, there are concerns about which activists are "hold[ing] the microphone" at intergovernmental meetings, and some issue as to whether Northern activists and other social movement participants with "professionalized" approaches are preventing other stakeholders (even "loud, militant, and difficult to control grassroots groups") from having a voice, defining "their 'take' on issues and strategic priorities" and setting the agenda (Batliwala 2002: 398). These are legitimate concerns and require transnational social movements and their carrier organizations to continue to play a role in "facilitating the voice of marginalized stakeholders" and "building bridges among diverse stakeholders" within global governance processes (Brown and Timmer 2006).

\subsubsection{Transnational Social Movement Sector}

The fourth transnational dimension is the broader social movement sector and industry to which Greenpeace and Friends of the Earth International belong, and which include local, national and transnational actors. The social movement sector includes people who identify with challenging the status quo and, therefore, constitute a pool of potential supporters and participants. The sector also includes existing networks and organizations with whom FoEI and Greenpeace collaborate in order to attain output goals, and with whom they compete in efforts to gain legitimacy, visibility, participants and resources.' 
FoEI and Greenpeace are part of a number of networks of social movements actors, including the Climate Action Network, that strive together to attain campaign goals.

Because Greenpeace and FoEI derive their funding from individual voluntary donations and foundation grants, these TSMOs are also in competition with other social movement actors for resources and participants. Cooley and Ron (2002: 36) describe the competition amongst SMOs as a "scramble" for resources that "often pushes [SMOs] to behave in rational and rent-seeking ways... like their for-profit counterparts." In contrast, Gerlach (1999: 94) argues that "competition between groups leads to escalation of effort" as SMOs differentiate themselves by becoming more radical to attract funding and participants. The potential of social movements to mobilize participants and support varies across the transnational arena (Brown et al. 2000: 278). Transnational mobilizing structures have been radically enhanced by new information and communication technologies and by affordable travel opportunities (Cohen and Rai 2000; Pickerill 2003). As Batliwala (2002: 395) writes, "individuals and organizations can exchange information, network, forge transnational alliances, and respond to new challenges and developments with unprecedented speed and ease." It is also true that there are significant disparities in access to these new technologies and there are relevant questions that can be posed regarding the ability of distant connections to mobilize and foster commitment to a movement in the way that face-to-face and local ties can (Warkentin 2001).

The transnational interactions amongst social movement actors require significant management of diversity (Smith 2002: 505). Jordan and van Tuijl (2000) highlight the tensions that occur with a failure to adequately address communication and language barriers between Northern and Southern groups. Ashman (2000) argues that tensions can result from the flow of financial resources from Northern country SMOs or offices to Southern activists, which can place Southern social movements in an uneven power relationship with their Northern colleagues. Both Greenpeace and FoEI transfer funding from well-resourced offices and national members, often those based in North America and Western Europe, to those that are under-resourced. These organizations have 
engaged in internal debates about the repercussions of this financial relationship. There has also been a North-South tension about which issues should be addressed in the global arena with Northern movements focusing on environmentalism, human rights, women's rights and good governance, and Southern groups supporting a more integrated approach to issues of environment, development, rights and empowerment (Clark 2003a: 179). There are also issues that arise from different working styles, time zones, languages (and resulting misunderstandings), and the use of email as a primary communication tool which can mask emotions and sometimes lead to misunderstandings. According to Clark (2003a: 179), solving tensions around cross-cultural communication and access to power in shaping the global agenda requires building "denser networks that span different segments of civil society as well as different regions of the world" and which can "provide forums for discerning strategies where synergies rather than squabbles can be developed."

I have discussed four dimensions - transnational issues, transnational organization field, political opportunity structures, and transnational social movement interactions - that are relevant to FoEI and Greenpeace (Rucht 1999: 207). The term "transnational" can equally refer to the organizational formation of these groups. Transnational structures are defined by Rucht (1999: 207) as "composed of closely interrelated groups and organizations that belong to more than one country" where "close interrelation means sustained interaction for coordinating mobilization to reach common - but not necessarily transnational - goals." Chapter Three provides details as to the transnational structure of Greenpeace and Friends of the Earth International, but I introduce the basic structure of these TSMOs here. Young (1991) characterizes a TSMO as "a complex participative process taking place in multiple, highly diverse and sometimes turbulent environments," which he argues aligns with a "federal model of organization." His definition of a "federation" differs somewhat from the definitions provided in the typologies highlighted in Chapter Three; however, Young's definition serves to identify the basic features of organizational structure that FoEI and Greenpeace have adopted in response to the transnational dimensions discussed above. 
As Young (1991) writes, "a federated association structure features a central organization and semi-autonomous local organizations or chapters that belong to the central organization." In the case of FoEI, the central "organization" is more accurately described as the biannual general meeting supported by a small coordinating Executive Committee and secretariat; however, it is true that both FoEI and Greenpeace have chapters in different countries that are interconnected by some central coordinating body, international policies and strategies in order to engage in common activities. Interestingly, Greenpeace and FoEI have developed this basic transnational structure in two different ways (McCarthy and Zald 1987). In the case of Greenpeace, the central organization largely determines the establishment of chapters; whereas in the case of Friends of the Earth International, organizations that are already active in their home countries solicit or are recruited to the FoEI network. As Young (1991: 933) notes, "in either case, the organizational problem is basically the same: the initial... international association established through collaboration must structure itself in a manner that is effective in developing and maintaining support and coordinated action by participating members in different countries." As will become apparent in the sections below, for social movement organizations that operate transnationally, this problem is compounded by difficulties in bridging across "distance, language, cultural, economic and political barriers...and significant difference in perspective among peoples from different parts of the world" (Young 1991: 922).

Greenpeace and FoEI are just two transnational social movement organizations in a large and growing population of transnational social movement actors that deal with different issue areas (e.g., human rights, peace, emergency relief, and development). TSMOs and transnational social movement activity are not a new phenomenon. Early examples include the Anti-Slavery Society formed in 1839; the World Alliance of Young Men's Christian Associations started in 1952; and the International Committee of the Red Cross formed in 1863 (Keck and Sikkink 1998: 39-78; Clark 2003a: 97). Since these early beginnings, TSMOs and international nongovernmental organizations have "proliferated spectacularly" (Boli and Thomas 1999) with a "fourfold increase in the past decades" (Brown et al. 2000: 287) based on estimates of about 800 in 1930, to over 2,000 in 1960s, 
to nearly 5,000 in 1993 (Union of International Associations 1993; Smith et al. 1997: 12;

Keck and Sikkink 1998: 10). Drawing on data from the Yearbook of International Associations, Smith (2005) has traced the growth of transnational social movement organizations, specifically, within this general increase of international activity. The results of her analysis are reproduced in Table 2.1 below. Smith (2005: 233) describes the rapid growth in the population of TSMOs over the past three decades, and makes the following observations of the data set:

Human rights TSMOs constitute the largest segment of the TSMO population, and they consistently remain around 25 percent of all TSMOs during the four periods examined here. In contrast, we found fairly rapid growth in the environmental and economic justice movement "industries," particularly in the most recent decades. The most dramatic change, however, is in the number of TSMOs that adopted "multi-issue" goals such as "environment and development" or "human rights to development" rather than the traditional, single-issue focus. The number of multi-issue groups doubled during the 1990s (growing at twice the rate of the overall TSMO population), and in percentage terms, they rose from less than 10 percent of all groups in the 1970s to 17 percent in 2000.

Table 2.1 Growth and Issue Focus of Transnational Social Movement Organizations (Smith 2005: 233)

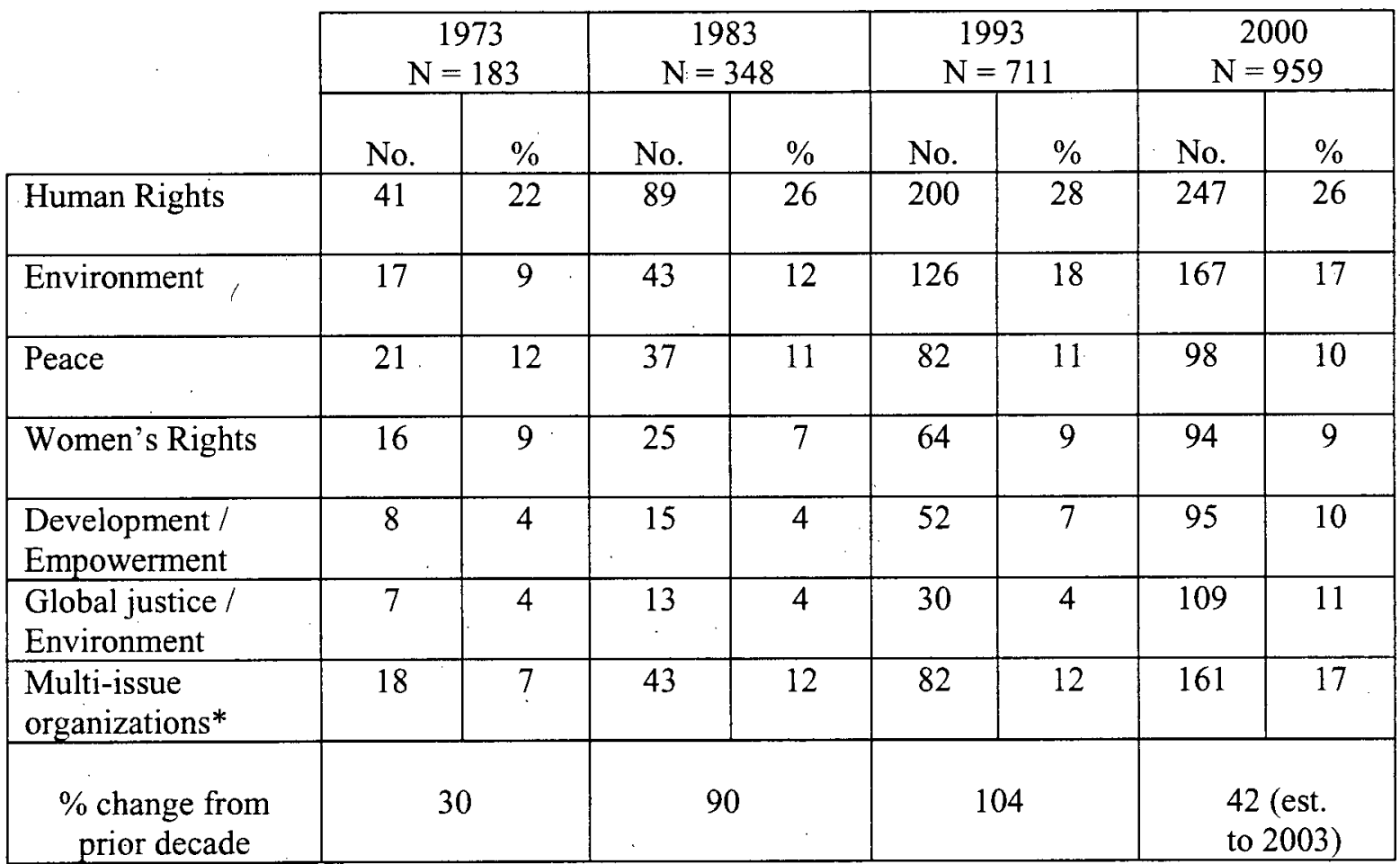

* This categorization overlaps some of the categories above - especially the global justice category.

Source: Yearbook of International Associations 
Greenpeace and Friends of the Earth International are part of the population of TSMOs in the "environment" category. In the upcoming sections, I argue that they also can be counted amongst the TSMOs that are adopting a multi-issue frame, which influences the strategies, tactics and organizational formations they select to be effective in attaining their goals within the transnational political environment. As Figure 2.2 displays, I am shifting my analysis from the environment within which SMOs operate to explore the processes by which SMOs interpret this environment, identify the problems they seek to address, define possible courses of action, and determine the tactics they will employ.

\section{Figure 2.2 Interpretive Frames and Action Repertoires}

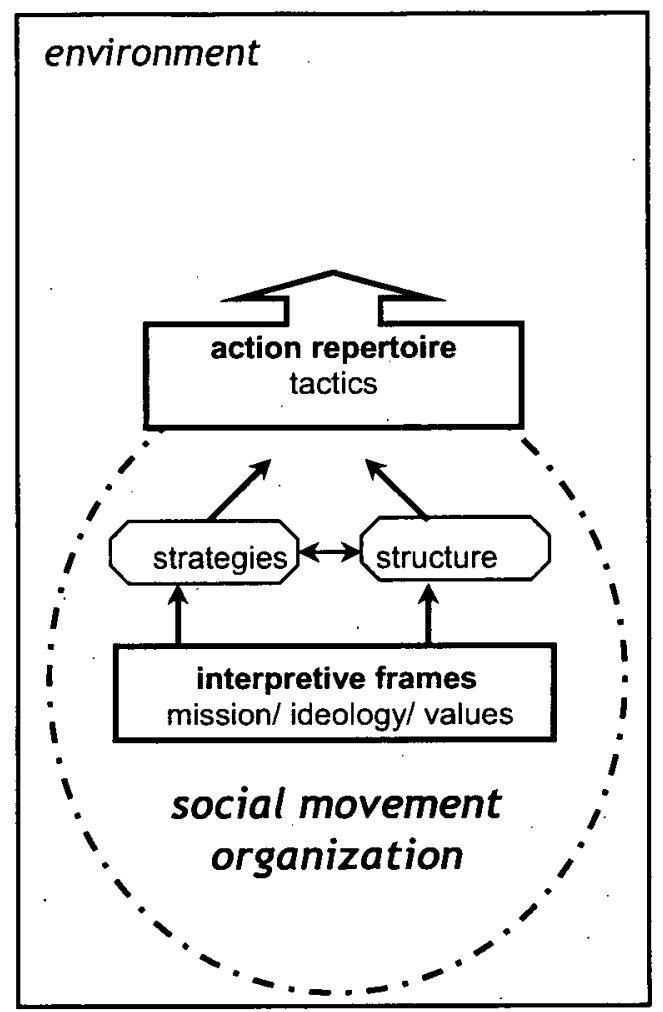

\subsection{Interpretive Frames}

Snow and his colleagues (Snow et al. 1986; Snow and Benford 1988; 1992) introduced the concept of "framing" into social movement theory in order to supplement the predominately structural and organizational focus of resource mobilization theory with an understanding of the social psychological, cultural and ideological factors that influence movement activity. As Snow et al. (1986) write, "the term 'frame' (and framework) is 
borrowed from Goffman (1974:21) to denote "schemata of interpretation" that enable individuals 'to locate, perceive, identify, and label' occurrences within their life space and the world at large." Movement participants actively produce frames in order to identify problems and to decide who or what is to blame for the problem - referred to as prognostic framing - and to specify viable courses of action to address these problems referred to as diagnostic framing (McCarthy et al. 1996; Benford and Snow 2000).

As a process, framing is the conscious strategic effort by individuals within social movement organizations to develop frames that align with their experiences, beliefs, values and interests (Lofland 1996: 266). This process within a SMO is often guided by individuals with "strategic leadership" that actively link political opportunities, mobilizing structures, framing processes and outcomes by drawing on their experience, beliefs and networks (Ganz 2000). Through the process of framing, SMOs "are actively engaged in the production of meaning for participants, antagonists, and observers... They frame, or assign meaning to and interpret, relevant events and conditions in ways that are intended to mobilize potential adherents and constituents, to garner bystander support, and to demobilize antagonists" (Snow and Benford 1988: 198). In addition, effective framing enables social movement organizations to sustain the commitment and motivate current movement participants, increase their legitimacy, acquire resources, generate media coverage and, ultimately, pursue their output goals and influence target actors. Through the process of framing, SMOs construct filters to interpret the characteristics of their issue, the source of the problem, the efficacy and acceptability of particular strategies and tactics, and the threats and opportunities in the political environment (Carmin and Balser 2002: 369).

The process of framing is interactive and an "intensely social activity" that takes place inside the social movement organization and extends beyond an organization's boundaries to its interactions with actors in the organization field (Jasanoff 2005: 24). Focusing on framing as an interactive process "within a movement and between movements, opponents and third parties" highlights that "frames are likely to develop and change over time" (Doherty 2002: 88). For transnational social movement organizations 
such as Greenpeace and Friends of the Earth International, deliberation on frames inside the organization is complicated by the diversity of actors involved across the central coordinating office, the national chapters and membership base. Even building a common identity from which to engage in joint framing processes is difficult due to “geographic boundaries, limited shared experiences, cultural diversity, and high transaction costs" (Smith 2002: 507). This diversity within transnational social movements can also be a strength in defining effective frames within the complex and dynamic transnational context thát reflect global interdependence (Young 1991; Warkentin 2001; Smith 2005: 239).

In addition to internal processes of framing, social movement organizations are engaged in the process of constructing meaning within their social movement and within the social movement sector. Within the environmental movement, Van der Heijden (1997: 212) notes that "there is no coherent ecological crisis as such: there are only story lines, problematizing various aspects of a changing physical and social reality." This does not deny that "of course, 'real' disruptive events happen all the time" such as the collapse of the fisheries stock off the east coast of Canada, the United Nations Earth Summit, or the Chernobyl nuclear plant accident; however, "framing allows us to see that events... have to be set within an interpretive context that allows them to function as a starting point for deliberation or concerted action" (Jasanoff 2005: 24).

For the environmental movement, differences amongst interpretive frames can be partly explained by variations in beliefs about the relationship of humans to nature, referred to as the environmental philosophy held by movement actors (Dalton 1994; Brulle 2000; Carmin and Balser 2002). Dalton (1994) draws a distinction between "conservationists" that interpret the environmental problem as an issue of wildlife preservation and the establishment of wilderness protected areas, and "ecology groups" that are concerned with environmental degradation and the negative impacts of industrialization (see also McCormick 1989: 46, 48). Other scholars have drawn further distinctions in terms of the environmental philosophy and the "philosophical discourses" that environmental organizations adopt (Dryzek 1997; Brulle 2000). Early debates on environmental issues, 
particularly in the industrialized west, focused on linking ecological and economic goals; however, more recently, environmental movement frames include issues of social justice and equity to reflect inequitable distributions of resource use and pollution (Lafferty 2004; Kates 2005). This shift resulted from interactions of environmental activists with participants in other social movements, such as the civil rights movement. It was also inspired by TSMO work with activists from countries outside of the industrialized North and from marginalized communities within industrialized countries who are directly affected by ecological degradation and pollution, and interpret environmental problems as inextricably linked to issues of development, poverty, and human rights.

The shift towards a complex, multi-issue frame of environmental issues is apparent in changes in the international agenda from an "environment" focus towards a focus on the interconnections amongst social, ecological and economic factors. In 1972, The United Nations Conference on the Human Environment was held in Stockholm, Sweden and "was the event that turned environment into a major issue at the international level" (UNEP 2002: 4). Even this international gathering reflected a multi-issue framing of the environmental problem as it was "the first global political conference designed to simultaneously address environment and development issues" (Selin and Linnér 2005: 2). Subsequently, the collective frame shifted further, as is evident in a report by the United Nations World Commission on Environment and Development, Our Common Future (1987). This report popularized a new frame: "sustainable development," defined as development that "meets the needs of the present without compromising the ability of future generations to meet their own needs" (WCED 1987: 43). The term sustainable development was "explicitly formulated as a 'bridging' concept - as an idea that could draw together apparently distinct policy domains, and unite very different interests, hopes and aspirations onto the banner of sustainable development" (Meadowcroft 2000: 371 emphasis in original). Definitions of the term 'sustainable development' vary in their description of what should be sustained and what should be developed and over which time horizon; however, there is a definite trend towards recognizing the interdependence and mutual reinforcement of three societal imperatives: environmental preservation, human economic development and social justice and equity (Kates 2005: 12; Doherty 
2002; Lafferty 2004). This trend is also evident in the evolution of the mission of Greenpeace and particularly of Friends of the Earth International. Box 2.1 presents the current mission statements for both organizations. Greenpeace remains predominately focused on environment and peace issues, but defines the root causes of these transnational problems as based in social, economic and political systems. Friends of the Earth International has made a considerable shift from its original mission "to promote... the preservation, conservation, restoration and rational use of the natural resources and beauty of the Earth" (Burke 1982: 107) to its current mission that incorporates environmental, social justice, rights, empowerment and democracy issues.

\section{Box 2.1 FoEI and Greenpeace Mission Statements}

\section{Friends of the Earth International - Mission}

1. To collectively ensure environmental and social justice, human dignity, and respect for human rights and peoples' rights so as to secure sustainable societies.

2. To halt and reverse environmental degradation and depletion of natural resources, nurture the earth's ecological and cultural diversity, and secure sustainable livelihoods.

3. To secure the empowerment of indigenous peoples, local communities, women, groups and individuals, and to ensure public participation in decision-making.

4. To bring about transformation towards sustainability and equity between and within societies with creative approaches and solutions.

5. To engage in vibrant campaigns, raise awareness, mobilize people and build alliances with diverse movements, linking grassroots, national and global struggles.

6. To inspire one another and to harness, strengthen and complement each other's capacities, living the change we wish to see and working together in solidarity.

(Source: FoEI Annual Report 2005)

\section{Greenpeace - Mission Statement}

Greenpeace is an independent, campaigning organization that uses non-violent, creative confrontation to expose global environmental problems, and to force solutions, which are essential for a green and peaceful future. Greenpeace's goal is to ensure the ability of the Earth to nurture life in all its diversity.

(Source: Greenpeace Annual Report 2005).

Smith (2005) argues that the shift to a multi-issue frame amongst transnational social movement organizations is, in part, due to the rise in number of international activists that interact at international events and gatherings, and form networks with other activists and organizations. These interactions and networks "have contributed to a growing 
awareness of global interdependencies... or a transformed understanding of movement issues that arises from the experience of activism itself" (Smith 2005: 234; see also Marullo et al. 1996). Some scholars argue that "meta-frames" have developed from this interaction amongst social movement organizations, including the "human rights" frame that has become "pervasive" within the transnational social movement arena (McCarthy 1997: 247). The "rights frame" is evident in the environmental movement in discussions of the right to a healthy environment, of human rights abuses connected with ecosystem degradation and pollution, and of the extension of rights to future generations and to other species and ecosystems (Gruen and Jamieson 1994; Agyeman 2002).

The process of framing an issue and of identifying possible solutions by a social movement organization occurs within the context of an "issue culture." This term was introduced by Gamson and Modigliani (1989) to describe the "mass public discourse around a social issue" (McCarthy 1997: 246). In other words, a social movement organization forms interpretations of an issue and of the efficacy of particular actions in relation to the meaning and interpretations of other actors in the organization field, such as the media, the scientific community, the private sector, governments, social movements and the general public.

The concept of framing is particularly important for this dissertation because it is, in large part, through framing that social movement organizations such as Greenpeace and FoEI seek "to manage the uncertain and typically volatile environments in which they find themselves" (McAdam 1996: 339). Framing plays an important role in mobilizing participants to join a social movement and its organizations, and in facilitating the creation of a collective identity within SMOs. The initial mobilization and establishment of the SMO is critical to its success but, as McAdam (1996: 340) notes in the following quotation, framing becomes especially important in adapting to a complex and dynamic environment:

Following initial mobilization..., the movement and the specific social movement organizations (SMOs) that are its carriers face a very different and arguably tougher, challenge. They now confront an established political environment composed of a number of critically important constituent publics with very 
different interests vis-à-vis the movement. Just how successfully the movement and its carrier SMOs negotiate the conflicting demands imposed by these established constituents will largely determine the ultimate fate of the struggle. And in seeking to manage the demands of this highly fluid and often hostile environment, the principal weapon available to the movement is its strategic use of framing processes. That is, in trying to attract and shape media coverage, win the support of bystander publics, constrain movement opponents, and influence state authorities, insurgents depend first and foremost on various forms of signifying work.

Seen in this light, framing is appropriately seen as part of a social movement organization's repertoire of action, the routine forms of activities and clusters of tactics that an organization uses in a given historical period (Tilly 1978).

\subsection{Action Repertoires}

Scholars often study framing through analyzing conscious formal expressions of frames within written documents, speeches and ideological pronouncements of social movement organizations; however, McAdam (1996: 340-341) notes that SMOs also "frame" through their actions and tactics. The process of framing through ideas, tactics and action by social movement organizations is evident at the transnational policy level where the strength of TSMOs lies in their ability to persuade power holders with credible, relevant and timely information and normative arguments (Bloodgood 2002). As Khagram et al. (2002: 4) argue, "one of the primary goals of transnational advocacy is to create, strengthen, implement and monitor international norms," the shared principles and ethics that coordinate values and expectations amongst actors and guide and constrain their behavior (see also Goertz and Diehl 1992; Finnemore 1996; Hurrell 2003).

For many environmental issues, such as the issues of acid rain, ozone depletion and climate change, scientific research plays a "seminal role... in defining the issues, in drawing attention to them, and in generating possible ways of viewing them" (van Eijndhoven et al. 2001: 187). In a study of the regimes formed to address acid rain, ozone depletion and climate change, van Eijndhoven and colleagues (2001: 187) found that social movement organizations were "largely absent from the early history of problem recognition and solution development," but they "played - jointly with other 
actors - a crucial amplifier role in the agenda-setting stage and a predominately monitoring role once implementation of serious management actions was underway." For many of their campaigns, Greenpeace and Friends of the Earth International produce their own scientific research and reports. In some countries, these reports have been perceived as being more trustworthy by the general public than research released by "scientific elites" and scientists operating out of government or industry (for United Kingdom polling results see O'Riordan 2000: 3; Gaskell et al. 2005).

The campaigns of FoEI and Greenpeace, such as those on genetically modified organisms, environmental pollution and climate change, are fundamentally political because they aim to engage in the framing process on deeply contested issues. The process of framing involves discussions on ethics and social values combined with deliberations about what counts as valid knowledge and information for decision-making (Jasanoff 2005). In analyzing the framing process, scholars have conceived of the transnational organization field as a "political space" in which different actors negotiate and struggle to make sense of complex issues and to define what is "real" in the world around them (Jasanoff 2005: 24). Frames are both determined by and contingent on the experiences; beliefs and values of the actors involved. The result of the framing process is the construction of frames that define representations of the world, and these frames are powerful in shaping social behavior. Although constantly negotiated, frames can also have "durability" (Jasanoff 2005: 25). Jasanoff (2005: 26) writes that the concept of "framing... provides an effective way of accommodating the solidity as well as the interpretive flexibility of the worlds in which policy gets made." In this context, framing is a tactic used by a SMO to promote a particular policy agenda.

In recent years, theorists have analyzed the diversity of tactics, the action repertoire, adopted by social movement actors operating at the transnational level in order to analyze the tactics employed and the effectiveness of transnational contention (e.g., Princen and Finger 1994; Fox and Brown 1998; Keck and Sikkink 1998; Florini 2000; Arts et al. 2001; Betsill and Corell 2001; Corell and Betsill 2001; Khagram et al. 2002; Clark 2003b; Yanacopulos 2005). Transnational activity by social movement organizations 
includes (1) responding to emergencies and disaster; (2) providing social services; (3) delivering policy analysis; (4) engaging in advocacy; and (5) participating in transnational problem solving (Brown et al. 2000: 281-282; Lindenberg and Bryan 2001). Friend of the Earth International and Greenpeace predominately focus on the last three functions by providing policy analysis and engaging in advocacy activities and problem solving at all scales (Brown et al 2000: 291). Keck and Sikkink (1998: 16) identify four key political tools and tactics that transnational social movement actors adopt in order to influence frames at the international level: "(1) information politics, or the ability to quickly and credibly generate politically usable information and move it to where it will have the most impact; (2) symbolic politics, or the ability to call upon symbols, actions or stories that make sense of a situation for an audience that is frequently far away; (3) leverage politics, or the ability to call upon powerful actors to affect a situation where weaker members of a network are unlikely to have influence; and (4) accountability politics, or the effort to hold powerful actors to their previously stated policies or principles." There is a growing interest in developing analytical tools to assess the effectiveness of these action repertoires. Betsill and Corell (2001) have developed an analytical framework for assessing the effectiveness of TSMOs in influencing frames within international environmental negotiations by defining 'influence' as the transmittal of information that alters the receiver's actions; by specifying the evidence required for establishing influence; and by defining the causal mechanisms between TSMO activity and influence.

Social movement organizations at all scales engage in a range of tactics that form their repertoire of action. McCarthy and Zald (2001: 537) distinguish between tactics employed by an SMO to recruit participants and supporters, which they label "technologies of mobilization," and activities that are aimed at attaining their social change and protest goals, which they label "technologies of protest." It is true that some tactics are specifically aimed at recruitment and mobilization (e.g., direct-mail and telephone campaigns); however, I would argue that there is significant overlap between technologies of mobilization and technologies of protest since protest activities can have 
the dual impact of influencing protest targets and of affecting the general legitimacy of the SMO and the readiness of bystander public to commit to the cause and to join a SMO.

The choice of which tactics to adopt as a protest activity is driven in part by whether the goal of the SMO is to seek change that simply requires the reform of existing institutions and distributions of power and wealth in society, or to seek social change that is radical, transformative, and revolutionary (Rees 1995; McAdam 1996: 341). Dryzek (1997) argues that reformist actors are predominately structuralists in that they focus their attention on changing socio-political structures, in contrast to radical actors that are focused on altering the ideas and belief systems that underlie these structures (see also Mercier 1997).

In addition to differentiating SMOs according to the degree of social change that is being sought by the organization, McAdam (1996: 341) draws a second distinction between "institutionalized" and "non-institutionalized" tactics. This distinction parallels the concept of "external institutionalization" by Van der Heijden (1997), defined as "the ways a social movement organization operates externally" including its choice of "conventional" or "unconventional" tactics in its action repertoire. Van der Heijden (1997: 32) defines five categories of action. Two of these categories fall under the definition of "conventional actions:" "conventional events (lobbying, press declarations, etc.)" and "direct-democratic events (referenda...)", and three of these categories fall under the definition of "unconventional actions": "demonstrative events (demonstrations, offering petitions etc.); confrontational events (occupations, blockades, etc.); [and] violent events (arson, violence against persons, etc.)." McCarthy and Zald (2001: 537) make similar distinctions based on the legality of tactics. Tactics can range "from relatively peaceful and legal activities, such as speaking to public gatherings, marches and demonstrations, and lobbying efforts" to "such activities that may be legal or illegal, such as boycotts, sit-ins, and other blockades of 'normal' civil activity, to illegal activity such as property damage, murder, arson, and theft." Greenpeace and Friends of the Earth International primarily employ confrontational, unconventional; non-institutionalized, illegal tactics, while still making use of non- 
confrontational, conventional, institutionalized, legal tactics when they are deemed to be strategically effective; however, both organizations reject the use of violence in the pursuit of their goals.

Social movements are defined by their ability to disrupt public order and pose a threat to status quo institutions. For this reason, McAdam (1996: 342) argues that "the most threatening movement groups are those who espouse revolutionary goals and rely on noninstitutionalized tactics[,] signify their threat through both their pronouncements and the their actions [, and are] willing and able to make use of violence in pursuit of their aims." There are disadvantages to violent tactics, as social movements that use violence are vulnerable to widespread opposition and to actions of "extreme repression" in response to their activities (McAdam 1996: 342). Equally, there are disadvantages to adopting institutionalized tactics. As Diani and Donati (1999: 16) note, social movement organizations represent "unvested interests" who attain political efficacy by either disruptive confrontation - non-institutionalized tactics - or by creating routinized ties to political decision-makers - institutionalized tactics - in order to influence policy negotiations. Both tactics have risks associated with them. "Full compliance with the rules of the game may grant official recognition but depotentiate their challenge; conversely; confrontation may increase their bargaining power on some occasions, but lead ultimately to their institutional marginalization" (Diani and Donati 1999: 16 emphasis added). Doherty (2002: 144) summarizes this tension as the choice between the "risk of depoliticization" and the "the risk of marginalization."

Winston (2002) categorizes this same distinction as the choice between being an 'engager' or being a 'confronter,' which other scholars define as the choice between being an 'insider' or an 'outsider' (Grant 2000; Richards and Heard 2005). Diani and Donati (1999) argue that these distinctions describe the primary difference between interest and pressure groups that use institutionalized practices to further their goals, and social movement organizations that adopt disruptive tactics to pursue their cause. Dalton (1994: 10) emphasizes that SMOs are distinct from interest groups because they "adopt unconventional methods of political action (protests, demonstrations and spectacular 
actions) as a standard part of their political repertoire." Supporting my analysis of the range of tactics employed by Friends of the Earth International and Greenpeace (see Chapter 5), Diani and Donati (1999) specify that social movement organizations still use conventional tactics, such as lobbying and petitioning, but primarily focus on confrontational tactics in their repertoires of action.

What are the key tactics employed by Greenpeace and FoEI? A study by Carmin and Balser (2002) sets out to compare the action repertoires of these two transnational social movement organizations. These scholars argue that tactical choices made by social movement organizations are shaped by structural factors, political opportunity structures, experience of action, and the shared values, beliefs and interpretations of the social movement members (Carmin and Balser 2002: 367). Their analysis of Greenpeace and FoEI focuses on the period from their founding in 1969 to 1976. Carmin and Balser (2002: 375) argue that, during this period, Friends of the Earth adopted a repertoire of action that reflected their "strong and positive views about the legitimacy of legal and political structures," which provides "citizens with obligations and rights to effect change." According to Carmin and Balser, this has led FoEI to use institutionalized tactics in the pursuit of their campaigns. In contrast, Greenpeace was strongly influenced by Quaker values and beliefs including the principle of bearing witness to ecological abuse and the principle of nonviolence. According to Carmin and Balser, it is these values that have led Greenpeace to adopt a repertoire of action primarily focused on nonviolent direct action.

Part of the distinction between the action repertoires of Friends of the Earth International and Greenpeace derives from their primary target of action. Wapner (1996) argues that transnational social movement organizations contribute to implementing sustainable development in three ways: political globalism, political localism and political internationalism. Wapner recognizes that each of these organizations engages in all three activities but place different emphases on the priority of each of these activities within their action repertoires. Wapner (1996: 57) argues that Greenpeace focuses its attention on "disseminating an ecological sensibility" amongst all individuals in society, 
and, subsequently, influencing "changes in lifestyle, art, consumer habits, fashion... as well as shifts in laws and policies" based on environmental awareness. This characterization of Greenpeace's action repertoire highlights its strategies and tactics aimed at "framing" environmental issues and representations of society, as well as on its "symbolic work" supported by lobbying and scientific analysis (McAdam 1996). As Doherty (2002: 88) notes, this strategy builds on "movements' work to create meaning" and, he argues that "the impact of movements depends in part on their ability to create frames that have popular resonance."

Wapner (1996: 72-116) argues that the international conservation organization, World Wide Fund for Nature (WWF), targets its efforts at the sub-state level by supporting grassroots empowerment, engaging in environment and development projects at the local scale, and building bridges between local and global processes. A "political localism" strategy aims at influencing international political debate on environmental issues by supporting a decentralized, bottom-up approach that focuses on facilitating "local (placeor enterprise-based) dialogues from which meaningful priorities can emerge" and on building "local support systems that will allow those priorities to be implemented" (Clark and Dickson 2003). This is a also a strong part of the action repertoire of Friends of the Earth International, which builds its action repertoire and strategic priorities on decentralized decision-making across its grassroots, local and national member networks (see Chapters 5, 6 and 8).

According to Wapner (1996: 118), Friends of the Earth International also engages in activities "that actually intersect with and affect the behavior of states" by "corner[ing] states into environmentally sound behavior." Activists in FoEI directly target national governments and other levels of government through a combination of institutionalized and non-institutionalized tactics. For example, FoEI confronts and seeks to influence governmental negotiators at intergovernmental arenas such as the United Nations and the World Trade Organization. They either target a specific country directly or, if the government is unyielding, FoE publicizes national violations in international forums as a way of encouraging international pressure by other non-violating nation-states on these 
intransigent countries, defined by some scholars as a "boomerang effect" (Risse et al. 1999).

Wapner's (1996) analysis contributes to the International Relations literature and, therefore, is primarily focused on action repertoires of TSMOs towards nation-states, and on the pull upwards to supra-state and downwards to sub-state institutional solutions to environmental problems. These vertical trends have been joined by a new horizontal pressure to seek institutional solutions through market-based approaches, internalization of environmental and social costs into price signals, adjustments of taxes and incentives towards sustainable ends, and certification and tradeable permit schemes (Alcock 2005). Both FoEI and Greenpeace seek changes in economic institutions and market mechanisms as part of their social change goals; however, they share their distrust of economic instruments and corporate commitments and retain their critical stance even as they encourage change in economic institutions. In the US, Friends of the Earth International, together with a coalition of women's health, environmental justice, labour and faith groups, pressured more than 100 cosmetics companies to remove toxic chemicals from their cosmetics by signing the Compact for Safe Cosmetics. ${ }^{16}$ Greenpeace predominately protests the activities of the corporate sector and international financial institutions; however, Greenpeace has also joined in the development of private sector solutions through its support of the creation of Greenfreeze refrigerator technology that avoids the use of ozone depleting HCFC gases. ${ }^{17}$ As Greenpeace reports in its annual report, "today there are over 100 million 'Greenfreeze refrigerators' in the world, produced by major European, Chinese, Japanese and Indian manufacturers". This has led to Unilever, Coca Cola and McDonald's seeking similar refrigeration technology. ${ }^{18}$

Although there is a growing recognition of the need for market-based mechanisms in addressing environmental problems, social movement organizations that embrace these mechanisms are vulnerable to criticism from other social movement actors of being co-

\footnotetext{
${ }^{16}$ FoEI (2004) Annual Report. FoEI, Amsterdam, The Netherlands.

${ }^{17}$ Greenpeace (2005) Annual Report. Greenpeace, Amsterdam, The Netherlands.

${ }^{18}$ Ibid.
} 
opted by private sector interests and supporting "greenwashing" by corporations (Gereffi et al. 2001). As Clark (2003a: 119) notes, partnerships amongst social movements and the private sector "require leaps of vision, can be fraught with ethical dilemmas, and can be readily misconstrued by rivals or supporters."

The diversity in action repertoires and tactics adopted by social movement organizations can be both a strength and a weakness for social movements. For Caldwell (1990), differences between actors in the environmental movement lead to a fragmented approach that undermines their political power. Diversity can also be conceived of as a weakness when it leads to inefficiency and the duplication of efforts that can result in a weaker impact, particularly if actors are operating at cross-purposes (Gerlach and Hine 1970).

Advantages of diversity include an increased capacity of the environmental movement to attract a broad base of supporters from different sectors of society; and an increased chance of political efficacy through the employment of diverse tactics. As Dalton (1994: 248) notes, "if we assume that to be successful a movement must vary its tactics with respect to the issue, opportunity structure, and other factors (Turner 1970), then a variety of groups gives the movement access to a broader range of political tactics." Variety is increased when factions develop within social movement organizations and split to form a new organization that pursues a different agenda or different tactics (Zald and Ash 1966: 336-7). Doherty (2002: 25) proposes that there are two generations of green protest within the environmental movement. The first generation became environmental movement organizations, including Greenpeace and Friends of the Earth International, and the Green Parties; whereas the second emerged as a reaction to the perceived failings of the first, including perceived internal institutionalization and routinization of protest. Within the countries that Doherty studies, the second wave is evident "in the anti-toxics campaigns and the environmental justice campaigns in the USA and in the non-violent direct action (NVDA) networks which grew in the USA and Australia in the 1980s and in Britain in the 1990s." These groups actively resist the institutionalization, and "sustain grassroots activism" within their organizations. Doherty argues that their existence has 
not led to the demise of the first generation of organizations but to a strengthening of the green movement as a whole.

Another advantage of diversity results from the joint effect of moderate and more radical social movement organizations in influencing adversaries. There is evidence that more moderate organizations (both in goals and in tactics) are strengthened in their ability to influence the behavior of target actors if their goals and actions appear restrained as compared to the more radical and disruptive confrontational tactics of other activists. Target actors are more likely to engage with more moderate organizations whose demands are perceived as "reasonable" if there is a threat that they would otherwise have to deal with more radical groups (Lofland 1996: 294). Haines (1984: 32) defines this as "positive radical flank effect" in which "the bargaining position of moderates is strengthened by the presence of more radical groups." The opposite phenomenon, "negative radical flank effect," can also occur if "intense fear provoked by the most militant of SMOs in the social movement precipitates reactive repression of the entire movement, setting back if not destroying the cause" (Lofland 1996: 294; see Haines 1984). Of course, there is equally a danger that more moderate players will undermine the ability of more revolutionary activists to gain access to power holders in society (Batliwala 2002). It is an advantage for more moderate social movement organizations to build their agenda in collaboration with more radical activists both for legitimacy reasons and also for strategic reasons. There are examples of priorities formed at the radical edge of a movement serving as an inspiration to moderate social movement participants with impressive results. The idea of women's suffrage, for example, was first proposed by a radical women's group and became a large-scale campaign when the idea was diffused to the broader women's movement (Keck and Sikkink 1998: 51-58). Moderate activists can embrace initially extreme ideas and endow these ideas with wider respectability and influence. Although there is a risk that radical ideas lose their disruptive and revolutionary potential through the process of translation by moderate groups, this translation can equally lead to revolutionary change. 


\subsection{Dynamics of Protest}

The discussion above of radical flank effects leads to the important topic of protest dynamics. In order to remain effective, social movement organizations need to adapt their strategies and tactics over time in reaction to changes in the framing of issues and solutions, in political opportunity structures, in the behavior of other social movement actors, and in the behavior of target actors. Zald and Ash (1966: 330) discuss changes in the political opportunity structure as the "ebb and flow of sentiment," which refers both to the sentiment base of potential adherents to a social movement cause and "the extent to which the larger society feels neutral toward, rejects, or accepts the legitimacy and value of the social movement and its organizational manifestations." The political opportunity structure affects the possibilities of failure and success of a social movement in achieving its goals. After campaign successes, Zald and Ash (1966: 333) argue that there are two possible outcomes: "new goals can be established maintaining the organization or the SMO can go out of existence." In the case of both FoEI and Greenpeace, individual campaign successes have not led to the demise of these TSMOs as these successes are only perceived as part of the overall mission of the organization. As McAdam and Scott (2005: 39 - 40) write,

When seen in their broader context, it becomes clear that no movement ever manages to "succeed" - to fulfill all the hopes of those who labored to instigate institutional change. Goals are transformed as they are translated, and today's "victories" give rise to tomorrow's disappointments, provocations, and eventually - to new reform efforts.

There are a number of dynamics at play as SMOs engage in protest activities and campaigns and as they adjust their goals over time. First, the actors that social movement organizations target with their tactics are not stable entities but evolve their interests and behavior in reaction to SMO actions and to changes in the political environment. These changes require corresponding adaptations in tactics by SMOs. For example, Hoffman (2001) traces the evolution in the response of the oil and chemical industries to the pressures of the environmental movement and notes that some companies have transformed from denial of environmental issues to adoption of minimum regulatory standards to a focus on corporate responsibility. In this case, the change in interests of the target actors represents a shift towards an alignment with environmental goals; however, 
this change can equally be negative or hostile toward social movement aims. Both FoEI and Greenpeace have been subjected to extreme hostile events in response to their protest activities. For example, Friends of the Earth International reports the mysterious death of activists from the Costa Rican FoEI member group after particularly heated campaigns against corporations. ${ }^{19}$ Greenpeace has been subject to numerous hostile attacks, most notably the sinking of the Greenpeace ship, the Rainbow Warrior, by the French government in 1985 which resulted in the death of a Greenpeace photographer (Shears and Gidley 1986; Dyson with Fitchett 1986).

McAdam (1983: 736) describes the dynamics between social movement organizations and movement opponents as a "tactical interaction" in which disruptive tactics developed by social movement organizations - defined as "tactical innovation" - lead opponents to counter these activities in order to neutralize the social movement activists - defined as "tactical adaptation." This, in turn, requires social movement organizations to innovate again in order to "devise protest techniques that offset their powerlessness" (McAdam 1983: 735). Tarrow $(1995 ; 1998)$ proposed the concept of a "protest cycle" to capture the dynamics that emerge over multiple episodes of tactical interaction within a particular social movement campaign. Some of the dynamics that Tarrow identifies include early social movement activists opening political opportunity structures and demonstrating viable strategies and tactics to movement activists that later join the protest activity. The ideas and practices of the first wave of activists are diffused and translated by what Tarrow terms the "easy riders," the movements that arise after the first wave of activists who take "advantage of a political opportunity structure that others struggle to open up" (Tarrow 1991: 84; see also McAdam 1995). Tarrow also proposes that competition for members and supporters amongst movement organizations rises during the protest cycle and is at its highest at the peak of the protest wave. In contrast to arguments that equate the development of social movement organizations with a de-radicalization of movement goals (e.g., Piven and Coward 1977), Tarrow argues that this competition drives SMOs to differentiate themselves by increasing radical protest (see also Gerlach 1999). Minkoff (1997) adds that the increase in number - density - of social movement organizations

\footnotetext{
${ }^{19}$ FoEI (1995) LINK, quarterly publication, FoEI, Amsterdam, The Netherlands.
} 
provides a stable base from which social movements can diffuse protest over time as new political opportunities open.

In summary, Friends of the Earth International and Greenpeace are pursuing their goals within the context of dynamic conditions including the ebb and flow of sentiment, protest cycles, hostile encounters and tactical interactions. Building on the analysis in this chapter, I argue that Greenpeace and Friends of the Earth International are complex organizations operating in a similar "increasingly complex and dynamic world" (Moore 1995: 70; see also Young 1991). I draw on systems theory to define "complex" as systems that contain a large number of interacting components that have a "degree of interdependence" (Roe 1998) and are "interconnected so that changes in some elements or their relations produce changes in other parts of the system" (Jervis 1997). This interconnectedness produces behaviours at the level of the entire system that are not predictable from analyzing the parts (Resnick 1995; 1996; Booth Sweeney 2001). A complex system also produces unanticipated and unpredictable effects, which results in increased uncertainty as to the consequences of any action (Sterman 1994; Sterman 2000; Kahane 2003). Complexity is compounded when systems are composed of interrelated subsystems that nest within each other and interact across different levels or scales (e.g., from local to global) (Holling 2001).

FoEI and Greenpeace are part of an interactive and political process of framing global environmental problems across scales, influence and are impacted by the development of multi-issue frames including the sustainable development frame, adopt and adapt tactics to pursue their goals, and respond to changing interests and behavior of actors in their transnational organization field. FoEI and Greenpeace are faced with the problem of developing workable structures that respond to these complex and dynamic conditions. The next chapter details the organizational arrangements and decision-making processes that these transnational social movement organizations have developed over time. 


\section{CHAPTER THREE: TSMO Structure}

\subsection{Resource Mobilization Theory and SMOs}

The purpose of this chapter is to analyze how Greenpeace and Friends of the Earth International are structured and to place this analysis within the context of how social movements are organized. As the previous chapters outlined, social movement organizations (SMOs) are distinct from other types of organizations because they challenge the status quo. SMOs such as Greenpeace and Friends of the Earth International are nonetheless organizations and can be analyzed as organizations.

This perspective was first introduced forty years ago in a seminal article, "Social Movement Organizations: Growth, Decay and Change" by Mayer Zald and Roberta Ash (1966). Zald and Ash argued that social movement organizations should be analyzed as embedded in, rather than separate from, broader social movement activity. The authors challenged the dominant perceptions of social movement organizations that portrayed SMOs as inevitably transforming into conservative bureaucratic structures that accommodate mainstream societal goals. By adopting an open systems model of organizations, Zald and Ash proposed a number of different trajectories that SMOs can follow over time as they adapt to internal and external pressures. Their approach was further developed in subsequent years by scholars in the social movement tradition (e.g., McCarthy and Zald 1977; Tilly 1984). This has become the foundation for the resource mobilization school within social movement theory. I adopt this resource mobilization approach in analyzing Friends of the Earth International and Greenpeace and the organizational structures they have developed as they interact with the changing environment and respond to internal conflicts.

In the introductory chapter of this thesis, I make the claim that Greenpeace and FoEI have adopted significantly different organizational structures (Clark 2003b: 4; Rucht 1999: 208). In this chapter, I substantiate this claim by discussing their organizational structures, and by comparing their structural configurations with the structural forms of other actors in their organization field. As Figure 3.1 signifies, this detailed examination 
of organizational structure will form the basis for the theoretical model and analysis of adaptive capacity in FoEI and Greenpeace in subsequent chapters.

\section{Figure 3.1 TSMO Structure}

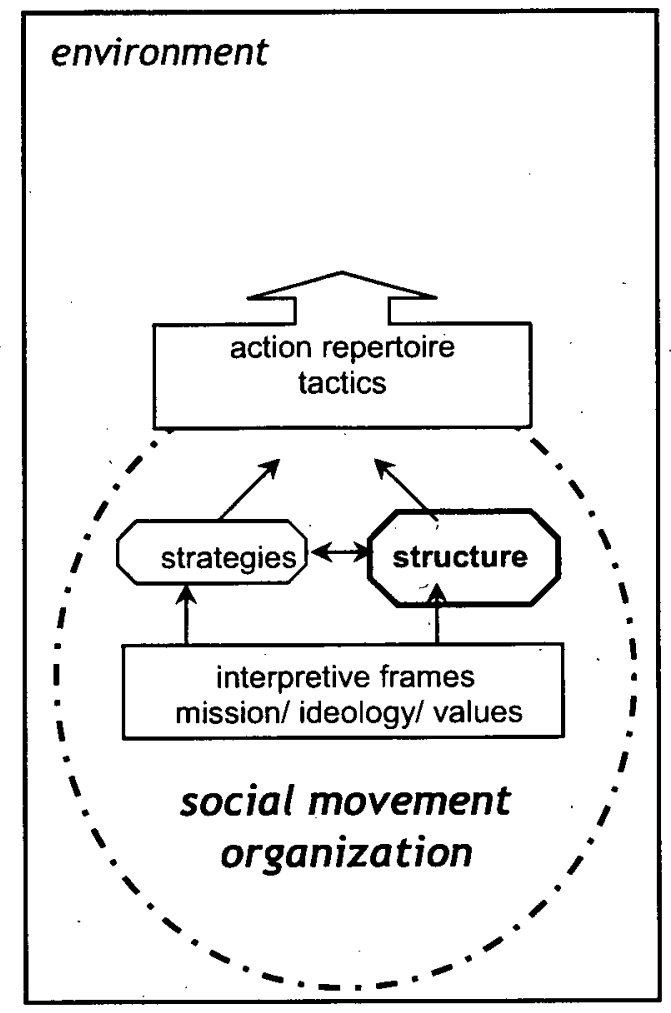

\subsection{Organizational Structure}

In this section, I draw on the work of Henry Mintzberg, an organizational theorist who has contributed substantially to understanding organizational structures $(1979 ; 1983$;

1998b). All organizations create structure in order to maintain a set of activities aimed at achieving their goals. Organizational structure is the design of an organization in terms of its elements (including people and resources) and of relations and coordination amongst these elements (including authority systems, incentives, resource allocation, information flows, and the division of work) (Mintzberg 1979; Young et al. 1999: 325). Structure is not only comprised of the established design of positions and functions but also includes the informal patterns of behavior that exist within an organization that are not necessarily captured in its written rules (Mintzberg 1979; Mintzberg 1983). In 
summary, organizational structure relates to "the division of labor into various tasks to be performed and the coordination of those tasks to accomplish this activity" (Mintzberg 1998b: 145 - emphasis in original).

Mintzberg (1998b: 144) identifies six basic parts of an organizational structure. The first part is composed of the groups of people within an organization who perform the production and service activities and form the operating core. In most organizations, except the simplest ones, one or more managers at the strategic apex oversee these organizational activities. As an organization grows, this management level frequently becomes more complex: the managers of the operating core form a middle line between the operating core and the 'managers of managers' who are situated at the strategic apex. As the complexity of the organization grows, another group can be added to form a technostructure that exists outside of the formal line of authority, performs the role of analyst, and assists in administrative work and the planning and control of the formal work of others. Complex organizations can also include support staff who operate facilities such as cafeterias and mailrooms, and who conduct such activities as legal work and public relations.

The sixth part of the organization is identified by Mintzberg (1998b: 144) as ideology, defined as the "strong culture" of an organization. This organizational culture "encompasses the traditions and beliefs of an organization and distinguish[es] it from other organizations and infuse[s] a certain life into the skeleton of structure" (Mintzberg 1998b: 144). I have adopted the concept of interpretive frames to explore this part of social movement organizations (See Section 2.2). Within organizational studies, scholars note the central role of underlying beliefs, values and cultural traditions in determining organizational structure and effectiveness. A particular example is their comparisons between the cultures of "competitive individualism" within American companies and of "coordinated interdependence" within Japanese businesses (e.g., Pascale and Athos 1981). Social movement organizations are fundamentally based in that movement's beliefs, values and interpretive frames. As Section 2.2 describes, these frames can unify or divide organizational participants. Internal conflicts are inherent in any organization 
as individuals and sub-groups offer different and often competing interpretations of internal and environmental pressures and the efficacy of different responses (Allison 1969). Mintzberg makes a similar point by distinguishing between ideology and politics. Just as interpretive frames are not static, ideology is also usefully perceived as being a dynamic concept. Ideology can be conceptualized as a force that is acting upon an organization, and can be contrasted with politics, its counterforce. Mintzberg (1989:257) states, "ideology represents the force of cooperation, for "pulling together" whereas "politics represents the force for competition, for 'pulling apart'." It is this part of the organization that I address in discussing the contested and negotiated character of interpretive frames.

An organizational structure is not only composed of its people and the forces of cooperation and competition but is also primarily driven by the tasks and activities that have brought people together into an "organized human activity" (Mintzberg 1998b: 145). Mintzberg identifies six basic mechanisms - mutual adjustment, direct supervision, and four types of standardization - that organizations can employ as systems of coordination and information flow in order to coordinate the division of labor of tasks and establish coherence in a set of desired activities. Mintzberg defines mutual adjustment as the informal communication between people interacting together to perform their work. This coordination mechanism is used in simple organizations but can also become the mode of coordination for SMOs in extremely difficult and complex circumstances. Direct supervision relies on individuals within the organization giving orders to others. This mechanism of coordination arises when the number of people working together exceeds the number that can coordinate through mutual adjustment. Standardization achieves coordination "in effect, automatically by virtue of standards that predetermine what people do and so ensure that their work is coordinated" (Mintzberg 1998b: 145). There are at least four forms that standardization can take: standardization of work processes, standardization of work outputs, standardization of the knowledge and skills required as inputs to work, and standardization of norms or common sets of beliefs that guide work. 


\subsection{Formalization and Centralization}

I argue that social movement organizations, including Greenpeace and FoEI, vary along two structural dimensions: their level of formalization and their degree of centralization (Gamson 1975: 91-93; Staggenborg 1988; Staggenborg 1989: 76; Clark 2003b: 4; Rucht 1999: 208). Formalization refers to "the degree to which an SMO has an explicitly (e.g., written) scheme of organization - division of labor - that it strives to enact in its routine activities" (Lofland 1996: 142-3). Centralization refers to "the degree to which an SMO's activities are devised and directed by a well-identified SMO-wide leadership as opposed to activities originating and pursued by multiple, relatively independent SMO subgroupings" (Lofland 1996: 143). The level of formalization is characterized by variation in the operating procedures of social movement organizations (Staggenborg 1988: 587), whereas the degree of centralization in an SMO is characterized by differences in the distribution of power (Fowler 2000: 158).

Formal organizational structures have "established decision-making and operational procedures, a developed division of labor by function, explicit membership criteria, and formal rules governing any subunits" (Staggenborg 1989: 76). Formalized social movement organizations are more easily able "to continue to function with changes in leadership" because rules, standards and division of labor are explicitly defined (Staggenborg 1988: 587), and because "norms and behavior patterns... are designed to operate independently of the characteristics of the individual actors" (Scott 2003: 59). A formal organizational structure has also been called a "bureaucratic" organization; however, I adopt the term 'formal' because, as Zald and Ash (1966: 329) argue, social movement organizations differ from " "full-blown' bureaucratic organizations" because of their goals to "restructure society or individuals, not to provide it or them with a regular service." Gamson (1975) does adopt the term "bureaucratic" to analyze social movement organizations (which he terms "challenging groups"). He argues that "by creating a structure of roles with defined expectations in the place of diffuse commitments, challenging groups can better assure that certain unnecessary tasks will be routinely performed" (Gamson 1975: 91). For Gamson (1975: 93), the three minimum characteristics that define a formal, or bureaucratic, structure are "formality of 
procedures, record keeping and some complexity of role differentiation." It is important to note that a formalized social movement organization can be "less formal in practice than on paper" (Staggenborg 1989: 80), particularly given the tension between "structure and spontaneity" that characterizes social movement activity (Freeman and Johnson 1999: 1).

In contrast, informal social movement organization structures have "few established decision-making and operational procedures, a minimal and changing division of labor, and loose membership requirements" based on the facilitation of loose interconnections amongst subunits (Staggenborg 1989: 76). Informal SMOs are characterized by "ad hoc" rather than routine decisions (cf. Rothschild and Whitt 1986), and by frequent adjustments in organizational structure to "meet immediate needs" (Staggenborg 1989: 590). Staggenborg (1989: 590) notes that the lack of established procedures provides the opportunity for "individuals [to]...exert an important influence on the organization." This is, in part, due to the fact that informal structures are "based on the personal characteristics and relations of the specific participants" rather than on the detailed, unambiguous operating procedures and clear role definition that characterizes more formalized structures (Scott 2003: 59).

A centralized social movement organization has a "single center of power" (Staggenborg 1989: 76). This concentration of power can refer to an individual leader or to subgroups that have responsibility and scope of authority over the decision-making in the organization, "whether or not this is formally sanctioned" or reflected in their position on the organizational chart (Gamson 1975: 93). This has obvious benefits to these governing groups or individuals by providing them with a span of control and power. Centralization can also have wider benefits in terms of information processing. As Mintzberg (1983: 95-96) argues, "centralization is the tightest means of coordinating decision-making in the organization" as decisions can be coordinated through one brain or a few brains at the headquarters or "strategic apex" of the organization. 
In a decentralized social movement organization, "power is dispersed to chapters or other subunits" (Staggenborg 1989: 76). This can be useful when the knowledge and information required to make decisions are not able to be accumulated, analyzed and synthesized in one brain or in the centralized body of an organization. This can be due to the nature of the information, that can be locally specific and difficult to transmit, or due to the complexity or the growth and expansion of an organization's activities, which can require many more brains for decision-making in order to prevent information overload and to ensure responsiveness to local conditions (Mintzberg 1998b: 154).

Decentralization can have the added benefit of stimulating and motivating staff to engage in the decision-making of the organization (Mintzberg 1983: 96-97).

It is important to distinguish delegation of responsibility from the decentralization of authority and power to subunits (Smillie and Hailey 2001: 126). Fowler (2000: 56-58) and Smillie and Hailey (2001:126) discriminate between deconcentration, which entails the allocation of responsibility and activities to subunits while ultimate decision-making authority is retained within a central body, and delegation, which entails a shift of authority and power to subunits. Various distinctions amongst types of decentralization have also been made by Mintzberg (1983: 99; 1998b). He differentiates between vertical decentralization - the dispersal of power down the chain of line authority to middle managers, and horizontal decentralization - the extent to which non-managers control decision-making processes. There is also a distinction between "selective decentralization - the dispersal of power over different decisions to different places in the organization" and "parallel decentralization - where power over various kinds of decisions is delegated to the same place" (Mintzberg 1988: 151).

Centralization of power is often discussed in parallel with descriptions of hierarchical structures, and decentralization and participatory decision-making are often associated with "flat" or nonhierarchical structures (Light 1998). As discussed in Chapter Two, Smillie and Hailey (2001: 126) emphasize that hierarchy can simply be defined as a system of organizing people and things in a graded order, and does not necessarily include a corresponding centralization of authority. In their research on Southeast Asian 
nongovernmental organizations, Smillie and Hailey found a disconnect between decentralized participation in decision-making and hierarchical structures. Some relatively flat organizations remained centrally governed, through direct supervision, by a small group of managers, and other organizations with steep hierarchical divisions of labor were found to embrace participatory and decentralized decision-making processes (Smillie and Hailey 2001: 122, see also Oerton 1996 and Bordt 1997). Friends of the Earth International and Greenpeace are both comprised of a number of levels of internal divisions and complex role differentiation across the local, national and international scales; however, their comparable "hierarchy" does not result in the same level of centralization. Section 3.6 below clarifies the definition of centralization adopted for this dissertation - the degree to which major decisions about governance, standards, strategies and activities are determined at the level of the international body of a transnational social movement organization (Clark 2003b: 4-5; Rucht 1999: 208).

One critical issue for this thesis is the extent to which centralization and formalization go together. Gamson (1975: 92-93) argues that the relationship between formal structures, which he terms bureaucracy, and centralization "remains to be determined." On the other hand, Lofland (1996: 143) argues that "in theory, these two variables [formalization and centralization] can vary independently, but in practice they tend to be rather strongly correlated" such that "an SMO high on one is likely to be high on the other and vice versa." This is the conclusion that Staggenborg (1989) arrives at in her comparison of two social movement organizations within the women's movement in Chicago. She classifies the Chicago Women's Liberation Union (CWLU) as being both decentralized and informal, and the Chicago chapter of the National Organization for Women (Chicago NOW) as adopting both a more centralized and more formalized structure. In the case of CWLU, she found that "there was parallel development of the two characteristics [formalization and centralization]" and that Chicago NOW experienced "substantial obstacles to the creation of a formalized, decentralized SMO" (Staggenborg 1989: 90). Akin to Staggenborg, I adopt the approach of analyzing centralization and formalization in parallel. I classify Friends of the Earth International as both decentralized and informal and Greenpeace as both centralized and formal. This 
classification will be supported in the description of the evolution of their organizational structures (Sections 3.4 and 3.5) and in the comparison with other transnational organizational forms (Section 3.6).

Before I begin this analysis, it may be useful at this point in the thesis to note how this classification will result in an answer to the central research question of my thesis: does the prevailing assumption hold that a decentralized and informal structure is the only way for transnational social movement organizations to maximize adaptability in complex and dynamic conditions? The central claim that I am making is that the different structural configurations of FoEI and Greenpeace are due, in part, to the distinct ways in which these organizations respond and adapt to organizational challenges. Building on Mintzberg's description, I align with Staggenborg (1989: 79) in claiming that organizations create structure not just to perform tasks and coordinate but also to "solve organizational problems." In the upcoming chapter, I create a typology of organizational challenges that confront a social movement organization. These challenges include whether an organization should make decisions democratically or unilaterally, hire professional staff or depend on volunteers, adopt a broad campaign strategy or focus its efforts and activities, and collaborate with partners or remain independent. I synthesize an array of theoretical propositions that situate formal and centralized structures or informal and decentralized structures as being more or less effective in responding to these challenges. It is through this analysis that I develop my theoretical construct, which identifies two ideal type models of adaptive capacity.

\subsection{Organizational Structure of Friends of the Earth International}

Friends of the Earth International is structured as "a federation of autonomous environmental organizations from all over the world. ${ }^{, 20}$ FoEI members frequently apply the terms "network" and "federation" in their descriptions of their organizational structure; for example, in a jointly created statement of their core values, visions, and mission at the Malaysian Biannual General Meeting in October 2005, FoEI members

${ }^{20}$ FoEI (2004) Annual Report. FoEI, Amsterdam, The Netherlands 
used the following words to describe their "Vision of the Network":

Friends of the Earth International is a worldwide grassroots environmental network campaigning for an ecologically sustainable, just and peaceful world. We are a vibrant, credible and effective federation, driving social transformation and securing sustainable, gender just and equitable societies.

Our strength comes from our solidarity, passion, and shared beliefs. We respect each other and we value our diversity. We inspire and bring about change by living according to our values, and we learn from our experiences. In turn, we are inspired by successful campaigns and strengthened by the friendships and alliances we forge.

We believe that our children's future will be better because of what we do. ${ }^{21}$

The structure of Friends of the Earth International is decidedly a "worldwide" network with member organizations in 70 countries. Table 3.1 lists the membership as reported in the 2004 FoEI Annual Report as well as the year of their admission as members. As I noted in the introductory chapter, Friends of the Earth was intended from the beginning to be an international body; however, its transnational structure is built by connecting national organizational members and local supporters, rather than by constructing a single international entity. In its 2004 Annual Report, FoEI describe itself as "a global federation of national environmental organizations" and the "world's largest grassroots environmental network, uniting [71] diverse national member groups and some 5,000 local activist groups on every continent... with approximately one million members and supporters around the world." 22 The FoEI network is connected by an internal website and intranet, a mailing list, LINK and interlinkages magazines that are circulated to all members, and by regular gatherings including at Biannual General meetings, international fora, and campaign meetings.

\footnotetext{
${ }^{21}$ FoEI (2005) Outcomes of the Penang Visioning Workshop, FoEI, Amsterdam, The Netherlands, October

${ }^{22}$ FoEI (2004) Annual Report. FoEI, Amsterdam, The Netherlands
} 
Table 3.1 Friends of the Earth International Members and Year of Admission (Source: FoEI Annual Reports)

\begin{tabular}{|c|c|c|c|c|c|}
\hline Country & $\begin{array}{l}\text { Year of } \\
\text { Admission }\end{array}$ & Country & $\begin{array}{l}\text { Year of } \\
\text { Admission }\end{array}$ & Country & $\begin{array}{l}\text { Year of } \\
\text { Admission }\end{array}$ \\
\hline Argentina & 1985 & Georgia & 1991 & Nigeria & 1996 \\
\hline Australia & 1974 & Germany & $1975 / 1989$ & Norway & $n / a$ \\
\hline Austria & $1982 / 1988$ & Ghana & 1986 & Palestine & 2000 \\
\hline Bangladesh & 1992 & Grenada & 1991 & $\begin{array}{r}\text { Papua New } \\
\text { Guinea }\end{array}$ & 2000 \\
\hline Belgium & 1976 & Guatemala & 1995 & Paraguay & 1992 \\
\hline $\begin{array}{r}\text { Belgium } \\
\text { (Flanders) }\end{array}$ & $\mathrm{n} / \mathrm{a}$ & Haiti & 1996 & Peru & 1999 \\
\hline Bolivia & 2002 & Honduras & 2002 & Philippines & 1991 \\
\hline Brazil & 1983 & Hungary & 1994 & Poland & $n / a$ \\
\hline Bulgaria & $\mathrm{n} / \mathrm{a}$ & Indonesia & 1989 & Scotland & 1978 \\
\hline Cameroon & 1999 & Ireland & $n / a$ & Sierra Leone & 1989 \\
\hline Canada & 1983 & Italy & 1977 & Slovakia & $\mathrm{n} / \mathrm{a}$ \\
\hline Chile & 1990 & Japan & 1983 & South Africa & 2002 \\
\hline Colombia & 1999 & Latvia & 1987 & South Korea & $\mathrm{n} / \mathrm{a}$ \\
\hline Costa Rica & 1988 & Lithuania & 1994 & Spain & 1979 \\
\hline Croatia & 1999 & Luxembourg & $n / a$ & Sri Lanka & 1999 \\
\hline Curaçao & 1990 & Macedonia & 1995 & Swaziland & $\mathrm{n} / \mathrm{a}$ \\
\hline Cyprus & 1984 & Malaysia & 1983 & Sweden & 1971 \\
\hline Czech Republic & 1993 & Mali & 1998 & Switzerland & 1995 \\
\hline Denmark & 1988 & Malta & 1991 & Togo & 1992 \\
\hline El Salvador & 1991 & Mauritius & 1999 & Tunisia & 1995 \\
\hline $\begin{array}{r}\text { England, Wales \& } \\
\text { Northern Ireland }\end{array}$ & 1970 & Nepal & 2002 & Ukraine & 1995 \\
\hline Estonia & 1988 & Netherlands & 1971 & United States & 1969 \\
\hline Finland & 1996 & New Zealand & 1983 & Uruguay & 1988 \\
\hline France & 197.0 & Nicaragua & 1999 & & \\
\hline
\end{tabular}




\subsubsection{FoEI Decision-making Processes}

Founder, David Brower, and early FoE members expressed a desire "not to be clearly organized or directed by some old tired formula from the top" (Brower 1985). Brower illustrated this sentiment with the metaphor of the "bristlecone pine" from the mountains in Eastern California, which "had no hierarchical coordinator and no highly organized bureaucratic structure" but "each bristlecone seed, given a chance, knew exactly what to do, and can last far longer than anything we ever dreamed up" (Brower 1985). Brower proposed a formula for organizing by "find[ing] good people with the right idea and let them move ahead their way" (Brower 1985). In keeping with this original vision, FoEI remains structured as a "highly decentralized" organization composed "of autonomous organizations many of which were established before joining the organization. ${ }^{, 23}$

Decision-making is concentrated in a week-long general meeting that is held every two years to determine "the policies and activities of the federation." 24

The decision-making process at the Biannual General Meeting is "democratic" and "all members have an equal say." ${ }^{25}$ The decentralized and democratic structure within Friends of the Earth International stems from its goal to exemplify the values that FoEI pursues in broader society and "liv[e] the change we wish to see." ${ }^{26}$ Once particular policies, bylaws and activities are decided upon, FoE member groups are expected to "comply with the guidelines established by the federation;,"27 however, there are few sanctions in place to discipline those members that do not comply, and only obvious inactivity on the international level or lack of compliance with membership criteria has resulted in the removal of membership status. ${ }^{28}$ Voting at the BGM is conducted through motions and amendments, secret ballots or through a show of voting cards, and can be determined by a either unanimous consent or majority. Members at the Biannual General meeting elect an Executive Committee (ExCom) to support the decisions made at the meeting in the intervening years. The Executive Committee is composed of a

\footnotetext{
${ }^{23} \mathrm{http}: / / \mathrm{www}$.foei.org/about

${ }^{24}$ Ibid.

${ }^{25}$ Ibid.

${ }^{26}$ FoEI (2005) Annual Report. FoEI, Amsterdam, The Netherlands, p.2.

${ }^{27}$ FoEI (2000). FoEI Handbook. Amsterdam, The Netherlands, FoEI.

${ }^{28}$ Interview with Ann Doherty, FoEI Communications Coordinator, July 2005.
} 
Chairperson directly elected at the BGM, a representative of the organization hosting the next BGM, and representatives of up to seven other member groups. No member group can have more than one seat on the Executive Committee and the positions are normally held for two years, although the Chairperson can be re-elected for a second term of an additional two years. The ExCom meets four times per year to administer the association, to enter into agreements, and to act on behalf of FoEI. This can include summoning members for an Extraordinary General Meeting if an additional meeting is deemed necessary. ${ }^{29}$

The Executive Committee also employs and oversees the work of an International Secretariat. Currently based in Amsterdam in the Netherlands, the International Secretariat is composed of twenty-three staff and volunteers and supports the network's processes, financial management, membership and regional group development, the Executive Committee operations, network campaigns and other activities "through" fundraising, campaign coordination, workshops, translations, electronic communications, information collection and dissemination, database maintenance and publications." 30 People from all around the world are hired to work and volunteer at the secretariat; for example, in 2004 through 2005, the secretariat "included staff and volunteers from Argentina, Belgium, Bulgaria, Canada, Costa Rica, China, Indonesia, Italy, the Netherlands, the Philippines, Poland, South Africa, Suriname, Uganda, the United Kingdom, and the United States." 31 Official secretariat positions include a Communications Coordinator and LINK editor, a Financial Manager, a Web Coordinator, a Systems Administrator, and an Office Coordinator. The Extranet Coordinator provides training in using the FoEI internal website, and the Media Coordinator provides support for media outreach and communications across the network. The international secretariat also hosts a number of campaign coordinators for specific international campaigns and an International Campaigns Facilitator and International Campaigns Coordinator that facilitate communication across campaigns.

${ }^{29}$ FoEI (2000). FoEI Handbook. Amsterdam, The Netherlands, FoEI.

${ }^{30} \mathrm{http}: / /$ www.foei.org

${ }^{31}$ FoEI (2004) Annual Report. FoEI, Amsterdam, The Netherlands, p.14. 
FoEI has two regional structures - FoE Europe and FoE Latin America and the Caribbean - in order to campaign at the regional level, exchange information within a region, and involve local and national groups in international campaigns within FoEI. There are other unofficial regional formations in Africa, Asia and Oceania and North America that are already coordinating informally and may become formal regional structures in the future. ${ }^{32}$ The FoEI members within these regions host region-wide events to discuss and decide upon activities at the regional level. Representatives of the regional structures report to the BGM about the plans that have been agreed upon by FoE regional members. The decision-making procedures that govern at the international level are the same at the regional level including respect for minorities and "voting rights and the rights to be elected in governing bodies for all (and only) full members, right to participate in discussions and activities for full, associate and affiliate members.",33 Similarly, decision-making within FoEI activities including issue campaigns is based on either consensus or, if consensus cannot be reached, on democratic voting procedures. If a member group is in disagreement with a decision reached at the AGM or in a campaign or program working group, the member group can continue to promote this position within its national campaigns as long as it is made clear that the position differs from that of the FoEI network. The campaign working group is the decision making body for FOEI Campaigns and includes campaign coordinators, regional coordinators and policy/issue coordinators.

FoEI is a network of national organizations joined together in an international federation, and therefore, FoEI members conduct much of their decision-making at the national level in an autonomous fashion. Although all FoEI members are selected, in part, based on their democratic internal procedures and elected Board, there is considerable variation amongst national groups as to their decision-making structures.

At the international level, the Biannual General Meeting serves as the primary decisionmaking venue for FoEI; however, the FoEI bylaws specify that between general

\footnotetext{
${ }^{32}$ Interview with Mae Ocampo, FoEI International Campaigns Development Coordinator, October 2004.

${ }^{33}$ FoEI (2000). FoEI Handbook. Amsterdam, The Netherlands, FoEI.
} 
meetings, decisions can be taken by the ExCom, the campaign working groups, thematic or regional groups. Campaign issues can be decided by campaign working groups.

Regional and thematic working groups can make decisions on geographically or thematically specific issues within campaigns. The ExCom "decides on all issues that are not explicitly reserved by the Constitution or the Bylaws to another deciding body, in particular issues that concern more than one campaign if campaigners fail to make a decision and need assistance from the ExCom, issues that do not relate to any specific campaign, emergent matters that have to be decided urgently, and allocating membership support fund money to member groups or campaigns." The ExCom also plays a leading role in organizing and preparing the agenda for the BGM, and polling the member groups on issues that emerge between BGMs.

\subsubsection{FoEI Division of Labour}

Friends of the Earth International activities span local to global scales. As FoEI reported in its 2004 Annual Report, the FoEI network members "are united by the common conviction that creating environmentally and socially sustainable societies requires both strong grassroots activism and effective national and global campaigning." National members, and their grassroots communities, are encouraged to be active in autonomous local and domestic campaigns, while engaging in at least one international campaign. FoEI distinguishes between three kinds of activities: programs, campaigns and projects. ${ }^{34}$

- A program covers a number of related issues pursuing the objectives of sustainability with specific goals and no specific time limit. Programs are very likely to generate campaigns and projects.

- A campaign is a joint effort of the whole or a substantial part of the federation to bring timely and effective pressure to bear on influential bodies to reach a concrete goal within a limited time span at the international level.

- A project is more limited in scope than a campaign with precise deadlines, a specific geographical location, and a practical outcome.

\footnotetext{
${ }^{34}$ FoEI (2000). FoEI Handbook. Amsterdam, The Netherlands, FoEI.
} 
Participation in FoEI activities is open to all interested member groups and can include involvement in program, campaign and project working groups, international activities, or national level activities.

Campaigns are proposed by member groups or the Executive Committee and voted upon by all members at the Biannual General Meeting (BGM). Individuals or groups proposing a campaign are required to write a policy paper and a work plan for concrete activities on the proposed campaign issue. They also need to enlist the support of one or two international coordinators and a working group of at least five member groups that commit to participate in the campaign. Campaign working groups meet throughout the two years between the BGMs and then have a final meeting at the BGM to report on progress and present the work plan for the next two years. This work plan is subject to approval by the FoEI members at the BGM, and follows an established reporting format in which campaign members outline specific goals, objectives, budget, strategies and tactics, and fundraising goals. The work plan identifies opportunities for FoEI members to support the campaign and specifies the types of support required, including staffing and coordination needs, secretariat contribution, southern capacity building need and small grant priorities, and translation requirements. The reporting format is also an evaluation tool wherein campaign coordinators can assess the effectiveness of the campaign activities over the past years.

The international coordinators, working groups and international secretariat share responsibility for fundraising for the campaign and are accountable to the network as a whole. In order to ensure effective interregional coordination and diverse representation, there are usually two international coordinators for each the campaign - one from a Northern country and one Southern or transition country. To take two current examples, the climate change campaign coordinators are from FoE England, Wales and Northern Ireland and from FoE Argentina, and the campaign on genetically modified organisms is co-coordinated by FoE Europe and FoE Nigeria. As Clark (2003b: 9) describes, "major international campaigns are shaped by FoEI, serviced by secretariat staff, and supervised by an FoEI sub-committee comprising senior staff from national members." There are 
currently ten international campaign coordinators for the international campaigns on international financial institutions, corporate accountability, trade, environment and sustainability, forests, climate change and genetically modified organisms. Some of these campaign coordinators are located in Amsterdam; however "FoEI philosophy has been and will remain that we attempt to pay coordinators but don't seek to have them located in the Secretariat, thereby avoiding centralization" (emphasis added). ${ }^{35}$

Network development coordinators are responsible for preparing and implementing the training and skill sharing activities of the FoEI. The content and types of network development activities are decided at the BGM depending on resource availability. The ExCom follows up on these decisions and organizes network development coordinators. Currently, there are three core themes adopted by the FoEI network and supported by network development activities:

- Protecting human and environmental rights,

- Protecting the planet's disappearing biodiversity, and

- Promoting the repayment of ecological debt owed by rich countries to those they have exploited for their own economic benefit.

Network development activities have been a part of FoEI activities since the introduction of organization-wide development activities on gender equity in the late 1990s.

There are numerous international events that are relevant and of interest to FoEI members (e.g., UN World Summit on Sustainable Development, the World Social Forum, Conference of the Parties to the UN Convention on Climate Change, meetings of the World Trade Organization). For each event, the international coordinators or the ExCom establish a structured delegation that is led by a coordinating person and key spokespeople for FoEI. Representatives can also be appointed to participate in international events for which FoEI does not have a campaign. The representative is appointed by the ExCom and is responsible for preparing a position paper and reporting to the BGM on the event.

${ }^{35}$ FoEI (2000). FoEI Handbook. Amsterdam, The Netherlands, FoEI. 
FoEI members can seek international support for their national campaigns. These FoEI activities are support and solidarity actions. For example, when LRC - KSK / FoE Philippines filed a lawsuit against the Philippines Mining Act and its provisions to allow the operation of $100 \%$ foreign-owned mining corporations in the Philippines, this member group was supported by 250 letters sent by other FoEI members to the Philippines government. ${ }^{36}$ The pressure from this national and internationally supported campaign contributed to a Supreme Court of Philippines decision to declare these provisions unconstitutional. This decision was later reversed following pressure from the political and corporate sectors but has strengthened the large-scale mining protests in the Philippines. ${ }^{37}$ Similarly, FoEI members supported FoE Norway in its successful campaign to protect 53 rivers under a new Norwegian River Protection Act (FoE 2004: 12). The campaign on International Financial Institutions specifies that FoEI members "support the struggles of communities against World Bank funded extractive industries projects, like the Chad-Cameroon pipeline." ${ }^{.38}$ In addition to solidarity activities undertaken by other FoEI member groups, the ExCom, International Secretariat, and Chair of the ExCom can provide assistance to national campaigns where possible and needed.

FoEI undertakes activities with official selected affiliates to the network that "share the same overall philosophy about environmental concerns as FoEI. ${ }^{.39}$ Members grant affiliate status to groups at the BGM for a renewable period of five years. In 2005, Friends of the Earth International has 16 affiliates from nine countries or regions, including A Seed Europe and the North Sea Foundation in the Netherlands, earthlife Africa, the Mineral Policy Institute and Rainforest Information from Australia, the Peace Boat in Japan, FoE Middle East, the Blue Planet Project from Canada, and corpwatch, the International Rivers Network and Rainforest Action Network in the US. Affiliates conduct joint projects with FoEI, such as co-sponsoring events and co-producing publications, but can not use the FoEI name and do not hold the voting or constitutional

\footnotetext{
${ }^{36}$ FoEI (2004) Annual Report. FoEI, Amsterdam, The Netherlands.

${ }^{37}$ Ibid., p. 10

${ }^{38}$ FoEI (2003) Annual Report. FoEI, Amsterdam, The Netherlands.

${ }^{39}$ FoEI (2000). FoEI Handbook. Amsterdam, The Netherlands, FoEI.
} 
rights of full members. Friends of the Earth is also part of wide range of collaborative networks and emphasizes that their "international positions are informed and strengthened by our work with communities and our alliances with indigenous peoples, farmers' movements, trade unions, human rights groups and others."40

In the year of FoEI's $25^{\text {th }}$ anniversary, FoEI created a Council of Patrons of "individuals in high standing who are influential in their own fields, from all parts of the world" such as "artists, authors and academics who care for the earth." ${ }^{" 41}$ Currently there are 12 individuals who form the Council of Patrons including Dr. Wangari Maathai, 2004 Nobel Peace Prize Winner and founder of the Green Belt Movement; Bruce Cockburn, musician and activist in environmental and human rights issues; Jakob von Uexkull, initiator of the Right Livelihood Award; Professor Mohammed Yunus, initiator of the Grameen Bank in Bangladesh; and Margaret Atwood, Canadian author. ${ }^{42}$ The involvement of Patrons in FoEI activities and events is determined individually, but does not include voting rights on FoEI policies and decisions.

FoEI fundraising is a shared responsibility across all members of the organization. Each FoE members is responsible for its own budget, contributes a percentage of its income to the FoEI network and can solicit funds from individual and group memberships, grants, and the sale of merchandise. Sixteen percent of FoEI's annual income derives from membership with the remainder primarily resulting from donor grants and a small contribution from merchandise sales. In 2004, FoEI received financial support from Dutch donor agencies HIVOS, NOVIB/ Oxfam Netherlands; the joint HIVOS-NOVIB Biodiversity Fund and PSO; the Dutch Ministry for the Environment (VROM); the Dutch Ministry of Foreign Affairs (DGIS-TMF); the Swedish Society for Nature Conservation; the C.S. Mott Foundation (United States); the Wallace Global Fund (United States); the Oak Foundation (Switzerland); the Sigrid Rausing Trust (United Kingdom); the Esmée Fairbairn Foundation (United Kingdom); the Polden Puckham Charitable Foundation (United Kingdom); the Network of Social Change (United Kingdom); Greenpeace

${ }^{40}$ FoEI (2004) Annual Report. FoEI, Amsterdam, The Netherlands, 2.

${ }^{41}$ FoEI (2000). FoEI Handbook. Amsterdam, The Netherlands, FoEI.

${ }^{42}$ http://www.foei.org 
International (the Netherlands); and Friends of the Earth England, Wales and Northern Ireland.

\subsubsection{FoEI Membership}

The membership of FoEI is composed of national environmental groups, rather than individuals. National FoE groups can have individual and local groups as members. A group wanting to become a member of the FoEI network is recommended to first ensure that there isn't already a FoEI member group within their country, as FoEI currently accepts only one group per country. ${ }^{43}$ There are a few exceptions to this rule; for example, there are two member groups in Belgium because these groups represent significantly different linguistic, cultural and historical regions within Belgium and can target different influential actors within the distinct regions (FoE Belgium, FoE Belgium (Flanders)). There have also been cases, such as in Austria and Sweden, where FoE groups have merged with another national environmental group in order to increase their

relevance and influence in the country. ${ }^{44}$ If a national FoEI member does not yet exist in a country, an interested environmental group can request an application from the international secretariat and submit this application to the Executive Committee. In addition, FoEI periodically engages in active recruitment of new members, particularly in countries and regions that are considered to be target areas for new programs, campaigns and projects. The application for membership includes a membership assessment questionnaire in which a potential member group self-assesses its eligibility and its possible contributions to the FoEI. The ExCom reports to the FoEI network on all potential applications at least one month in advance of the Biannual General Meeting (BGM). Those applications that are supported, in writing, by at least one full member organization or by the ExCom will be considered by the FoEI members at the BGM. The potential new member group can circulate information about itself to the network and send a representative to the $\mathrm{BGM}$.

\footnotetext{
${ }^{43} \mathrm{http}: / / \mathrm{www}$. foei.org

${ }^{44}$ Interview with John Hontelez, FoEI Chair 1986-1996, May 2006.
} 
FoEI members vote on the recommended new members and are guided by the following membership criteria: FoEI members should be

- Independent from political parties, economic interests, state, religious and ethnic organizations;

- Working on both the national and the grassroots levels;

- Working on the main environmental issues in their countries (i.e., they should not be single-issue groups) and participating in international campaigns of FoEI whenever relevant;

- Operating in an open and non-sexist way using democratic structures;

- Considering environmental issues in their social, political and human rights contexts;

- Working as pressure group (as far as possible within the national context), campaigning, educating and doing research; and

- Seeking cooperation with other organizations as a crucial tactic for mobilizing the broadest possible range of resources and views to focus on the same goals.

All new groups begin as associate members for at least the first year of their membership (to a maximum of four years), and can apply to be admitted as a full member during the next general meeting. National members are not required to adopt the name "Friends of the Earth"; however, FoEI bylaws state, "members are encouraged to consider changing their name into Friends of the Earth (in their own language) or take measures to make as clear as possible the connection between FoEI and the national group, including the use of the FoEI-logo."45 Approximately half of the member groups have changed their name or adopted the name 'Friends of the Earth' in their own languages, whereas other members continue to use different name. ${ }^{46}$

Members sign a "contract of agreement between FoEI and member organizations" which obligates members to the bylaws, mission statement, and rules agreed upon at the BGM. The contract also requires the member to contribute $1 \%$ of its unrestricted revenue plus $0.1 \%$ of all of its other revenue (excepting funds that are entirely passed on others) as membership fees. Members are able to claim up to $10 \%$, and in some special

\footnotetext{
${ }^{45}$ FoEI (2000). FoEI Handbook. Amsterdam, The Netherlands, FoEI.

${ }^{46} \mathrm{http}: / /$ www.foei.org
} 
circumstances up to $25 \%$, of the funds, which they raise for FoEI and its international campaigns. Membership is withdrawn when a member group writes a request of withdrawal to the International Secretariat. Membership is also withdrawn when the FoEI network votes at the BGM for "dissolution of a FoEI member" because the member group is dissolved in its home country, or the member group has significantly changed internally in ways that no longer align with the membership criteria, or the member group fails to fulfill its obligations to the FoEI network (e.g., is not participating in any international campaigns). ${ }^{47}$ For example, membership was withdrawn from FoE Hong Kong when it became apparent that this national group had close ties with a multinational corporation. $^{48}$

The membership is supported in a number of ways by the international secretariat, ExCom and, specifically, by the Membership Development Coordinator and Committee. This support includes providing assistance for and pre-screening membership applications, engaging in proactive recruitment of members in target areas, supporting participation of low-income groups in FoEI activities, facilitating conflict resolution amongst members, and assisting with fundraising and reports to funders. The secretariat administers the FoEI's Membership Support Fund which, in 2004, “distributed more than 800,000 Euro to 39 .. members worldwide" and which "recommended that US $\$ 80,000$ be granted by the Global Greengrants Fund to 13 communities and organizations all over the world. ${ }^{49}$ The objective of the fund is to assist the development of the network, to build capacity amongst FoEI members, to reinforce national and local level campaigns, and to assist member groups by facilitating their participation in international campaigns. In 2004, the support fund supported a range of projects including projects in Nigeria, the Ukraine and Georgia on genetically modified organisms, monitoring large scale infrastructure projects in Brazil and illegal logging in Cameroon, and training workshops and skills development in Central and Eastern Europe and Malaysia. The ExCom and Membership Development Committee can also request an

\footnotetext{
${ }^{47}$ FoEI (2000). FoEI Handbook. Amsterdam, The Netherlands, FoEI.

${ }^{48}$ Samuel, Pierre (1992) Remembrance of Things Past. In FoEI LINK: $25^{\text {th }}$ Anniversary Special. July/August. Issue 73, p.8.

${ }^{49}$ FoEI (2004) Annual Report. FoEI, Amsterdam, The Netherlands, p.14.
} 
assessment of a FOEI member in order to gain further understanding of the member office in its national context, clarify feedback provided by other FoE members that led to an assessment, evaluate the alignment of the FoE member to the membership criteria, and provide the Membership Development Committee with information about membership status. The assessment is guided by principles of transparency, openness, inclusive participation, and objectivity, with a clearly defined duration, scope and purpose.

\subsection{Organizational Structure of Greenpeace}

Greenpeace is "a global environmental organization, consisting of Greenpeace International (Stichting Greenpeace Council) in Amsterdam, and 27 national and regional offices around the world, providing a presence in 41 countries. $"{ }^{\circ 0}$ Greenpeace is committed to the values of transparency and democracy within its structure "while maintaining the high level of internationalism and rigid adherence to its principles" of "non-violence, political and economic independence and internationalism." Sil Similar to the national member groups within Friends of the Earth International, Greenpeace national offices are granted a degree of autonomy with regard to their national activities and governance. Unlike FoEI, Greenpeace decision-making at the international level is not governed by a meeting wherein all members have an equal say. Instead, there is a system of established decision-making bodies at the international level that determine a relatively more centralized and formal set of policies and strategies to which national offices must adhere. Greenpeace International was established as an overarching coordinating by Greenpeace offices in Europe and North America in 1979.

Greenpeace's governance system has evolved from a system where everybody was involved in everything and decisions were made by consensus, to a system where governance and executive powers are clearly separated, providing mechanisms for accountability throughout the organization and trying to avoid conflicts of interests as much possible. ${ }^{52}$

From 1969 until 1979, Greenpeace focused on raising funds to support specific protests. Carmin and Balser (2002: 378) describe the transition from early Greenpeace efforts to

\footnotetext{
${ }^{50} \mathrm{http} / /$ www.greenpeace.org/international/about

${ }^{51}$ Ibid.

${ }^{52}$ Greenpeace International (2003). Greenpeace Governance Handbook. Amsterdam, The Netherlands, Greenpeace International, p. 1.
} 
its consolidation into a worldwide organization under the coordination of Greenpeace International, in the following quotation:

The initial bylaws of the Don't Make a Wave Committee (Stowe 1971) state that the organization "will raise funds, primarily by donation, for the purposes of acquiring a boat to sail to Amchitka."... Although they were successful in raising funds for the Amchitka voyage, as well as the initial Moruroa voyage, by the mid1970 s, the organization had massive debt. At the same time, independent groups using the Greenpeace name were springing up around the world. Although efforts were made to centralize the organization in Vancouver in 1977, it took until 1979, when Greenpeace Europe paid the Canadian debt and united the independent organizations under the umbrella of Greenpeace International, for internal coordination to emerge (Carmin and Balser 2002: 378).

At a meeting of Greenpeace activists in Amsterdam in 1979, a new organizational structure was established with the intent to resolve coordination, fundraising issues, internal conflicts and the licensing of the Greenpeace name. The Board Manual developed by Greenpeace International specifies six elements of Greenpeace Governance Structures: $:^{53}$

1. National and Regional Offices (NROs)

2. The Greenpeace Council

3. The Greenpeace International Board

4. The International Executive Director

5. NRO Boards

6. Voting Memberships

In my description of Greenpeace organizational structure below, I will add other elements to this list - the international headquarter staff, communications team, scientists, direct action teams, and volunteers. These groups are responsible for different aspects of the decision-making processes of Greenpeace and different activities within the organizational division of labour.

${ }^{53}$ Greenpeace International (2004). The Board Manual: Greenpeace's Guide to Board Members who want to know about Governance, Boards and Greenpeace. Amsterdam, The Netherlands, Greenpeace International. 


\subsubsection{Greenpeace Decision-Making Processes}

There are currently 27 Greenpeace National and Regional Offices (NROs) worldwide spanning 41 countries and four continents. Table 3.2 lists the NROs and their year of origin. The creation of a new Greenpeace office, or the appointment of a new Greenpeace representative within a country, is "an organization-wide decision which has to be agreed upon by [the Greenpeace] International Board and approved by [the] international Annual General Meeting." 54 Unlike Friends of the Earth International, Greenpeace "does not adopt, incorporate, or otherwise subsume existing organizations into its structure." $" 55$ Decisions to open new offices are determined by a combination of human and financial resource availability and campaign and strategic priorities.. For example, Greenpeace has recently expanded in Asia (India, Thailand and China) to respond to a growing strategic and campaign focus on environmental problems in these rapidly industrializing countries. When a new office is created, the NRO enters into a number of Framework Agreements to establish the mutual obligations, rights, and responsibilities of the NRO and Stichting Greenpeace Council. For example, the License Agreement grants the NRO the exclusive use of the name 'Greenpeace' within their country or region, and, in exchange, requires the NRO to adhere to the Greenpeace Council's policy and decisions and to provide Greenpeace International access to the NRO in order to review NRO planning and performance. In 1995, Greenpeace International acquired new powers in monitoring NRO performance through Organizational Development Plans (ODPs), and "the right to help shape and to monitor objectives for improving that performance and the right to intervene in and assist those offices experiencing severe difficulties. ${ }^{, 56}$ NROs provide Greenpeace International with $18 \%$ of their gross independent income unless this percentage is prohibited within national law or is otherwise altered based on the Organizational Development Plans.

\footnotetext{
${ }^{54} \mathrm{http} / /$ www.greenpeace.org/international/faq

${ }^{55}$ Ibid.

${ }^{56}$ Greenpeace International (1996). Greenpeace International: Program of Reform. Amsterdam, The Netherlands, Greenpeace International.
} 
Table 3.2 Greenpeace National and Regional Offices and Year of Origin Source: Greenpeace International (2004). The Board Manual: Greenpeace's Guide to Board Members who want to know about Governance, Boards and Greenpeace. Amsterdam, The Netherlands, Greenpeace International, p. 3.

\begin{tabular}{|r|l|r|l|}
\hline Country/Region & Year of Origin & Country / Region & Year of Origin \\
\hline Argentina & 1986 & Japan & 1989 \\
\hline Australia / Pacific & $1977 / 1999$ & Luxembourg & 1985 \\
\hline Austria / CEE** & $1984 / 2001$ & Mediterranean & 1995 \\
\hline Belgium & 1981 & Mexico & 1992 \\
\hline Brazil & 1991 & Netherlands & 1978 \\
\hline Canada & 1971 & New Zealand & 1974 \\
\hline Chile & 1990 & Nordic & $1999^{* * *}$ \\
\hline China & 1996 & Russia & 1989 \\
\hline Czech Republic & 1991 & Spain & 1984 \\
\hline France & 1977 & Southeast Asia & 2000 \\
\hline Germany & 1980 & Switzerland & 1984 \\
\hline Greece & 1991 & UK & 1976 \\
\hline India & 2000 & USA & 1976 \\
\hline Italy & 1986 & &
\end{tabular}

* The Pacific office (in Fiji) was established in 1995 but merged with Australia in 1999

** Central and Eastern Europe was formed in 2001

*** The Nordic office formed from a merger of the offices in Sweden (1983), Norway (1988), Denmark (1980), and Finland (1989)

Each NRO has a Board of Directors who plays a "supervisory and steward role" and is responsible for the organization's performance and adherence to its obligations to its voting membership, Greenpeace International and other NROs when applicable. ${ }^{57}$ NRO Boards monitor the financial status of the NRO and ratify the annual budget. NRO Boards are often accountable to and elected by a voting membership. Voting memberships are also known as General Assemblies, "may consist of 30 to 100 members depending on the relevant laws of the country $[, \ldots]$ are established to avoid the selfselection and self-perpetuation of NRO Boards" and "are constitutionally required to represent a balanced mix of interests, covering local and broader international interests of Greenpeace." 58 It was decided during the 2000 AGM that NRO staff are not allowed to serve on voting memberships - in order to prevent conflict of interest - unless an exception is granted by the International Greenpeace Council. ${ }^{59}$ There is some variation

\footnotetext{
${ }^{57}$ Greenpeace International (2004). The Board Manual: Greenpeace's Guide to Board Members who want to know about Governance, Boards and Greenpeace. Amsterdam, The Netherlands, Greenpeace International, p. 3.

${ }^{58}$ Ibid., p. 7.

${ }^{59}$ Greenpeace International (2003). Greenpeace Governance Handbook. Amsterdam, The Netherlands, Greenpeace International.
} 
as to the process of appointing Board members and voting on NRO activities and policies. As Anheier and Themudo (2001: 204) write, "the board of Greenpeace US is self-appointed and members have no voting rights," whereas in Spain, "members have voting rights and elect Greenpeace Spain's board democratically because national law requires most NGOs to be 'associations'." The national historical and legal conditions, in large part, determine the governance and decision-making structures within NROs, and also influence the minimum criteria for voting within Stichting Greenpeace Council. NROs have an Executive Director who is responsible for the day-to-day operations of the National or Regional Office, and is monitored and guided by the NRO Board. The Executive Director attends the biannual Executive Directors' Meeting (EDM) and provides guidance to the International Executive Director on strategy and planning for Greenpeace worldwide. NROs send a representative, usually the Chair of the NRO Board, to represent the NRO at the Greenpeace Council and to elect the International Board of Directors. This representative is appointed by the NRO Board and is referred to as a Trustee.

Trustees assemble once a year at the Annual General Meeting (AGM) of Greenpeace and constitute The Greenpeace Council (Stichting Greenpeace Council). According to the Greenpeace Governance Handbook, ${ }^{60}$ the terms Stichting Greenpeace Council and Greenpeace International can be used interchangeably, although the handbook clarifies that the Council is only one of a number of international entities (e.g., Stichting Marine Services and Greenpeace Communications Ltd.) that operate at the international level (see Section 3.5.2 below). The Council performs central coordinating functions, supervises the Greenpeace organization, sets the ceiling on spending for Greenpeace International'ṣ budget, deliberates wide-ranging strategic and campaigning issues, discusses and approves a Long Term Strategic Plan, makes changes to the governance structure, and provides feedback to the International Board and Executive Director. The Council elects the International Board, receives the International Board Report and is empowered to remove International Board members if deemed necessary. The decision

${ }^{60}$ Greenpeace International (2004). Greenpeace Governance Handbook: For Board Members and Trustees. Amsterdam, The Netherlands, Greenpeace International. 
as to whether to open a new Greenpeace office is also determined by the Greenpeace Council at the AGM. If needed, the Council has the power to call an Extraordinary General Meeting. The Governance Handbook specifies a series of criteria, which a Greenpeace National or Regional office needs to fulfill in order to have voting status within Greenpeace Council. These requirements include:

- An NRO Board to be selected according to the provisions given by the National Office Agreement and Guidelines.

- An NRO Executive Director to be entrusted by the Board with the management and operation of the organization through clear roles and authority. The Board is also responsible for his/her appointment and dismissal.

- Financial systems and reporting including financial controls and reporting, audit and financial statements.

- Supporter base, an achievable fundraising strategy, fulfillment of national fundraising standards and an internationally approved fundraising program as part of the Organizational Development Plan.

- At least two different campaigns in two different international campaign areas.

- An approved Organizational Development Plan.

- Minimum financial and performance criteria depending upon the economic position, size, population and demographics of the country or countries in which the organization operates and on the potential negative impact of international and national campaigns on the supporter's base.

The national economic and support conditions of the NRO's country as well as the relative age and size of NROs determine the degree to which the NRO needs to adhere to all of these criteria. Newer and smaller offices require correspondingly less financial income than larger and older offices in order to qualify for a vote. In the majority of decision-making, all NRO votes are counted equal; however, "voting on the annual GPI budget ceiling is conducted by a weighted system, in which each NRO's vote is proportional to its financial contribution to the organization."

${ }^{61}$ Greenpeace International (2004). The Board Manual: Greenpeace's Guide to Board Members who want to know about Governance, Boards and Greenpeace. Amsterdam, The Netherlands, Greenpeace International, p. 4. 
The Greenpeace International Board is composed of five to seven members who are elected by and accountable to the Greenpeace Council. They are selected because of their status as distinguished individuals and experts in their field. Board members serve a three-year term and can stand for re-election. Greenpeace employees, NRO Board members, and other individuals with conflicts of interests are not eligible for International Board membership. The International Board is described within the Board Manual as "the guarantor of the integrity of the organization" and "an independent source of expertise and contacts that can assist and support management." a Chairperson, elects the International Executive Director (IED) of Greenpeace International and assists and advises the IED. Other responsibilities of the Board include the ratification of decisions of Greenpeace Council including the annual budget ceiling, approval of strategic and campaign direction based on recommendations by the IED, approval of new campaigns and offices, closure of NROs when necessary or appropriate, control of finances and the appointment of external auditors, approval of financial statements, review and approval of internal Greenpeace policies, and control of the use of the name 'Greenpeace'. ${ }^{63}$

The International Executive Director manages all the offices, including the international office, at the executive level, provides leadership to the organization, and represents Greenpeace externally. The "primary mission" of the IED "is to ensure the efficient planning, coordination, and execution of effective international campaigns to protect the earth's oceans, forests and sky." ${ }^{64}$ Together with senior managers, the IED is responsible for developing the strategic direction and annual planning process of Greenpeace. The IED is guided in this activity by wide consultations with national and regional level staff, and by consultations with National and Regional Office Executive

\footnotetext{
${ }^{62}$ Greenpeace International (2004). The Board Manual: Greenpeace's Guide to Board Members who want to know about Governance, Boards and Greenpeace. Amsterdam, The Netherlands, Greenpeace International, p. 5.

${ }^{63}$ Greenpeace International (2003). Greenpeace Governance Handbook. Amsterdam, The Netherlands, Greenpeace International.

${ }^{64}$ Greenpeace International(1997) Annual Report. Amsterdam, The Netherlands, Greenpeace International, p. 18.
} 
Directors gathered at the biannual Executive Directors' Meeting. The responsibility of the IED also includes implementing Board decisions, monitoring the financial performance of the organization, determining and recommending the voting status of NROs to the International Board, working with the International Board on hiring NRO Executive Directors, and calling, attending or delegating a representative to NRO Board Meetings. Monitoring the performance of NROs is also part of the responsibility of the IED, and this includes gathering sufficient information to assess performance, accepting or rejecting Organizational Development Plans, and intervening in NRO operations where necessary. The International Executive Director oversees the work of the international headquarters. Unlike the relatively small coordinating international secretariat of Friends of the Earth International, Greenpeace International headquarters employs a staff of over 100 people organized in a number of departments (e.g., legal, financial, human resources - see below) that support the National and Regional Offices and assist in the delivery of Greenpeace's international activities.

\subsubsection{Greenpeace Division of Labour}

Greenpeace engages in a number of activities in pursuit of its goals, which I will group into three main areas: (1) campaigning, (2) management and strategic planning, and (3) fundraising and membership.

The campaigning activities span from national and regional campaigns, to which Greenpeace International provides a limited number of grants, to global campaigns. The National and Regional Offices deliver a number of autonomous national and regional campaigns; however, these campaigns are required to be designed to integrate with and complement global campaigns. As I describe in the introductory chapter, Greenpeace engages in a range of global campaigns (stop climate change, protect ancient forests, save the oceans, stop whaling, say no to genetic engineering, stop the nuclear threat, eliminate toxic chemicals, and encourage sustainable trade). Global campaigns are originally proposed and developed by the Greenpeace Council with contributions from the National and Regional offices and the international headquarter office. Together, all of these offices are committed "to coordinating their activities in a way which maximizes the 
effectiveness of [the] global campaigns and the combined strength of [the] more than two and half million members." 65 Greenpeace has a direct action approach to campaigning, which shapes both the style and tactics of campaigning as well as the division of labour established within Greenpeace to effectively deliver campaigns. This approach to campaigning is summarized in the following quotation from Greenpeace's website:

Greenpeace has been campaigning against environmental degradation since 1971 when a small boat of volunteers and journalists sailed into Amchitka, an area north of Alaska where the US Government was conducting underground nuclear tests. This tradition of 'bearing witness' in a non-violent manner continues today, and our ships are an important part of all our campaign work.

We exist to expose environmental criminals, and to challenge government and corporations when they fail to live up to their mandate to safeguard our environment and our future.

In pursuing our mission, we have no permanent allies or enemies. We promote open, informed debate about society's environmental choices. We use research, lobbying, and quiet diplomacy to pursue our goals, as well as high-profile, nonviolent conflict to raise the level and quality of public debate. ${ }^{66}$

Global campaigns are led by Campaign Directors who, in turn, are assisted by the International Programs Director. Together with the International Output Director, these directors create the International Campaigns Program. Campaign and program decisions are made at the Joint Program Meeting (previously the Joint Campaign Meeting) where major global campaign proposals are presented, discussed and approved. The focus of campaigns is not restricted to areas of the world where Greenpeace has offices but can ex́tend to any other region where environmental challenges occur.

Campaigns are delivered by participating national and regional offices, international staff, and direct action activists teams. In order to support campaign team, Greenpeace has developed an extensive support staff - a technostructure in Mintzberg's terms (1979; 1983) - including experienced trainers that instruct activists on how to successfully carry out direct action tactics (e.g., hang banners, navigate inflatable boats, or block industrial outflow pipes). This training is supervised by the Stichting Actions and Marine Services department based at international headquarters. This department also ensures the development and maintenance of the Greenpeace fleet. The fleet currently includes three

\footnotetext{
${ }^{65}$ Greenpeace International(1997) Annual Report. Amsterdam, The Netherlands, Greenpeace International, p. 18.

${ }^{66} \mathrm{http}: / / \mathrm{www}$. greenpeace.org
} 
large ships (the Rainbow Warrior, the Arctic Sunrise, and the Esperanza), a number of small inflatable boats, and the Greenpeace Hot Air Balloon.

Because of the confrontational nature of Greenpeace campaigning actions, activists are supported by a Legal Department that coordinates responses to lawsuits and imprisonment. For example, activists Greenpeace USA won a legal victory in 2004 when Greenpeace was acquitted for conspiracy charges made by the US Government. ${ }^{67}$ Greenpeace campaigns are also supported by Political and Scientific Units that provide research and scientific analysis to strengthen campaign claims. The Political Unit and campaigners throughout Greenpeace use a combination of direct action techniques and "lobbying and quiet diplomacy" towards target actors, and are armed with the policy research they undertake and reports they publish. Greenpeace Research Laboratories at the University of Exeter in the United Kingdom form the Science Unit of Greenpeace International. The scientists at the unit span a variety of disciplines including toxicology, organic and inorganic analytical chemistry, biochemistry and terrestrial and marine ecology. The scientific advice and analytical support that the Science Unit provides can significantly assist campaigns. An example can be found in the list of 2004 Greenpeace Victories. ${ }^{68}$

Greenpeace sent papaya seeds, sold by Thailand's Department of Agriculture's own research station, for tests because it suspected they were genetically engineered. Independent laboratory examinations proved them right. An uncontrolled field trial, 'contained' only by barbed wire and banana trees, had released genetic contamination into the environment.

Greenpeace Communications Ltd. services both the global campaigns and NROs "to secure maximum media coverage of Greenpeace campaigns... and to provide international news agencies with photo, print and video material originated or acquired by Greenpeace." ${ }^{\prime 69}$ Greenpeace Communications Ltd. was established in 1986 by Greenpeace International to bring together the functions of Greenpeace Films and the

\footnotetext{
${ }^{67}$ Greenpeace International (2005) Annual Report. Amsterdam, The Netherlands, Greenpeace International.

68. Ibid.

· ${ }^{69}$ Greenpeace Communications Ltd. (1991) A Resource Handbook. Greenpeace Communications Ltd. Amsterdam, The Netherlands.
} 
(then dormant) Photo Department in Paris, and to provide state of the art communications services for Greenpeace activities.

Greenpeace International is also engaged in activities that support the management and strategic planning activities of Greenpeace worldwide, through organizational departments that focus on governance and internal communications, national office monitoring, fundraising and marketing, human resources, and finance and administration. Greenpeace management support staff monitors the organizational development of Greenpeace offices, administer Organizational Development Plans for NROs, hire new employees, support current staff and volunteers, and monitor compliance with core policies. As mentioned in the section above, Greenpeace engages in a detailed strategic planning process to develop directions and plans for the organization. This process is led by the Greenpeace Council and includes the involvement and consultation with other actors in Greenpeace such as the International Executive Director, Campaign Directors, and all NROs. Through the multi-level structure consisting of National Offices, Regional Offices, and the International entities and directors, "it is possible to implement both internationally coordinated strategic planning and decision-making and creative local campaign development.",70

The Budgetary Process for Greenpeace International is an organizational activity overseen by the International Board. Greenpeace "does not solicit or accept funding from governments, corporations or political parties" and "neither seeks nor accepts donations which could compromise its independence, aims, objectives or integrity."71 The income for Greenpeace international headquarters is predominately composed of the contributions by self-sufficient NROs (18\% of their gross independent income except where exceptions have been made). GPI also receives donations from individual supporters, bequests, major donors and grant-giving charitable foundations, and a

\footnotetext{
${ }^{70}$ Greenpeace International (2004). The Board Manual: Greenpeace's Guide to Board Members who want to know about Governance, Boards and Greenpeace. Amsterdam, The Netherlands, Greenpeace International, p. 2.

${ }^{71} \mathrm{http}: / / \mathrm{www}$.greenpeace.org/international
} 
relatively much smaller income from merchandising and licensing. ${ }^{72}$ Fundraising is a shared responsibility of Greenpeace International and the national and regional offices, and is based on voluntary donations of individual supporters and grants from foundations. In addition to direct action activists at the operating core of the organization, Greenpeace enlists volunteers as fundraisers and canvassers that sell memberships and Greenpeace merchandise in support of Greenpeace activities and operations.

\subsubsection{Greenpeace Membership}

The term membership within Greenpeace refers to individual voluntary contributors that, through financial donations, support the work of Greenpeace. Although Greenpeace calls these contributors 'members,' there are no formal mechanisms for Greenpeace members to participate in Greenpeace decision-making or have a voice in the election of campaign staff, executives and Boards. However, in addition to showing their financial support of Greenpeace, Greenpeace also encourages these same supporters to undertake actions themselves:

And we believe that the struggle to preserve the future of our planet is not about us. It's about you. Greenpeace speaks for 2.8 million supporters worldwide, and encourages many millions more than that to take action every day. ${ }^{73}$

Although there are opportunities to volunteer for Greenpeace campaigns, not many members participate in Greenpeace's nonviolent direct actions because of the personal risk involved. However, individuals joining Greenpeace can still contribute more than their money to the organization. As the Greenpeace website states, members "can help Greenpeace in many ways - by volunteering your time or services to an existing Greenpeace office, or by becoming a cyberactivist and taking actions." "74 Greenpeace gains legitimacy and support through its large membership, and pursues its goals with the backing of this membership.

Table 3.3 below provides an overview comparison of the structures of Friends of the Earth International and Greenpeace.

\footnotetext{
${ }^{72}$ Greenpeace International(2005) Annual Report. Amsterdam, The Netherlands, Greenpeace International.

${ }^{73} \mathrm{http} / / / \mathrm{www}$.greenpeace.org/international

${ }^{74}$ Ibid.
} 
Table 3.3 Comparison of FoEI and Greenpeace Structures

\begin{tabular}{|c|c|c|}
\hline & Friends of the Earth International & Greenpeace \\
\hline $\begin{array}{l}\text { Decision- } \\
\text { making } \\
\text { structure }\end{array}$ & $\begin{array}{l}\text { Decisions are made through } \\
\text { decentralized, democratic decision- } \\
\text { making processes amongst FoEI } \\
\text { national member groups; major } \\
\text { policies and decisions are decided at } \\
\text { the Biannual General Meeting; which } \\
\text { is the highest decision-making body; } \\
\text { every FoEI member group has a vote; } \\
\text { voting is determined by consensus or } \\
\text { majority; in the intervening two years } \\
\text { between BGMs, decisions on } \\
\text { international activities are made by } \\
\text { international campaign working } \\
\text { groups, regional bodies, and, where } \\
\text { appropriate, the Executive Committee } \\
\text { and the International Secretariat }\end{array}$ & $\begin{array}{l}\text { Major policy, campaign and strategic } \\
\text { decisions are centrally coordinated by } \\
\text { the Stichting Greenpeace Council. The } \\
\text { Council is composed of one } \\
\text { representative (Trustee) from each self- } \\
\text { sufficient National and Regional Office } \\
\text { (NRO). The Council elects an } \\
\text { International Board and the } \\
\text { International Executive Director. } \\
\text { These entities and staff based at the } \\
\text { international headquarters form the } \\
\text { decision-making structure of } \\
\text { Greenpeace International. Decision- } \\
\text { making within NROs is by Boards, } \\
\text { Executive Directors, and, in some } \\
\text { cases, voting memberships. . }\end{array}$ \\
\hline $\begin{array}{l}\text { Division of } \\
\text { labor. }\end{array}$ & $\begin{array}{l}\text { International campaigns involve a } \\
\text { decision-making body (the working } \\
\text { group), the participating FoE members, } \\
\text { and one or two international campaign } \\
\text { coordinators; cross-cutting theme } \\
\text { activities and network capacity- } \\
\text { building are coordinated by Network } \\
\text { Development Coordinators; The } \\
\text { ExCom and International Secretariat } \\
\text { support the FoEI activities through } \\
\text { communication, information collection } \\
\text { and dissemination, publications, } \\
\text { campaign coordination; membership } \\
\text { support and funding, fundraising and } \\
\text { membership development activities; } \\
\text { FoE members fundraise and lend } \\
\text { support and solidarity to national } \\
\text { campaigns. }\end{array}$ & $\begin{array}{l}\text { Autonomous national and regional } \\
\text { campaigns are required to be in line } \\
\text { with the set of Global Campaigns } \\
\text { determined by Council (in consultation } \\
\text { and discussion with other entities). } \\
\text { The Campaigns are coordinated by } \\
\text { Directors, Program Directors, and } \\
\text { carried out by activists throughout the } \\
\text { organization with the support of the } \\
\text { Political, Science, Communications, } \\
\text { Legal, and Actions Units. } \\
\text { Management and strategic planning } \\
\text { activities are centrally coordinated } \\
\text { through the International Council and } \\
\text { supported by organizational staff. } \\
\text { Fundraising and membership } \\
\text { recruitment are the responsibility of } \\
\text { both the international office and NROs }\end{array}$ \\
\hline Membership & $\begin{array}{l}\text { FoE members are admitted one per } \\
\text { country based on criteria (independent, } \\
\text { working at grassroots and national } \\
\text { level, environmental focus, open and } \\
\text { democratic, campaigning, educating, } \\
\text { conducting research; cooperative } \\
\text { approach); members pay } 1 \% \text { of their } \\
\text { unrestricted revenue plus } 0.1 \% \text { of all } \\
\text { of its other revenue to FoEI; members } \\
\text { participate in at least one international } \\
\text { FoEI campaign; Members are subject } \\
\text { to assessments. }\end{array}$ & $\begin{array}{l}\text { Greenpeace members are the } \\
\text { individuals and groups that provide } \\
\text { voluntary donations and grants to } \\
\text { Greenpeace in order to support its } \\
\text { activities. Some members provide } \\
\text { additional support, for example, by } \\
\text { volunteering for Greenpeace offices or } \\
\text { campaigns, joining the nonviolent } \\
\text { direct action teams, or participating in } \\
\text { cyberactivist protests. }\end{array}$ \\
\hline
\end{tabular}




\subsection{Transnational Organizational Forms}

How do the structures of Greenpeace and Friends of the Earth International compare with other actors in their organization field? There has been a recent surge in interest in specifying the various forms that transnational actors and partnerships adopt (Keck and Sikkink 1998; Lindenberg and Dobel 1999; Rucht 1999; Anheier and Themudo 2001; Lindenberg and Bryant 2001; Khagram et al. 2002; Clark 2003a and b; Risse 2003). I review this literature here in order to shed light on the degree of centralization and level of formalization of Greenpeace and Friends of the Earth International. Although Greenpeace is more centralized and formalized than FoEI, I suggest that this classification is a relative assessment based on the comparison between these two transnational social movement organizations. When situated within their organization field, FoEI and Greenpeace have been clustered together in other classifications and portrayed as being relatively more or less formalized and more or less centralized than other actors and partnerships. The purpose of this section is to highlight this complexity while maintaining the claim that, relative to each other, FoEI is more decentralized and informal than Greenpeace.

The level of formalization of Greenpeace and FoEI is often contrasted with other actors and coalitions of actors operating at the transnational level. Smith (2002: 212) clusters Greenpeace and Friends of the Earth together in terms of their "formalization and hierarchy" and their "federated structures," and then distinguishes this level of formalization from groups that sustain a "loose network-like structure relying heavily on electronic communication and affinity groups." Affinity groups are "reticular [networklike] and decentralized, composed of many small, loosely linked cells" that "reflect the insight that people enter into many social movement activities in social molecules, with friends and acquaintances, rather than as atomized individuals" (Gamson 1987: 5). In comparing the internal structure of transnational actors, Risse (2003) similarly draws a distinction between formal organizations (e.g., transnational social movement organizations and multinational corporations) and looser "network" configurations. Keck and Sikkink (1998:8) provide an analysis of these informal network structures, which they define as "forms of organization characterized by voluntary, reciprocal, and 
horizontal patterns of communication." Examples of networks include both coalitions of economic actors and firms (Keck and Sikkink 1998: 1) and "epistemic communities." Epistemic communities are networks of individuals and organizations, such as scientific and expert networks, that gain their authority and legitimacy in decision-making processes through their professional ties and claims to consensual knowledge and shared causal ideas (Haas 1992). Keck and Sikkink draw a further distinction between economic, scientific and experts networks and what they call "transnational advocacy networks" defined as "networks of activists, distinguishable largely by the centrality of principled ideas or values in motivating their formation" (Keck and Sikkink 1998: 1 emphasis added). In their typology of transnational actors, Khagram et al. (2002: 6-8) also differentiate between, on the one hand, formal organizations that operate in several countries and, on the other, transnational networks. Within the second category, they further differentiate between transnational networks that are characterized by information sharing, common analyses and shared discourses; transnational coalitions that share strategies and coordinate tactics on a specific transnational campaign in addition to building network capacities; and transnational social movements that have a stronger sense of common identity, threaten establish social order, and add the capacity to mobilize collective action in multiple countries (see also Gordenker and Weiss 1995). These networks can either be composed of civil society actors - such as partnerships between FoEI and indigenous peoples networks - or composed of actors from different sectors - such as the campaign to ban landmines that included governmental, nongovernmental and corporate actors (Florini 2000).

The actors, networks and movements in the organization field of FoEI and Greenpeace can also be distinguished by their degree of centralization. Clark (2003b: 4-5) focuses on the forms adopted by civil society actors at the transnational level and provides a useful typology of these forms organized by their level of centralization. This typology is presented in Box 3.1 below. Clark categorizes the organizational forms of civil society actors as international civil society organizations (International CSOs), civil society organization networks (CSO networks), and social movements. International CSOs and CSO networks are analogous to the term transnational social movement organization 
(TSMO) used in this dissertation, and it is within these two categories of Clark's typology that the case study organizations, Greenpeace and FoEI, are placed. For Clark, international CSOs such as Greenpeace are "single coherent organizations" in which "major decisions are reached globally by international boards; politics are implemented by global secretariats or head offices; [and] there is a global hierarchy of staff accountability." The subcategory of centralized association that characterizes Greenpeace's type of International CSO "provide greater national autonomy; but major decisions are made by global headquarters, which also control the use of name and standards." In contrast, Friends of the Earth International is depicted as a CSO network, defined as "collaborative arrangements formed for broad partnership amongst likeminded organizations or cooperation on specific activities," possibly with international boards and secretariats "but most power and implementation capacity remains with CSO members." In another version of this typology, Clark (2003a: 112) draws a distinction between federations and confederations. Federations are "networks comprising national members with a common name and charter but also national self-determination," with "strong global boards, comprising members' delegates, making binding decisions," and with a secretariat that is "largely responsible for implementation." Confederations are network organizations wherein "network members are fully independent but agree to a set of common ground rules and work together on specific activities where there is mutual advantage... examples include... Friends of the Earth International" (Clark 2003b: 4). 
Box 3.1: Typology of Organizational Forms (Clark 2003b: 4 - 5)

International civil society organizations.(CSOs): single, coherent organizations; major decisions are reached globally by international boards; politics are implemented by global secretariats or head offices; there is a global hierarchy of staff accountability. Within this form there is considerable variation, depending upon the degree of autonomy vested in the national branches or sections. It includes:

- Unitary structures: the equivalent of transnational corporations (TNCs), these are CSOs with global decision-making processes (albeit with some devolution). Examples include the Catholic Church, Human Rights Watch (HRW) and Plan International.

- Centralized associations: these provide greater national autonomy; but major decisions are made by global headquarters, which also control the use of name and standards. Examples include Greenpeace and CARE.

- Federations: global boards (representing the member CSOs) make global decisions in a framework of subsidiarity (considerable autonomy at the national level). They are serviced by strong global secretariats, accountable to the boards. Examples include Amnesty International (AI), CIVICUS (World Alliance for Citizen Participation) and Consumers International $(\mathrm{CI})$.

CSO networks: these are collaborative arrangements formed for broad partnership amongst likeminded organizations or cooperation on specific activities. They may have international boards and secretariats; but most power and implementation capacity remains with the CSO members. They comprise:

- Confederations: network members are fully independent but agree a set of common ground rules and work together on specific activities where there is mutual advantage. Examples include the World Council of Churches, the International Confederation of Free Trade Unions (ICFTU), Oxfam International (OI), Friends of the Earth International (FOE-I), and international inter-faith networks (such as the United Religions Initiative).

- Informal networks: CSOs come together around a common cause to seek cooperation but with little agreed governance arrangements, leadership or membership requirements.

Examples include the International Campaign to Ban Landmines (ICBL) and the Jubilee 2000 movement for developing-world debt relief.

Social movements: these comprise amorphous and fluid groupings of activists, CSOs and supporters in which the bonds are common grievances or convictions, and shared goals for societal and policy change (rather than structure). They connect people with causes through developing communities of interest around shared conditions and include:

- Rooted movements: these are webs of citizens formed at the national level to attack mutually experienced grievances. International exchange and networking with counterparts in other countries can be powerful for sharing ideas and boosting morale; but mobilization and analysis is primarily at the national level. Examples include feminist, agrarian reform, gay rights, and civil rights movements.

- Transnational movements: where the policy changes sought are largely determined by international governmental or corporate actors, movements become more transnational in character, although the boundary of this is not clear cut. Working internationally is not just for sharing ideas and building solidarity but also for forging collective energy and a globally coherent strategy around shared social change goals. Examples include the human rights movement, the climate change movement, and the modern protest movement relating to globalization. 
In a similar classification, Rucht (1999) distinguishes between two types of transnational structures: coalitions and more formal organizations. He further divides formal organizations into two types: a more decentralized structure and a more centralized structure. In formal organizations, transnational coordination involves not only the interactions of national or sub-national groups but also includes the formation of an international body which facilitates both vertical and horizontal coordination. In this quote, Rucht (1999: 208) describes the two types of formal organization, while indicating that "most empirical cases lie somewhere in between."

First, the overall structure could be decentralized, thus limiting the power of the international body, and facilitating a flow of communication from the bottom to the top as well as direct communication among national sections. An example of this structure is Friends of the Earth International, a worldwide environmental umbrella organization that allows only one group per country to become a member. The second model implies a more centralized structure characterized by one or several bodies beyond the national level that, in substantial matters, can impose their will on national groups. In this case, the flow of communication is predominately vertical and top-down. Such a centralized structure presupposes or induces ideational and structural similarities between national groups - a trait that is most likely when all national groups are part of the same organization.

Amnesty International is an example of a moderately centralized movement organization that is part of a broader cross-national human rights network (Ennals 1982). By contrast, Greenpeace International has a highly centralized structure (emphasis added).

A comparison of the typology developed by Rucht (1999) with that proposed by Clark (2003b) suggests that perceptions of relative degrees of decentralization across civil society vary across typologies. Rucht categories Greenpeace International as "highly decentralized"; however according to Clark's typology, Greenpeace can be perceived as being relatively less centralized than Human Rights Watch and Plan International. The evolution of Clark's own typology (2003a: 111 and 2003b: 4-5) reveals his initial categorization of the organizational forms of Human Rights Watch and Greenpeace within one category labeled centralized organizations (2003a: 111) which he later separates into two categories - unitary structures and centralized associations - to describe different levels of centralization (2003b: 4). 
The same relative assessments are true in depictions of levels of formalization. On the one hand, FoEI is relatively less formal than Greenpeace but both of these organizations are "never as bureaucratic as more established organizations such as corporations and government agencies" (Staggenborg 1988: 587). This is particularly the case because social movement organizations exhibit both a "describable structure" and the "noticeable spontaneity" of SMO participants counteracting formal operational procedures which they perceive as constraining the pursuit of SMO goals (Freeman and Johnson 1999: 1). Conversely, neither Greenpeace nor FoEI are as decentralized and informal as the social movements within which they are embedded. Based on their analysis of the black power and Pentecostal movements, Gerlach and Hine (1970) characterized social movements as having three structural characteristics that correspond with their high degree of decentralization and level of informality. Gerlach (1999: 85) defines these features in the following way:

[Social movements are:]

Segmentary: Composed of many diverse groups, which grow and die, divide and fuse, proliferate and contract.

Polycentric: Having multiple, often temporary and sometimes competing leaders or centers of influence.

Reticulate: Forming a loose, integrated network with multiple linkages through travelers, overlapping membership, joint activities, common reading matter, and shared ideals and opponents.

Assessments of the organizational structure of Greenpeace and FoEI depend on the vantage point of the observer; however, it remains clear that Greenpeace is relatively more centralized and formalized than Friends of the Earth International. How do these different structures affect their adaptive capacity: their ability to strategically respond to complex and dynamic internal and external pressures over time? I return to the analysis by Smith (2005), who suggests an answer to my central research question, and which, as I stated in Chapter One, provides the starting point for my response and main theoretical contribution.

In Section 2.1.4, I reviewed the growth in the number of transnational social movement organizations as analyzed by Smith (2005), and based on the data of the Yearbook of 
International Associations (Union of International Associations). In the same study, Smith assesses the organizational structure of transnational social movement organizations embedded within the human rights, peace, women's rights, development, global justice, and environment social movements and across these movements. Smith (2005) contrasts a more centralized and formalized structure, which she labels a federation structure, with a more decentralized and informal structure, which she labels a coalition structure. Smith's description of federation and coalition structures aligns closely with the discussion and typologies of organizational structures detailed above. A more centralized and formal "federated" structure "involves the division of the organization into national sections that are certified by the international secretariat," provide resources to the secretariat, and attend international gatherings. In return, national groups within the federation are granted the use of the organizational name and operate under established "international guidelines regarding political claims, governance, and activities" developed in the international secretariat (Smith 2005: 235). The decentralized and informal "coalition" structures are characterized by "fewer requirements for conformity with a broad set of organizational rules, goals and procedures as defined in the organization's secretariat or international office." Although there are variations within this form, Smith argues that the main feature of a coalition structure "is that affiliates are asked to adopt a relatively limited shared ideological framework, and they maintain fairly wide autonomy within the coalition framework", (1995: 235). Smith does not classify Greenpeace as a "federation" and Friends of the Earth International as a "coalition"; however, her descriptions of these two organizational forms closely match the structures of Greenpeace and FoEI. Smith provides data on the changes in the population of TSMO structures over time, and I have reproduced her analysis in Table 3.2 below. The table displays the number of federation structures and coalition structures in the years 1973, 1983, 1993, and 2000. 
Table 3.4 Organizational Structures of TSMOs

(Smith 2005: 235 - Source: Yearbook of International Associations)

\begin{tabular}{|l|c|c|c|c|}
\cline { 2 - 5 } \multicolumn{1}{c|}{} & $\begin{array}{c}1973 \\
\%\end{array}$ & $\begin{array}{c}1983 \\
\%\end{array}$ & $\begin{array}{c}1993 \\
\%\end{array}$ & $\begin{array}{c}2000 \\
\%\end{array}$ \\
\hline $\begin{array}{l}\text { Federation } \\
\text { Structure }\end{array}$ & $\mathbf{5 0}$ & $\mathbf{3 8}$ & $\mathbf{2 8}$ & $\mathbf{1 8}$ \\
\hline $\begin{array}{l}\text { Coalition } \\
\text { Structure }\end{array}$ & $\mathbf{2 5}$ & $\mathbf{3 1}$ & $\mathbf{4 3}$ & $\mathbf{6 0}$ \\
\hline
\end{tabular}

The following quotation presents her conclusions based on this data:

The most dramatic change in the TSMO population over the past three decades is that these groups are adopting the more decentralized and informal coalition form. It is probably no coincidence that this same phenomenon is happening in the corporate sector, as firms seek to maximize the ability of their diverse regional and national operations to adapt quickly to changing market forces (see, e.g., Sklair 2001). The coalition form accelerates decision making and therefore adaptability of groups by decentralizing authority within the organization. In a rapidly changing and uncertain political context, such flexibility is essential.

Smith equates decentralized and informal coalition structures with adaptability. In Chapter 4, I take issue with this conclusion and propose that centralized and formal federation structures represent another unique and viable approach to building adaptive capacity. Table 3.4 traces a decline in the percentage of TSMOs adopting a relatively more centralized and formalized structure - the federation structure. This can be interpreted as indicating the possible slow demise of this structural configuration at the transnational level. Based on my analysis of Greenpeace, and evidence of the recent emergence other TSMOs at the transnational level with a 'federation' structure (e.g., Human Rights Watch), I argue that this structural configuration remains a viable and effective option for TSMOs. In upcoming chapters, I explore the benefits associated with this structural configuration, which I suggest will ensure that this structural choice will remain attractive to TSMO founders. 


\section{CHAPTER FOUR: Adaptive Capacity}

\subsection{The Transformation of Social Movement Organizations}

In this dissertation, I refer repeatedly to the complex and dynamic internal and external pressures that transnational social movement organizations are subject to, and the influence that these pressures have on the effectiveness and structure of TSMOs. Much of social movement theory identifies factors that determine the mobilization and participation of people in a movement (Davis et al. 2005: 189). Equally important is an explanation of why certain social movements endure over time, and "take on an organizational framework, morphing into social movement organizations" (SMOs) (Davis et al. 2005: 189). Analyses of the emergence of SMOs have been complemented by investigations into the "growth, decay and change" of these organizations, particularly as SMOs are "subject to a range of internal and external pressures which affect their viability, their internal structures and processes, and their ultimate success in attaining goals" (Zald and Ash 1966: 327). I provided a brief description of the emergence of Greenpeace and Friends of the Earth International in the introductory chapter; however, in this dissertation, my dominant focus is on their three decades of organizational development. As displayed in Figure 4.1, I focus in this chapter on the adaptive capacity of TSMOs, the ability of a TSMO to strategically respond to key internal and external organizational challenges over time. 


\section{Figure 4.1 Adaptive Capacity and Organizational Challenges}

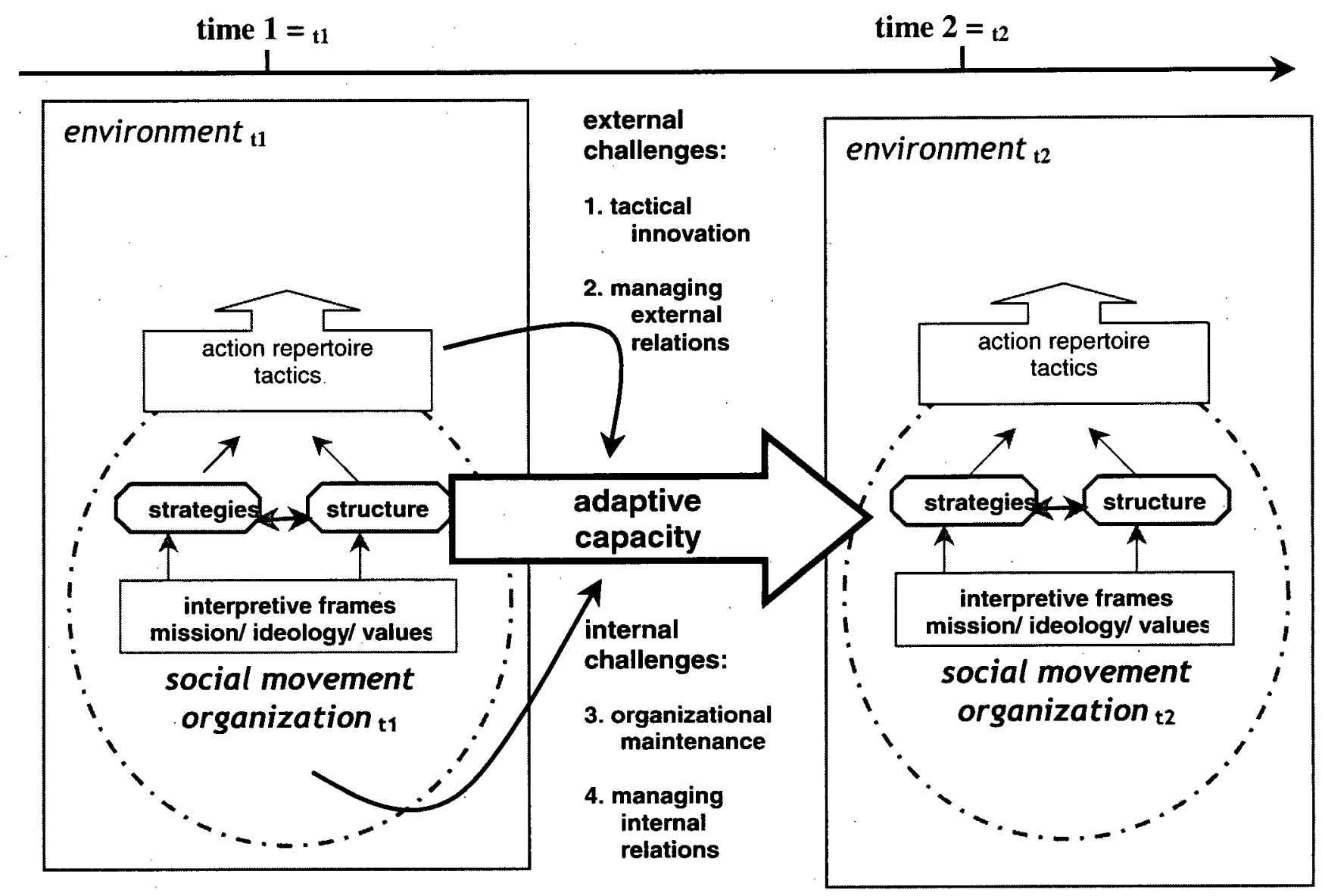

Historically, theorists researching organizational development have proposed a number of generalizations regarding the transformation of organizational structures over time in response to internal and external pressures. These include theorists who assert that organizations inevitably become more formalized, centralized and less radical over time (e.g., Michels 1949 [1911]; Weber 1958 [1924] - also referred to as institutionalization (Van der Heijden 1997). I follow in the tradition of theorists who challenge the idea that there is one trajectory of organizational development (e.g., Zald and Ash 1966;

Rothschild and Whitt 1986; Doherty 2002). As the introductory chapter outlined, my aim is to challenge the growing consensus within the social movement and organizational literatures that there is one ideal organizational development trajectory within complex and dynamic conditions. Although there is broad agreement amongst organizational theorists that different structures have distinct advantages and disadvantages, there is a growing consensus that decentralized and informal structures are the only effective 
structural formation for maximizing adaptability in a complex and dynamic environment (Fowler 2000; Anheier and Themudo 2001; Clark 2003a: 111; Smith 2005). This claim inherently challenges earlier assumptions about the inevitability of centralization and formalization in organizations. Jenkins (1983) writes that "the major debate over the organization of movements has been between proponents of a centralized bureaucratic model...and those arguing for a decentralized informal model."

In dispelling generalizations about "inevitable" organizational transformations over time, I attempt to move beyond this dichotomy of defining the effectiveness of either centralized formal or decentralized informal models. Instead, I join other theorists in emphasizing the effectiveness of alternative organizational models in advancing multiple support and output goals (e.g., Rothschild and Whitt 1986; Young et al. 1999). In contrast to scholars who take issue with assumptions of the "institutionalization" (e.g., centralization, formalization, de-radicalization) of social movement organizations (e.g., Zald and Ash 1966; Rothschild and Whitt 1986; Staggenborg 1989; Doherty 2002), I question theories that detail processes of decentralization and informality in movements (e.g., Fowler 2000; Smith 2005). Despite this difference, my position echoes that of Staggenborg (1999: 130), as illustrated in the following quotation:

Classical theories of the "natural history" of a movement focus on the institutionalization of the movement as a whole and ignore variations in the experiences of different SMOs within the movement. My research shows that SMOs vary in the way in which they deal with internal organizational problems and changes in the environment.

In this and upcoming chapters, I explore how alternative organizational models and structures maximize adaptability in complex and dynamic conditions.

I follow a line of analysis that is similar to studies rejecting the inevitability of bureaucratization, centralization and conservatism of social movement organizations; therefore, I will briefly review these studies here. The argument for inevitable transformation in organizational structure stems from the work of Michels (1949 [1911]) and Weber (1958 [1924]) and can be characterized as follows: as organizations gain in legitimacy and support within society, there is a tendency to replace charismatic leaders 
and create a routinized, formalized, or bureaucratic structure. As mentioned above, this transformation has been referred to as the institutionalization of an SMO (Van der Heijden 1997; Doherty 2002).

Institutionalization is associated with three processes that are problematic for organizations seeking to prioritize social change output goals and facilitate participatory decision-making processes inside their organization. First, the organization experiences goal transformation, "always in the direction of greater conservatism (the accommodation of organizational goals to the dominant societal consensus)" (Zald and Ash 1966: 327). Second, the support goals of the organization become the primary focus, as participants in the organization acquire an increased stake in organizational maintenance rather than in achieving the output goals for which the organization was established. This process "is accompanied by conservatism, for the original goals must be accommodated to societal norms in order to avoid conflicts that could threaten the organization's viability" (Zald and Ash 1966: 327). Third, Michels is concerned with the extent to which power becomes concentrated in the hands of a minority of organizational participants in a process of oligarchization. Michels" "iron law of oligarchy" is a process that he argued "can never be entirely avoided" (Michels 1949 [1911]: 429), and which results in increased conservatism and a loss of democratic and dispersed decisionmaking power. The group that is holding decision-making power has a "self-interested nature" (Doherty 2002: 114) and becomes predominately focused on organizational maintenance and the creation of "self-reproducing authority structures" rather than on attaining output goals (Davis et al. 2005: 189).

The process of goal transformation refers to the tendency of an organization to move away from changing the status quo and towards accommodating mainstream societal values. This is particularly problematic for social movement organizations, because a shift from an SMO's original mission can lead to accusations that the SMO is "caring more for their organization than for their cause" and not engaging in disruptive protest and collective action to alter the reward distribution and social structure of society (Moore 2000: 192). A study by Piven and Cloward (1977), on social movement 
organizations in "poor people's movements", supports the notion that centralized and formalized organizations diffuse protest.

In contrast, Doherty (2002: 123) argues that an increase in institutionalization does not necessarily lead to de-radicalization as long as SMOs "avoid co-option." In this way, Doherty is drawing a distinction that is similar to one made by Van der Heijden (1997: 31) between "internal institutionalization", defined as an SMO's formalization and centralization, and "external institutionalization", defined both as an increase in cooperation between an SMO and its former adversaries, and as a decrease in an SMO's use of confrontational tactics. External institutionalization is problematic for social movement organizations because they are defined by their disruptive approach and their goals of influencing societal and personal change. It is this "outsider" position that differentiates a social movement organization from an interest group. Interest groups adopt routinized and stable ties with government and other adversaries, whereas social movements do not establish such ties (Lowi 1971; Useem and Zald 1987). Doherty's claim that internal institutionalization does not necessarily lead to de-radicalization stems from his analysis of "institutionalized" environmental organizations, including Greenpeace and Friends of the Earth International, which he assesses as maintaining a continued commitment to "radical political change" even as they become more formalized in their structures (2002: 19). He also argues that these relatively more formal organizations need to be evaluated as part of a broader set of actors that form the "green movement," with which they share radical goals of "ecological rationality, social justice and participatory democracy" and "in which they increasingly play a specialized role" (Doherty 2002: 4, 19). Doherty defines Greenpeace and Friends of the Earth International as "mass environmental movement organizations" whose activities are complemented by the collective actions of relatively more formalized Green Parties and of more informal and decentralized direct action groups and local environmental protest groups.

Chapter One notes the importance of social movement organizations attending to both output goals and support goals. Similarly, Brown and Moore (2001) argue that a successful social movement organization develops a strategy that combines the goals of 
value creation, of securing legitimacy and support, and of building operational capacity. The process of organizational maintenance refers to a "preoccupation with internal affairs and organizational function that results in...devoting far more ... time and energy to "institutional maintenance' than to political outreach and substantive organizing work" (Garrow 1985: 15 - emphasis added). Social movement organizations that supplant output goals or value creation with a predominate focus on support goals can be accused of being "motivated by a crass desire to stay employed" and engaging in "self-interested empire building" (Moore 2000: 192-3). Jordan and Maloney (1997:18) argue that this has already happened in some social movement organizations - an argument which they base partly on their analysis of the UK branch of Friends of the Earth. Jordan and Maloney label these transformed organizations "protest businesses," defined as "professional bureaucratic, mainstream groups... led by managers, staffed by professional economists, lawyers and biologists, and supported by sophisticated public relations and fund-raising departments" that mobilize supporters for their financial support rather than their involvement. McCarthy and Zald (1973) describe a similar phenomenon in their concept of a "professional social movement organization" that includes staff with "social movement careers" and a "paper membership" supporting, but not engaging in, SMO activities. Rather than critiquing this organizational development, McCarthy and Zald (1977) celebrate numerous advantages of more formalized and professional social movement organizations including operational efficiency, a level of campaigning sophistication, stable ties to constituents and supporters, and possibilities for benefiting from economies of scale in delivering protest actions (see also Gamson 1975; Tilly 1978; Diani and Donati 1999). Lofland (1996) also does not correlate professionalism with a focus on support goals. Instead, he argues that the correct balance in prioritizing between support and output goals is not attributable to one or other SMO organizational structure, but rather to SMO participants managing the tension between realizing support goals and attaining output goals. Lofland (1996: 258) acknowledges the potential for output goals to be inappropriately supplanted by a dominant focus on support goals, but also emphasizes that successful organizational maintenance is essential for pursuing output goals as it "helps make major goal achievement more possible." 
The process of oligarchization - the concentration of power in the hands of a few individuals - is problematic within a social movement organization because SMOs are often guided by principles of participatory democracy and the decentralization of power (Doherty 2002). Scholars have questioned the extent to which oligarchization is inevitable in SMO development. Tarrow (1994: 136) argues that Michels' iron law of oligarchy "is far less common than is supposed, and the power of centralized movements is often an illusion." In fact, Staggenborg's (1999: 129) research of SMOs in the prochoice movement concludes that the opposite of the "iron law of oligarchy" can also be true. Her sample of formalized SMOs "seem[s] more democratic than informal SMOs because they follow routinized procedures that make it more difficult for individual leaders to attain disproportionate influence." This tendency towards oligarchy within informal and less institutionalized SMOs has been referred to as the "tyranny of structurelessness" (Freeman 1973).

Smillie and Hailey (2001: 126) came to a similar conclusion about the benefits of a certain degree of structured division of labor within social movement organizations in order to support democratic processes. They argue that the problem of control being inappropriately concentrated in the hands of a few people does not always stem from the formalization of roles and the establishment of hierarchy within SMOs. They recommend analyzing "how hierarchy functions" in each organization (Smillie and Hailey 2001: 126). "Flat" and more informal structures can result in the concentration of power because "the founder wanted to keep an eye on everything," and, in contrast, some hierarchies "can be compatible and complementary" with participatory management and democratic processes if the decentralization of authority is prioritized (Smillie and Hailey 2001: 131). This finding is echoed by Rothschild and Whitt (1986) in their study of hundreds of "collectivist organizations" (including cooperatives, collectives and alternative institutions) which adopt organizational democracy and participation as a central operating value. The organizations included in their study resisted the oligarchization of power even as they struggled to maintain participatory processes in light of "inherent trade-offs [such as potential increases in decision-making time, cost and internal conflict] that go with the pursuit of democracy" (Rothschild and Whitt 1986: 3). 
Members of a "collectivist" organization decentralize power because this governance arrangement aligns with their ideological commitment to participatory values. This commitment has been found to be attractive to potential movement supporters that similarly value participatory democracy (Downey 1986; Kitshelt and Hellemans 1990). In addition to rejecting the concentration of power because of their democratic values, SMO members often reject oligarchization because of their opposition to centralized power structures within broader society. As Lofland (1996: 144) writes, "beyond aiming to abolish these features in the larger society (an adversary belief), many SMOs have sought to "walk the talk" and to implement exemplary forms of less formalized and decentralized SMO organization." Social movement organizations that do not follow the trajectory of oligarchization depicted by Michels (1949 [1911]) consciously and actively resist this transformation. An antioligarchic tendency has also been found in SMOs within the peace movement, political Green Parties, and the women's movement (Dalton 1994: 9).

This review indicates that the institutionalization of social movement organizations does not necessarily lead to processes of goal transformation, of preoccupation with organizational maintenance, or of oligarchization. In much the same way, I question the growing consensus that internal and external pressures on social movement organizations lead organizational participants to adopt decentralized and informal structures in order to maximize adaptability within complex and dynamic conditions.

\subsection{Structure and Adaptability}

The structures that Friends of the Earth International (FoEI) and Greenpeace have developed over time are expressions of their learned and routine responses to internal and external pressures. I provide an overview of the pressures facing Greenpeace and FoEI in Chapter Two, including internal conflicts about interpretive frames stemming from the diversity of actors engaged in these transnational social movement organizations (TSMOs), substantive changes in their issue area, and shifts in the interests of actors with whom they interact. I argue that these pressures can be considered to be both complex and dynamic, and that these characteristics require FoEI and Greenpeace to be adaptive in 
order to effectively achieve their output and support goals over time: As mentioned in the introductory chapter, I define the ability of a TSMO to develop strategic responses to complex and dynamic internal and external pressures as its adaptive capacity. Over time, organizations typically develop a pattern of evoking those strategies that reliably and repeatedly resolve organizational challenges. This patterned response becomes embedded in the structures and strategies of a TSMO. In this dissertation, I take for granted that Greenpeace and FoEI have built adaptive capacity and operate effectively within complex and dynamic conditions. I base these assumptions on the continued viability of FoEI and Greenpeace (see Section 1.2.3) and I analyze these organizations to uncover the factors that explain their adaptive capacity and uncover how these organizations have built this capacity. It is not my intention to develop an objective measure of viability but, instead, to posit that Greenpeace and FoEI have established distinct and equally viable approaches to building adaptive capacity as indicated by their different structural configurations. Accordingly, I challenge the growing consensus that adaptive capacity is maximized in decentralized and informal structures (Fowler 2000; Anheier and Themudo 2001; Clark 2003a: 110; Smith 2005), and propose that a more centralized and formal structure can enable adaptability within complex and turbulent conditions.

In order to build my argument, I will first review the features and characteristics that, according to current scholars, provide an adaptive advantage to a decentralized, informal structure. To reiterate earlier quotations within this dissertation, Smith (2005: 235) argues that a decentralized and informal structural configuration within a TSMO maximizes the "ability of subgroups to adapt quickly" and accelerates decision-making by decentralizing authority. Anheier and Themudo (2001: 201) claim that decentralized and informal structures - which they label as "relational" or network forms - "are somewhat 'fluid' organizations particularly suited for highly variable task environments" due to the fact that "without central coordination for everyday management tasks and operations, decisions are made at the local levels with a minimum of costs for consultation and negotiation." Anheier and Themudo continue by noting some of the disadvantages of the relational form, such as lack of coordination, and advantages of 
more centralized structures, such as sharing development costs; however, these authors conclude that "adaptability is maximized when undertaken by small independent units rather than large bureaucratic structures" and "on balance, and on largely economic grounds, the global organizational environment for CSOs [civil society organizations] would favor the network form with decentralized and autonomous units" (2001: 202) Smith (2005: 235) similarly adopts an economic argument by stating that organizations operating transnationally adopt "organizational structures aimed at limiting ... transaction costs." In addition to attributing higher transaction costs to more centralized and formal structures, Smith (2005: 236) describes such structures as being "rigid and hierarchical" rather than flexible and adaptive. Smith is not alone in this assertion; for example, Bloodgood (2002: 305) describes Greenpeace as a "strict hierarchy" and assumes its structural inflexibility.

Anheier and Themudo (2001) and Clark (2003a) adopt the lens of private sector organizational theory to examine the evolution of organizational structures over time. During the industrial revolution, large factories adopted a unitary form (U-form) or organization that centralized and formalized all decision-making within one management body. The multi-divisional form (M-form) emerged when companies expanded their operations and created branches for new products and new locations. These branches were frequently given a degree of decision-making autonomy. More recently, a new organizational form, the network form ( $\mathrm{N}$-form) has developed to "develop more fluid ways of working," decentralizing authority and prioritize information exchange and rapid and frequent horizontal exchanges amongst people and units (Clark 2003a: 110). Clark (2003a: 110) applies these organizational structural configurations to actors in civil society and argues that Greenpeace represents an M-form structure, while Friends of the Earth International represents a $\mathrm{N}$-form. Critical for this dissertation, Clark (2003a: 110) aligns the $\mathrm{N}$-form with adaptability.

Networks have clear advantages of adaptability and problem-solving. They can reach decisions faster and more swiftly discover and adopt new techniques developed elsewhere, but established firms set in old ways find it difficult to shift to this new mode.... The transition from $\mathrm{U}$-form to $\mathrm{N}$-form means increasing flexibility and unit-autonomy while decreasing hierarchy, but also less predictability and stability (emphasis added). 
Clark argues that social movement organizations, which he labels civil society organizations (CSOs), are currently facing a test in how they adapt to the network age. The successful SMOs gain in output effectiveness, legitimacy and support, although with some problems; while the unsuccessful SMOs "are likely to stagnate" (Clark 2003a:

111). Clark identifies four challenges that network forms are better suited at addressing:

- Working globally: developing North-South links and international campaign strategies; speaking with a single, loud, global voice - albeit with national variations in how they work and what they work on;

- Managing information: establishing two-way information systems so that campaigns are well informed by ground realities and the grassroots are empowered to be full and active campaign participants;

- Managing strategic partnerships: strengthening links with new as well as traditional allies, even if there is little in common beyond the issue at hand, because the scope of global challenges goes well beyond the boundaries of individual CSOs;

- Responding rapidly: as ICT has speeded up news and current affairs, CSOs able to respond rapidly to political opportunities derive a valuable premium; this is often difficult for established CSOs.

There are at least two problems with the characterization of decentralized, informal structures as being more effective in adapting to complex and dynamic internal and external pressures than centralized and formal structures: (1) the conceptualization of structure and (2) the definition of adaptability. First, I take issue with the depiction of centralized and formal structures as being necessarily rigid. This assumption is based on a conception of structure as static and inflexible; however, structures are more usefully conceived as a fluid set of arrangements that include both established rules governing behavior and informal interactions amongst organizational participants (Mintzberg 1998b). I draw on recent developments in the social sciences that move away from a conceptualization of structure as "deterministic..., given or independent... [with] fixed parameters" towards a dynamic exploration of structure as "active sites of creation and change" that simultaneously are expressions of the constant interactions amongst actors and place constraints on the expressions and actions of organizational actors (Jasanoff 2005: 20). In other words, structures are the negotiated expressions of actors within a social movement organization (SMO), and these structures, in turn, partially limit future interpretive frames (representations) and action repertoires of SMO actors. This 
conceptualization of structure has emerged from the synthesis of micro-theories of "agency" and macro-theories of "structure" as reflected in this quotation from Bourdieu (1989: 15):

On the one hand, the objective structures... form the basis for ... representations and constitute the structural constraints that bear upon interactions: but, on the other hand, these representations must also be taken into consideration particularly if one wants to account for the daily struggles, individual and collective, which purport to transform or to preserve these structures.

Structural arrangements, in this context, are repeated patterns of behavior. As Gamson (1975: 91) notes, a formal structure, which he labels a "bureaucratic organization" can assist "with the problem of pattern maintenance" by "creating a structure of roles with defined expectations in the place of diffuse commitments" (emphasis added). Mintzberg (1998b: 153) also equates formalization of structure with repetition and greater predictability of behavior. Similarly, Van der Heijden (1997: 31) refers to the formalization of social movement organizational structure as institutionalization defined as "the process by which originally personal norms, expectations, goals and values tend to form a collective pattern, a pattern by which interactions and communications are regulated and structured" (emphasis added). I adopt this conceptualization of structure and argue that although Greenpeace is more centralized and formal than Friends of the Earth International, its structure remains dynamic as Greenpeace actors are partially constrained by their past decisions and established rules while still remaining empowered to craft and adapt their structural configuration and respond to changes in internal and external pressures. This flexibility of structure is particularly evident within social movement organizations that are defined by their combination of both "structure" and "spontaneity" (Freeman and Johnson 1999: 1). Centralization and formalization can lead to inflexibility if rules and command structures are too rigidly adhered to or are perceived and implemented in uncompromising ways; However, I assert that higher levels of centralization and formalization can continue to provide a dynamic structure that enables adaptability. By adopting this approach to structure, I offer a characterization of two unique and viable approaches to building adaptive capacity - which I label as the Agility and Resilience models - that correspond with two different structural configurations as embodied by Friends of the Earth International (decentralized and informal) and by 
Greenpeace (more centralized and formal). As will become evident in the Section 4.4 of this chapter, these different structural configurations lead both to different approaches to building adaptive capacity and to different dynamics of organizational change.

In proposing two adaptive capacity models, I raise the second problem with the assumption of the current literature: the narrow characterization of the factors that define a decentralized and informal structure as facilitating adaptability. I contend that it is necessary to develop additional clarity in responding to the question: 'adaptive to what?' In the upcoming section of this chapter, I offer an answer to this question. I build on scholarly studies that analyze social movement organization structures and that investigate how different structures allow organizations to pursue their multiple, and sometimes conflicting, goals (e.g., Freeman 1987; Staggenborg 1989; Young 1991; Young et al. 1999; Anheier and Themudo 2001; Clark 2003a). There is broad agreement amongst these scholars that the structural alternatives that organizations adopt have different advantages and disadvantages in solving organizational challenges. As Young (1991: 927) writes, "one should not anticipate that there are optimal structures" but that "a variety of environmental factors and internal concerns make particular structures more appropriate for some circumstances than others." The following quotation from Clark (2003a: 111) illustrates this point.

CSOs [civil society organizations] working internationally are wrestling with what structure best helps them with the growing range of tasks they feel they need to do (see Lindenberg and Dobel 1999). The tradeoffs are between maintaining a coherent "brand" worldwide and permitting local autonomy; between ensuring quality control and capacity for quick response; between wanting rapid expansion and retaining standards of style and ethos; and between professional ethos and fostering grassroots voluntarism.

Other scholars have similarly reviewed the tradeoffs and organizational challenges that organizations such as transnational social movement organizations face, and specifically explored the influence of their structures in resolving the strategic dilemmas involved (e.g., Young 1991; Wilson 1992; Young et al. 1999; Anheier and Themudo 2001; Lindenberg and Bryant 2001; Warkentin 2001; Clark 2003a and b). Young et al. (1999) and Warkentin (2001) argue that organizational structures can be assessed based on their 
ability to respond in an "adaptive," "flexible" or dynamic way to changes in political environments, subject issue area, stakeholder needs, and civil society in different locations. As I noted above, Smith (2005) and Anheier and Themudo (2001) argue that a TSMO needs to be adaptive to local conditions, to the need for accelerated decisionmaking, and to the transaction costs associated with transnational operations.

To date, most scholars have listed the aspects of the external environment to which SMOs should respond and describe the tradeoffs inherent in adopting alternative structures; however, few scholars have focused specifically on adaptability as a criterion for assessing the effectiveness of different structures in managing these tradeoffs. Those theorists that do focus on adaptability highlight the adaptive advantages of decentralized and informal structures (Fowler 2000; Anheier and Themudo 2001; Smith 2005). For example, Anheier and Themudo (2001: 202) argue that "adaptability is maximized" in decentralized and informal structures, even though "there are many advantages to the centralization of activities." According to these scholars, it is within a dynamic and complex task environment that decentralized and informal structures have their adaptive advantage. Scholars note a "general historical trend" towards decentralized and informal structures as the environmental within which transnational social movement organizations operate has become increasingly uncertain and turbulent (Anheier and Themudo 2001: 202; Smith 2005: 237).

There is a paradox here that requires explanation. Greenpeace and Friends of the Earth International both operate under similar complex and dynamic conditions, and yet, as Chapter Three illustrates, Greenpeace does not fit the decentralized, informal structural model. In fact, Greenpeace is not the only centralized and formal transnational social movement organization that is remaining viable and relevant within a turbulent transnational political environment (e.g., Human Rights Watch, see Clark 2003b: 4). The conclusion that decentralized and informal structures facilitate adaptability does not account for the ways in which more centralized and formal structures resolve organizational challenges and build adaptability. The current literature does not explain the benefits of centralized and formal structures for building adaptive 


\section{capacity. I suggest that this is a theoretical gap given the continued viability and}

relevance of more centralized and formal structures under conditions of complex and dynamic internal and external pressures.

In this and the upcoming chapters, I aim to address this theoretical gap by grouping the pressures facing Friends of the Earth International and Greenpeace into four key organizational challenges (see Section 4.3 below). Two of these challenges represent external pressures ('tactical innovation' and 'managing external relations') and two of these challenges are internal ('organizational maintenance' and 'managing internal relations'). In defining these organizational challenges, I am specifically interested in the relationship between structure and adaptability. How do alternative structures shape a TSMO's adaptive capacity in order to strategically and repeatedly respond to these organizational challenges in order to ensure long-term organizational viability? Subsequently, I use this classification of organizational challenges to explain two unique and viable approaches to organizing for adaptability (Section 4.4).

\subsection{Organizational Challenges and Strategic Dilemmas}

Table 4.1 below summarizes the four key organizational challenges that I propose. In brief, tactical innovation refers to the challenge for a social movement organization of creatively adjusting tactics and devising new tactics in order to respond repeatedly to changing external conditions and to persistently disrupt - or threaten to disrupt - the status quo. Transnational social movement organizations are faced with a choice as to the degree to which the organization should operate independently or to join in partnership with other actors in order to attain its goals. I refer to this organizational challenge as the challenge of managing external relations. Internally, SMOs are faced with the challenge of continuously securing various combinations of financial support (money) and human power (activism) in order to survive, grow and remain relevant. This is characterized as the challenge of organizational maintenance. Finally, the diversity of individuals and groups within social movement organizations poses the challenge of managing internal relations, including both conflicts and opportunities for cohesion. 
Table 4.1 Summary of Challenges and Strategic Dilemmas

(Continued on the next page)

\begin{tabular}{|c|c|c|c|}
\hline Challenge & $\begin{array}{l}\text { Description of } \\
\text { Challenge }\end{array}$ & $\begin{array}{l}\text { Strategic } \\
\text { Dilemma }\end{array}$ & Description of Dilemma \\
\hline $\begin{array}{l}\text { 1. Tactical } \\
\text { Innovation }\end{array}$ & $\begin{array}{l}\text { The challenge of } \\
\text { creatively adjusting and } \\
\text { devising new tactics in } \\
\text { order to repeatedly } \\
\text { respond to changing } \\
\text { external conditions and } \\
\text { persistently disrupt - or } \\
\text { threaten to disrupt - the } \\
\text { status quo. }\end{array}$ & $\begin{array}{c}\text { expansion } \\
\text { vs. } \\
\text { specialization }\end{array}$ & $\begin{array}{l}\text { If an organization is too } \\
\text { broad in its tactical } \\
\text { approach, then it is at risk } \\
\text { of overextending, of being } \\
\text { outcompeted and of being } \\
\text { inefficient. If the tactics } \\
\text { adopted by an organization } \\
\text { are too narrow, it is } \\
\text { vulnerable to becoming } \\
\text { rigid, being out of sync with } \\
\text { external conditions, and } \\
\text { being irrelevant. }\end{array}$ \\
\hline $\begin{array}{l}\text { 2. Managing } \\
\text { External } \\
\text { Relations }\end{array}$ & $\begin{array}{l}\text { The challenge of } \\
\text { negotiating partnerships } \\
\text { with external actors in } \\
\text { order to achieve common } \\
\text { goals or of operating } \\
\text { independently under } \\
\text { pressures to partner. }\end{array}$ & $\begin{array}{c}\text { collaboration } \\
\text { vs. } \\
\text { independence }\end{array}$ & $\begin{array}{l}\text { The need to cooperate and } \\
\text { collaborate in partnership } \\
\text { with other actors within a } \\
\text { social movement and within } \\
\text { society is in tension with } \\
\text { the desire of SMOs to } \\
\text { operate independently in } \\
\text { order to ensure quality, } \\
\text { coherent style and ethics } \\
\text { and to carry out costly } \\
\text { forms of collective action. }\end{array}$ \\
\hline
\end{tabular}


Table 4.1 Summary of Challenges and Strategic Dilemmas

(Continued from previous page)

\begin{tabular}{|c|c|c|c|}
\hline Challenge & $\begin{array}{l}\text { Description of } \\
\text { Challenge }\end{array}$ & $\begin{array}{l}\text { Strategic } \\
\text { Dilemma } \\
\end{array}$ & Description of Dilemma \\
\hline $\begin{array}{l}\text { 3. Organizational } \\
\text { Maintenance }\end{array}$ & $\begin{array}{l}\text { The challenge of } \\
\text { ensuring continued } \\
\text { organizational } \\
\text { viability through } \\
\text { securing various } \\
\text { combinations of } \\
\text { financial support } \\
\text { (money) and human } \\
\text { power (activism) in } \\
\text { order to survive, } \\
\text { grow and remain } \\
\text { relevant. }\end{array}$ & $\begin{array}{c}\text { grassroots / } \\
\text { voluntarism } \\
\qquad \text { vs. } \\
\text { professional } \\
\text { ethos }\end{array}$ & $\begin{array}{l}\text { Social movement } \\
\text { organizations choose } \\
\text { between mobilizing a mass } \\
\text { membership and a } \\
\text { grassroots / voluntary base; } \\
\text { or mobilizing a smaller, } \\
\text { select cadre of committed } \\
\text { activists to form a } \\
\text { professional group } \\
\text { supported by financial } \\
\text { donations. }\end{array}$ \\
\hline $\begin{array}{l}\text { 4. Managing } \\
\text { Internal } \\
\text { Relations }\end{array}$ & $\begin{array}{l}\text { The challenge of } \\
\text { facilitating internal } \\
\text { cohesion and of } \\
\text { managing internal } \\
\text { conflict within a } \\
\text { social movement } \\
\text { organization }\end{array}$ & $\begin{array}{c}\text { participatory } \\
\text { democracy } \\
\text { vs. } \\
\text { unity of } \\
\text { command }\end{array}$ & $\begin{array}{l}\text { Internal cohesion can either } \\
\text { be achieved through a } \\
\text { centralization of decision- } \\
\text { making power or through } \\
\text { decentralizing decision- } \\
\text { making to the SMO } \\
\text { membership. SMOs } \\
\text { experience the tension } \\
\text { between the need for a } \\
\text { quick and unified response } \\
\text { and benefits of inclusive } \\
\text { participatory democratic } \\
\text { processes despite the time, } \\
\text { effort and cost involved. }\end{array}$ \\
\hline
\end{tabular}


Over time, the strategic responses of individuals within an organization develop into established patterns within the organization and become embedded in their structures (Schein 1985; Mintzberg 1998a; 1998b). Subsequently, future responses are partially constrained by past decisions. The term strategy is often used to describe explicit, predetermined, top-down plans; however, Mintzberg et al. (1998) argue that the notion of strategy needs to be extended beyond these deliberate strategies to include strategies that emerge in a bottom-up way, without prior intention, through patterns of decisionmaking and behavior before being adopted as an organization-wide strategy. They refer to these as emergent strategies. This distinction is important within this dissertation because, although Greenpeace has a history of developing deliberate strategic plans, the process of strategy formation within Friends of the Earth International more closely aligns with this depiction of emergent strategies. It is also important to note that TSMOs are faced with internal challenges to which they need to devise internal responses. In other words, I will discuss the internal challenges facing TSMOs, including securing organizational resources and resolving internal conflict, as exogenous factors to which all TSMOs must devise internal strategic responses.

Whether they are deliberate or emergent, "all strategic choices have not only benefits but significant costs as well" (Lofland 1996: 282). Anheier (2000: 12) writes that SMOs need "to balance different, often contradictory elements" and strategically position themselves within a "complex push-and-pull of divergent models and underlying dilemmas and choices." Strategic decisions can lead to organizational advantages but, inherently, every decision encompasses a tradeoff. This leads to a "situation of the strategic dilemma" (Lofland 1996: 282) as described in the following quotation by McAdam, McCarthy and Zald (1988: 728).

SMOs must balance the need to respond... to pressures from other organizations ... with the need to maintain the strength and viability of the organization. It matters little [for example] if one has attracted media attention, if in the process, one has antagonized support and jeopardized the flow of resources to the organization.... Any number of such strategic dilemmas confronts SMOs as they seek both to adapt to and shape the ongoing macro and micro environment they confront. 
Brown and Moore (2001) capture these strategic dilemmas within their "Strategic Triangle Model," which I describe in the introductory chapter. To repeat their central argument here, the three points of the triangle - value creation, legitimacy and support and operational capacity - represent "three crucial calculations that [TSMO] leaders must make if their organization is to survive, produce socially valuable results and successfully adapt to changing circumstances" (Brown and Moore 2001). "Strategy" is depicted at the centre of the strategic triangle to indicate that TSMOs require a commitment "to a particular vision of how the organization will operate to create value and sustain itself in the immediate future" (Moore 1995:183). Brown et al. (2003) argue that "effective strategies for carrying out [TSMO] missions need to take account of all three issues [value creation, legitimacy and support, and operational capacity -] simultaneously." This is to ensure that an adopted strategy is "feasible, value creating and sustainable" (Moore 2000: 194). In the following quotation, Brown and Moore (2001) discuss the need for international nongovernmental organizations (INGOs), including transnational social movement organizations, to develop a balanced approach to managing different organizational challenges.

If the INGO has value and support, but no capability, it will not deliver on its promises. If the INGO has value and capability but no support, it will fail for want of resources or legitimacy. If the INGO has support and capacity, but produces little of value, it survives, but only at the price of wasting resources.

In order to accomplish this balancing act, INGOs, including transnational social movement organizations, need to "scan their authorizing environments for potential changes in the collective, political aspirations that guide their operations; search their substantive task environments for emergent problems to which their organizations might contribute some part of the solution; and review the operations of their own and other organizations in search of new programs or technologies that their organizations could use to improve performance in existing (or conceivably new) missions" (Moore 1995: 72). Scanning the external environment and reflecting on internal organizational capabilities can reveal that the strategies that a TSMO has crafted fit well and produce the desired results. However, as pressures in the environment change or as internal capabilities shift, inconsistencies can emerge that require INGOs to strategically realign 
their mandate and adjust their organizational capabilities and activities to ensure continued relevance and value creation. Even when a TSMO is perceived as being legitimate and is receiving support and when the internal operations of a TSMO are functioning well, actors within the TSMO need to regularly check to make sure that their frames - their judgments of what is valuable and effective - are indeed correct, particularly in light of shifting demands or new opportunities that can redefine what is considered valuable, problematic and an effective course of action (Moore 1995). Moore (1995: 70) argues that strategies for positioning an organization within the environment are essential in what he deems to be "an increasingly complex and dynamic world." Adaptive capacity is tied directly to the capacity of a transnational social movement organization to learn. As Brown and his colleagues (2003: 42) argue "there are few substitutes for the capacity to learn when the [organization] must operate in complex and rapidly changing environments - as do most INGOs concerned with social, political and economic development."

The capacity to learn refers to the ability of a TSMO to be both critically self-aware and insightful about the environment.(Fowler 2000). There is a growing literature on TSMOs and nongovernmental organizations that draws on organizational learning theory and highlights the criticality of learning capacity for organizational effectiveness (Edwards 1997; Hailey 1999; Letts et al 1999; Fowler 2000; Hailey and James 2002; Smillie and Hailey 2001; Ebrahim 2003). These studies emphasize the importance of learning for reassessing social movement organization interpretive frames - their worldviews - and in shifting relations of power within an organization (Ebrahim 2003) as well as the importance of SMO leadership that embraces learning as central to their leadership style (Hailey 1999; Fowler 2000). Warkentin (2001) defines this as the capacity of "cognizance" and argues that is exhibited by nongovernmental organizations (NGOs) through informed activism. Warkentin (2001:24) defines a cognizant NGO as one that "demonstrates an understanding of its role(s) or 'place' in the broader scheme of world politics, purposively engages in activities with particular social and / or political ends in mind, and recognizes; to the extent possible, the social and political implications of its activities." Fowler (2000) argues that learning should not be compartmentalized within an 
organization, and similarly Staber and Sydow (2002: 190) recommend the "institutionalization of reflexivity" throughout an organization.

Learning is a critical component of the interpretive framing process described in Chapter Two and is a knowledge-intensive process based on both reflection and action. The process of learning itself can be depicted as a spiral that cycles from action to reflection to learning and to planning and then spirals up to lead to new action based on learning (Fowler 2000: 137). Learning can be depicted as consisting of three stages: acquiring information and personal learning, testing knowledge through dialogue to create relevant interpretations of organizational reality, and applying this wisdom through a process of organizational change and adaptation (Fowler 2000). Learning occurs when an intended strategy and resulting action lead to the anticipated outcome, but it can equally occur when there is a mismatch between intentions and outcomes that requires an organization to adapt and correct (Argyris 1999: 67). The information process and knowledge generation only translates into adaptive capacity when the information and knowledge are translated into actions to implement the new insights and wisdom. Fowler (2000) refers to this combination of knowledge and action as the "insightful agility" of an organization, and differentiates adaptation based on insight from opportunistic adaptation. Fowler (2000: xii) indicates that "both organizational insight and agility" are essential in "adapting to an ever-changing world." Letts et al (1999) argue that it is this "ability to ask, listen reflect and adapt" that is often an overlooked resource for achieving the goals of social movement organizations (see also Weick and Quinn 1999: 366). Within social movement literature, the analysis of the relationship between ideas and action is based on the concept of framing (Snow et al. 1986; Snow and Benford 1988).

For Schein (1985), it is the process of learning and adaptation that over time shapes the distinct culture of an organization. For other scholars, the term culture refers to the observed behavior, norms, dominant values, philosophy, rules or "climate" of an organization; however, as this quotation illustrates, Schein (1985: 6) adopts a different definition. 
I argue that the term "culture" should be reserved for the deeper level of basic assumptions and beliefs that are shared by members of an organization, that operate unconsciously, and that define in a basic "taken-for-granted" fashion an organization's view of itself and its environment. These assumptions and beliefs are learned responses to a group's problems of survival in its external environment and its problems of internal integration. They come to be taken for granted because they solve those problems repeatedly and reliably (emphasis in original).

There is considerable overlap between this definition of "culture" and the notion of framing defined in Chapter Two and of learning and adaptation discussed above. Schein's definition of culture reintroduces the dimension of time. Learned responses become embedded in the frames - beliefs and interpretations - of organizational actors and also become embedded in the structures that organizational actors develop to support their activities. The partial constraints imposed by culture and frames are also imposed by structure; however, these historical factors do not overrule individual intentions and strategic choice altogether. In this dissertation, I agree with Mintzberg and his colleagues (1998: 299) that it is worth considering "not the existence of choice, but the conditions that enlarge and restrict its breadth." Rothschild and Whitt (1986) in their analysis of collectivist organizations, similarly examine the conditions under which democratic modes of organization are realized or undermined. As was discussed in Section 4.1, Rothschild and Whitt join other social movement theorists in rejecting the assumption that organizational processes of oligarchization, goal transformation and an inappropriate focus on organizational maintenance are inevitable, but argue instead that organizational transformation over time is conditional. I draw on their investigation into the internal and external factors that determine the capacity of any organization to be "directly democratic," (Rothschild and Whitt 1986) and also share with them the conclusion that there are no correct organizational responses to these conditions but that every strategic choice inevitably encompasses advantages and disadvantages. This is illustrated in this quote by Rothschild and Whitt (1986: 76) about their study.

Much as we have tried to identify the organizational conditions that support the participatory ideal, these conditions are not a recipe for organizational success. Each carries with it important trade-offs and raises perplexing dilemmas for the would-be collectivist organization. In the abstract it may be easy to commit one's newly forming group to a democratic course, but in the concrete practice of 
everyday life, continued commitment to democracy is neither obvious nor easy. For each condition that we identify, we ascertain the corresponding dilemma that follows.

As Table 4.1 describes, each of the organizational challenges that I have identified also represents a strategic dilemma. For the challenge of tactical innovation, a transnational social movement organization is choosing between expanding to develop a broad set of tactics or specializing by concentrating its efforts on a focused set. TSMOs balance the need for collaboration through partnerships and the benefits of operating independently in response to the challenge of managing external relations. Internally, TSMOs seeking resources for organizational maintenance are faced with a choice as to whether to mobilize grassroots and voluntary mass-based activism or to mobilize financial donations and build a professional protest team. In order to manage internal relations, TSMOs choose between participatory democratic processes or centralizing power and unifying command structures in order to reduce conflict and enhance coherence. Just as with Rothschild and Whitt (1986: 76), the organizational challenges that I have selected and investigated "are organizational features over which members have some control."

Greenpeace and Friends of the Earth International have made strategic choices regarding their response to each of these organizational challenges, just as the actors within these TSMOs have made strategic choices about the organizational structures they will adopt to attain their multiple goals (Anheier and Themudo 2001). The connection between organizational structure and strategic choice was initially proposed by organizational theorist, Chandler (1962), and popularized by Child (1972). Child argued that organizations could mitigate the internal and external pressures they face by making strategic choices in terms of their location, clients and employment base. Rather than contextual factors such as competition, use of technology and external actor relations constraining organizations and determining their structures, strategic choice was the key explanatory factor for organizational structure. According to Child (1979: 382-383), "the critical link lies in the decision-maker's evaluation of the organization's position in the environmental areas they regard as important, and the action they may consequently take 
about its internal structure." Aligning with Staggenborg (1989: 75), I argue that different SMO structures are deliberately chosen or emerge to reflect different "ways in which SMOs deal with organizational problems." As I will outline in detail in Section 4.4 below, I propose that the different organizational structures developed by Friends of the Earth International and Greenpeace are the result of strategic patterned responses to the four organizational challenges outlined below.

\subsubsection{Tactical Innovation}

Friends of the Earth International and Greenpeace rely on a set of tactics that they have deemed effective in achieving their goals. As Chapter Two described, the typical set of activities and dominant approach that social movement organizations adopt to promote change and ensure political efficacy is referred to as their action repertoire. As Carmin and Balser (2002: 367) note, this action repertoire is "shaped by structural factors and sociopolitical conditions" as well as "the shared values, beliefs and understandings of organizational actors." A TSMO's political environment changes over time and, therefore, "the problem for movement organizations is to create organizational models that are sufficiently robust to stand up to opponents, but flexible enough to change with new circumstances and draw on energies at the base" (Tarrow 1994: 136). Tactics that work in particular situation, or against a particular target actor, or at a particular point in a protest cycle may not be as effective in other conditions. McAdam (1983) discusses this organizational challenge as the challenge of remaining innovative throughout a campaign. The following quotation illustrates McAdam's central argument as to the dynamics of protest and SMO reactions.

The pace of ... insurgency [is] an ongoing process of tactical interaction between insurgents and their opponents. Lacking institutional power, challengers must devise protest techniques that offset their powerlessness. This [is] a process of tactical innovation. Such innovations, however, only temporarily afford challengers increased bargaining leverage. In chess-like fashion, movement opponents can be expected, through effective tactical adaptation, to neutralize the new tactic, thereby reinstating the original power disparity. To succeed over time, then, a challenger must continue to search for new and effective tactical forms (McAdam 1983: 752, emphases in original). 
Lofland (1996: 282) argues that although "SMOs differ greatly in their degree of tactical innovation and adaptation," it is useful in considering tactical interaction to conceive of an SMO "as a probing and flexible creature that is responsive to target reactions and innovative in continuously (or at least periodically) revising its strategies as a function of target reactions." I assume, given their viability and continued relevance, that both Friends of the Earth and Greenpeace do not fit with Lofland characterization of an unresponsive $\mathrm{SMO}$, which is "strategically frozen and $\operatorname{slog}[\mathrm{s}]$ on irrespective of target and other responses" (Lofland 1996: 283). As I will explore in Chapters 5, 6 and 7, these two TSMOs have continued to modify their tactical approach in response to the reactions of target actors and changing conditions. Letts et al. (1999) argue that the ability to be innovative is a critical part of building adaptive capacity. Drawing on Light (1998), Letts and her colleagues (1999: 18) propose that social movement organizations' adaptive capacity rests on their innovativeness, defined as "the capacity to innovate repeatedly." Doherty (2002: 16) makes a similar point in noting the dynamic nature of strategy formulation that is always "changing as a result of the experience of activists."

I propose that social movement organizations are faced with a strategic dilemma as to how to remain continuously innovative in their tactics. In a complex and dynamic environment, social movement organizations can choose to concentrate their efforts on a focused set of tactics and innovate within this narrow range. Other SMOs may choose to adopt an exploratory approach and develop a multifaceted range of tactics and innovate across a wide set of tactical possibilities. These two choices echo a distinction made within the business literature by Miles and Snow (1978). These scholars distinguish between four different strategic types: defenders, prospectors, analyzers and reactors. Defenders "are organizations which have narrow product-market domains" that adopt a narrow focus, "do not tend to search outside of their domain for new opportunities...[,] seldom need to make major adjustments in their technology, structure or methods of operation [, and] instead... devote primary attention to improving the efficiency of their existing operations." In contrast, Prospectors are "organizations that almost continually search for market opportunities,...regularly experiment with potential responses to emerging environmental trends[,]... are often the creators of change and uncertainty to 
which their competitors must respond." Analyzers are organizations that combine both of these strategies, and reactors are organizations that fail to create a strategy.

The typology suggested by Miles and Snow has proven to be analytically robust in explaining private sector product strategies, and has been applied in the nonprofit context (Brown and Iverson 2004). A similar distinction has been made within the organizational learning literature between "exploration" strategies that adopt a broad focus and "exploitation" strategies that adopt a more narrow focus (March 1991; Staber and Sydow 2002). Both "exploration" and "exploitation" strategies have advantages and disadvantages. Within a complex and dynamic environment, an SMO that is exploratory in its tactics benefits from the diverse and changing resources available within this turbulent context (Kraatz and Zajac 2001); whereas, an SMO that selects a specific and narrower niche within the environment can benefit from exploiting a set of known and predictable resources and competencies in order to support its concentrated activities (Kraatz and Zajac 2001). In reality, organizations benefit from drawing on both approaches to innovation, as is evident in Miles and Snow's (1978) description of the "Analyzer" approach and as is illustrated in this quotation.

If the systems [e.g., organizations] engage in exploitation alone, it will find itself trapped in some sub-optimal state, failing to discover new directions or to develop competence in them. If the system engages in exploration alone, it never secures the advantages of its discoveries, never becoming good enough at them to make them worthwhile (March 1992-93: 31 as quoted in Ebrahim 2003: 108).

Similar to private sector organizations, many social movement organizations will resolve the strategic dilemma of tactical expansion versus tactical specialization by selecting one or other approach as their dominant but not exclusive approach to tactical innovation.

\subsubsection{Managing External Relations}

Greenpeace and Friends of the Earth International operate in a transnational organization field that contains a diversity of actors including governments, business and industry, international organizations, and other social movement actors (see Section 2.1 above). Fowler (2000: 143) defines this as the "relational web" of a TSMO. He argues that under complex and dynamic conditions, TSMOs need to manage these relationships in terms of 
"expectations, relational ties and commitments that bind" and "legal constraints" in order to enable room to adjust and negotiate changes in these relationships to ensure their own ability to adapt while maintain their reputation and viability. For example, Fowler (2000: 143) cautions against TSMOs entering into resource relationships that are characterized by dependency or commitments that require a social movement organization to be "mortgaged with less room to maneuver and adapt." The advantages of maintaining a degree of independence within the organizational field also include the capacity to ensure quality, coherent style and ethics and to carry out costly forms of collective action without concern about the behavior of or the consequences to other actors in the organization field (Clark 2003a: 111). Sometimes this independence is forced upon the TSMO even if the TSMO is willing to cooperate and collaborate with other actors. For example, competition for resources and participants can deter social movement actors from engaging in joint activities (Cooley and Ron 2002). Collaboration amongst TSMOs and the governments, corporations, international organizations and individuals they target with their actions may not transpire because of accusations of illegitimacy and accountability from both parties (Clark 2003a: 169). When TSMOs "rub up against powerful interests who think they wield disproportionate influence," these targeted actors often subject TSMOs to intense scrutiny about their legitimacy and governance practices (Clark 2003b: 16) and pose question "whether self-appointed advocates have gained too much influence" (Economist 1999: 21; see also Scholte 2004). This is also due to the fact that TSMOs sometimes "think it is better to take the opportunistic chances to achieve real change and be approximately right rather than be scrupulously accurate and miss the boat" (Clark 2003a: 86). The gain in speed and flexibility in targeting actors with specific campaigns can be undermined and the reputation of a TSMO can be compromised if the TSMO is found to lack in credibility and quality information to support its campaigns (Clark 2003a: 102).

Even with these factors that encourage TSMOs to operate independently, scholars have correlated the adaptability of social movement organizations with their willingness to collaborate (e.g., Letts et al. 1999; Brown et al. 2000). As Brown and Moore (2001) argue, transnational social movement organizations require the active participation of 
partners outside of the TSMO who have additional resources, legitimacy, power and scope of authority to produce desired results. In fact, the political agenda pursued by Greenpeace and Friends of the Earth International (e.g., sustainable development) is considered to be achievable only through the engagement of actors across sectors in networked configurations that enable learning and adaptive management (Juma 2002; Lafferty 2004): There are distinct advantages in creating these partnerships, particularly within complex and dynamic task environments, as inter-organizational collaboration can produce "co-evolutionary arrangements" whereby collaborating organizations jointly adapt to environmental changes through "division of labour, mutual learning and the diffusion of best practices" (Anheier and Themudo 2001: 206). These advantages can outweigh the challenges that face a TSMO in bridging the many differences across the actors with whom it engages. These challenges are evident in collaborative arrangements amongst social movement actors and can become even more acute in transnational collaboration across sectors. Brown et al. (2000) and Juma (2002) argue that TSMOs have been particularly effective in disrupting the status quo and halting decision-making processes, but have been less involved in initiating and participating in large-scale inter-sectoral efforts to solve critical problems. This is in part because social disruption, protest and confrontation are defining characteristics of social movement organizations, and because social movement organizations have significantly lower levels of resources in comparison with government, business and international organizations to initiate and participate in transnational problem-solving processes or implement solutions to global problems (Brown et al. 2002; Brown and Timmer 2006).

The challenge of managing external relations remains critical for transnational social movement organizations because there is increasing recognition that solving many transnational issues requires interaction amongst state, market and civil society and may not be served by TSMOs adopting only a protest / confrontational approach. As Juma (2002) writes, "the art of protest has many exponents... [who] have done a grand job of alerting the world to environmental degradation and injustices in development;" however, he argues that "protest is no longer the only path to progress [and] in many cases, it may even be its undoing." I still consider confrontational and non-institutionalized tactics to 
be essential for solving transnational problems and, therefore, take issue with Juma's conclusion that "the future of the reduction of poverty, and protecting the planet, now lies in cooperation not in conflict." There are legitimate reasons why civil society actors are hesitant to engage exclusively in cooperative, intersectoral relations, in large part because their mission and objectives have not been met and require continued confrontation with the societal mainstream. Also, intersectoral relations can be rife with misunderstandings and "characterized by value-laden stereotypes, struggles over power and resources, and resistance to joint action even when some interests are clearly shared" (Brown et al. 2000: 289).

Civil society actors are critically aware of the importance of autonomy and confrontation in interactions with the power of the international organizations, government and private sector, and are rightfully cautious of cooperation that can sometimes be a front for cooptation (Doh and Teegen 2003). Securing the collaboration of TSMOs can serve as an important source of legitimacy and credibility to other sectors. TSMOs can also alert the government and business sectors to issues of importance; however, there is a risk that other actors can seek to placate TSMOs by adopting progressive language without changing behavior or by attempting to co-opt TSMOs. Covey and Brown (2001) argue that, for example, civil society-business initiatives are "marked by the presence of both conflicting and convergent initiatives," which they propose involves "a pattern of interaction" called "critical cooperation." Critical cooperation "requires attention to power asymmetries, the recognition of rights, interest based negotiations, and management of relations with key stakeholders" (Covey and Brown 2001: 1). TSMOs engaged in critical cooperation retain the right to withdraw from cooperative engagements and confront the other actors if mutually negotiated principles and rules are not adhered to. For Brown (2002), this requires the establishment of mutual accountability, defined as "accountability among autonomous actors committed to sharing values and visions and to relationships of mutual trust and influence that enable renegotiating expectation and capacities to respond to uncertainty and change." 
Despite these difficulties of intersectoral polarization, there are many examples of intersectoral negotiation and problem-solving at the local and national scale (Weber 2003), and increasingly at the international level (Florini 2000; Fox and Brown 2000; Khagram et al. 2002; Clark et al. 2003; Risse 2003). Reinicke et al. (2000) characterize these arrangements as global public policy networks (GPPN) which bring together actors across sectors and across national boundaries using new information technologies to address critical global issues. They argue that "creative new arrangements are needed urgently to allow governments, other organizations both public and private, and individuals around the world to work together to address pressing global problems - from weapons control to the lack of adequate labor standards to climate change - as they arise... [by] marshalling resources - intellectual financial, physical - to bring to bear on those problems" (Reinicke et al. 2000: 6; see also Reinicke 1998). Brown et al. (2002) propose a set of criteria that can be used to evaluate the effectiveness of such multisectoral partnerships including efficient use of resources, democratic accountability, actualization of core values and social learning. These authors conclude that although "multisectoral cooperation is difficult and expensive," it has the potential to "reconcile civil society actors' interests and mobilize their comparative advantages with those of intergovernmental agencies and multinational corporations in some circumstances and contribute to more rapid and responsive social learning as well" (Brown et al. 2002: 292).

\subsubsection{Organizational Maintenance}

In order to ensure their continued organizational viability, transnational social movement organizations face the challenge of securing various combinations of financial support (money) and human power (activism) in order to survive, grow and remain relevant. As the following quotation illustrates (Diani and Donati 1999: 15), the challenge of mobilizing resources for organizational maintenance is usefully conceived as two alternatives: the mobilization of 'time' (human power and activism) or of 'money' (financial support).

SMOs face a difficult choice between two fundamental options. They may try to mobilize the largest possible support from the general public, and therefore the resources, which are essential to the maintenance of a semi- or quasi-professional group. Available strategies range from calling upon broadly supported sets of 
values to the provision of selective incentives to prospective members / subscribers (in the form of services, leisure time, activities, discount packages). SMOs, however, may also try to mobilize smaller, but more carefully selected, groups of committed activists.

For Clark (2003a: 111), this represents the choice between "professional ethos and fostering grassroots voluntarism." For Doherty (2002: 88) this organizational challenge is part of the "strategic questions that social movements face" in which he includes the tension between "grassroots and professional campaigning." Building on these authors, I define the strategic dilemma associated with this organizational challenge as the SMO's choice between mobilizing a mass membership and a grassroots / voluntary base; or mobilizing a smaller, select cadre of committed activists to form a professional group supported by financial donations. It is important to note that this does not preclude grassroots based organizations from professionalism; in fact, long-term volunteers can be as professional in their positions as paid staff, and, as will become clear in this thesis, decentralized structures can support a responsiveness to local conditions that is complex and skilled. For the purposes of this dissertation, the term 'professional' is tied to a relatively more centralized and formalized structure because of its association with specialization and an established system of rules - a bureaucracy.

Traditionally, social movements and social movement organizations have depended upon recruiting a broad base of grassroots citizens into voluntary activist involvement, and, indeed, this traditional or "classical" mobilization strategy is still part of many existing social movement organizations (McCarthy 2005: 195). As Section 4.1 outlined, this traditional form has been joined by social movement organizations that have adopted a more professional form, raising concerns about "bureaucratization, a declining performance in relation to organizational resources, and a loss of initiative and emphasis particularly amongst rank and file [grassroots]" (Rucht 1999: 218). For Jordan and Maloney (1997: 18), the shift to a professional social movement form, which they label as a "protest business," is a deeply problematic shift away from what they deem to be the appropriate form for a social movement organization, namely “decentralized, nonhierarchically structured organizations that reflects the participatory tendencies of their 
members." Other scholars, some of which are reviewed in Section 4.1, provide a different analysis of professional versus grassroots / voluntary forms and argue that each has its own advantages and disadvantages (Gamson 1975; Lofland 1996; Staggenborg 1999; Doherty.2002).

There is some debate as to whether a professional or grassroots organizational form is more effective in maintaining social movement organizations over the long term. Lofland (1996: 159) labels these alternatives as "cadre versus mass membership" and argues that this choice relates to "the question as to the degree to which an SMO strives to be a large, stable, enduring and democratic association versus a smaller, temporary and absorbing cadre formation." A number of other scholars argue that increasing professionalism of a social movement organization actually leads to a more enduring structure. For example, Doherty (2002: 141) writes, "where money is the main resource, environmental movement organizations have to develop a bureaucracy capable of providing efficient long-term administration" (emphasis added). This enduring structure is often supported by paid staff (Van der Heijden 1997). Staggenborg (1999: 116) argues that professional staff results in a "broader capacity for organizational maintenance" than informal social movement organizations dependent on volunteers where "it is much more difficult to command the necessary time [for organizational maintenance activities] on an ongoing basis" even if these volunteers have dedicated many years, or a lifetime, to movement activities (see also Staggenborg 1988). In contrast, professional paid staff "can be relied on to be present to carry out tasks such as ongoing contact with the press and fund-raising in a routine manner" (Staggenborg 1999: 115).

As has been argued throughout the dissertation, organizational maintenance is a support goal, and part of the concern about an increasingly professional paid staff is that their personal dependency on the social movement organization for their income and career can lead to an inappropriate emphasis on organizational survival instead of a focus on attaining output goals (Zald and Ash 1966; McCarthy and Zald 1977). Doherty (2002: 132) notes that the recruitment of professional paid staff does not necessarily lead to deradicalization because the staff often share the values and goals of the organization, as is 
evident from their acceptance of lower pay and more vulnerable employment status. Although some scholars and activists remain concerned that professional structures too closely resemble the organizational forms of the actors that social movement organizations are seeking to challenge (Doherty 2002: 134), other scholars have highlighted the destabilizing and disruptive effect of "the adoption of conventional organizational models [which] may be destabilizing as it exposes contradictions within the existing system" (Clemens 1993: 768; see also Gamson 1975). It is not necessarily the form that leads to a lack of disruptive or confrontational tactics, because massmembership organizations have been found to be equally vulnerable to de-radicalization (Piven and Cloward 1977; Diani and Donati 1999).

Social movement organizations that mobilize a professional staff are well-positioned to undertake certain critical tasks within social movement activities, including developing effective campaigns. As Doherty (2002: 133) writes, “ a major campaign requires considerable planning and co-ordination of research, press, finances, and information for supporters." Gamson (1975: 91) argues that the bureaucratization of social movement organizations enhances their "readiness for action" or "combat readiness" by creating a division of labour that ensures that roles can be routinely performed and sustained even in periods between confrontations and campaigns (see also Staggenborg 1999: 115). The "capacity for quick response" (Clark 2003a: 111) is essential in processes that require "rapid-fire interventions" máde possible by small teams of professional activists (Batliwala 2002: 398) although, in contrast, Doherty (2002: 133-34) notes that "higher professional standards' can equally lead to "slower and more cumbersome campaign" if the "threat of legal action is taken into account" in deciding the pace of protest. Campaigns require "dependable, active, informed and experienced advocacy" (Rosenbaum 2002: 26), including teams of legal specialists, researchers and scientists, and media experts. A degree of professionalism is also essential for undertaking risky and technologically sophisticated campaigns, such as direct action tactics, that require safety and technology training for activists, as well as a high degree of commitment from activists with regard to the personal risks involved. A small cadre of committed activists is also critical for retaining a degree of secrecy in order to launch surprise confrontations 
with target actors, although this secrecy needs to be balanced with demands for increased transparency of TSMO operations by supporters and the wider public.

Professionalism leads to "specialization of tasks, objective rather than personal criteria in decision-making and clear lines of authority.... in order to achieve certain tasks such as supporting long-term development of policy, media and other expertise" (Doherty 2002: 141). The persuasive powers of social movements is, in part, dependent on this division of labor and the ability of TSMOs to develop credible science and technical expertise and research to support their arguments. The recruitment of specialized staff can result in problems. As Yearley (2003: 42) notes "increasingly technical cadres" and "professionalized scientific staffs" of TSMOs can become "distant from the supporters on whose funding and occasional participation they depend." SMOs that focus on mobilizing a grassroots and voluntary base are considered to have an advantage in facilitating participatory democracy. As Doherty (2002: 141), SMOs "where time is the principal resource, participatory structures are better than hierarchical ones at making members feel valued and necessary." These organizations have more "political legitimacy" because they exemplify democratic inclusiveness (Brown and Moore 2001; see also Warkentin 2001). Professional social movement organizations are perceived as having "checkbook members" (McCarthy 2005: 195; Jordan and Maloney 1997) and vulnerable to oligarchization: the centralization of power in the hands of a small group within the social movement (Zald and Ash 1966). Although it is not necessarily the case that professional social movement organizations reject democratic processes (as will be discussed in the section below), it is certainly true that social movement organizations that choose to mobilize human power and activists rather than financial donations have the tendency to prioritize participatory democratic processes in their decision-making structures (Rothschild and Whitt 1986; Staggenborg 1989).

\subsubsection{Managing Internal Relations}

Transnational social movement organizations contain a diversity of individuals and subgroups. A key challenge for any organization is in managing internal relations in order to foster a common identity and purpose and resolve conflict (Gamson 1975; Schein 1985). 
Internal cohesion can be achieved either through a centralization of decision-making power or through decentralizing decision-making to the SMO membership. Either approach can be assisted through the use of a shared intranet or web connections which allow organizational members to communicate across the vast distances that often separate activists within transnational social movement organizations (Warkentin 2001; Doherty 2002: 129; Pickerill 2003). The strategic dilemma for SMOs is the choice between the need for a unified response and the benefits of inclusive participatory democratic processes. Anheier and Themudo (2001) describe this strategic dilemma as the tension between the desire for decentralization and the need to formalize interactions between organizational units in order to increase predictability across the organization.

The differences between these two ways of managing internal relations stems from the locus of decision-making power (Clark 2003b: 7). Clark (2003a: 11) notes that although some international nongovernmental organizations "contribute to democracy, ...most influential NGOs are not, in themselves, democratic." Clark (2003b: 7) distinguishes between transnational social movement organizations which place the locus of decisionmaking power with the membership-base and those which focus decision-making control at the international secretariat. He highlights that each of these ways of managing internal relations has advantages and disadvantages in that "activists are both frustrated by top-down decision-making (Greenpeace has experienced this) and by losing critical opportunities because democratic processes are slow" (Clark 2003a: 113). As Simon (2002) notes, "there is that delicate balance that [activists] try to achieve in organizations between the ideal of a full democracy and the reality of a kind of hierarchy that is needed to make an organization work."

In Section 4.1, I review the debate over whether centralization of power, oligarchization, of social movement organizations is inevitable. The section highlights a number of scholarly studies that have demonstrated that some SMOs consciously resist this transformation by prioritizing democratic principles (e.g., Rothschild and Whitt 1986). Social movement organizations may choose to "lead by example" and create decisionmaking processes that are "democratic, inclusive and transparent" (Young et al. 1999: 
338). The degree to which SMOs adopt democratic processes can vary greatly across SMOs (Doherty 2002: 131) with some fully decentralizing power to a grassroots membership base and others engaging in elections in order to establish a representative democracy. For Warkentin (2001: 24), it is useful to examine SMOs according to their "inclusiveness." He defines an inclusive organization as one that "establishes organizational relationships with other actors and uses these as a basis for cooperatively pursuing common goals; encourages and facilitates mutually respectful relationships, as well as open and wide-ranging dialogue on relevant issues, objectives and strategies; and seeks to accommodate difference to the extent that doing so remains broadly consistent with its key organizational principles" (Warkentin 2001: 24). This inclusiveness is particularly important in bridging across cultural, language and geographic barriers within transnational social movement organizations (Batliwala 2002; Smith 2002).

According to Gamson (1975), internal cohesion and conflict resolution can also be resolved by centralization of power. Gamson (1975: 93) argues that it is through centralization of power that SMOs "deal with the problem of internal conflict and through which they are able to achieve unity of command." When organizations lack a single centre of power, Gamson suggests that they become more "coalition-like" as "the entities that make up the group as a whole maintain separate identities and importance." This can lead to issues of "ongoing difficulties of the control of local agents" in order to ensure coherence (McCarthy 2005: 222). For Clark (2003a: 111), this captures the tradeoffs "between maintaining a coherent "brand" worldwide and permitting local autonomy." Doherty (2002: 142) similarly notes that social movements "seek to develop their own brand identity" that sets them apart from other SMOs and highlights their distinct competencies. The brand coherence enables "collective action" and "increases the legitimacy of the organization to speak as one voice" (Anheier and Themudo 2001: 201). Unity of command can be achieved in a number of ways. Mintzberg (1998b: 1456) suggests that organizations can create cohesion, "the glue that holds the organization together" and the coordination of activities, through such processes as direct control or the standardization of outputs, work processes, skills or norms. Wilson (1992: 161) argues that social movement organizations, by selecting unity of command structures, can 
"reduce the costs of contacting offices and members" and "the time, effort and other expenditure in maintaining liaison and coordination between offices." This conclusion is contrary to the conclusion drawn by Anheier and Themudo (2001) and Smith (2005) who suggest that participatory democracy reduces transaction costs by situating the locus of decision-making at the local level.

Both unity of command and democratic processes can enable SMO activist to respond to changing circumstances in a coherent way. As Young et al (1999: 339) argue, "membership organizations are least likely to be flexible [in quick responses] because change requires consensus among the largest number of constituents." On the other hand, in an earlier article Young (1991: 930) notes that democratic designs can "facilitate adaptation and performance under turbulent conditions" by being responsive to changes in local conditions. Ebrahim (2003: 15) makes a similar point in emphasizing the utility of participatory and democratic processes in the "joint diagnosis of problems and solutions" although he also emphasizes the contribution of "some necessary hierarchy" in building adaptive capacity. The flexibility and flow that comes with some decentralization needs to be balanced with the tradeoffs such as lack of coherence and quality control (Podolny 1998; see also Anheier and Themudo 2001).

\subsection{Adaptive Capacity: Agility and Resilience}

Friends of the Earth International and Greenpeace are faced with the organizational challenges and strategic dilemmas outlined above. The strategic choices they have made and the organizational structures they have developed have evolved out of "the effort to find a workable balance between this mix of sometimes seemingly contradictory goals" (Halcli 1999: 136). I suggest that it is the iterative interaction amongst the frames, strategies, structures and actions of Greenpeace and FoEI that build their ability to respond to complex and dynamic internal and external pressures. Over time, FoEI and Greenpeace have built an ability to repeatedly respond to these pressures, which I define as their adaptive capacity. In order to develop these adaptive capacity types, I analyzed the case study organizations - Friends of the Earth International and Greenpeace - and noted tendencies in terms of their interpretive frames, action repertoires, strategic choices 
in response to key organizational challenges and structures that displayed tendencies towards a particular pattern and routine response to pursuing their support and output goals. These tendencies are certainly not the only structural components and behavior that is apparent in Greenpeace and Friends of the Earth International, particularly given their complex, transnational structures. These are inherently messy and multi-faceted systems and communities; however, I propose that there are patterns and tendencies that, if expressed in logical extremes, may provide insights as to "ideal types" of adaptive capacity. In Chapter 9, I highlight the existence of variations within these ideal types and suggest that there likely are other unique models of adaptive capacity.

Max Weber (1958: 90) adopted a similar approach in identifying organizational "ideal types" that are "not a description of reality but [aim] to give unambiguous means of expression to such a description." Doherty (2002: 17) writes, "the concept of an ideal type was intended as a way of defining characteristics that would help empirical investigation." Ideal, in this context, is not "better" but represents an idea or "theoretical construction," and "its usefulness depends on whether it helps us to understand and explain empirical cases" (Doherty 2002: 17). According to Weber (1958: 93), "research faces the task of determining in each individual case, the extent to which this idealconstruct approximates to or diverges from reality." I undertake this task by presenting two ideal types of adaptive capacity (this Chapter), analyzing their expression within Friends of the Earth International and Greenpeace (Chapters Five through Eight), and presenting some conclusions as to the utility of these mental constructs (Chapter Nine).

Rothschild and Whitt (1986) adopt a similar approach in determining the relationship between organizational structure and the goal of internal democracy and participation. In contrast to scholars that portrayed the inevitable bureaucratization of organizations (e.g., Michels 1949 [1911]), these authors developed two organizational ideal types -the bureaucratic organization and the collectivist-democratic organization. Rothschild and Whitt distinguish these two organizational forms along a number of dimensions that express features of each type, and highlight the strategic dilemmas inherent in adopting one or other form. Ultimately, by identifying the logical extremes, the authors are able to 
"classify actual organizations along a continuum, rather than ... plac[ing] them in discrete categories" (Rothschild and Whitt 1986: 50). As Lofland and Lofland (1984: 98) note, "it is helpful to develop ideal types in pairs or polars (that is, logically or theoretically opposed) extremes" since "such a pairing makes it clear that practically all empirical instances range along the continuum between the given extremes." Lofland and Lofland suggest that "by providing new concepts and their components..., the range of ordered experience will be widened and our understanding of it enhanced" (Lofland and Lofland 1984: 100). It will become apparent in the upcoming chapters that FoEI and Greenpeace are hybrid systems that tend towards these logical extremes while remaining multifaceted and complex.

Following this approach, I identify two ideal types of adaptive capacity that represent hypothetical and "pure" cases of patterned responses of an organization to internal and external pressures, which I have labeled the Agility Model and the Resilience Model based on their dynamics of organizational change (described below). Table 4.2 summarizes the ideal-type differences between the two modes of adaptive capacity. There are three dimensions to these ideal types: organizational structure, strategic responses to organizational challenges, and dynamics of adaptation. I have discussed the features of the first two dimensions above. To summarize, I suggest that within the Agility Model, social movement organizations adopt a decentralized and informal structure, which shapes their strategic responses to the four organizational challenges which, in turn, reinforces a decentralized and informal structural configuration. This ideal type of SMO prioritizes tactical expansion, collaborative interactions with external actors, the mobilization of a grassroots and voluntary base, and internal participatory democracy. Social movement organizations that align with a Resilience Model adopt a more centralized and formal organizational structure, and this structural choice is shaped by and influences the SMO's response to organizational challenges. This ideal type of SMO prioritizes a tactical specialization, independent operations within the transnational organization field, a professional ethos, and a unity of command governance structure in order to manage internal conflict and to foster cohesion. 
Table 4.2 Comparison of two ideal type Adaptive Capacity models

\begin{tabular}{|c|c|c|}
\hline Dimension & Agility & Resilience \\
\hline \multicolumn{3}{|l|}{ A) Organizational Structure: } \\
\hline Formalization & Informal & Formal \\
\hline Centralization & Decentralized & Centralized \\
\hline \multicolumn{3}{|c|}{ B) Strategic Responses to Organizational Challenges } \\
\hline 1) Tactical Innovation & Expansion & Specialization \\
\hline 2) Managing External Relations & Collaborative & Independent \\
\hline 3) Organizational Maintenance & Grassroots / Voluntarism & Professional \\
\hline 4) Managing Internal Relations & Participatory democracy & Unity of Command \\
\hline \multicolumn{3}{|c|}{ C) Dynamics of Organizational Change: } \\
\hline Motto & Flow & Restore \\
\hline Tempo of Adaptation & Continuous & Episodic \\
\hline Pattern of Adaptation & Spiral & Cycle \\
\hline
\end{tabular}




\subsubsection{Organizational Change and Adaptation}

How do these structural and strategic choices affect the dynamics of organizational change over time? In a complex and turbulent environment, social movement organizations innovate, respond, and adjust their interpretive frames, action repertoires, strategies and structures in response to internal and external pressures. Organizational changes, defined as adaptations within social movement organizations, can, at the most general level, be conceived of as both a phenomenon of time and of perception (Ford and Ford 1994). Change takes place over a period of time and results in a shift wherein aspects of the organization are different as a result of the change. This difference is given meaning by the perceptions of individuals and is "understandable only in terms of individuals' accounts of definitions of the situation" (Wilson 1992: 7). Analyzing organizational change requires clarity as to the level at which change is occurring within an organization. Change can occur at "the broadest, most conceptual level (for example, in mindset or culture) to the narrowest and most concrete (for example change in a piece of equipment or recruitment of a new staff person). I am particularly interested in organization-wide change. Of equal importance, I am interested in understanding how change occurs over time and describing patterns of organizational change. These patterns serve as a heuristic, rather than an accurate reflection of reality. By describing different patterns, I aim to create an image that captures the organizational change dynamics that arise from specific combinations of strategy and structure.

In order to gain insight into different organizational change dynamics, I draw on organizational change literature (e.g., Mintzberg and Westley 1992; Van de Ven and Poole 1995; Weick and Quinn 1999) and on systems theory (e.g., Holling 1973; 2001). I propose that the two ideal types of adaptive capacity express themselves as two unique dynamics of organizational change. This proposition is based on Weick and Quinn (1999) and their suggestion of different "tempos of change" defined as "the characteristic rate, rhythm or pattern of work or activity." Weick and Quinn (1999) distinguish between episodic change, defined as change that is "infrequent, discontinuous and intentional" and continuous change, defined as change that is "ongoing, evolving and 
cumulative." As this quotation suggests, Weick and Quinn suggest that organizations encompass both of these tempos of change at different levels within their organization.

From a distance (the macro level of analysis), when observers examine the flow of events that constitute organizing, they see what looks like repetitive action, routine and inertia dotted with occasional episodes of revolutionary change. But a view from closer in (the micro level of analysis) suggests ongoing adaptation and adjustment.

Staber and Sydow (2002) make a similar distinction between long-run adaptability of organizations as compared with the short-run adaptations within episodes of change. Mintzberg and Westley (1992) differentiate between episodes of organizational change which are "distinct periods in which some shift or set of them takes place" and are "patterned responses to specific problems or opportunities," and patterns of organizational change over a longer time period. As Mintzberg and Westley (1992: 49) write, "at the broadest level, change episodes and stages sequence themselves to form patterns of evolution that describe the overall history of an organization." I propose that Weick and Quinn's distinction between episodic and continuous change is equally applicable to different patterns of organizational change as it is to different levels of change within an organization. This pattern of organizational change encompasses both slow evolutionary trends, unexpected and potentially revolutionary shifts, as well as stages of decline within the social movement organization (Mintzberg and Westley 1992). I am interested in the overall pattern of organizational change that emerges over the life history of an organization rather than within particular episodes and stages of this history. I propose that the Agility and Resilience ideal types embody two unique patterned responses to internal and external pressures, which result in two unique dynamics of organizational change.

\subsubsection{Dynamics of Organizational Change in Agility and Resilience}

The word 'agility' is used to characterize the first ideal type approach to building adaptive capacity because of the term's association with nimbleness and flexibility, with the ability of an organization to manage change in an unpredictable context that demands rapid response to unexpected changes, and the ability to move and adjust quickly and easily (Fowler 2000). I suggest the motto "flow" for the Agility ideal type to reflect the 
tendency of social movement organizations adopting this approach of "embrac[ing] change" (Larman 2004: 25) and "reinventing" themselves (Staber and Sydow 2002: 410). This motto corresponds with Anheier and Themudo's (2001) portrayal of many social movement organizations as being "in more or less "constant reorganization"" resulting from their response to a complex and turbulent environment. Within the Agility Model, SMO adaptation is not aimed at achieving "an optimal end state but as a dynamic process of continuous learning and adjustment that permits ambiguity and complexity" (Staber and Sydow 2002: 410). Orlikowski (1996: 66) writes, "there is no beginning or end point in this change process." Fundamental changes across the organization emerge from "ongoing variations in practices" and are the result of organizational actors "redirecting what is already underway" (Weick and Quinn 1999: 377). These variations can be perceived as "a series of fast mini-episodes of change" that are based on past variations and create "continuous disequilibrium as variations beget variations" (Weick and Quinn 1999: 377; see also Marshak 1993).

Organizational members adjust their actions continuously and focus on organizing for flexibility and discretion rather than stability and control (Quinn 1988; see also Wheatley 1992). Forming strategies for organizational change within the Agility Model requires managing for change and also "managing by change" (Lapierre 1980: 9 in Mintzberg et al. 1998: 176). Flux rather than stability is the norm and strategy processes emerge out of the constant mutual adjustments made in interaction amongst organizational members. This is a grassroots model of strategy formation. Mintzberg (1998c: 308) argues that organizational members in this context are less concerned with formulating and then implementing strategies than with managing a process through which strategies almost seem to form by themselves" (emphasis in original). Deliberate, pre-determined plans that are imposed on and implemented in a top-down way throughout the organization cannot be relied upon. Instead, strategy formation is part of an iterative, incremental process of thinking, framing and acting in order to respond creatively and flexibly to changing pressures. Strategies emerge as themes and patterns, which do not settle into periods of convergence but remain in constant flux. An organization that builds adaptive capacity as agility is "not only able to function at times without strategic focus, but 
positively thrive on it" and "periodically clean[se] itself of its existing strategic baggage" (Mintzberg 1998c: 318). Quinn and Voyer (1998: 109) discuss this process of organizational change as "logical incrementalism" wherein "real strategy evolves as internal decisions and external events flow together to create a new, widely shared consensus for action." Organizational structures and resources are constantly changing and "highly organic" with "little formalization of behavior" (Mintzberg 1998c: 308; Kraatz and Zajac 2001). These social movement organizations adapt in ways captured by the systems theory concept of "complex adaptive systems" (Kauffman 1994; Resnick 1995; 1996), wherein the local interactions of "many basic but interacting units [e.g., organizational members]...lead to coherent collective phenomena" that emerge and evolve over time (Coveney and Highfield 1995). Organizational changes "tend to be ongoing, evolving and cumulative" (Weick and Quinn 1999: 375).

Fowler (2000) portrays agility as a spiral that increases the ability of an organization to respond to dynamic internal and external pressures through learning and adaptation while building a social movement organization reputation, enhancing its performance and aligning its activities with the changing demands of the environment. Learning about the effectiveness of past performance, about changes in reputation, and about the functioning of its learning processes leads to and informs the adjustments made by the SMO in the form of organizational change and adaptation. This then leads to changes in performance and reputation, which leads to further insight and learning and further adaptation. As Fowler (2000: 152-3) describes, this is a social movement organization that is "comfortable with and effective at continuous, insightful change." A spiral pattern of change aligns with Mintzberg and Westley's (1992: 51) depiction of a "regular progress" pattern of change, wherein an organization is "steadily revitalizing" and is engaged in "more-or-less steady adaptation." The changes that emerge from the interaction of organizational members "are repeated, shared, amplified, and sustained" over time and can "produce perceptible and striking organizational changes" (Orlikowski 1996). Lofland and Lofland (1984: 107) emphasize that the spiral pattern of organizational change is not aimed at relative stability but is a "continuously spreading and accelerating increase or decrease" which can lead to an "escalation and deescalation" or "an 
accelerated movement to a "stronger" or "weaker level of operations." Sztompka (1993: 16) defines a spiral pattern as "an open cycle" which can be recognized by a change in the level of complexity of the variable being observed: if it the complexity is higher, then it is a "developmental (or even progressive) cycle," and if the complexity is lower, then it is a "regressive cycle."

In contrast, I suggest the term "resilience" for the second adaptive capacity approach because of its definition as "a property that allows a system to absorb and utilize (or even benefit from change)" (Holling 1979: 104; see also Yohe and Tol 2002; Janssen and Onas 2005). This definition builds on earlier definitions of resilience as "a property that allows a system to absorb change and still persist" (Holling 1973); however, this definition led to assumptions of organizations avoiding all pressures to change due to possible collapse. In the first definition, resilience refers to the capacity to "restore" (Holling 1973; 1996) (the motto I propose for this model) in a way that "explicitly recognizes the unknown,..., the ability to survive and benefit from 'failure' [through] trial-and-error learning" (Holling 1979: 104-105). Instead of organizing for flux and continuous change (the Agility Model), social movement organizations adopting a resilience approach to adaptive capacity buffer from continuous change, focus on building stability and control in order to "foster efficiency" (Staber and Sydow 2002: 409) while benefiting from periods of episodic change in response to internal and external pressures. Brown and Iverson (2004: 382) emphasize that "more centralization should be possible" in the Resilience Model "because of the focus on efficiency and tight control of existing processes." SMOs adopting a Resilience Approach "value predictability" (Anheier 2000), and often develop activities, proven routines and strategies that are sealed off or buffered "from external disturbances so that [they] can operate continuously and efficiently" (Miles and Snow 1978: 37). In this way, these organization "create stability through a series of decisions and actions which less the organization's vulnerability to environmental change and uncertainty" even under conditions of complex and dynamic pressures (Miles and Snow 1978: 37). 
Stability and control are partially achieved through establishing rules and standards, and through creating robust structures, also referred to as “deep" structures (Weick and Quinn 1999: 366) to support the core strengths of the organization, streamline its routines, and tighten its resource belts (Harrison 1994). This approach is considered useful for the "development of common identity and strategy" (Staber and Sydow 2002: 418). SMOs adopting a Resilience approach maintain and adapt the organization and its rules to fit with existing structures and rules within stable periods (stabilizing periods of convergence); however, these SMOs undertake episodes of widespread organizational change (destabilizing periods of divergence) when there is a "growing misalignment between an inertial deep structure and perceived environmental demands" or internal pressures (Weick and Quinn 1999: 365; see also Tushman and Romanelli 1985 on punctuated equilibrium). This destabilizing period can either result in a return to previous structures and rules, incorporating lessons learned from the change, or a shift to a new state. Kraatz and Zajac (2001: 635) argue that resource-rich, large organizations are more likely to restore to earlier states after periods of divergence, even though they "still have a primary need to maintain environmental coalignment through strategic change." In general, resources are perceived as being stable, incrementally shifting, and able to be exploited to maintain existing structures, strategies and commitments (Kraatz and Zajac 2001: 632) and to support the unique capabilities, also known as the “distinctive competence," (Selznick 1957), or "strategic intent" of the organization (Hamel and Prahald 1989). Boisot (1995: 36) argues that "this simple yet robust orientation...can be pursued with some consistency over the long term in spite of the presence of turbulence." Similarly, Kraatz and Zajac (2001:636) argue that "the development and exploitation of existing resources, may provide an alternate path to organizational success, even in periods of substantial environmental turbulence." Forming strategies for organizational change within the Resilience Model is often by more deliberate and formal plans than in the Agility Model, since episodic change requires both equilibrium breaking and transitioning to a newly created equilibrium (Weick and Quinn 1999: 371; see also Lewin 1951). 
If adaptive capacity as agility can be depicted as a spiral that evolves over time while in state of constant flux, adaptive capacity as resilience can be portrayed as a cycle, illustrated as two loops that intersect to form the shape of an infinity symbol (Holling 1986; Hurst 1995; Folke et al. 1998a; Folke et al. 1998b; Gunderson and Holling 2001). This depiction of change is based on research on cycles of crisis and renewal in natural, disturbed and managed ecosystems (Holling 1986). I draw on Hurst (1995) and translate the ecological cycle to the organizational context. The first phase of the cycle is the exploitation or growth phase during which an organization establishes its systems and structures. This is followed by the conservation phase - a period of convergence during which an organization creates, deepens and fine-tunes a stable set of routines, rules and structures. Over time, these elaborate and tightly bounded structures and systems become "overconnected," vulnerable to internal and external pressures to change, and "brittle" (Folke et al. 1998a: 7). Hurst (1995) continues the cycle with an organizational crisis and episode of change, which are sometimes triggered by changes in systems at other higher or lower scales (e.g., changes triggered by subgroups within the organization or by larger scale changes in the political environment) (Gunderson and Holling 2001). This aligns with the release phase in ecological cycles. It represents a period of divergence during which organizational members undergo stress, confusion, innovation and learning in order to enter the phase of reorganization. During reorganization, the organization renews and restores structures and systems. Previously marginalized individuals, ideas or structures can unexpectedly come to dominate the organization (Hurst 1995). For organizations that build adaptive capacity as resilience, this cycle leads an organization to another period of growth, conservation and convergence wherein deep structures and systems, and a degree of stability, are established. This is distinct from the response of an organization building adaptive capacity as agility that adapts to complex and dynamic conditions by organizing for constant change and flux. For Mintzberg and Westley (1992: 49), this pattern of organizational change is a pattern of "periodic bumps" wherein "an organization experienc[ing] long periods of relative stability, at least at the broadest level (in overall organization and basic strategic thrust), is interrupted periodically by dramatic revolutions as episodes to wrench it back into synchonization with its environment." 
Lofland and Lofland (1984: 106) define cycles as an organizational process that has a degree of relative stability where the first and last steps are connected. In contrast with the "open cycle" of a spiral, Sztompka (1993: 16) argues that change processes which follow "discernible patterns of repetition or at least similarity" (where "virtual recurrence is observable") can be defined as "circular" or "closed cycles."

\section{Figure 4.2 Patterns of Adaptation for Agility and Resilience}

\section{AGILITY}
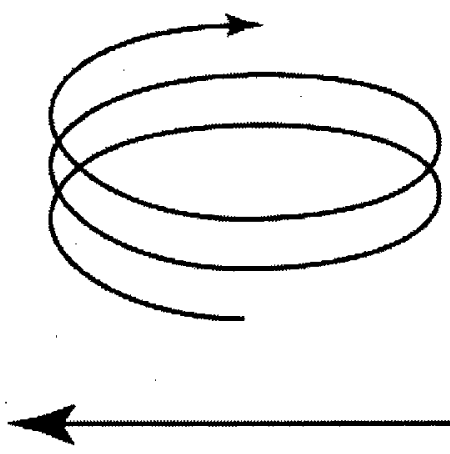

RESILIENCE

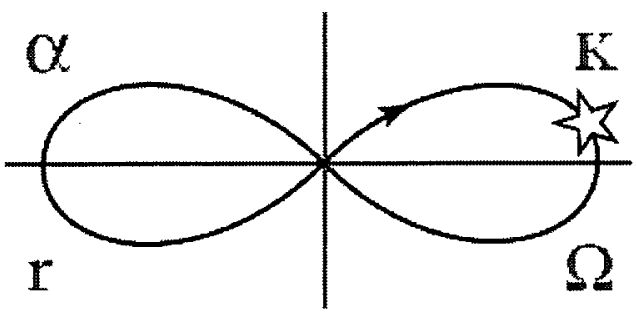

\section{Episodic change}

Figure 4.2 depicts the two ideal types of adaptive capacity along a continuum, displaying their relative alignment with continuous and episodic change and their pattern of organizational change and adaptation. Sztompka (1993: 14) notes that both of these change processes are "non-directional (or fluid)" processes which do not necessarily . follow a linear progression from one state to another. Instead, the organizations operating under these patterns of organizational change can experience progressive and regressive tendencies. In other words, the social movement organization can grow or decline and still follow a pattern of a cycle or a spiral. For Staber and Sydow (2002), the distinguishing feature between these two patterns is the degree of proaction or reaction on the part of organizational members, with the agility approach aligning with a proactive stance. However, I take issue with this perception and argue that the resilience approach is equally a strategic choice of how to operate effectively and adjust strategically under complex and dynamic conditions. In the upcoming chapters, I will explore the extent to which Greenpeace and Friends of the Earth International exemplify these two ideal types 
of adaptive capacity and analyze the ways in which they deviate from the Agility Model and the Resilience Model. 


\section{CHAPTER FIVE: Tactical Innovation}

\subsection{Introduction}

Friends of the Earth International started as a rather symbolic international movement; 'think globally, act locally'. The Annual General Meeting was the only structured event, FoEI was an organization of persons rather than groups with mainly informal communication. The focus was on [the] rich industrialized parts of the world, as the group were based there. Since the beginning of the eighties, the need for a better organizational structure was felt more and more. Partly because new groups joined with another perspective .... But also the world gradually started to accept that environmental problems are global in nature.... FoEI has to redefine its position in this confusing surrounding. ${ }^{75}$

The environment within which we work is constantly changing and, in general, we aim to catalyze change. This, of course, is of major importance in plotting Greenpeace's direction. If we do not take into account external factors when taking strategic decisions we will be unable to identify opportunities to exploit and threats to defend against. At worst, our work will be irrelevant. ${ }^{76}$

As the quotations above suggest, Friends of the Earth International and Greenpeace scan their external environment for changes and strive to strategically respond to these changes in order to remain viable and effective over the long-term. FoEI and Greenpeace are also social movement organizations and, therefore, aim to trigger societal change and pressure target opponents to shift their behavior. In the second quotation, the speaker notes that Greenpeace "aim[s] to catalyze change." FoEI is similarly aware of its role in influencing external developments, such as increased government cooperation on environmental issues and the growth in the number of Southern citizen organizations addressing environmental issues over the past four decades. In an internal FoEI strategy document, the FoEI Executive Committee notes,

These developments did not simply happen to us. They were stimulated, encouraged and welcomed by members of FoEI. ${ }^{77}$

\footnotetext{
${ }^{75}$ Executive Committee (1988) Annual General Meeting paper about the future of Friends of the Earth International. Amsterdam, The Netherlands, $25^{\text {th }}$ August, p. 1

${ }^{76}$ Greenpeace UK (1998) Campaign Guide compiled by Rick Le Coyte with Chris Rose, based on a presentation by Chris Rose to the Greenpeace International Climate Campaign Meeting (February 1996).

${ }^{77}$ Executive Committee (1994) Discussion Paper about the Need for an International Agenda for FoEI. FoEI, Amsterdam, The Netherlands, 10 August, p.2.
} 
How do Greenpeace and Friends of the Earth International catalyze social change? In this chapter and the two that follow, I answer this question by analyzing the historical evolution of FoEI and Greenpeace and their patterned strategic responses to changes in the external political environment. In Chapter Four, I refer to the organizational capacity to repeatedly disrupt the status quo and stimulate social change as a social movement organization's capacity for "tactical innovation." I build on research by McAdam (1983), which analyzes how social movement organizations engage in a process of tactical interaction with powerful actors in society whom they target with their activities. Below, I review how tactical interaction happens within specific confrontations and campaigns. I then make the argument that to understand the effectiveness of FoEI and Greenpeace in addressing the challenge of tactical innovation, it is necessary to widen the analytical lens beyond these individual 'battles' to understand how these organizations are strategically responding in order to 'win the war' of values, ideas and the appropriate path for societal development. Building on the mission statements of FoEI and Greenpeace, I define 'winning the war' as triggering a fundamental shift in the worldview and behavior of people around the world in order to secure a sustainable and peaceful future. Greenpeace strives for a "green and peaceful future" 78 and FoEI seeks "a peaceful and sustainable world based on societies living in harmony with nature."79 There are certainly examples of progress towards this goal, such as international environmental agreements. Indeed, both FoEI and Greenpeace indicate their successful involvement in thousands of individual battles (see Appendix I and II for a timeline of FoEI and Greenpeace reported victories); however, there are also clear trends that point in the opposite direction.

The continued degradation of the environment and rising economic inequality amongst the world's population are detailed in recent international reports, such as the Millennium Ecosystem Assessment (2005) and the UN World Development Report (2005). Since 2001, the US-led 'War on Terrorism' has dominated the geopolitical agenda. There is a broad scientific consensus around the existence and consequences of climate change. Despite this, a rapid shift away from a fossil fuel driven economy is not evident and

\footnotetext{
${ }^{78}$ Greenpeace (2005) Annual Report. Greenpeace International, Amsterdam, The Netherlands.

${ }^{79}$ FoEI (2005) Annual Report. FoEI, Amsterdam, The Netherlands.
} 
powerful governments, such as the USA, and corporations, such as ExxonMobil, continue to question the existence and urgency of the issue. Continued economic growth remains the overriding promise of candidates seeking election, and the dominant focus of discussions at the World Economic Forum, the World Trade Organization and within growing economies such as India and China. Decades of environmental education campaigns to expose unsustainable consumption and production patterns have not led to an overarching shift in lifestyle and industrial production practices within industrialized countries; nor have they resulted in a change to the desirability of high-consumption lifestyles for the rising middle-classes in developing countries. In other words, the status quo persists, as does the behavior of the general public, governments and corporations. These trends challenge FoEI and Greenpeace to repeatedly recreate their tactical approach in order to confront these trends at the transnational level.

I began this dissertation by outlining the continued viability of both Greenpeace and FoEI, and here I assume that their survival and membership support reflects a wide public perception that these transnational social movement organizations remain relevant actors in the protracted 'war' against unsustainable development. I am interested in their longterm viability and, therefore, in the patterned strategic response they have developed to advance their mission. Because FoEI and Greenpeace are transnational social movement organizations, I focus particularly on the approach they have developed to working globally in order to confront transnational trends away from sustainable and peaceful societies.

In this chapter, I briefly summarize the thesis argument from previous chapters and describe the empirical data analyzed for my investigation of FoEI and Greenpeace. I then examine the process of tactical innovation at the level of particular time-bound confrontations and longer-term campaigns before presenting the distinct approaches Greenpeace and FoEI have taken to working globally to 'win the war' over time. In the final section of this chapter, I present my comparative analysis of FoEI and Greenpeace in order to provide an analytical lens for the descriptions of their historical development within Chapters Six (FoEI) and Chapter Seven (Greenpeace). In Chapter Eight, I 
investigate how the tactical approach which FoEI and Greenpeace have adopted to working globally influences their responses to managing external relations, maintaining their organizational viability, and managing their internal relations.

\subsection{From Theory to Empirical Data}

In Chapter One, I make the case that FoEI and Greenpeace have maintained their organizational viability over the three decades of their existence by effectively adapting to changing internal and external pressures. This assessment of their viability provides the foundation for this dissertation. It also underpins my challenge of the emerging scholarly consensus (Fowler 2000; Anheier and Themudo 2001; Clark 2003a: 110-111; Smith 2005) that a decentralized and informal structure maximizes adaptability in a TSMO. I argue that both Greenpeace and FoEI exhibit adaptive capacity despite significant differences in their level of formalization and degree of centralization (Section 3.4 and 3.5), which stem from ideological differences and distinct interpretive frames (Section 2.2). I am primarily interested in the long-term organizational viability of Greenpeace and FoEI and in exploring how these TSMOs have addressed organizational challenges repeatedly over time. In this chapter and the upcoming three chapters, I present empirical evidence of the typical strategic responses of FoEI and Greenpeace to complex and dynamic conditions in order to illuminate their approach to building adaptive capacity.

In Chapter Four, I present my central theoretical framework by detailing four common organizational challenges facing transnational social movement organizations (TSMOs) as they adapt to complex and dynamic conditions: tactical innovation, managing external relations, organizational maintenance, and managing internal relations. In Section 2.3, I explain that every TSMOs has an action repertoire, defined as the routine forms of activities and clusters of tactics which are used in a given historical period (Tilly 1978). Tactical innovation refers to the challenge for TSMOs to create new tactics and adapt tactics in order to repeatedly disrupt, or threaten to disrupt, the status quo. TSMOs are also faced with managing their relations with external actors in order to reap the benefits of partnership while ensuring their relative independence to pursue their 
objectives. Building long-term adaptive capacity requires a TSMO to address both the need for organizational maintenance through acquiring resources in order to survive and the challenge of managing internal conflicts and fostering a degree of internal cohesion within the TSMO.

I conclude Chapter Four by clustering possible TSMO strategic responses to these four organizational challenges into two ideal type approaches to building adaptive capacity: the Agility Model and the Resilience Model. These ideal types are inspired by my empirical analysis of Friends of the Earth International and Greenpeace; however, it will become apparent within this chapter and the upcoming chapter that, although these TSMOs exhibit tendencies that correspond to one or other type, they do not wholly or categorically correspond to these ideal types but remain dynamic hybrids. I propose that it is largely the case that FoEI corresponds to the Agility approach to building adaptive capacity, and I argue that Greenpeace predominately corresponds to the Resilience Model; however, I also explore the ways in which FoEI and Greenpeace opportunistically incorporate elements of their respective opposite model. Through my analysis of these organizations, I have found that TSMO actors actively and creatively shape their strategic responses to internal and external pressures. In other words, FoEI and Greenpeace have typical patterned responses to organizational challenges that guide and partially constrain their future responses; however, FoEI and Greenpeace activists remain creative agents of change within these organizations and make intentional choices to adjust their approach, borrow tactics and strategies, mimic other successful organizations and their tactics, and adopt wholly new approaches within certain contexts in order to achieve their objective of social change. I aim to explore the typical strategic choices that FoEI and Greenpeace have made when confronted with organizational challenges while highlighting the sheer diversity of responses of which they are capable. 


\section{The purpose of this chapter and the coming three chapters is to analyze how the}

strategic responses to the four organizational challenges are expressed empirically in Friends of the Earth International and Greenpeace. The focus herein is necessarily one of 'how' these two organizations operate "on the ground." In Section 1.7, I review the sources of data that serve as the basis for my empirical analysis and my theoretical framework: scholarly literature, popular literature, internal organizational documents, serial publications, biographies, and semi-structured interviews. Triangulation across these sources of data was critical for understanding how these organizations operate and function on the ground. This is particularly important because many public organizational documents published by FoEI and Greenpeace, such as Annual Reports, primarily serve as promotional materials rather than in-depth explorations of organizational strategy, successes, failures, and learning. A similarly one-sided perspective was evident in the critical writing of journalists, scholars, and antagonistic actors that seek to portray FoEI and Greenpeace in a negative light. I found a much richer source of empirical data within my semi-structured interviews with FoEI and Greenpeace campaigners, scholarly analyses of specific campaigns, and internal organizational documents, including letters, historical interviews and strategic documents. Table 5.1 provides a list of the twenty-one individuals whom I interviewed and their position within FoEI or Greenpeace. Appendix D provides a full list of data sources on FoEI and Greenpeace that I analyzed for this dissertation. I also draw upon field observations made during my visits with these organizations and during my examination of campaigners 'in action' in contexts such as the UN World Summit on Sustainable Development. Throughout this chapter and the next three, I use footnotes to indicate empirical data that underpin my claims, and I have italicized quotations from the semi-structured interviews that were conducted for this dissertation. Within bracketed citations embedded in the text, I also note the work of other scholars that conflict with or support my arguments. 
Table 5.1 FoEI and Greenpeace Interviews Conducted for this Dissertation

\begin{tabular}{|l|l|}
\hline \multicolumn{2}{|c|}{ Friends of the Earth International } \\
\hline Mike Childs & Head of Campaigns, FoE England, Wales and Northern Ireland (EWNI) \\
\hline Ann Doherty & Communications Coordinator, FoEI \\
\hline Kevin Dunion & FoEI Chair (1996-2003), Executive Director, FoE Scotland (1991-1996) \\
\hline John Hontelez & FoEI Chair (1986-1996) \\
\hline Tony Juniper & FoEI Vice-Chair (2000- present); Executive Director, FoE EWNI \\
\hline Daniel Mittler & FoE Germany 1996-2004; Greenpeace International 2004 - present \\
\hline Mae Ocampo & International Membership Development Coordinator \\
\hline Beatrice Olivastri & Co-founder and CEO, FoE Canada \\
\hline Meena Raman & FoEI Chair (2004 - present), Sahabat Alam Malaysia (FoE Malaysia) \\
\hline Marijke Torfs & FoEI International Coordinator (1998 - present) \\
\hline & \multicolumn{2}{|c|}{ Greenpeace } \\
\hline Gerd Leipold & Executive Director, Greenpeace International \\
\hline Brian Fitzgerald & New Media Director, Greenpeace International \\
\hline Marcelo Furtado & Campaigner, Greenpeace Brazil \\
\hline Josselien Janssens & Campaign Direction Officer, Greenpeace International \\
\hline Michael M'Gonigle & Greenpeace campaigner (1976- 1982) \\
\hline T. Mohan & Board, Greenpeace India \\
\hline Rémi Parmentier & $\begin{array}{l}\text { Co-founder of Greenpeace France (1974), Greenpeace campaigner } \\
\text { including Political Director, Greenpeace International (1974- 2005) }\end{array}$ \\
\hline Steve Sawyer & $\begin{array}{l}\text { Climate and Energy Policy Advisor, Greenpeace International; Past } \\
\text { Executive Director of Greenpeace USA (1986-88); Past Executive } \\
\text { Director of Greenpeace International (1988-1993) }\end{array}$ \\
\hline Jenny Stannard & $\begin{array}{l}\text { Manager, Greenpeace Governance and Board Relations, Greenpeace } \\
\text { International }\end{array}$ \\
\hline Guido Verbist & $\begin{array}{l}\text { Greenpeace campaigner (1972 - 2006), Author of Greenpeace: How a } \\
\text { Group of Ecologists, Journalists and Visionaries Changed the World } \\
\text { (2004) }\end{array}$ \\
\hline Rex Weyler & \multicolumn{1}{|l}{. } \\
\hline
\end{tabular}

\subsection{Tactical Innovation}

Friends of the Earth International and Greenpeace rely on a set of tactics - an action repertoire - which they have deemed to be effective in achieving their goals. As Section 2.4 describes, TSMOs have a diversity of tactics at their disposal including conventional tactics (e.g., lobbying, press releases, legal battles and referenda) and unconventional tactics (e.g., demonstrations, sit-ins, petitions, blockades, boycotts, and direct actions) (Van der Heijden 1997). As social movement organizations, FoEI and Greenpeace use both conventional and unconventional tactics in their attempt to disrupt the status quo and achieve their objectives (McCarthy and Zald 2001). They strategically and opportunistically apply a wide range of tactics that can possibly stimulate social change in the direction of their goals. This multi-pronged approach is reflected in the following 
quotation by Ricardo Navarro, Chair of Friends of the Earth International (2000 - 2003), who notes,

FoE activists are omnipresent - demonstrating in the streets, attending company shareholder meetings, sitting in trees and lobbying in the halls of the United Nations. ${ }^{80}$

David McTaggart, Greenpeace International Executive Director and Chair (1979-1991), describes a similarly varied tactical approach to campaigning for Greenpeace. He writes,

Our early formula was simple and still sound: Basic research to find the weak points, quiet approach to government and industry outlining our concerns and possible responses if those concerns are not met.... If no response, WHAM: hit them with everything we have: Mail Outs, members, actions, media, letters, votes, boycotts, ads, articles, all in a coordinated way: if it wasn't hard enough to hurt them, better not to bother. $^{81}$

McTaggart's statement expresses the central purpose of employing tactics: to influence target opponents and to catalyze change. The aim of transnational social movement organizations is indeed to stimulate social change and to influence key decision-makers and power-holders in society. However, the actors, such as governments and corporations, that TSMOs target with their activities and campaigns are not passive recipients of a TSMO's tactics. They often have a vested interest in ignoring, resisting and actively undermining attempts at social change. Because of these dynamic conditions, all TSMOs are faced with the challenge of tactical innovation in order to disrupt, and continue to disrupt, the status quo. Since a TSMO's political environment is changing over time and target actors are responding to TSMO tactics, "the problem for movement organizations is to create organizational models that are sufficiently robust to stand up to opponents, but flexible enough to change with new circumstances" (Tarrow 1995: 136).

McAdam (1983: 752) describes social movement organizations (SMOs) as engaged in an "ongoing process of tactical interaction" between an SMO and its opponents. Because

\footnotetext{
${ }^{80}$ FoEI (2001) Annual Report. FoEI, Amsterdam, The Netherlands, p.3.

${ }^{81}$ McTaggart, David (1992) Letter to the organization from David McTaggart, Greenpeace International Honorary Chair, $18^{\text {th }}$ August, p. 4.
} 
SMOs are, by definition, less powerful than those they target with their tactics, McAdam. argues that they "must devise protest techniques that offset their powerlessness." McAdam notes that these techniques only "temporarily' afford challengers increased bargaining leverage" as the opponents will likely counter these tactics "in a chess-like fashion" and re-establish their power. For example, corporations are being advised by a new generation of business consultants to "fight back" with "power plays" in order "to beat the activists and survive in the twenty-first century" (Nichols 2003: 151).

Corporations are urged "to be creative, in many instances learn from how activists behave and the tactics they employ, and turn the tables" by, for instance, constantly changing tactics, using activists statements against them, and forming alliances in order "to increase their fire power and staying power" (Nichols 2003: 151). FoEI and Greenpeace campaigners are well aware of the dynamic conditions within which they operate. Internal documents, annual reports, campaign documents and personal interviews frequently refer to the "chess-like" moves of target opponents, their reactions of "organizing and fighting back" in order to reverse the "alarming levels" of environmental threats that challenge their organization. ${ }^{82}$ For FoEI and Greenpeace campaigners, a forceful reaction by a target opponent is not necessarily perceived as having a negative effect on a campaign as it can also lead to the opponent being "an easier target" and to a public outcry against the opponent. ${ }^{83}$ For example, in the Greenpeace campaign to protect whales, Russian whalers initially responded to the presence of Greenpeace activists by ignoring their efforts to shield whales from harpoons and continuing their whale hunt. ${ }^{84}$ After Greenpeace photographs and films of the whale hunt reverberated through the mass media and caused widespread public alarm, the Russian whalers responded to the second Greenpeace protest voyage by covering their harpoons and calling off the hunt in recognition of how the blood-soaked images of the previous year had made them an easy target for criticism.

${ }^{82}$ e.g., Sawyer, S. (1991) Saving the World the Greenpeace Way. Introduction to the International Executive Director's Report to the 1991 Stichting Greenpeace Council Annual General Meeting; Blackwelder, B. (1996) "Reminiscences and Challenges" in LINK, FoEI, Amsterdam, The Netherlands, July/August, p. 18.

${ }^{83}$ Sawyer, S. (1991) Saving the World the Greenpeace Way. Introduction to the International Executive Director's Report to the 1991 Stichting Greenpeace Council Annual General Meeting.

${ }^{84}$ Hunter 2002: 170. 
In order to maintain leverage over their target opponents, McAdam (1983: 752) concludes that social movement organizations need to "continue to search for new and effective tactical forms" in order "to succeed over time." TSMOs operating in a complex and dynamic environment need to build the capacity to innovate their tactics repeatedly the capacity for innovativeness - as the effectiveness of a particular tactic in a particular campaign is often short-lived (Letts et al. 1999). How does tactical innovation unfold given the empirical evidence? I propose that tactical innovation can be observed at different timescales, and I will examine three:

- Short-term episodes and events within campaigns;

- Longer-term campaign strategy; and

- Long-term organizational strategy.

Continuous tactical innovation often requires rapid response on the part of campaigners, as one FoEI campaigner notes,

I have found that campaigning has to be a flexible and fleet-footed activity. You need to do things quickly and move with those things that you can't control. ${ }^{85}$

It also involves the capacity for organizational learning and strategy over extended periods of time to respond to long-term trends in, for example, the behavior of target opponents or public understanding of environmental issues.

\subsubsection{Short-term Campaign Episodes and Tactical Innovation}

First, tactical innovation occurs at the level of the individual campaigner within a particular event or episodes within a specific campaign. This level is most evident during a specific confrontation or direct action between a FoEI or Greenpeace activist and a target opponent. For Friends of the Earth International, these confrontations frequently involve local communities and indigenous people fighting to protect their land and livelihood from industrial development. For example, Friends of the Earth supports the work of the Australian Aboriginal Mirrar in their fight to end uranium open-pit mining adjacent to their traditional lands and to hold the mining corporations responsible

\footnotetext{
${ }^{85}$ Interview with Tony Juniper, Vice-Chair Executive Committee Friends of the Earth International, Executive Director, FoE England, Wales, Northern Ireland, January 2006.
} 
for cleaning the waste tailings. ${ }^{86}$ Since the mine opened in 1980s, the Mirrar people have experienced severe health and social problems. Together with FoEI, they launched an oppositional campaign against Energy Resources of Australia, which included legal actions, education campaigns, demonstrations, and blockades including one in which 550 people were arrested. Once mine development was halted, partly due to Mirrar opposition and also due to the drop in market price for uranium, FoE and the Mirrar people have switched their tactics again to lobby Rio Tinto, a UK multinational mining company who has purchased the uranium mine, to return the land to park status.

This example is only one of many "clashes with corporate giants" which FoEI member groups engage in, often in coalition with local peoples. ${ }^{87}$ In the case of the Mirrar, continuous adjustment of their tactics was somewhat successful in halting uranium mine development; however, the community is still campaigning for the clean-up of the radioactive tailing and remains vulnerable to the re-opening of the mine. In other cases, the tactical innovation of FoEI and local peoples has not resulted in changes in the behavior of target corporations and their development plans; for example, a combination of tree occupations, blockading and lobbying in protest to the development of an oil pipeline through Ecuador has resulted in increased violence and repression against activists but has not halted the pipeline's development. ${ }^{88}$ Even international pressure has not helped. As the campaigners note, "despite international media attention to the negative implications of the project and global campaigning all over the world, the OCP [Oleoducto de Crudos Pesados (OCP) - the oil pipeline] seems likely to proceed as planned." Since many of the confrontations use the same tactics (e.g., global pressure, demonstrations, education, lobbying, blockades), it is beyond the scope of this dissertation to assess why certain confrontations with corporations and governments have resulted in the withdrawal of an environmentally and socially destructive development

${ }^{86}$ FoEI (2001) "A Life of Resistance: Fighting Australia's Uranium Mines" in Sparks of Hope, Fires of Resistance: FoEI celebrates the Sustainable Path Forward: $30^{\text {th }}$ Anniversary Publication. FoEI, Amsterdam, The Netherlands, p. 36.

${ }^{87}$ FoEI (2002) Clashes with Corporate Giants: 22 Campaigns for Biodiversity and Community. FoEI, Amsterdam, The Netherlands.

${ }^{88}$ FoEI (2002) "Tree sits, blockades and protests: Local and global mobilization against Ecuadorian pipeline" in Clashes with Corporate Giants: 22 Campaigns for Biodiversity and Community. FoEI, Amsterdam, The Netherlands, p. 20-21. 
(e.g., Shell's withdrawal from gas exploration in Kirthar National Park in Pakistan; Occidental Petroleum's departure from the U'Wa territory in Colombia) whereas other campaigns do not have the desired result (e.g., the continued development of a General Motors car factory adjacent to farmlands in Czech Republic despite extensive opposition).$^{89}$ In these confrontations, it is clear that sustained tactical innovation and pressure from activists at the local to international level, as well as political will and supportive public opinion in the country, are essential for increasing the likelihood of success.

Similarly, in Greenpeace confrontations, activists are challenged with repeatedly adjusting their tactics in response to the reactions of target opponents. An example of Greenpeace campaigners quickly adjusting their tactics is the campaign to protest the dumping of toxic waste at sea. Greenpeace activists initially maneuvered inflatable boats underneath ship cranes poised to release waste barrels into the ocean; however, the corporations and crew quickly responded to this direct action by fastening large metal cages under the cranes within which the barrels could be released. ${ }^{90}$ No longer able to physically stop the barrels being released into the ocean, Greenpeace activists adapted their strategy by clamping themselves onto the cages and the crane. This tactic required the ship crews to forcibly remove the activists and delay their operations. In another example, tactical innovation occurred over a longer time period. In the campaign to end clear-cut logging on the west coast of British Columbia, Greenpeace campaigners engaged in a broad panoply of tactics to force MacMillan Bloedel to change its logging practices, including demonstrations, blockades, and direct action at logging sites. ${ }^{91}$ MacMillan Bloedel responded by forming a non-profit organization, the BC Forest Alliance, to pursue public education campaigns in favor of the forest corporation's practices. Greenpeace responded by catalyzing public outcry in Europe through vibrant direct action campaigns and successfully lobbying European governments, consumers, and UK companies that purchased $\mathrm{BC}$ wood and paper products to boycott $\mathrm{BC}$ products.

\footnotetext{
${ }^{89}$ FoEI (2002) Clashes with Corporate Giants: 22 Campaigns for Biodiversity and Community. FoEI, Amsterdam, The Netherlands.

${ }^{90}$ Greenpeace 1996: 27.

${ }^{91}$ Boettger and Hamdan 2001
} 
While corporate representatives of MacMillan Bloedel toured Europe in an effort to convince the public of their sustainable forest practices, Greenpeace campaigners traveled to Hollywood to convince film producers to take their film production elsewhere until a forestry practices code outlawed clear-cutting practices. This tactical interaction continued and Greenpeace's sustained pressure contributed to the formation of new forestry laws within British Columbia; however, in other campaigns, tactical innovation did not achieve the desired result. A decades-long Greenpeace campaign on behalf of the victims of the chemical accident in Bhopal, India in 1984, which, as of 2006, has not resulted in a clean-up operation by Union Carbide nor compensation for those affected by the accident.

Tactical innovation is also required within diplomatic settings, such as intergovernmental meetings. Negotiations amongst governments within these international arenas can change rapidly and Greenpeace and FoEI lobbyists need to remain abreast of changes in order to recognize threats and seize opportunities for influence. One campaigner revealed how this fast-paced lobbying is assisted by cell phones, with activists calling each other to coordinate multi-pronged lobbying efforts with messages such as "Chinese delegates are entering the front doors of the conference hall - I'm going after the Germans, you discuss this proposal with the Chinese. ${ }^{, 92}$ These insider lobbying tactics are frequently supported by demonstrations outside the intergovernmental meetings. For example, Greenpeace campaigners lobbied for regulations on corporate behavior within the halls of the UN Conference on Environment and Development, while a Greenpeace boat blocked the harbor of Rio de Janeiro to protest the rainforest logging practices of Aracruz, a Brazilian pulp producer. ${ }^{93}$ At meetings of the signatories of the UN Convention on Climate Change, Friends of the Earth International campaigners pressure governments to adopt stringent targets to combat climate change, while outside the conference building, FoEI campaigners and other protestors staged vibrant

\footnotetext{
${ }^{92}$ Interview with Marcelo Furtado, Greenpeace Brazil, September 2002.

${ }^{93}$ Greenpeace (1992) Annual Report. Greenpeace International, Amsterdam, The Netherlands.
} 
demonstrations, including building a 500 meter long and 1.5 meter high sand dike of 50,000 sandbags to surround the conference facility. ${ }^{94}$

\subsubsection{Longer-term Campaign Strategies and Tactical Innovation}

The ability to react quickly within a particular confrontation needs to be complemented with the endurance that is required in longer-term campaign strategies. For both FoEI and Greenpeace, individual confrontations often fit within a broader, longer-term campaign that requires its own level of tactical innovation. For example, Greenpeace has been campaigning to protect whales since the launch of "Project Ahab" in 1974 and the inaugural protest voyage to shield whales from Russian harpoons in $1975 .{ }^{95}$ Although there have been decided victories in this campaign over the past thirty years, Greenpeace continues to pressure for concessions within the International Whaling Commission (IWC) and engage in tactical interaction with governments that continue to illegally harvest whales, including Japan, Norway and Russia.

Early Greenpeace direct action campaigns succeeded in exposing whaling activities and in catalyzing a public outcry against commercial whaling. Greenpeace activists launched voyages to obstruct whaling operations repeatedly throughout the late seventies and early eighties, and distributed such vivid images of whale slaughter and Greenpeace direct actions to protect the whales that they were transmitted by the mass media around the world. In 1980, Australia closed its whaling station. In 1982, the International Whaling Commission adopted a moratorium on all commercial whaling, and in 1994, agreed to establish a whale sanctuary around Antarctica. Greenpeace is credited for having influenced these decisions (Stoett 1997), but the issue is far from resolved. After the 1982 IWC agreement, Greenpeace ships continued to monitor illegal whaling activity in Russia; to galvanize a boycott of Iceland fish to pressure the Icelandic government to close its whaling stations, and to block Norwegian ships on their way to hunt Minke whales. ${ }^{96}$ To this day, whale hunts continue under the auspices of scientific research, and

\footnotetext{
${ }^{94}$ Donelly, S. (2000) "Sandbag Solidarity" in LINK: Friends of the Earth International, Amsterdam, The Netherlands, vol.95.

${ }^{95}$ Boettger and Hamdan 2001: 254.

${ }^{96}$ Boettger and Hamdan 2001: 254-265.
} 
whaling nation-states maintain their pressure to reverse the IWC agreement. In 2002, Greenpeace reports, "despite mounting a vigorous campaign, Japan fails to win any concessions in favor of whaling at the $54^{\text {th }}$ meeting of the International Commission in the whaler's home port of Shimonoseki." ${ }^{97}$ Throughout the thirty years of campaigning to protect whales, Greenpeace has combined direct action with diplomatic lobbying and scientific research to influence governments and the public. Greenpeace campaigners have continuously adjusted to the tactical adaptations of whaling nations and will need to maintain their ability to continuously modify their tactics in the foreseeable future:

Friends of the Earth International's campaign against genetically modified organisms (GMOs) has similarly required regular tactical innovation to counter the activities of governments and corporations intent on the dissemination of genetically modified products. ${ }^{98}$ The FoEI GMOs campaign began in 2000. Since the start of the campaign, FoEI member groups have engaged a wide range of tactics across multiple countries. These include lobbying supermarkets to remove GMO products from shelves; organizing public protests - such as postcard actions - to pressure governments into adopting legislation banning GMOs; launching consumer education campaigns; and pressuring food producers to commit to being GMO free. Direct action tactics were also used, for instance the illegal removal of GM crops from fields to halt their production and to prevent the contamination of nearby farming fields. ${ }^{99}$ In Europe, this campaign has led to a number of reported victories including the removal of GM products from canteen lunches in France and the commitment by major supermarkets in the UK to stop carrying GM products. FoEI member groups also focus their efforts beyond Europe to campaign in developing countries receiving food aid by lobbying developing country governments to ban food aid with GM products. Working together with environmental and citizens groups in countries such as Bolivia, Guatemala and Nicaragua, FoEI were responding to the discovery of GMOs in food aid through citizen-based monitoring. FoEI disseminated

\footnotetext{
${ }^{97}$ Greenpeace (2002) Annual Report. Greenpeace International, Amsterdam, The Netherlands. ${ }^{98}$ This overview of the GMO campaign draws on the campaign reports in FoEI Annual Reports from $2000-2005$.

${ }^{99}$ FoE (1992) Friends of the Earth 1971-1992: 21 Years of Friends of the Earth. Friends of the Earth Ltd. London, UK.
} 
GMO test kits to activists groups around the world in order to continue these citizen tests. In 2003, the UN Protocol on Biosafety came into force, and although FoEI recognized this as a campaign victory, they also note, "many issues are still pending, and we are calling for the immediate establishment of an effective liability mechanism under the Protocol to ensure that corporations are held financially responsible for damage they cause, for instance through the contamination by genetically engineered crops." 100 FoEI activists involved in the GMO campaign are continuously challenged by new responses of target opponents, particularly by the biotech corporations and by the actions of the US government through the World Trade Organization to mandate the acceptance of GM products within Europe and developing countries.

\subsubsection{Long-term Organizational Strategy and Tactical Innovation}

The campaigns and confrontations outlined above are part of a larger set of activities selected by FoEI and Greenpeace campaigners to catalyze social change towards a sustainable and secure future. Appendix I and $\Pi$ provide an historical overview of their confrontations and campaign achievements as reported by these TSMOs in their official documentation; however, FoEI and Greenpeace campaigners are acutely aware of the trends in globalization and government and corporate behavior that move in the opposite direction from the achievement of sustainable societies. Despite successes in particular campaign battles, are they winning the war of securing a green, socially just and peaceful future? These organizations reached their first decade, their twenty-fifth, thirtieth and thirty-fifth anniversaries. They have experienced the emergence of an international environmental and then sustainable development agenda from the 1972 UN Conference on the Human Environment to the 1992 UN Conference on Environment and Development to the 2002 World Summit on Sustainable Development. At these milestone events, FoEI and Greenpeace campaigners have paused to reflect on their capacity for tactical innovation at the transnational level to counter larger environmental, social, economic and political trends. The following quotation from the $25^{\text {th }}$ Anniversary publication of Greenpeace illustrates a common concern amongst FoEI and Greenpeace campaigners,

${ }^{100}$ FoEI (2003) Annual Report. FoEI, Amsterdam, The Netherlands, p. 9. 
There are many times when you feel like a $\operatorname{cog}$ in a giant wheel, when you wonder if you are really making a difference. It seems to take an age to lobby for a particular piece of legislation, to write a report, to pull together a direct action. Then the legislation is passed, the report is published, the action is over, and you wonder, have I really made any difference? ... Whales are still being killed, oceans are still being polluted and over-fished, there are still enough nuclear weapons to annihilate humanity several times over.... Ultimately the answer to the question posed by those of us who have doubted our efforts, wondered if it was all worth it, is a resounding Yes. Not because of the whales we did or did not save, the nuclear tests we did or did not prevent, or the toxic waste shipments we did or did not stop, but because of all those things - successes and failures alike - have helped build an ever-growing sense of awareness of the many complex environmental issues we face. In the process, Greenpeace has helped create something that is far bigger than all the individuals involved, that will outlive them all and even Greenpeace itself: a growing global community, environmentally aware and willing to make a stand and be heard, in its quest for a green and peaceful planet. ${ }^{101}$

As the quotation above suggests, this campaigner looks beyond Greenpeace's individual campaigns and victories, and notes the level at which he feels the effectiveness and relevance of Greenpeace lies: Greenpeace's ability to stimulate a fundamental shift in perception of environmental issues and to inspire activism towards this goal. In FoEI campaigners come to a similar assessment of the "ongoing neoliberal economic globalization that is threatening environmental sustainability and social justice around the world;" ${ }^{102}$ however, this organization plays a different role in reversing this trend and faces a different challenge. Despite individual victories within confrontations and campaigns, Meena Raman, the current FoEI Chair, writes,

The road ahead will not be easy, as we face an increasingly unipolar world which continues to undermine ecological sustainability and exacerbate global inequalities between rich and poor. As a truly unique network of dedicated environmental activists and campaigners, Friends of the Earth International's challenge is to work effectively in unity, given our diversity, and to bring about real changes that will contribute to a better world. ${ }^{103}$

\footnotetext{
${ }^{101}$ Mulvaney, K. (1996) Greenpeace Witness: Twenty-Five Years on the Environmental Frontline. London, UK: André Deutsch Limited, p. 33.

${ }^{102}$ Raman, M. (2004) "Moving Forward" in FoEI Annual Report. Amsterdam, The Netherlands, p. 3

${ }^{103}$ Ibid.
} 
Like Greenpeace, the effectiveness of FoEI is ultimately dependent on its ability to challenge trends that move society away from a sustainable and secure future. For Greenpeace, the strategic response to this challenge is to focus on catalyzing activism and a global awareness of environmental issues. In contrast, FoEI is faced with an internal challenge of combining the strength of its dozens of national member groups to present a coherent critique of the status quo and a common international agenda to rally around. It is these two distinct organizational strategies in response to long-term transnational trends that are the focus of the remainder of this chapter and the upcoming two chapters.

Below, I present my comparative analysis of the strategic response to tactical innovation at the level of organizational strategy. To summarize my argument, FoEI and Greenpeace are faced with a similar challenge of organizing themselves in order to continuously adapt in response to long-term transnational trends. I conclude that FoEI's organizational strategy to this challenge is to adopt a wide approach to its international organizational strategy and action repertoire. In other words, FoEI campaigners cast a wide net across a complex set of issues, adopt a broad array of tactics, search for root causes to environmental and social problems, promote solutions and alternatives, and work through multiple channels from local to global scales. I label this a 'tactical expansion' approach.

In contrast, I argue that Greenpeace has developed its strategic response to tactical innovation at the international level around a focused set of tactics, namely a combination of nonviolent direct action to bear witness and confront environmental threats, which is supported by mass media communication, scientific and technological research, and diplomatic lobbying. Greenpeace has adopted this strategy to achieve concrete changes in the behavior and policies of governments, international organizations and corporations, and to catalyze a shift in consciousness within society towards an ecological sensibility. Greenpeace repeatedly amends this tactical approach by finetuning and creatively adjusting its direct action and issue or target specific campaigns, which I label a "tactical specialization" approach. This conclusion which differentiates between an "expansion" and a "specialization" approach closely aligns with 
the analysis of other scholarly work, which I will review in the upcoming chapters (e.g., Pearce 1996; Wapner 1996; Warkentin 2001; Doherty 2002; Suter 2002/3).

\subsection{Working Globally: An Analytical Comparison of FoEI and Greenpeace}

As I detailed in Chapter 2, FoEI and Greenpeace operate in a transnational political environment and seek solutions to global problems. FoEI and Greenpeace may succeed in innovating within specific confrontations and in achieving victories within particular campaigns, but their overarching challenge is in maintaining their viability over the longterm through finding an effective way of working globally. Greenpeace and FoEI not only face strong opponents within specific confrontations and specific campaigns, but also challenge actors pursuing a transnational agenda which they deem to be ecologically and socially detrimental. FoEI and Greenpeace express deep concern about powerful actors, such as nation-state governments, corporations and international organizations, whose interest lie in furthering the status quo model of global development aimed at unfettered economic expansion despite environmental and social consequences. In response, Greenpeace and FoEI have evolved into transnational organizations aimed at confronting these powerful actors repeatedly and promoting an alternative of a sustainable and peaceful future.

My argument can be characterized as follows: if ultimately the long term strategic mission of FoEI and Greenpeace is to shift the international political agenda and the behavior of governments, international organizations and corporations that operate transnationally, then the clearest indication of their capacity for tactical innovation within this context would be their ability to formulate a strategic approach to working globally in order to create a paradigm shift at the transnational level. For the analysis below, I adopt the definition of Clark (2003a: 111) that "working globally" for TSMOs implies "developing North-South links and international campaign strategies; speaking with a single, loud, global voice - albeit with national variations in how they work and what they work on." Clark (2003a: 110) argues that TSMOs with decentralized and informal structures have "clear advantages of adaptability" which help them with the challenge of working globally. In contrast, I illustrate how both FoEI and 
Greenpeace - despite the latter's relatively more centralized and formalized structure have developed effective approaches to working globally, while indicating the difficulties both have faced in developing this approach. I assume that both TSMOs are effective in working globally and aim to examine how this is expressed empirically.

In order to make this argument, I divide Clark's definition into four key components for working globally:

- North-South links,

- International campaigns,

- One, single, loud global voice, and

- National variation in how they work and what they work on.

In my analysis of the historical evolution of Greenpeace and FoEI, I discovered that these TSMOs have developed their approach to working globally in distinct ways. Figure 5.1 displays these two trajectories according to the four components outlined above.

Figure 5.1 Historical Evolution of Working Globally in FoEI and Greenpeace Decade FoEI Greenpeace

1970 s

1980s

1990s

2000s

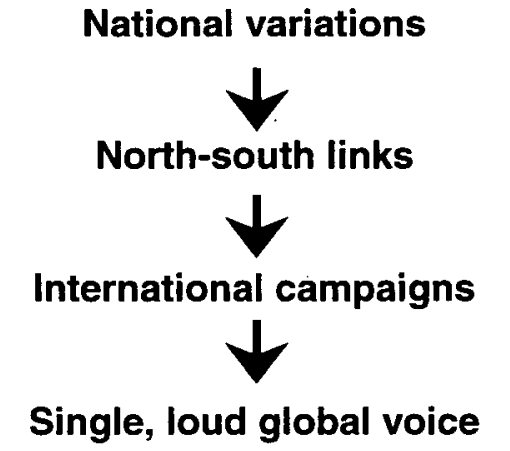

International campaigns

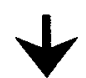

Single, loud global voice

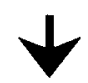

National variations

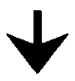

North-south links

Briefly, I argue that Friends of the Earth International was founded as a loose collection of national environmental groups. The inclusion of Southern member groups into FoEI led to the introduction of a Southern perspective on environmental issues, and a transition towards greater international collaboration and international campaigns. Over the past decade, FoEI national member groups have embarked on a strategic planning process to develop an international agenda as well as set out an umbrella strategy to inform their 
local, national campaigns and international campaigns, and to present a more cohesive transnational position.

In contrast, Greenpeace evolved out of a series of international campaigns, and, within the first decade, developed into a relatively centralized global campaigning organization with a recognizable name, position and signature tactics. As Greenpeace expanded to new countries, its tactical approach and name recognition was fine-tuned to new national contexts, particularly in the unique context of Southern countries; however, Greenpeace predominately maintains its overarching style, tactical approach and issue focus. In Chapters Six and Seven, I examine this historical trajectory in detail, accompanied by clear references and empirical evidence.

In the remainder of this chapter, I provide a slightly longer overview of the evolution of FoEI and Greenpeace's approach to working globally that builds on the description in this paragraph and is based on the detailed histories and full scholarly and empirical data references in Chapters Six and Seven. I then present my comparative analysis that contrasts FoEI and Greenpeace's distinct and viable approaches to tactical innovation at the level of working globally. This discussion provides an analytical lens for the upcoming chapters.

\subsubsection{Historical Overview of FoEI}

Friends of the Earth International is first and foremost a federation of national environmental groups collaborating to have an international impact. This is apparent in FoEI annual reports that describe both activities at the international level and active campaigns at the local and national level. As Chapter Six will explore in more detail, FoEI has undergone a historical evolution towards greater international coordination over its three decades of existence. Table 5.2 presents some of the key events in this trajectory. 
Table 5.2 Key Events in FoEI Evolution towards Working Globally

\begin{tabular}{|c|l|}
\hline Date & Event \\
\hline 1971 & Friends of the Earth International established \\
\hline 1981 & International Secretariat established \\
\hline 1986 & First Annual General Meeting in a developing country - Malaysia \\
\hline 1994 & International Agenda adopted at AGM - Ecological Debt campaign \\
\hline $2005-2006$ & Strategic Planning Process \\
\hline
\end{tabular}

At the first FoEI meeting in 1971, national groups from the United States and Europe gathered to share information and exchange tactical ideas, but not to work together on international campaigns. "Think globally, act locally" was a constant motto in the first decade of FoEI, during which member groups repeatedly decided against any outright international coordination but did instigate a quarterly magazine to continue information sharing between meetings. International collaboration on any issue or campaign was driven by the personal and informal efforts of individuals in FoEI. Over this time, national groups experimented with a vast and varied array of tactics across diverse environmental campaigns including against nuclear power, wilderness destruction, and species extinction. As meetings amongst national groups continued in the late $1970 \mathrm{~s}$, the agenda for discussion at these meetings began to cover environmental problems with transnational implications, such as rainforest destruction and air pollution.

In the early 1980s, the upsurge of right-wing politics in the USA and United Kingdom under the conservative governments of Ronald Reagan and Margaret Thatcher led FoE member groups in those countries to seek support and strength through the FoEI network. In 1981, FoEI established an International Secretariat to support coordination amongst national groups; however, the secretariat remained a small part-time staff of one to four people with an irregular funding base and changing location throughout the 1980s. The strength of FoEI continued to lie with the activities of national groups within local and national contexts. FoEI expanded its national group membership from 24 groups in 1980 to 44 groups in 1990 . The new members were predominately environmental groups which existed before their membership in FoEI and had gained a reputation for effectiveness within their own country. Sahabat Alam Malaysia (SAM - FoE Malaysia) was accepted into FoEI in 1985 and catalyzed a shift in FoEI during the Annual General 
Meeting held in Malaysia in 1986. For SAM, national environmental problems were inherently international and required purposeful international cooperation for their resolution. For example, the destruction of rainforests in Malaysia could not be halted without placing pressuring on foreign-owned multinational corporations and western governments who controlled loan allocation and development projects through international financial institutions. Subsequent to this 1986 meeting, FoEI further developed its nascent international campaign areas to reflect the needs of developing countries, and adapted its mission and vision statements to incorporate a greater emphasis on social justice and equity.

The United Nations Conference on Environment and Development (UNCED) in Rio de Janeiro in 1992 marked the growing recognition of environmental issues as intertwined with social and economic imperatives. In a follow-up to UNCED, FoEI member groups expanded their collaborative efforts. They ran parallel national sustainability assessments under the Sustainable Societies Program and developed a cross-cutting agenda of supporting human rights and the protection of biological as well as cultural diversity. FoEI instigated international campaigns in areas such as trade, mining, and protecting the ozone, and they targeted transnational bodies such as international financial institutions and multinational corporations. By 1994, FoE member groups agreed to develop a common international agenda to establish some links amongst the hundreds of initiatives at the grassroots, local, national, regional and international levels. The International Secretariat gained in staff members and capacity, while remaining in a coordinating role in support of the decentralized and informal decision-making process amongst FoEI member groups. Campaign coordinators began to meet to discuss common positions and an International Campaigns Officer was appointed to support collaboration and coherence amongst campaigns.

In 2004, FoE member groups decided to embark on FoEI's first strategic planning exercise to define a set of common values, mission, vision and campaign strategies for FoEI and to outline a roadmap for implementing the strategic plan. It is important to note that FoEI remains committed to an umbrella strategy that identifies common positions 
and supports cohesive campaign work amongst autonomous national groups. As predicted in an earlier FoEI discussion paper, FoEI national member groups, in addition to 'thinking globally and acting locally', now have greater opportunities to 'think at all levels and act at all levels,' although the focus within FoEI remains on furthering grassroots, local and national campaigns. ${ }^{104}$ In 2005 and 2006, FoEI evolved an approach to working globally in order to develop a coherent critique of social and environmentally destructive globalization and to create a common position on sustainable solutions. This has resulted in greater international collaboration, while maintaining FoEI's focus on furthering grassroots, local and national sustainability.

\subsubsection{Historical Overview of Greenpeace}

Greenpeace's reputation as a key player in the international environmental movement is largely based on its unique tactical approach of nonviolent creative direct actions against target "environmental criminals," with images of the confrontations disseminated through the mass media. Each Greenpeace campaign has both a practical concrete purpose of pressuring change in the behavior of the target opponent and a broader purpose of encouraging activism and catalyzing change in public conscience on environmental issues. Greenpeace has evolved its approach to working globally over time, while retaining its core competence in tactical innovation. Table 5.3 presents a number of key events in the evolution of Greenpeace.

\section{Table 5.3 Key Events in Greenpeace Evolution towards Working Globally}

\begin{tabular}{|l|l|}
\hline Date & Event \\
\hline 1971 & Protest voyage against US nuclear tests, Amchitka, Alaska \\
\hline 1979 & Greenpeace International established \\
\hline 1985 & The bombing of the Rainbow Warrior \\
\hline 1995 & Brent Spar campaign \\
\hline 1999 & One Greenpeace \\
\hline
\end{tabular}

Greenpeace's first campaign, the 1971 protest voyage against US nuclear testing in Alaska, contained all the elements that would become characteristic of Greenpeace's

${ }^{104}$ Executive Committee (1994) Discussion Paper about the Need for an International Agenda for FoEI. FoEI, Amsterdam, The Netherlands, 10 August. 
tactical approach. It was an international campaign because of the global scope and consequences of the problem (nuclear testing) and the Canadian origins of Greenpeace.

The campaign involved genuine acts of resistance by Greenpeace activists and nonviolent direct action tactics, in this case, sailing a boat within the legal boundary of the nuclear test site. It drew on the power of the mass media in communicating the campaign to a wider public in the hopes of triggering a widespread public outcry. The campaign was supported by technical information and scientific research about possible impacts of the nuclear blast, reinforced by diplomatic lobbying at the US Atomic Energy Commission. These four components - an international campaign, nonviolent direct action, mass media communication, and support from diplomatic lobbying and research - have remained at the core of Greenpeace activities throughout its three decades of existence. The Greenpeace formula is also apparent in its second campaign, which focused on the protection of whales. The name 'Greenpeace' still evokes the image of Greenpeace activists in inflatable boats shielding whales from the harpoons of the whaling fleets. It was the powerful message that these direct actions transmitted and the relative success of the early campaigns that led to a spontaneous emergence of Greenpeace groups throughout the industrialized world in the mid-1970s.

In 1979, these offices were consolidated as one global campaigning organization, first housed in Washington DC and latèr in Amsterdam, directed by a representative council, the Stichting Greenpeace Council, and a new international secretariat, Greenpeace International. Under this new structural arrangement, national offices continued to use the Greenpeace tactical approach within agreed international issue areas and adapted direct action to new campaigns against toxic waste dumping at sea, nuclear power, industrial pollutants and drift-net fishing, and for the protection of Antarctica from development.

Greenpeace's visibility in taking action against environmental abuse by governments and corporations led to an increase in financial support through membership dues. This enabled Greenpeace to build its capacity for direct action through the purchase of ships, inflatable boats, and a hot air balloon. Greenpeace membership surged as a result of 
public outcry from the 1985 bombing of its ship, the Rainbow Warrior, in a New Zealand harbor by French secret service agents. The organizational growth resulting from this financial support enabled Greenpeace to expand its operations into new areas (such as climate change) and to new regions (including Latin America), to increase the sophistication of its direct actions, and to establish a communications office and science unit. The expansion into new issue areas and countries has led to further modification and elaboration of Greenpeace's tactical approach in new settings. At the same time, it has led to a stronger commitment to the tactic of engaging in creative confrontations on environmental issues. Greenpeace's ability to focus attention through direct action and communications. media was again reinforced in its highly reported and visible campaign against the sea disposal of the Brent Spar oil platform in 1995.

Since its first campaign, Greenpeace has engaged in strategic planning to find effective ways of working globally. The tactical approach I describe above has been repeated in strategic documents throughout Greenpeace's 35 years of existence as being the Greenpeace 'formula.' 105 In order for this tactical approach to work, internal strategic documents emphasize the need for Greenpeace to focus on a small number of large-scale confrontations which focus organizational resources on a few targeted campaigns that achieve specific objectives and capture the imagination of the public. According to Greenpeace campaigners, Greenpeace's strength lies in delivering a number of quality direct actions, supported by research and diplomatic work. Strategic discussions have recently led to an internal dialogue - called the "blue skies" debate - in which Greenpeace campaigners explored how best to organize Greenpeace to deliver a few quality international campaigns. The conclusion of that discussion was the need to build 'One Greenpeace' that consolidates all Greenpeace activists and offices towards a shared vision, shared resources and shared responsibility to create a global campaigning

\footnotetext{
${ }^{105}$ e.g., Bode, T. (1997) Greenpeace International Long Term Strategic Plan. Greenpeace International, Amsterdam, The Netherlands, September; Durrant, C. (1999) One Greenpeace. Discussion paper submitted to the Board and the 1999 Stichting Greenpeace Council Annual General Meeting.
} 
organization that can effectively confront transnational actors, inspire public imagination, and respond quickly to world events. ${ }^{106}$

\subsubsection{North-South Links and International Campaign Strategies}

According to Clark (2003a: 111), the ability of transnational social movement organizations to work globally is defined by their capacity to develop linkages between the global North and South and to devise international campaign strategies. Clark assumes that this capacity is maximized within TSMOs which adopt a decentralized and informal organizational structure, such as FoEI. I take issue with this assumption. I have found that both FoEI and Greenpeace have developed North-South links and international campaign strategies, but in distinct, equally viable ways. In order to explore these distinctions, I review four dimensions: the character of FoEI and Greenpeace's international campaigns, their relative focus on ecological or social sustainability; their response to the growing complexity of global issues; and the evidence they provide in making their campaign claims. Table 5.4 summarizes the conclusions of my comparative analysis.

Table 5.4 Comparison between FoEI and Greenpeace on international campaigns and North-South linkages

\begin{tabular}{r|c|c} 
Dimension & FoEI & Greenpeace \\
\hline $\begin{array}{r}\text { International } \\
\text { campaigns }\end{array}$ & $\begin{array}{c}\text { Southern perspective } \\
\text { transferred to the North }\end{array}$ & $\begin{array}{c}\text { Northern tactical approach } \\
\text { transferred to the South }\end{array}$ \\
\hline $\begin{array}{r}\text { Ecological vs. Social } \\
\text { sustainability }\end{array}$ & $\begin{array}{c}\text { Social justice } \\
\text { with environmental issues }\end{array}$ & $\begin{array}{c}\text { Environmental issues } \\
\text { with social justice }\end{array}$ \\
\hline Complexity & $\begin{array}{c}\text { Decentralized approach } \\
\text { to complex issues }\end{array}$ & $\begin{array}{c}\text { Simple communicable message' } \\
\text { approach to complex issues }\end{array}$ \\
\hline Evidence & $\begin{array}{c}\text { Grassroots and } \\
\text { local community testimony }\end{array}$ & $\begin{array}{c}\text { Expeditions and scientific } \\
\text { analysis }\end{array}$ \\
\hline
\end{tabular}

FoEI and Greenpeace began their international campaigns on very similar issues but have since taken somewhat different paths in campaign focus and tactical approach. In the 1970s, FoEI and Greenpeace were both campaigning against the nuclear and whaling industries, although with different tactics. FoEI groups in the USA and Europe

${ }^{106}$ Lawrence, E., C. Rose, K. Rigg (1999) Some thoughts on what has come to be called 'Blue Skies' submitted to the 1999 Executive Directors Meeting as a discussion document, 29 July. 
predominately focused their campaigns at the national level, whereas Greenpeace drew on the power of the mass media to launch international level confrontations. As I mention above, the initial impetus to move towards truly international campaigns within FoEI came as a result of FoEI's engagement of national groups from Eastern and Southern developing countries. These new groups called for a more formalized approach to international collaboration in order to tackle the international level causes of national environmental and social degradation. Consider this quotation from Meena Raman, FoEI Chair from Sahabat Alam Malaysia (SAM - FoE Malaysia) who notes,

SAM had always had an international perspective on issues. When we look at the environmental problem, we are development oriented and we realize that in Malaysia we are a subset of what is happening in the rest of the world. The economic model that is pursued in Malaysia stems from the same development model in the north and so we have always had an international perspective. We work with allies in the north to change power relations and influence agencies that shape policies at the international level. For example, when we are working on the issue of logging companies in the tropics and tropical hardwood, we have worked together with allies to halt the destruction and fight for native land rights. The government grants concessions to the companies and are feeding a design that caters to the timber trade. The EU and Japan are involved as the consumers of the tropical hard wood. Unless we address the trading system, we will not make any headway on these campaigns. To take another example of the expansion of hydropower in Malaysia, this is being supported by an international organization, the World Bank, and rooted in institutions and policies that are run in the North. The campaigns we run require a fundamental re-dress of the policies that are being made around the world. In this, Friends of the Earth is an important ally. ${ }^{107}$

As the quotation suggests, SAM is focused on national-level campaigns but requires international cooperation and international-level campaigning to resolve local and national problems. As stated in one FoEI official document, "FoE groups will work on the local and national levels, while coordinating activities on the broader regional and international level for maximum impact." 108 This cooperation across borders is aimed at achieving FoEI's broader agenda: "challenging governments and policy makers worldwide to adopt policies that contribute to sustainable societies and encourage local

${ }^{107}$ Interview with Meena Raman, FoEI Chair, February 2006.

${ }^{108}$ Navarro, R. (2001) "Introduction: resisting the big, celebrating the small" in FoEI Sparks of Hope, Fires of Resistance: FoEI Celebrates the Sustainable Path Forward: $30^{\text {th }}$ Anniversary Publication. FoEI, Amsterdam, The Netherlands, p.2. 
community initiatives." 109 As FoEI evolved to increasingly focus on local livelihoods and community level solutions, FoEI campaigners began to shape their international campaigns to incorporate issues of social justice, empowerment, land rights, cultural diversity, and equity. FoE member groups work alongside grassroots and indigenous peoples and local communities all over the world, confronting powerful actors operating on short-term economic imperatives. These local struggles are equally evident in Northern FoEI countries, such as Scotland and the USA, where local, often marginalized, communities face environmentally and socially destructive developments which require similar grassroots campaigns as communities in developing countries. Because of this, FoEI campaigners increasingly emphasized the social side of sustainability as critical to protecting ecosystems and local livelihoods.

In contrast, the founders of Greenpeace embarked on international campaigns that focused on defining their personal "political relationship with the planet" through nonviolent direct action, on stimulating activism and "practical, intelligent actions to stem the tide of planetary destruction," and on bringing about "a mass change in consciousness" regarding the human relationship with the environment through the mass media. ${ }^{110}$ A critical component of Greenpeace's identity is its action-oriented approach. Greenpeace campaigners take themselves to the point of confrontation - where environmental threats are evident - and bear witness to ecological abuse and undertake acts of resistance to physically stop destructive behavior. Although the first Greenpeace campaigns were undertaken by Northern activists, the inspiration for this tactical approach came from both Northern movements (e.g., the Quakers' tradition of bearing witness, the Provos in Amsterdam, and Saul Alinsky's suggested rules for radical movements in the US) and from Southern social movements (e.g., Gandhi's nonviolent protest as an act of resistance and symbolic tool for communication). ${ }^{111}$ Throughout its

${ }^{109}$ Navarro, R. (2001) "Introduction: resisting the big, celebrating the small" in FoEI Sparks of Hope, Fires of Resistance: FoEI Celebrates the Sustainable Path Forward: $30^{\text {th }}$ Anniversary Publication. FoEI, Amsterdam, The Netherlands, p.2.

${ }^{110}$ Sturmanis and Sturmanis 1978: 51.

${ }^{111}$ Weyler 2004; Zelko 2004; Interview with Rex Weyler, Greenpeace campaigner (1972 - 2006), Author of Greenpeace: How a Group of Ecologists, Journalists and Visionaries Changed the World (2004), November 2004. 
global expansion, "the Greenpeace strategy for campaigning through the media was a golden, inspired notion that would need little fine-tuning as it left Canada" as "the name itself - with that swashbuckling spirit now embedded within it - had become a precious commodity." 112 Early global expansion of Greenpeace was focused on western industrialized countries; however, in the late 1980s and early 1990s, Greenpeace expanded to Latin America, Japan and Eastern Europe and, in the late 1990s, Greenpeace has opened offices in China; India and a regional office in South East Asia. Nonviolent direct action tactics are adapted to these new national contexts, and Greenpeace remains focused on its original issue areas. As one Greenpeace campaigner notes,

At the moment we are strong in South East Asia. Over the last five years, we have established offices there... The environmental problems there are huge and the related development issues are immensely delicate and complex. The environment and development issues all come together in those countries and in the idea of sustainable development: Greenpeace focuses on translating its areas of expertise (campaigns on environmental, energy and disarmament issues) to the local situation, and searches for socially equitable solutions. Campaign focuses in new offices depend on the individual office's capacity and what Greenpeace's internationally agreed main priority is locally. ${ }^{113}$

Unlike FoEI, Greenpeace has not shifted towards a social sustainability agenda with its expansion into Southern and Eastern countries but remained focused on ecological sustainability. Greenpeace certainly incorporates social justice issues into its campaigns; for example, Greenpeace highlights the impact of environmental destruction on local communities and their livelihoods and emphasizes the health effects of toxins on communities exposed to industrial chemicals. Greenpeace also lends its political clout and advises local communities engaged in their own confrontations with powerful governmental and corporate actors (Sachs 1995: 14); however, even in these cases, Greenpeace advises on areas of its expertise - energy, environmental issues, disarmament. Although Greenpeace's tactical approach and issue focus can be said to have originated in the North, nonviolent direct action have a history in many of these countries, such as India, and environmental issues are equally a concern to Greenpeace

\footnotetext{
${ }^{112}$ Dale 1996: 105

${ }^{113}$ Interview with Josselien Janssens, Campaign Direction Officer, Greenpeace International, September 2002.
} 
campaigners in developing countries. In establishing a new office, Greenpeace connects with local activists in order to build a staff with experience in campaigning on environmental issues within the specific national or regional context. ${ }^{114}$

Greenpeace's international campaigns are selected to advance ecological sustainability. Greenpeace highlights threats to ecosystem and human health from toxins, nuclear waste, genetically modified organisms, climate change and industrial effluent, and threats to species extinction, such as whale and seal hunts and overfishing. Greenpeace also strives to provide a voice for the global commons through campaigns to protect Antarctica, the Amazon rainforest, and the oceans and climate for future generations. Greenpeace is a transnational environmental organization and remains focused on environmental threats. Table 5.5 presents a comparison between the international campaigns of FoEI and Greenpeace, and indicates their overlapping and distinctive campaign areas.

Table 5.5 Comparison between FoEI and Greenpeace's Similar and Distinct International Campaign Areas ${ }^{115}$

\begin{tabular}{|c|c|}
\hline Friends of the Earth International & Greenpeace \\
\hline \multicolumn{2}{|c|}{ Similar International Campaigns } \\
\hline $\begin{array}{l}\text { - } \text { Climate change } \\
\text { - } \text { Genetically-modified organisms } \\
\text { - } \text { Trade } \\
\text { - Maritime } \\
\text { - Core theme: biodiversity } \\
\text { - Corporate accountability } \\
\end{array}$ & $\begin{array}{l}\text { - Stop climate change } \\
\text { - Say no to genetic engineering } \\
\text { - } \text { Protect our ancient forests } \\
\text { - Encourage sustainable trade } \\
\text { - Save our oceans } \\
\text { - } \text { Focuses on threats to planet's biodiversity } \\
\end{array}$ \\
\hline \multicolumn{2}{|c|}{ Distinctive International Campaigns } \\
\hline $\begin{array}{l}\text { - International financial institutions } \\
\text { - } \text { Mining } \\
\text { - Human and environmental rights } \\
\text { - Ecological debt }\end{array}$ & $\begin{array}{l}\text { - Demand peace and disarmament } \\
\text { - Eliminate toxic chemicals } \\
\text { - End the nuclear age }\end{array}$ \\
\hline
\end{tabular}

The comparison between the social sustainability focus of FoEI and the ecological sustainability focus of Greenpeace is clearly apparent in the campaigns which are unique to each organization. As FoEI member groups began raising their sights to the regional

\footnotetext{
${ }^{114}$ Interview with T. Mohan, Board, Greenpeace India, September 2002.

${ }^{115}$ FoEI (2005) Annual Report, FoEI, Amsterdam, The Netherlands; Greenpeace (2005) Annual Report, Greenpeace International, Amsterdam, The Netherlands.
} 
and international level to find the root causes and possible solutions to local and national problems, FoEI began to campaign to change the functioning and role of international financial institutions (IFIs) in economic globalization and the projects they finance. For example, FoEI is calling for the IFIs to completely phase-out public financing of destructive oil, mining and gas projects. ${ }^{116}$ With the mining campaign, FoEI collaborates with 65 organizations around the world to address the impact of mining on local communities, and to demand open democratic decision-making between mining corporations and local communities that results in the recognition of their community rights. Increasingly, FoEI is campaigning on both environmental and human rights with the aim that FoEI "will work to protect environment and people alike against the aggressions of neoliberal economic globalization." "17 One of the most radical expressions of this combined approach of social justice and the environment is FoEl's campaign on Ecological Debt,

FoEI is campaigning for the negotiation and payment of ecological debt, the result of decades of resource exploitation by the North in impoverished southern countries. This would include the reparation of environmental devastation caused by natural resource extraction and other unsustainable activities, the repatriation of cultural and natural heritage, and compensation for damage related to climate change caused by northern dependency on fossil fuels. ${ }^{118}$

The concept of Ecological Debt has since been adopted by other nonprofit organizations and was a central lobbying demand for FoEI member groups at the UN World Summit on Sustainable Development.

In comparison, Greenpeace's distinctive international campaigns focus on the ecological and human health effects of toxins and nuclear waste. The toxics campaign is aimed at maintaining pressure on governments to stop the industrial manufacturing and release of hazardous chemical compounds into the environment, including halting the development of waste incineration plants. In addition, the toxics campaigners aim to rid households of

\footnotetext{
${ }^{116}$ FoEI (2001) Annual Report, FoEI, Amsterdam, The Netherlands, p. 11.

${ }^{117}$.FoEI (2004) Our Environment, Our Rights: standing up for people and the planet. FoEI, Amsterdam, The Netherlands, p. 4.

${ }^{118}$ FoEI (2002) Annual Report, FoEI, Amsterdam, The Netherlands, p. 11.
} 
toxins used in household products and, therefore, pressure industry to devise nonhazardous alternatives. Greenpeace campaigners play a watchdog role in ensuring that industrialized countries are not shipping their hazardous wastes to developing countries, and that high environmental standards are set in terms of working conditions for hazardous waste disposal globally. On nuclear power, Greenpeace campaigns globally against the development of nuclear power from its position that "in the absence of a viable solution to nuclear waste disposal, the nuclear industry cannot be defended."119 Greenpeace has also engaged in a long-term campaign for nuclear disarmament and continues to disrupt nuclear testing sites all around the world pressuring governments such as the USA, France, and China to halt nuclear testing. In each of these campaigns, Greenpeace highlights both the ecosystem and human health costs associated with toxic and nuclear pollutants; however, for the most part, Greenpeace does not become directly involved in community level campaigns other than lending expertise and clout. Exceptions include the Greenpeace campaign in support of the victims of the chemical accident in Bhòpal, India. ${ }^{120}$

The top half of Table 5.5 is the same as Table 1.4, which I employed to emphasize the comparability between Greenpeace and FoEI. It is true that FoEI and Greenpeace focus on a number of the same campaigns and form partnerships in a number of contexts, such as to lobby governments at the UN Convention on Climate Change intergovernmental meetings (Arts et al. 2001) and at the UN Convention on Biological Diversity (Purdue 2000). Their collaborative work on climate change has resulted in a recent joint tactical innovation. FoEI and Greenpeace campaigners are partnering with other NGOs and US

- states in launching legal challenges against the United States government and export credit bodies for not taking climate change into account when financially supporting fossil fuel projects. This campaign is referred to as the Climate Justice Program, launched in 2003, which engages dozens of organizations and lawyers in filing lawsuits on behalf of communities affected by climate change, particularly in developing

${ }^{119}$ Greenpeace (2001) Annual Report. Greenpeace International, Amsterdam, The Netherlands, p. 5. ${ }^{120}$ Greenpeace (2002) Annual Report. Greenpeace International, Amsterdam, The Netherlands, p. 14-15. 
countries. ${ }^{121}$ The concept of "climate law enforcement" stems from the belief that "as long as politicians and industry refuse to make the big cuts in emissions that are needed, and to compensate those facing damages, the judges will be asked to sort it out."122

Even in FoEI and Greenpeace's overlapping international campaign areas, there are notable differences in approach. For example, in the forests and biodiversity campaigns, FoEI member groups align with local communities and indigenous peoples to secure their land ownership and rights through demonstrations, blockades, lobbying and education campaigns. FoEI's International Secretariat raises funds to directly support local communities in their struggle to protect forests and biodiversity essential to their livelihoods. FoEI campaigning at the intergovernmental level includes fighting for the inclusion of human rights in international environmental conventions. For instance, FoEI campaigners "fought successfully for the recognition of indigenous peoples' rights when protected areas are established, as well as indigenous rights in legal instruments dealing with biopiracy, the threat of genetic resources and traditional knowledge." ${ }^{123}$. In contrast, Greenpeace engages in strategic confrontations and unanticipated monitoring expeditions to draw attention to threats to forests and biodiversity. In Brazil, Greenpeace campaigners used "two helicopters, two light aircraft and five trucks" to conduct "a raid which recovered over $7000 \mathrm{~m}^{3}$ of illegally cut mahogany." 124 Other Greenpeace forests and biodiversity campaigns utilize Greenpeace ships, helicopters, motorbikes, inflatable boats, hot air balloon, and willing direct action volunteers and campaigners to unexpectedly disrupt industrial operations and illegal activity. These actions not only take place at the site of environmental destruction but also in, for instance, the harbors of countries receiving the products of resource extraction. Greenpeace aims to create a confrontation in order to force a solution. As Ann Doherty, FoEI's International Communications Coordinator notes,

Greenpeace has the money to have boats and do a lot more attractive and sexier actions than we do but we get out in the streets and shout loud... we're grassroots

\footnotetext{
${ }^{121} \mathrm{http} / /$ www.foei.org/publications/link/rights/52.html

${ }^{122} \mathrm{http} / /$ greenpeace.org/international/press/releases/bring-on-the-judges\#

${ }^{123}$ FoEI (2004) Annual Report. FoEI, Amsterdam, The Netherlands, p. 8.

${ }^{124}$ Greenpeace (2002) Annual Report. Greenpeace International, Amsterdam, The Netherlands, p. 17.
} 
based and so mobilize people better and they are better at organizing stunts. ${ }^{125}$

Greenpeace's capacity to organize "creative confrontations" that aims to capture the public's imagination is directly related to its relatively more centralized and formalized structure, as one past FoEI Chair notes,

When you compare the decentralized, informal structure with the structures adopted by World Wide Fund for Nature, Greenpeace and so on, they have the possibility to act in a very concentrated manner.... Typically our groups can't organize concentrated actions in terms of expeditions on ships or that kind of thing. Instead, we are built on active local groups who work on local issues. .... Friends of the Earth is especially notable in our ability to tackle complicated issues. ${ }^{126}$

The international campaigns mobilized by FoEI member groups evolve out of the discussions held at the annual general meetings, at campaign meetings and in on-line exchanges. Ultimately, FoEI international campaigns are aimed at resolving local and national conflicts. As a result, these campaigns highlight the complex intersections amongst social justice, environmental, economic, political, and cultural issues across scales. Greenpeace campaigners also understand and analyze the complexity of global environmental problems, but the focus of Greenpeace on global level campaigning has required a degree of categorization, as one Greenpeace campaigner notes,

For practical and organizational reasons we have to divide the world up into chunks in order to address specific issues, and we've experimented with many ways of doing that. At the moment we have forests, oceans, climate, nukes, disarmament, GMOs, and toxics and those identify the main strands of issues that we work on. At any given moment, you come up against something that will cross a variety of those issues. Just because we have taken the world and divided it up this way, it doesn't mean that the world responds. So, often we put together groups of people in teams to cover what we call 'cross-sectoral issues' like governance issues or trade issues. ${ }^{127}$

By developing cross-sectoral teams within Greenpeace, campaigners are able to respond to the complex intersections amongst issue areas; however, Greenpeace is still faced with the problem that media, such as television, is not particularly well suited to

${ }^{125}$ Interview with Ann Doherty, FoEI Communications Coordinator, July 2005.

${ }^{126}$ Interview with John Hontelez, FoEI Chair 1986-1996, May 2006.

${ }^{127}$ Interview with Steve Sawyer, Climate and Energy Policy Advisor, Greenpeace International; Past Executive Director of Greenpeace USA (1986-88); Past Executive Director of Greenpeace International (1988-1993), October 2004. 
communicating complex ideas (Dale 1996). The nonviolent direct action tactics employed by Greenpeace are best suited to situations where there is a target enemy and a clear point of confrontation, and the challenge for Greenpeace is to make complex issues comprehensible and visually arresting, as one past Greenpeace campaigners affirms,

Greenpeace is a communications organization. The strength of Greenpeace in the early years, we could create images that traveled on the media - the delivery. systems as we called it - and these images would carry the message and we could change consciousness on these issues on a mass scale.... [Greenpeace's aim is to] create the image that is going to completely throw the issue into a new realm in a way that your opposition can't deal with.... Climate change is hard [to communicate]. Genetic engineering is hard but nobody cares that it's hard.... You still have to figure out a way to communicate.... [It's] not that things aren't complex - they are complex - but if Greenpeace is going to comment on something, their comment has to be clear. ${ }^{128}$

In the case of the campaign against GMOs, Greenpeace has not had much success in finding vibrant images of GMO impacts and has focused on street theatre in front of biotech companies and on tracking GMO products globally. Within the climate change campaign, Greenpeace has found more striking images by documenting the retreat of glaciers around the world and the impact of global temperature rise on the Arctic and Antarctic. In the Arctic North, in addition to monitoring ecosystem change, Greenpeace records the accounts of the Inuit people and documents their evidence of climate change impacts. This is not the only time that Greenpeace has included local witness accounts of environmental damage. At the World Trade Organization meeting in Doha, Qatar in 2001, the Greenpeace ship had on board "“witnesses' from communities around the world, people whose traditional livelihoods are threatened by trade liberalization: a farmer who fights against transgenic crops in the USA, a fisherman from India, a Lebanese campaigner against toxic waste dumping and an environmentalist and human rights activist from Chad."129 Although sometimes Greenpeace employs the testimony of local witnesses, Greenpeace campaigners predominately draw on evidence from the

${ }^{128}$ Interview with Rex Weyler, Greenpeace campaigner (1972 - 2006), Author of Greenpeace: How a Group of Ecologists, Journalists and Visionaries Changed the World (2004), November 2004.

${ }^{129}$ Greenpeace (2002) Annual Report. Greenpeace International, Amsterdam, The Netherlands, p. 19. 
monitoring conducted by Greenpeace activists on expeditions to assess corporate adherence to national and international law (e.g., on driftnet fishing or whaling) and the scientific analyzes these campaigners conduct (e.g., in water and air quality). In contrast, FoEI predominately draws on the direct accounts of local FoEI campaigners, which reveal "the accumulated massive evidence that corporate-led economic globalization exerts enormous costs on societies and the environment."130 Like the Greenpeace activists engaged in expeditions and direct actions on the ground, FoEI campaigners working at the grassroots and local level are able to monitor the implementation of international commitments by governments and corporations and campaign to hold these powerful actors accountable for their activities.

The distinctions between Greenpeace and FoEI outlined above are directly tied to their structural configurations. As a decentralized and informal organization, FoEI was open to a bottom-up transformation towards a greater degree of international collaboration and towards a shift in focus of international campaigns to social sustainability. For FoEI, international campaigns are deeply informed by and support the myriads of local and national campaigns undertaken by their members. In contrast, Greenpeace campaigners recognized the unique and powerful features of their tactical approach, and developed a structural configuration to support repeated delivery of nonviolent direct actions and to create an infrastructure of research, policy analysis, marine services, and communications to support these actions. A relatively more centralized and formal structure enables Greenpeace to deliver quality, unanticipated, often illegal and dangerous, and technical "creative confrontations" and to act quickly to respond to reports of ecological abuse. As will become apparent in the section below, FoEI and Greenpeace's structural response to the challenge of working globally is a strategic choice that is repeatedly reinforced because of its perceived effectiveness in advancing a sustainable and peaceful future.

${ }^{130}$ Navarro, R. (2001) "30 years is not enough!" in FoEI Annual Report. FoEI, Amsterdam, The Netherlands, p. 3. 


\subsubsection{Single, loud, global voice with National variation}

In addition to creating North-South links and international campaign strategies, the ability of transnational social movement organizations to work globally in an effective way is defined as the capacity to speak with "a single, loud, global voice - albeit with national variations in how they work and what they work on" (Clark 2003a: 111). I argue that this capacity is evident in both FoEI and Greenpeace in very different ways. Table 5.6 details the four dimensions that I analyze within this section: FoEI and Greenpeace's approach to national variation, the role of the international secretariat in each organization, the character of the international agenda or strategic plan in each TSMO, and their overarching structural configuration for working globally.

Table 5.6 Comparison between FoEI and Greenpeace on national variations and a single, loud, global voice

\begin{tabular}{r|c|c} 
Dimension & FoEI & Greenpeace \\
\hline National variation & $\begin{array}{c}\text { Local and national campaigns } \\
\text { with voluntary involvement in } \\
\text { international activities }\end{array}$ & $\begin{array}{c}\text { International priorities carried out } \\
\text { through national, regional, and } \\
\text { global campaigns }\end{array}$ \\
\hline $\begin{array}{r}\text { International agenda/ } \\
\text { strategic plan }\end{array}$ & $\begin{array}{c}\text { Coordinating and supporting } \\
\text { FoEI national member groups } \\
\text { subgroup autonomy in developing } \\
\text { tactics }\end{array}$ & $\begin{array}{c}\text { Strategic planning, direction and } \\
\text { coordination for the organization }\end{array}$ \\
\hline $\begin{array}{c}\text { Clearly defined, and } \\
\text { internationally established tactics } \\
\text { that are delivered through } \\
\text { national, regional, and campaign } \\
\text { offices and direct action } \\
\text { volunteers }\end{array}$ \\
\hline Structure for \\
working globally
\end{tabular}

The distinction between FoEI and Greenpeace is particularly evident in their different approaches to national offices (Wapner 1996: 123). Friends of the Earth International was established as a collection of autonomous national organizations. New FoEI member groups are previously formed national environmental groups who express interest or are solicited to join FoEI. FoEI accepts one member group per country and mandates that these national level groups participate in at least one international-level activity within FoEI. Greenpeace offices are established as part of an international campaign strategy with the intent of being present in areas "where the future of the environment is being 
determined." ${ }^{\prime 131}$ Although initially the expansion of Greenpeace offices into new countries was relatively ad hoc, since the late 1980s, Greenpeace has adopted a very strategic approach, as this quotation from a Greenpeace International campaigner reflects,

Greenpeace established offices in Latin America in the 1990s but also closed a few again because they were not able to be self-sufficient and it was decided that there may be more mileage in doing things regionally.... Before we decide to expand into a region, we make contact on the ground and ask people who have knowledge in their area about how to go about setting up the office. The demands are different in different regions. We try to do research to make political contacts and to get a real grasp of the picture on the ground - who is active, what is the political receptivity to our work, how do we start the office on the ground, should we work on this or this international campaign. Ultimately, the local priorities need to fit into international strategies and, in turn, those strategies need to fit into a global campaign priority. That is the criteria for setting up offices. Greenpeace's unique expertise in the world is that it is a fairly radical organization with a strong international outlook and we can put issues on the international agenda. There are a lot of nationally-focused organizations, like the Sierra Club in the US, but Greenpeace has a strong international focus and works to put issues on the international agenda. This is how we decide to start national and regional offices and stop non-self-sufficient offices - according to how the local presence furthers the international approach. ${ }^{132}$

The international campaign focus adopted by Greenpeace has led to a unique approach to its sub-global offices. Greenpeace has established both national and regional offices, and consolidated national offices in some regions, such as the Nordic region, into a regional body. Some of the national offices are designed to focus on national issues, such as the Chinese office, whereas others are campaign offices designed to carry out a particular part of a campaign, such as the Mediterranean office which coordinates the campaign on industrial pollutants in the Mediterranean Sea. FoEI also has regional structures; however, these serve to coordinate national member group activities and support the local and national FoEI member group campaigns. The national member group structure is central to FoEI's approach to working globally. In noting the different national positions that are brought to discussions at the international level, one FoEI campaigner describes

${ }^{131}$ Bode, T. (1999) Greenpeace Global Presence. Submitted to Executive Directors Meeting of Sept/October of 1999 by Greenpeace International for discussion.

${ }^{132}$ Interview with Josselien Janssens, Campaign Direction. Officer, Greenpeace International, September 2002. 
FoEI as "a mini UN."133 In contrast, one Greenpeace Executive Director emphasizes that "Greenpeace should become a perfect campaigning organization and not a United Nations for the environment." "134 This aim of global-level campaigning has led to a large role for Greenpeace's international secretariat, particularly in defining the strategic direction of Greenpeace. Since the initial expansion of Greenpeace offices outside of Canada were nationally-based, this expanded role for the international secretariat has not developed without conflict, as I will discuss in more detail in Section 8.4 on internal relations. As one Greenpeace campaigner notes,

There had always been this ongoing power struggle between national offices that wanted to see a loose-knit federation of Greenpeace offices and the Greenpeace International model...[which is] heavier on the hierarchical side of decisionmaking. ${ }^{135}$

Although this tension between decentralization and centralization remains to a certain extent, Greenpeace International has a central role in conducting and coordinating international campaigns, monitoring national and regional Greenpeace offices, representing Greenpeace worldwide, organizing fundraising, and organizing the overall strategic debate in Greenpeace. ${ }^{136}$ In contrast, Friends of the Earth International has a relatively small, although expanding, International Secretariat, whose primary function is to serve the needs of national FoEI member groups and to encourage participation at the international level. As the FoEI International Communications Coordinator notes,

This is our role here - it is to digest all the information and put it into more manageable packages.... FoEI member groups have their national work and they have lots to do there but we want them to stay involved in the international network and not just every two years at the AGM and not just in terms of one or two campaigns that they are working on but really in the general operation of the network. $^{137}$

${ }^{133}$ Interview with Beatrice Olivastri, co-founder and CEO, FoE Canada, September 2004.

${ }^{134}$ Bode, T. (1995) The Future of Greenpeace. Internal strategy document. Greenpeace International, Amsterdam, The Netherlands, p. 4.

${ }^{135}$ Interview with Brian Fitzgerald, New Media Director, Greenpeace International, October 2004.

${ }^{136}$ Greenpeace (1998) "Prioritizing the Core Functions of Greenpeace International" extracted from the 1998 Long Term Strategic Plan as agreed at the March 1998 Executive Directors Meeting and submitted by the Strategic Management Team to the Stichting Greenpeace Council Annual General Meeting and agreed by Council.

${ }^{137}$ Interview with Ann Doherty, Communications Coordinator, FoEI, September 2002. 
FoEI member groups have maintained a small International Secretariat because of their commitment to a decentralized and participatory structure; however, as the need for international-level campaigning became increasingly clear, FoEI member groups began to discuss a more cohesive international approach,

Friends of the Earth has a very small central administrative and policy core. The strength of FoE lies with its national groups. This is not how it is done in Greenpeace or World Wide Fund for Nature where these organizations have a strong central direction. This is not wanted and not possible for Friends of the Earth. We began to get to that point where we recognized that although Friends of the Earth adopts a different approach, that is no reason to be incoherent and not have clear outcomes to the discussion and carry the outcomes to effect. ${ }^{138}$

For FoEI, this recognition of the need for expanded international coordination resulted in a series of initiatives to jointly define an international agenda. The first initiative in this direction was a 1988 Executive Committee document requested by and submitted to the FoEI member groups at the Annual General Meetings (AGMs). ${ }^{139}$ This was subsequently followed by a discussion at the 1994 AGM which defined an international agenda for FoEI. ${ }^{140}$ In 2004, an extensive bottom-up strategic planning exercise was launched throughout FoEI, with the intention of developing an umbrella strategy that can support FoEI national and local campaigns. For FoEI, the goal of this structural configuration is not only to support the "global federation of national environmental organizations" but also to nurture the continued development of the "world's largest grassroots network" in order to become a force to be reckoned with at the transnational level. $^{141}$. In building a global grassroots movement, FoEI has forged alliances with other social movements and grassroots networks in order to collaborate and build on each other strengths. I will return to FoEI's alliance-building and partnership approach to external relations in Section 8.2. As one FoEI Chair states, "we find inspiration in the growing

\footnotetext{
${ }^{138}$ Interview with Kevin Dunion, FoEI Chair (1996-2003), Executive Director, FoE Scotland (1991-1996), November 2005.

${ }^{139}$ Executive Committee (1988) Annual General Meeting paper about the future of Friends of the Earth International. Amsterdam, The Netherlands, $25^{\text {th }}$ August.

${ }^{140}$ Executive Committee (1994) Discussion Paper about the Need for an International Agenda for FoEI. FoEI, Amsterdam, The Netherlands, 10 August.

${ }^{141}$ FoEI (2003) Annual Report. FoEI, Amsterdam, The Netherlands.
} 
wave of coordinated resistance to corporate-led globalization sweeping the planet."142 In one sense, FoEI is not a movement as such but an organization composed of one member group per country; however, FoEI can be seen as a "movement within the environmental movement" because of its bottom-up, grassroots approach to working globally (Suter 2002/2003: 69).

In contrast, the international approach adopted by Greenpeace is to develop a relatively more centralized and formal organizational structure, as is evident in the following quotation from an internal strategy document,

Greenpeace can only achieve its objectives if it fully utilizes its unique strengths which others do not have and overcome its endemic weaknesses. Our strengths are those qualities which make us distinct from other organizations, and those activities which Greenpeace does best. Greenpeace's unique position in the world is that we work as an international campaigning organization, planning and conducting global campaigns in a co-ordinated manner which could not be achieved by one single country or only a few... The external world has changed considerably... The trend towards a global world is putting demands on Greenpeace to act more effectively on a global scale. We can only achieve this, however, if we are a global campaigning organization and not a loose federation of National Offices. This goal requires that we perceive ourselves and act as one Greenpeace, which is not yet the case. Not acting as one organization is a waste of resources and creates missed opportunities. Our choice is clear: either we bind our strengths together into One Global Greenpeace, or we become irrelevant. ${ }^{143}$

As the quotation indicates, the strategic response which Greenpeace has developed to international sustainability challenges is to focus on becoming a global campaigning organization, and not to take the path of FoEI and form a federation of national organizations. In sum, the key distinction between FoEI and Greenpeace's approach to working globally is FoEI's focus on building a global grassroots movement and Greenpeace's focus on building a global campaigning organizations. The upcoming two chapters explore the evolution of these two organizations in detail in order to provide further empirical evidence of these different approaches to working globally. I will also

142 Navarro, R. (2002) "Ten Years down the Road" in FoEI Annual Report. FoEI, Amsterdam, The Netherlands.

${ }^{143}$ Bode, T. (1998) International Executive Director's Report to the Board, 1998: Review of 1995-1998 and the Challenges Ahead. Greenpeace International, Amsterdam, The Netherlands. 
note the work of other scholars who have come to similar conclusions about FoEI and Greenpeace (e.g., Pearce 1996; Wapner 1996; Warkentin 2001; Doherty 2002; Suter 2002/3). In Chapter Eight, I investigate the ways in which these different approaches to working globally have influenced the strategic responses which FoEI and Greenpeace have developed to managing external and internal relations and maintaining the viability of their organizations. 


\section{CHAPTER SIX: FoEI and Tactical Expansion}

\subsection{Introduction}

Friends of the Earth International has always been guided by the motto "think globally, act locally" as this transnational social movement organization (TSMO) is composed of national groups collaborating together at the international level to support local and national campaigns. ${ }^{144}$ FoEI has become an increasingly global network, as its membership has grown from an initial 6 groups from 6 industrialized countries to its current membership of 71 groups from 70 developed and developing countries. The name "Friends of the Earth International" can refer to the relatively small international secretariat operating out of Amsterdam in The Netherlands; however, I employ its broader definition and use FoEI to refer to the national group membership in its entirety.

In establishing FoEI as an international organization, David Brower recognized the value in sharing ideas and tactics across national borders in order to strengthen local and national campaigns. ${ }^{145}$ This remains a central purpose of FoEI today: to be a network of like-minded national groups that "inspire one another" and "harness, strengthen, and complement each other's capacities." 146 FoEI is an organization rather than a movement as FoEI member groups specify exclusive membership criteria which allow only one member per country, with the exception of Belgium which has two members representing distinct cultural groups. FoEI members have established a supporting infrastructure of staff, publications, offices and funding. Still, when FoEI member groups recently agreed on their vision of the FoEI network, they used the terms network and federation to describe FoEI in order to capture its decentralized and informal structure:

Friends of the Earth International is a worldwide grassroots environmental network campaigning for an ecologically sustainable, just and peaceful world. We are a vibrant, credible, effective federation, driving social transformation and securing sustainable, gender just and equitable societies. ${ }^{147}$

\footnotetext{
${ }^{144}$ Burke 1982; Interview with Tony Juniper, FoEI Vice-Chair (2000 - present); Executive Director, FoE EWNI, January 2006.

${ }^{145}$ Brower 1990

${ }^{146}$ FoEI (2005) Outcomes of the Penang Visioning Workshop, FoEI, Amsterdam, The Netherlands, October.

${ }^{147}$ Ibid.
} 
As the quotation above suggests, FoEI member groups choose to become part of the network because it provides opportunities for "campaigning for an ecologically sustainable, just and peaceful world." Joint campaigning was not always a part of FoEI: it began as a forum for sharing information. As will become evident below, this evolution towards a more structured form of international collaboration was driven in part by external events, and also by the demands made by new national member groups, particularly those from developing countries. Because of the decentralized and informal structure of the network, FoEI members were open to the influence of external change and the perspectives of new members, and allowed FoEI to evolve in order to reflect new external demands and to accommodate the experiences and needs of members from all corners of the globe.

Since FoEI is first and foremost a collection of national environmental organizations, I begin this chapter by describing a few examples of tactical innovation within the vast and varied national campaigns undertaken by FoEI member groups. The success of many of these campaigns stands alone as evidence of the tactical innovation of FoEI. These groups have come together within FoEI because of their recognition of the transnational factors that impact national and local issues. These factors include the transnational activities of actors such as governments and corporations, the increasingly global character of environmental problems, and the growing consensus around certain development policies such as current models of economic globalization. The majority of this chapter is devoted to exploring the approach that FoEI has adopted to strategically respond to these transnational challenges. As I discuss in Chapter Five, I have found that FoEI has adopted a "tactical expansion" approach to working globally. Rather than concentrating the efforts of its national groups on a series of global campaigns (the Greenpeace approach), FoEI member groups have remained committed to a decentralized and informal approach while agreeing on a common international umbrella strategy and engaging voluntarily in certain overarching international campaigns. 
In Section 6.3, I explore the origins of FoEI and the extent to which FoEI member groups 'worked globally' during its first two decades. I then trace the development of a more coherent and explicit international agenda in the 1990s and during the past decade in Section 6.4. Returning to the definition by Clark (2003a: 111) of working globally, I analyze the impact that "North-South links" have had on FoEI's tactical approach at the transnational level (Section 6.5). In particular, I investigate the impact of a social justice perspective, first introduced by developing country member groups, on FoEI's mission and international campaigns. I then return to the national group level to explore the impact of this historical development of an international agenda on the national campaigns undertaken by member groups (Section 6.6). In Section 6.7, I propose that FoEI's approach to working globally and its tactical innovation at the transnational level result from its annual and biannual general meetings which inspire creativity and sharing across cultures through their democratic participatory processes. I conclude with a general discussion of FoEI's strategy for working globally (Section 6.8) and draw on the work of two other scholars who have come to similar conclusions about FoEI's approach (Wapner 1996; Suter 2002/03). Table 6.1 and Figure 6.1 below place key external and internal events on a historical timeline and serve as a reference for the historical discussions throughout this section. 
Table 6.1: Select Events in Friends of the Earth International History

\begin{tabular}{|c|c|c|}
\hline Code & Date & Event \\
\hline A & 1971 & First international meeting of FoEI - Agreement to an Anti-nuclear position \\
\hline B & 1972 & $\begin{array}{l}\text { United Nations Conference on the Human Environment, Stockholm, Sweden - } \\
\text { FoEI and The Ecologist publish, ECO, a daily newspaper }\end{array}$ \\
\hline $\mathrm{C}$ & 1976 & $\begin{array}{l}\text { Rejection by FoEI members of any formal international coordination through a } \\
\text { Secretariat at the Annual General Meeting (AGM) }\end{array}$ \\
\hline $\mathrm{D}$ & 1978 & The inaugural publication of FoEI publication, LINK magazine \\
\hline $\mathrm{E}$ & 1979 & $\begin{array}{l}\text { International issues placed on the agenda of AGM including tropical forests, } \\
\text { global warming and Antarctica }\end{array}$ \\
\hline $\mathrm{F}$ & 1979 & $\begin{array}{l}1979 \text { Article in LINK magazine about Northern groups imposing campaign } \\
\text { models on the South }\end{array}$ \\
\hline $\mathrm{G}$ & 1980 & Experimental International Secretariat established in Brussels \\
\hline $\mathrm{H}$ & 1981 & International Secretariat formally established \\
\hline I & 1982 & Appointment of Lead Groups for each international issue \\
\hline $\mathrm{J}$ & 1983 & Establishment of the FoEI Executive Committee \\
\hline $\mathrm{K}$ & 1985 & FoEI organized International Citizens Working Conference on Acid Rain \\
\hline $\mathrm{L}$ & 1986 & First Annual General Meeting held in a developing country - Malaysia \\
\hline M & 1986 & $\begin{array}{l}\text { Establishment of a regional coordinating body for European FoE member } \\
\text { groups - Européanne des Amis de la Terre (CEAT) - otherwise referred to as } \\
\text { FoE Europe }\end{array}$ \\
\hline $\mathrm{N}$ & 1988 & $\begin{array}{l}\text { Discussion paper "The Future of Friends of the Earth International" is debated } \\
\text { at the AGM }\end{array}$ \\
\hline $\mathrm{O}$ & 1992 & UN Conference on Environment and Development \\
\hline $\mathrm{P}$ & 1992 & Launch of FoEI's Sustainable Societies Program \\
\hline Q & 1992 & $\begin{array}{l}\text { Expansion of the role of the FoEI Chair to facilitate the development of an } \\
\text { international agenda }\end{array}$ \\
\hline $\mathrm{R}$ & 1994 & $\begin{array}{l}\text { Discussion Paper on "The Need for an International Agenda for FoEI" debated } \\
\text { at the AGM }\end{array}$ \\
\hline $\mathrm{S}$ & 1994 & Ecological Debt campaign launched \\
\hline $\mathrm{T}$ & 1995 & $\begin{array}{l}\text { Two of the International Campaign Coordinators housed at Secretariat for the } \\
\text { first time }\end{array}$ \\
\hline $\bar{U}$ & 1996 & $\begin{array}{l}\text { International Campaigns Officer position created to facilitate interaction } \\
\text { amongst campaigns }\end{array}$ \\
\hline $\mathrm{V}$ & 1998 & First Campaign Coordinators' meeting \\
\hline W & 2001 & Establishment of FoEI regional network in Latin America and the Caribbean \\
\hline $\mathrm{X}$ & 2004 & AGM decision to embark on the first strategic planning process for FoEI \\
\hline $\mathrm{Y}$ & 2005 & Completion of FoEI Strategic Plan Phase I: Values, Vision, and Mission \\
\hline $\mathrm{Z}$ & 2006 & $\begin{array}{l}\text { Completion of FoEI Strategic Plan Phase II: A Roadmap for Strategy } \\
\text { Implementation }\end{array}$ \\
\hline
\end{tabular}


Figure 6.1 Reference Timeline for Chapter 6

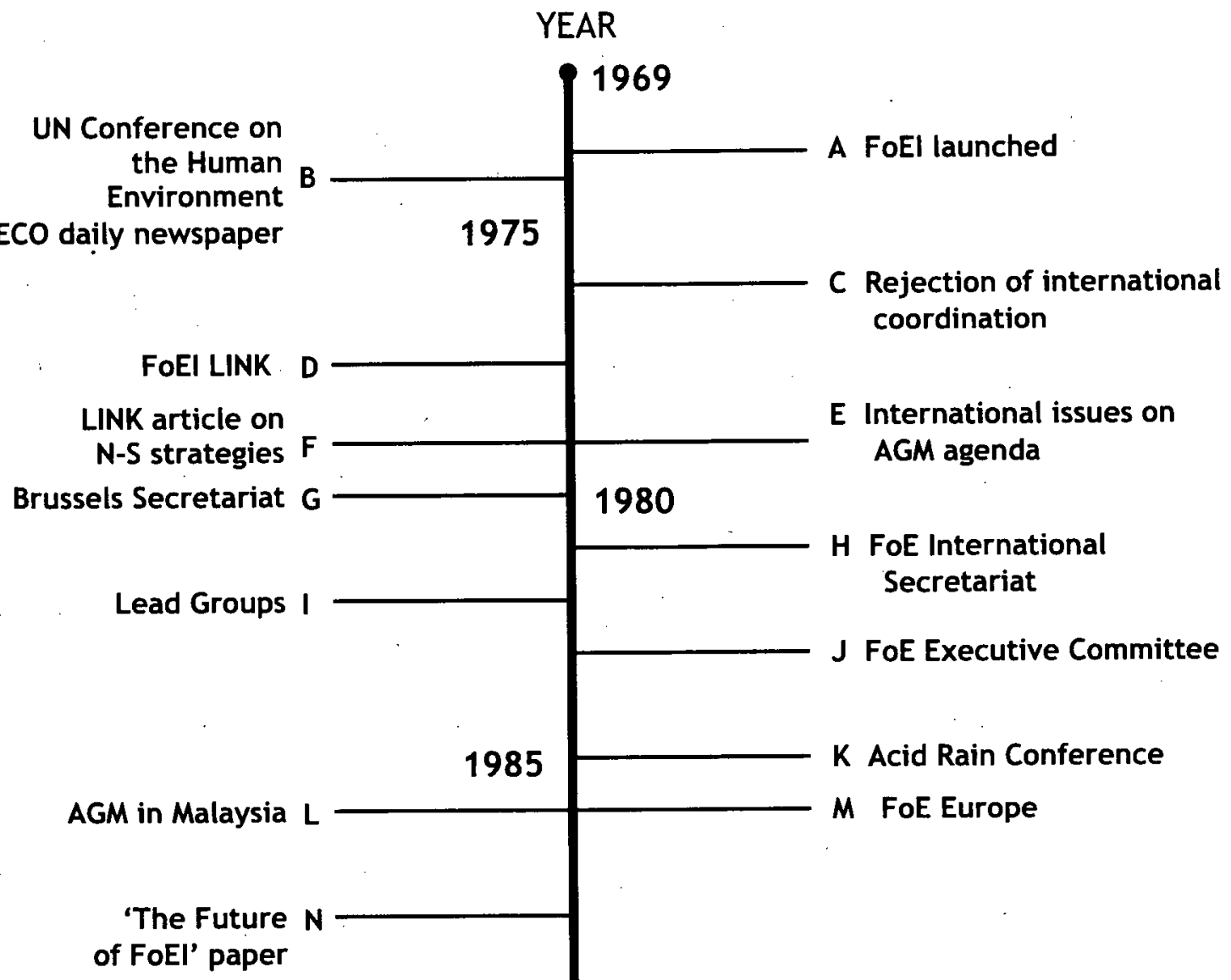

1990

UN Conference on

Environment and

Development

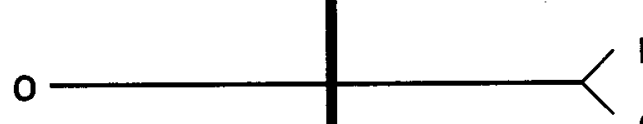

P Sustainable Societies

Q International agenda

'International Agenda' R paper

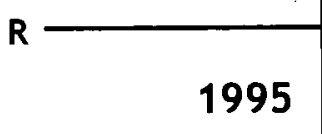

$S$ Ecological Debt campaign

$T$ Intl Campaign Coordinators at FoEI Secretariat

International $\mathbf{U}$

Campaign

Officer
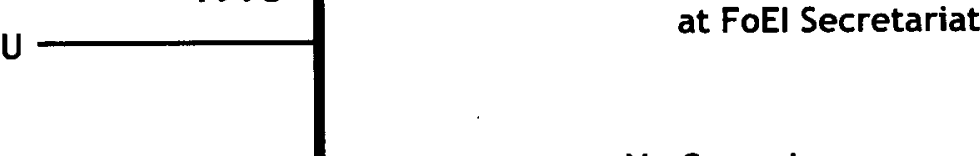

V Campaign

Coordinators Meeting

2000

Regional Network w

in Latin America /

Caribbean

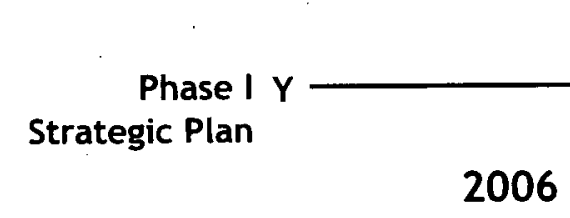

$X$ Launch: Strategic Planning

Z Phase II Strategic Plan 


\subsection{National Level Tactical Innovation}

FoEI member groups engage predominately in campaigns to raise awareness about and to stop environmentally and socially harmful development, and they modify their tactics during these campaigns in order to maintain pressure on target actors. For example, in the early years of Friends of the Earth in the United States, FoE US launched successful campaigns to halt the development of an oil pipeline in Alaska in order to allow for an environmental assessment, to stop the construction of a German chemical plant in South Carolina, and to end plans to build super-sonic transport passenger aircrafts within the USA. ${ }^{148}$ FoE US used a combination of legislative lobbying, public awareness campaigns and litigation to pressure the US government and the private sector. ${ }^{149}$ Their selection of tactics was driven by the political ideology of the founding members of FoE US, which framed their interpretation of democracy and their perception of the degree of access to political processes, as the following quotation suggests,

The participatory ideology and pluralist interpretation of the political environment maintained by staff members at FOE contributed to their perceptions that there were multiple points of access to the political process. They believed that the nature of the legislative and electoral processes led elected officials to be responsive to the participation by environmental activists. Consequently, FOE sought political influence through a combination of practices such as testimony before Congress, letter writing campaigns to legislators, litigation, and direct lobbying. FOE adopted more aggressive tactics than were previously associated with environmental organizations, but these activities still relied on institutional political forums. ${ }^{150}$

Today, FoEI member groups engage in similar campaigns and adopt multiple tactics to halt unsustainable development. For instance, FoE Japan is active in halting the unsustainable use of tropical timber for building construction in Japan through using a combination of information campaigns, lobbying for forest act revisions, and pressuring for domestic forest certification within the construction industry. ${ }^{151}$ FoE Ukraine (Zelenyi Svit) employs multiple tactics including litigation, lobbying and media campaigns in an

\footnotetext{
${ }^{148}$ Turner, Tom (1986) Friends of the Earth: The First Sixteen Years. San Francisco, USA, Earth Island Institute.

${ }^{149}$ Ibid.

${ }^{150}$ Carmin and Balser 2002: 382

${ }^{151}$ FoEI (2001) Sparks of Hope, Fires of Resistance: FoEI Celebrates the Sustainable Path Forward: $30^{\text {th }}$ Anniversary Publication. FoEI, Amsterdam, The Netherlands, p. 34.
} 
effort to halt the expansion of a car battery factory. The activists succeeded in stopping this factory's development and in securing more stringent national environmental laws. ${ }^{152}$ FoE Uruguay successfully lobbied the government to call a referendum on the privatization of public services, which led to more than $60 \%$ of Uruguayan people supporting the inclusion of water as a right in the national constitution. ${ }^{153}$

In addition to halting unsustainable development, the original members of FoEI engaged in promoting sustainable alternatives through, for example, detailed research and analytical reports. In the early 1970s, FoE US published research by FoE activist Amory Lovins on "soft energy paths," which outlined a renewable energy pathway for development as an alternative to a dependence on fossil fuels. ${ }^{154}$. Today, FoEI member groups engage in a wide range of initiatives aimed at securing sustainable livelihoods, particularly at the local and grassroots level. For instance, FoE Costa Rica (Communidades Ecologistas la Ceiba (Coecoceiba)) have involved local women in forest conservation efforts by supporting the establishment of women's organizations and providing the tools for local women to engage in butterfly farming. ${ }^{155}$ FoE Middle East provided a Bedouin community with "solar generators to pump and purify water, supply energy for domestic use, and power up schools, small production facilities and clinics." 156 As an example of FoE combining pressure tactic with a solutions-oriented approach, FoE Germany has engaged hundreds of students in signing a bet with their governments that they can reduce their schools' carbon dioxide emissions by eight percent in eight months in order to demand that their governments to do the same for their constituent areas. ${ }^{157}$

FoEI annual reports and the FoEI quarterly, LINK, provide many examples of successful campaigns and sustainable solutions. I have included a number of these in the timeline of

${ }^{152}$ FoEI (2004) Our Environment, Our Rights: standing up for people and the planet. FoEI, Amsterdam, The Netherlands, p. 14.

${ }^{153}$ FoEI (2004) Annual Report. FoEI, Amsterdam, The Netherlands, p. 10.

${ }^{154}$ Turner, Tom (1986) Friends of the Earth: The First Sixteen Years. San Francisco, USA, Earth Island Institute.

${ }^{155}$ FoEI (2001) Sparks of Hope, Fires of Resistance: FoEI Celebrates the Sustainable Path Forward: $30^{\text {th }}$ Anniversary Publication. FoEI, Amsterdam, The Netherlands, p. 35.

${ }^{156}$ Ibid., p. 27

${ }^{157}$ Ibid., p. 26 
FoEI reported achievements in Appendix A. Of course, not all campaigns have been successful. For example, FoE England Wales and Northern Ireland, along with other activists, were not able to halt the construction of the Newbury Bypass highway. ${ }^{158}$ FoE Greece did not succeed in pressuring the government to remove genetically modified crops which, according to FoE Greece, threaten local sustainable beekeeping endeavors. ${ }^{159}$ What remains clear in reviewing the thousands of local and national campaigns is the sheer diversity of tactics employed by FoEI national member groups. A small window into the range in FoEI's action repertoire is evident from the member group victories listed in FoEI's 2003 Annual Report. Friends of the Earth Korea filed a petition signed by their members and local citizens to the national court, which encouraged the court's decision to suspend the development of an ecologically damaging sea wall. FoEI Spain organized, trained and provided lodging and equipment for volunteers to assist in the clean up of a devastating oil spill off the Galician coast. FoE Chile (CODEFF) demonstrated in active opposition to the construction of mega-project, including an aluminum plant, within a pristine ecological area. In order to improve waste collection, recycling and composting in seven Slovakian towns, FoE Slovakia organized training seminars, issued a practical manual, constructed compost sites, and successfully lobbied at the national level for packaging waste regulation. Many of the campaigns of FoEI member groups take place entirely within their country; however, these groups have joined FoEI because they also seek to engage in campaigns that cross national borders. I will now turn my attention to FoEI's strategic response to the challenge of working globally in order to support this transnational activity, respond to global issues, and challenge economic globalization.

${ }^{158}$ FoE (1992) Friends of the Earth 1971-1992: 21 Years of Friends of the Earth. Friends of the Earth Ltd. London, UK.

${ }^{159}$ FoEI (2001) Sparks of Hope, Fires of Resistance: FoEI Celebrates the Sustainable Path Forward: $30^{\text {th }}$ Anniversary Publication. FoEI, Amsterdam, The Netherlands, p. 17. 


\subsection{FoEI International Activity in the 1970s and 1980s}

In the 1970s and early 1980s, international interaction within FoEI amounted to an informal annual gathering, which enabled the exchange of information amongst internationally-minded individuals from industrialized countries, as suggested by the following quotation,

Friends of the Earth was conceived from the beginning as an international body. Originally, David Brower simply appointed friends of his living outside the United States to be his personal representatives. This rather dirigiste approach to internationalization soon gave way to a more formal recruitment process.... Recruitment became a response to spontaneous initiatives in countries in which the idea spread by a process more akin to osmosis than conscious policy. ${ }^{160}$

As this recruitment process continued, national member groups recognized the benefit of operating as an international organization, particularly as it enabled joint accreditation to United Nations bodies, such as the United Nations Economic and Social Council (ECOSOC). ${ }^{161}$ Initial meetings resulted in FoEI members agreeing to a common position against nuclear power and nuclear proliferation; however, for the most part, the annual meetings were conversations amongst concerned environmentalists from different countries lending each other support and sharing ideas. As one early FoE member from FoE France (Les Amis de la Terre) describes, "FoEI was small, but promising... [and] ties were close and personal."162

As one of their first international activities, FoEI campaigners attended the 1972 United Nations Conference on the Human Environment to lobby governments on environmental and nuclear issues. Jointly with staff from The Ecologist magazine in the United Kingdom, FoE campaigners instigated the publication of a daily newspaper, $\boldsymbol{E} \boldsymbol{C} \boldsymbol{O}$, during the UN conference negotiations. The $\boldsymbol{E} \boldsymbol{C O}$ publication was well-received by government delegates, officials, civil society actors and the media, particularly when $\boldsymbol{E} \boldsymbol{C} \boldsymbol{O}$ staff gained access to a closed meeting hosted by Chinese delegates and released the secret

\footnotetext{
${ }^{160}$ Burke 1982: 106

${ }^{161}$ Ibid.

${ }^{162}$ Samuel, Pierre (1992) Remembrance of Things Past. In FoEI LINK: $25^{\text {th }}$ Anniversary Special. July/August. Issue 73, p.8.
} 
Chinese proposal in $\boldsymbol{E C O}$ the following morning. ${ }^{163} \mathrm{FoE}$ has since published $\boldsymbol{E C O}$ at dozens of international conferences, some by invitation and others as a campaigning device. ${ }^{164}$ Even though FoEI member groups were engaged in common activities, the member groups decided against any formal collaborative structure. In 1976, a proposal to open an official FoEI coordinating body was rejected by other member groups and, in fact, "the dominant desire for the national organizations to assert their independence led to successive decisions not to establish a secretariat."165

By 1978, the "volume of international communication" had grown to such an extent that one FoE member group initiated the production of FoE LINK, an internal publication produced five times per year from the San Francisco office of FoE USA. ${ }^{166}$ Prior to LINK, the annual meetings served as the main coordination mechanism and opportunity for information exchange at the international level. As one FoE member recalls,

Throughout the first ten years, FoEI members had worked, in general, on their own issues. Some of these were common concerns, of course, with the nuclear threat dominating the agenda. A few groups crossed paths regularly while others made contact only now and then. Information exchange and a limited amount of internal debate happened through FoE LINK, produced by David Chatfield's office in San Francisco. The 1976 Meeting had rejected the idea of any formal co-ordination, such as a Secretariat. International work in FoE's name sprang mainly from individual initiatives.... But when we met in Reagan's America in 1981 the mood had darkened. ${ }^{167}$

The 1981 FoEI Annual General Meeting in Washington took place in a new context and triggered a critical shift within Friends of the Earth International. FoEI member groups were dismayed at the reversal of hard-won victories from the 1970s by Ronald Reagan's newly elected Republican government in the United States and believed that they needed

${ }^{163}$ Turner, Tom (1986) Friends of the Earth: The First Sixteen Years. San Francisco, USA, Earth Island Institute.; Innis, Stuart (1993) "Friends of the Earth: Earth Gets a New Friend" Senior Thesis. FoEI historical archive, Amsterdam, The Netherlands.

${ }^{164}$ MacArthur, Mairi (1989) The Growth of FoEI: A Personal View. July. FoEI historical archive, Amsterdam, The Netherlands.

${ }^{165}$ Burke $1982: 107$

${ }^{166}$ MacArthur, Mairi (1993) Location of FoEI Annual Meetings, Location of Secretariat. FoEI historical archive, Amsterdam, The Netherlands.

${ }^{167}$ MacArthur, Mairi (1991) Mairi MacArthur takes a personal look back at her memories of FoE International as the network enters its third decade. FoEI historical archive, Amsterdam, The Netherlands. 
to modify their tactics to deal more effectively with a government that strongly advanced economic growth without consideration of environmental and social impacts. In addition, promises made by governments at the United Nations conferences - including the Stockholm UN Conference on the Human Environment - were not being met by government action. FoE members were also faced with new evidence in the form of the newly released World Conservation Strategy (IUCN 1980) and the Brandt Commission report on North-South issues (Brandt 1980), which exposed both the increasing degradation of natural systems as well as the growing gap between rich and poor. For FoE member groups, the lack of action by governments on these critical social and ecological issues was alarming and made worse by the new US government "which willfully ignored or distorted environmental concerns."

These external triggers began to shift FoEI member group focus from emphasizing only tactical adjustments made within specific local and national campaigns towards "working globally" and adopting a broader international interpretive frame for tactical innovation. If the powerful actors in society were reversing individual campaign victories, FoEI would need to respond by widening its horizons and tackling the root causes of environmentally and socially harmful development which they felt would require a higher level of coordination at the international level. A one-person Secretariat was established as an experiment in 1980-1981 in Brussels, which led to an agreement that better communication amongst groups was needed to cooperate effectively at the international level and strategically counter political trends. Box 6.1 presents the historical changes in the staff and location of the International Secretariat.

\footnotetext{
${ }^{168}$ MacArthur, Mairi (1991) Mairi MacArthur takes a personal look back at her memories of FoE International as the network enters its third decade. FoEI historical archive, Amsterdam, The Netherlands.
} 


\begin{tabular}{|ll|}
\hline Box 6.1: & $\begin{array}{l}\text { Location and Staff of FoEI's International Secretariat } \\
\text { Source: FoEI Historical Archives }\end{array}$ \\
{$[1978-1980$} & $\begin{array}{l}\text { FoE LINK produced approximately 5 times per year, } \\
\text { from San Francisco office of FoE USA] }\end{array}$ \\
$1980-1981$ & $\begin{array}{l}\text { Brussels, Belgium (Nils Hoch, part-time) } \\
1982-1983\end{array}$ \\
$1983-1987$ & $\begin{array}{l}\text { Gothenburg (Per Ohlsson, part-time) } \\
\text { Lamsterdam, The Netherlands (Marie-Jose Goedmakers, 1983-85; Pieter }\end{array}$ \\
$1988-1990$ & $\begin{array}{l}\text { London, United Kingdom (Nicole Mueller, full-time) } \\
\text { Amsterdam, The Netherlands (initially Bert van Pinxteren, Eka Morgan, } \\
1991-\text { present }\end{array}$ \\
& $\begin{array}{l}\text { Theo Ruyter, Jenni Richardson; many volunteer part-time, full-time staff } \\
\text { over the years) }\end{array}$ \\
\hline
\end{tabular}

In 1981, the International Secretariat was welcomed by member groups as a structural addition to support FoEI's international collaboration, as this FoE member describes,

In 1981, I recall little disagreement about the way forward. The meeting decided to make the Secretariat permanent and Per Ohlsson volunteered to run it part-time from Sweden. It was a turning point for FoEI. There have been many discussions about where and how the Secretariat should be organized but its actual existence has never been questioned. ${ }^{169}$

The need for collaboration at the international level was also supported because FoE member groups had placed a number of international issues - including tropical forests, global warming and Antarctica - on the agenda of the annual meetings starting in 1979. These global issues joined the anti-nuclear and anti-whaling discussions of earlier years. At the meeting in 1981, discussions expanded to other international problems including global air pollution, food and toxic chemicals. FoE members made commitments to voluntarily working together and campaigning at the global level on a broader array of global environmental issues, a tactical approach that was reassessed at the AGM in 1982. FoEl was learning how to establish its campaigning and tactics at the global level, as this quotation describes,

\footnotetext{
${ }^{169}$ MacArthur, Mairi (1991) Mairi MacArthur takes a personal look back at her memories of FoE International as the network enters its third decade. FoEI historical archive, Amsterdam, The Netherlands.
} 
In 1982 we had to admit that our grand plans of the year before - to campaign for the entire global commons - had made little progress and we adopted the formula of a 'Lead Group' in the hope of a clearer focus on each issue.

The 'Lead Group' consisted of a FoEI member group who would stimulate discussion and action on a particular international issue during the months between general meetings. This organizational arrangement has evolved in the years since 1982 with a later amendment which mandated the selection of two lead groups - one from the North and one from the South - and also the appointment of international campaign coordinators. In 1983, an Executive Committee was created to further support international coordination between meetings. In 1995, the first international coordinators for specific campaigns were housed at the International Secretariat. In 1996, the AGM created a part-time support position, an International Campaigns Officer (which in 2000 became the International Campaigns Coordinator), to support all the diverse international campaigns. The first international campaign coordinator meeting was held in 1998 to address discrepancies and find synergies across campaigns. It is important to note that the international coordinators, Executive Committee and staff at the International Secretariat are largely elected from the FoEI member groups themselves rather than being hired from outside the network. Also, the mandate of all of these positions is to stimulate and support campaign activity rather than to direct campaign activity. As one FoE campaigner notes regarding the International Secretariat,

The FoEI secretariat has always been small. They help facilitate the work of member groups. They facilitate conversation, development of strategy, fundraising for member groups, especially for members groups from the South. They are a small number of people who can only do so much. Today it is not that much bigger and still has these functions. This is unlike organizations such as World Wildlife Fund or Greenpeace where campaigns are driven more from the centre than FoE. ${ }^{170}$

In another personal interview, the interviewee corrected me when I asked if the working group, regional coordinator or thematic group was "underneath" the international campaign coordinator by saying that the international campaign coordinator is not

${ }^{170}$ Interview with Mike Childs, Political Coordinator, FoE England, Wales and Northern Ireland (EWNI), February 2005. 
underneath, but supporting the work of the campaign. ${ }^{171}$ FoEI remains a decentralized structure.

By instigating all of these organizational changes, FoE member groups developed what has become referred to as FoEI's "3-tier structure" at local, national and international levels. ${ }^{172}$ Other structural adjustments to FoEI have since been made in order to support FoEI member groups in thinking and acting outside of their national boundaries and working at the regional level. In 1986, the European member groups of Friends of the Earth International created a regional network, CEAT (Coordination Européanne des Amis de la Terre - also known as FoE Europe) to coordinate activities within the European Union, specifically in response of the growing importance of the European Community. ${ }^{173}$ The regional network structure has since been imitated in Latin America and the Caribbean (2001). The creation of these structures was designed to increase the effectiveness of FoE member group campaigns and enable region-wide and international level campaigns, while maintaining FoE's commitment to local and national autonomy and campaigns and to a decentralized, participatory structure.

As described above, David Brower instigated international level brainstorming and some joint international activity in the early years of FoEI; however, this voluntary international participation was questioned at the 1986 Annual General Meeting in Malaysia. FoE Malaysia (Sahabat Alam Malaysia (SAM)) challenged FoEI member groups to adopt a more coherent international agenda and to join together on international campaigns. Malaysian national environmental issues could not be addressed without such international campaigning. For example, halting the destruction of Malaysian tropical forests required changes in the policies and activities of foreign corporations and

${ }^{171}$ Interview with Mae Ocampo, FoEI International Membership Development Coordinator, October 2004.

${ }^{172}$ FoEI (1991) Friends of the Earth International. Brochure, FoEI historical archive, Amsterdam, The Netherlands.

${ }^{173}$ Executive Committee (1994) Discussion Paper about the Need for an International Agenda for FoEI. FoEI, Amsterdam, The Netherlands, 10 August. 
governments. ${ }^{174}$ At the 1987 Annual General Meeting, FoEI member groups responded to FoE Malaysia's challenge by calling for a detailed examination into the development of Friends of the Earth International. The result was the 1988 paper on "The Future of FoEl", written by an elected working group and the Executive Committee. The paper outlined proposals for increasing the number and effectiveness of international campaigns, the expansion of the International Secretariat, the movement towards regional cooperation amongst member groups, the representation of FoEI at international meetings, and collaboration and contacts with other organizations and networks. ${ }^{175}$ The paper begins by noting the historical beginnings of FoEI as "a rather symbolic international movement" with the annual meeting.as the sole coordinating body. ${ }^{176}$ The paper notes some of the key changes that require FoEI to adopt a more international level coordination, including political changes, global environmental problems, and the emergence of other key civil society players on the international stage including Greenpeace and a host of issue-based networks. According to the authors of the 1988 paper, the strategic response they recommend to these changing conditions is the following,

FoEI has to redefine its position in these confusing surroundings. We want to maintain our decentralized structure, with member-groups being autonomous. We want to maintain our character of being grassroots based, linking environmental issues with social issues, linking environmental consciousness with the need for structural and cultural changes. But we need to make our organization stronger: sufficient information exchange, more commitment from member-groups to each other, international campaigners with enough resources, the start of a publications and press policy. Being present at the international level whenever [it is] relevant to our campaigns or [promotes] the image of our organization. ${ }^{177}$

In this quotation and in the paper, the authors emphasize those features that make FoEI unique: its decentralized structure, its commitment to participatory democracy, its national and international presence, its recognition of the interconnectedness of social and

${ }^{174}$ Interview with Meena Raman, FoEI Chair (2004 - present), Sahabat Alam Malaysia (FoE Malaysia), February 2006.

${ }^{175}$ Executive Committee (1988) Annual General Meeting paper about the future of Friends of the Earth International. Amsterdam, The Netherlands, $25^{\text {th }}$ August.

${ }^{176}$ Executive Committee (1988) Annual General Meeting paper about the future of Friends of the Earth International. Amsterdam, The Netherlands, $25^{\text {th }}$ August.

${ }^{177}$ Ibid. 
environmental issues, its search for root structural causes to local, national and international problems, and its promotion of solutions and alternatives. These fundamental elements have remained remarkably robust as guiding principles of FoEI over the years. The 1988 paper also identified triggers for greater international collaboration, including the challenge to address a transnational political environment, to tackle global environmental issues, and to meet the needs of developing country member groups. In order to create the conditions for international collaboration, the authors recommended fundraising specifically for international activity and hiring or appointing international campaign coordinators, who both represent FoEI at intergovernmental meetings and brief, inform and stimulate FoE national groups. ${ }^{178}$ The authors note that collaboration has not been an equal priority for all FoEI member groups,

FoE groups vary in size, strength, importance in their own country, strategy, issues etc. For some, being a member of FoEI is important for their image, for others not. Some work on the international level anyhow, also outside FoEI, others not. This causes inequality and tension. ${ }^{179}$

The authors note that member groups have a particular responsibility to be involved in international activities because FoEI has a policy of one member group per country. Each group, therefore, has been specially recruited and needs to be involved at the international level. The authors note that an early attempt to outline these responsibilities in a "contract of agreement" resulted in a response from FoEI member groups that was "quite embarrassing" as only seven of the thirty-two member groups signed. Similarly, member groups' response to paying the annual subscription to FoEI was "not very positive." It would not be until the 1990s that international collaboration would reach a more established form.

${ }^{178}$ Executive Committee (1988) Annual General Meeting paper about the future of Friends of the Earth International. Amsterdam, The Netherlands, $25^{\text {th }}$ August, p. 3.

${ }^{179}$ Ibid. 


\subsection{Building an International Agenda: $1990-2006$}

At the 1992 Annual General Meeting, FoE member groups agreed to "officially [see] itself as a 'federation,' not merely a 'network'". ${ }^{180}$ This change signaled a step towards "a clearer international image and role", and the "structure of still autonomous organizations but with some clear mutual commitments and the will to present themselves jointly." ${ }^{182}$ At the same 1992 meeting, FoEI member groups expanded the role of the FoEI Chairperson by providing the Chair with a particular mandate to develop an international agenda. In January 1994, the Executive Committee began discussions on the need to develop such an agenda and, in August of 1994, presented the FoE member groups with a discussion paper "about the need for an international agenda for FoEI". ${ }^{183}$

The discussion paper opens with the following statement,

We are a federation of organizations that on specific issues work together, but we lack a common picture of what are the most essential steps to be taken to achieve our common aim: a sustainable and socially just global society. National members of FoEI are keen not to get international responsibilities imposed on them, but as we are together building up FoEI as an effective and impressive international movement, our obligations grow to have active input in international discussions and events. FoEI members do recognize that to a certain extent and agreed in 1992 on a special mandate for the FoEI Chair person that gives some potential for developing an international agenda.

An international agenda might guide representatives of FoEI and its members in indicating what we stand for and therewith increase our influence. It should not replace our bottom-up approach of identifying campaigning areas by identifying willingness of national groups to cooperate, but add to that approach another one, looking at the needs on the international level and then looking at the possibilities FoEI has or should develop.... It is not our intention to come to a concrete international agenda right now, but to get an idea about the need for such an agenda and the character of it. ${ }^{184}$

The Executive Committee encouraged FoEI member groups to "think globally, act on all levels" rather than only on the local and national level. Reinforcing the informal nature

${ }^{180}$ FoEI (1992/1993) LINK. FoEI, Amsterdam, The Netherlands, December - January, Issue 52, p. 17 .

${ }^{181}$ Ibid, p. 16

${ }^{182}$ Executive Committee (1994) Discussion Paper about the Need for an International Agenda for FoEI. FoEI, Amsterdam, The Netherlands, 10 August, p.3.

${ }^{183}$ Executive Committee (1994) Discussion Paper about the Need for an International Agenda for FoEI. FoEI, Amsterdam, The Netherlands, 10 August, p.3.

${ }^{184}$ Ibid. 
of FoEI, the authors emphasized that the international agenda would not require new internal rules for the organization but was meant to improve mutual understanding of an international agenda and the "opportunities and obligations of the members towards this agenda." The 1994 discussion paper presents a historical overview in which it outlines the primarily grassroots, local and national focus of FoEI member groups in the 1970s, and the gradual shift in the 1980 s towards more international collaboration. The authors argue that this change stemmed from three developments which were partly catalyzed by FoEI efforts: the growing coordination of governments at the international level; the expansion of civil society activity on environmental issues in the South including the inclusion of new FoEI members from non-industrialized countries; and the shift in perception from individual environmental problems to an integrated approach that touches on elements of international cooperation. In response, FoE member groups expanded their international work. In the 1990s, this was further stimulated by three other developments: the growth in the environmental movement and recognition of sustainability in the lead-up to and following the 1992 United Nations Conference on Environment and Development, the transitions in Central and Eastern Europe, and the aggravating international economic climate due to economic crises in industrialized countries. The paper also notes new targets such as the UN Commission on Sustainable Development, Multilateral Development Banks, and the increasing interest amongst business, industry and other interest groups in environmental issues. The Executive Committee concludes the paper by noting that that "the slogan "think globally act locally" is too limited at this time since international developments require the environmental movement to be present at the international level in addition to the focus on the local and national levels.

The Executive Committee notes, in the 1994 paper, that discussions of international collaboration at annual general meetings have not necessarily resulted in action once the FoEI campaigners returned to their national contexts, as this quotation from the paper describes,

It is actually quite disappointing to see the vast difference between the commitments the representatives of FoEI-members make during AGMs and the outcome. It seems that only a few groups really have internalized international FoEI-work in their own 
agenda. In most groups the whole concept of FoEI stays with a few individuals, the majority of the activists do not or hardly realize they are part of it or do not see the relevance for their own activities.... This needs to be changed and if this does not happen, FoEI might run the risk of gradually becoming of less importance, as also those that do not understand the need will get disappointed with the lack of response. And as the image of FoEI will disappear, so will its ability to raise funds and assist its member groups. ${ }^{185}$

As one FoE member notes, the democratic and bottom-up structure of FoEI and the autonomous campaigns carried out by the FoEI member groups result in FoEI "missing out on maximizing impact with the work that we do because only specific campaigners in the campaign know about it and the rest of the network doesn't." ${ }^{\text {"186 }}$ There has been a tendency towards greater international collaboration and cohesion across FoEI member groups since the 1994 discussion paper was released. This was partly due to the impassioned plea made by Ricardo Navarro, from FoE El Salvador (Centro Salvadoreño de Tecnologia Apropiada (CESTA)), at the 1994 Annual General Meeting. One FoE member describes this moment in the following way:

The most recent AGM will be remembered in FoEI history as the inauguration of a political debate on the role of the network. The passionately political words of Ricardo Navarro from FoE El Salvador pushed us headlong into a high-level discussion. He proposed to repudiate existing development models in favour of universal sustainability, which entails a fair society with access to resources, political justice, and respect for diverse traditions.... My impression is that we planned FoEI activities differently, and more maturely, in Estonia. In addition to the old agenda from past AGMs (campaigns, programs, financial difficulties), we added something new: the examination of campaigns, programs and projects through the lens of FoEI's political challenge. ${ }^{187}$

Ricardo Navarro was encouraging FoEI member groups to create political declarations that outline the FoEI position on existing globalization and development paths.

\footnotetext{
${ }^{185}$ Executive Committee (1994) Discussion Paper about the Need for an International Agenda for FoEI. FoEI, Amsterdam, The Netherlands, 10 August.

${ }_{186}$ Interview with Daniel Mittler, FoE Germany 1996 - 2004; Greenpeace International 2004 present, August 2002.

${ }^{187}$ FoEI (1994) Towards Universal Sustainability in LINK, FoEI, Amsterdam, The Netherlands, Issue 62/63, p. 26.
} 
In 1994, Navarro's statements and general discussion on international issues resulted in the FoEI member groups deciding "to develop an international agenda, which will offer an alternative vision for the future." 188 . This international agenda evolved over the years through discussions, international campaigns and publications, some of which I will describe in the sections below, and has recently been further supported by the first strategic planning exercise for FoEI, which began in 2004. The Executive Committee presented "a roadmap for a comprehensive and coherent strategic planning process for the federation". at the AGM in Croatia in 2004. This roadmap "recognized our thinking has been at times fragmented, the strategic 'whole' has not always been clear" with the result that "FoEI has not always been able to leverage, to the extent that we can, the enormous strength that we have" and "make the best use of our diversity, our outreach capacity of being the respected yet hard-hitting campaign organization that we are."189 The strategic planning process was accepted at the 2004 AGM and FoEI member groups embarked on a two phase process of defining a strategic plan. In 2005, FoEI member groups defined the core set of values, vision and mission for the organization. In 2005 and 2006, local, national and regional meetings were held to define strategies to achieve the vision outlined in Phase I; a roadmap for strategies, structure or processes by which the strategies can be implemented; and a means to measure progress for strategy implementation. The creation of an international agenda and strategic plan was triggered by the increase in transnational activity by governmental and corporate actors and by the need to respond to global environmental issues. A third trigger for changē came from inside FoEI as its global expansion resulted in a creative clash amongst different cultures. It is the impact of the FoEI's establishment of North-South links that I address next in developing an understanding of the specific "expansion" approach which FoEI has adopted to working globally.

\footnotetext{
${ }^{188}$ FoEI (1994) Annual Report. FoEI, Amsterdam, The Netherlands, p. 4

${ }^{189}$ Executive Committee (2004) Making FoEI Strategy Focused: Strategic Planning for Friends of the Earth International. FoEI, Amsterdam, The Netherlands.
} 


\subsection{North-South Links and Social Justice}

In 1985, FoE hosted the International Citizens Working Conference on Acid-Rain in the Netherlands. It was attended by 80 delegates from 28 countries and served as the launching platform for an international coalition to fight acid rain. ${ }^{190}$ According to one FoE member, this conference was part of a shift in FoEI having a more "international feel" as the conference was supported by representatives from "North, South, East and West". However, the conference organizers "realized too late" that "the content of the conference had been planned from a mainly Northern viewpoint."191 The speakers from the North focused their discussions on energy alternatives and pollution control, and were met by "the different perspectives of the South which now came openly and forcefully [with] intense discussions about broader underlying problems such as poverty and economic injustice." 192

This was not the first time that FoE had been confronted with cultural differences in tactical approach and interpretive frames of environmental and social issues. In 1979, FoE published in $\boldsymbol{E} \boldsymbol{C} \boldsymbol{O}$ and LINK an article by Anil Agarwal, an activist from India, strongly warning campaign groups from the North not to impose their models of campaigning and tactics on Southern groups. ${ }^{193}$ Further discussion on Third World issues was stimulated by discussions in LINK during 1980 and 1981 ; $^{194}$ however, it was not until 1986 and the first Annual General meeting held within a developing country that FoEI was forced to innovate its tactics and approach again, changing how it works globally and altering its interpretive frame on the nature and causes of global environmental problems. I have already hinted at this evolution and a greater emphasis on the interconnections of social and ecological issues and the structural roots of global

\footnotetext{
${ }^{190}$ MacArthur, Mairi (1989) The Growth of FoEI: A Personal View. July. FoEI Historical Archives.

${ }^{191}$ MacArthur, Mairi (1991) Mairi MacArthur takes a personal look back at her memories of FoE International as the network enters its third decade. FoEI historical archive, Amsterdam, The Netherlands.

${ }^{192}$ MacArthur, Mairi (1991) Mairi MacArthur takes a personal look back at her memories of FoE International as the network enters its third decade. FoEI historical archive, Amsterdam, The Netherlands.

${ }^{193}$ Ibid.

${ }^{194}$ Ibid.
} 
problems in the discussion in Section 6.3 above. According to John Hontelez, Chair of Friends of the Earth International from 1986 until 1996, this shift in perception can be traced to a particular event in the FoEI history: the Annual General Meeting in Malaysia. In my interview with him, Hontelez recalled the change:

When I arrived, the first developing country [nongovernmental organizations] NGOs had just joined FoE, and the most articulate of these was FoE Malaysia. In fact, the [Annual General Meeting] AGM where I was elected was in Malaysia [in 1986]. FoE Malaysia didn't like the volunteeristic relationship inside FoE International. For them, international ... cooperation was not an add-on but a necessity. For the US and the $E U$, it wasn't like this - even with the nuclear debate and even on other issues such as oceans (which is inherently international). These groups worked on issues like air pollution and water pollution and, especially in industrialized countries, you can do a lot at a national level. The international cooperation was really an add-on and something that also depended on personal interest. The meetings of FoE during the first years - the international annual meetings - were the only thing that happened at the international scale.

Malaysia challenged that. If the groups were not committed to an international campaign then FoEI is worth nothing. They said that, in our [non-industrialized] countries, issues such as the destruction of tropical forests can not be sorted out nationally. The consumers and companies that are doing this are in your countries - the western countries (US and EU and also Japan). For them it was, by definition, an absolute necessity to work internationally.... The real push for a stronger and more centralized FoE came from Malaysia. It led to some good discussions and it challenged everyone to keep radical. ....

This is one of the things that I found interesting about working in FoEI. These [non-industrialized country] groups were teaching the industrialized country people that, at least in their situation, it was not possible to separate environment from health from development from justice and from human rights. These issues are separated in our democracies. They are struggles that are organized by different civil organizations that hardly work together. In developing countries, it is artificial to separate these issues. ${ }^{195}$

FoE Member groups, particularly from industrialized countries, were challenged by FoE Malaysia to shift their interpretive frames and recognize the international linkages inherent within their campaigns and adapt their tactics accordingly. FoEI's founding mission "to promote...the conservation, restoration and rational use of the natural resources and beauty of the Earth" (Burke 1982: 107) has evolved over time to incorporate these new insights. Appendix $\mathrm{C}$ details the evolution of the mission statement and description of FoEI at its founding, and at critical points in its evolution in

${ }^{195}$ Interview with John Hontelez, FoEI Chair 1986-1996, May 2006. 
$1985,1992,2002,2003$ and 2005. One observation that can be made is that there has been an increasing emphasis placed on the social aspects of sustainability including issues of peoples' sovereignty and human and peoples' rights, equity and justice, the promotion of ecological and cultural diversity, and the empowerment of indigenous peoples, local communities, women, groups and individuals. This is in large part due to the global expansion of FoEI into developing countries, who introduced their integrated perspective on environmental and social issues as John Hontelez describes in the quotation above. In the 1985 report, environmental issues are described as being interconnected with social, economic and cultural factors, and the problems of poverty, land reform, and decentralization of power to those who are affected by decision-making. By 1992, the mission statement includes references to ecological, cultural and ethnic diversity, participatory democracy, and the need to achieve "social, economic and political justice and equal access to resources and opportunities for men and women on the local, national, regional and international levels." ${ }^{, 196}$ As one FoE member noted, "words such as 'social', 'human', or 'cultural' come through much more clearly" at the 1992 FoEI AGM than in the past. ${ }^{197}$ In a 1994 position paper, the FoEI Executive Committee suggests that "social and justice dimensions, the equity principle between nations and individuals" sets FoEI apart from conservation organizations, "centralized populist organizations like Greenpeace International as well as narrowly focused oneissue networks." $" 198$

It is important to note that the focus on social justice issues was driven not only by developing country member groups. One FoE campaigner from FoE Scotland reflects on the importance of a justice focus for his work in Scotland,

Some academics try to paint the picture that there are rich well-resourced Northern FoE groups focusing on traditional conservation issues in contrast with the poor, radical, dynamic Southern FoE groups that are focused on people and humanity. This isn't the case... This didn't fit with my experience with the groups that I worked with in Scotland where poor people were living next to landfill sites. The

${ }^{196}$ FoEI (1992) Annual Report. FoEI, Amsterdam, The Netherlands, p. 2.

${ }^{197}$ FoEI (1992/1993) LINK. FoEI, Amsterdam, The Netherlands, December - January, Issue 52, p.1.7.

${ }^{198}$ Executive Committee (1994) Discussion Paper about the Need for an International Agenda for FoEI. FoEI, Amsterdam, The Netherlands, 10 August, p. 4. 


\section{issue of environmental racism is relevant in the North as much as the South and connects to the United States environmental justice movement. ${ }^{199}$}

For this FoEI campaigner, the social justice issue was an issue that connects campaigners across the North and the South. Similarly, another FoEI campaigner expresses this same sentiment,

Most environmental problems are caused by the rich and dumped on the poor and this plays itself out as a race issue. In Europe, it is more class than race and in North America it is race. It is critical to understand how environmental issues and justice issues are interlinked. ${ }^{200}$

As social justice and equity issues became central to FoEI's work, FoEI member groups developed a radical international campaign that specifically addressed questions of inequality amongst countries globally. This cross-cutting campaign is on Ecological Debt, described in the following way within FoEI's $30^{\text {th }}$ anniversary publication:

Repayment of southern [financial] debt is increasing seen as ecologically impossible, unjust and humane. But Friends of the Earth's new Ecological Debt Campaign, led by FoE Ecuador, takes the case further. The balance of repayments, they argue, should actually be reversed. [In other words,] ecological debt cancels external debt. "Ecological debt" is defined as the cumulative debt of northern industrialized nations to Third World countries for resource plundering, environmental damage, and the free occupation of environmental space to deposit wastes from industrial countries. Ecological debt is closely related to illegitimate external debt, which burdens impoverished people, is contracted fraudulently or for wasteful projects, or grows due to compounding interest payments and unilaterally raised interest rates. ${ }^{201}$

As an example of inequality in environmental issues, FoEI cites the issue of climate change, because its origins are predominately Northern and its impacts on ecological and social systems will be felt strongly in Southern countries. Similarly, nuclear testing and toxic waste disposal by industrialized countries has had health impacts on ecosystems and people in non-industrialized countries. FoEI argues that by canceling external debt, developing countries would be able to undertake sustainable natural resource management rather than unsustainable developments, such as shrimp farming in Ecuador,

\footnotetext{
${ }^{199}$ Interview with Kevin Dunion, FoEI Chair (1996-2003), Executive Director, FoE Scotland (1991-1996), November 2005.

${ }^{200}$ Interview with Daniel Mittler, FoE Germany 1996 - 2004; Greenpeace International 2004 present, August 2002.

${ }^{201}$ FoEI (2001) Sparks of Hope, Fires of Resistance: FoEI Celebrates the Sustainable Path Forward: $30^{\text {th }}$ Anniversary Publication. FoEI, Amsterdam, The Netherlands, p. 32.
} 
established to create the financial resources to repay loans. In order to further the Ecological Debt campaign, FoEI member groups have established the "Ecological Debt Creditors Club" for Southern peoples as a "counterpart to the Paris Club of industrialized creditor countries that meet to negotiate Third World foreign debt." This newly established creditors club demands not only financial compensation but also the restoration of ecosystems and natural resources. Since its launch in 2001, the Ecological Debt campaign has been adopted by other non-profit organizations and become a component of FoEI activities, as this quotation notes,

Some aspects of the way we have focused on ecological debt have come through the systems of FoEI. For example, the debt agenda has influenced FoE discussions on trade, environment and sustainability and have also manifested themselves in presentations that FoE makes at the UN Commission on Sustainable Development and in lobbying around the World Summit on Sustainable Development in Johannesburg. ${ }^{202}$

The Ecological Debt campaign and FoEI's focus on social justice and equity issues has also led to further exploration amongst FoEI member groups of the connections amongst environmental and human rights, and the publication of a common position report that highlights the intersections between these two issues. ${ }^{203}$ Generally, FoEI members describe FoEI campaigners as being "social environmentalists"204 that work on "social and environmental aspects at the same time. ${ }^{, 205}$ In 2005, FoE member groups agreed to a new set of core values, vision statements and mission which explicitly reference the intersection of social and ecological issues (see Appendix C). The list of core values includes ecological and cultural diversity; peoples' sovereignty, human and peoples' rights; and equity and environmental, social, economic and gender justice. ${ }^{206}$ This shift is also evident in the 2005 FoEI vision statement and its explicit focus on the social aspects of environmental issues:

${ }^{202}$ Interview with Kevin Dunion, FoEI Chair (1996-2003), Executive Director, FoE Scotland (1991-1996), November 2005.

${ }^{203}$ FoEI (2004) Our Environment, Our Rights: standing up for people and the planet. FoEI, Amsterdam, The Netherlands.

${ }^{204}$ Interview with Ann Doherty, FoEI Communications Coordinator, July 2005.

${ }^{205}$ Interview with Mae Ocampo, FoEI International Membership Development Coordinator, October 2004.

${ }^{206}$ FoEI (2005) Outcomes of the Penang Visioning Workshop, FoEI, Amsterdam, The Netherlands, October. 
Our vision is of a peaceful and sustainable world based on societies living in harmony with nature. We envision a society of interdependent people living in dignity, wholeness and fulfillment where equity and human and peoples' rights are realized. This will be a society built upon peoples' sovereignty and participation. It will be founded on social, economic, gender and environmental justice and free from all forms of domination and exploitation, such as neo-liberalism, corporate globalization, neo-colonialism and militarism.

Friends of the Earth International is a worldwide grassroots environmental network campaigning for an ecologically sustainable, just and peaceful world. We are a vibrant, credible and effective federation, driving social transformation and securing sustainable, gender just and equitable societies. ${ }^{207}$

In this excerpt from the vision statement, it is apparent that FoEI member groups place as much emphasis on the social justice, equity and empowerment as on environmental issues. Notably, the mission agreed on in 2005 is the first FoEI mission statement to place social issues as its first mission item rather than the historical priority given to an opening environmental statement. The mission statement begins with FoEI's aim "to collectively ensure environmental and social justice, human dignity, and respect for human rights and peoples' rights so as to secure sustainable societies." This is followed by its environmental aim "to halt and reverse environmental degradation and depletion of natural resources, nurture the earth's ecological and cultural diversity, and secure sustainable livelihoods." ${ }^{208}$. Other mission statement items include FoEI's aim of empowerment of all peoples and its commitment "to bring about the transformation towards sustainability and equity." The critical question is: how has this growing trend towards an integrated social and environmental agenda - as well as the increasing emphasis on international collaboration - influenced campaigning at the local, national, regional and international level? The next section aims to answer this question.

\subsection{FoEI Member Groups, Social Sustainability, and the International Agenda}

There are at least two different ways in which FoEI member groups have been affected by the development of a growing focus on social sustainability and on creating an international agenda: bilateral solidarity campaigns and international programs campaigns. By bilateral solidarity campaigns, I am referring to tactics used by FoEI

${ }^{207}$ FoEI (2005) Annual Report. FoEI, Amsterdam, The Netherlands.

${ }^{208}$ Ibid. 
member groups to support other predominately local or national campaigns outside of their country. FoEI member groups use a diversity of tactics in order to support and strengthen the work of other FoEI member groups at their national level. These tactics include providing financial and organizational support, writing letters and sending petitions to decision-makers, joining in demonstrations within the home country of the campaign, raising awareness and establishing solidarity campaigns within their own countries in order to exert international pressure on target opponents. Although FoEI is not a development aid organization, it engages in extensive support of member groups, particularly in non-industrialized countries. As FoEI expanded its organization into developing countries in Eastern Europe and the global South, FoEI evolved substantial systems of funding, information and campaign support. I will discuss this system in more detail in Section 8.3. For example, FoEI launched a special organization, Milieukontakt Oost-Europa (based in the Netherlands), to support Eastern member groups with funding and office equipment. ${ }^{209}$ In another example, FoEI sponsored FoE Nigerian activist, Nnimmo Bassey, on a tour of communities threatened by the practices of oil companies in their area in order to exchange ideas and share tactics with community activists in these countries. ${ }^{210}$ These exchanges seek to overcome typical North-South barriers as communities threatened by developments of environmentally and socially irresponsible corporations in Scotland and the USA participate in information sharing.

Solidarity demonstrations and actions are common within the FoEI network and often tied to FoEI annual general meetings or Executive Committee meetings. For example, after a FoEI Annual General Meeting in Bogotá in 1999, FoEI representatives joined the U'wa people, an indigenous peoples of Colombia, in a protest march against the American oil company Occidental Petroleum and the Colombian government. ${ }^{211}$ In 2001, after the Executive Committee meeting in El Salvador, FoEI Executive Committee members made public appearances on local and national media to show support for the

\footnotetext{
${ }^{209}$ Interview with John Hontelez, FoEI Chair (1986-1996), May 2006.

${ }^{210}$ FoEI (2003) Annual Report. FoEI, Amsterdam, The Netherlands.

211 van den Hoek, A. (1999) "At the Cliff's Edge: Demonstrating with the U'wa in Colombia" LINK: Friends of the Earth International, Amsterdam, The Netherlands, vol. 91.
} 
work of FoE El Salvador, particularly in encouraging the use of bicycles. ${ }^{212}$ In 1996, Deniza Ismael from the Philippines noted the importance of the international solidarity work of FoEI groups in supporting the Masinloc communities displaced by a coal-fired thermal power plant in the Philippines, especially the tactics employed by FoE Japan in mobilizing a large public campaign in support of the community. ${ }^{213}$ In at least two cases, FoEI solidarity actions have contributed to the release of FoE activists from imprisonment. ${ }^{214}$

Bilateral actions are not only aimed at supporting developing country campaigns, but also offer solidarity in Northern efforts. In the campaign by Milieu Defensie (FoE Netherlands) against a planned expansion to Amsterdam's Schiphol airport, FoE Netherlands launched a legal suit on behalf of 28 Southern Groups including FoE groups in Argentina, Benin, Brazil, Ghana, Togo, Sierra Leone, and Uruguay, against the airport claiming that the airport authorities had not considered the costs due to climate change of the development expansion. ${ }^{215}$ These solidarity actions assume that the target opponents in each of these campaigns are ultimately global targets for the FoEI network as a whole. One FoE activist from Malaysia expressed this sentiment at a meeting of local FoE groups in the United Kingdom:

When we talk about global problems, what are global problems but an accumulation of local problems? It is safe water, clean air, safe land, real forests, a quality of life where you can look forward to waking up in the morning. So many of the things that I see you in the North are fighting for, we are fighting for at home. My appeal to you is because we are fighting the same battles, that you have to stake your battles beyond your local communities. The same company you are fighting against also goes to Scotland, goes to Ireland, goes to Malaysia and goes to Africa. The way your government votes in the World Bank, the way overseas development aid is being spent or mis-spent, the way your money goes into commercial banks and those banks invest in destructive projects: these are the global links to your local democracy. This

${ }^{212}$ FoEI (2001) Friends of the Earth International Annual Report. Friends of the Earth International, Amsterdam, The Netherlands, p. 6.

${ }^{213}$ Doherty, A. (1996) "Deniza Ismael, FoE Philippines" LINK: Friends of the Earth International, Amsterdam, The Netherlands, vol. 73.

${ }^{214}$ FoEI (2001) Sparks of Hope, Fires of Resistance: FoEI Celebrates the Sustainable Path Forward: $30^{\text {th }}$ Anniversary Publication. FoEI, Amsterdam, The Netherlands.

${ }^{215}$ FoEI (1996) Friends of the Earth: 26 Years for the Planet, for People. FoEI, Amsterdam, The Netherlands, p. 13. 
is thinking globally and acting locally. We have to do both. My appeal to you is that we fight together. ${ }^{216}$

The campaign on tropical rainforest preservation provides an interesting empirical example of how this tactical innovation of bilateral and multilateral support translates into tactical changes on the ground. A clear case is Radio Amazonia, an FoEI project sponsored by Friends of the Europe which "provides isolated communities of forest dwellers with networks of radio transceivers" in response to requests by the Amazon peoples to protect their land and their health. ${ }^{217}$ Since its inception in 1991, radio equipment powered by solar batteries have been delivered to almost 200 villages in the Amazon and through the resulting communication with government officials, villagers have access to markets for their sustainable forest products and transport for health emergencies. In addition, the villagers provide "eyes on the ground" by monitoring illegal tropical hardwood harvesting, which they report back to officials and FoEI groups.

The tactical shift towards bilateral and multilateral campaigning is reported by FoE England, Wales and Northern Ireland (FoE EWNI). In the 1970s, FoE EWNI primarily campaigned on national campaigns such as packaging and product waste, an Endangered Species Act, energy and transport issues, otter protection and seal hunts. Its international campaigns were in protest of whaling activities and nuclear power and in support of FoEI activities at the UN Conference on the Human Environment. ${ }^{218}$ In response to initial discussions on tropical rainforests at a series of FoEI annual meeting since 1979, FoE England, Wales and Northern Ireland launched a tropical rainforest campaign in 1985. They drew up a list of tropical hardwoods, advising consumers on which woods to use and which to avoid. ${ }^{219}$ In 1986 and 1987, FoE EWNI organized financial and political support for Sahabat Alam Malaysia (FoE Malaysia) and their campaign to assist the

${ }^{216}$ Extract from speech given by Chee Yoke Ling of Sahabat Alam Malaysia (FoE Malaysia) to FoE England, Wales and Northern Ireland's Local Groups Conference, September 1992 as quoted in 1992 FoEI Annual Report p. 2.

${ }^{217}$ FoEI (1999) Friends of the Earth International Annual Report. Friends of the Earth International, Amsterdam, The Netherlands, p. 9.

${ }^{218}$ Burke, Tom (1981) A History of Friends of the Earth. FoEI historical archive, Amsterdam, The Netherlands, February.

${ }^{219}$ FoE EWNI (1992) Friends of the Earth 1971-1992: 21 Years of Friends of the Earth. Friends of the Earth Ltd. London, UK. 
Penan indigenous people of the Sarawak rainforest in their blockades of logging roads. In 1987 and 1989, FoE EWNI launched a specific campaign targeted at Coca-Cola Foods and high street banks reportedly contributing to their withdrawal from development projects in rainforest regions. Partly in response to lobbying by FoE EWNI and many other civil society organizations and networks, the European Parliament passed a resolution to control imports of tropical hardwoods to Europe in 1989 and the World Bank agreed to stop funding logging projects in primary moist tropical forests in $1991 .{ }^{220}$ In 1993, Brazilian forest peoples' leaders demonstrated outside of the British department store, Harrods, to demand action against the sale of mahogany, which influenced the decision of five superstores in the UK to announce that they would no longer sell mahogany. ${ }^{221}$ In 1997, FoE EWNI and FoE Chile lobbied unsuccessfully to place mahogany on the list of endangered species of the Convention on Trade and Endangered Species (CITES). "Despite support from EU and many Latin American countries and 60 percent vote in favour, the listing failed to get through due to strong lobbying by the Brazilian government and a US timber industry group." In 2002, the CITES governments protected mahogany on the CITES list.

As the current Executive Director of FoE England, Wales and Northern Ireland notes, participation in FoEI has resulted in a significant shift in the issues which his organization addresses,

Our national situation has been informed by the international federation and particularly by campaigning from our Southern partners. Three years ago our strategic ambition at the national level was a list of things such as traffic, GM crops and other issues. Then we took a step back to look at the bigger things that lie behind all of these issues: energy, corporations, and consumption. ${ }^{222}$

For Juniper, this approach reflects "the scale of the issues" by dealing with "root causes" such as production and consumption patterns. This shift was driven, in part, by one of

\footnotetext{
${ }^{220}$ FoE EWNI (1992) Friends of the Earth 1971-1992: 21 Years of Friends of the Earth. Friends of the Earth Ltd. London, UK.

${ }^{221}$. FoEI (1993) Friends of the Earth International Annual Report. FoEI; Amsterdam, The Netherlands.

${ }^{222}$ Interview with Tony Juniper, Executive Director of FoE EWNI and Vice-Chair of FoEI's Executive Committee, January 2006.
} 
FoEl's most extensive international programs to date, the Sustainable Societies program. Launched after the 1992 United Nations Conference on Environment and Development, the Sustainable Societies program was inspired by a publication from FoE Netherlands (Vereniging Milieudefensie): “Action Plan Sustainable Netherlands." ${ }^{, 23}$ This publication addressed the Earth's ecological limits and argued that world citizens should be allocated a "fair share of environmental space" in order to meet their needs. Environmental space is the total amount of energy, non-renewable resources, land, water, forests and other resources which can be used per capita without causing environmental damage or impinging on the rights of future generations. ${ }^{224}$ The Sustainable Societies program, with its focus on environmental space, expresses FoEl's commitment to both people and the natural systems. Other themes of the publication included protecting human and environmental rights and biodiversity.

The 1992 "Action Plan" publication inspired the "Sustainable Societies" campaign in which European and other member groups assessed their national path towards sustainability. The program was supported by the European Union, the Dutch, German and Norwegian governments and the United Nations Environment Program and others. It sought to create "a coherent and comparable basis for discussing sustainability in Europe" and of concrete "policy recommendations relevant to national circumstances."225 For high-consumption countries, these assessments endeavored to raise issues of lifestyles and unsustainable production and inequitable consumption patterns. ${ }^{226}$ Because of FoEI's membership within non-industrialized countries, the Sustainable Societies program also addresses North-South issues and the trade-related aspects of the environmental space program. The program involves FoE Ghana, FoE Uruguay, FoE Indonesia, FoE Georgia and other groups from Russia, Nigeria, Brazil, Senegal and India

\footnotetext{
${ }^{223}$ Buitenkamp, M, H. Venner et al. (1993) Action Plan Sustainable Netherlands. Amsterdam, The Netherlands, Vereniging Milieudefensie: Friends of the Earth Netherlands.

${ }^{224} \mathrm{http}: / / \mathrm{www}$.foei.org/publications/sustainability/sustain.html

${ }^{225} \mathrm{http}: / / \mathrm{www}$.foei.org/publications/sustainability/sustain.html

${ }^{226}$ For example, Milieudefensie (2002) Sustainable Production and Consumption. Amsterdam, The Netherlands, Vereniging Milieudefensie: Friends of the Earth Netherlands.
} 
to study "the potential impact of reduced Northern resource use on Southern and Eastern economies.",227

FoEI member groups are involved in bilateral activities and in international programs such as the Sustainable Societies program. They have also developed their approach to international campaigns. For example, FoEI lobbied at the intergovernmental discussions on ozone-depleting chemicals and in the international processes designed to address this global atmospheric issue. Bloodgood (2002: 255) proposes that FoEI was effective in its contribution to the ban of stratospheric ozone-depleting chemicals, and attributes FoEI's effectiveness to its "two-pronged strategy... combining information lobbying to decision-making to enact national legislation and international treaties concerning the ozone layer, with public education campaigns geared to inform people about the dangers of ozone-depleting chemicals and convince them to change their buying habits." At the international level, FoEI campaigns on such issues as international financial institutions, trade, mining, forests, and genetically-modified organisms.

FoEI employs tactics such as lobbying, demonstrations, policy and scientific reports, public education, and petitions. FoEI has also engaged in symbolic actions as part of their campaigns. At the UN Conference on Environment and Development in Rio de Janeiro in 1992, FoEI members and street children marched a 30-foot inflatable chainsaw down the streets of Rio in an attempt to draw attention to rainforest destruction. FoEI has received media attention for a number of symbolic actions created for intergovernmental meetings on climate change. These included a sandbag dike, a lifeboat, and an art installation of ice sculptures on oil barrel pedestals that melted within a few hours in an attempt to draw attention to the urgency of the climate change. At the World Summit on Sustainable Development in 2002, FoEI created an installation, entitled "Hear Our Voices", as a critique of what FoEI perceives to be 'corporate-led' globalization. The installation included a 20 -foot tall robot representing the corporate world and painted with logos of transnational corporations standing amongst hundreds of papier-maché 3foot tall sculptures representing people impacted by corporate activities. The speakers

${ }^{227}$ http://www.foei.org/publications/sustainability/sustain.html 
distributed amongst the 'people' transmitted prerecorded messages from communities and individuals protesting development projects, who urge governments to advance sustainable development. These testimonies were gathered from communities and organizations directly involved or in alliance with FoEI and were designed to be a symbol of a widespread grassroots movement against the current model of economic globalization and in favour of sustainable and equitable societies.

FoEI's local and national reach informs not only the creation of symbolic actions but also joint positions on international issues. This development of international positions held by the entire network has become an increasingly common practice of FoEI as it has shifted its focus towards some of the cross-cutting root causes of unsustainable development. One past FoEI Chair clarifies the difference between the positions created on single-issues compared to those developed to tackle the transnational political environment and global issues:

A unique part of the Friends of the Earth network is that if the network decides to adopt a stance to oppose whaling, FoE Norway and FoE Japan can still have a policy that allows for whaling and be part of the network. They would not be openly criticized for this and they can maintain their national agenda within this single issue. However, as we move to a position on the worldview of sustainable development, then you can't have parts of the network with an entirely different agenda. You can't have Friends of the Earth groups going to the Commission on Sustainable Development with 10 to 15 different perspectives. ${ }^{228}$

With these international cross-cutting issues, such as sustainable development or economic globalization, FoEI member groups have, since 1994, agreed that common positions are essential. Arriving at these positions is an entirely different matter. The decentralized and informal structure of FoEI determines the way in which these international positions are reached:

Friends of the Earth International is very democratic. Every two years, we have a meeting where everything is discussed in plenary. There are endless discussions which can be rather daunting at the beginning, and tiny decisions can take days. In the end, people agree and people are happy with that.

If you compare this to Greenpeace, we are very different. We work on the same issues and also work together in a productive way but our structures are very

${ }^{228}$ Interview with Kevin Dunion, FoEI Chair (1996-2003), Executive Director, FoE Scotland (1991-1996), November 2006. 
different. Greenpeace is extremely hierarchical with a few people calling the shots on how to campaign and who is going to work on which issue. We decide everything from the bottom-up - from the local to the global - and we work with outside movements which takes even longer.

It is sometimes tedious work because it can take years to get to a position on something. For example, the discussion on trade and agriculture was very drawn out but then we were able to draft a position paper and now the whole network has signed on to it. We all agree that this is the position we want to take - which is very powerful. Even if this is a process of consensus, our positions are radical and the process itself is radical. ${ }^{229}$

As this quotation illustrates, FoEI is committed to a decentralized, informal and democratic process. Through this decision-making process, FoEI has agreed to common positions on such issues as corporate accountability, trade, agriculture, human and environmental rights, and the privatization of water. In the 2001 Annual Report, Ricardo Navarro, as Chair of FoEI, stated that FoEI "offers a coherent, radical critique to current neo-liberal economic globalization model, as well as workable and sustainable alternatives." 230 For FoEI member groups, it is at the annual general meetings that these coherent international positions are developed. In many ways, these meeting serve as a catalyst which enables FoEI groups to strategically respond to the challenge of working globally.

\subsection{Annual General Meetings}

I propose that FoEI's general meetings serve as the key driver for continuous tactical innovation at the level of "working globally." It is in these meetings that FoEI member groups exchange ideas and share experiences, deliberate on critical issues and possible alternatives, and develop a vision of working together towards a common goal of sustainable and just societies. Table 6.2 details the location of the general meetings from their origins in 1971.

${ }^{229}$ Interview with Ann Doherty, Communications Coordinator, FoEI, September 2002.

${ }^{230}$ FoEI (2001) Annual Report. FoEI, Amsterdam, The Netherlands, p.3. 
Table 6.2 Friends of the Earth International Annual General Meetings

\begin{tabular}{|c|c|c|c|}
\hline Year & \begin{tabular}{|l|} 
Country \\
\end{tabular} & City & Groups present \\
\hline 1971 & \begin{tabular}{|l} 
France \\
Sweden
\end{tabular} & \begin{tabular}{|l|} 
Paris \\
Roslagen \\
\end{tabular} & $4 / 4$ \\
\hline 1972 & Wes Germany & Frankfurt & $\mathrm{n} / \mathrm{a}$ \\
\hline 1973 & France & Paris & $\mathrm{n} / \mathrm{a}$ \\
\hline 1974 & \begin{tabular}{|l} 
The Netherlands \\
\end{tabular} & Haarlem & $8 / 10$ \\
\hline 1975 & England & London & $12 / 13$ \\
\hline 1976 & England & London & $4 / 13$ \\
\hline 1977 & Belgium & \begin{tabular}{|l|} 
Brussels \\
\end{tabular} & $16 / 19$ \\
\hline 1978 & Germany & Frankfurt & $15 / 20$ \\
\hline 1979 & \begin{tabular}{|l|} 
Sweden \\
\end{tabular} & Gothenburg & $12 / 22$ \\
\hline 1980 & Spain & Madrid & $10 / 24$ \\
\hline 1981 & USA & Washington, DC & $15 / 29$ \\
\hline 1982 & Scotland & Edinburgh & $10 / 29$ \\
\hline 1983 & Portugal & Foz do Arelho, Lisbon & $13 / 27$ \\
\hline 1984 & \begin{tabular}{|l|} 
Italy \\
\end{tabular} & Castelgandolfo, Rome & $14 / 28$ \\
\hline 1985 & England & London & $17 / 31$ \\
\hline 1986 & Malaysia & Penang & $16 / 32$ \\
\hline 1987 & The Netherlands & Amsterdam & $24 / 32$ \\
\hline 1988 & \begin{tabular}{|l|} 
Poland \\
\end{tabular} & \begin{tabular}{|l|} 
Krakow \\
\end{tabular} & $27 / 34$ \\
\hline 1989 & \begin{tabular}{|l|} 
USA \\
\end{tabular} & Washington, DC & $30 / 39$ \\
\hline 1990 & Ghana & Accra & $30 / 44$ \\
\hline 1991 & Brazil & Sao Paolo & $33 / 48$ \\
\hline 1992 & Spain & Valsain & $47 / 52$ \\
\hline 1993 & \begin{tabular}{|l|} 
Indonesia \\
\end{tabular} & \begin{tabular}{|l|} 
Cisarua, West Java \\
\end{tabular} & $46 / 54$ \\
\hline 1994 & Estonia & Jäneda & $40 / 55$ \\
\hline 1995 & \begin{tabular}{|l|} 
Togo \\
\end{tabular} & Nambéto & $41 / 54$ \\
\hline 1996 & United Kingdom & Leeds & $52 / 57$ \\
\hline 1997 & \begin{tabular}{|l|} 
Uruguay \\
\end{tabular} & \begin{tabular}{|l|} 
Montevideo \\
\end{tabular} & $46 / 58$ \\
\hline 1998 & Australia & Melbourne & $45 / 60$ \\
\hline 1999 & Ecuador & Quito & $41 / 62$ \\
\hline 2000 & USA & \begin{tabular}{|l|} 
West Virginia \\
\end{tabular} & $49 / 66$ \\
\hline 2001 & $\begin{array}{l}\text { Benin (south-south } \\
\text { conference) }\end{array}$ & Cotonou & $41 / 66$ \\
\hline 2002 & Switzerland & Beatenberg & $56 / 69$ \\
\hline 2003 & $\begin{array}{l}\text { Colombia (extraordinary } \\
\text { GM) }\end{array}$ & Cartagena & $51 / 69$ \\
\hline 2004 & Croatia & \begin{tabular}{|l} 
Stubicke Toplice \\
\end{tabular} & $57 / 72$ \\
\hline 2005 & $\begin{array}{l}\text { Malaysia (extraordinary } \\
\text { GM) }\end{array}$ & Penang & $58 / 72$ \\
\hline 2006 & Nigeria & Abuja & $49 / 71$ \\
\hline
\end{tabular}


The decentralized and informal nature of these meetings and strong personal commitment of the members encourages a vibrant exchange which, I argue, is the lifeblood of the organization. After the 1992 AGM, one FoEI member noted the "strong opinions, raised voices and heated debates" amongst members while "it was still clear... that these FoE folks liked each other and cared intensely about our organization" and "differences of opinion were invited [and] debate encouraged."231 Mairi MacArthur, the first FoEI Chair, similarly notes the power of the annual general meeting:

FoEI was not invented, in any one place or according to any one model. It has evolved as its members have evolved and it is still doing so. The autonomy of the FoE groups is partly due to this history and their first period as a loose federation with no central structure at all. But the principle of autonomy is also central to what makes FoEI unique. The groups share the commitment to "Think Globally" but, from the beginning, "Acting Locally" has meant working in ways best suited to their people's cultural, social and political traditions. It is basic to what makes FoEI international (rather than multinational). The groups have long recognized, however, that their diversity can also be a weakness. Some have many more staff and resources than others, some develop greater expertise in certain areas, some place the priority of international work high and some low. Yet, once a year, these inevitable differences must take second place to the common task of moving the international agenda forward. It is excellent that the Annual Meeting has become such an important, wellattended event in the FoEI calendar in recent years. Once around that table, each Council Member, large or small, has something valid to contribute; each voice carries the same weight. Listening to each other, with patience and perception, is always necessary and we were not particularly good at it in the early 1980s. The North has had to learn to listen to the South, the West to the East, old groups to the new and native English speakers to everyone. ${ }^{232}$

Innovation flows from this interaction between different perspectives: North, South, East and West; old and new; problems and solutions; social justice and the environment; and grassroots and international. It is this dynamic exchange and tension between different perspectives that ensures innovation within FoEI. In one interview, Beatrice Olivastri, Chair of FoE Canada, remarked that "there is a continuing tension about how you weigh issues and how you interpret priorities into an international campaign" which unfolds through strategy sessions at the meetings. She notes:

${ }^{231}$ FoEI (1994) A Gift From FoEI in LINK, FoEI, Amsterdam, The Netherlands, Sept-Dec, Issue $62 / 63$, p. 25.

${ }^{232}$ MacArthur, Mairi (1989) The Growth of FoEI: A Personal View. July, FoEI historical archives, Amsterdam, The Netherlands. 
When I talk about creative tension, I am referring to the Biannual General Meetings and the planning and decision-making that occurs at those sessions... It's the $e b b$ and flow of passion and energy and opinions that all are in one room when you get all these high energy organizations together with different priorities with their national priorities and needs and plans. What I always find quite interesting is the process where this person from this country has this set of ideas and, I tell you, passion about what they want to achieve and someone else from another country has another set of ideas or different take on it. What I like about FoE - I refer to the meetings as raucous - something comes out of those meetings - in that exchange of heat, energy, people. ${ }^{233}$

These general meetings support international collaboration across national groups and contribute to FoEI's creation of a global grassroots movement.

\subsection{Global Grassroots Movement}

As I detail in Chapter Five, I propose that FoEI's approach to working globally is to nurture the development of a global grassroots movement for sustainable and just societies. There are two key reasons for this strategic response. First, FoEI is committed to being "the world's largest grassroots environmental network" rather than a more centralized global campaigning organization. FoEI member groups reinforce both the autonomy of the national member groups and their local constituencies as well as the FoEI commitment to a decentralized structure. ${ }^{234}$ Second, FoEI member groups believe that the trends away from sustainable development at the transnational level require international campaigns in addition to local and national efforts. Consider the description of FoEI's broader agenda: "challenging governments and policy makers worldwide to adopt policies that contribute to sustainable societies and encourage local community initiatives." 235 The FoEI member groups combine "grassroots activism with international advocacy" in order to encourage changes in the practices and policies of governments and international organizations as well as "community level solutions," which they perceive as being "the seeds of future sustainable societies." 236 In order to achieve this

\footnotetext{
${ }^{233}$ Interview with Beatrice Olivastri, co-founder and CEO, FoE Canada, September 2004

${ }^{234}$ FoEI (2003) Annual Report. FoEI, Amsterdam, The Netherlands, p.2

${ }^{235}$ FoEI (2001) Sparks of Hope, Fires of Resistance: FoEI Celebrates the Sustainable Path Forward: $30^{\text {th }}$ Anniversary Publication. FoEI, Amsterdam, The Netherlands, p.2

${ }^{236}$ Ibid.
} 
purpose, FoEI member groups collaborate with other organizations and movements who share their worldview,

We find inspiration in the growing wave of coordinated resistance to corporate-led globalization sweeping the planet. This is what has blossomed in the decade since the Earth Summit [1992 UNCED], and our joint campaigns for trade justice, rights for communities, the repayment of the ecological debt, and rules for big business are gathering momentum. ${ }^{237}$

By working globally through FoEI and through alliances with like-minded organizations and movements, FoEI member groups within their own countries aim to change national policy. In his scholarly analysis of FoEI, Wapner proposes that FoEI is focused on "political internationalism" and influencing nation-state governments to play a major role in environmental protection. FoEI accomplishes this by combining institutionalized tactics - such as lobbying - with influencing "the numerous interdependencies that impinge upon [nation-state] maneuverability and behavior" including "economic, cultural, social and governmental activities that are interstate, trans-governmental or transnational in character" (Wapner 1996: 126). Some of FoEI's tactics are aimed at municipalities, provinces, regions, and corporations. The strategy is to "use those pockets of jurisdiction [and corporate pressure] to advance initiatives with national and global impact" (Wapner 1996: 128). As the following quotation suggests, Wapner (1996: 132) argues that FoEI also uses the economic marketplace and international organizations to pressure states:

FOE focuses on transnational economic practices and uses the international market to create incentives for international accords. Friends of the Earth recognizes that economic practices are becoming global in scope and that constraining them in one domestic setting can have international implications.... While FOE pursues much of its work by expanding outward, that is, from local to national to international settings, it also pinpoints the interdependencies that function in the other direction. It manipulates processes that are, at first, international, and uses them to impose environmental constraints at the national and local levels of interaction. This is one of FOE's most significant endeavours. Foremost in its strategies, FOE focuses on international regimes... [which] institutionalize international behavior by developing rules, norms and conventions.

${ }^{237}$ Navarro, R. (2002) "Ten Years Down the Road" in FoEI Annual Report. FoEI, Amsterdam, The Netherlands. 
Wapner (1996) continues by highlighting the role of FoEI in influencing multilateral development banks that affect and impinge upon the ability of national governments, particularly in developing countries, to secure their ecological well-being. FoEI pursue these multiple targets in order to "corner" states into particular ecologically sound behaviors and to alter the way that states perceive their interests. In other words, "transnational activists manipulate the entanglements of states [in an attempt] to create conditions that will constrain the activities of all significant actors, especially states" and to hold states accountable (Wapner 1996: 144). FoEI member groups provide an "account" of their interpretations of environmental challenges and facilitate the voices of marginalized peoples to express their perspectives to governments and other influential actors. Wapner (1966: 148) describes Friends of the Earth's strategy as "political internationalism" because "internationalism traditionally aspires to universal aims higher than those embodied in state action yet prescribes enlisting states in the realization of this larger project." FoEI embodies political internationalism because it employs an array of tactics to nudge states in the service of global environmental well-being and holds them accountable to the ecological impacts of their actions. Wapner (1996) notes that this is not simple.

Building a system of global accountability in environmental affairs is obviously, no small undertaking, especially for a nonstate actor. It is the enormity of the task, however, that makes it necessary for groups such as FoEI to cast their nets wide and work through multiple channels and levels of world political life to do so. Because of their relative weakness compared to other actors, transnational environmental groups seek to create as many checks and oversights as possible and use them to influence states and thus scramble the often anti-environmental imperatives of the state system.

I agree with Wapner that FoEI casts its net wide. I label this an "expansion" approach to working globally. Suter (2002/2003) similarly concludes that FoEI has adopted a broadbased approach to working globally and notes the challenge of cohesion. He describes FoEI as "a movement within the movement" that defines environmental issues to include a strong social dimension and that carries out campaigns on a wide range of issue areas.

FoEI has been very active in particular campaigns. It probably regards itself as more active in campaigns than any other environmental organization. But while the activities are there, there is no basic, uniting belief system that underpins them. This may become more of a problem as FoEI increases its geographic spread and takes on an increasingly diverse range of national/local sections. What will hold all the 
national sections/ local branches together? Diversity can be a great strength - but it can also be a great weakness... FoEI's special vulnerability derives from its policy of defining the environment so broadly and trying to deal with so many issues.

In the 1993 FoEI Annual Report, John Hontelez, past Chair of FoEI, expressed a similar assessment of the challenge facing FoEI,

Our uniqueness lies in our ability to combine the strengths of our [member] groups into global strategies, while taking into account our social, economic, political and cultural differences. Our ability to combine these strengths cannot be taken for granted. It needs to be constantly reassessed and re-established. This is Friends of the Earth International's greatest challenge. ${ }^{238}$

The FoEI approach is certainly broad and embracing of diversity. I would also argue that it is FoEI's greatest strength to embrace an "expansion" approach to tactical innovation. Rather than concentrating on specific issues or particular tactics, as I argue Greenpeace has done (Chapter Seven), FoEI has remained an open networked organization that welcomes the flux and flow that comes with celebrating cultural differences and maintaining a commitment to an informal, decentralized structure. In Chapter Nine, I discuss some of the strengths of this approach while also highlighting weaknesses, including the issue of overextension and lack of coherence discussed above.

One would think that with all of FoEI's internal diversity, the member groups would experience difficulty in developing a common position on their values, mission and vision; however, in the 2005 strategic planning process, FoEI member groups have done just that (see Appendix C). In 2006, FoEI expanded on this common framework by defining its common campaign strategies through a bottom-up and democratic process and specifying the approach it will take to implementing their strategic plan together. FoEI's unique approach to working globally has emerged from the iterative interaction of members across cultures and scales spanning the grassroots level to the global political arena. As the current FoEI Chair describes, this approach has the potential to enable both coherence and diversity:

So you see that we do have the richness and different ways of working and that is the challenge. Our approach is that before we could understand how we work differently, we had to understand why we work. What is the core of our work?

${ }^{238}$ FoEI (1993) Annual Report. FoEI, Amsterdam, The Netherlands, p. 3. 
What is our mission? So we share the same mission in how we want to influence the world. Then, afterwards, we can explain to each other how we do things in different ways but dream the same dream. ${ }^{239}$

As this quotation suggests, FoEI member groups have slowly evolved a more coherent umbrella strategy at the international level; however, local and national perspectives and campaigns remain the foundation upon which FoEI is built and international coherence remains a challenge. In the next chapter, I will explore how Greenpeace has adopted a very different strategic response to tactical innovation, which emphasizes a coherent approach to delivering international campaigns.

${ }^{239}$ Interview with Meena Raman, FoEI Chair (2004 - present), Sahabat Alam Malaysia (FoE Malaysia), February 2006. 


\section{CHAPTER SEVEN: Greenpeace and Tactical Specialization}

\subsection{Introduction}

Greenpeace is renowned for its unique approach to environmental activism through nonviolent direct action. Greenpeace activists bear witness to environmentally damaging activities of governments or corporations, protesting their actions by providing "an unwavering presence at the site of environmental abuse whatever the risk" (Wapner 2001: 568). With film and photo cameras, they document the problem and disseminate images of the ecological abuse through the mass media in an effort to transform public opinion, inspire activism and stimulate change in the behavior of their targets (Wapner 2001). This tactical strategy is at the core of Greenpeace's approach to working globally, and is evident in their mission statement,

Greenpeace is an independent campaigning organization that uses non-violent, creative confrontation to expose global environmental problems and to force solutions which are essential to a green and peaceful future. ${ }^{240}$

I begin this section by describing different aspects of this tactical approach in detail; as it is considered Greenpeace's "signature amongst activist groups" (Wapner 2001: 568; see also Brown and May 1989: 4 and May 2006: 66). I propose that the adaptability of Greenpeace derives from its fine-tuning and elaboration of this approach over timewhich I label a specialization approach to tactical innovation. Greenpeace campaigners adjust their tactics in response to the organization's expansion into new issue areas, countries and regions and, at the same time, have retained the core elements introduced by Greenpeace's founders. Over three decades, Greenpeace has increased the sophistication of its tactical approach from its first loosely organized protest against US government nuclear testing in Amchitka, Alaska to its current highly developed global campaign infrastructure. In my analysis of its confrontational tactics, I explore the international focus of Greenpeace actions, the political act undertaken by Greenpeace activists to protest environmental abuse, the use of the mass media for communicating these actions to a wider audience, Greenpeace's diplomatic lobbying in its campaigns, and its use of scientific research and technological innovations. I describe the way in

${ }^{240}$ Greenpeace (2005) Annual Report. Greenpeace International, Amsterdam, The Netherlands. 
which Greenpeace combines its direct action, scientific evidence, mass media campaigning and diplomatic lobbying in an integrated way within its campaigns. I then highlight some of the weaknesses inherent in Greenpeace's approach. In the final two sections of this chapter, I return to the areas discussed in the analytical comparison within Sections 5.4.3 and 5.4.4 and explore Greenpeace's approach to working globally in more depth.

Based on this analysis, I challenge the notion that decentralized and informal transnational social movement organizations such as Friends of the Earth International have an advantage in working globally over a relatively more centralized and formalized TSMO structure. The definition of "working globally" as "developing North-South links and international campaign strategies; speaking with a single, loud, global voice albeit with national variations in how they work and what they work on" (Clark 2003a: 111) guides this section as it did Section 5.4 above. FoEI is developing a "single, loud, global voice" through a decentralized process of defining an international agenda while remaining a federation of national groups. In contrast, Greenpeace - and particularly Greenpeace International - has placed a greater emphasis on building a centralized and coherent global campaigning organization. As will become evident below, this focus on centralizing and formalizing Greenpeace's strategic approach to working globally has resulted to a very different approach to national variation and North-South issues than that exhibited by FoEI. Table 7.1 and Figure 7.1 below place key external and internal events on a historical timeline and serve as a reference for the historical discussions throughout this section. 
Table 7.1: $\quad$ Select Events in Greenpeace History

\begin{tabular}{|c|c|c|}
\hline Code & Date & Event \\
\hline $\mathbf{A}$ & 1971 & Protest voyage against US nuclear tests on Amchitka Island, Alaska \\
\hline $\mathbf{B}$ & 1975 & Campaign to protect whales \\
\hline $\mathbf{C}$ & 1976 & Campaign to protect seals, Newfoundland \\
\hline $\mathbf{D}$ & 1982 & International Whaling Commission Moratorium on Commercial Whaling \\
\hline $\mathbf{E}$ & 1983 & Protest against nuclear power by hot air balloon from West to East.Germany \\
\hline $\mathbf{F}$ & 1984 & Campaign for World Park Antarctica begins \\
\hline $\mathbf{G}$ & 1985 & Bombing of the Rainbow Warrior in New Zealand by French secret service \\
\hline $\mathbf{H}$ & 1986 & $\begin{array}{l}\text { Establishment of Greenpeace Communications and Establishment of the } \\
\text { Science Unit }\end{array}$ \\
\hline I & 1988 & Purchase and refurbishment of bus to be used as a laboratory in the Baltic States \\
\hline $\mathbf{J}$ & 1989 & Protest against French landing strip construction in Antarctica \\
\hline $\mathbf{K}$ & 1990 & $\begin{array}{l}\text { Greenpeace reverses its support of US ban on foreign tuna imports (due to } \\
\text { dolphin bycatch) in support of Latin American tuna fishermen }\end{array}$ \\
\hline $\mathbf{L}$ & 1992 & Development of the Greenfreeze fridge \\
\hline $\mathbf{M}$ & 1992 & $\begin{array}{l}\text { Email from David McTaggart, past Greenpeace International Executive } \\
\text { Director and Honorary Chairman, about the original ideas behind Greenpeace to } \\
\text { guide the shape of Greenpeace in the future }\end{array}$ \\
\hline $\mathbf{N}$ & 1992 & Antarctica Treaty protects Antarctica, Greenpeace base in Antarctica dismantled \\
\hline $\mathbf{O}$ & 1992 & Campaign to establish a Whale Sanctuary around Antarctica begins \\
\hline $\mathbf{P}$ & 1994 & $\begin{array}{l}\text { Agreement by International Whaling Commission to establish a Whale } \\
\text { Sanctuary around Antarctica }\end{array}$ \\
\hline $\mathbf{Q}$ & 1995 & $\begin{array}{l}\text { Campaign to pressure Shell to dismantle a disused oil platform, Brent Spar, on } \\
\text { land }\end{array}$ \\
\hline$\overline{\mathbf{R}}$ & 1995 & $\begin{array}{l}\text { 'The Future of Greenpeace' strategic plan by International Executive Director, } \\
\text { Thilo Bode (1994-2000) }\end{array}$ \\
\hline $\mathbf{S}$ & 1996 & Greenfreeze fridge production begins in China \\
\hline $\mathbf{T}$ & 1996 & $\begin{array}{l}\text { Unveiling of the Greenpeace commissioned fuel-efficient prototype car, smILE, } \\
\text { based on Renault Twingo }\end{array}$ \\
\hline$\overline{\mathbf{U}}$ & 1999 & $\begin{array}{l}\text { 'One Greenpeace' strategic document by Greenpeace Chair of the Board of } \\
\text { Directors, Cornelia Durrant }\end{array}$ \\
\hline $\mathbf{V}$ & 2000 & Greenpeace Offices open in India and South East Asia \\
\hline $\mathbf{W}$ & 2001 & $\begin{array}{l}\text { 'Breaking Down the Walls' strategic plan by International Executive Director, } \\
\text { Gerd Leipold ( } 2001 \text { - present) }\end{array}$ \\
\hline $\mathbf{X}$ & 2002 & $\begin{array}{l}\text { Debate about Poverty and Development issues and their incorporation into } \\
\text { Greenpeace campaigns at the debate at the Stichting Greenpeace Council } \\
\text { Annual General Meeting }\end{array}$ \\
\hline $\bar{Y}$ & 2005 & $\begin{array}{l}\text { Greenpeace Argentina campaign (using motorbikes and helicopters) to protect } \\
\text { the rainforest land of the indigenous people, the Wichi, is successful }\end{array}$ \\
\hline
\end{tabular}


Figure 7.1 Reference Timeline for Chapter 7

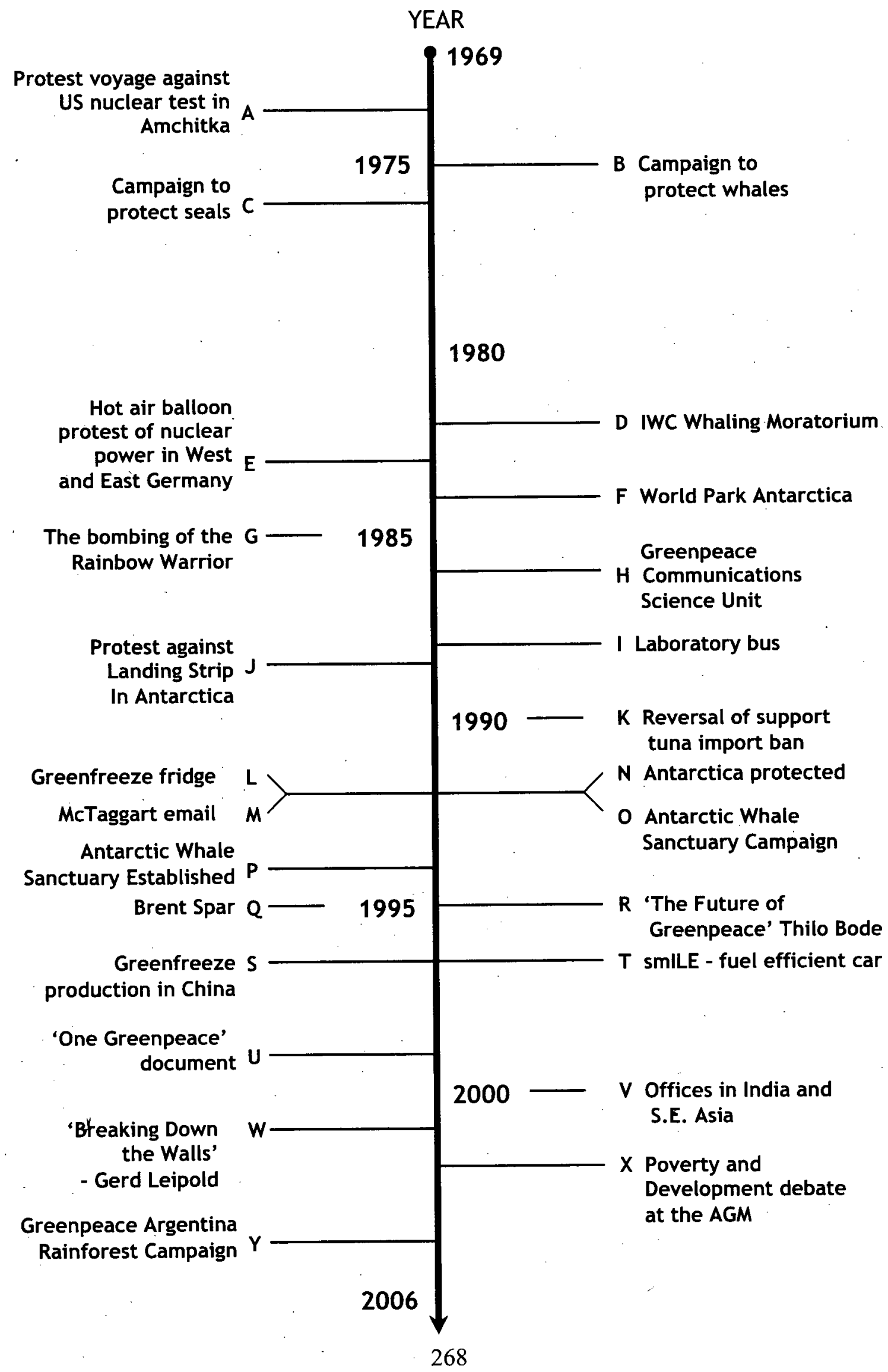




\subsection{The Greenpeace Legend}

The origins of Greenpeace and its initial campaigns to end nuclear testing and halt commercial whaling have taken on an almost mythological quality. The story of the first ten years of Greenpeace, which has been told and re-told from the late 1970s until the present day, remains a legendary tale of an unlikely group of loosely organized protestors who successfully took a stand against powerful governments and industries. ${ }^{241}$ On the initial Greenpeace voyage to blockade US nuclear testing in Alaska, the protestors were keenly aware of the challenges of their task,

None of us had ever put so much effort into anything like this in our lives. We were in an attack on the greatest power in human history - the American Military Industrial Complex. And the way things were going, it looked for a time as though we might actually win.... We were Canadians. Which was important. It meant that the U.S. navy or Coast Guard would not be able to tow us out of the danger area - without committing an act of piracy. Ships would be warned to stay at least fifty miles from the site. We would challenge that limit. Twelve of us - mainly environmentalists would put our bodies on the line. Such a passivist-type action was far from new. But it had never been done before in the name of such a cause as preserving the Earth. Not just did we want peace. We wanted a green peace. ${ }^{242}$

As this quotation indicates, Greenpeace was an international environmental movement from its inception and, unlike FoEI, environmental issues were immediately framed as global environmental issues rather than as national interests with international implications. Greenpeace founders wanted "to define our political relationship with the planet" and saw their actions as a "kernel of what will have to sooner or later become a planetary political system. ${ }^{243}$ Greenpeace was based in the science of ecology that "teaches that humans aren't the centre of life on the planet." ${ }^{244}$ For the founders, ecology was both a scientific concept and a spiritual movement "because it returns sacredness to the Earth." 245 It was a "science-religion" that encouraged Greenpeace activists to work for "a higher cause than your own individual self" - the protection and restoration of the

${ }^{241}$ For example: Keziere and Hunter 1972; McTaggart 1973; McTaggart with Hunter 1978; Hunter 1979; Sturmanis and Sturmanis 1978; Brown and May 1989; Bohlen 2001; McTaggart 2002; Mulvaney 2003; Hunter 2004; Weyler 2004; Zelko 2004.

${ }^{242}$ Keziere and Hunter 1972: 2

${ }^{243}$ Robert Hunter quoted in Stumaris and Stumaris 1978: 51

${ }^{244}$ Robert Hunter quoted in Weyler 2004: 50

${ }^{245}$ Weyler 2004: 63 
Earth from the impacts of industrial society. ${ }^{246}$ This focus on "planetary politics" is evident in Greenpeace today: as its website states, "Greenpeace exists because this fragile earth deserves a voice." ${ }^{247}$ The first Greenpeace voyage inspired people across Canada and the US to volunteer to crew the second ship into the test zone. ${ }^{248}$ By the second protest voyage into the French nuclear testing site at Mururoa in the French Islands, Greenpeace could not be slated as being solely "anti-American" but concerned about nuclear testing wherever on the planet it occurred. ${ }^{249}$ As one founder notes, "that was an incredible psychological jump to make from something that is threatening your life directly to something that is threatening it indirectly."250

Throughout its history, Greenpeace's international campaigns have focused on global environmental problems, including nuclear contamination, pollution, toxic chemicals, unsustainable trade, and genetically modified organisms. In addition, it has focused on protecting and conserving the global commons, including the oceans, species, ancient forests, the climate, the ozone layer, Antarctica and the Amazon. Key to its global approach is an apolitical stance or "transpolitical" approach. ${ }^{251}$ Greenpeace has never been aligned with any particular political party or ideology, and is committed to "political independence." ${ }^{252}$ This commitment derives from Greenpeace's political ideology and view of "democratic governments as exclusive and primarily receptive to the interests of powerful corporate and economic actors" with only a "few points of access and only limited opportunities to participate in political process" for the general citizenry (Carmin and Balser 2002: 382). This interpretive frame has led Greenpeace activists to employ non-institutionalized tactics in order to "challenge governments and corporations when they fail to live up to their mandate to safeguard our environment and our future."253

\footnotetext{
${ }^{246}$ Patrick Moore quoted in Stumaris and Stumaris 1978: 17.

${ }^{247} \mathrm{http}: / /$ www.greenpeace.org/international/

${ }^{248}$ Keziere and Hunter 1972: 98

${ }^{249}$ Ben Metcalfe quoted in Dale 1996: 85

${ }^{250}$ Rob Marining quoted in Stumaris and Stumaris 1978: 17

${ }^{251}$ Robert Hunter quoted in Stumaris and Stumaris 1978: 27

$252 \mathrm{http}: / / \mathrm{www}$.greenpeace.org/international/mission/

${ }^{253}$ Ibid.
} 
Rather than engaging in a battle of words within the political system, Greenpeace activists take direct action in response to environmental problems. Direct action has activists literally placing themselves "between the natural world and the forces that seek to destroy it," whether that be sailing a boat into a nuclear test site, driving an inflatable boat between whalers and a whale, illegally occupying an oil platform slated to be dumped in the ocean, boarding a ship carrying toxic waste, or unlawfully removing genetically modified crops out of farmers' fields. ${ }^{254}$ The initial protest voyage into the nuclear test site was inspired by similar actions undertaken by Quakers, a spiritual community that has its origins in seventeenth century religious dissenters in England (Zelko 2004: 198). Some of the founding members of Greenpeace were Quakers (Irving and Dorothy Stowe and Jim and Marie Bohlen). They introduced the Quaker tactic of "bearing witness" to environmental abuse and the philosophy of "non-violence" originally inspired by Gandhi and his peaceful protest movement in India (Zelko 2004: 1999).

\subsection{Direct Action as a Political Act of Resistance}

In Section 7.4 below, I will discuss the significance of direct action as a tactic that is a symbolic act; however, it is important to note that first and foremost, direct actions are an "act of resistance: a political act" by the activists that are placing their bodies at risk in order to physically halt environmentally destructive behavior. ${ }^{255}$ Although the activists are part of a larger organization and movement, they ultimately have to draw on their

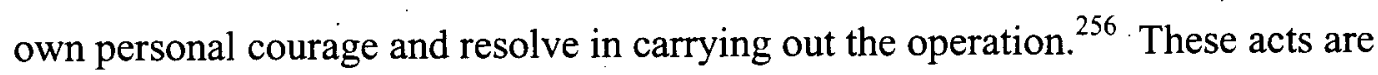
personal political statements by each individual activist and it is this commitment which carries them through moments of crisis. Consider this statement from one activist halting Russian nuclear submarines and ships in the Mediterranean Sea by climbing the anchor chain of one of the ships,

\footnotetext{
${ }^{254}$ Brown and May 1989: 3

${ }^{255}$ Boettger, C. "The Role of Photography in Greenpeace's Strategy" in Boettger and Hamdan (2001): 12

256 e.g., Greenpeace (1996) Witness: Twenty-Five Years on the Environmental Frontline. London, UK: André Deutsch Limited, p. 35-38; Hunter 2002: 200
} 
The [Greenpeace] captain was in constant contact with the ship, informing them of the non-violent nature of our actions, but we can never predict their reaction. In fact, the fire hoses were turned on me straight away but I was very focused. I'm totally opposed to nuclear development, so I knew exactly why I was there. ${ }^{257}$

Moments later, the Russian ship captain began to lower the cable into the water, resulting in the activist having to jump off to avoid drowning. As this scenario highlights, the Greenpeace commitment to the practice of non-violence does not guarantee a peaceful response. Confrontations can result in dramatic and violent reactions by those targeted in the action. During the Greenpeace protest of the French nuclear site at Mururoa, the Greenpeace ship was boarded by French military and Greenpeace campaigners were severely beaten. ${ }^{258}$ This was only the first of many direct attacks on Greenpeace activists "who have allowed themselves to be beaten, dragged away and arrested" in the service of the cause ${ }^{259}$ and serve on the "frontlines of environmental activism." 260 The most dramatic event of violence in Greenpeace history was the 1985 bombing of the Greenpeace ship, the Rainbow Warrior, by French secret service agents to stop a protest voyage against nuclear testing, which resulted in the tragic death of Fernando Pereira, a Greenpeace photographer. ${ }^{261}$

Outside of direct action encounters, Greenpeace activists are targeted with death threats, have their phones tapped and are monitored by governments and corporations. ${ }^{262} \mathrm{I}$ was asked for personal identification upon arrival at Greenpeace International because of past experiences with infiltration of Greenpeace operations, and of corporate and government representatives posing as researchers and journalists. Prominent Greenpeace Brazil activist, Paulo Adario received death threats and learned there was a price on his head when he led a campaign to expose illegal mahogany extraction in the Amazon. Partly because several prominent Brazilian environmentalists had been murdered before, Adario

${ }^{257}$ Grace O'Sullivan, Greenpeace activist quoted in Greenpeace (1996) Witness: Twenty-Five Years on the Environmental Frontline. London, UK: André Deutsch Limited, p. 36.

${ }^{258}$ McTaggart 1973; McTaggart with Hunter 1978; McTaggart 2002

${ }^{259}$ Boettger and Hamdan 2001: 42

${ }^{260}$ Greenpeace 1996

${ }^{261}$ Dyson 1986; Shears and Gidley 1986; Sunday Times 1986

${ }^{262}$ Interview with Rémi Parmentier, Co-founder of Greenpeace France (1974), Greenpeace campaigner including Political Director, Greenpeace International (1974- 2005), November 2005; Hunter 2002. 
decided to move his family out of Brazil, evacuate his home, and move houses continuously with great personal risk in order to continue with 'Operation Mahogany' and lead a large Greenpeace confrontation to expose illegal logging. ${ }^{263}$

Assaults and monitoring by target governments and corporations result in part because Greenpeace actions are public acts of dissent that challenge established policies and laws. ${ }^{264}$ For some environmentalists, there is no justification for breaking the law in order to engage in political protest of environmental destruction; ${ }^{265}$ however, Greenpeace activists justify their actions through reference to "superior law" (including the "law of nature, international or constitutional law") that they believe deserve defense and development "even by breaching subordinate law, if necessary." 266 Since their first protest actions, Greenpeace activists have sought the assistance of lawyers in liberating activists arrested for their actions, in releasing ships and equipment seized during protests, and in pursuing court action for violent attacks by police. This legal support has developed into Greenpeace International's Legal Unit that reviews potential actions to consider legal implications and supports activists in case of arrests and legal action.

Beyond the legal risks, Greenpeace direct action activists are faced with risks associated with simply carrying out specific actions, which often include climbing onto moving objects, fastening small boats onto large ships, and operating Greenpeace fleet vehicles. Greenpeace activists frequently practice actions prior to their implementation. Over time, Greenpeace has institutionalized these practice exercises into an extensive training program to support activists in learning safe and effective tactics and the operation of Greenpeace ships and vehicles. ${ }^{267}$ Activists are equally, encouraged to be informed by the spiritual commitment and good humor that inspired the original Greenpeace protestors

${ }^{263}$ Greenpeace (2002) Annual Report. Greenpeace International, Amsterdam, The Netherlands, p. 16-17.

${ }^{264}$ Greenpeace 1996: 42

${ }^{265}$ Interview with William K. Reilly, World Wildlife Fund US, March 2003.

${ }^{266}$.Günther, M. (1996) "Greenpeace and the Law" in Das Greenpeace Buch.

${ }^{267}$ Boettger and Hamdan 2001: 200; Interview with Guido Verbist, Actions Coordinator, Greenpeace International, October 2004. 
who created the direct action tactical approach "out of a blend of bold creativity and modest humor."268

One of the Greenpeace founders refers to Greenpeace as an "eco-strikeforce"269 and, although Greenpeace is a nonviolent organization, Greenpeace campaigners have sometimes drawn inspiration from the military for many of the tactics and tools they use during direct actions. For example, the use of the signature Greenpeace inflatable boats during water bound protests were inspired by the zodiacs used by the French in attacking Greenpeace in its second nuclear test campaign. ${ }^{270}$ Greenpeace has also purchased a number of ex-military and Coast Guard ships for use in its campaigns, predominately in order to keep up with the speed and navigation of the boats they confront. ${ }^{271}$ Over the years, and in response to the needs of different campaigns, Greenpeace has invested in a significant fleet of ships and other vehicles. This has resulted in the development of Marine Services division at Greenpeace International, as "actions with ships require a special infrastructure and appropriate skills on the part of those working for the organization."272

Greenpeace currently owns three ships in its international fleet - The Arctic Sunrise, The Esperanza, and the Rainbow Warrior. Its fleet has included ice breakers to support campaigns in the Arctic and Antarctic and other ships which are outfitted with helicopter landing pads and scientific laboratories. ${ }^{273}$ For land-based campaigns, Greenpeace has adapted its direct action tactics and purchased other vehicles. For example, in 1983, two Greenpeace activists from Germany launched a hot air balloon in West Germany and crossed to East Germany to protest nuclear weapons testing. During a 2005 rainforest protection campaign in Argentina, activists rode motorbikes painted as Jaguars and were

\footnotetext{
${ }^{268}$ Weyler 2004: 405

${ }^{269}$ Bob Hunter as quoted in Weyler 2004: 11

${ }^{270}$ Hunter 1979: 127

${ }^{271}$ Mulvaney, K. (1996) in Greenpeace Witness: Twenty-Five Years on the Environmental Frontline. London, UK: André Deutsch Limited.

${ }^{272}$ Boettger and Hamdan 2001: 172

${ }^{273}$ Boettger and Hamdan 2001: 234-241; http://www.greenpeace.org/international/
} 
guided by helicopters to physically halt bulldozers clearing the forests. ${ }^{274}$ Regardless of the tools used to facilitate a direct action, ultimately these are political and moral statements by the activists, as one Greenpeace campaigner makes clear,

The protest action is not slavish sensation-seeking or an adventure holiday, nor is it an end in itself. It is a precisely though-out strategic action - albeit incredibly invigorating - that goes without saying. Each action is also a protest against powerlessness and paralysis in this world of ours. ${ }^{275}$

\subsection{Mindbombs, the Greenpeace Message and the Mass Media}

As the quotation notes, Greenpeace's direct action campaigns are strategic, and one element of that strategy has always been to communicate the protest to a broader public audience through the use of media coverage. The 1971 Amchitka voyage to protest nuclear tests included print journalists, a radio commentator, and a photographer. This was because, as one of the Greenpeace founders writes, "having learned a lesson from the voyage of the Golden Rule, the Quaker protest vessel of the 1950s, we believed that extensive media involvement would be crucial to the success of our campaigns [because] we wanted to be in full control of what the public heard."276 The Greenpeace founders were inspired by Gandhi's approach to nonviolent civil disobedience combined with communication savvy, and by scholar Marshall McLuhan's writing on media and society. ${ }^{277}$ One of the founders, Bob Hunter, coined the term "mindbomb" to reflect the revolutionary potential of an iconic symbol transmitted through mass communication systems.

If the pen was a hundred or a thousand times mightier than the sword, we can only estimate that television is at least a million times more powerful. Not only can it be used across immense distances (in fact distance makes no difference now), but it can be targeted with complete accuracy to strike at a point precisely two inches between the victim's eyes.... Consider the first landing on the moon.... A mindbomb of sorts had gone off in hundreds of millions of individual and human brains simultaneously. ${ }^{278}$

\footnotetext{
${ }^{274} \mathrm{http}: / /$ www.greenpeace.org/international/forests/; Movie - Greenpeace: Making a Stand (2006) OMNI Productions, Vancouver, Canada.

${ }^{275}$ Harald Zindler, Greenpeace Germany quoted in Boettger and Hamdan 2001: 172.

${ }^{276}$ Bohlen 2001: 33

${ }^{277}$ Hunter 1979; Dale 1996

${ }^{278}$ Hunter 1971: 217-218
} 
Hunter saw the same potential for a "mindbomb" with the 1971 protest voyage to Amchitka Island to bear witness to the nuclear tests. Although there had already been demonstrations along the Canada-US border and other forms of protest against the test, "the fish boat from Vancouver [was] the most visible symbol of public outrage" and triggered a widespread public outcry against the tests across Canada and in the United States. ${ }^{279}$ A similar impact was achieved with the protest voyages to Mururoa, particularly due to the media coverage of the violent attacks by the French military on Greenpeace crew. ${ }^{280}$ The bombing of the Rainbow Warrior in 1985 had an even greater effect of "underlin[ing] the seriousness of [Greenpeace's] endeavors and... heighten[ing] its sense of purpose" while triggering public outrage against the actions of the French and a vast increase in financial support and in Greenpeace membership. ${ }^{281}$

Even these events did not have the symbolic power of the anti-whaling expeditions, and particularly of one moment captured on film during the first whaling protest voyage in 1976. Two Greenpeace activists had steered an inflatable boat between the whaling ship and a sperm whale in order to shield the whale from harpoons; however, the Russian whaler still fired a two-hundred-fifty pound harpoon from the ship which flew over the activists heads, narrowly missing them as they ducked, and struck the sperm whale. Despite the choppy water, rolling waves and failing film camera battery, a Greenpeace filmmaker captured this moment on film. When the filmed sequence was released, it was disseminated by media outlets around the world. The New York Times noted, "for the first time in the history of whaling, human beings had put their lives on the line for whales." 282 In an analogy to the impact of the American Revolution, Hunter writes that "the sound of that harpoon became the 'shot heard around the world" of eco-activists" which boosted Greenpeace from a small group in Vancouver to "international fame" and drew attention to the issue of whaling. ${ }^{283}$ Again, there had been active campaigns against

\footnotetext{
${ }^{279}$ Weyler 2004: 132

${ }^{280}$ McTaggart 1973; McTaggart with Hunter 1978; McTaggart 2002

${ }^{281}$ Brown and May 1989: 125

${ }^{282}$ As quoted in Mulvaney 2003: 13

${ }^{283}$ Hunter 2002: 170
} 
whaling for years, but this 'mindbomb' presented a clear image that focused public attention on the issue.

This is a common pattern for Greenpeace, which often répackages existing issue campaigns, building on the research and groundwork of other advocacy groups, and uses their direct action and communication tactics to achieve strategic objectives. ${ }^{284}$ Greenpeace uses powerful images as a political tool to hold target opponents to account, and, as this quotation from Hunter (2002) suggests, the wide dissemination through the mass media pressures actors to change their behavior,

Our film, showing gigantic ships and tiny whales, plus the black-and-white photos we got of a dead juvenile whale in the water, were so mediagenic that it caused even the seemingly invincible Soviets to back down. The next years, when we went out again to confront them, the whalers covered the harpoon with a tarpaulin to hide it from the cameras, and called off the hunt. Indeed, at one point we had a six-hundred-foot factory ship and a fleet of seven big steel chaser boats fleeing across the water ahead of us, while we pursued them with nothing more lethal than a camera. In a time of near-instantaneous global communications, a billion television sets, and an uncountable number of newspapers, all hungry for dramatic images, the camera had become mightier than the harpoon. ${ }^{285}$

From the quotation above, it is also possible to identify many of the powerful communications elements that have remained Greenpeace signature images. The first is the portrayal of the target opponent as giant (e.g., "oil giant BP"286), emphasizing their large size (e.g., on Japanese whalers - "the factory ship is huge"287) and vast power to exploit or destroy species or ecological systems. Second, the victims of the destructive power are shown as vulnerable, innocent and fragile. In their ocean ecosystem campaigns, Greenpeace images of the bloody slaughter of whales, seals and dolphins and of ocean mammals trapped in driftnets designed for tuna harvesting deliver a direct visual assault through television. Shocking blood-soaked images often confound scientific,

\footnotetext{
${ }^{284}$ Dale 1996: 212

${ }^{285}$ Hunter 2002: 170

${ }^{286}$ Greenpeace (2003) Annual Report. Greenpeace International, Amsterdam, The Netherlands.

${ }^{287}$ Greenpeace (2002) Annual Report. Greenpeace International, Amsterdam, The Netherlands, p.11
} 
economic or historical arguments about the communities whose livelihoods depend on these ocean resources and about the sustainability and humaneness of their harvesting. ${ }^{288}$

Greenpeace has also highlighted local communities and indigenous peoples as the victims of environmental abuse. Greenpeace has documented the impact of French atmospheric nuclear testing on the French Island people of Rongelap (1985), the decades of detrimental effects on the people of Bhopal, India from a chemical explosion in an industrial plant, and the impact of unregulated resource extraction on local farmers and fishermen. ${ }^{289}$

In direct actions without direct, identifiable victims, the vulnerable figures are the Greenpeace activists who accept personal risk to bear witness and implement a direct action toward a specific target, and who seek to represent a broader concerned public and the Earth. Greenpeace photographers and filmmakers not only produce images to bear witness to ecological abuse but also consistently capture Greenpeace activists taking action and engaging in a creative confrontation against powerful target opponents in a 'David versus Goliath' battle. ${ }^{290}$. For the most part these activists are unidentified citizens; however, Greenpeace has always recognized the power of celebrity in drawing attention to an issue. Ever since Bridget Bardot flew to the Northern Canadian sealing grounds to protest the seal hunt in 1977 , celebrities have repeatedly been part of Greenpeace campaigns. A 2005 example is the Argentinian soccer star who lent his support to the Greenpeace campaign to stop rainforest destruction in the homeland of the Wichi indigenous peoples, which reportedly drew the attention of the Argentinian President and contributed to the establishment of a protected area. ${ }^{291}$

As the number of photographs and films of these confrontations swiftly increased, Greenpeace established an official communications arm, Greenpeace Communications

\footnotetext{
${ }^{288}$ Dale 1996: 154

${ }^{289}$ For Rongelap see Brown and May 1989: 108-112; Greenpeace 1996: 40; Boettger and Hamdan 2001: 38; For Bhopal and local farmers and fishermen see Greenpeace (2002) Annual Report. Greenpeace International, Amsterdam, The Netherlands, p.7, 8-9, 14-15.

${ }^{290}$ Brown and May 1989: 62; Dale 1996: 18

${ }^{291}$ Movie - Greenpeace: Making a Stand (2006) OMNI Productions, Vancouver, Canada.
} 
Ltd., in 1986, bringing together its film and photo departments to house and disseminate Greenpeace communications material. ${ }^{292}$ Greenpeace Communications "maintains contact with international media around the world, coordinates press releases, hires photographers and cameramen to cover Greenpeace activities, and edits and distributes video and pictures for broadcast and publication on television and in magazines and newspapers. ${ }^{.293}$ Further infrastructure to support the communications side of activities carried out by Greenpeace is coordinated by national action coordinators and by the Actions Coordinator at Greenpeace International. The latter facilitates communication amongst action coordinators across countries and across issue areas and provides support for common problems such as how to deal with underwater photography. ${ }^{294}$ Initially Greenpeace worked predominately with radio, print and documentary films but in the late 1970s, Greenpeace campaigners shifted their focus to international news services. ${ }^{295}$ Through its coordinated media work, Greenpeace is able to provide media with "cameraready events and ready-cut video footage in order to increase the chance that such footage will be used by producers short of time and resources and thereby ensuring that Greenpeace's interpretation will be presented intact;" ${ }^{296}$ however, the release of this footage has the consequence that the footage can be used to misrepresent an issue or against Greenpeace. ${ }^{297}$ Despite these risks, Greenpeace "targets news outlets with hard news stories" and "thinks about what broadcasters need, what news desks need to tell these stories" rather than focusing on softer outlets such as public education campaigns through educational material. ${ }^{298}$ Greenpeace was one of the pioneers in the use of the Internet and has made extensive use of Internet-based communication tools for both coordinating actions within Greenpeace and communicating images, galvanizing

\footnotetext{
${ }^{292}$ Greenpeace Communications Ltd (1991) A Resource Handbook. Greenpeace Communications Ltd, United Kingdom.

${ }^{293}$ Greenpeace 1986: 23

${ }^{294}$ Interview with Guido Verbist, Actions Coordinator, Greenpeace International, October 2004.

${ }^{295}$ Dale 1996: 114

${ }^{296}$ Eden 2005: 603

${ }^{297}$ Dale 1996: 114

${ }^{298}$ Andy Booth, past Greenpeace US campaign director and Head of International communications from 1990 to 1992, as quoted in Dale 1996: 107.
} 
supporters and 'cyberactivists', providing background information and reports, and sharing the personal diaries of activists on direct action campaigns and expeditions. ${ }^{299}$

With the initial campaigns against nuclear testing, whaling and sealing, Greenpeace activists had a clear location to stage their protest; however, as Greenpeace campaigners turned their attention to new campaigns such as toxic waste and industrial pollutants, activists and campaigners had to adapt the direct action and 'mindbomb' tactics to these new issue areas. For some campaigns, the new site of confrontation remained clear; for example, campaigns against toxic waste dumping at sea in the early 1980 s led to direct actions with inflatable boats positioned under the cranes releasing toxic barrels into the ocean. ${ }^{300}$ Inflatable boats and Greenpeace activist divers are also used to blockade shipments of toxic waste, nuclear weapons, fossil fuels, logs, and chemicals and other environmentally harmful products and to monitor and stop driftnet and illegal fishing and whaling boats. In targeting corporations, Greenpeace stages protests at industrial plants, stores, warehouses, gas stations and corporate headquarters, and purchases corporate shares in order to influence shareholder and Annual General meetings. The outflow pipe from an industrial plant has become a key site for Greenpeace activists protesting industrial pollutants and high levels of hazardous chemicals in industrial discharge. ${ }^{301}$ Since 1981, Greenpeace activists have harnessed themselves in mountaineering equipment to climb industrial smokestacks, nuclear power plant cooling towers, and construction cranes to hang banners and illegally occupy the site to draw attention to environmentally damaging practices. Greenpeace activists hang banners, fly hot-air balloons, cast projected messages and paint signs on an array of symbolic icons for their campaign areas including national icons, such as Big Ben in London, the Statue of Liberty in New York and the Taj Mahal in India. ${ }^{302}$ In 2003, climate change campaigners painted the logos of large fossil fuel companies such as ExxonMobil on the toe of a glacier to draw attention to the retreat of glaciers due to climate change and to identify

\footnotetext{
${ }^{299}$ Interview with Martin Lloyd, Internal Information Technology, Greenpeace International, October 2004; Warkentin 2001: 77; Eden 2004: 603

${ }^{300}$ Boettger and Hamdan 2001: 65

${ }^{301}$ Greenpeace 1996: 134, 137, 152

${ }^{302}$ Brown and May 1989: 98-99; Boettger and Hamdan 2001: 41
} 
corporations responsible for supplying the oil and gas that fuels climate change. ${ }^{303}$ Even public protest demonstrations in front of businesses, national government offices, and intergovernmental gatherings frequently include visually striking street theatre in addition to placards and petitions, for example, activists pretending to be caught in driftnets or staging mock deaths in protest of industrial pollutants. ${ }^{304}$

There are a number of weaknesses that are inherent in a direct action approach combined with a mass media communications outreach strategy. First, actions can lose their political integrity by becoming too symbolic. The actions have to match the moral and political statements that come with it. The risks that individual activists participating in actions are willing to undertake for a larger cause have to be genuine and real, and not faked. ${ }^{305}$ The direct actions which Greenpeace undertake attract the attention of target opponents and the public because of the political act of individuals who place their safety and personal freedom or property at risk. This requires activists to place themselves at the point of confrontation, rather than engaging in symbolic actions at international conferences or other relatively safer environments. Declaring Greenpeace positions "by mechanically employing actions and confrontational acts contradicts the pattern set by campaigns which are determined in a largely unpredictable game between Greenpeace's opponents and allies, and not by the dates of conferences." 306 Second, actions can lose their symbolic power and media interest if they become repetitive. This was a concern expressed by early Greenpeace campaigners who worried that "tactics get old" and that following the Greenpeace formula can "dull the cutting edge."307 Greenpeace is challenged with continuously innovating on the specific tactics it uses in order to remain vibrant and fresh enough to attract public and media attention. This is particularly the case in "mature countries" where Greenpeace has been active for a number of years, and

${ }^{303}$ Greenpeace (2004) Annual Report. Greenpeace International, Amsterdam, The Netherlands. ${ }^{304}$ Boettger and Hamdan 2001

${ }^{305}$ Interview with Rex Weyler, Greenpeace campaigner (1972 - 2006), Author of Greenpeace: How a Group of Ecologists, Journalists and Visionaries Changed the World (2004), November 2004; Interview with Guido Verbist, Actions Coordinator, Greenpeace International, October 2004.

${ }^{306}$ Bode, T. (1995) Greenpeace and International Conferences. Discussion paper, Greenpeace International, Amsterdam, The Netherlands, May.

${ }^{307}$ Susi Newborn as quoted in Weyler 2004: 481; and Weyler 2004: 488 
where the public, target opponents and media are accustomed to Greenpeace actions. ${ }^{308}$ Creativity and risk are essential in the production of stimulating Greenpeace actions rather than "smaller, often disappointing (both internally and externally) 'actions' which involve hanging yet another banner, or chaining yet another group of people to something vaguely symbolic."309

Third, there are a number of inherent problems with engaging the media. Greenpeace campaigning can become overly focused on creating media-friendly direct actions rather than strategically scanning for opportunities for influence, as the following comment suggests,

There is a saying that if all you have is a hammer then the whole world starts to look like a nail and you have to be careful about that - if the only tool you have is the media then everything looks like a media story and in some cases, there is a potential victory that is not a media story and you have to be prepared to win that victory with whatever tool and resources you have. ${ }^{310}$

Media-focused campaigns are also at the mercy of how the media seeks to portray an event. Since Greenpeace is committed to non-violence, the portrayal of Greenpeace activists as terrorists is damaging to the reputation of Greenpeace. ${ }^{311}$ This is particularly problematic if Greenpeace campaigners seeking access to decision-makers in order to lobby for a particular position are tainted by such a misperception in the media, and lobbying is certainly a regular part of Greenpeace's activities.

\subsection{Quiet Diplomacy and Double Pincer Moves}

As part of the first campaign against nuclear testing, Greenpeace representatives traveled to meetings of the U.S. Atomic Energy Commission, and to the United Nations to lobby

${ }^{308}$ Greenpeace (1998) Summary of Mature Offices' Meeting, March 16 and 17, Greenpeace, Amsterdam, The Netherlands; Rose, C. (1999) Mature Offices or Campaign Environments and the Case to Change Campaigning - Some Factors Relevant to the 1999 Program. Greenpeace UK.

${ }^{309}$ Sawyer, S. (1994) Organizational Objectives for Greenpeace. Submitted to the Stichting Greenpeace Council Board, July, p. 5.

${ }^{310}$ Interview with Rex Weyler, Greenpeace campaigner (1972 - 2006), Author of Greenpeace: How a Group of Ecologists, Journalists and Visionaries Changed the World (2004), November 2004.

${ }^{311}$ Dale 1996 
for the French tests to be placed on the agenda of the UN Conference on the Human Environment in Stockholm in $1972 .^{312}$ With the anti-whaling campaign, Michael M'Gonigle organized the first Greenpeace delegation to the International Whaling Commission in 1976 which led to the decades-long campaign to halt commercial whaling. ${ }^{313}$ Lobbying was adopted as a complementary tactic to non-institutionalized protests and direct action in order to hold decision-makers accountable and directly "speak truth to power" within international negotiations.

From these first ventures into intergovernmental meetings, Greenpeace has built an increasingly sophisticated negotiating team to attend international meetings such as the London Dumping Convention, the World Trade Organization, the UN Commission on Sustainable Development, the International Tropical Timber Organization, and the UN Conventions on Trade in Endangeréd Species, Biodiversity, and Climate Change. For some of these international conventions, Greenpeace is credited a having an influence in both the creation of the convention and its negotiation, such as the 1993 ban on trade in toxic waste through UN Basel Convention ${ }^{314}$; however, in other cases, Greenpeace efforts have not succeeded in significantly shifting international discussions, such as on nuclear testing and reinforcing non-proliferation of nuclear weapons. Scholars attribute this lack of effectiveness to entrenched geopolitical positions, "deep rooted ideologies, backed by powerful interest groups within the military, defense industries and political class" (Johnson 2000: 78; see also Bloodgood 2002). In certain campaigns, such as the Greenpeace campaign to protect Antarctica from development (World Park Antarctica 1984-1992), diplomatic negotiation took priority over Greenpeace's signature direct actions $^{315}$, although the establishment of a Greenpeace year-round station in Antarctica to monitor the activities and impact of governmental bases, and demonstrations in

\footnotetext{
312 Dale 1996, p. 179

${ }^{313}$ Interview with Michael M'Gonigle, Greenpeace campaigner (1976-1982), August 2004.

${ }^{314}$ Krueger, J. 1999

${ }^{315}$ David McTaggart as quoted in Ostertag, B. "Greenpeace Takes over the World" in Mother Jones. March / April 1991, p. 33.
} 
Antarctica against the construction of a French landing strip (1989) assisted in drawing attention to the issue. ${ }^{316}$

The establishment of a Greenpeace International Political Unit in the late 1980s supported Greenpeace negotiators but also subjected Greenpeace to critique that it was losing its political edge and moving towards a role as a lobbying interest group rather than a radical direct action organization (e.g., Dowie 1995). This assessment overlooks the fact that diplomatic lobbying has always been a part of Greenpeace's strategy, and that, predominately, Greenpeace lobbyists are the same people as the direct action activists and campaigners. ${ }^{317}$ The negotiators remain confrontational through the radical demands they pose to decision-makers, such as banning toxic waste dumping or shifting to renewable energy rather than fossil fuels. These confrontations within an institutionalized setting are seen by Greenpeace as being a positive contribution to increasing democratic participation within the international arena. ${ }^{318}$ For Greenpeace, global expansion into developing countries - such as Lebanon, the Soviet Union, China and Turkey - has a secondary aim to resolving environmental problems, which is opening democratic debate and citizen access to decision-makers within those countries. ${ }^{319}$ For Greenpeace campaigners in these developing countries, there are distinct advantages to being part of an international organization. Their association with an international organization and the associated monitoring of international press helps these campaigners avoid violent reactions by their government and arrest. ${ }^{320}$ Greenpeace provides a degree of protection to Eastern and Southern campaigners through its commitment to non-

\footnotetext{
${ }^{316}$ Boettger and Hamdan 2001

${ }^{317}$ Interview with Marcelo Furtado, Greenpeace Brazil, September 2005; Interview with Steve Sawyer, Climate and Energy Policy Advisor, Greenpeace International; Past Executive Director of Greenpeace USA (1986-88); Past Executive Director of Greenpeace International (1988-1993), October 2004.

${ }^{318}$ Leipold, G. and Eleanor O'Hanlon (Gem Partners Ltd) (1998) Quality in Campaigning: A Study for Greenpeace, Phase I: Standard Quality Systems and Other Organizations. Greenpeace International and Gem Partners Ltd, October, p. 13.

${ }^{319}$ Leipold, G. (2001) "A Force for Change" in Greenpeace (2001) Annual Report. Greenpeace International, Amsterdam, The Netherlands, p. 3.

${ }^{320}$ Bode, T. (1998) "People of the World Practicing Moves to Democracy" in Frankfurter Allgemeine Zeitung. $31^{\text {st }}$ December.
} 
violence. ${ }^{321}$ By focusing campaigns on issues such as toxic trade, Greenpeace campaigners in developing countries are also tolerated by local governments because they are not the targets of the campaign. Instead, the campaign is aimed at changing the behavior of industrialized countries who are exporting the waste. ${ }^{322}$ In addition, Greenpeace uses its international network, political clout and expertise to support local community fights for environmental protection, to halt ecologically damaging development and to influence national government policy, as I will discuss with examples in Chapter Eight (Section 8.3). ${ }^{323}$ In these cases, Greenpeace often has more political clout and international recognition than the grassroots protestors and that enables Greenpeace to carry out quiet lobbying on their behalf and place pressure on national decision-makers (Sachs 1995: 14).

Greenpeace campaigns regularly make use of direct action combined with media communication and diplomatic lobbying; in fact, for many campaigns, these tactical approaches are combined in a "left-right" move to increase pressure on decision-makers and to expose often secretive and unknown intergovernmental meetings to the eye of civil society and the media. ${ }^{324}$ One internal Greenpeace document outlines that campaigns need to operate at the practical level - concrete changes in the behavior of governments and/or corporations - and on the symbolic level - to demonstrate the capacity to change the world in "very public and spectacular ways," and to do these two levels in combination,

Without clear, practical and intelligent strategies driven by careful planning, we are nothing more than professional stunt men or emotional ideologues we are often accused of being by our detractors. Without the public, symbolic, emotional, and moral appeal created by our public campaigning, we are nothing but another lobby group. The art lies in providing the correct amount of each at the right time. ${ }^{325}$

${ }^{321}$ Dale 1996: 32

322 Ibid.

${ }^{323}$ Interview with Marcelo Furtado, Greenpeace Brazil, September 2002; Noparumpa, P. (2002)

"Double Standards are Not Acceptable" in Greenpeace (2002) Annual Report. Greenpeace International, Amsterdam, The Netherlands.

${ }^{324}$ Dale 1996: $179-180$

${ }^{325}$ Sawyer, S. (1994) Organizational Objectives for Greenpeace. Submitted to the Stichting Greenpeace Council Board, July, p. 3. 
Within Greenpeace, this double strategy is sometimes referred to as a "double pincer move" ${ }^{326}$ that combines "insider" (institutional tactics such as lobbying) and "outsider" (non-institutional tactics such as demonstrations and direct action) strategies in a coordinated way to "strengthen insider muscle by mustering public support.",327 There are many examples of such coordinated campaigns within Greenpeace's history. For example, the waste trade campaign supported its investigative monitoring expeditions and direct actions with insider negotiations at the Basel Convention and at the national level. ${ }^{328}$ Some campaigns focus on insider strategies, such as the Climate Change campaign, whereas others, such as the campaign against Genetic Engineering and the Brent Spar campaign against ocean disposal of oil platforms, relied solely on outsider tactics. ${ }^{329}$ A clear example of an integrated campaign is the Greenpeace campaign for establishing a whale sanctuary in the waters around Antarctica (1992 - 1994),

Greenpeace was able to deploy a varied arsenal in support of its case. Its direct actions and expeditions to Antarctica had produced footage which was used to show the natural beauty of Antarctica, and contrasted with scenes of whales being killed there. Its scientific experts and advisers helped provide evidence to demonstrate the need to protect the remaining whale stocks. Campaigners around the world worked tirelessly to drive the message home and gather political support. The effort was spearheaded by Greenpeace's political team, lobbying governments and IWC representatives whenever and wherever possible. The combined offensive proved instrumental in turning opinion in support of the proposal. At its annual meeting in 1994, the IWC voted overwhelmingly to adopt the Southern Ocean Sanctuary. ${ }^{330}$

This quotation highlights a third aspect of Greenpeace campaigning: scientific research and analysis. Both scientific and policy activities remain supportive endeavours to Greenpeace's nonviolent direct action tactics; however, these supportive activities have gained in sophistication over the decades of Greenpeace's development.

\footnotetext{
${ }^{326}$ Interview with Brian Fitzgerald, New Media Director, Greenpeace International, October 2004.

${ }^{327}$ Leipold, G. and Eleanor O'Hanlon (Gem Partners Ltd) (1998) Quality in Campaigning: A Study for Greenpeace, Phase I: Standard Quality Systems and Other Organizations. Greenpeace International and Gem Partners Ltd, October, p. 12.

${ }^{328}$ Ibid., p. 13

${ }^{329}$ Ibid., p. 13

${ }^{330}$ Mulváney, K. (1996) in Greenpeace Witness: Twenty-Five Years on the Environmental

Frontline. London, UK: André Deutsch Limited, p. 29.
} 


\subsection{Greenpeace Science and Technological Innovations}

Not all Greenpeace direct actions involve a confrontation between activists and target opponents. Exceptions include expeditions to monitor the bycatch of drift net fishing or to document glacier retreat. These activities do not necessarily endanger activists with possible arrest or confrontation. Predominately, however, Greenpeace is engaged in direct actions that involve illegal entry to industrial sites or national monuments and possible arrest and violence in response to civil disobedience. In these confrontations, the photographic and film record from Greenpeace cameras becomes essential in protecting activists from attack and in providing evidence in court cases. ${ }^{331}$ Activists occupy a particular site or chain themselves to the object of protest in order to prolong the act of resistance. For example, in 1995, Greenpeace activists occupied the Brent Spar oil platform three times during several weeks preventing Shell oil company from sinking its disused rig into the sea, and stimulating a public solidarity campaign and boycott that forced Shell to dismantle the rig on land. ${ }^{332}$ Greenpeace protested the sinking of Brent Spar on the grounds that "waste does not belong in the sea" and that sinking Brent Spar would establish a precedent for sinking the additional 100 other oil rigs in the North Sea. ${ }^{333}$ Although Greenpeace was supported by the press and public for this moral claim during the height of its campaign, Greenpeace's position against using the ocean to dispose of waste has since come under critique after Greenpeace sank its bombed ship, the Rainbow Warrior, off the coast of New Zealand to create an artificial reef. ${ }^{334}$

Brent Spar also became a battle of scientific fact between Shell and Greenpeace who both found evidence of the environmental advantages of their proposed disposal method. Although Greenpeace primarily presented its side on the basis of the dangerous precedent an ocean disposal would set, Greenpeace campaigners also provided scientific reports to support the environmental benefits of land based disposal and, subsequently, were

\footnotetext{
${ }^{331}$ McTaggart 1973; Brown and May 1989: 91

${ }^{332}$ Rose 1998; Boettger and Hamdan 2001: 206 - 213

${ }^{333}$ Boettger and Hamdan 2001: 206

${ }^{334}$ Simon Rozendaal (1996) "De vliegvakanties van de bazen van de Milieuclubs" in "Zeker Weten" within Elsevier, The Netherlands: http://www.elsevier.nl
} 
heavily criticized for a mistake made in calculating the remaining oil in the platform. ${ }^{335}$ Scientific research and analysis has increasingly become a key part of Greenpeace campaigning to provide justification for targeting a particular corporation or government and to provide evidence for an issue campaign (Keck and Sikkink 1998: 21). As Pearce (1996: 74) notes, "science was never on top: the ethical agenda still dominated but it was increasingly 'on tap' with Greenpeace press releases increasingly adorned with references to scientific papers and backed up by specially commissioned research and monitoring programs." Although scientific and technical knowledge has been a part of Greenpeace since its inception - for example in providing data on whaling populations and the location of whaling fleets ${ }^{336}$ - the scientific capacity of Greenpeace grew with the opening of a Greenpeace Science Unit in 1986 at Queen Mary and Westfield College at the University of London. This unit was later housed at the Earth Resources Centre at the University of Exeter and supported by laboratories in Boston and Kiev. ${ }^{337}$ Greenpeace purchased a former fire patrol boat in 1984, renamed the Beluga, from which Greenpeace campaigners monitor pollution levels and water quality. In 1988, Greenpeace also converted a bus into a mobile laboratory for assessing water quality in the Baltic Region and for other research expeditions. ${ }^{338}$

In 1991, the scientific and technological work of Greenpeace took a new turn with the production of a chlorine-free spoof edition of the German newspaper Der Spiegel as part of the Greenpeace campaign against chlorine-bleaching and in response to industry claims that a chlorine-free paper would not be feasible. ${ }^{339}$ Since this initial endeavor, Greenpeace has presented other "technical solutions as partial solutions in a greater ecological conflict and as important intermediate steps on the way to an ecologically sound economy." 340 An example of technological innovation is the Greenfreeze refrigerator developed without ozone-depleting chemicals in 1992 by Greenpeace in

\footnotetext{
${ }^{335}$ Jordan 2001; Entine 2002

${ }^{336}$ Hunter 1979

${ }^{337} \mathrm{http}: / / \mathrm{www}$.greenpeace.to

${ }^{338}$ Greenpeace 1986: 23; Brown and May 1989: 150

${ }^{339}$ Greenpeace (1991) Annual Report. Greenpeace International, Amsterdam, The Netherlands.

${ }^{340}$ Bode, T. (1995) Confrontation and Solutions. Discussion Paper for the Solutions Conference, Dublin; June, p. 1
} 
cooperation with German scientists and a fridge manufacturer. Launched in Chinese markets in 1993, this fridge was in full production within China by $1996 .{ }^{341}$ The symbolic value of an ozone-friendly refrigerator is considerable; however, recent assessments of the impact of the Greenfreeze refrigerator in terms of energy consumption shows that energy savings are not significant. ${ }^{342}$ In 1996, Greenpeace supported the creation of a fuel-efficient prototype car, SmILE, based on the Renault Twingo to challenge the resistance from industry to fuel efficiency. ${ }^{343}$ Another example of a Greenpeace technological innovation is the release of a PVC-free credit card made from plant material in the UK, Brazil and USA. ${ }^{344}$

With these technological alternatives, Greenpeace steps out of its traditional role of saying "no" towards a new perspective that "every no needs a yes." 345 There are inherent risks that accompany cooperative engagement with the private sector in order to develop environmentally-friendly products, which I will return to in my discussion of managing external relations in Chapter Eight (Section 8.2). Internally, Greenpeace shifted from its ad hoc approach to technological innovations to a more formal approach by hiring two consultants in 1998 to assess past Greenpeace solutions work. ${ }^{346}$ Through their analysis, the consultants conclude that Greenpeace "should follow up on more promising technologies in a more systematic way" and that Greenpeace should "be present in a more convincing way in non-industrialized countries" in order to respond to "the need for radically energy and resource efficient technologies in developing countries." ${ }^{\text {"347 }}$ This conclusion was echoed in a 2002 Greenpeace discussion on Greenpeace offices in Asia,

${ }^{341}$ Greenpeace (1992-1993) Annual Report. Greenpeace International, Amsterdam, The Netherlands; Greenpeace (1996) Twenty-five Years as a Catalyst for Change. Greenpeace International, Amsterdam, The Netherlands.

${ }^{342}$ Wait Chi, Greenpeace China, as quoted in 2002 Stichting Greenpeace Council Annual General Meeting notes p. 4.

${ }^{343}$. Bode, T. (1998) "Driving Technology towards Sustainable Development" published in Time Magazine, 23 March.

${ }^{344}$ Greenpeace (1997) Annual Report. Greenpeace International, Amsterdam, The Netherlands, p. 23.

${ }^{345}$ Boettger and Hamdan 2001: 222

${ }^{346}$ Bode, T. (1999) A Perspective on Technological Innovations. Discussion paper submitted to the Executive Directors of Greenpeace, August.

${ }^{347}$ Ibid. 
with the Executive Director for South East Asia emphasizing the importance of solutions work, because "just saying 'no' and 'stop' is not enough in Asia.",348

\subsection{North-South Tactics and Issues within Greenpeace}

This is not the first time that the distinction between developed and developing countries, North and South and West and East issues has been considered within Greenpeace. With the global expansion of Greenpeace offices into new regions outside of North America and Europe, Greenpeace campaigners have repeatedly assessed the effectiveness of direct action campaigns and media communication within new geographical contexts. In many ways, the unique tactical approach adopted by the founders of Greenpeace, including their innovative use of communications media, has proven to be easily transferable to other countries. $^{349}$ In the 1970 s, this certainly appeared to be the case as by 1975 , "offices had sprouted around the world" operating autonomously in Canada (Victoria, Prince George, Edmonton, Calgary, Saskatoon, Toronto, Ottawa, Montreal, Inuvik); in the United States (Portland, Seattle, San Francisco and Boston); in London, United Kingdom; in Reykjavik, Iceland; in Carlton, Australia; and in Auckland New Zealand, and adopting the same non-violent direct action tactics initiated in Vancouver. ${ }^{350}$ In addition to early confrontations with US and French military and Russian and Japanese whalers, Greenpeace direct action tactics by US environmentalists were effective in drawing attention to the slaughter of dolphins in Japan between 1979 and $1981 .^{351}$

Since these early campaigns, non-violent direct action tactics have been employed by Greenpeace campaigners around the world, although there can be regional variations. On the one hand, South East Asian Greenpeace campaigners report that "the Asian offices believe in actions and non-violence, the latter being the most important common denominator in Asian offices" as "confrontation is not common in Asian cultures." "352 On

\footnotetext{
${ }^{348}$ Jiragoran Gajseni, Executive Director of Greenpeace in Southeast Asia, quoted in 2002 Stichting Greenpeace Council Annual General Meeting Minutes, p. 4.

${ }^{349}$ Dale 1996: 105

${ }^{350}$ Weyler 2004: 347

${ }^{351}$. Brown and May 1989: 66-67

352 Jiragoran Gajseni, Executive Director of Greenpeace in Southeast Asia, quoted in 2002 Stichting Greenpeace Council Annual General Meeting Minutes, p. 4.
} 
the other hand, there are distinct cultural differences within Asia. For example, Japanese Greenpeace campaigners attending a nonviolent direct action workshop organized by Greenpeace International reportedly questioned the idea of symbolically placing Greenpeace swimmers in front of a targeted boat in order to stop it coming into harbor, unless the swimmers were willing to not swim away and literally put their lives on the line for the cause as was the case for the Japanese Kamikaze pilots in the Second World War. ${ }^{353}$ The Japanese activists also introduced new adaptations to traditional direct action and media tactics such as using cellular telephones equipped with cameras and Internet connections during direct action protests to record their actions and create realtime personal diaries on the web. ${ }^{354}$ I already noted Greenpeace Argentina's adaptation of Greenpeace tactics through their use of motorbikes and helicopters to track and halt bulldozers leveling rainforest. ${ }^{355}$

These modifications of Greenpeace's signature direct action tactics stem in part from the fact that Greenpeace hires local people - often well-known environmentalists - to the staff and Board of new Greenpeace offices. National staff brings their own past experience and ideas for nonviolent direct action to Greenpeace. ${ }^{356}$ In fact, Greenpeace campaigners from the older established offices in developed countries welcome the spark and fresh approaches that emerges from Southern and Eastern offices, and, as this quotation from an interview with a Greenpeace Brazil campaigner demonstrates, tactical sharing is happening from Southern offices to Southern offices as well,

Our work in Asia, for example, changed the way we do campaigning and actions in the organization because we've learned so much from an existing movement in India and in the Philippines and in Thailand and we are using different tactics in Brazil. This is from a recent experience that I have had. What you do is you learn something there and you transport it to Brazil and then do it there. For example, after a tour of India that we did with our ships, we took some models from India straight to Brazil and Argentina and then we did actions just like we did in India and they worked perfectly. ${ }^{357}$

${ }^{353}$ Interview with Guido Verbist, Actions Coordinator, Greenpeace International, October 2004 ${ }^{354}$ Ibid.

${ }^{355}$ Movie - Greenpeace: Making a Stand (2006) OMNI Productions, Vancouver, Canada

${ }^{356}$ Interview with T. Mohan, Board, Greenpeace India, September 2002.

${ }^{357}$ Interview with Marcelo Furtado, Greenpeace Brazil, September 2002. 
The fine-tuning and refinement of 'classic' Greenpeace tactics within different contexts is supported by the work of the Actions Coordinator at Greenpeace International. ${ }^{358}$ As was apparent in the discussion of Friends of the Earth International in the previous section, expansion into the East and South not only results in the introduction of new tactical approaches but also in significantly different perspectives on environmental issues. For example, Southern environmentalists predominately perceive of environmental issues as being intertwined with social, political and economic concerns, which presents a challenge to the environmental focus of Greenpeace. As one Greenpeace India Board member notes,

That is a challenge that Greenpeace has taken on by moving to the South and setting up offices in the South. That is very difficult for a large organization to do because it brings in very different cultural extremes to the table. It can often result in destabilization because you are dealing with an entirely different cultural context. $^{359}$

There is evidence that a degree of destabilization has occurred. For example, in 1990, Greenpeace reversed its position on dolphin-safe tuna labeling in response to a plea from Greenpeace Latin America. The Latin American campaigners argued that US ecolabeling was a protectionist move on the part of US tuna lobby to shut out Latin American competitors. ${ }^{360}$ Greenpeace has been at the receiving end of severe critique by social justice and indigenous peoples before, particularly in relation to the sealing campaigns that were perceived as undermining Canadian native populations. ${ }^{361}$ On the other hand, Greenpeace had also been the subject of critique for siding with labour; for example, in 1976, after Greenpeace founder Bob Hunter struck a deal for Greenpeace to join with Newfoundland sealers against industrial sealers from Norway, a significant number of Greenpeace supporters cancelled their membership. ${ }^{362}$ In taking a stance against the US ban of foreign tuna imports, Greenpeace was considering international consequences of a boycott on tuna from Latin America for the fishermen and their

\footnotetext{
${ }^{358}$ Interview with Guido Verbist, Actions Coordinator, Greenpeace International, October 2004.

${ }^{359}$ Interview with T. Mohan, Board, Greenpeace India, September 2002.

${ }^{360}$ Dale 1996: 160-177

${ }^{361}$ Dale 1996: 92

${ }^{362}$ Hunter 1979: 262
} 
communities. The consequence was intense critique by other US environmental groups who saw this stance as introducing "a nightmarish web of conflicting policy imperatives" that are not easily communicated in the black-and-white "save the dolphins" language of a typical Greenpeace's media. ${ }^{363}$ Greenpeace's expansion to offices in Latin America, Soviet Union and Japan after 1987 triggered new debates within Greenpeace as Steve Sawyer, Climate and Energy Policy Advisor, Greenpeace International, and ex-Executive Director of Greenpeace International notes,

It was a struggle, it was huge, it was difficult - difficult on the ground, difficult financially, difficult issue-wise - introducing a whole panoply of social justice and welfare issues to the organization that didn't necessarily want to hear about them. We had huge fights and debates over integrating social justice and a more peopleoriented approach into the environmental framework within which we were comfortable - which now seems ludicrous but in those days the environment was a fairly separate box.... That all changed after Rio. ${ }^{364}$

At the United Nations Conference on Environment and Development in Rio de Janeiro in 1992, Greenpeace facilitated discussions on Third World Debt and the impact of international financial institutions and trading systems; however, internally Greenpeace campaigners expressed concern about whether Greenpeace was entering a contentious arena of social, political and economic issues and "turning its back on a long-successful public relations strategy: of focusing on specific attainable goals; of campaigning on issues easily understood and conveyed in the pictorial language of television; of staying away from political controversies or ideological debates in which the organization could lose public sympathy." ${ }^{365}$ The 2002 meeting of the Stichting Greenpeace Council included an in-depth discussion of how poverty and development issues could be integrated into Greenpeace work. ${ }^{366}$ Although there were mixed views about how these issues should be incorporated, it was generally held that Greenpeace should not move into a new direction or dilute its mission by campaigning directly on poverty and development issues. Instead, Greenpeace campaigners should incorporate these issues

${ }^{363}$ Dale 1996: 177

${ }^{364}$ Interview with Steve Sawyer, Climate and Energy Policy Advisor, Greenpeace International; Past Executive Director of Greenpeace USA (1986-88); Past Executive Director of Greenpeace International (1988-1993), October 2004.

${ }^{365}$ Dale 1996: 47

${ }^{366} 2002$ Stichting Greenpeace Council Minutes p. 12-17. 
into existing environmental and disarmament campaigns and be informed by poverty and development perspectives through aligning with groups working in these areas.

The ecological sustainability focus of Greenpeace is evident in the campaign areas adopted in developing country offices. For example, Greenpeace Argentina established in 1987 with a focus on toxics in order to "avoid being dismissed as being too idealistic" within "a country where a large sector of the population strives to make ends meet."367 Similarly, Greenpeace's strategy for establishing an office in Tunisia was to "conduct classic Greenpeace campaigns in the old manner (pollution of waters) or to be concerned with water resources or desertification rather than work on 'modern' campaigns such as global warming, the ozone hole or propagating closed production and recycling loops." 368 Even the reasons for expanding into specific countries and regions are linked to environmental criteria. Consider this discussion by Thilo Bode, International Executive Director of Greenpeace (1994-2000) on the global presence of Greenpeace,

Whilst in principle it is clear that Greenpeace would like to be globally represented, in practice any global expansion should be driven by campaign priorities. However, historically, it has proved impossible to define a comprehensive global long-term campaign strategy which could be used as a guideline for future expansion. What has remained unchanged, despite constant reworkings of a blueprint for global presence is, that in order to fulfill our long-term campaign goals, maintain public credibility as a global organization, and have utmost impact on saving the global environment, we must be present in those countries where the future of the global environment will be decided. $^{369}$

Based on their assessment of critical regions for the global environment, Greenpeace expanded to China in 1996 (Williamson 2005) and into South East Asia and India in 2000 and works with organizations in Sub-Saharan Africa on environmental issues. ${ }^{370}$ Greenpeace campaigners recognize the importance of national and regional sensitivity in terms of issue area and tactical approach. National and regional offices are "an important

\footnotetext{
${ }^{367}$ Brown and May 1989: 145

${ }^{368}$ Bode, T. (1995) The Future of Greenpeace. Internal strategy document. Greenpeace International, Amsterdam, The Netherlands, p.4.

${ }^{369}$. Bode, T. (1999) Greenpeace Global Presence. Submitted to' Executive Directors Meeting of Sept/October of 1999 by Greenpeace International for discussion.

${ }^{370} 2002$ Stichting Greenpeace Council Minutes p. 11:
} 
testing ground" for tactical innovation, which Greenpeace International can subsequently assist in spreading throughout the organization. ${ }^{371}$. There is also a broad recognition that national and regional level campaigns can play a significant role in building local support for Greenpeace. ${ }^{372}$

Ultimately, however, Greenpeace campaigners aim to subsume the interests of national and regional offices under the interests of the organization as a whole. Vibrant, international campaigns are perceived as being critical for building national and regional strength. ${ }^{373}$ In other words, "national campaigns must have a clear relationship to international Greenpeace campaigns [and]... can't be based on completely different issues." 374 One internal Greenpeace document notes that "being an international organization some decisions which may maximize the overall return may have a negative impact on a national level" and "sometimes this can't be avoided and has to be taken as a necessary sacrifice for being an international organization." 375 This is echoed in the Approved International Policies, Guidelines and Procedures in which Greenpeace discourages the use of a veto by national and regional offices to an international campaign that may damage their national viability, and encourages NROs to "first assess whether the future of the office is more important in the long term than the success of a campaign."376 The question is why does Greenpeace focus on the international organization rather than building strength through local and national campaigns like Friends of the Earth International? The final section seeks to answer this question.

${ }^{371}$ Bode, T. (1998) The Strategic Direction of Greenpeace. Discussion document submitted to the Stichting Greenpeace Council Board meeting, $4^{\text {th }}$ September.

${ }^{372}$ McTaggart, David (1992) Letter to the organization from David McTaggart, Greenpeace International Honorary Chair, $18^{\text {th }}$ August, p.1; Bode, T. and Upsall, D. (2000) The Role of Greenpeace in Society. In Greenpeace International Organizational Development Plan.

${ }^{373}$ Bode, T. and Upsall, D. (2000) The Role of Greenpeace in Society. In Greenpeace International Organizational Development Plan.

${ }^{374}$ Bode, T. (1995) The Future of Greenpeace. Internal strategy document. Greenpeace International, Amsterdam, The Netherlands.

${ }^{375}$ Greenpeace (1998) Summary of Mature Offices' Meeting, March 16 and 17, p. 3

${ }^{376}$ Greenpeace International (2000) Extract from Approved International Policies, Guidelines and Procedures. Compiled from formal Board, Council, and Executive Director Meeting Agreements from 1979 to the present. 


\subsection{One Greenpeace: Working Globally to Create an Ecological Sensibility}

It is possible to trace the origins of a more centralized and formalized Greenpeace to the year 1979. There were two Greenpeace meetings in 1977 and 1978 with Greenpeace campaigners from offices all over the world. These meetings were aimed at defining the authority structure of Greenpeace, the allocation of financial resources and the control of the Greenpeace name. ${ }^{377}$ It was not until 1979 that this debate about organizational structure and decision-making processes would come to resolution as the result of an internal dispute. One of Greenpeace co-founders, Patrick Moore, an ecologist, was leading the Greenpeace Vancouver office, which under his leadership had launched a lawsuit against the San Francisco Greenpeace office about the use of the Greenpeace name and the distribution of its funds. Michael $M^{\prime}$ Gonigle, a Greenpeace campaigner active in the campaign to protect whales, expressed concern about Moore's approach to establishing one cohesive Greenpeace entity in a newspaper article,

Certainly the International Greenpeace movement needs coordinated organization. But the sort of centralization that Greenpeace Vancouver seeks is just not appropriate to the environmental movement. To control the proceeds of foreign offices would produce irresponsibility at home and demoralization abroad. Cooperation, not authoritarianism, must be the goal. ${ }^{378}$

M'Gonigle aligned his efforts to reconcile this internal conflict with another member of Greenpeace, David McTaggart. McTaggart had joined the Greenpeace campaigns in 1972 when he volunteered to sail his boat, the Vega, into the French bomb-test zone in the Mururoa Atoll. McTaggart was one of the crew who were severely beaten by French military during the protest voyage. ${ }^{379}$ McTaggart contributed to the rapid growth of Greenpeace offices in Europe and he saw potential in building Greenpeace as a global organization. McTaggart was concerned that the internal battles between the Vancouver and San Francisco offices could undermine the opportunity to build on Greenpeace's unique approach and international reputation. Reflecting on this moment in Greenpeace history, McTaggart wrote in his autobiography,

${ }^{377}$ Weyler 2004: 485, 491

${ }^{378}$ M'Gonigle, M. (1979) "No peace in Greenpeace: Vancouver Leadership Challenged." In the Vancouver Sun, July.

${ }^{379}$ McTaggart 1973; McTaggart with Hunter 1978 
We've captured the public's imagination, and if we stay focused, we can win big time... I'm trying to stay focused on the real game, building an organization so big and popular - that no democratic government can afford to ignore us....Getting this point across inside Greenpeace was one of my biggest challenges in building the organization. Since most environmental issues are absolutely international - whales don't stop at border crossings and neither does pollution - we need to work together internationally. Partly it would just make us bigger, and our voice would be harder to ignore for any government. But is also would mean that we can focus our energy on the paramount issues, instead of dissipating it getting involved in little national campaigns. Essentially, I don't want to build small fires around the world that could go out in the first big storm. I want to build one big fire that can't be put out. ${ }^{380}$

McTaggart is widely credited within Greenpeace for creating a relatively more centralized and formalized structure based on his vision of an international campaigning organization. In a tribute to McTaggart after his death, Greenpeace notes "it is largely as a result of his leadership that Greenpeace became a truly global force."381 He was singleminded about his approach in consolidating the national offices and building a strong secretariat at Greenpeace International that could provide strategic direction for the organization. McTaggart emphasized the importance of prioritizing a "limited number of focused campaigns, pursuing victory ruthlessly., ${ }^{382}$

In 1992, McTaggart, then Honorary Chairman of Greenpeace International, circulated a memo to Greenpeace staff to remind them of his view of the "original concepts" that define Greenpeace. McTaggart articulated his focused approach in his discussion of international and national campaigns,

Concentrating on two or three was more than a way to focus limited resources. It was also an attempt to build a record of success by declaring a goal, pressing it hard, declaring the victory and moving up to the next rung. ${ }^{383}$

\footnotetext{
${ }^{380}$ McTaggart 2002: 147-148

${ }^{381}$ Greenpeace (2001) Annual Report. Greenpeace International, Amsterdam, The Netherlands, p. 23.

${ }^{382}$ Pearce 1996: 74

${ }^{383}$ McTaggart, David (1992) Letter to the organization from David McTaggart, Greenpeace International Honorary Chair, $18^{\text {th }}$ August.
} 
He outlined three main "golden rules" for campaigning:

No campaign should be begun without clear goals.

No campaign should be begun unless there is possibility that it can be won.

No campaign should be begun unless you intend to finish it off. ${ }^{384}$

Pearce (1996: 75) writes that "such rules to a large extent define what Greenpeace does and does not attempt to do" specifying that Greenpeace "generally rules out involvement in complex issues about environment and development in the Third World."

McTaggart's email was aimed at clarifying Greenpeace's unique role within the environmental movement, particularly because Greenpeace was going through an identity crisis, as this quotation suggests,

I think it was the early 1990s and mid-1990s - 1992 or 1993 - where we assumed everyone else was doing it better and we were looking at everybody else's governance and getting in consultants to tell us what we should be doing. It took Thilo Bode, I think, to just go 'we are the best Greenpeace-type organization in the world so let's just do it and stop looking at Red Cross because we're not Red Cross. We're not Friends of the Earth." I don't think it's uncommon to go through a crisis of identity and I actually think it's a good thing because you come through a little bit more grown-up. ${ }^{385}$

Thilo Bode became Greenpeace International's Executive Director in 1995 with the mandate that Bode would bring reform to Greenpeace's structures to improve the effectiveness of Greenpeace. Similar to McTaggart, Bode assessed that Greenpeace's strengths lie in its capacity at the international level. In 1995, Bode produced a strategic document, The Future of Greenpeace, which outlines this vision in detail,

The image of Greenpeace should be one of a radical and competent international organization that implements significant political change nationally and internationally by intelligent and confrontative campaigning. Lobbying draws its strength from good campaigns; putting emphasis first on lobbying and then on campaigning doesn't work. Greenpeace should become a perfect campaign

\footnotetext{
${ }^{384}$ McTaggart, David (1992) Letter to the organization from David McTaggart, Greenpeace International Honorary Chair, $18^{\text {th }}$ August.

${ }^{385}$ Interview with Jenny Stannard, Greenpeace Governance and Board Relations, Greenpeace International, October 2004.
} 
organization and not a United Nations for the environment. Competence and radicalism supplement each other in an important way. ${ }^{386}$

Bode's vision of a coherent global campaigning organization has had a significant influence on the development of Greenpeace. He rejected the approach of "a loose federation of National Offices" in favor of a "global campaigning organization." 387 Under Bode's leadership, Greenpeace undertook a 'blue skies' discussion in which Greenpeace campaigners explored how Greenpeace "could be the most effective global campaigning organization possible."388 Within this discussion, Greenpeace campaigners even considered the possibility that a headquarter / national and regional office structure may be constricting campaign activity, and that campaigns could instead be operated out of International Greenpeace Centers. ${ }^{389}$ During this discussion, the term 'One Greenpeace' was frequently used to highlight the need to consolidate campaign activities. Greenpeace internal documents highlight the changing external conditions as the key reason for consolidating Greenpeace into a relatively more globally-focused structure, as this quotation suggests,

The world Greenpeace works in is changing. The old national boundaries - political, economic, and social - are crumbling. Globalization means that polluting industries, resource extraction companies and markets move quickly around the world to wherever there is a profit to be made. Few Greenpeace campaigns can now be fought and won in just a single country or region. The power of nation states is declining making it harder for citizens and pressure groups to hold their governments accountable and to force change through national political pressure. The power of the large corporation is rising, raising new issues of corporate accountability and new opportunities for consumer pressure. The pace of change is increasing. The ability to change, to respond creatively and quickly to external events, is now one of the main criteria for success for corporations and organizations.

New forms of communication are changing the way people get information, widening their areas of concern and increasing the possibilities for action by individuals. Citizens are becoming "global". In some of the developed Greenpeace countries, the remaining national environmental issues are comparatively small. These offices increasingly want, and need, to work across national borders on more

${ }^{386}$ Bode, T. (1995) The Future of Greenpeace. Internal strategy document. Greenpeace International, Amsterdam, The Netherlands.

${ }^{387}$ Bode, T. (1998) International Executive Director's Report to the Board, 1998: Review of 1995-1998 and the Challenges Ahead. Greenpeace International, Amsterdam, The Netherlands.

${ }^{388}$. Lawrence, E., C. Rose, K. Rigg (1999) Some thoughts on what has come to be called 'Blue Skies' submitted to the 1999 Executive Directors Meeting as a discussion document, 29 July. ${ }^{389}$. Ibid. 
pressing regional issues. The challenges facing Greenpeace with its campaign priorities - climate and Amazon - are greater than any other in its history. They are truly global problems and require a global response. They also require more financial and human resources, and more imagination, than anything we've done before.

The role of Greenpeace in this new world is to engage effectively with these seemingly overwhelming environmental threats, challenge the transnational corporations wherever they go, and harness the power of the new technologies to catalyze change. We can only do this if we become global in our identity, thinking, reach and connections. An organization without boundaries in a world without boundaries. ${ }^{390}$

Gerd Leipold, Greenpeace International's current Executive Director places a similar emphasis on a concentrated approach, and states that "being strategic means having a limited number of campaigns that are very focused." ${ }^{391}$ Building on the 'One Greenpeace' discussion, Leipold released his own strategic document, Breaking Down the Walls (2001), with "bigger global campaigns" as a key part of its mission. ${ }^{392}$ Ultimately, the purpose of this relatively more centralized approach is to capitalize on Greenpeace's ability to produce memorable nonviolent direct actions, as this internal Greenpeace document discusses:

The public supports Greenpeace because of 'how' it works and we should use our unique strength to be distinct from others and continue to do what others do not do, or are unable to do. Greenpeace has to pursue large international campaign targets and conflicts where we can communicate emotional values. These conflicts can most likely be created around the protection of the global commons where there is an absolute distinction between good and bad.... All so called 'national campaigns' or the success of National Offices is dependent on Greenpeace creating these large international theatres. ${ }^{393}$

Greenpeace is unique in how it works globally through its signature confrontations. In this tactical approach, Greenpeace as an "organization [has] secured its niche in the ecology of ecologists: non-violent, creative and media savvy direct action." 394 With this in mind, international campaigns are chosen not only for their urgency but also for their

${ }^{390}$ Cornelia Durrant, One Greenpeace. Discussion Paper submitted to the Board and 1999 Stichting Greenpeace Council Annual General Meeting.

${ }^{391}$ Gerd Leipold as quoted in Williamson 2005

${ }^{392}$ Greenpeace (2002) Council Meeting Minutes. Greenpeace International, Amsterdam, The Netherlands.

${ }^{393}$.Greenpeace (1998) Summary of Mature Offices' Meeting, March 16 and 17, Greenpeace, Amsterdam, The Netherlands.

${ }^{394}$ Weyler 2004: 490. 
symbolic power in inspiring activism against ecological abuse and a change in consciousness towards an environmental sensibility. For example, Bode refers to the Amazon campaign as "filling the gap left in Greenpeace's campaign profile since the end of the Antarctic Campaign for a large-scale habitat protection campaign with great symbolic and imaginative power." 395 In his scholarly analysis of Greenpeace, Wapner (1996) comes to a similar conclusion of Greenpeace's unique approach to transnational politics. According to Wapner (1996:50), Greenpeace tactics of bearing witness and direct nonviolent action derive from Greenpeace's interpretation of environmental problems as a problem of framing.

Key to all of Greenpeace's efforts is the insight that people do not damage the ecosystem as a matter of course. Rather they operate in an ideational context that motivates them to do so.... People process experience into action through general conceptions or interpretations of the world. At the most general level, but also the most important, then, an important step toward protecting the earth is to change the way vast numbers of people understand the world. It involves persuading them to abandon their anti-ecological or non-ecological attitudes and practices, and to be concerned about the environmental well-being of the planet. In short, it requires disseminating an ecological sensibility.

Wapner refers to this approach as political globalism and argues that the primary aim of Greenpeace is to influence the values, norms, discourse and interpretations of reality of both the general public and of governments, corporations and ordinary citizens contributing to environmental problems. Within the public realm, Greenpeace employs a range of strategies, including direct action, media dissemination, research and documentation, to bring attention to environmentally harmful practices - wherever they occur on the planet - and to "sting" people with an ecological sensibility (Wapner 1996: 54): According to Wapner, Greenpeace also engages in "accountability politics" (Keck and Sikkink: 1999: 16) by exposing the disconnect between the promises and practices of individuals, governments, corporations and international organizations. Greenpeace confronts these actors, pushing them to live up to their pronouncements, to "walk the talk". In short, political globalism is "not foremost about building institutions" or about influencing the nation-state but is "the attempt to infuse all people's practices with a

${ }^{395}$ Bode, T. (1998) International Executive Director's Report to the Board, 1998: Review of 1995-1998 and the Challenges Ahead. Greenpeace International, Amsterdam, The Netherlands. 
conscience about environmental well-being." Similarly Dale emphasizes the unique niche that Greenpeace plays within the spectrum of environmental organizations in spreading a global environmental consciousness through symbolic and powerful creative confrontations. Dale (1996: 206) writes,

Perhaps this is the most appropriate role for an organization like Greenpeace; perhaps its ability to capture headlines on a massive scale, to stir outrage at brazen assaults on the environment, and so to trigger the economic and political pressure needed to hold the aggressor in check makes it uniquely capable of springing into action in times of crisis. There can be little doubt; as well, that this type of performance will be required in the future: given a seemingly endless supply of governmental and corporate miscreants - given that polluters are continually seeking out new frontiers around the world - it may be that environmentalists are destined to spend most of their time fighting a rearguard action, keeping watch over the planet, ready to sound the alarm when the most offensive acts are about to be committed.

Greenpeace has created a viable tactical approach for working globally which builds on the unique Greenpeace "formula" with the purpose of drawing attention to ecological abuse, inspiring activism, and catalyzing a change in consciousness on global environmental issues. In Chapter Eight, I analyze how this tactical approach translates into Greenpeace's strategic response to managing external and internal relations and maintaining its organizational viability. It will become apparent that the path towards a global campaigning organization has many challenges, including from within Greenpeace itself. 


\section{CHAPTER EIGHT: External and Internal Relations, and Organizational Maintenance}

\subsection{Introduction}

Transnational social movement organizations (TSMOs), including Friends of the Earth International (FoEI) and Greenpeace, are faced with external and internal demands that challenge their long-term organizational viability. In Chapter Four, I build on social movement and organizational theory in proposing four organizational challenges tactical innovation, managing external relations, organizational maintenance and managing internal relations - which confront TSMOs. The organizational viability of a TSMO is largely dependent on its ability to develop a reliable and effective strategic response to each challenge. Table 8.1 briefly summarizes these internal and external challenges again and notes the strategic dilemmas associated with each challenge.

Table 8.1 Overview of the Organizational Challenges

\begin{tabular}{|l|l|l|}
\hline $\begin{array}{l}\text { Organizational } \\
\text { Challenge }\end{array}$ & Description & Strategic Dilemma \\
\hline $\begin{array}{l}\text { Tactical } \\
\text { Innovation }\end{array}$ & $\begin{array}{l}\text { The challenge of creatively adjusting } \\
\text { tactics and devising new tactics in order } \\
\text { to repeatedly respond to changing } \\
\text { external conditions and persistently } \\
\text { disrupt - or threaten to disrupt - the } \\
\text { status quo }\end{array}$ & $\begin{array}{l}\text { expansion } \\
\text { vs. } \\
\text { specialization }\end{array}$ \\
\hline $\begin{array}{l}\text { Managing } \\
\text { External Relations }\end{array}$ & $\begin{array}{l}\text { The challenge of negotiating partnerships } \\
\text { with external actors in order to achieve } \\
\text { common goals } \\
\text { or of operating independently despite } \\
\text { pressures to partner }\end{array}$ & $\begin{array}{l}\text { collaboration } \\
\text { vs. } \\
\text { independence }\end{array}$ \\
\hline $\begin{array}{l}\text { Organizational } \\
\text { Maintenance }\end{array}$ & $\begin{array}{l}\text { The challenge of ensuring continued } \\
\text { organizational viability through securing } \\
\text { various combinations of financial support } \\
\text { (money) and human power (activism) in } \\
\text { order to survive, grow and remain } \\
\text { relevant }\end{array}$ & $\begin{array}{l}\text { grassroots / voluntarism } \\
\text { vs. } \\
\text { professional ethos }\end{array}$ \\
\hline $\begin{array}{l}\text { Managing Internal } \\
\text { Relations }\end{array}$ & $\begin{array}{l}\text { The challenge of facilitating internal } \\
\text { cohesion and of managing internal } \\
\text { conflict within a social movement } \\
\text { organization }\end{array}$ & $\begin{array}{l}\text { participatory democracy } \\
\text { vs. } \\
\text { unity of command }\end{array}$ \\
\hline
\end{tabular}


To summarize the previous chapters' discussion on tactical innovation, the organizational viability of TSMOs is partly determined by their capacity to calibrate their tactics to catalyze social change and maintain leverage over powerful actors in society. In the previous three chapters, I make the case that a relatively more centralized and formal organizational structure can also facilitate the creation of a viable strategic response to the challenge of tactical innovation. Both FoEI and Greenpeace have not only exhibited the capacity to modify their tactics within the context of specific encounters with target opponents and during particular campaigns, but also have developed a typical patterned response to tactical innovation that has facilitated their continued viability over time. Both FoEI and Greenpeace are, to put it colloquially, 'in it for the long haul' to secure a sustainable and peaceful future at the global level. Therefore, these organizations have developed an organizational strategy for working globally. This strategy enables them to repeatedly challenge ecologically and socially detrimental activities of societal actors within the transnational political environment, to address global environmental and social issues, and to propose sustainable alternatives.

As Chapter Six illustrates, Friends of the Earth International has responded to this longterm tactical challenge with an "expansion" approach, defined as innovating across a wide range of tactics in order to support their campaign activities across scales from the grassroots level to the global level. This strategic response emerged from FoEI's commitment to participatory democracy and decentralized, 'bottom-up' structure, and reinforces this commitment and configuration. FoEI member groups also share an interpretive frame that defines "environmental issues [as], in essence, social and political matters, and that we must build up common positions and make alliances" in order to address these issues. ${ }^{396}$ FoEI national member groups are "united by the common conviction that creating environmentally and socially sustainable societies requires both strong grassroots activism and effective national and global campaigning" and, therefore, strive to build, what I have labeled, a global grassroots movement.

\footnotetext{
${ }^{396}$ FoEI (2005) Annual Report. FoEI, Amsterdam, The Netherlands, p. 9.
} 
In contrast, Greenpeace has responded to the challenge of continuous tactical innovation by concentrating on a focused range of tactics, which I label a "specialization" approach. Ever since its first campaigns, Greenpeace has elaborated its signature tactical approach of nonviolent direct action, in which activists bear witness to and protest against environmental abuse and communicate this act of resistance through the mass media. This tactical approach has both the goal of directly halting environmentally and socially destructive behavior of governments and corporations, as well as broader goals of catalyzing further public dialogue and activism and of provoking a shift in consciousness around environmental issues. As Greenpeace notes "our organizational objectives are generally about setting new trajectories [and] at this level, we are involved in symbolic fights about the future of the environment and industrial development involving clashes of values and concepts." ${ }^{, 397}$ In order to repeatedly deliver this tactical approach, Greenpeace was developed as "an independent campaigning organization" (which I label a global campaigning organization), supported by a relatively more centralized and formalized structure for delivering "non-violent creative confrontations to expose environmental problems and to force solutions... essential to a green and peaceful future., 398

\section{How do these tactical choices influence FoEI and Greenpeace's strategic response to} the other three organizational challenges? First, transnational social movement organizations (TSMOs) are faced with the challenge of managing external relations with other actors in their political environment including civil society actors, governments and corporations. The challenge lies in determining whether to collaborate with these actors in order to advance shared goals, or to remain independent and avoid the time commitment, negotiation and possible cooptation that can occur in collaborative alliances. Second, TSMOs seeking to remain active over many years need to secure resources in order to maintain their organizations. As I discuss in Chapter One, this is not an 'output goal' such as winning a campaign, but is an essential 'support goal' that enables a TSMO to repeatedly deliver outputs and activities. Typically in social

${ }^{397}$ LeCoyte, R. (1998) Greenpeace Campaign Guide. Greenpeace UK, London.

${ }^{398}$ Greenpeace (2005) Annual Report. Greenpeace International, Amsterdam, The Netherlands. 
movement organizations, the resources that sustain an organization are combinations of financial donations and volunteer support. TSMOs that seek to create a broad grassroots base depend heavily on the contribution of human time through volunteer efforts. In contrast, TSMOs that seek to develop a professional cadre of activists depend primarily on financial donations. As will become evident below, both of these strategic responses to organizational maintenance have strengths and weaknesses. Finally, the long-term survival and viability of TSMOs is dependent on the capacity of the individuals within TSMOs to resolve internal disputes and nurture internal cohesion. A TSMO is faced with the option of engaging its members, through participatory democracy, in resolving these internal issues, or empowering a smaller group within the TSMO with the power to set a coherent direction and settle conflicts. In this chapter, I analyze the strategic responses of FoEI and Greenpeace to these three organizational challenges. This dissertation is grounded in the assumption that both organizations have exhibited organizational viability over their three decades of existence. I explore the ways in which they have achieved this by analyzing empirical evidence of how they address these challenges over time. Table 8.2 summarizes my conclusions as to FoEI and Greenpeace's typical strategic responses to the four organizational challenges.

Table 8.2 FoEI and Greenpeace's Typical Strategic Responses to the Four Organizational Challenges

\begin{tabular}{r|c|c} 
Dimension & $\begin{array}{c}\text { Friends of the Earth } \\
\text { International }\end{array}$ & Greenpeace \\
\hline Tactical Innovation & $\begin{array}{c}\text { Innovating across a } \\
\text { wide range of tactics }\end{array}$ & $\begin{array}{c}\text { Innovating within a } \\
\text { focused range of tactics }\end{array}$ \\
\hline $\begin{array}{r}\text { Managing } \\
\text { External Relations }\end{array}$ & $\begin{array}{c}\text { Building alliances } \\
\text { around shared } \\
\text { root cause' goals }\end{array}$ & $\begin{array}{c}\text { Strategic partnerships } \\
\text { supported by financial } \\
\text { contributions }\end{array}$ \\
\hline $\begin{array}{r}\text { Organizational } \\
\text { Maintenance }\end{array}$ & Grassroots / voluntarism \\
Internal Relations & Managing for diversity & \begin{tabular}{c} 
Managing for coherence \\
\hline
\end{tabular} \\
\hline
\end{tabular}

As I describe above, FoEI's typical strategic response to the challenge of tactical innovation is to embrace a wide range of tactics, whereas Greenpeace concentrates its 
efforts on elaborating its focused range of tactics. This tactical approach translates into very different responses to the challenge of managing external relations. Since FoEI aims to build a global grassroots movement, FoEI member groups build numerous alliances with other civil society actors and networks that share the same goals and positions. In contrast, Greenpeace predominately operates independently as a global campaigning organization; however, Greenpeace campaigners engage in strategic partnerships in order to advance specific campaign goals or to operate effectively within particular settings, such as intergovernmental meetings. In response to the challenge of organizational maintenance, FoEI depends heavily on grassroots volunteers for its local, national and international campaigning, whereas Greenpeace has evolved a professional campaigning and activist staff that are supported by financial donations. It will become apparent below that both FoEI and Greenpeace have wrestled with internal conflicts and issues of cohesion; however, FoEI has remained committed to participatory democracy and engaged in a decentralized process in resolving these issues, whereas Greenpeace has established a relatively more centralized internal structure for conflict resolution and consistency. For FoEI, the challenge is managing internal issues in a way that builds on its internal diversity. For Greenpeace, the challenge is managing internal disputes in order to align campaigners and activities and deliver a coherent organizational image and output. In the sections below, I explore evidence of these typical strategic responses within FoEI and Greenpeace, while also highlighting exceptions. By making the case that Greenpeace has developed equally viable and distinct strategic responses and that FoEI experiences problems as a result of its responses, I challenge the emerging consensus that TSMOs with decentralized and informal structures have an adaptive advantage over TSMOs with relatively more centralized and informal structures. Instead, I argue that both can be effective structures for building adaptive capacity.

\subsection{Managing External Relations}

FoEI and Greenpeace operate in a "relational web" of different actors including governments, business and industry, international organizations, media, the general public, and other social movement actors, organizations and networks (Fowler 2000, p. 
143, see Section 2.1.2 and 2.1.4). I propose that the external pressure and desire to cooperate and collaborate in partnership with other actors is in tension with the benefits of operating independently in order to enable flexibility, to ensure quality and a coherent style and to resist cooptation and conservatism of goals. Sometimes independence is forced upon the TSMO even if the TSMO is willing to cooperate and collaborate with other actors. This can be due to resource competition amongst social movement actors (Cooley and Ron 2002), or due to accusations of illegitimacy or lack of accountability by potential partners (Clark 2003a, p. 169). There are distinct advantages in creating partnerships, particularly within complex and dynamic environments, as interorganizational collaboration can produce "co-evolutionary arrangements" whereby collaborating organizations jointly adapt to environmental changes through "division of labour, mutual learning, and the diffusion of best practices" (Anheier and Themudo 2001, p. 206). There are also disadvantages as building and maintaining partnerships require time and resources, and require TSMOs to negotiate campaign goals, strategy and tactics with other actors.

Both FoEI and Greenpeace present an official position on partnerships within their mission statements. FoEI seeks "to engage in vibrant campaigns, raise awareness, mobilize people and build alliances with diverse movements, linking grassroots, national and global struggles." 399 The FoEI vision statement also notes that FoEI is "strengthened by the friendships and alliances we forge." ${ }^{400}$ In contrast, Greenpeace states that it is "an independent campaigning organization" which "has no permanent allies or enemies" for its activities "in exposing threats to the environment and in working to find solutions., From these official positions, it appears that FoEI and Greenpeace have significantly different approaches to external relations. In this section, I analyze the extent to which these differences remain apparent upon closer examination of these two organizations and empirical evidence of their partnering activities. It is also the purpose of this section to examine whether a collaborative approach, such as the one proposed by FoEI, maximizes adaptability in contrast with a strategic partnerships approach, such as the one

${ }^{399}$ FoEI (2005) Annual Report, FoEI, Amsterdam, The Netherlands, p. 2.

${ }^{400}$ Ibid.

${ }^{401}$ Greenpeace website - mission statement - http://www.greenpeace.org/international/about 
adopted by Greenpeace. According to Clark (2003a: 111), the decentralized and informal structure adopted by FoEI provides FoEI with an advantage in "managing strategic partnerships," defined as "strengthening links with new as well as traditional allies, even if there is little in common beyond the issue at hand, because the scope of global challenges goes well beyond the boundaries of individual [TSMOs]." The analysis below will determine whether this capacity for building strategic partnerships is maximized by FoEI's strategic response to the challenge of external relations. I have organized my analysis according to four key groups with whom TSMOs interact: civil society, local and indigenous peoples, government, and the private sector. Table 8.3 summarizes my conclusions as to FoEI and Greenpeace's typical relations with each of these groups. FoEI predominately collaborates with civil society actors and local and indigenous peoples, engages in some strategic partnerships with governmental actors, and has a limited engagement with corporations. Greenpeace remains predominately independent but engages in strategic partnerships with all of these groups for specific campaigns.

Table 8.3 Comparison between FoEI and Greenpeace on Managing External Relations

\begin{tabular}{l|l|l} 
Dimension & FoEI & Greenpeace \\
\hline Civil Society & $\begin{array}{l}\text { Alliances with like-minded } \\
\text { organizations and networks on } \\
\text { shared issues }\end{array}$ & $\begin{array}{l}\text { Predominately independent; } \\
\text { some strategic partnerships }\end{array}$ \\
\hline $\begin{array}{l}\text { Local and indigenous } \\
\text { peoples }\end{array}$ & $\begin{array}{l}\text { Long-term alliances } \\
\text { for joint campaigning }\end{array}$ & $\begin{array}{l}\text { Episodic interaction } \\
\text { on specific campaigns }\end{array}$ \\
\hline Government & $\begin{array}{l}\text { Funding, strategic partnerships } \\
\text {-nonpartisan }\end{array}$ & $\begin{array}{l}\text { Strategic partnerships } \\
\text { - nonpartisan }\end{array}$ \\
\hline Corporations & Limited engagement & Strategic partnerships \\
\hline
\end{tabular}

\subsubsection{FoEI, Civil Society and Local and Indigenous Peoples}

Friends of the Earth International builds extensive alliances with civil society actors and networks and with local and indigenous peoples in order to advance its campaigns (Wapner 1996: 125; Suter 2002/2003). FoEI not only engages in networks that align with their particular goals and objectives, but also remains open to the interpretive issue frames and tactics of other civil society and local groups with whom they engage. In 
other words, FoEI's “international positions are informed and strengthened by our work with communities, and our alliances with indigenous peoples', farmers movements, trade unions, human rights groups and others." ${ }^{402}$ A historical analysis reveals that FoEI certainly has a history of forging partnerships, building alliances, initiating new issuebased networks, and jointly campaigning with allied organizations, networks and movements. When David Brower officially launched Friends of the Earth in 1969, FoE US was founded as a partnership with the John Muir Institute for Environmental Studies, which would conduct research assessments on development projects, and the League of Conservation Voters, which would assess the performance of and endorse environmentally-minded elected officials. ${ }^{403}$ in 1972, FoEI joined forces with staff from The Ecologist journal in the UK in order to publish the daily newspaper, ECO, at the UN Conference on the Human Environment. ${ }^{404}$ From the early beginnings, FoEI established a tradition of forging alliances to accomplish campaign goals. From early annual reports, collaboration was identified as a fundamental concept driving the organization. For example, the 1984/1985 annual report states,

Through cooperation with other organizations, FoE works to build networks of people approaching the same problem from differing perspectives. In addition to FoE national groups, we are linked directly or indirectly with dozens of other environmental, consumer, human rights and peace organizations worldwide. ${ }^{405}$

This statement remains as true today, as Marijke Torfs, FoEI's International Coordinator expressed,

We've always worked with other groups - maybe we are moving now towards working more with other social movements but that is only a natural evolution.... It is an essential part of being a campaigner, you seek support, you find other groups to join your cause.... To make that happen, you have to negotiate, coordinate, find common ground.... That has been the way since the start of FoEI. It is one of our principles: you can't do it alone. ${ }^{406}$

${ }^{402}$ FoEI (2004) Annual Report. FoEI, Amsterdam, The Netherlands, p.2.

${ }^{403}$ Turner, Tom (1986) Friends of the Earth: The First Sixteen Years. San Francisco, USA, Earth Island Institute p. 2.

404 Ibid., p. 12

${ }^{405}$ FoEI (1984/1985) Annual Report. FoEI, Amsterdam, The Netherlands, p. 4

${ }^{406}$ Interview with Marijke Torfs, FoEI International Coordinator (1998 - present), October 2004. 
For example, FoEI is a member of the World Conservation Union (IUCN), the Antarctic and Southern Oceans Coalition, the Nuclear Free Pacific Network, and the Central and . Eastern Europe Bankwatch Network. Not only has FoEI engaged with other civil society networks, but it has also been instrumental in initiating them; for example, FoEI was a founding partner in the Environmental Liaison Centre International in Nairobi and the European Environmental Bureau. ${ }^{407}$ FoE groups in Malaysia, Brazil and the United States were founding members of the Pesticide Action Network; the Air Pollution Action Network was established at FoEI's major conference on acid rain in 1985; and FoEI launched the Ecological Debt Creditors Alliance in $2000{ }^{408}$ FoE Ecuador was the founder of the Oil Watch Network, which brings together communities affected by oil companies. ${ }^{409}$ Within national contexts, FoEI member groups are often at the centre of, or initiating, alliances. For instance, FoE Poland launched the Coalition to Support Organic Agriculture which unites 25 NGOs, research institutions and farmers associations in Poland. ${ }^{410}$ This has sometimes led FoEI to collaborate with unusual partners, such as the collaboration between FoE Austria and chimneysweeps in a climate change campaign. ${ }^{411}$

Predominately, FoEI builds these alliances around particular campaign areas. Once FoEI campaigners have selected an international campaign issue area and negotiated a position amongst member groups, it becomes possible to seek out civil society actors with similar positions or to agree to collaborate with organizations and networks striving for the same goals. As mentioned above, the international positions determined by FoEI can be influenced by input from external civil society actors. For example, in the forest campaign, the positions agreed to by FoEI member groups were developed in interaction with their partners including the World Rainforest Movement, Via Campesina, the

\footnotetext{
${ }^{407}$ MacArthur, Mairi (1989) The Growth of FoEI: A Personal View. July. FoEI historical archives, Amsterdam, The Netherlands.

${ }^{408}$ Turner, Tom (1986) Friends of the Earth: The First Sixteen Years. San Francisco, USA, Earth Island Institute; FoEI (2002) Annual Report. FoEI, Amsterdam, The Netherlands, p. 11.

${ }^{409}$ Interview with Ann Doherty, Communications Coordinator, FoEI, July 2005.

${ }^{410}$ FoEI (2001) Sparks of Hope, Fires of Resistance: FoEI Celebrates the Sustainable Path Forward: $30^{\text {th }}$ Anniversary Publication. FoEI, Amsterdam, The Netherlands.

${ }^{411}$ FoEI (2001) Sparks of Hope, Fires of Resistance: FoEI Celebrates the Sustainable Path Forward: $30^{\text {hh }}$ Anniversary Publication. FoEI, Amsterdam, The Netherlands, p. 28.
} 
Landless Rural Workers' Movement, the Global Forest Coalition and indigenous and environmental organizations. ${ }^{412}$ In the quotation on the previous page, Marijke Torfs discusses FoEI's increasing involvement with social movements. Torfs continues by identifying some of these social movement partners, including movements that formed in opposition to the economic development model and trade regime proposed by the World Trade Organization,

Network building is something that FoEI prioritizes a lot in comparison with other NGOs. This is particularly true for the trade work we do, and also for our campaign on Ecological Debt. We were heavily involved in coalition building before the World Trade Organization meeting in Seattle and still are involved in all the trade networks that have come out of that time, such as the "Our World is Not for Sale" network, the "From Seattle to Brussels" network for environmental issues, and, of course, the World Social Forum and the Alternative Forum at the World Economic Forum in Davos every year. In all of these instances, we are key players in the coalitions that have sprung up around these issues. Usually a specific campaign group will know which networks exist around an issue; for example, for our climate change campaign, we are part of the Climate Action Network. So again, we work in coalition with others. ${ }^{413}$

Many of these international coalitions also include local and indigenous peoples organizations and networks, and FoEI member groups regularly organize events and campaigns jointly with local and indigenous peoples. For example, FoEI collaborated with the International Alliance of Tribal-Indigenous Peoples of the Tropical Forests at the World Sustainability Hearings at the UN World Summit on Sustainable Development. ${ }^{414}$ FoEI local and national campaigns are predominately driven and delivered jointly by local and indigenous peoples affected by socially and environmentally destructive developments. ${ }^{415}$ FoE Malaysia (Sahabat Alam Malaysia) has campaigned alongside the Penan indigenous peoples to protect their livelihood and the rainforest; FoE Australia works with the Mirrar aboriginal people to fight for compensation for uranium mining on their traditional lands; FoE Colombia has worked alongside the U'Wa indigenous peoples to protect their lands from oil development. FoEI adopts the position that a sustainable

\footnotetext{
${ }^{412}$ FoEI (2005) Annual Report. FoEI, Amsterdam, The Netherlands, p. 9.

${ }^{413}$ Interview with Daniel Mittler, FoE Germany 1996 - 2004; Greenpeace International 2004 present, August 2002.

${ }^{414}$ FoEI (2002) Annual Report. FoEI, Amsterdam, The Netherlands, p.9.

${ }^{415}$ FoEI (2002) Clashes with Corporate Giants: 22 Campaigns for Biodiversity and Community. FoEI, Amsterdam, The Netherlands.
} 
future is one in which local livelihoods of local peoples are protected; for instance, FoEI notes that "protecting biological diversity is critical not only for its intrinsic value..., but for the vital role that biodiversity plays in people's lives." ${ }^{, 416}$

For local community groups, civil society organizations and networks that FoEI collaborates with frequently, FoEI has established a special category of membership entitled "affiliate status." FoEI affiliates are "specialist, single-issue groups working on a related issue; or other existing networks that are international in membership or political outreach; or groups oriented towards education or research rather than campaign/activist work. ${ }^{4417}$ FoEI affiliates include:

- Group de Trabalho Amazonico (GTA), a network which unites 602 grassroots groups in the Amazon region in joint campaigns to protect local livelihoods and ecosystem health ${ }^{418}$

- Earthlife Africa, a volunteer activist organization working for environmental and social justice ${ }^{419}$

- CEE Bankwatch a network of Central and Eastern European organizations raising public awareness about international financial institutions ${ }^{420}$,

- EcoPeace - Friends of the Earth Middle East (FoEME) which is "a unique umbrella organization representing leading Middle East environmental nongovernmental organizations" which work to promote cooperative efforts for environmental protection, ${ }^{421}$

- A SEED Europe (Action for Solidarity, Equality, Environment and Development Europe) which is "an European network linking youth groups and individuals all over Europe" to "forge alliances among young people committed to social and environmental justice, ${ }^{\text {,422 }}$

- International Rivers Network which support local communities, environmental and human rights groups around the world working to protect their rivers and watersheds. ${ }^{423}$

In sum, FoEI's strategic response to external relations with local and indigenous peoples and civil society actors aligns closely with the description by Clark (2003b: 6) of the

\footnotetext{
${ }^{416}$ Ibid., p. 2

${ }^{417}$ FoEI (2000) Friends of the Earth International Handbook, FoEI, Amsterdam, The

Netherlands.

${ }^{418} \mathrm{http}$ ://www.gta.org.br

${ }^{419} \mathrm{http} / / / \mathrm{www}$.earthlife.org.za

${ }^{420} \mathrm{http}: / / \mathrm{www}$. bankwatch.org

${ }^{421} \mathrm{http}: / / \mathrm{www}$.foeme.org

${ }^{422} \mathrm{http} / / / \mathrm{www}$.aseed.net

${ }^{423} \mathrm{http}$ ://www.irn.org
} 
"dense webs" formed by decentralized and informally structured TSMOs like FoEI. He describes these organizations as forging "many collaborative links with outside partners," which work in "horizontal clusters of networks based on shared goals [in] voluntary cooperation rather than leverage." It is important to note that these alliances predominately coalesce around a particular position and specific issue area. My analysis of FoEI reveals it to be multi-level web of individuals, groups and networks. It is a decentralized and informally structured organization that has affiliate networks, and that partners with networks, forms networks, and is even composed of networks. Many of the member groups that join FoEI are already networks or umibrella organizations in their own country. For example, FoE Finland is a coalition of diverse Finnish groups and FoE Haiti is an umbrella organization of peasant groups and popular organizations. ${ }^{424}$ According to Clark (2003a: 110), TSMOs that adopt a collaborative approach to managing external relations benefit from increasing their strength as "the scope of global challenges goes well beyond the boundaries of individual social movement organizations." Collaborative engagement supports adaptability by encouraging innovation and building bridges across diverse partners (Gerlach 1999).

\subsubsection{Greenpeace, Civil Society and Local and Indigenous Peoples}

In contrast to FoEI's approach to managing external relations, Greenpeace is an "independent campaigning organization" that flexibly shifts partnerships in accordance with its aims and objectives. The Greenpeace website provides insight into Greenpeace's response to managing external relations with civil society. Unlike Friends of the Earth International that highlights its collaboration with communities, indigenous peoples, farmers' movements, trade movements, and human rights groups, Greenpeace emphasizes the organization's relationship with the general public, namely to encourage their activism on environmental issues. ${ }^{425}$

We believe that the struggle to preserve the future of our planet is not about us. It's about you. Greenpeace speaks for 2.8 million supporters worldwide, and encourages millions more to take action every day. ${ }^{426}$

${ }^{424}$.FoEI (1996) Annual Report. FoEI, Amsterdam, The Netherlands.

${ }^{425} \mathrm{http}: / / \mathrm{www}$.greenpeace.org/

${ }^{426} \mathrm{http}: / / \mathrm{www}$.greenpeace.org/international/about' 
The Greenpeace official documents encourage concerned citizens to become involved in issue areas through their own campaigns or as volunteers in direct action campaigns within Greenpeace. Campaign websites highlight the work of three groups: Greenpeace staff, volunteers and 'cyberactivists' (those who take action using the Internet such as sending email protest letters or signing online petitions), and direct action activists. ${ }^{427}$ Greenpeace staff include the teams who participate in expeditions on Greenpeace vessels and the professional negotiators, scientists, and policy experts who pressure target opponents with technical and political reports and who lobby governments. Campaign staff work alongside "volunteers and cyberactivists [who] keep up the pressure on lawmakers and corporations [and] our activists [who] put their safety and freedom on the line for even the smallest chance to save the world. ${ }^{, 428}$ In reality, there is a great deal of overlap between the staff campaigners and the direct action activists as nearly all Greenpeace campaigners have undertaken direct action. For instance, the current Greenpeace International Executive Director, Gerd Leipold, flew a hot air balloon across the West and East German border in 1983 in protest of nuclear testing and has since been on numerous protest voyages on Greenpeace ships. ${ }^{429}$ According to one Greenpeace campaigner, activism is essential for maintaining "the flare in your heart" that makes a good campaigner within, for example, the diplomatic settings at intergovernmental meetings. ${ }^{430}$ In contrast to FoEI which emphasizes its long-standing partnerships with organizations, networks and social movements, Greenpeace emphasizes its relationship with individuals that have taken action to stop ecological abuse,

As you read about our protests and direct actions, keep in mind that they all depended on individuals, usually just regular people, who made a personal choice to help save the world. $^{431}$

'Saving the world' the Greenpeace way refers to the delivery of its tactical approach: confronting the enemy in highly visible protests that combine "radical words and

\footnotetext{
${ }^{427} \mathrm{http} / /$ www.greenpeace.org/international/climate-change/our_work

${ }^{428} \mathrm{http} / / /$ www.greenpeace.org/international/climate-change/our_work

${ }^{429}$ Boettger and Hamdan 2001: 35

${ }^{430}$ Interview with Marcelo Furtado, Greenpeace Brazil, September 2002.

${ }^{431} \mathrm{http}: / /$ www.greenpeace.org/international/climate-change/our_work
} 
practical actions," as well as propose positive alternatives. ${ }^{432}$ For each of these "creative confrontations", Greenpeace campaigners need to ensure the secrecy of the proposed action, quality research and political analysis to support its campaign, coherent style and a clear communications message, and legal backup and training for the direct action activists. Even when all campaigning preparations are followed, Greenpeace campaigns can go wrong, such as the unexpected seizing of Greenpeace boats in Moruroa in $1995 .{ }^{433}$ With all these complicated procedures and personal and organizational risks, Greenpeace campaigners have undertaken the vast majority of these actions alone. Of course, their independent delivery of such confrontations is also critical for maintaining public support and financial contributions as Greenpeace is seen as being active in halting environmental threats (see Section 8.3 below on organizational maintenance). Greenpeace operates independently within its direct action confrontations, and this tactical approach has resulted in Greenpeace campaigners concentrating internally on how to deliver the most effective confrontations. Consider this internal review of four Greenpeace strategic plans (1983, 1993, 1994, and 1997) which concluded that Greenpeace International did not incorporate within its strategic plans an analysis of other actors and an assessment of Greenpeace's role within a broader field of actors:

An area which is almost entirely neglected in the plans is that of public perception of the organization and its position in relation to society - to other groups, business, governments, media. Also neglected is the part played by Greenpeace's ways of working, in particular the role of direct action. This inward looking approach is reflected in the sections on Greenpeace identity.... Further research, discussion and analysis is merited in this area [of external analysis] and results would have implications for Greenpeace's future identity. ${ }^{434}$

Doherty (2002: 18) notes that "Greenpeace usually appears marginal in the analysis of movement networks because of its policy of relative independence from other environmental groups." This independent approach also extends beyond its direct action

\footnotetext{
${ }^{432}$ Sawyer, Steve (1991) Saving the World the Greenpeace Way. Introduction to the International Executive Director's Report to the 1991 Stichting Greenpeace Council Annual General Meeting, p.5.

${ }^{433}$ Lawrence, E. (1995) Extract from the Evaluation of Actions at Moruroa. Greenpeace International, Amsterdam, The Netherlands.

${ }^{434}$ Lawrence, E. (1997) Comparison of International Strategic Plans of 1987, 1993, 1994 and 1997. Research paper by Elaine Lawrence. Annex 2 of the 1997 Long Term Strategic Plan, Greenpeace International, Amsterdam, The Netherlands.
} 
campaigns into the other campaigning arenas, such as intergovernmental negotiations. At the United Nations Conference on Environment and Development in 1992, Greenpeace remained predominately outside of civil society coalition-building efforts while remaining prominent during the UNCED process in lobbying governments and in direct actions (Chatterjee and Finger 1994: 78). An "independence approach" to managing external relations can cause tensions with other civil society actors, as this Greenpeace campaigner notes,

We had a reputation and we had a little bit of money coming in. There was this sense that when Greenpeace walks into the room with a civil society coalition meeting that everybody is going to say "Okay Greenpeace, how are you going to fund what we all want to do?" We had to say to the coalition "we have our own niche here and we're not going jump into a wide coalition that is going to serve up a petition. We have a different way of working." So that was tough. A lot of my early lessons in working with Greenpeace and with civil society coalitions was how to find a way to ensure that we were working to our strength and other people were working to their strength. ${ }^{435}$

As Chapter Seven highlights, Greenpeace strength lies in its tactical approach in targeted campaigns, and there are a number of reasons for remaining predominately independent in delivering these campaigns. First, Greenpeace campaigners are concerned with avoiding the dilution of Greenpeace's message and profile through involvement with civil society coalitions. Consider this extract from the internal strategic document by past Executive Director of Greenpeace International, Thilo Bode,

Greenpeace has its own political and media profile and works together with other groups in temporary alliances but never gives up its own profile. The Greenpeace profile needs to remain unique in the world, adapting to different cultural environments but never watered down by permanent coalitions. ${ }^{436}$

The current Executive Director, Gerd Leipold expresses a similar concern for the diluting effects of coalitions, and also indicates that networks can reduce flexibility,

NGOs are used to forming coalitions based on shared objectives and values. Coalitions increase legitimacy, but they are slow and tend to create positions that reflect the need for internal compromise rather than relevance to the external world.... Typically coalitions in earlier stages of a campaign are less useful,

\footnotetext{
${ }^{435}$ Interview with Brian Fitzgerald, New Media Director, Greenpeace International, October 2004.

${ }^{436}$ Bode, T. (1996) Thoughts on the Role of Greenpeace International in the World. discussion paper submitted to the February 1996 Executive Director's Meeting.
} 
sometimes even detrimental, because they reduce mobility and blunt the sharpness of the argument. ${ }^{437}$

Third, coalitions with other civil society groups can result in an expenditure of time and resources that are not necessarily reflected in campaign outcomes. As one Greenpeace Board member expressed, this is the "tradeoff between the efficiency of working alone and the dynamic of working together." 438 When asked about civil society coalitions, Greenpeace Brazil campaigner, Marcelo Furtado, stated that these alliances "can be a big waste of time because you spend so much time agreeing on what you should say that by the time you agree then you have lost your opportunity. ${ }^{, 439}$ On the other hand, Furtado also noted that "networks can be very good when they are strategic [because] you have to be first and foremost strategic." This conclusion is similar to that expressed by Gerd Leipold, who noted that there is value in "strategic alliances based on shared interests."

[These alliances] have the advantage that they are more likely to lead to action. They reduce the need for coordination and allow for independent activities. They can help to push an issue onto centre-stage (and increase the 'market' and thereby the profile of all involved). Strategic alliances are pragmatic, are intended to last for limited periods, and should ideally involve members from various areas (development, environmental, human rights). ${ }^{40}$

\section{This quotation highlights Greenpeace's strategic response to managing external} relations, which is to engage in strategic, often time-bound, partnerships around particular campaigns with very specific goals. Clark (2003b: 6) describes this approach to managing external relations as remaining "predominately independent" while engaging "on a pragmatic basis" in "strategic partnerships" which are "well-defined, usually not dense" and emphasize the TSMO's own work. According to one scholarly study of TSMO effectiveness, a "strategic partnership" approach to managing external relations is the "most flexible and adaptive approach because [the organization] can engage in a variety of temporary national, regional and local partnerships that can be

${ }^{437}$ Leipold, G. (2000) "Campaigning: a fashion or the best way to change the global agenda? In Development in Practice. Vol. 10, No. 3 \&4, August.

${ }^{438}$ Interview with T. Mohan, Board Member, Greenpeace India, September 2002.

${ }^{439}$ Interview with Marcelo Furtado, campaigner Greenpeace Brazil, September 2002.

${ }^{440}$ Leipold, G. (2000) "Campaigning: a fashion or the best way to change the global agenda? In Development in Practice. Vol. 10, No. 3 \&4, August. 
changed over time" (Young et al. 1999: 338). These scholars argue that a collaborative approach to managing external relations, such as the strategic response of FoEI, is "likely to be least flexible because change requires consensus among the largest number of constituents." By establishing time-bound engagements, SMOs can ensure that "no resource dependency exists" such that "claims on the organization's presence, resources, and expertise rest on 'continuous' negotiation and reappraisal of appropriate role and function" (Fowler 2000: 161). These scholars challenge the emerging consensus that the collaborative strategic response adopted by FoEI necessarily provides an adaptive advantage.

One Greenpeace campaigner offers an example of strategic partnering in action within the campaign to protect Antarctica led by then Greenpeace International Chairman, David McTaggart,

This is what David McTaggart mastered with the International Whaling Commission. We'd sit down with the World Wide Fund for Nature (WWF) and they'd go after the Princes and the Heads of States because they could talk to them and we'd be out on the streets generating the news because they couldn't do that. It was a nice partnership and it worked very well.... It was very much a deliberate partnership. That was McTaggart's stamp. He'd look around and say "ah you can get to Prince Philip" or "you can get him to write a letter to this paper in this country because they're a swing vote in the whaling issue. At the same time, we're going to be out in front of their embassy throwing blood (I.wasn't a fan of that tactic), or whatever, and doing a very high level confrontation, so that the editorial will appear in the paper the same day that we're doing the action." That's a 'double pincer move.' He had an eye for that. He would say "this is your strength, this is your strength and this is your strength" and get all those balls in the air.

This strategic partnering with other civil society actors continues today. In fact, according to Steve Sawyer, Climate and Energy Policy Advisor in Greenpeace International, "an important difference between now and ten or fifteen years ago is that we work with other organizations more than we used to. ${ }^{441} \mathrm{He}$ cites the collaboration amongst Greenpeace, Friends of the Earth International, World Wide Fund for Nature, Oxfam, Consumers International, Danish '92, and ANPED (Northern Alliance for

\footnotetext{
${ }^{441}$ Interview with Steve Sawyer, Climate and Energy Policy Advisor, Greenpeace International; Past Executive Director of Greenpeace USA (1986-88); Past Executive Director of Greenpeace International (1988-1993), October 2004.
} 
Sustainability), who campaigned together in the lead-up to and at the UN World Summit on Sustainable Development in 2002. FoEI International Membership Coordinator, Mae Ocampo, similarly notes the cooperation between FoEI and Greenpeace on specific campaigns and intergovernmental meetings,

Greenpeace is very different from $F o E I$. We have worked with them on the corporate [accountability] campaign, on climate change issues and on the UN World Summit on Sustainable Development. We are strategically aligned with Greenpeace. Some of our national members say that we can't align with Greenpeace because we don't share their positions in other areas. We are strategic in that sense. If we want to campaign against a corporation in a particular country then we work Greenpeace if they are working on this issue. ${ }^{442}$

As the quotation above suggests, FoEI periodically engages in strategic partnerships to achieve specific campaign goals, which is a departure from its typical strategic response of establishing long-term alliances with civil society organizations, networks and social movements. Similarly, Greenpeace does depart from its strategic partnerships approach in certain campaign areas and engages in a limited number of longer-term civil society coalitions. Greenpeace, with FoEI, is part of the Climate Action Network, and participates in the coalition Abolition 2000, which is an alliance of over two thousand civil society organizations in 90 countries working for a global treaty to eliminate nuclear weapons. ${ }^{443}$. Both organizations are opportunistic in this way, even though they predominately tend towards a typical strategic response to managing external relations. This inconsistency in strategic responses is also apparent in Greenpeace's interactions with local and indigenous peoples: In Section 8.4, I will analyze Greenpeace's involvement in grassroots community struggles in more detail; however, it is important to note that Greenpeace has typically aligned with local and indigenous peoples for specific time-bound campaigns rather than in long-term alliances. For example, Greenpeace Argentina delivered a series of direct action confrontations in a campaign alongside the Wichi indigenous peoples to protect the rainforest and their traditional homeland. ${ }^{444}$ Greenpeace is campaigning alongside farmers in Oaxaca, Mexico to draw attention to the

\footnotetext{
442 Interview with Mae Ocampo, FoEI International Membership Development Coordinator, October 2004.

${ }^{443} \mathrm{http} / /$ www.abolition2000.org

${ }^{444}$ Movie - Greenpeace: Making a Stand (2006) OMNI Productions, Vancouver, Canada
} 
recent discovery of the contamination of their traditional maize varieties by genetically engineered maize. ${ }^{445}$ In a few cases, Greenpeace has led longer campaigns alongside local peoples, such as the campaign for compensation for the victims of the chemical plant accident in Bhopal, India; ${ }^{446}$ however, Greenpeace predominately engages in shorter-term strategic partnerships with local and indigenous peoples. As the next section will illustrate, this typical strategic response extends to Greenpeace's interaction with governments and corporations.

\subsubsection{Managing Relations with Governments and Corporations}

FoEI and Greenpeace are faced with the challenge of managing their external relations with governments and corporations. Traditionally governments and corporations are the powerful opponents in TSMO campaigns and the target of their tactics; however, these actors are also potential allies for TSMOs in the implementation of environmental and social objectives, particularly when these actors seek to advance sustainability goals, policies and activities (see Section 2.1.2). For some scholars, the effectiveness of a TSMO is partly dependent on its ability to seize opportunities to support and cooperate with governmental and corporate sustainability initiatives, rather than solely confronting these actors with protest actions. For instance, Cohen and Kennedy (2000: 338) argue that the ability to operate in partnerships with "powerful elite interests" is increasingly central to the performance of transnational social movement organizations,

Partly, what enables green groups to be globally effective is their capacity to construct viable linkages between different countries, groups and issues. But what also empowers them is their growing ability to collaborate with powerful elite interests when that appears useful while activating transnational grassroots support for more radical agendas whenever the opposition to change displayed by the former makes this necessary.

For some civil society activists, cooperating to a certain degree with powerful actors, such as governments and corporations, can be considered a new responsibility for TSMOs, particularly if this leads to evident social change such as poverty reduction (Naidoo 2000: 12). However, SMOs need to ensure that these cooperative efforts allow

${ }^{445}$ Greenpeace (2002) Annual Report. Greenpeace International, Amsterdam, The Netherlands, p. 8-9.

${ }^{446}$ Ibid., p. 14-15 
them to protect their autonomy and critical stance (Covey and Brown 2001). As social movement organizations seeking to change the status quo, FoEI and Greenpeace are keenly aware of possible cooptation of their agenda by engaging with governments and corporations; however, they have both found that there are certain cases in which cooperation can result in the advancement of their objectives. A clear example is within the context of intergovernmental negotiations, as FoEI and Greenpeace campaigners need to work with cooperative governments in order to introduce text into international negotiations. In this section, I begin by discussing FoEI's strategic response to managing relations with governments and corporations and then explore the approach that Greenpeace has taken in interacting with governments and corporations.

In the section above on FoEI and managing relations with other civil society actors and local and indigenous peoples, I conclude that FoEI has developed a collaborative strategic response and built extensive networks with civil society coalitions to advance its goals. Therefore, it may appear inconsistent that one of its past Chairs, Kevin Dunion, describes FoEI as "fiercely independent." ${ }^{, 477}$ From my discussion above, this description would seem to align more closely with Greenpeace's strategic response to managing external relations; however, it is also applicable to FoEI as it defines its relationship to those actors whom it targets with its activities - governments and corporations. Dunion also describes FoEI as being "genuinely radical" and it is this commitment to a radical position that informs FoEl's policies on interacting with government and corporations. In developing criteria for membership, FoEI national member groups agreed that any new member group must be "independent from political parties, economic interests, state, religious and ethnic organizations. ${ }^{, 448}$ The FoEI groups take this criterion seriously; for example, there was considerable debate in the 1980s as to the nonpartisan nature of FoEI Italy (Amici della Terra) and its possible expulsion as it initially had ties to an Italian political party, 'The Radicals' (Diani 1995: 25). In the case of FoE Hong Kong, FoEI

\footnotetext{
${ }^{447}$ FoE Scotland (2003) Kevin Dunion Departs Friends of the Earth Scotland. Press Release, FoE Scotland, 14 February.

${ }^{448}$ FoEI (2000) Friends of the Earth International Handbook, FoEI, Amsterdam, The Netherlands, p. 4.3.
} 
member groups voted to terminate its membership in light of the fact that this group was closely tied to a corporation. ${ }^{449}$

Although it is largely the case that FoEI remains independent from corporations and government, there are situations in which there are exceptions and FoEI member groups cooperate with governments and corporations towards specific goals. Relationships with government have been particularly complicated to navigate within FoEI because of the multiple levels at which FoEI operates,

The issue of building alliances with governments is a tricky area. On the one hand, some members choose or are forced to do so due to the local and national realities they live in. There are some FoEI member groups that are working with local municipalities on local projects (partnership rather than alliances). Then when we discuss it within the FoEI network as a whole, another national member group of FoEI will say "you can't enter into an alliance with government officials." We have to be careful because these members have local members or constituents who are critical of national FoEI member groups that enter into alliances with the government. We pursue our campaign goals with hard-hitting cases that are highly critical of national or local governments. We have case studies showing how governments have failed communities. We have strong relationships and allies with local communities, and partnering with governments may jeopardize the trust built with them. They will say "sorry you are working with government and we don't trust you anymore." A lot of national member groups don't get into cooperative arrangements with governments because the local groups will be critical and we cannot risk losing our most valued relationship with the communities. We have to strike a balance on how we manage this diversity of approaches from members. ${ }^{450}$

Although FoEI national groups and their local constituents remain predominately independent from alliances with government, the FoEI network as a whole has some ties with governmental bodies. FoEI is part of the World Conservation Union (IUCN), which includes both nongovernmental and governmental actors in its network. FoEI also receives funding from governments, including foundation grants from the Dutch and Swedish governments, in support of its work. According to one FoEI staff member, these government grant-making bodies have not placed any political restraints on the use of these funds and do not undermine their independence, and I have not found evidence to

${ }^{449}$ Samuel, Pierre (1992) Remembrance of Things Past. In FoEI LINK: $25^{\text {th }}$ Anniversary Special. July/August. Issue 73, p.8.

${ }_{450}$ Interview with Mae Ocampo, International Membership Development Coordinator, October 2004. 
the contrary in my analysis; however, this funding base does partially link FoEI's longterm organizational viability to the policies and funding priorities of these governments. ${ }^{451}$

In the case of managing FoEI relations with corporations, FoEI member groups have agreed on an official position which limits interaction with corporations. The impetus for creating these "Rules of Engagement with TNCs" (Transnational Corporations) came from a 1996 meeting of the Sustainable Societies Program in Brussels organized by European FoEI member groups. These European member groups invited a number of TNCs, such as British Petroleum, to present on conference panels and to engage in dialogue with them as to the nature of a sustainable future. The Sustainable Societies meeting coincided with a meeting of the FoEI Executive Committee, which included representatives from developing country FoEI member groups. John Hontelez, past FoEI Chair, recalls how the situation unfolded when these developing country representatives attended the European Sustainable Societies meeting,

The developing country and Latin American FoEI members were shocked at the conversation between the European groups and the multi-national corporations about sustainable societies. The discussion with the MNCs reached a constructive level and, in the end, I was skeptical. If you are talking to British Petroleum, you can get into an agreement about how the world should be in 50 years but you can not get into an agreement about what to do today to get there. For example, it is difficult to get them to talk about environmental fiscal reform and regulation. I know that after that meeting there was a tough discussion about how FoE should relate to MNCs. In 1997, I heard that at the Annual General Meeting, there was a tough debate. ${ }^{452}$

At the Annual General Meeting in Uruguay in 1997, there was an extensive discussion about the appropriate level of interaction with corporations. The conclusion of this discussion was summarized by the then FoEI Chair, Kevin Dunion in the 1997 Annual Report,

As an organization working locally, nationally and globally we are confronted with industry in all of its guises. Without a doubt, there are some companies which are open to exploring our agenda, and examples exist of businesses which have made substantial progress in the right direction. This is to be welcomed. But by and large,

${ }^{451}$ Interview with Ann Doherty, Communications Coordinator, FoEI, September 2002.

${ }^{452}$ Interview with John Hontelez, FoEI Chair (1986-1996), May 2006. 
business-as-usual continues within most companies and even within those same TNCs which figure prominently in the sustainability debate. Why is it that the same case studies and the same spokespersons are omnipresent at the emerging proliferation of 'green industry' conferences?

... [We] are also both aware and wary of corporate double standards. Northern environmental groups are courted by companies which simultaneously take advantage of poor environmental and political structures in the South and attempt to marginalize the critique of our groups there. It is for this reason that FoEI adopted a much more cautious and critical engagement with TNCs in 1997. This 'political precautionary principle' prevents the possibility of unwitting cooptation, whilst ensuring that we continue to press for - and, where appropriate, acknowledge - positive changes in industry. ${ }^{453}$

As this quotation suggests, this discussion at the AGM resulted in a set of rules that outlined that FoEI member groups should "operate under a "political precautionary system' [which] means that TNCs will not be regarded as part of a sustainable future" until demonstrated otherwise. ${ }^{454}$ Any change in the position of FoEI regarding a particular corporation would need to be agreed to by all of the FoEI member groups. Within these rules, FoEI member groups are expected to engage with corporations only within specific campaigns with specific goals. Dialogue amongst FoEI and corporations can only include "presenting our campaign demands; [and] securing measures which will counteract the negative effects of the TNCs activities." ${ }^{455}$ In the rules, FoEI member groups determined that FoEI groups make any interactions with a corporation publicly available knowledge. The member groups also agreed not to declare that a corporation is "more sustainable" but rather that they are "less harmful in their impact" in order to avoid supporting a false green image of a corporation. FoEI member groups decided to reject invitations to corporate conferences, events or dialogues, and only to engage in debates with corporations if the dialogue advances a campaign goal. Although these rules have clarified FoEI member group interactions with corporations, they were not intended to prevent all interaction with corporations, and FoEI member groups continue to engage in limited way with corporations in order to further their aims. For example, FoEI England,

${ }^{453}$ Dunion, K. (1997) "Global Warming and Hot Air" in Annual Report. FoEI, Amsterdam, The Netherlands, p. 3.

${ }^{454}$ FoEI (1997) Rules of Engagement with TNCs. in FoEI Handbook, May 2000, FoEI, Amsterdam, The Netherlands.

${ }^{455}$. FoEI.(1997) Rules of Engagement with TNCs. in FoEI Handbook, May 2000, FoEI, Amsterdam, The Netherlands. 
Wales and Northern Ireland has "tactical dealings with businesses" which are "not strategic partnerships" but rather are designed to stimulate corporations "to shout for change on big issues. ${ }^{, 456}$ For example, FoEI EWNI approached retailers using toxic chemicals, such as furniture stores, to place pressure on the chemical industry make products that are not harmful for children. ${ }^{457}$

Greenpeace adopts a similar approach to governments and corporations as it has with its interactions with civil society and local and indigenous peoples - independence combined with some strategic partnerships. According to Greenpeace, independence from governments and corporations is critical for enabling Greenpeace to carry out its campaigns,

Greenpeace works internationally on well-defined and focused campaign goals of global significance, challenging the most powerful forces in society, exposing those governments and corporations responsible for environmental crimes. By maintaining such independence of funding from corporate, government and such bodies as the UN and the European Union, Greenpeace is free to act without fear of external political control or influence which could otherwise lead to compromises in its goals or tactics. $^{458}$

As this quotation suggests, Greenpeace "does not solicit or accept funding from governments, corporations or political parties" and, therefore, "neither seeks nor accepts donations that could compromise its independence, aims, objectives and integrity.", 459 Independence is perceived "as one of [Greenpeace's] primary strengths" which "must not be compromised by joining forces with other organizations to achieve specific campaign objectives, no matter what the character of the other organization. ${ }^{, 460}$ In terms of external relations with governments, Greenpeace has remained "apolitical" in the sense that it aligns with governmental actors in order to achieve campaign objectives but does

\footnotetext{
${ }^{456}$ Interview with Mike Childs, Head of Campaigns, FoE England, Wales and Northern Ireland (EWNI), February 2005.

${ }^{457}$ Interview with Mike Childs, Head of Campaigns, FoE England, Wales and Northern Ireland (EWNI), February 2005.

${ }^{458}$ Bode, T. and Upsall, D. (2000) The Role of Greenpeace in Society. In Greenpeace International Organizational Development Plan.

${ }^{459} \mathrm{http}: / / \mathrm{www}$.greenpeace/international/about

${ }^{460}$ Greenpeace International (2000) Extract from Approved International Policies, Guidelines and Procedures. Compiled from formal Board, Council, and Executive Director Meeting Agreements from 1979 to the present.
} 
not engage in long-term alliances with governments. ${ }^{461}$ Governments can be temporary allies, for example, in promoting a particular position within an intergovernmental negotiation; however, Greenpeace reserves the right to target that same government in a subsequent or parallel campaign. For instance, the United States government was an ally in the campaign to protect whales, but was a target of the campaign against nuclear testing, to combat climate change, and to stop the spread of genetically modified organisms.

For its relations with corporations, Greenpeace is also predominately independent while engaging in some strategic partnerships. In many campaigns, corporations are the targets of Greenpeace actions. A classic example is the campaign against Shell in 1995 for its proposed disposal of the Brent Spar oil platform in the North Sea. Greenpeace has even adopted unusual tactics to protest corporations, including purchasing shares in Shell in order to voice Greenpeace's concerns at shareholder meetings. ${ }^{462}$ This is a tactic that has also been used by FoEI member groups in their campaigns. Similar to FoEI Rules for Engagement of TNCs, a Greenpeace internal document circulated at a Greenpeace conference in 1996 identified "Seven No-No's of Industry Co-operation." "463 These principles included not receiving funding from corporations, not endorsing the environmental record of a company or a special product of companies, not offering exclusive cooperation with any company, and not offering any restriction of critique or action on other matters than the specific issue of cooperation. ${ }^{464}$ Like FoEI, Greenpeace only cooperates with industry on clearly defined campaign goals within a limited time frame. For example, Greenpeace campaigners at the World Summit on Sustainable Development engaged in a joint press conference with the World Business Council on Sustainable Development on climate change. ${ }^{465}$ As Steve Sawyer, Climate and Energy Policy Advisor, Greenpeace International, recalls, this collaboration emerged as

\footnotetext{
${ }^{461}$ Stumaris and Stumaris 1978

${ }^{462}$ Interview with T. Mohan, Board Member, Greenpeace India, September 2002.

${ }^{463}$ Haerlin, B. (1995) The Seven No-No's of Industry Cooperation. Discussion document submitted to the Greenpeace Solutions Conference, Dublin, June.

${ }^{464}$ Ibid.

${ }^{465} \mathrm{http}: / / \mathrm{www}$. wbcsd.ch/plugins/docsearch/details.asp?DocId $=332$
} 
Greenpeace and WBCSD recognized their common agenda of pressuring governments to adopt certain policies to address climate change,

We hatched that particular plan for that event [the press conference] right after the Bali preparatory conference for the World Summit on Sustainable Development. It was basically as a result of IUCN, the World Conservation Union, and a panel that they had put together at Bali which had Greenpeace, the World Wide Fund For Nature and Oxfam on one side and the World Business Council on Sustainable Development, Business Alliance for Sustainable Development, and the International Chamber of Commerce on the other. They were expecting a fiery debate about what was wrong or not with the Summit process, and actually we found a degree of commonality around the fact that governments were not accepting their responsibility. NGOs were saying what the business community was saying as well, which was that governments need to set the rules and set the framework and then let the NGOs and business people fight over their regulation and implementation. If the governments don't set the framework, then we don't have anything to work with. I think a lot of people were surprised at the commonality in interests. ${ }^{466}$

This commonality of interest did not protect the WBSCD and Greenpeace from critique from the business and the civil society communities respectively once they had issued their joint statement. In fact, the head of WBCSD was almost fired for cooperating with Greenpeace on this event; however, both parties maintain that it was an important cooperative effort to pressure governments into taking action. ${ }^{467}$ This is just one example of the strategic partnerships that Greenpeace has undertaken with corporations and industry partners. Some other cooperative efforts have focused on Greenpeace's development of technological alternatives to unsustainable products, such as the Greenfreeze refrigerator and chlorine-free paper discussed in Chapter Seven (see Section 7.6). Greenpeace also undertakes limited cooperative engagements with industries that align with their interests, such as Greenpeace's support of Ecover, a toxin-free cleaning agent company, on its toxics campaign (SustainAbility 2000: 157). These strategic partnerships are not perceived within Greenpeace as undermining its independence but are aimed at achieving concrete results. Consider this interview with Thilo Bode, past Executive Director of Greenpeace International, for the Financial Times,

\footnotetext{
${ }^{466}$ Interview with Steve Sawyer, Climate and Energy Policy Advisor, Greenpeace International; Past Executive Director of Greenpeace USA (1986-88); Past Executive Director of Greenpeace International (1988-1993), October 2004.

${ }^{467}$ Ibid.
} 
Bode wants to talk to business. The environment is on the corporate agenda, a significant change since the early days of Greenpeace. Bode's business approach raises suspicion in some quarters, but he believes there are business allies that can help the cause. "Industry is the main player in society... That is why we need to talk to them." He dismisses the idea that cooperation might become collaboration. "We don't lose our ability to confront and attack by talking to them. It is important to know your adversary." It is not a cynical exercise in getting to know the enemy. Again, it is more complex, says Bode. "We can intervene physically, without violence against environmental destruction, such as the killing of whales. This holds true where the destruction is visible. But you can't see global warming, so here we have to find the most effective confrontation."...

But he promises that large corporations and governments are not off the hook. Greenpeace will seek to hold them to commitments made at the Rio Summit on climate change in 1992. "Big corporations today have a responsibility that goes beyond their aim to make a profit. The focus is on social, moral and ethical obligations. There is a very progressive agenda, our obligation is to say to industry "This is what you write. What is it you do?",468

Greenpeace's strategic engagement with corporations and governments in developing sustainable alternatives and in issuing joint statements on critical global issues has led some to perceive that Greenpeace is softening its confrontational stance. McCormick (1991) notes that, over time, Greenpeace has become "less confrontational and more inclined to use tactics of lobbying and discrete political influence." Suter (2002/2003: 71) writes, "unlike Greenpeace, which is entering into dialogue with some transnational corporations, FoEI remains hostile to them and is insisting on far greater corporate accountability." In my assessment, Greenpeace does engage in strategic engagements with governments and corporations, but maintains its radical and critical stance (see also Doherty 2002). For instance, the conference on corporate accountability at the World Summit on Sustainable Development was jointly organized by FoEI and Greenpeace and issued radical demands as to international regulation of corporate entities. Greenpeace is opportunistic in its engagements with others for specific campaign objectives and these alliances remain temporary in order to maintain their independence. As will become apparent in the section below, Greenpeace's radical position has also been called into question in relation to Greenpeace's strategic response to organizational maintenance.

${ }^{468}$ Jones, S. (1996) "Industrial Relations" in the Financial Times. 10 January. 


\subsection{Organizational Maintenance}

In order to build adaptive capacity, FoEI and Greenpeace need to develop strategic responses to internal as well as external challenges (Rawcliffe 1998: 100-101). As I discuss in Chapter One, one of the internal challenges facing transnational social movement organizations is in mobilizing resources in order to achieve the goal of survival and continuous viability. Diani and Donati (1999) identify at least two distinct resources that social movements can mobilize: time (activism and human power) and money (financial doriations).

Friends of the Earth International strategic response to organizational maintenance is focused on the mobilization of activist time and volunteer efforts. FoEI national member groups are "oriented towards the grassroots" and a broad volunteer and activism base "rooted and formed in [each] country itself." 469 These national member groups and their local members and grassroots groups are the lifeblood of FoEI as their viability determines the strength and effectiveness of international activities. In contrast, Greenpeace has strategically responded to the challenge of organizational maintenance by soliciting financial donations. These donations are collected from individuals who choose to contribute in order to support Greenpeace campaigners, professional negotiators and direct action activists. Although Greenpeace refers to these financial donors as "members," they do not influence Greenpeace decision-making processes and predominately do not become involved in Greenpeace campaigns. Instead, these supporters donate in order to maintain Greenpeace and support their creative confrontations and campaign work. Greenpeace campaigners accept these donations as evidence of a broad based support for environmental protection. As the 2005 Annual Report notes, "the continued growth of Greenpeace - as laid out in this annual report shows that even in economically difficult times people have a vision of a different world." ${ }^{470}$ Greenpeace notes that it "speaks for", its financial supporters and, therefore, partially derives its legitimacy from their continued backing. ${ }^{471}$

${ }^{469}$ FoEI (1994) Annual Report. FoEI, Amsterdam, The Netherlands, p. 4.

${ }^{470}$ Greenpeace (2005) Annual Report. Greenpeace International, Amsterdam, The Netherlands, p. 5.

${ }^{471} \mathrm{http} / / / \mathrm{www}$.greenpeace/international/about 
Traditionally, social movement organizations have drawn on volunteer and human resources in order to sustain their organizations and activities; however, "professional social movement organizations" sustain their organizations and their campaigners through soliciting funds from a "paper membership" that does not engage in the SMO's activities (McCarthy and Zald 1977). In Section 4.1, I discuss some of the concerns with this second approach to organizational maintenance and, in this section, I will group these concerns into three areas: conservatism of goals, lack of grounding in the 'grassroots,' and loss in flexibility. In my discussion of these three areas of concern, I aim to analyze the differences between the FoEI and Greenpeace strategic responses to organizational maintenance and to highlight the strengths and weaknesses of their approaches. Table 8.4 summarizes my conclusions. Briefly, I argue that both FoEI and Greenpeace have maintained their radical stance despite different strategic responses to organizational maintenance (Diani and Donati 1999; Doherty 2002). I propose that FoEI is fundamentally grassroots oriented and driven, whereas Greenpeace plays a bridging role between grassroots communities and international political processes. Finally, I conclude that both strategic responses to organizational maintenance provide the organizations with flexibility. FoEI is able to respond flexibly to local conditions, whereas Greenpeace can more readily spring into action to respond to an emerging issue or urgent problem.

\section{Table 8.4 Comparison between FoEI and Greenpeace on} Organizational Maintenance

\begin{tabular}{l|l|l} 
Dimension & FoEI & Greenpeace \\
\hline $\begin{array}{l}\text { Radical } \\
\text { Diani and Donati 1999) }\end{array}$ & $\begin{array}{l}\text { Participatory protest } \\
\text { organization }\end{array}$ & $\begin{array}{l}\text { Professional protest } \\
\text { organization }\end{array}$ \\
\hline Grassroots & Grassroots oriented & $\begin{array}{l}\text { Bridge between international } \\
\text { and grassroots }\end{array}$ \\
\hline Flexibility & $\begin{array}{l}\text { Responsiveness to local } \\
\text { conditions }\end{array}$ & Readiness for action \\
\hline
\end{tabular}




\subsubsection{Radical Protest Organization or Conservative Interest Group}

As I discuss in Section 4.3.3, a number of scholars criticize social movement organizations that focus on securing funds, such as Greenpeace, rather than on stimulating grassroots activism, such as FoEI. These scholars equate the acquisition of financial resources and the resulting institutionalization of a social movement organization as signaling a shift away from disruptive and confrontational tactics (e.g., McCarthy and Zald 1973, 1977; Jordan and Maloney 1997). Jordan and Maloney (1997: 22) describe SMOs that mobilize financial resources as "protest businesses" which draw on financial supporters rather than on members, decide policy centrally without the engagement of the membership, and undertake campaign activities with professional staff rather than individual supporters. Supporters do not form a community but are frequently unknown to each other. Jordan and Maloney (1997: 72) conclude that social movement organizations that rely on financial supporters are closer in character to institutionalized interest groups and should be considered "protest businesses." These authors write that "their hierarchical organization, lack of internal democracy, political strategies and tactics all undermine their categorization within the new social movement rubric" (Jordan and Maloney 1997: 72). Unlike social movement organizations, interest groups are relatively more conservative in their goals and are not aimed at catalyzing change in the status quo.

In my analysis, both FoEI and Greenpeace have remained radical in their positions and tactical approach. Within their campaigns, these organizations call for deep-rooted changes in economic development models, and directly challenge governments and corporations to fundamentally change their policies and industrial practices towards sustainable alternatives. In terms of their tactical approach, FoEI and Greenpeace engage in non-institutionalized, confrontation tactics. Greenpeace relies on individual donations not only to engage in "quiet diplomacy" through lobbying, which is akin to an interest group, but primarily to carry out nonviolent direct actions aimed at directly confronting powerful actors in society, triggering a change in their behavior, catalyzing broader public awareness of environmental issues, and encouraging the general public to engage. in activism to secure a sustainable future. Greenpeace's strategic decision to collect funding for a smaller trained team of political activists is directly related to the personal 
risks involved in engaging in their campaign activities. As Greenpeace has developed into a more professional and sophisticated global campaigning organization, it has maintained its commitment to challenging the status quo and to radical positions through its positions and tactics (Doherty 2002). Diani and Donati (1999) have come to this same conclusion and provide an analytical framework that distinguishes between the 'interest group' categorization suggested by Jordan and Maloney (1997) and a categorization that is more suitable to Greenpeace's approach. They write, "SMOs face at least two elementary dilemmas, having to choose between professional vs. participatory organizational models, and disruptive vs. conventional forms of pressure" (Diani and Donati. 1999: 16). Diani and Donati derive four organizational types from the combinations of these variables:

1. The Public Interest Lobby: A political organization managed by professional staff, with weak participatory inclinations and emphasis on traditional pressure tactics, this comes closes to the conventional interest group.

2. The Participatory Protest Organization: Emphasis on participatory action and subcultural structures combined with a strong inclination to disruptive protest. This model is closest to the classic idea of the decentralized, grassroots SMO, prepared and equipped, given its organizational traits - to adopt confrontational strategies.

3. The Professional Protest Organization: This model shares with the public interest lobby the emphasis on professional activism and the mobilization of financial resources. However, it includes confrontational tactics among its tactical options, along with more conventional ones.

4. The Participatory Pressure Group: Similarly to the participatory protest organization, rank-and-file members and sympathizers are involved in organizational life but the focus is on conventional lobbying techniques rather than protest.

Diani and Donati emphasize that regardless of the resource mobilization strategy, a social movement organization can move towards a more institutionalized form and remain radical. They also highlight the fact that professionalism does not necessarily result in a movement away from confrontational and disruptive tactics. I would also add that participatory organizations often exhibit professionalism in their operations, even if the term is being applied solely to one set of organizations in Diani and Donati's analysis. In the following quotation, Diani and Donati (1997: 23) discuss the "professional protest organization."

Greenpeace comes closest to this model. It has never adopted a mass participatory model but has always been highly centralized and professional, and has depended on 
material resources rather than activism from its members.... While its repertoires often include conventional lobbying, Greenpeace has also differed from other major environmental organizations in its inclination towards spectacular confrontational strategies.

In the professional protest organization, protest and confrontation are disentangled from mass, grass-roots participation. Action on behalf of the public interest is conducted by substituting for the 'logic of numbers' a particular version of the 'logic of bearing witness' (della Porta and Diani 1999: 202-210). The former regards mass involvement in collective action as the key to social movement success. The latter emphasizes the role of a small minority of activists who face high personal risks to re-affirm an ethical or moral principle.

The authors continue by suggesting that this 'logic of bearing witness' does not inspire activism amongst the concerned public but is oriented towards the media in order to command further financial resources from the public. They argue that this encourages a 'vicarious activism' by the public "which is actually media-oriented rather than grassroots-oriented" as they are not directly involved in the campaign,

The atomization and fragmentation of the general public no longer prevents protest and contention, as the latter is managed by small professional units. The capacity of protest groups like Greenpeace to attract media attention provides them with easy access to their potential constituency, from which they may generate the resources necessary to organizational maintenance.

Diani and Donati are making two claims here that are worth further analysis: the claim of 'vicarious activism' and the claim that Greenpeace gears its campaigns towards gaining media attention and securing further resources. First, Diani and Donati claim that an organizational maintenance strategy focused on securing financial donations leads to 'vicarious activism' rather than engaging in campaigns. Other scholars have expressed concern that financial members of Greenpeace are able to remain passive supporters of the environmental movement and do not become personally active in catalyzing social change (Dale 1996: 126); however, both Greenpeace and FoEI aim to inspire activism and stimulate a broader public awareness on environmental issues through their activities, despite their different strategic responses to organizational maintenance. In FoEI, their focus on voluntarism and participation supports this goal as "one of the reasons why people get attracted to $[\mathrm{FoEI}]$ is the wide variety of forms of participation it offers" from rallies and demonstrations, to lobbying to community education programs (Suter 
2002/2003: 69). Although FoEI primarily engages the public through their voluntary activism, it is important not to overstate this focus on grassroots activism and volunteerism. As Suter (2002/03: 72) notes,

There is no one standard FoEI activist or member. Members are recruited for what they can contribute to the work. For some, it could be financial donations, while others may have more time but less money available and so serve as a volunteer. FoEI's flexibility enables people to do what they can.

Although the vast majority of FoEI member groups engage a broad base of activists and volunteers at the local and national level, some FoEI groups, such as FoE England, Wales and Northern Ireland and FoE Canada, receive membership fees through direct mail solicitation from individual financial supporters.

In contrast, Greenpeace does not have as many avenues to get involved in its organizational activities. There are opportunities to volunteer for direct actions, to participate in campaigns through cyberactions (Internet based protest), and, to some extent, to volunteer to help at Greenpeace offices; however, predominately, Greenpeace operates with a hired staff of campaigners who carry out Greenpeace campaigns. Beyond offering some volunteer opportunities with Greenpeace, the organization aims to "inspire global activism to catalyze environmental solutions" and provides visitors to its website with recommendations for personal action. ${ }^{472}$ One Greenpeace campaigner states that "encouragement to take action is in fact Greenpeace's most important task [as] we cannot achieve much on our own and we have always been aware of that." which Greenpeace actually inspires individuals to take action is difficult to measure; however, there is evidence that people are inspired by Greenpeace once they become engaged in a local struggle and reach out to them for support. For example, I interviewed a woman from Mozambique at the World Summit for Sustainable Development, engaged in a prolonged citizen's protest against waste incineration and dam construction, whose group was inspired by Greenpeace and contacted Greenpeace for advice in their campaign,

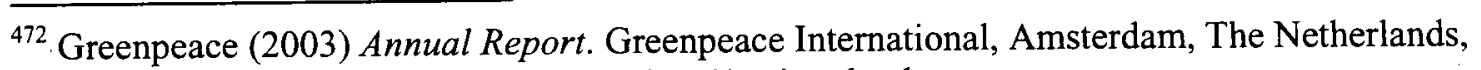
p.10; http://www.greenpeace.org/international/getinvolved

${ }^{473}$ Harald Zindler, Greenpeace Germany, as quoted in Boettger and Hamdan 2001: 284. 
We emailed Greenpeace because for us and for a lot of people, we feel that, with Greenpeace, that they are not scared of anything. If something is wrong then Greenpeace is going to help. Now that we are involved in the International Rivers Network we know a lot of other organizations but when we started the only group we knew was Greenpeace. That is why we asked them. We've known about Greenpeace for years. My son and niece are members. I have always been inspired by them - for years and years. With Greenpeace, everyone knows who they are and they are quite strong. When we wrote to them, they responded and we now deal with them on a weekly, if not daily basis, especially in a situation when I am asking them what to do. They will help me.

Sometimes they give me their opinion but it doesn't apply in Mozambique so we need to change and do it in a different way because it is a different country. But they are a big support when meeting with governments. They say that our government has signed this international agreement and that agreement and we didn't even know anything about agreements. We ask Greenpeace campaigners if we can see this agreement and they would fax or email it over. 24 hours later I am reading the international document with my group. It was a big help and if we didn't have Greenpeace then we would lose our campaign.... I don't think civil society can go anywhere if you don't have support. There is a lot of information that you need and you are not going to easily know where to find it. There are a lot of conventions and treaties that can be very important in supporting whatever battle you have in your country. ${ }^{474}$

Greenpeace can be a source of inspiration for citizen activism and, as I will discuss further in section 8.3.2 below, can serve as a bridge between grassroots struggles and international policy processes.

With regard to the second issue raised by Diani and Donati regarding the media focus of Greenpeace campaigns in order to secure funds, there is certainly evidence that Greenpeace embarks on campaigns in order to both achieve a practical campaign goal and to increase its profile in order to secure further donations. Consider the following internal Greenpeace document describing elements of "effective campaigning." ${ }^{475}$ The Greenpeace International Campaigns Director describes a "good campaign" as "one that raises a public debate over an important environmental/peace issue and achieves a specific and measurable objective to promote a positive alternative or otherwise eliminate a threat." Notably, he describes a "better" campaign as one that does the above and "also

\footnotetext{
${ }^{474}$ Interview with Anabela Arnaulth de Lemos, community activist, Mozambique, August 2002.

${ }^{475}$ Hinck, J. (1996) Effective Campaigning, An internal discussion document distributed at the Executive Directors Meeting, 18 October.
} 
boosts the campaign's image as a successful, positive and exciting force worthy of widespread support." This description supports the portrayal of Greenpeace actions as media events designed to stimulate financial donations; however, I argue that this is only part of the purpose of the campaign and may not be as distinct from achieving campaign objectives as Diani and Donati suggest. In Section 2.3, I discuss the scholarly distinction between tactics employed by an SMO to recruit supporters and participants ('technologies of mobilization') and those tactics aimed at attaining social change and protest goals ('technologies of protest') (McCarthy and Zald 2001: 537). I will reiterate my conclusion that there is a significant overlap between these two tactics since recruitment and the garnering of financial support is tied in many ways to the effectiveness of campaigns in influencing protest targets. This is why the internal Greenpeace document describes a "still better campaign" as one that encompasses concrete outcomes, increased profile for continued support, and "takes the enthusiasm of the victory and creates momentum for the broader goal of resolving the more difficult obstacles to achieving a genuine green peace. ${ }^{, 476}$ Although FoEI needs to report to its foundation and government donors, there remains a particular challenge which Greenpeace experiences more than FoEI, which is the needs to communicate with its broad funding base of individuals,

Greenpeace communication goes both ways.... You have to be able to deliver the message outward and then be able to turn around and deliver that message back to your base-your support base and communicate to them why it is important to save whales or to stop nuclear power or whatever. You have to be able to turn back around to your support base and tell them why it is important to support these things. They are connected but are also different forms of communication.... The message can go both ways when people...are actively putting themselves at the point of contact, at the point of conflict and they're taking their punishment in whatever form it comes. They are maintaining their values. They are not resorting to violence and they are not destroying property. They are just doing it. If they get jail time, they do the jail time.... This message is easily turned around.... But if you've got a banner on one end, then what are you going to say to your support base "give me more money so that we can take another banner and hold up the banner"?

${ }^{476}$ Hinck, J. (1996) Effective Campaigning, An internal discussion document distributed at the Executive Directors Meeting, 18 October.

${ }^{477}$ Interview with Rex Weyler, Greenpeace campaigner (1972 - 2006), Author of Greenpeace: How a Group of Ecologists, Journalists and Visionaries Changed the World (2004), November 2004. 
As this quotation suggests, Greenpeace members send their financial contributions because they support Greenpeace's approach of creative confrontations and respect the fact that Greenpeace activists place themselves in points of confrontation, often with personal risk, in order to prevent ecological abuse and to alert the broader public to environmental threats. Acts of political resistance and bearing witness are the signature tactical approach of Greenpeace which enable this organization to rely on individual contributions. Greenpeace is aware of this reason for support and quotes one Greenpeace supporter as saying, "I joined Greenpeace because I believe in its objectives....

Greenpeace's actions, always peaceful, demonstrate effectively why they are carried out and I think they are the best tool to get big and important achievements." ${ }^{478}$ It is for this reason that Greenpeace internal strategy documents emphasize a few strategic high profile international confrontations, along with quieter diplomatic lobbying and complex campaigns that build on these direct actions, in order to both maximize its effectiveness in pressuring for social change as well as delivering the nonviolent direct actions for which it is known. ${ }^{479}$ As a participatory protest organization, FoEI depends less on its high profile and more on its ability to "mobilize people and build alliances with diverse movements linking grassroots, national and global struggles." ${ }^{.480}$

\subsubsection{Connection with the Grassroots and Flexibility}

As discussed in section above, FoEI is built on a broad base of volunteers and grassroots campaigners at the local and national level. Consider this description from the 1994 Annual Report on the occasion of FoEI member groups adopting their first international agenda,

Although this international agenda might not seem unusual, in fact it is for an organization that has been oriented towards the grassroots for the past 23 years. During its existence, FoEI has become important and attractive to its members because of its decentralized and highly democratic structure, which gives national groups decision-making power about international activities and strategies. There

${ }^{478}$ Clara Raggio, Member of Greenpeace Argentina as quoted in Greenpeace (2001) Annual Report. Greenpeace International, Amsterdam, The Netherlands, p. 27.

${ }^{479}$ e.g., Bode, T. (1998) International Executive Director's Report to the Board, 1998: Review of 1995-1998 and the Challenges Ahead. Greenpeace International, Amsterdam, The Netherlands.

${ }^{480}$ FoEI (2005) Annual Report. FoEI, Amsterdam, The Netherlands. 
exists a natural variety among FoEI member groups, as they are not branches set up by an international organization, but are rather rooted and formed in the country itself. This rich diversity has always been the strength of FoEI as it leads to demands and campaigns that are politically balanced and powerful.

It is FoEI's roots in local and national contexts that leads FoEI to claim to be the "worldwide largest grassroots network" through its federation of national groups with their local and grassroots constituents. The original FoEI Chair notes that it is "the variety and vitality and grassroots contact which generate [FoEI's] unique character." 481 According to one early FoEI campaigner, the grassroots orientation stems from David Brower's slogan "think globally, act locally" which inspired the process by which "grassroots groups ultimately and organically made up the global network that is FoEI.,"482 FoEI campaigners today similarly describe how FoEI "evolved organically" from these grassroots foundations into an international federation. ${ }^{483}$ Although there is little doubt that FoEI uniqueness lies in its decentralized federated structure of national organizations, there is more of a question as to what precisely is meant by grassroots. When I asked Marijke Torfs, FoEI's International Coordinator (1998 - present), she responded,

What is grassroots? I don't know exactly how you define what grassroots is. We refer back to the national groups and they refer back to their national context to shape our international decisions. How far that goes and how many people these national groups involve depends on the national context. If you live in Switzerland that involvement extends very far, reaching out to many people who are part of the many local groups. But in Nigeria less people might be directly involved because the national group has a different structure, because the country functions differently. In the Nigerian context, it is just much harder to directly engage people at the local village level. In the Philippines, outreach to the local grassroots level goes beyond belief far. Nigeria is nevertheless also grassroots but it is grassroots at a different level. ${ }^{484}$

There is great deal of variation amongst FoEI member groups in terms of their involvement of local and grassroots groups. National member groups remain responsive

${ }^{481}$ MacArthur, Mairi (1991) Mairi MacArthur takes a personal look back at her memories of FoE International as the network enters its third decade. FoEI historical archive, Amsterdam, The Netherlands.

${ }^{482}$ Lammers, P. "Recollections" in FoEI Historical Archives.

${ }^{483}$ Interview with Beatrice Olivastri, co-founder and CEO, FoE Canada, September 2004.

${ }^{484}$ Interview with Marijke Torfs, FoEI International Coordinator (1998 - present), October 2004 
to their local and national contexts, and inform international positions with their national perspectives. For example, the FoEI international position on corporate accountability emerged from internal discussions in which developing country member groups alerted industrialized country groups to the fact that corporate promises to operate in socially and environmentally sensitive ways were not being implemented by those corporations on the ground. ${ }^{485}$ Because local and national level campaigns are not centrally coordinated, FoEI member groups are able to respond quickly to changes in their local and national contexts. There is a broad scholarly consensus that this decentralized and informal structure ensures the flexibility of a TSMO. Smith (2005: 235) argues that this structure "accelerates decision-making and therefore the adaptability of groups" as it limits transaction costs associated with a more vertical structure. As Fowler (2000: 142) notes, "continual referrals up and down a decision-making chain reduce speed and introduce stiffness rather than flexibility." Anheier and Themudo (2001: 201-202) come to a similar conclusion that "without central coordination for everyday management tasks and operations, decisions are made at the local level with a minimum cost for consultation and negotiation;" therefore, "adaptability is maximized when undertaken by small independent units rather than large bureaucratic structures." Clark (2003a) also states that "networks can reach decisions faster" because they are not hampered by decision-making layers.

These conclusions are certainly true for FoEI's local and national campaigns in which FoEI member groups can make autonomous decisions separate from further consultation with other FoEI groups; however, I challenge these conclusions when it comes to executing international level campaigns. Consider the following responses from three interviews conducted with FoEI campaigners when I asked them about the implications of their decentralized and informal structure,

Democracy takes time. It is also the case that we need to react quickly and it isn't . entirely possible to follow the full procedure that we would prefer to in all cases. This, of course, causes problems afterwards because people feel that they haven't been consulted or that they disagree with a decision that was taken. ${ }^{486}$

${ }^{485}$ FoEI (1997) Annual Report. FoEI, Amsterdam, The Netherlands.

${ }^{486}$ Interview with Daniel Mittler, FoE Germany 1996 - 2004; Greenpeace International 2004 present, August 2002. 
The structure has made things very slow especially when you compare it to Greenpeace which has a very top-down executive level in Amsterdam which decides and everyone does it. Of course, it's more complex than that. In our case, we operate by consent and the national members do it.

The usefulness of the slowness comes from the durability and credibility. The strategies are brought in by national members. Once something is decided it commands energy and is followed through because national members were involved. In an international federation, the international priorities have to resonate with the national and grassroots level or else it wouldn't work.

There are tensions though with international campaigning because I have found that campaigning has to be a flexible and fleet-footed activity. You need to do things quickly and move with those things that you can't control and understand what you want to do yourself. This is obviously in conflict with the long timetables and long time for reaching agreements. ${ }^{487}$

That is what Greenpeace is good at-getting issues out there. They are very strong at that because they can decide at any moment to get involved. They are not restricted to follow decision-making procedures as we are. It takes a long time to come to a decision within FoEI. Imagine, we have to go through the different structures and processes. In their case, Greenpeace International talks with Greenpeace India and then they get on with it. For us to do that, we have to go through several layers. ${ }^{488}$

These FoEI campaigners highlight a disadvantage of a decentralized, informal and grassroots oriented structure for a transnational social movement organization, namely the transaction costs and slow pace when trying to operate at the international level and come to a consensus on international positions. FoEI has developed a number of strategic responses to this problem. FoE member groups can participate in international activities in their own capacity as a national organization by, for example, signing onto a civil society petition as "FoE Germany" rather than "Friends of the Earth International;" ${ }^{489}$ however, this can lead to confusion and inconsistency when FoE member groups issue different positions at the same intergovernmental meeting or within the same campaign. FoEI member groups launched the 2005 and 2006 strategic planning process at the international level in order to resolve some of this confusion, to enable

${ }^{487}$ Interview with Tony Juniper, FoEI Vice-Chair (2000 - present); Executive Director, FoE EWNI, January 2006.

${ }^{488}$ Interview with Mae Ocampo, International Membership Development Coordinator, February 2006.

${ }^{489}$ Interview with Daniel Mittler, FoE Germany 1996 - 2004; Greenpeace International 2004 present, August 2002. 
quicker decision-making at the international level, and to develop common international positions which can guide national group and international activity, while still allowing national groups to remain autonomous.

The FoEI campaigners quoted above also suggest a second approach to being flexible, using the relatively more centralized and formal structure adopted by Greenpeace as an example. Building on the work of Gamson (1999), I label this approach "readiness for action," defined as the capacity to respond quickly to changing conditions. Based on my analysis of Greenpeace's approach to tactical innovation, I propose that it is an equally viable strategic response to reducing transaction costs and operating effectively at the international level. Whereas FoEI's flexibility lies in its "responsiveness to local conditions" and capacity to operate autonomously at the national level, Greenpeace's flexibility lies in its capacity to deliver a coherent response quickly to changing conditions at the global level. As is evident in its official documents, this is a deliberate strategic choice,

Greenpeace's strength lies in its ability to respond swiftly and decisively to fastchanging circumstances. In order to do so, executive power is concentrated in the hands of a relatively small core. ${ }^{.49}$

Greenpeace is an organization with the capacity to respond immediately and effectively to world events. Wherever an environmental disaster happens, whenever an opportunity presents itself, Greenpeace has the ability, and the imagination, to be there. ${ }^{491}$

Greenpeace cannot be everywhere that environmental abuse is being perpetrated, and, therefore, Greenpeace campaigners select the issues that they work on and the specific confrontations that they engage in given their finite amount of resources. Greenpeace can take action quickly to mobilize around a particular campaign, and place themselves at a point of confrontation, such as placing activists in front of a ship transporting illegal rainforest products or hazardous chemicals, or removing maize from fields that has been tested as genetically modified.

${ }^{490}$ Greenpeace (1996) Twenty-five Years as a Catalyst for Change. Greenpeace International, Amsterdam, The Netherlands, p. 12.

${ }^{491}$ Durrant, C. (1999) One Greenpeace. Discussion paper submitted to the Board and the 1999 Stichting Greenpeace Council Annual General Meeting. 
Greenpeace is effective in campaigning because they are able to mobilize a quick reaction to an issue. If we need an organization to popularize a campaign, they are effective at that and that's their niche in the environmental movement. That is their advantage. We appreciate that work. On the grassroots level, they are not as effective as FoEI as we go through an intensive process of negotiating amongst groups at all scales. ${ }^{492}$

The difference between FoEI and Greenpeace in terms of grassroots orientation is evident in the differences in their global expansion. Whereas FoEI expands to new national member groups in order to expand its "worldwide grassroots movement," Greenpeace has elected to maintain a limited number of offices that can be managed as a more centralized and formal global campaigning organization. For FoEI, new national member groups bring further connections to the grassroots and to local and national activists, which are their base and central resource. For Greenpeace, offices are established, merged, and closed down according to international level priorities, which are aimed at maximizing Greenpeace's strength in delivering strong global campaigns. Figure 8.1 depicts the steady increase of FoEI member groups and the relatively stable number of Greenpeace national and regional offices from 1999 until 2005.

Figure 8.1 Comparing the number of FoEI National Members and Greenpeace National and Regional offices over time (Source: FoEI and Greenpeace Annual Reports 1999 - 2005)

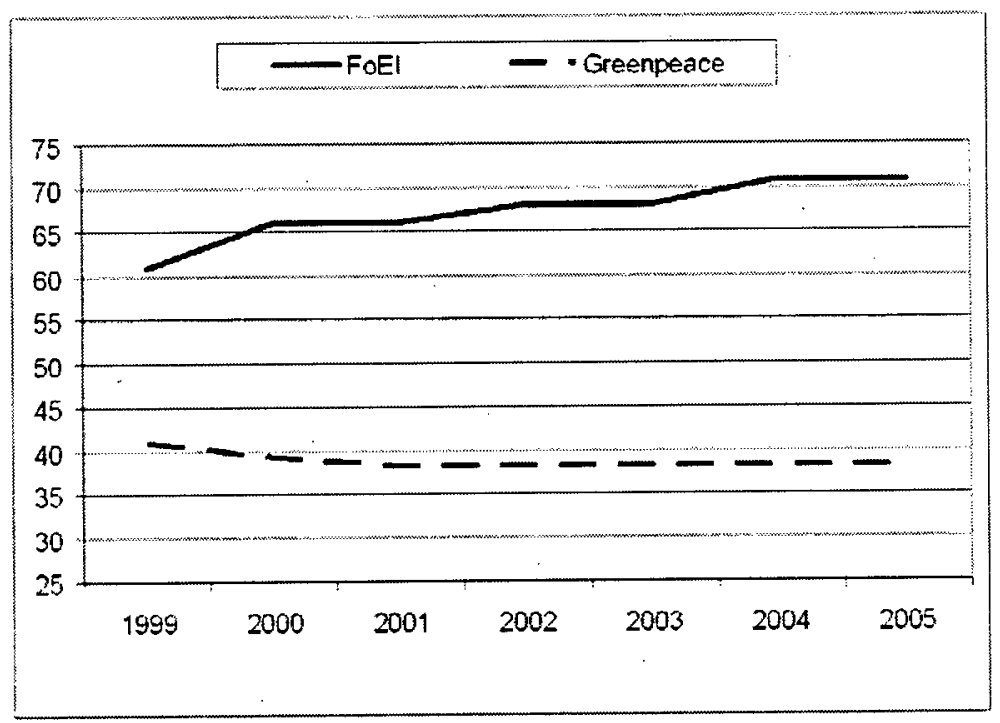

${ }^{492}$ Interview with Mae Ocampo, FoEI International Membership Development Coordinator, February 2006. 
Although Greenpeace does not work at the grassroots level, it is important to note that Greenpeace is also not entirely separated from grassroots struggles. ${ }^{493}$ Above, I describe a local struggle in Mozambique and the support offered by Greenpeace. Internally, Greenpeace campaigners discuss this as their "bridging role" between international processes and actors and grassroots groups and communities. ${ }^{494}$ Another internal strategy document notes,

Greenpeace is not a grassroots or community based organization though Greenpeace works in strategic alliances with such groups and its work complements and helps such groups attain their own goals. ${ }^{495}$

Sachs (1995: 14) supports this claim in his analysis of Greenpeace and the ways in which it lends political clout and advice to local community struggles. In my interview with Greenpeace Brazil campaigner, Marcelo Furtado, he reinforced this perspective,

I think that groups like Greenpeace can provide a platform by doing dramatic things that draw attention to grassroots struggles.... We have staff that link grassroots work to national and international work but primarily we are an international organization. We should not attempt to be what we are not. So if you ask me 'are you a community organizer' - no I am not and I will not try to be one. ${ }^{496}$

Furtado provided an example of a community struggle against Shell in Brazil. The community asked for Greenpeace Brazil's assistance when Shell Brazil refused to meet with them. When Shell Brazil refused to meet with Greenpeace Brazil as well, he contacted Greenpeace in The Netherlands who placed pressure on the Shell headquarters. As he recalls, "immediately there is a phone call from the Netherlands and the CEO of the Brazilian plan calls us to schedule a meeting." This grassroots cooperation is common within Greenpeace campaigns. It is interesting to note that these interactions

${ }^{493}$ For this discussion, I am adopting the definition of 'grassroots' as a local community struggle; however, the term 'grassroots' can also be applied to the realm of activism. In this context, the direct action activists who participate in Greenpeace campaigns can be perceived as adopting classically 'grassroots' activism tactics, namely direct action. Greenpeace, more than FoEI, own the image of direct action activists.

${ }^{494}$ Sawyer, S. (1994) Organizational Objectives for Greenpeace. Submitted to the Stichting Greenpeace Council Board, July, p. 15.

${ }^{495}$. Bode, T. (1997) Greenpeace International Long Term Strategic Plan. Greenpeace International, Amsterdam, The Netherlands, September.

${ }^{496}$ Interview with Marcelo Furtado, Greenpeace Brazil, September 2002. 
have not led Greenpeace to orient towards grassroots issues. Greenpeace remains focused on global environmental problems. In fact, during the 2002 Greenpeace Council meeting, Greenpeace campaigners decided not to launch campaigns focused specifically on poverty and development issues because "past experience of poverty alleviation and development work indicates that unless such work is grassroots-based, it causes more problems than it solves." 497.

Instead of building a grassroots base, Greenpeace has focused on building a professional, global campaigning organization. As Chapter Seven explores, Greenpeace has evolved increasingly sophisticated systems to support its unique tactical approach to addressing global environmental issues. This has led to a certain degree of formalization of Greenpeace operations in order to ensure quality campaigning and to cope repeatedly with the demands of delivering high-profile direct actions, of undertaking the political and scientific analysis to support these actions, of supporting an increasingly professional team of negotiators that engage in "quiet diplomacy" with governments and corporations, and handle the day-to-day organizational maintenance of a multi-million dollar operation. As the current Executive Director notes, Greenpeace "like other global NGOs - faces the same complicated management challenges as multinational companies" (as quoted in Williamson 2005). In order to accomplish this, Greenpeace International operates as "an umbrella organization where all decisions are made that are relevant to the day to day running of Greenpeace" and campaign planning meetings establish measurable goals and monitoring programs for campaign implementation. ${ }^{498}$ Because of this level of formalization, Greenpeace has been the subject of critique of becoming an "ecobureaucracy" that is not efficient; for example, ex-Greenpeace campaigner, Paul Watson, points to the effectiveness of his relatively more informally structured social movement organization, the Sea Shepherd Conservation Society, that engages in similar marine

\footnotetext{
${ }^{497}$ Greenpeace International (2002) Stichting Greenpeace Council Annual General Meeting Minutes, Greenpeace International, Amsterdam, The Netherlands, p. 16.

${ }^{498}$ Interview with Josselien Janssens, Campaign Direction Officer, Greenpeace International, September 2002.
} 
direct action confrontations as Greenpeace without its large structure. ${ }^{499}$ Internally, Greenpeace campaigners have repeatedly discussed the appropriate amount of bureaucracy for the delivery of quality campaigns while maintaining flexibility in order to enable flexibility,

Chaos and creativity plus initiative are of essential importance to Greenpeace. Highly motivated individuals work for Greenpeace. It is important for survival that this motivation is not choked by bureaucratic processes. ${ }^{500}$

The challenge that faces an organization as it becomes more professional and establishes internal rules and systems is to leave space for creativity. This is critical for any organization but particularly critical for social movement organizations that need to engage in tactical interaction with their target opponents and continuously innovate in order to stimulate social change. The following two quotations are taken from interviews with Greenpeace campaigners who discuss this point:

The tricky thing is that within an organizational framework, you can't stop creativity and sometimes you have to be bold and try something new. You have to go for it. In order to do that you need to build confidence in each campaigner that they are decision-makers.... Although we are talking about strategy and project specification in Greenpeace, we have to have a little room to be crazy, to be creative, and you have to have an organization that accepts that. ${ }^{501}$

An organization like Greenpeace can change more and evolve but it ultimately it has to deal with the question: what do you hardwire in a social movement organization and what do you leave free for creative thinking on the ground on the spot at that moment of confrontation.... The more that Greenpeace develops a bureaucracy that can't move quickly then other organization are going to spring up, like the Ruckus Society and Earth First! that are able to move faster because they are impatient and there is a sense of urgency.... Greenpeace came into existence because of the urgency of the issues we faced and now either we react to the moment and to the situation or you lose the possibility for confrontation. It would be nice to devise an organization that was so creative in its ability to react that it could do both - it could sustain itself and react to change.... It's a huge challenge and it is not done very often very well. ${ }^{502}$

${ }^{499}$ Watson, P. (2002) "The Second Greenpeace Foundation" in Future Positive.

http://futurepositive.synearth.net/2002/05/26

${ }^{500}$ Bode, T. (1995) The Future of Greenpeace. Internal strategy document. Greenpeace International, Amsterdam, The Netherlands, p. 6.

${ }^{501}$ Interview with Marcelo Furtado, Greenpeace Brazil, September 2002.

${ }^{502}$ Interview with Rex Weyler, Greenpeace campaigner (1972 - 2006), Author of Greenpeace: How a Group of Ecologists, Journalists and Visionaries Changed the World (2004), November 2004. 
Greenpeace continuously seeks this balance between formalization and openness to creativity. For Greenpeace campaigners, there is considerable room to experiment within the established protocols of Greenpeace and to think and act creatively. For example, the Greenpeace collaborative effort with the World Business Council on Sustainable Development was predominately designed and delivered by two Greenpeace campaigners who took the freedom to follow their instinct as to a critical campaign action. ${ }^{503}$ This challenge is also experienced within FoEI, which has "become more professional, more structured" with "more things written down and more agreed upon" over time. FoEI member groups would add new bylaws and rules "as FoEI was provoked and people asked questions and problems emerged." Although FoEI is relatively informal in its structure as compared with Greenpeace, it is important not to overstate its informality particularly as transnational coordination has become increasingly important (Wapner 1996: 124-125). Annual General Meetings are subject to Robert's Rules of Order, and FoEI has established a constitution and bylaws that guide FoEI activities. On the other hand, FoEI is also flexible with these rules, as Marijke Torfs, FoEI International Coordinator (1998 - present) notes,

FoEI is changing continually. There has never been one dramatic event that demanded a total revision of the bylaws. But the federation continues to grow. We always identify new needs, processes that need to change. We are not so bureaucratic that once we've established bylaws then that's it....

The network is alive, it moves constantly. But change does not always need to be captured in new rules. We are trying to make sure that the rules accompany us as time goes by. At times, new rules are needed but not often. Most of the real changes are the result of ongoing discussions between groups that lead to a better understanding of what we are doing, how we work together. Based on these experiences, we change the way we operate. For many of us, our motto is to live and learn, constantly seek to improve the way we interact and work with each other. If new rules need to follow, they will. ${ }^{504}$

The adaptability of FoEI rules is tied to the commitment by FoEI member groups to participatory democracy and an openness to changes that emerge through the continuous dialogue amongst the different groups. FoEI member group commitment to decentralized

${ }^{503}$ Interview with Steve Sawyer, Climate and Energy Policy Advisor, Greenpeace International; Past Executive Director of Greenpeace USA (1986-88); Past Executive Director of Greenpeace International (1988-1993), October 2004.

${ }^{504}$ Interview with Marijke Torfs, FoEI International Coordinator (1998 - present), October 2004. 
decision-making also shapes its approach to managing internal cohesion and resolving internal conflicts.

\subsection{Managing Internal Relations}

In addition to tactical innovation, managing external relations and organizational maintenance, transnational social movement organizations are faced with the challenge of managing their internal relations. TSMOs are composed of individuals, the vast majority of whom are committed, passionate activists with their own interpretation of environmental and social problems and of effective campaigns and solutions. In fact, TSMOs are collections of these individuals and are therefore subject to all the politics and camaraderie that occur in any gathering of human beings. In order to remain viable over the long term, the individuals within TSMOs need to devise an approach to resolving inevitable conflicts and to fostering cohesion within the organization. In this section, I explore the tensions that FoEI and Greenpeace experience in determining the appropriate level of centralization or decentralization, in responding to pressure to operate in a democratic way, and in strategically and repeatedly responding to internal conflicts as they emerge. Table 8.4 summarizes my conclusions of this analysis. As I discuss in Chapter Three, FoEI is a member-controlled, participatory democracy that has evolved and maintained a decentralized and informal structure in order to manage for diversity. In contrast, the strategic direction and decision-making authority lies with Greenpeace International, the secretariat, which holds executive power and manages for coherence, while remaining accountable to national and regional offices and the International Board of Greenpeace.

Table 8.5 Comparison between FoEI and Greenpeace on Managing Internal Relations

\begin{tabular}{l|l|l} 
Dimension & FoEI & Greenpeace \\
\hline $\begin{array}{l}\text { Decentralization - } \\
\text { Centralization }\end{array}$ & Member-controlled & Secretariat-controlled \\
\hline Democracy & Participatory democracy & $\begin{array}{l}\text { Unity of command with } \\
\text { accountability }\end{array}$ \\
\hline Strategic response & Managing for diversity & Managing for coherence \\
\hline
\end{tabular}


As I have discussed throughout this dissertation, FoEI and Greenpeace evolved very different solutions to the issue of centralization and decentralization. The Friends of the Earth International member groups have repeatedly decided to rest authority with the autonomous national groups because of their commitment to participatory democracy,

FoEI has grown into an international environmental force that is making a difference. It took a long time to build because the building had to take place from the bottom-up but that was worth it, because the democracy that is inherent in the three-tier-system make FoEI very different and more of an agent of change than all of the other international environmental organizations. Greenpeace and the like are organized more like a multinational. FoEI have members from all parts of the world, which makes a desperately needed non-western view to the ecological crisis more visible. ${ }^{505}$

This commitment to democracy stems from their desire for participatory democracy in society as a whole and, therefore, to exemplify the change they wish to see in society. ${ }^{506}$ FoEI is also committed to managing for diversity in order to benefit from different cultural and political perspectives. These commitments became evident in my analysis of the tools and systems that FoEI member groups have established in order to facilitate the development of common international positions and campaigns and to manage internal conflict. One of the first organizational changes that facilitated member-led, participatory democracy and the exchange of diverse perspectives was the extension of the annual general meeting time from three to six days in 1987 in order to allow for more discussion amongst member groups. ${ }^{507}$ Above, I discussed the internal conflict that emerged in 1997 amongst FoEI member groups with regards to their interactions with corporations. A similar conflict emerged regarding FoEI's involvement in the World Summit on Sustainable Development, after which certain member groups were unhappy with the message and approach that FoEI adopted during the Summit. One FoEI member groups, FoE Ecuador, resigned as a result of the conflict, because they felt that FoEI was not radical enough in its international positions and campaigns,

Because of FoE Ecuador resigning and the conflict about WSSD, we had to take a step back and recognize that we have gotten bigger and need to manage our diversity. Since WSSD, we've focused on internal issues in order to improve our

\footnotetext{
${ }^{505}$ Lammers, P. "Recollections" in FoEI Historical Archives.

${ }^{506}$ FoEI (2005) Outcomes of the Penang Visioning Workshop, FoEI, Amsterdam, The Netherlands, October.

${ }^{507}$ Interview with John Hontelez, FoEI Chair (1986-1996), May 2006.
} 
structures. We asked several questions and some of them were: do we lack a system that will watch for differences and manage conflict within a campaign? Where do our conflicts stem from - political differences or strategic differences? Do we have the same values? Where can we improve? We held an emergency meeting in 2003 in Cartagena, Colombia and the FoEI member groups discussed whether we can still function as a federation or whether it was time to break up. The member groups decided that we didn't want to break up and that FoEI is a fluid federation that is worth continuing despite the differences. We are a diverse federation and we come from different contexts and realities. We have to understand how huge these differences are and how to manage them. ${ }^{508}$

For FoEI, the meeting at Cartagena was a turning point in which FoEI member groups experimented with different tools to increase their ability to managing the organization's growing diversity. For example, the FoEI member groups hired an external facilitator for the meeting. They also worked with three tools for communicating across cultural and political divides: an Internet based discussion forum (the 'insite' communication system); an entirely open agenda that allows members to define the agenda and come up with solutions to complex issues (open space dialogue); and the 'inner/outer circle' in which delegates are chosen to represent the larger membership group in dialogues. These methods were all aimed at managing the diversity of FoEI member groups without moving towards a centralized decision-making system. Reporting on this meeting in the Annual Report, FoEI states that the Cartagena meeting was "a successful experiment in managing diversity and conflict resolution" that embraces FoEI as "a microcosm of planet Earth" which requires "democracy, transparency, accountability, participation and equity in decision-making at all levels." ${ }^{509}$ The report continues by noting that the commitment to a decentralized democratic structure and to managing diversity is challenging,

Managing this breadth and depth of diversity has been overwhelming at times, especially as the number of opinions and norms increases with the number of groups. But to allow our dialogues to fall into fractured, unproductive dissent is to fail at our very purpose: finding ways for people around the world to discuss and take action towards environmentally and sustainable and socially equitable societies. That is why we consider the process of decision-making as important as the decision itself. Within Friends of the Earth International, policy decisions are reached largely by

\footnotetext{
${ }^{508}$.Interview with Mae Ocampo, International Membership Development Coordinator, October 2004.

${ }^{509}$ FoEI (2003) Annual Report. FoEI, Amsterdam, The Netherlands, p. 3.
} 
consensus. To this end, we apply the principles of broad-based democracy, transparency, and accountability to all that we do. ${ }^{510}$

The meeting at Cartagena provides an example of FoEI managing its internal conflicts, and it is these same tools that are now being used to facilitate internal cohesion. As Anheier and Themudo (2001) note, TSMOs with decentralized and informal structures have the disadvantage that they can result in a "lack of coordination." In his analysis of FoEI, Clark (2003a: 114) concluded that FoEI "has no intention of harmonizing, strongly emphasizing local autonomy." As Chapter Six describes, FoEI member groups have become increasingly intent on resolving the issue of internal cohesion and have adopted the same tools (facilitator, insite communications, open space dialogue, inner/outer circle) to the recent strategic planning process (2005 and 2006). Consistent with FoEI's decentralized structure, the strategic planning process has developed from the bottom-up, beginning with national level discussions and then moving to regional level and then international level dialogues. FoEI Chair, Meena Raman, expressed amazement at the fact that this decentralized process led to the agreement of a common set of values, mission and visions across all 100 campaigners from 71 FoEI member groups. As she writes in the 2005 Annual Report, "the results of this general meeting seemed almost miraculous." $" 511$ When I asked her about her experience of FoEI's decision-making process, Meena Raman expressed,

The most important thing is that no matter. how good the structure is, it is the people who make the difference. It is about how the membership drives the federation. It is about the values such as valuing the diversity of the federation and at the same time wanting to be effective.... We are all committed to the process and want to make sure that the regions have a say. We are looking to see if there are bottlenecks and different points of view. We are finding the root. We are learning. There is no prescribed model for this process. Even our experienced facilitator commented that this is a federation that invests time in finding ways of sorting itself out and in experimenting a lot of the time.... It became clear that the federation only exists as far as people invest in it and we have the commitment to engage. ${ }^{512}$

${ }^{510}$ FoEI (2003) Annual Report. FoEI, Amsterdam, The Netherlands, p. 6.

511 Raman, M. (2005) "We have a vision!" in FoEI Annual Report. FoEI, Amsterdam, The Netherlands, p. 3.

${ }^{512}$ Interview with Meena Raman, FoEI Chair (2004 - present), Sahabat Alam Malaysia (FoE Malaysia), February 2006. 
Strategic planning is a new process for Friends of the Earth International. Historically, FoEI resolved conflicts and fostered cohesion during the general meetings and through the coordinating work of such FoEI structures as the Executive Committee and the International Secretariat. Although there have been some discussion papers circulated at the general meetings, FoEI embarked on its first organization-wide strategic plan in 2005. This is largely due to its structure, as this FoEI campaigner notes,

Friends of the Earth came out of the grassroots with local groups and grassroots action at its base. There are some obvious and direct tensions with the strategic process. These are very big questions that relate to how decisions are taken in a way that can retain grassroots credibility while also creating a structure. ${ }^{513}$

In contrast, Greenpeace has a long history of producing strategic plans, predominately written by Greenpeace International's Executive Director. Although later internal Greenpeace analyses of these strategic plans posed questions as to how these plans could be more effective in providing direction, ${ }^{514}$ the fact that there are Greenpeace long-term strategic plans is a significant indicator of the difference between Greenpeace and FoEI. Whereas FoEI is a decentralized, member-led, participatory democracy, Greenpeace is largely secretariat-led. As I discuss in Chapter Three, this centralized structure was formally established by David McTaggart after the 1979 resolution of the internal conflict between Greenpeace Vancouver and Greenpeace San Francisco. McTaggart designed Greenpeace International to operate as a hierarchical structure of command, accountable to a trusteeship council composed of national and regional office representatives. As is apparent from this extract from a 1992 internal memo, McTaggart had little patience for democratic structures,

The goal in building Greenpeace was to build it internationally - to not allow it to fall into the trap of the many groups which tried to forge so called 'International' organizations without paying attention to centralized decision making. Yes I know, we don't like the words 'centralized decision-making.' But the multinational corporations and governments whose policies we are trying to change fear those words in the context of mass movements and oppositions....

\footnotetext{
${ }^{513}$ Interview with Tony Juniper, FoEI Vice-Chair (2000 - present); Executive Director, FoE EWNI, January 2006.

${ }^{514}$ Lawrence, E. (1997) Comparison of International Strategic Plans of 1987, 1993, 1994 and 1997. Research paper by Elaine Lawrence. Annex 2 of the 1997 Long Term Strategic Plan, Greenpeace International, Amsterdam, The Netherlands.
} 
To be international, we agreed there was a need for a simple leadership structure that combined fast decision making with wide accountability to the whole organization.... We needed strong national boards to appoint a strong international board to appoint a strong Executive. We agreed that by funneling accountability in that way, we avoided the impossible situation of an international executive answering to more than a dozen bosses. The leaders of the organization were supposed to keep us focused and effective....

And they had to be able to take some heat, because this was not intended to be a consensus organization. Any group of homogenous, like-minded people who can all agree on everything is living in twinkie land. That's for the Moonies and the Scientologists and the Flat Earth Society and all the other groups that are doomed to the fringe, where they talk to themselves and to the people who agree with them and nobody else. Consensus is not the way to build a massive international movement. It needs the bitter, cold-blooded natural selection of argument and debate, not molasses, compromise and dilution. ${ }^{515}$

According to Gamson (1999), this type of centralized organizational form is more effective at managing internal conflict and fostering cohesion. As McTaggart (2002) wrote in his autobiography, his decision to centralize decision-making power led to many internal conflicts between those who sought a secretariat-led international campaigning organization and those campaigners who supported the decentralization of power to national offices. The debate between decentralization and centralization had already been present in the first 10 years of Greenpeace (e.g., Weyler 2004: 404; 459), but they became intense under McTaggart's reign. For a time, this debate split Greenpeace into two camps,

We used to have our own Cold War balance of power across the Atlantic with the USA, Latin America, New Zealand, Australia and the other smaller countries and Greenpeace International tending towards a centralized model and the 'Barons' (the Brits, the Dutch and the Germans) as the more nationalistic group in Europe. You could characterize the forces of centralization and decentralization in that way. But that had changed by the early 1990s and that is long gone now to the point where most of the Greenpeace campaigners today would not even recognize that as part of our history. ${ }^{516}$

Even when this particular divide dissolved, the centralization and decentralization debate still continued and led to the "One Greenpeace" discussions in the mid 1990s. This

\footnotetext{
${ }^{515}$ McTaggart, David (1992) Letter to the organization from David McTaggart, Greenpeace International Honorary Chair, $18^{\text {th }}$ August, p. 2-3.

${ }^{516}$ Interview with Steve Sawyer, Climate and Energy Policy Advisor, Greenpeace International; Past Executive Director of Greenpeace USA (1986-88); Past Executive Director of Greenpeace International (1988-1993), October 2004.
} 
extract from the 1993 Greenpeace Strategic Plan captures some of the frustration and challenges that are felt inside Greenpeace in trying to manage for coherence in an organization composed of diverse national and regional offices.

For many years, great inefficiencies and wasted efforts have resulted from arguments over the rights and responsibilities of "national" and "international". Political, economic, and legal battles over this contested line have sapped our energy and diverted some of our most skilled people away from important work. While there may have been reasons for it in earlier times, this distinction has now become, on balance, a destructive force. The time has come to move forward. We are one organization, not a federation of national domains. A National or Regional Office Executive Director should be seen as the person responsible for Greenpeace's activity in a specific geographic area. They are Greenpeace's ambassador to that country, not that country's ambassador to Greenpeace.... We are one organization and we are all simply looking after different parts of it. ${ }^{517}$

Greenpeace's main tool for managing for coherence has been the strategic plan. It is through this document that Greenpeace International and the Executive Director have set the direction for Greenpeace and repeatedly encouraged Greenpeace offices and campaigners to think of Greenpeace as one global campaigning organization,

This is "One Greenpeace." Not an association of 27 offices who put their own agendas, interests, and national allegiances first, but a truly integrated and international organization which is creative, flexible, fast, diverse, dynamic and unified. ${ }^{518}$

Recently, the "coherence" effort by Greenpeace International has led to a restructuring in which Greenpeace International reduced the budgets held at the international level and the number of staff coordinators at the headquarters and, in exchange, the national and regional offices agreed to provide a greater degree of resources at the disposal of the whole organization. ${ }^{519}$ This restructuring was not accompanied by a movement towards a participatory democracy and a decentralized structure. Given growing pressures on TSMOs to be accountable and prove their legitimacy in targeting powerful interests in

${ }^{517}$ Greenpeace (1993) Strategic Plan. Greenpeace International, Amsterdam, The Netherlands, October, p. 12.

${ }^{518}$ Durrant, C. (1999) One Greenpeace. Discussion paper submitted to the Board and the 1999 Stichting Greenpeace Council Annual General Meeting.

' 519 Interview with Steve Sawyer, Climate and Energy Policy Advisor, Greenpeace International; Past Executive Director of Greenpeace USA (1986-88); Past Executive Director of Greenpeace International (1988-1993), October 2004. 
society (see Section 1.4), Greenpeace has been subject to critique due to this lack of internal participatory democratic structures (e.g., Clark 2003a). This criticism is having some impact on internal discussions within Greenpeace, and the latest version of the Board Manual discusses the "concerns raised regarding the legitimacy of Greenpeace democratic structures" particularly after the 1995 Brent Spar and Mururoa campaigns. ${ }^{520}$ When I asked the current Greenpeace International Executive Director, Gerd Leipold about democracy in Greenpeace he responded by saying,

We have democratic control in Greenpeace. After all, there are different ways of democratic control.... In Greenpeace, there are the Boards of Directors of each of the national offices who elect Board Chairs who, in turn, elect the Greenpeace International Board. The International Board appoints the Executive Director for limited periods of time. They set objectives and evaluate the performance of the Executive Director on a yearly basis in a very elaborate process. In the end, this ensures more accountability than a participatory democracy on the executive level. If the Board gets involved in the day to day work on a regular basis, then the accountability and ultimate responsibility is diffused; whereas, in the case of Greenpeace, if I make a decision then the responsibility rests on my shoulders. ${ }^{521}$

He continues by noting that Greenpeace contributes to democracy within societies as a whole by opening public space for dissent, particularly in newly democratic countries, and by stimulating public dialogue around environmental issues. In order to play this role in society, Greenpeace has deliberately chosen to be a global campaigning organization that focuses on a limited number of campaigns to achieve concrete objectives. As Leipold expressed in an interview with the Financial Times, "the model is to do peaceful direct actions and reach the media, and use the media coverage to exert pressure on business and politics, which also reaches the general public, that then gives us money; so that we can do more campaigning" (Williamson 2005). In this way, Greenpeace is managing for coherence and a coherent public image, in order to ensure that it is effective and stands out as a unique force for change within the environmental movement. I conclude this chapter by noting that the strategic response for managing internal relations is directly tied to Greenpeace's tactical approach to working globally through building a 'global campaigning organization'. Similarly, FoEI's strategic

${ }^{520}$ Greenpeace (2004) Board Manual. Greenpeace International, Amsterdam, The Netherlands, p. 44.

${ }^{521}$ Interview with Gerd Leipold, Greenpeace International Executive Director, October 2004. 
response to managing internal relations links with its approach to working globally through building a 'global grassroots movement', and as one FoEI campaigner notes, this has both its advantages and disadvantages,

A global organization is easier to grasp. We are a little vaguer and the edges are not as defined. It could be that now FoEI can become better known because we have an International Media Coordinator. Some strategies would embrace that move towards greater cohesion but I don't think we want to take that on. We don't want to be Greenpeace. We want to move on to be something different. Our focus is on the grassroots and on making alliances with other movements. We want to make a broader movement not a higher one. ${ }^{522}$

In this chapter, I have analyzed how Friends of the Earth International and Greenpeace have strategically responded to four organizational challenges to their viability. In the upcoming conclusion, I will summarize this analysis and explore how these strategic responses amount to an approach to building adaptive capacity.

${ }^{522}$ Interview with Ann Doherty, Communications Coordinator, FoEI, September 2002. 


\section{CHAPTER NINE: Conclusion}

\subsection{Summary of the Central Argument}

In this dissertation, I take issue with the emerging consensus amongst scholars that "adaptability is maximized" by decentralized and informal structures (Fowler 2000; Anheier and Themudo 2001; Clark 2003a: 110; Smith 2005), such as the structural configuration of Friends of the Earth International (FoEI). Instead, I propose that both FoEI and Greenpeace have developed adaptability. This proposal is based on evidence of the organizational viability, including their strong income levels and membership numbers (Section 1.2). In this dissertation, FoEI and Greenpeace's organizational viability serves as a surrogate measure of their effectiveness in attaining both their support goals of maintaining their organizations and advancing their outputs goals including specific campaign targets (FoEI 2005; GPI 2005). I suggest that Greenpeace and Friends of the Earth International are subject to a range of complex and dynamic internal and external pressures. Within this context, their continued effectiveness over time indicates that these TSMOs have built adaptive capacity, the ability to repeatedly and strategically respond to these pressures.

I analyze FoEI and Greenpeace to clarify the relationship between organizational structure and adaptability. I am guided by the research question: does the prevailing assumption hold that a decentralized and informal structure is the only way for transnational social movement organizations to maximize adaptability in complex and dynamic conditions? As I outline in the introductory chapter and Chapter Three, formalization refers to "the degree to which an SMO has an explicitly (e.g., written) scheme of organization - division of labor - that it strives to enact in its routine activities" (Lofland 1996: 142-3). Centralization refers to "the degree to which an SMO's activities are devised and directed by a well-identified SMO-wide leadership as opposed to activities originating and pursued by multiple, relatively independent SMO subgroupings" (Lofland 1996: 143). I make the case that Greenpeace is relatively more centralized and formal than Friends of the Earth International. 
My main theoretical contribution is in proposing two ideal types of adaptive capacity. The Agility Model aligns with a decentralized and informal structure, and the Resilience Model aligns with a relatively more centralized and formal structural configuration. The adaptive capacity of a social movement organization (SMO) evolves from a particular combination of strategy and structure developed over time by the SMO's campaigners which, in turn, is informed by their collective interpretive frames and ideology. This combination of factors is influenced by and shapes the strategic responses of SMO campaigners to internal and external pressures and determines the SMO's action repertoire, the routine forms of activities and clusters of tactics that the SMO campaigners use. In particular, I suggest that there are four organizational challenges to which SMO campaigners must repeatedly respond: 1) tactical innovation; 2) managing external relations; 3) organizational maintenance; and 4) managing internal relations. Moreover, the routine responses of organizational members to these four organizational challenges result in a response pattern which, over time, precludes certain strategic responses while encouraging others.

In Chapters Five through Eight, I analyze the strategic responses of Friends of the Earth International and Greenpeace to the four organizational challenges in order to shed light on their typical approach to the challenges and to the strategic dilemmas they encompass. In this concluding chapter, I summarize the main finding this analysis. I also explore the extent to which the approach which FoEI and Greenpeace have developed to building adaptive capacity align with the two ideal type models that I propose in Chapter Four. I conclude that FoEI and Greenpeace tend towards the two extremes while exhibiting characteristics that diverge from these two models. The Agility Model and Resilience Model provide a useful heuristic for understanding FoEI and Greenpeace's approach to building adaptive capacity, while also highlighting that TSMOs are hybrid and dynamic open systems that diverge from these ideal types. In Section 9.4, I explore the implications of my research and recommend areas for further research. I propose that other adaptive capacity models are possible at the organizational, social movement and global governance levels, and encourage further theoretical 
and empirical analysis to identify these distinct models. I conclude by exploring the need for adaptability in light of the sustainability challenge.

\subsection{The Adaptive Capacity of FoEI and Greenpeace}

In Chapters Five through Eight, I investigate the ways in which Friends of the Earth International and Greenpeace strategically respond to the challenges of tactical innovation, managing external and internal relations and organizational maintenance. Rather than identify which of these two transnational social movement organizations (TSMOs) is more effective in responding to these challenges, I suggest that both are effective, based on their continued organizational viability. I directly challenge the emerging consensus that the decentralized and informal structure adopted by FoEI provides FoEI campaigners with an adaptive advantage given the complex and dynamic nature of their transnational political environment and the internal organizational conditions that beset SMOs. In addition to highlighting the strengths of FoEI's approach, I indicate its weaknesses and also discuss the relative strengths and weaknesses of Greenpeace's approach. Table 9.1 summarizes this analysis by comparing the strategic responses of FoEI and Greenpeace to the four organizational challenges. I also note the adaptive functionality - the strengths - of each strategic response in terms of its contribution to the adaptability of FoEI and Greenpeace. 
Table 9.1 Comparison between the Strategic Responses of FoEI and Greenpeace

\begin{tabular}{|l|l|l|}
\hline Dimension & \multicolumn{1}{|c|}{ FoEI } & \multicolumn{1}{|c|}{ Greenpeace } \\
\hline Strategic Responses to Organizational Challenges
\end{tabular}

${ }^{523}$ Clark 2003b: 6 
Tactical innovation is the ability of a social movement organization to creatively adjust and devise new tactics in order to repeatedly respond to changing external conditions and persistently disrupt - or threaten to disrupt - entrenched social and institutional behavior. In Chapter Five, I argue that the capacity for FoEI and Greenpeace to respond to the challenge of tactical innovation is determined by its response to "working globally," defined as "developing North-South links and international campaign strategies; speaking with a single, loud, global voice - albeit with national variations in how they work and what they work on" (Clark 2003a: 111). This is due to the global nature of environmental issues, and the transnational character and activities of those actors whom FoEI and Greenpeace target with their campaigns. FoEI and Greenpeace have developed very different but equally viable responses to this challenge.

As a federation of national environmental organizations, FoEI member groups have evolved an international agenda and, recently, a strategic plan, which serve as an umbrella strategy for their local and national campaigns and their international campaigns and activities. The strength of this approach lies in FoEI's ability to innovate across a wide range of tactics, across issues and scales - which I label an "expansion" approach. In contrast, Greenpeace campaigners developed a unique tactical response to global environmental problems by engaging in nonviolent direct action confrontations communicated through the mass media. Early campaign victories drew public support to the organization and encouraged Greenpeace campaigners to elaborate and fine-tune its tactical approach. This led to the development of a relatively more centralized 'global campaigning organization' structure and an increasingly formalized and sophisticated infrastructure to deliver creative confrontations against environmental abuse. The strength of this response lies in the ability of Greenpeace campaigners to innovate within this focused set of tactics - which I label a "specialization" approach.

FoEI and Greenpeace have also developed different responses to managing external and internal relations and organizational maintenance. Whereas FoEI has developed numerous permanent alliances with like-minded civil society organizations and networks, Greenpeace remains predominately independent in delivering its signature high-profile 
campaigns. Greenpeace does engage in temporary strategic partnerships with other civil society actors, particularly in diplomatic settings such as intergovernmental meetings and on a pragmatic basis within specific campaigns. The strength of FoEI's strategic response is in building bridges and collaborating with other civil society actors and, therefore, expanding the potential for impact and the opportunities for shared learning. The strength in Greenpeace's approach lies in Greenpeace's flexibility to shift partnerships according to campaign needs and changes in external and internal conditions. Both organizations remain predominately independent from government and corporate partnerships in order to preserve their autonomy and to maintain their radical and critical stance, but do engage in some limited engagements when cooperative activities advance their campaign goals.

The strategic response that FoEI and Greenpeace have developed for maintaining their organizations differ significantly. FoEI relies mainly on grassroots activism and volunteer efforts, while Greenpeace relies on financial donations by individual supporters to sustain a professional campaigning team. FoEI has the adaptive advantage of responding quickly to changes in conditions at the local level, as the campaign decisions and activities are decentralized. This advantage comes with deficiencies as FoEI is faced with problems in developing and sustaining coordinated international campaigns across diverse national members. Greenpeace, on the other hand, has developed a relatively more centralized organization in order to support its readiness for action at the international level and its ability to move quickly into new campaign areas and to confront urgent cases of ecological abuse. For Greenpeace, this requires a coherent organizational response. Therefore, Greenpeace strategic direction is determined by an Executive situated at the secretariat level. This Executive has repeatedly responded to problems of internal conflict by emphasizing the need for coherence and by building a global campaigning òrganization focused on a limited number of campaigns. In contrast, FoEI member groups are committed to a decentralized and democratic decision-making process, which supports the diversity of cultural and political perspectives of the member groups and which enables the resolution of conflict through facilitated dialogue. 
Having analyzed each of the strategic responses to the four organizational challenges in isolation, I now return to my proposal of the two ideal types of adaptive capacity: the Agility Model and the Resilience Model. In Chapter Four, I argue that the strategies and structure developed by a TSMO can combine over time into a coherent approach to building adaptive capacity. As FoEI and Greenpeace campaigners are faced with internal and external changes, these campaigners routinely repeat the same strategic responses to the same organizational challenges because they perceive that they have successfully and reliably responded to these challenges in the past. These responses become institutionally embedded in the values, interpretive frames, strategies, structures and action repertoires of Greenpeace and FoEI, and also are consciously selected by FoEI and Greenpeace campaigners. I developed the Agility Model and the Resilience Model, in part, from my analysis of FoEI and Greenpeace and, therefore, these models align closely with the strategic responses I have defined above. I present Table 4.2 again here as Table 9.2 in order to allow for a comparison of the model descriptions and the descriptions of FoEI and Greenpeace. 
Table 9.2 Comparison of two ideal types of adaptive capacity

\begin{tabular}{|c|c|c|}
\hline Dimension & Agility & Resilience \\
\hline \multicolumn{3}{|l|}{ A) Organizational Structure: } \\
\hline Formalization & Informal & Formal \\
\hline Centralization & Decentralized & Centralized \\
\hline \multicolumn{3}{|c|}{ B) Strategic Responses to Organizational Challenges } \\
\hline 1) Tactical Innovation & Expansion & Specialization \\
\hline 2) Managing External Relations & Collaborative & Independent \\
\hline 3) Organizational Maintenance & Grassroots / Voluntarism & Professional \\
\hline 4) Managing Internal Relations & Participatory democracy & Unity of Command \\
\hline \multicolumn{3}{|c|}{ C) Dynamics of Organizational Change: } \\
\hline Motto & Flow & Restore \\
\hline Tempo of Adaptation & Continuous & Episodic \\
\hline Pattern of Adaptation & Spiral & Cycle \\
\hline
\end{tabular}


In comparing Table 9.1 and Table 9.2, it is immediately apparent that the descriptions of the structural configuration and strategic responses to organizational challenges overlap; for example, in the case of managing internal relations, both tables highlight the distinction between a 'participatory democracy' and a 'unity of command' response. I have not yet discussed the final category - the dynamics of organizational change. I suggest that there is evidence that the historical evolution of FoEI and Greenpeace align with the dynamics of organizational change described in the Agility and Resilience Models. Friends of the Earth International has exhibited an ability to be repeatedly adaptive, as this quotation suggests,

Is FoE truly an organization for all seasons?... Given its protean capacity to reinvent itself, and in the process to help the whole environmental movement do the same, I suspect that's more than likely. And I can't help thinking that the world will be a better place because of it. ${ }^{524}$

I argue that FoEI member groups have achieved this adaptability through continuously and steadily expanding their global reach and embracing new perspectives and tactical approaches as they were introduced by new members and partners. FoEI began as a collection of concerned individuals from industrialized countries, and has since expanded globally to include member groups from all continents and from 70 developed and developing countries. Their goals initially focused on the preservation, conservation and restoration of the natural environment, and have since evolved its definition of environmentalism to focus on social justice and equity issues in addition to environmental issues. FoEI began by focusing entirely on local and national campaigns. As transnational problems became increasingly apparent, FoEI member groups developed international campaigns and, later, an international agenda in order to strengthen FoEI's voice at the global level in support of local and national struggles. This continuous, organic expansion stems from the FoEl member group commitment to a democratic, decentralized and informal structure, which repeatedly allows a flow of dialogue amongst FoEI groups to renew and redefine the scope and reach of FoEI. Until 2004, this structural arrangement challenged FoEI member groups in their development of a

${ }^{524}$ Porritt, J (1996) "Foreward" in Lamb, R. in collaboration with FoE Promising the Earth. Routledge, London and New York, p.xi. 
common international agenda; however, FoEI member groups place their hopes in the $2005-2006$ strategic planning process in building this international umbrella strategy. FoEI member groups seek to build bridges between local and national campaigns and global processes, while preserving the autonomy of and nurturing cultural and political differences amongst their national groups.

Because new member groups were fully formed organizations in their own countries that joined the FoEI federation, the new campaigners from these groups not only brought new perspectives to the annual general meetings but also new campaign issues and tactics to add to the multitude of local, national and international activities. FoEI has forged longstanding alliances with like-minded civil society organizations, networks and social movements, and FoEI member groups actively incorporate the perspectives, campaigns and tactics of these partnerships to enrich and strengthen their campaigns. FoEI's progressive and steady expansion while maintaining its inclusiveness evokes the image of a spiral. FoEI member groups build on past ideas, activities, member groups and alliances. FoEI seeks to create a context within which learning can spiral upwards as member groups incorporate new ideas, activities and member groups. FoEI is in continuous flow, or as one FoEI campaigner said, "The [FoEI] network is alive - it moves constantly. $" 525$

In contrast, Greenpeace campaigners have actively focused their organizational development on creating a unique niche within the environmental movement, namely to deliver high profile nonviolent confrontations to draw attention to and halt ecological abuse. These confrontations have a dual purpose of achieving concrete changes in specific governmental or corporate activities, and of catalyzing a broader shift in consciousness towards an environmental sensibility. Greenpeace campaigners have evolved a sophisticated and elaborate infrastructure of national and regional offices, campaigners, volunteers, policy and scientific analysts, legal and marine technology experts, professional lobbyists, nonviolent direct action trainers, and support staff that enable Greenpeace to efficiently and effectively focus its attention on a limited set of

${ }^{525}$ Interview with Marijke Torfs, FoEI International Coordinator (1998 - present), October 2004. 
campaigns. Repeatedly, Greenpeace strategic discussions have harkened back to the basic principles underlying Greenpeace actions - bearing witness, nonviolence, direct action, mass media communication - and the integrated Greenpeace formula -

confrontations supported by quiet diplomacy and research. Episodic renewal appears to be a pattern within Greenpeace, as this quotation suggests,

One senior Greenpeace USA staff member suggests that the "convulsive" changes of the mid-1990s were part of a larger and "very cyclical" organizational growth pattern, whereby periods of a extreme allegiance to primary principles - during which administrative aspects of the NGO's work suffer - alternate with a focus on "putting the house in order" at the expense of attention to Greenpeace's "primary directive." He contends that, throughout this process, there remains a principled core sensibility that "keep things on track." 526

New Greenpeace national and regional offices are established to support international campaign goals and to undertake Greenpeace actions in new political and cultural contexts. Greenpeace campaigners have adjusted their tactics to new issues and new countries; however, the basic formula has remained the same. Greenpeace's episodic adjustments to return to its basic principles and reestablish its signature tactical approach evokes an image of a cycle wherein periods of divergence lead to periods of convergence to restore Greenpeace's core identity and niche. Other scholars and campaigners have come to the same conclusion,

The past suggests that Greenpeace is nothing if not resilient. To write the organization off now would be to ignore its considerable history of crisis and rebirth (Dale 1996: 207)

Greenpeace is focused on high profile direct action campaigning, which is interesting....I think they are going to be big high-profile action organization for a time yet.... Greenpeace has fantastic communication and outreach. Their brand is well known and it would rival the brand recognition of many companies. ${ }^{527}$

During my interviews, FoEI and Greenpeace campaigners noted that the different approaches adopted by both organizations have enabled these TSMOs to operate effectively but in distinct ways,

${ }^{526}$ Interview with Greenpeace campaigner in Warkentin (2001), p. 69.

${ }^{527}$ Interview with Mike Childs, Head of Campaigns, FoE England, Wales and Northern Ireland (EWNI), February 2005. 
FoEI achieves certain things and Greenpeace achieves other things, which has to do with their different functions, structures, activities and roles in the movement. ${ }^{528}$

\section{I am happy that both FoEI and Greenpeace exist because it is clear that both approaches have their pros and cons. ${ }^{529}$}

As the quotations above suggest, each adaptive capacity type has weaknesses and disadvantages in addition to strengths. The Agility Model is particularly well-suited for individuals who "dislike both structural rigidity and the concentration of power" or, in other words, embrace informal and decentralized structures that encourage "more democracy with less bureaucracy" (Mintzberg 1998c: 322). It is this characteristic that is also one of this approach's deficiencies. Many individuals seek order and stability within their organizations, and the agility approach can generate frustration and anxiety due to its "fluidity" and "confusion" (Mintzberg 1998c: 322), "considerable ambiguity and complexity, with contradictions that are difficult to manage and with payoffs that are rarely immediate" (Staber and Sydow 2002: 409). There are also difficulties with the “expansion" tactical approach of this model. Rumelt (1995) warns organizations about exploring and expanding to new areas that are too far from their initial domain as they may have negative consequences for their reputation and legitimacy in the eyes of their stakeholders. Kraatz and Zajac (2001: 636) make the point that a propensity to constantly explore new opportunities can have negative effects on the internal culture and resources of an organization in terms of building competence and identity.

This is a potential weakness for Friends of the Earth International. The disadvantages of an exploratory approach to innovating strategies and tactics can lead to "mission creep" away from its original purpose (Moore 2000). For example, Amnesty International (AI) is an effective human rights transnational social movement organization, whose success has led to a "mandate explosion" in which AI has extended its mission from its original founding mandate - "to release prisoners of conscience, whether held on religious or political grounds" - to include new mission clauses that cover "topics as diverse as armed

\footnotetext{
${ }^{528}$. Interview with Rémi Parmentier, Co-founder of Greenpeace France (1974), Greenpeace campaigner including Political Director, Greenpeace International (1974- 2005), November 2005. ${ }^{529}$ Interview with John Hontelez, FoEI Chair 1986-1996, May 2006.
} 
opposition groups, laws on war, homosexuality, female genital mutilation, human rights promotion and education, forcible exits, fair trade, the International Criminal Court; and landmines (Clark 2003a: 125). According to Clark (2003a: 125), this mission creep has become a "millstone" about which few of Amnesty International's staff "have a good grasp." Although each of the issues are legitimate in its own right, tackling all of them prevents AI "from responding flexibly to world events as they arise" (Clark 2003b: 21). This mission creep emerged within AI "in particular as Southern and transition country AI groups have proliferated," as "diverse specialist groups and networks have formed," and "as AI works more closely with others (such as development nongovernmental organizations and unions)." These trends are evident in FoEI as well and can lead to overextension, a "constant shuffling" in response to internal and external pressures, and ineffectiveness (Miles and Snow 1978: 58). The search for "flexibility" can result in an organization "seldom attaining the efficiency necessary to reap...benefits" from its past activities, strategies and tactics (Miles and Snow 1978: 58). Social movement organizations that are focused on tactical expansion can become "outcompeted by rivals who are better adapted to the current state" (Staber and Sydow 2002: 411; see also Weick 1979: 135-136). On the other hand, an expansion strategy has the benefit of enabling a social movement organization to solve problems imaginatively, as an organization with this tactical approach can draw on a wide range of options rather than applying a tactical solution indiscriminately.

There are also disadvantages associated with the Resilience Model for building adaptive capacity. The very strengths of this approach - the focus on efficiency and stability downplay the fact that a particular set of tactics can become too rigidly adhered to (Granovetter 1979) and can become vulnerable to being out of sync with the environment (Levinthal and March 1993: 102). A social movement organization that adopts a "specialization" and focused approach to tactical innovation "runs the risk of fairly rapid extinction in the event of a major...shift, for it is gambling on the continued viability of its limited set" of strategies and tactics (Miles and Snow 1978: 39). The strategy associated with adaptive capacity as resilience also has implications for the deep structures, systems and resources that an organization has chosen, as these structures and 
systems are often chosen to optimally respond to the present context and are potentially less suited to constant flux and shifts. In the case of Greenpeace, the strategies and tactics of direct action and bearing witness remain relevant within the current political environment; however, Greenpeace will need to remain continually responsive and innovative to changes in this context.

In sum, the challenges facing FoEI are in benefiting from its strategy of tactical expansion without overextending, collaborating while remaining true to its core values and principles, enhancing local responsiveness through grassroots/voluntary activism without sacrificing quality and coherence, and facilitating participatory democracy without losing the capacity to act quickly. The challenges facing Greenpeace are to exploit its success in nonviolent direct actions while supporting the tactics of the broader environmental movement, to remain independent without reinforcing unproductive biases across sectors; to facilitate professionalism while building bridges to the voluntary and supporter base; and to maintain the coherence of a global organization while embracing cultural and political diversity within its decision-making structure.

\subsection{TSMOs as Hybrid and Dynamic Open Systems}

The previous chapters discuss some of the ways that Greenpeace and Friends of the Earth International diverge from the ideal types I have proposed. This divergence is to be anticipated given the fact that ideal types are developed as archetypal descriptions rather than accurate descriptions of reality. FoEI aligns closely with the Agility Model and Greenpeace aligns more closely with the Resilience Model; however, these organizations are hybrid and dynamic open systems that encompass nuanced and varied behavior within their structures. These nuances are to be anticipated given the complexity of FoEI and Greenpeace as organizations. As Anheier (2000) writes, social movement organizations are "multiple organizations" with multiple constituencies that have "internal federations or coalitions" that complicate their analysis. For Zald and Berger (1987), the behavior, power relations and politics amongst subgroups within social movement organizations can be analyzed in the same way that social movement theorists analyze SMOs within its political environment. The internal and external 
pressures on social movement organizations result in a complex relationship between the task environment and organizational structure, as Anheier (2000: 9) notes in the following quotation:

Some parts of the organizational task environment are best centralized, such as controlling or fundraising; other parts of the organizational task environment could be either decentralized or centralized, depending on managerial preferences and the prevailing organizational culture; other parts, typically those involving greater uncertainty and ambiguity are best organized in a decentralizing way. In other words, nonprofit organizations are subject to both centralizing and decentralizing tendencies. For example, environmental organizations are often caught between the centralizing tendencies of a national federation that emphasizes the need to "speak with one voice" in policy debates, and the decentralizing efforts of local groups that focus on local needs and demands.

My analysis of Greenpeace and FoEI indicate that these tensions are evident within these TSMOs. This suggests that there may be agility and resiliency tendencies within both of these organizations, even though they align with one or other approach at the organizational level. Future analyses of Greenpeace and Friends of the Earth International can investigate the expression of each adaptive capacity type on particular campaigns undertaken by Friends of the Earth International and Greenpeace. This research can also involve the analysis of the impact of TSMO campaigns and their effectiveness in achieving their goals, and build on scholarly research on TSMO output effectiveness (e.g., Arts et al. 2001; Betsill and Corell 2001). Further research can also be undertaken to analyze sub-groups within these TSMOs, including national and regional offices and support units (e.g., legal, scientific, political). Since FoE and Greenpeace national offices and members differ in their degree of formalization and centralization (Anheier and Themudo 2001: 204), I anticipate that these offices would differ in their approach to building adaptive capacity, even if the TSMO as a whole tends toward one or other type. This can be a productive area for further research.

Building on Clark (2003a: 116), I would argue that investigation into sub-groups should examine the affinity structures within functional and issue areas (e.g., legal units, 
climate change activists) that are emerging within and across social movement organizations.

The Internet facilitates affinity groups within CSO networks; hence old subdivisions (global network, national chapters, local groups) are no longer the only way of dividing the pie. Amnesty, for example, now has global groupings of lawyers, medics, teachers, and youth, as well as those working on the death penalty, homosexual rights, and rights abuse in specific countries. A similar pattern occurs in Oxfam, Greenpeace, Friends of the Earth, and other CSO networks. Activists may now feel more identity with their affinity groups than with their national chapter. And as these compete with one another, pressure groups arise within pressure groups. Networks find they can achieve much more overall by encouraging affinity groups. This parallels the experience of firms; dense networks permit more effective information flow, which is highly prized in an age where information is power.

I anticipate that Friends of the Earth International and Greenpeace are becoming increasingly multifaceted as they expand their activities into rapidly industrializing regions such as China and India, as they add other national and regional offices, and as they adopt an increasingly multi-issue frame combining social justice, economic development and ecological issues. They will also be faced with the complexities of the "implementation phase" of the sustainable development agenda (Juma 2002), the emerging power of Southern civil society actors, and the growing possibilities of the Internet for building internal coherence and for activism.

There is likely a hybrid version of the Agility and Resilience Models. Although FoEI tends towards the Agility Model and Greenpeace tends towards the Resilience Model, I investigate in the case study chapters how elements of the alternative model are present in each TSMO. For example, Greenpeace concentrates its tactical innovation within select issue-specific campaigns using nonviolent direct action; however, Greenpeace also engages in some tactical innovation that aligns with the expansion approach in the Agility Model. I use the Greenpeace campaign for Greenfreeze technology as an example in Chapter Seven, although I note that Greenpeace's focus on developing technological solutions is relatively minimal in comparison with its emphasis on delivering nonviolent direct action campaigns. Therefore, it is interesting to consider whether there may be an additional approach to adaptive capacity that is a hybrid combination of the 
Agility and Resilience Model. In their typology of strategic types, Miles and Snow (1978: 553) propose the "Analyzer" strategic type that combines the "Prospector" (Agility) and "Defender" (Resilience) types which adopts a "balanced approach" with a goal "to minimize risk while maximizing the opportunity for profit." According to Brown and Eisenhardt (1997), this combined strategic approach is the hallmark of most successful firms in the computer industry. By combining the processes and structures of each end of the spectrum, these firms "had well-defined managerial responsibilities and clear project priorities while also allowing the design processes to be highly flexible, improvisational and continuously changing" (Weick and Quinn 1999: 371). The potential weakness of this approach is its inconsistency. By trying to incorporate the best aspects of an organization built for constant change and flux and of an organization structured for stability, an organization that adopts a combined approach can be pulled apart by the tensions that exist between these two approaches. Anheier (2000: 13) discusses these tensions by noting that "different organizational components may unknowingly become locked in a stalemate, unable to change matters without giving up its own position." Despite these weaknesses, a combined Agility and Resilience approach may still be a viable strategy for building adaptive capacity and exploring its existence within TSMOs may be a fruitful area of future research.

\subsection{Implications for Theory and Recommendations for Further Research}

This dissertation primarily addresses the scholarly community investigating the adaptability of organizations of all types. My central purpose is in critiquing a limited conception of adaptability. I challenge the emerging consensus portraying decentralized and informal structures as maximizing adaptive capacity in complex and turbulent conditions (Fowler 2000; Anheier and Themudo 2001; Clark 2003a: 110; Smith 2005) by proposing another viable trajectory and organizational style for building adaptive capacity. In this and previous chapters, I suggest the Resilience Model as a second feasible strategy for building adaptive capacity, as exemplified by Greenpeace and the relatively more centralized and formal structures. 
Is the Resilience Model unique to Greenpeace or are there other organizations that exhibit this approach to building adaptive capacity? A detailed investigation of this question is beyond the scope of this research; however, I would propose that the Resilience Model may apply to other organizations adopting a centralized and formal structure. Drawing on Clark (2003b: 7), I suggest that civil society actors such as CARE International, the Catholic Church, Third World Network, Social Watch, and FOCUS on the Global South may be comparable to Greenpeace in their structural configuration, and it would be worth investigating whether they also adopt a Resilience Model to building adaptive capacity. For example, I would recommend an analysis of the human rights transnational social movement organization Amnesty International in comparison with the relatively more centralized and formalized Human Rights Watch (Clark 2003b: 4). I anticipate that Human Rights Watch may align closely with the Resilience Model, whereas Amnesty International may align with the Agility Model. There will likely be critical distinctions as well: Amnesty International's structure is comparable to Friends of the Earth International in some ways, including its decentralized forum for decisionmaking; however, Amnesty differs from FoEI by exhibiting relatively more centralized strategic planning at the international level (Clark 2003b). This difference indicates that Amnesty International will likely exhibit a distinct approach to building adaptive capacity.

I am certain that critical distinctions will also become evident amongst centralized and formalized civil society actors. For example, there is evidence that the Catholic Church, with its centralized and formalized structure, has adopted its own unique model of building adaptive capacity, which Mintzberg and Westley (1992: 52) characterize as "enclaving...the carefully controlled integration of learning within the existing structure, its 'capture,' if you will from a particular enclave" (Mintzberg and Westley 1992: 52). Based on Mintzberg and Westley's research, I propose that 'enclaving' may be a modification of the Resilience Model which maintains the model's key characteristic adaptation through buffering from change - while incorporating a new unique element the integration or 'capturing' of dissenting external enclaves. Further research would be required to analyze this point. It may also be fruitful to compare the Catholic Church 
with relatively more decentralized and informal Christian communities such as the United or Protestant Churches.

I have developed two models of adaptive capacity that encompass extremes on a continuum; however, I suggest that these models encompass a range of possible adaptive capacity approaches across this continuum. I encourage further research that combines theoretical and empirical analysis of social movement organizations to test the Agility and Resilience models, and to uncover modified and hybrid models. This research can be guided by the two axes of centralization and formalization. The Agility and Resilience Models were developed by analyzing centralization and formalization in parallel (see Section 1.1). This is an approach that is not uncommon in the scholarly community. For example, Staggenborg (1989) and Rothschild and Whitt (1986) provide similar comparisons between a decentralized and informally structured social movement organization and a relatively more centralized and formally structured one, and they highlight the relative weaknesses and strengths of each structural choice.

It may be fruitful to distinguish between these two axes - centralization and formalization - and analyze organizations that represent other configurations. There is evidence that a decentralized and formal organizational structure is possible and viable. For example, in his review of different actors in the radical environmental movement, Doherty (2002) contrasts "mass environmental movement organizations" including Greenpeace and Friends of the Earth International with Green Parties, ecological direct action groups and local environmental protest groups. As Doherty (2002: 155) notes, these organizations are "rooted in an alternative culture" which is manifested in their "nonhierarchical form of organization." This structural configuration is more decentralized and informal than FoEI and suggests the Agility ideal type; however, ecological direct action groups, as implied by the term employed by Doherty (2002), engage in and specialize in direct action (see also Scarce 1990). Similar to Greenpeace and the Resilience Model, this tactical orientation has resulted in a focus on fine-tuning direct action tactics and led to the development of strategy guides that 
elaborate on particular routine tactics of direct action (e.g., Link 1993; Watson 1993).

Research into the adaptive capacity of ecological direct action groups may reveal a third adaptive capacity ideal type that combines a decentralized and informal structure and a Resilience approach to tactical innovation. In fact, I have identified two different structural arrangements, four organizational challenges, and eight typical strategic responses. Analyses of different combinations of these factors may lead to the identification of other new adaptive capacity models. Although $I$ have identified two TSMOs that have developed effective combinations of these strategies and structures, I expect that there are some combinations which are less effective or ineffective. I would recommend additional investigation into failed TSMOs in order to shed light on the combinations of strategies and structure that may or may not support organizational viability and adaptability. In sum, I encourage the development of other models of adaptive capacity based on a combination of grounded theory and empirical case study research of transnational social movement organizations and civil society actors.

\section{My research on the adaptive capacity of transnational social movement} organizations has implications for analyzing the adaptability of social movements as whole. Throughout his study Doherty (2002: 219) emphasizes that although the green actors he investigates identify with three core themes of "ecology, egalitarianism and grassroots democracy," the overall strength of the environmental movement is in its diversity of approaches and strategies. The following quotation outlines this conclusion (Doherty 2002: 221).

Some have argued that as the green movement has become more differentiated it has lost it social movement character because there is no longer a common green project (Jamison, Eyerman and Cramer 1990). But an alternative means of approaching this is to see the differentiation of the movement as a product of its collective learning. Greens have diversified as new opportunities have emerged, but they have not fragmented into a wholly unconnected movement....

The green movement is much more divided over strategy than over ends. Most have argued that means and ends ought to be consistent, but the nature of the relationship between the two is still open to varying interpretations. While authoritarian strategies are ruled out because they contradict green commitments 
to democracy and social justice and their understanding of the limits of stateimposed change, this still leaves a range of reformist and radical possibilities which are compatible with the green ideological framework. But, one radical possibility that is ruled out is a vanguard revolutionary position. When green ends are so open and multiple it is impossible to be certain that only one strategy can be right.

The questioning and critiquing of their own actions and the actions of others is also part of what constitutes the vitality of the green movement, what keeps it moving. As we have seen greens have been characterized by processes of collective learning in which they recognized mistakes of over-optimism, or unnecessary failures of trust, and capacity building, in which skills and knowledge about the consequences of particular forms of action were passed on. There is nothing inevitable about this process, there are many lacunae in understanding of the past, and losses as well as gains in the move from previous ways of action, but overall there is evidence of progress (emphasis added).

Just as Doherty proposes an adaptive advantage to the interaction amongst green parties, environmental movement organizations, ecological direct action groups and local environmental protest groups, I suggest that there is an adaptive functionality to the diversity amongst environmental movement organizations. As an ecosystem benefits from species diversity, I argue that the environmental movement benefits from organizational diversity.

This proposition is supported by the conclusions of other scholars researching diversity amongst social movement organizations. As Doherty (2002: 142) notes, "resource mobilization theory (RMT) view social movements organizations (SMOs) such as FoE and Greenpeace as part of a 'social movement industry' (McCarthy and Zald 1977) in which different SMOs cooperate and compete." He writes, "according to this logic, organizations seek niches in the market and develop strategies that best exploit this specialism" and I would add that the variation amongst SMOs affects the adaptive functioning of social movements as a whole. Gerlach and Hine (1970) propose that a diversity of organizational forms within social movements ensures the adaptability of the movement by encouraging inter-competition and innovation amongst decentralized subunits, resisting suppression by authorities and targeted elites through its internal redundancy, building bridges across cultural and class cleavages, and enabling division of labour across the movement. I agree with Freeman (1979) and Staggenborg (1989) that 
social movements are strengthened when the diverse organizational nodes of social movements are composed of both decentralized and informal social movement organizations and centralized and formal social movement organizations. As Freeman (1979) states, "the most viable movement is one with several organizations that can play different roles and pursue different strategic possibilities." This point is echoed in Staggenborg (1989: 90) who writes, "successful social movements are likely to include a variety of SMOs with different organizational structures" as "different types of SMOs make different contributions to the 'success' of a social movement." As is evident in the following quotation, Carmin and Balser (2002: 384), in their study of Greenpeace and FoEI, also attribute adaptability of the environmental movement to the diverse interpretive frames, structures and action repertoires of organizations.

The differentiation and distinctiveness among [environmental movement organizations] EMOs ... not only contributes to the overall structure and character of the environmental movement but may also provide a hedge against both homogeneity and professionalization. This, in turn, may help invigorate and revitalize the environmental movement for many years to come.

In dispelling the assumption that a decentralized and informal social movement organizational structure maximizes adaptability, I encourage scholars to explore other viable structural and strategic approaches to adaptability and also to broaden their analytical scope to examine the adaptive capacity of the social movement as a whole. The danger in highlighting decentralized and informal structures as being more effective than centralized and formal structures is in promoting a homogenization of SMO structures. I argue that Greenpeace plays a different role within the environmental movement than Friends of the Earth International and both roles have strengths and weaknesses. As Freeman (1979) argues, the main problem facing SMOs is not an inappropriate structure (i.e. failing to adopt the "one best" generic structure) but "the attempt to pursue strategies for which their structures are inappropriate." This argument has been made by scholars dispelling the assumption of inevitable oligarchization, conservatism, and goal transformation of social movement organizations (e.g., Zald and Ash .1966; Rothschild and Whitt 1986; Doherty 2002), and I make the 
same argument here and suggest that different structures can be effective in and adapted to similar complex and dynamic conditions.

\section{My research may also have implications for the structural configuration of global}

governance institutions. Similar to the debate on degrees of centralization and

formalization in social movement organizations, scholars disagree on the most effective institutional structure for global governance. Proponents of a centralized and formalized model support such structures as the World Trade Organization and the International Monetary Fund, as well as the establishment of a World Environment Organization (Juma 2002). Other scholars herald the end of monolithic, centralized structures and promote a decentralized and informal network configuration for addressing transnational issues, characterized by some as global public policy networks (GPPN) (Reinicke 1998; Reinicke et al. 2000; Juma 2002). A notable example of decentralized intersectoral global governance is the International Campaign to Ban Landmines (ICBL), which was successful in triggering the drafting, negotiation and signing by 122 states of an international treaty against landmines in 1997 (Mekata 2000). Lloyd Axworthy (1998: 453), then Foreign Minister to Canada and a central player in the campaign, wrote that "the landmines campaign was the harbinger of the new multilateralism: new alliances among states, new partnerships with non-state actors, and new approaches to international governance." In receiving the Nobel Prize for their efforts, the ICBL coordinator Jody Williams underlined Axworthy's comments by stating "together, we are a superpower" (quoted in Clark 2003a: 169; see also Scott 2001). Just as the role of Greenpeace is not undermined by the existence of Friends of the Earth International, I would encourage research on whether more centralized and formal structures can co-exist with decentralized and informal structures within global governance regimes and fulfill different roles within this international arena.

\subsection{Adaptive Capacity and the Sustainability Transition}

Friends of the Earth International, Greenpeace and other transnational social movement organizations play a prominent and increasingly influential role in global governance on environmental issues (Stoett 1997; Newell 2000; Arts et al. 2001). Their continued 
effectiveness within these transnational governance arenas is dependent on their ability to adapt to changing internal and external pressures. Current research on the nature of global environmental issues suggests that these pressures will only become more acute as human population and consumption continues to grow and ecological systems are subject to multiple, cumulative, and interacting stresses (Vitousek et al. 1997; NRC 1999; MA 2005a). Global efforts to manage human interactions with natural systems are hampered by "pervasive uncertainty" in understanding these systems and the effects of their interactions (Keohane and Nye 2000). This will tax existing governance institutions and environmental regimes. As the following quotation illustrates, Meyer (2001b: 144) argues that existing adaptive mechanisms may also be undermined.

Global-scale and rapidly developing crises may tax the adaptive mechanisms that have coped with smaller problems and avoided disaster. As human activity expands in its scale and magnitude, so do its possible disruptive effects. A functioning biosphere itself appears more starkly than ever as a threatened resource for which there are no substitutes, the experience of past successes less reliable a guide to action than before, and the arguments for precaution, restraint and limits in human interference with the global environment more compelling than ever (Meyer 2001: 144).

In light of the complexity and uncertainty of future environmental challenges, global governance regimes will require adaptive management and transnational social learning mechanisms to continue to learn and adjust collective frames and actions over time. - Greenpeace and Friends of the Earth International and other transnational social movement organizations play critical roles in catalyzing continued transnational social learning (Brown and Timmer 2006). Within global governance processes, they assist in identifying issues, facilitating the voice of marginalized stakeholders, amplifying the importance of issues, building bridges amongst diverse stakeholders, and monitoring and assessing solutions. In an equally important role, transnational social movement organizations pressure, protest and disruptively confront governments, the private sector and international organizations in order to trigger these actors to pursue the scale of changes required. As Nemetz (2002-3) writes, "progress has indeed been made, [but] the issues underlying sustainable development are far more complex than has been generally realized" such that "nothing short of a revolution in our economic systems will suffice to achieve sustainable development." There are notable examples of policies and actions 
that advance sustainability (Kates 2005); however, these isolated examples are not at the scale of change necessary so that "the challenges of sustainability simply overwhelm the adequacy of our responses" (Annan 2000: 56).

As compromises are made to advance the implementation of environmental policies and the sustainable development agenda, society as a whole remains on an unsustainable path (O'Riordan 2002). Meadowcroft (2000: 380) poses the question "to what extent are the policy responses elicited so far likely to lead to ultimate outcomes which are congruent with the long term objective of sustainable development?" By continuing to challenge and disrupt the status quo, transnational social movement organizations, such as Friends of the Earth International and Greenpeace, play a critical role in highlighting the scale and nature of social and personal change required, and pressuring individuals and society to match their actions with the goal of enhancing quality of life and preserving the lifesupport systems of the planet. At the opening address of the 1992 Earth Summit in Rio de Janeiro, the Secretary-General of the conference, Maurice Strong, voiced this challenge that will require adaptability from all sectors of society in answering its call (quoted in Shabecoff 1996: 162).

We are all in this together. No place can remain an island of affluence in a sea of poverty. No part of the world can live in the indulgence of unrestrained consumption....North-South, rich-poor, we must have a new global partnership for a more secure and hospitable planet... The damage to the planet has been largely inadvertent. But we now know what we are doing. We have lost our innocence. If we lapse into business as usual we will have lost our historic opportunity to bequeath a better world to the future.

According to O'Riordan (2002), the nature of the challenge of sustainability lies in "ensuring the capacity to absorb, to learn and to repair is incorporated into both the social and the natural worlds so as to create an adapting and self-organizing unity." The emergent and, often, unpredictable nature of future challenges will require the adaptability of all societal actors. By being "adaptive activists," Greenpeace and Friends of the Earth International remain critical players in developing and sustaining this adaptive capacity, encouraging public debate on social and environmental issues, and promoting the implementation of solutions for a sustainable future. 


\section{BIBLIOGRAPHY}

Adamson, F. (2002). The Logic of Transnational Mobilization: Beyond Liberal Archetypes in the Study of Transnational Networks. 43rd Annual International Studies Association Convention, New Orleans, LA.

Agyeman, J. (2002). "Constructing Environmental (In)justice: Transatlantic Tales." Environmental Politics 11 (3): 31-53.

Alcock, F. (2005). Conflicts and Coalitions Within and Across the ENGO Community. 2005 Berlin Conference on the Human Dimensions of Global Environmental Change: International Organizations and Global Environmental Change, Potsdam, Germany.

Aldrich, H. E. (1979). Organizations and Environments. Englewood Cliffs, NJ, Prentice-Hall.

Aldrich, H. E. (1999). Organizations Evolving. London, UK; Thousand Oaks, CA; New Delhi, India, Sage Publications Ltd.

Allison, G. T. (1969). "Conceptual Models and the Cuban Missile Crisis." The American Political Science Review 63(3): 689-718

Anheier, H. K. (2000). Managing non-profit organisations: towards a new approach. London, UK, London School of Economics.

Anheier, H. K. and N. Themudo (2001). "Organisational Forms of Global Civil Society: Implications of Going Global." Global Civil Society 2002. H. K. Anheier, M. Glasius and M. Kaldor. London, UK, London School of Economics: 191-216.

Anheier, H. K., M. Glasius, et al., Eds. (2001). Global Civil Society 2001. Oxford, UK, Oxford University Press.

Annan, K. (2000). We the Peoples: the Role of the United Nations in the 21st Century. New York, NY, United Nations.

Argyris, C. (1999). On Organizational Learning. Cambridge, MA, Blackwell.

Arts, B., M. Noortmann, et al., Eds. (2001). Non-state Actors in International Relations. Aldershot, UK; Burlington, VT, Ashgate Publishing Company.

Ashkenas, R., D. Ulrich, et al. (2002). The Boundaryless Organization. San Francisco, CA, Jossey-Bass.

Axworthy, L. (1998). "Towards a New Multilateralism.” To Walk Without Fear: The Global Movement to Ban Landmines. M. Cameron. Toronto, CA, Oxford University Press.

Bailey, K. D. (2001). "Systems Theory." Handbook of Sociological Theory. J. H. Turner. New York, NY, Kluwer Academic / Plenum Publishers.

Batliwala, S. (2002). "Grassroots Movements as Transnational Actors: Implications for Global Civil Society." Voluntas: International Journal of Voluntary and Nonprofit Organizations 13(4): 393-410. 
Beckwith, C., K. Glenzer, et al. (2002). "Leading learning and change from the middle: reconceptualizing strategy's purpose, content and measures." Development in Practice $12(3 \& 4): 409-423$.

Benedick, R. E. (1991). Ozone Diplomacy: New Directions in Safeguarding the Planet. Cambridge, MA; London, UK, Harvard University Press.

Benford, R. D. and D. A. Snow (2000). "Framing Processes and Social Movements: An Overview and Assessment." Annual Review of Sociology 26: 611-639.

Berkes, F., C. Folke, et al., Eds. (1998). Linking Social and Ecological Systems: Management practices and social mechanisms for building resilience. Cambridge, UK, Cambridge University Press.

Bloodgood, E. A. (2002). "Influential Information: Non-governmental Organizations' Role in Foreign Policy-Making and International Regime Formation." Department of Politics, Princeton, NJ, Princeton University.

Boettger, C. and F. Hamdan (2001). Greenpeace: Changing the World. Steinfurt, Germany, . Druckhaus Tecklenborg.

Bohlen, J. (2001). Making Waves: The Origins and Future of Greenpeace. Montreal, Canada, Black Rose Books.

Boli, J. and G.M. Thomas. (1999). Constructing World Culture: International Nongovernmental Organizations since 1875. Stanford, CA, Stanford University Press.

Booth Sweeney, L. (2001). "Learning to Understand the Dynamics of a Complex World: A Theoretical Review of Three Frameworks for Systems-Based Inquiry." Harvard Graduate School of Education. Cambridge, MA, Harvard University: 120.

Bordt, R. (1997). The Structure of Women's Nonprofit Organizations. Bloomington, Indiana, Indiana University Press.

Botkins, J. W., M. Elmandjra, et al. (1979). No Limits to Learning: Bridging the Human Gap. Exeter, UK, A. Wheaton and Co. Ltd.

Brandt, W., Ed. (1980). North-South: A Program for Survival: Report of the Independent Commission on International Development Issues under the Chairmanship of Willy Brandt. Cambridge, MA, MIT Press.

Brower, D. (1984-5). "Foreword" Friends of the Earth International Annual Report 1984-5. FoEI. Amsterdam, The Netherlands, Friends of the Earth International.

Brower, D. (1990). For Earth's Sake: The Life and Times of David Brower. Layton, Utah, Peregrine Smith Books.

Brown, L. D. (1999). "Social learning in North-South Coalitions: Constructing knowledge systems across social chasms." International Perspectives on Voluntary Action. D. Lewis. London, UK, Earthscan Publications Ltd. 
Brown, L. D. (2002). Multiparty Social Action and Mutual Accountability. Cambridge, MA, Hauser Center for Nonprofit Organizations, KSG, Harvard University.

Brown, L. D. and D. Ashman (1999). "Social Capital, Mutual Influence, and Social Learning in Intersectoral Problem-Solving." Organizational Dimensions of Global Change. D. L. Cooperrider and J. E. Dutton. Thousand Oaks, CA, Sage Publications.

Brown, L. D. and M. H. Moore (2001). "Accountability, Strategy, and International NonGovernmental Organizations." Nonprofit and Voluntary Sector Quarterly 30: 569-587.

Brown, L. D., M. H. Moore, et al. (2003). "Building Strategic Accountability Systems for International NGOs." AccountAbility Forum 2: 31-43.

Brown, L. D. and V. J. Timmer (2006), "Civil Society Actors as Catalysts for Transnational Social Learning." Voluntas: International Journal of Voluntary and Nonprofit Organizations.

Brown, L. D., S. Khagram, et al. (2000). "Globalization, NGOs, and Multisectoral Relations." Governance in a Globalizing World. J. S. Nye and J. D. Donahue. Washington, DC, Brookings Institutions.

Brown, M. and J. May (1989). The Greenpeace Story. Scarborough, ON, Prentice-Hall Canada Inc.

Brown, S. L. and K. M. Eisenhardt (1998). Competing on the Edge: Strategy as Structured Chaos. Boston, MA, Harvard Business School Press.

Brown, W. A. and J. O. Iverson (2004). "Exploring Strategy and Board Structure in Nonprofit Organizations." Nonprofit and Voluntary Sector Quarterly 33(3): 377-400.

Brulle, R. J. (2000). Agency, Democracy and Nature: The U.S. Environmental Movement from a Critical Theory Perspective. Cambridge, MA, MIT Press.

Bryner, G. C. (2001). Gaia's Wager: Environmental Movements and the Challenge of Sustainability. Lanham, Maryland; Boulder, CO; New York, NY; Oxford, UK, Rowman and Littlefield Publishers, Inc.

Burke, T. (1982). "Friends of the Earth and the Conservation of Resources." Pressure Groups in the Global System. P. Willetts. London, UK, Frances Pinter (Publishers) Ltd.

Caldwell, L. K. (1990). Between two worlds: Science, the environmental movement, and policy choice. Cambridge, UK, Cambridge University Press.

Campbell, D. (2002). "Outcomes Assessment and the Paradox of Nonprofit Accountability." Nonprofit Management and Leadership. 12(3): 243-259.

Campbell, J. L. (2005). "Where do we stand? Common mechanisms in organizations and social movements research." Social Movements and Organization Theory. G. F. Davis, D. McAdam, R. W. Scott and M. N. Zald. Cambridge, UK, Càmbridge University Press. 
Carmin, J. and D. B. Balser (2002). "Selecting Repertoires of Action in Environmental Movement Organizations." Organization and Environment 15(4): 365-388.

Chandler, A. D. (1962). Strategy and Structure: Chapters in the History of the American Industrial Enterprise. Cambridge, MA, MIT Press.

Chatterjee, P. and M. Finger (1994). The Earth Brokers: Power, Politics and World Development. London, UK; New York, NY, Routledge.

Child, J. (1972): "Organizational structure, environment and performance: the role of strategic choice." Sociology 6: 1-22.

Christiensen, C. M. and M. Overdorf (2000). "Meeting the Challenge of Disruptive Change." Harvard Business Review 78(2): 66-78.

Clark, J. (2003a). Worlds Apart: Civil Society and the Battle for Ethical Globalization. London; Bloomfield, CT, Earthscan Publications Ltd.; Kumarian Press.

Clark, J. D., Ed. (2003b). Globalizing Civic Engagement. London, UK, Sterling, VA.

Clark, W. C. and N. M. Dickson (2003). "Sustainability Science: The emerging research program." PNAS - Proceedings of the National Academy of Sciences of the United States of America 100(14): 8059-8061.

Clark, W. C., J. Jäger, et al. (2001). "Managing Global Environmental Change: An Introduction to the Volume." Learning to Manage Global Environmental Risks: A Comparative History of Social Responses to Climate Change, Ozone Depletion and Acid Rain. T. S. L. Group. Cambridge, MA, MIT Press.

Coates, B. and R. David (2002). "Learning for change: the art of assessing the impact of advocacy work." Development in Practice 12(3 \& 4): 530-551.

Cohen, J. L. (1985). "Strategy and identity: New theoretical paradigms and contemporary social movements." Social Research 52: 663-716.

Cohen, R. and S. M. Rai (2000). Global Social Movements. London, UK; New Brunswick, NJ, The Athlone Press.

Cooley, A. and J. Ron (2002). "The NGO Scramble: Organizational Insecurity and the Political Economy of Transnational Action." International Security 27(1): 5-39.

Corell, E. and M. M. Betsill (2001). "A Comparative Look at NGO Influence in International Environmental Negotiations: Desertification and Climate Change." Global Environmental Politics 1(4): 86-107.

Coveney, P. and R. Highfield (1995). Frontiers of Complexity: The Search for Order in a Chaotic World. London, UK, Faber and Faber.

Covey, J. and L. D. Brown (2001). "Critical Cooperation: An Alternative Form of Civil Society Business Engagement." IDR Reports 17(1). 
Creswell, J. W. (1998). Qualitative Inquiry and Research Design: Choosing Among Five Traditions. Thousand Oaks, CA; London, UK; New Delhi, India, Sage Publications.

Dale, S. (1996). McLuhan's Children: The Greenpeace Message and the Media. Toronto, Canada, Between the Lines.

Dalton, R. J. (1994). The Green Rainbow: Environmental Groups in Western Europe. New Haven, CT; London, UK, Yale University Press.

D'Aveni, R. (1994). Hypercompetition: Managing the dynamics of strategic maneuvering. New York, NY, Free Press.

Davidow, W. H. and M. S. Malone (1992). The Virtual Corporation. New York, NY, Harper Collins.

Davis, G. F., D. McAdam, et al. (2005). Social Movements and Organization Theory. Cambridge, UK, Cambridge University Press.

Davis, J. (2000). Organizational Effectiveness Literature Review. Washington, DC; San Francisco, CA, The Lewin Group for the David and Lucile Packard Foundation, Organizational Effectiveness and Philanthropy Program: 26.

della Porta, D., H. Kriesi, et al., Eds. (1999). Social Movements in a Globalizing World. London, UK; New York, NY, MacMillan Press Ltd; St. Martin's Press Inc.

Diani, M. (1992). "The concept of social movement." The Sociological Review: 2-25.

Diani, M. and P. R. Donati (1999). "Organizational Change in Western European Environmental Groups: A Framework for Analysis." Environmental Politics 8: 13-34.

Dobbin, F. (2001). "The Business of Social Movements." Passionate Politics: Emotions and Social Movements. J. Goodwin, J. M. Jasper and F. Polletta. Chicago, IL; London, NY; University of Chicago Press.

Doh, J. P. and H. Teegan, Eds. (2003). Globalization and NGOs: Transforming Business, Government, and Society. Westport, Connecticut; London, UK, Praeger.

Doherty, B. (2002). Ideas and Actions in the Green Movement. London, UK; New York, NY, Routledge.

Downey, G. (1986). "Ideology and the clamshell identity." Social Problems 33: 101-117.

Downs, A. (1972). "Up and down with ecology: The 'issue-attention cycle'." The Public Interest 28: $38-50$.

Dryzek, J. S. (1997). The Politics of the Earth: Environmental Discourses. Oxford, UK, Oxford University Press.

Dryzek, J. S., D. Downes, et al. (2003). Green States and Social Movements: Environmentalism in the United States, United Kingdom, Germany and Norway. Oxford, UK, Oxford University Press. 
Dyson, J. and J. with Fitchett (1986). Sink the Rainbow! An enquiry into the 'Greenpeace Affair'. London, UK, Victor Gollancz Ltd.

Ebrahim, A. (2003). NGOs and Organizational Change: Discourse, Reporting and Learning. Cambridge, UK, Cambridge University Press.

Economist (1999). "The non-governmental order." The Economist: 20-21.

Eden, S. (2004). "Greenpeace." New Political Economy 9(4): 595-610.

Edwards, M. (1997). "Organizational learning in nongovermental organizations: what have we learned?" Public Administration and Development 17(235-250).

Edwards, M. (2000). NGO Rights and Responsibilities: A New Deal for Global Governance. London, UK, The Foreign Policy Centre.

Edwards, M. and D. Hulme (1996). Beyond the Magic Bullet: NGO Performance and Accountability in the Post-Cold War World. West Hartford, CT, Kumarian Press.

Entine, J. (2002). "Shell, Greenpeace and Brent Spar: the politics of dialogue." Case Histories in Business Ethics. C. Megone and S. J. Robinson. London, UK; New York, NY, Routledge.

Finger, M. and P. Verlaan (1995). "Learning our way out: A conceptual framework of socialenvironmental learning." World Development 23(3): 503-513.

Finnemore, M. (1996). "Constructing Norms of Humanitarian Intervention." The Culture of National Security: Norms and Identity in World Politics. P. J. Katzenstein. New York, NY, Columbia University Press.

Florini, A. (2000). The third force : the rise of transnational civil society. Tokyo, Japan Center for International Exchange; Washington D.C.: Carnegie Endowment for International Peace: Brookings Institution Press [distributor].

Folke, C., L. Pritchard, et al. (1998a). "The Problem of Fit between Ecosystems and Institutions." Bonn, Germany, International Human Dimensions Programme on Global Environmental Change.

Folke, C., F. Berkes, and J. Colding. 1998. Ecological practices and social mechanisms for building resilience and sustainability. Pages 414-436 in F. Berkes and C. Folke. Linking social and ecological systems. London, UK, Cambridge University Press.

Forbes, D. P. (1998). "Measuring the unmeasurable: Empirical studies in nonprofit organization effectiveness from 1977 to 1997." Nonprofit and Voluntary Sector Quarterly 27: 183202.

Ford, J. D. and L. W. Ford (1994). "Logics of identity, contradiction, and attraction in change." Academy of Management Review 20(3): 541-57.0. 
Fowler, A. (2000). The Virtuous Spiral: A Guide to Sustainability for NGOs in International Development. London, UK; Sterling, VA, Earthscan Publications Ltd.

Fox, J. A. and L. D. Brown (1998). The struggle for accountability: the World Bank, NGOs, and grassroots movements. Cambridge, Mass., MIT Press.

Freeman, J. H. (1973). "The tyranny of structurelessness." Ms. 2: 76-78, 86-89.

Freeman, J. H. (1975). The Politics of Women's Liberation. New York, NY, Longman.

Freeman, J. H. and V. Johnson, Eds. (1999). Waves of Protest: Social Movements since the Sixties. Lanham, Maryland, Rowman and Littlefield Publishers Inc.

Galaskiewicz, J. and W. Bielefeld (1998). Nonprofit Organizations in the Age of Uncertainty: A Study of Organizational Change. New York, NY, Aldine de Gruyter.

Galbraith, J. R. (1994). Competing with Flexible Lateral Organizations. Reading, MA, AddisonWesley Publishing Company, Inc.

Gallopin, G. C. and K. Christianson (2000). Sustainable Development, Society, and the Environment: A Conceptual Framework for Tracking the Linkages. Stockholm, Sweden, Stockholm Environment Institute: 51.

Gamson, W. A. (1968). Power and Discontent. Homewood, IL, Dorsey.

Gamson, W. A. (1975). The Strategy of Social Protest. Homewood, IL, Dorsey Press.

Gamson, W. A. (1987). Introduction. Social Movements in an Organizational Society. M. N. Zald and J. D. McCarthy. New Brunswick, NJ, Transaction Publishers.

Gamson, W. A. (1990). The Strategy of Social Protest. Belmont, CA, Wadsworth.

Gamson, W. A. and A. Modigliani (1989). "Media Discourse and Public Opinion on Nuclear Power." American Journal of Sociology 95(1-38).

Ganz, M. (2000). "Resources and Resourcefulness: Strategic Capacity in the Unionization of California Agriculture." American Journal of Sociology 105(4): 1003-1062.

Garrow, D. (1985). "Don't Fall for Media Madness." Democratic Left: 15.

Gaskell, G., E. Einsiedel, et al. (2005). "Social Values and the Governance of Science." Science 310: 1908-1909.

Gereffi, G., R. Garcia-Johnson, et al. (2001). "The NGO-Industrial Complex." Foreign Policy.

Gerlach, L. P. (1999). "The Structure of Social Movements: Environmental Activism and Its Opponents." Waves of Protest: Social Movements since the Sixties. J. H. Freeman and V. Johnson. Lanham, Maryland; Oxford, UK, Rowman and Littlefield Publishers Inc.

Gerlach, L. P. and V. H. Hine (1970). People, Power, Change: Movements of Social Transformation. Indianopolis, IN, New York, NY, Bobbs-Merrill. 
Ghoshal, S. and D. E. Westney (2005). Organizational Theory and the Multinational Corporation. New York, NY, Palgrave MacMillan.

Goertz, G. and P. F. Diehl (1992). "Toward a Theory of International Norms: Some Conceptual and Measurement Issues." Journal of Conflict Resolution 36(4): 634-664.

Goffman, I. (1974). Frame Analysis. New York, NY, Harper Colophon.

Gordenker, L. and T. G. Weiss (1995). "NGO Participation in the International Policy Process." Third World Quarterly 16(3): 543-555.

Gouldner, A. W. (1959). Organizational Analysis. Sociology Today. R. K. Merton, L. Broom and L. S. Cottrell, Jr. New York, NY, Basic Books.

Granovetter, M. (1979). "The idea of 'advancement' in theories of social evolution and development." American Journal of Sociology 85: 489-515.

Grant, W. (2000). Pressure Groups in British Politics. Hampshire, UK, MacMillan Press Ltd.

Greenpeace (1996). Witness: Twenty-five Years on the Environmental Frontline. London, UK, André Deutsch Ltd.

Gross, E. (1968). "Universities as Organizations: A Research Approach." American Sociological Review 33: 518-544.

Gruen, L. and D. Jamieson, Eds. (1994). Reflecting on Nature: Readings in Environmental Philosophy. New York, NY, Oxford University Press.

Guidry, J. A., M. D. Kennedy, et al., Eds. (2000). Globalizations and Social Movements: Culture, Power and the Transnational Public Sphere. Michigan, MN, University of Michigan.

Gunderson, L. H. and C. S. Holling, Eds. (2001). Panarchy: understanding transformations in human-and natural systems. Washington, D.C., Island Press.

Haas, P. M. (1992). "Introduction: Epistemic Communities and International Policy Coordination." International Organization 46(1): 1-36.

Haas, P. M. and E. J. Haas (1995). "Learning to Learn: Improving International Environmental Governance." Global Governance 1(3): 255-285.

Hailey, J. and R. James (2002). "Learning Leaders: the key to learning organizations." Development in Practice 12(3 \& 4): 398-408.

Haines, H. H. (1984). "Black radicalism and the funding of civil rights: 1957-1970." Social Problems 32: 31-43.

Hamel, G. (1996). "Strategy as Revolution." Harvard Business Review: 69-8̀2.

Hamel, G. and C. K. Prahalad (1994). "Competing for the Future." Harvard Business Review: 122-128. 
Hannan, M. T. and J. H. Freeman (1977). "The Population Ecology of Organizations." American Journal of Sociology 82: 929-964.

Harrison, B. (1994). Lean and mean: The changing landscape of corporate power in the age of flexibility. New York, NY, Basic Books.

Hartley, J. F. (1994). "Case studies in organizational research." Qualitative Methods in Organizational Research. C. Cassell and G. Symon. London, UK, Sage Publications.

Held, D., A. McGrew, et al. (1999). Global Transformations: Politics, Economics and Culture. Cambridge, Polity Press.

Herman, R. D. and D. O. Renz (1998). "Nonprofit Organizational Effectiveness: Contrasts between Especially Effective and Less Effective Organizations." Nonprofit Management and Leadership 9(1).

Herman, R. D. and D. O. Renz (1999). "Theses on Nonprofit Organizational Effectiveness." Nonprofit and Voluntary Sector Quarterly 28(2): 107-126.

Heymann, P. B. (1987). The Politics of Public Management. New Haven, CT, Yale University Press.

Hoffman, A. J. (2001). From Heresy to Dogma: an Institutional History of Corporate Environmentalism. Stanford, CA, Stanford University Press.

Holling, C. S. (1973). "Resilience and the Stability of Ecological Systems." Annual Review of Ecology and Systems 4: 2-23.

Holling, C. S. (1979). "Myths of Ecological Stability: Resilience and the Problem of Failure." Journal of Business Administration and Policy Analysis: 97-109.

Holling, C. S. (1996). Engineering resilience vs. ecological resilience. Engineering Within Ecological Constraints. P. C. Schulze. Washington, D.C., National Academy Press.

Holling, C. S. (2001). "Understanding the Complexity of Economic, Ecological and Social Systems." Ecosystems 4: 390-405.

Hunter, R. (1971). The Storming of the Mind. Toronto, ON, McClelland and Stewart Ltd.

Hunter, R. (1978). To Save a Whale: The Voyages of Greenpeace. North Vancouver, BC, Canada, Douglas and McIntyre Ltd.

Hunter, R. (1979). Warriors of the Rainbow. New York, NY, Holt, Rinehart and Winston of Canada, Ltd.

Hunter, R. (2002). 2030: Confronting Thermageddon in our Lifetime. Toronto, ON, McClelland and Stewart Ltd.

Hunter, R. (2004). The Greenpeace to Amchitka: An Environmental Odyssey. Vancouver, Canada, Arsenal Pulp Press. 
Hurrell, A. (2003). "Norms and Ethics in International Relations." Handbook of International Relations. W. Carlsnaes, T. Risse and B. A. Simmons. London, UK; Thousand Oaks, CA; New Delhi, India, Sage Publications.

Hurst, D. K. (1995). Crisis and Renewal: Meeting the Challenge of Organizational Change. Boston, MA, Harvard Business School Press.

IUCN, UNEP, et al. (1980). World Conservation Strategy: Living Resource Conservation for Sustainable Development. Gland, Switzerland, International Union for the Conservation of Nature and Natural Resources (IUCN).

Janssen, M. A. and E. E. Osnas (2005). "Adaptive Capacity of Social-Ecological Systems: Lessons from Immune Systems." EcoHealth 2: 1-10.

Jasanoff, S. (2005). Designs on Nature: Science and Democracy in Europe and the United States. Princeton, NJ; Oxford, UK, Princeton University Press.

Jenkins, C. J. (1983). "Resource Mobilization Theory and the Study of Social Movements." Annual Review of Sociology 9: 527-553.

Jervis, R. (1997). System Effects: Complexity in Political and Social Life. Princeton, NJ, Princeton University Press.

Johnson, R. (2000). "Advocates and Activists: Conflicting Approaches on Nonproliferation and the Test Ban Treaty." The Third Force: The Rise of Transnational Civil Society. A. Florini. Washington, DC; Tokyo, Japan, Japan Center for International Exchange and Carnegie Endowment for International Peace.

Jordan, G. (2001). Shell, Greenpeace and the Brent Spar. New York, NY, Palgrave.

Jordan, G. and W. A. Maloney (1997). The Protest Business? Mobilizing Campaign Groups. Manchester, UK, Manchester University Press.

Jordan, L. and P. Van Tuijl (2000). "Political Responsibility in Transnational NGO Advocacy." World Development 28(12): 2051-2065.

Juma, C. (2002). "How Not to Save the World." New Scientist: 24.

Kahane, A. (2003). The Potential of Talking and the Challenge of Listening. Changing our Organizations to Change the World: Systems Thinking in Action 2003: The 13th Annual Pegasus Conference, Boston, MA, Pegasus Communications, Inc.

Kaldor, M. (2003). "Civil Society and Accountability." Journal of Human Development 4(1): 427.

Kaplan, R. S. (2001). "Strategic Performance Measurement and Management in Nonprofit Organizations." Nonprofit Management and Leadership 11(3): 353-370.

Kates, R. W., T. M. Parris, et al. (2005). "What is Sustainable Development? Goals, Indicators, Values and Practice." Environment 47(3): 9-21. 
Kates, R. W., W. C. Clark, et al. (2001). "Sustainability Science." Science 292: 641-642.

Kauffman, S. (1995). At Home in the Universe: The Search for Laws of Self-Organization and Complexity. Oxford, UK, Oxford University Press.

Kearns, K. P. (1996). Managing for Accountability: Preserving the Public Trust in Public and Nonprofit Organizations. San Francisco, CA, Jossey-Bass Inc.

Keck, M. and K. Sikkink (1998). Activists without Borders. Ithaca, NY, Cornell University Press.

Keohane, R. and J. S. Nye (2000). Introduction. Governance in a Globalizing World. J. S. Nye and J. D. Donahue. Washington, DC, Brookings Institution.

Keziere, R. and R. Hunter (1972). Greenpeace. Toronto, ON, McClelland and Stewart Ltd.

Khagram, S. (2002). "Restructuring the Global Politics of Development: The Case of India's Narmada Valley Dams." Restructuring World Politics: Transnational Social Movements, Networks, and Norms. S. Khagram, J. V. Riker and K. Sikkink. Minneapolis, MN; London, UK, University of Minnesota Press.

Khagram, S., J. V. Riker, et al., Eds. (2002). Restructuring World Politics: Transnational Social Movements, Networks, and Norms. Minneapolis, MN, University of Minnesota Press.

Killingsworth, M. J. and J. S. Palmer (1992). Ecospeak: Rhetoric and Environmental Politics in America. Carbondale and Edwardsville, Southern Illinois University Press.

Kitshelt, H. and S. Hellemans (1990). Beyond the European Left: Ideology and political action in the Belgian ecological parties. Durham, Duke University Press.

Klandermans, B. (1997). The Social Psychology of Protest. Cambridge, MA, Blackwell.

Kraatz, M. S. and E. J. Zajac (2001). "How Organizational Resources Affect Strategic Change and Performance in Turbulent Environments: Theory and Evidence." Organization Science 12(5): 632-657.

Kriesberg, L. (1997). "Social Movements and Global Transformation." Transnational social movements and global politics: solidarity beyond the state. J. Smith, C. Chatfield and R. Pagnucco. Syracuse, NY, Syracuse University Press.

Krueger, J. (1999). International Trade and the Basel Convention. London, UK, Royal Institute of International Affairs; Earthscan Publications Ltd.

Lafferty, W. M. (2004). "Introduction: form and function in governance for sustainable development." Governance for Sustainable Development: The Challenge of Adapting Form to Function. W. M. Lafferty. Cheltenham, UK; Northampton, MA, Edward Elgar.

Lamb, R. (1996). Promising the Earth. London, UK; New York, NY, Routledge.

Larman, C. (2004). Agile and Iterative Development: A Manager's Guide. Patparganj, Delhi, Pearson Education, Inc. 
Lawrence, P. R. and J. Lorsch (1967). Organization and Environment: Managing Differentiation and Integration. Boston, MA, Graduate School of Business Administration, Harvard University.

Lax, D. and J. Sebenius (1986). The Manager as Negotiator: Bargaining for Cooperation and Competitive Gain. New York, NY, Free Press.

Lee, K. N. (1993). Compass and Gyroscope: Integrating science and politics for the environment. Washington, OR, Island Press.

Letts, C. W., W. P. Ryan, et al. (1999). High Performance Nonprofit Organizations: Managing Upstream for Greater Impact. New York, NY, John Wiley and Sons, Inc.

Levinthal, D. A. and J. G. March (1993). "The Myopia of Learning." Strategic Management Journal 14: 95-112.

Levy, M. A., O. R. Young, et al. (1995). "The Study of International Regimes." European Journal of International Relations 1: 267-330.

Lewin, K. (1951). Field Theory in Social Science. New York, NY, Harper and Row.

Light, P. C. (1998). Sustaining Innovation: creating nonprofit and government organizations that innovate naturally. San Francisco, Jossey-Bass, Inc.

Lindenberg, M. (2001). "Are we at the cutting edge or the blunt edge?. Improving NGO performance with private and public sector management frameworks." Nonprofit Management and Leadership 11(3): 247-270.

Lindenberg, M. and C. Bryant (2001). Going Global: Transforming Relief and Development NGOs. Bloomfield, CT, Kumarian Press Inc.

List, P. C. (1993). Radical Environmentalism: Philosophy and Tactics. Belmont, CA, Wadsworth Publishing Company.

Lloyd, R. (2005). The Role of NGO Self-regulation in Increasing Stakeholder Accountability. London, UK, One World Trust: 1-16.

Lofland, J. (1996). Social Movement Organizations: Guide to Research on Insurgent Realities. New York, NY, Aldine de Gruyter.

Lofland, J. and L. H. Lofland (1984). Analyzing Social Settings: A Guide to Qualitative Observation and Analysis. Belmont, CA, Wadsworth.

Lowi, T. J. (1971). The Politics of Disorder. New York, NY, Basic. 
MA (2005). Millennium Ecosystem Assessment Synthesis Report: Strengthening Capacity to Manage Ecosystems Sustainably for Human Well-Being, Millennium Ecosystem Assessment - IEG India, SCOPE France, UNEP Kenya, UNEP WCMC UK, WRI and Meridian Institute USA, RIVM Netherlands, WorldFish Center Malaysia: 219.

Marshak, R. J. (1993). "Lewin meets Confucius: a review of the OD model of change." Journal of Applied Behavioural Science 29: 393-415.

Martens, K. (2001). "Applying the concept of 'political opportunity structures' in European and International Studies." Transnational Associations 1: 2-9.

Mathews, J. T. (1997). "Power Shift." Foreign Affairs 76(1): 195-211.

McAdam, D. (1983). "Tactical innovation and the pace of insurgency." American Sociological Review 48: 735-754.

McAdam, D. (1995). "Initiator' and 'Spin-off' Movements: Diffusion Processes in Protest Cycles." Repertoires and Cycles of Collective Action. M. Traugott. Durham, NC, Duke University Press.

McAdam, D. (1996). "The framing function of movement tactics: strategic dramaturgy in the American civil rights movement." Comparative Perspectives on Social Movements: Political Opportunities, Mobilizing Structures, and Cultural Framing. D. McAdam, J. D. McCarthy and M. N. Zald. Cambridge, UK, Cambridge University Press.

McAdam, D. and R. W. Scott (2005). "Organizations and Movements." Social Movements and Organization Theory. G. F. Davis, D. McAdam, R. W. Scott and M. N. Zald. Cambridge, UK, Cambridge University Press: 4-40.

McAdam, D., J. D. McCarthy, et al. (1988). "Social Movements." Handbook of Sociology. N. Smelser. Newbury Park, CA, Sage Publications.

McAdam, D., J. D. McCarthy, et al., Eds. (1996). Comparative Perspectives on Social Movements: Political Opportunities, Mobilizing Structures, and Cultural Framing. Cambridge, UK, Cambridge University Press.

McAdam, D., S. Tarrow, et al. (2001). Dynamics of Contention. Cambridge, UK, Cambridge University Press.

McCarthy, J. D. (1997). "The Globalization of Social Movement Theory." Transnational Social Movements and Global Politics. J. Smith, C. Chatfield and R. Pagnucco. Syracuse, NY, Syracuse University Press.

McCarthy, J. D. (2005). "Persistence and change among nationally federated social movements." Social Movements and Organization Theory. G. F. Davis, D. McAdam, R. W. Scott and M. N. Zald. Cambridge, UK, Cambridge University Press.

McCarthy, J. D. and M. N. Zald (1973). The Trend of Social Movements in America:

Professionalization and Resource Mobilization. Morristown, NJ, General Learning Press. 
McCarthy, J. D. and M. N. Zald (1977). "Resource Mobilization in Social Movements: A Partial Theory." American Journal of Sociology 82: 1212-1241.

McCarthy, J. D. and M. N. Zald (2001). "Resource Mobilization Theory: Vigorous or Outmoded?" Handbook of Sociological Theory. J. H. Turner. New York, NY, Kluwer Academic / Plenum Publishers.

McCarthy, J. D., J. Smith, et al. (1996). "Media Discourse, Movement Publicity, and the Generation of Collective Action Frames: Theoretical and Empirical Exercises in Meaning Construction." Comparative Perspectives on Social Movements: Political Opportunities, Mobilizing Structures, and Cultural Framing. D. McAdam, J. D. McCarthy and M. N. Zald. Cambridge, UK, Cambridge University Press.

McCarthy, J. J. and M. N. Zald (1987). "Resource Mobilization and Social Movements: A Partial Theory." Social Movements in an Organizational Society. M. N. Zald and J. D. McCarthy. New Brunswick, NJ, Transaction Publishers.

McCormick, J. (1989). The Global Environmental Movement: Reclaiming Paradise. London, UK, Belhaven Press.

McCormick, J. (1991). British Politics and the Environment. London, UK, Earthscan.

McTaggart, D. (1973). Outrage! the ordeal of Greenpeace III. Vancouver, BC, J. J. Douglas Ltd.

McTaggart, D. and H. Slinger (2002). Shadow Warrior: The Autobiography of Greenpeace International Founder David McTaggart. London, UK, Orion Books.

McTaggart, D. and R. Hunter (1978). Greenpeace III: Journey into the Bomb. London, UK, William Collins Sons \& Co Ltd.

Meadowcroft, J. (2000). "Sustainable Development: a New(ish) Idea for a New Century?" Political Studies 48(2): 370-387.

Mekata, M. (2000). "Building Partnerships toward a Common Goal: Experiences of the International Campaign to Ban Landmines." The Third Force: The Rise of Transnational Civil Society. A. Florini. Tokyo, Japan; Washington, DC, Japan Center for International Exchange; Carnegie Endowment for International Peace.

Melucci, A. (1989). Nomads of the Present. London, UK, Hutchinson Radius.

Mercier, J. (1997). Downstream and Upstream Ecologists: The People, Organizations, and Ideas Behind the Movement. Westport, CT, Praeger Publishers.

Meyer, D. S. and S. Tarrow, Eds. (1998). Towards a Movement Society? Lanham, MD, Rowman and Littlefield.

Meyer, J. W. and B. Rowan (1977). "Institutionalized Organizations: Formal Structure as Myth and Ceremony." American Journal of Sociology 83(2): 340-363.

Meyer, M. W. and L. G. Zucker (1989). Permanently Failing Organizations. Newbury Park, CA, Sage. 
Meyer, W. B. (2001b). "Human Impacts on Earth." Encyclopedia of Global Change:

Environmental Change and Human Society. A. S. Goudie and D. J. Cuff. Oxford, UK, Oxford University Press: 607-613.

Michels, R. (1949 [1911]). Political Parties. New York, NY, Collier.

Milbrath, L. W. (1989). Envisioning a sustainable society: Learning our way out. Albany, NY, State University of New York Press.

Miles, R. E. and C. C. Snow (1978). Organizational Strategy, Structure, and Process. New York, NY, McGraw-Hill Book Company.

Minkoff, D. (1997). "The Sequencing of Social Movements." American Sociological Review 62(779-799).

Mintzberg, H. (1979). The Structuring of Organizations. Englewood Cliffs, New Jersey, PrenticeHall, Inc.

Mintzberg, H. (1983). Structures in Fives: Designing Effective Organizations. Englewood Cliffs, NJ, Prentice-Hall, Inc.

Mintzberg, H. (1989). Mintzberg on Management: Inside our Strange World of Organizations. New York, London, The Free Press, Collier MacMillan Publishers.

Mintzberg, H. (1998a). "Five Ps for Strategy." Readings in the Strategy Process. H. Mintzberg and J. B. Quinn. Upper Saddle River, NJ, Prentice-Hall Inc.: 10-17.

Mintzberg, H. (1998b). "The Structuring of Organizations." Readings in the Strategy Process. H. Mintzberg and J. B. Quinn. Upper Saddle River, NJ, Prentice-Hall Inc.: 143-161.

Mintzberg, H. (1998c). "The Innovative Organization." Readings in the Strategy Process. H. Mintzberg and J. B. Quinn. Upper Saddle River, NJ, Prentice-Hall, Inc.: 309-323.

Mintzberg, H. and F. Westley (1992). "Cycles of Organizational Change." Strategic Management Journal 13: 39-59.

Mintzberg, H. and J. B. Quinn (1998). Readings in the Strategy Process. Upper Saddle River, NJ, Prentice-Hall Inc.

Mintzberg, H., B. Ahlstrand, et al. (1998). Strategy Safari: A Guided Tour through the Wilds of Strategic Management. New York, The Free Press.

Mitchell, R. B. (2002). "International Environment." Handbook of International Relations. W. Carlsnaes, T. Risse and B. A. Simmons. London; Thousand Oaks; New Delhi, Sage Publications.

Montgomery, C. A. (1995). “Of diamonds and rust: A new look at resources." Resource Based and Evolutionary Theories of the Firm: Towards a Synthesis. C. A. Montgomery. Boston, MA, Kluwer Academic Publishers. 
Moore, M. H. (1995). Creating Public Value: Strategic Management in Government. Cambridge, MA; London, UK, Harvard University Press.

Moore, M..H. (2000). "Managing for Value: Organizational Strategy in For-profit, Nonprofit, and Governmental Organizations." Nonprofit and Voluntary Sector Quarterly 29(1, Supplement): 183-204.

Morgan, G. (1997). Images of Organization. Thousand Oaks, CA, Sage.

Morgan, G. (1999). Imaginization: New Mindsets of Seeing, Organizing and Managing. San Francisco; Thousand Oaks, CA, Berrett-Koehler; Sage Publications Ltd.

Mulvaney, K. (2003). The Whaling Season: An Inside Account of the Struggle to Stop Commercial. Whaling. Washington, DC, Shearwater Books.

Nemetz, P. (2002-3). "Sustainable Resource Management: Reality or Illusion? Introduction and Summary." The Journal of Business Administration and Policy Analysis 30-31: 9-46.

Newell, P. (2000). Climate for Change: Non-state Actors and the Global Politics of the Greenhouse. Cambridge, UK, Cambridge University Press.

Nichols, N. (2003). "Stopping the Activist Attackers." New Activism and the Corporate Response. S. John and S. Thomson. New York, NY, Palgrave MacMillan: 137-151.

NRC (1999). Our Common Journey: A Transition toward Sustainability. Washington, D.C., National Academy Press.

Oerton, S. (1996). Beyond hierarchy: gender, sexuality and the social economy. Bristol, PA; London, UK, Taylor and Francis.

O'Riordan, T., Ed. (2000). Environmental Science for Environmental Management. Harlow, Essex, UK, Pearson Education Ltd.

Orlikowski, W. J. (1996). "Improvising organizational transformation overtime: a situated change perspective." Information Systems Research 7(1): 63-92.

Pal, N. and D. C. Pantaleo (2005). The Agile Enterprise: Reinventing your Organization for Success in an On-Demand World. New York, NY, Springer Science + Media, Inc.

Parson, E. A. and W. C. Clark (1995). "Sustainable Development as Social Learning: Theoretical Perspectives and Practical Challenges for the Design of a Research Program." Barriers and Bridges to the Renewal of Ecosystems and Institutions. L. H. Gunderson, C. S. Holling and S. S. Light. New York, NY, Columbia University Press.

Pascale, R. T. and A. G. Athos (1981). The Art of Japanese Management: Applications for American Executives. New York, NY, Simon and Schuster.

Pearce, F. (1996). "Greenpeace: Storm-Tossed on the High Seas." Green Globe Yearbook of International Co-operation on Environment and Development. T. F. N. Institute. Oxford, UK, Oxford University Press: 73-79. 
Perrow, C. (1970). Organizational Analysis: A Sociological View. Belmont, CA, Wadsworth.

Perrow, C. (1986). Complex Organizations: A Critical Essay. New York, NY, Random House.

Pettifor, A. (2000). Jubilee 2000 and the Multilateral Institutions. FORUM 2000: Human Security: New Definitions and Roles for Global Civil Society, Montreal, Quebec, Forum International de Montreal.

Pfeffer, J. and G. R. Salanick (1978). The external control of organizations. New York, NY, Harper and Row.

Pickerill, J. (2003). Cyberprotest: Environmental Activism Online. Manchester, UK; New York, NY, Manchester University Press.

Piven, F. F. and R. A. Cloward (1977). Poor People's Movements. New York, NY, Vintage Books.

Princen, T. and M. Finger (1994). Environmental NGOs in world politics: linking the local and the global. London; New York, Routledge.

Purdue, D. A. (2000). Anti-GenetiX: The emergence of the anti-GM movement. Aldershot, UK; Burlington, Vermont, Ashgate Publishing Ltd.

Putnam, R. (1988). "Diplomacy and Domestic Politics: The Logic of Two-Level Games." International Organization 42: 427-460.

Quinn, J. B. and J. Voyer (1998). "Logical Incrementalism: Managing Strategy.” Readings in the Strategy Process. H. Mintzberg and J. B. Quinn. Upper Saddle River, NJ, Prentice-Hall, Inc.

Quinn, R. E. (1988). "The Competing Values Model: Redefining Organizational Effectiveness and Change." Beyond Rational Management: Mastering the Paradoxes and Competing Demands of High Performance. R. E. Quinn. San Francisco, CA, Jossey-Bass.

Rawcliffe, P. (1998). Environmental Pressure Groups in Transition. Manchester, UK; New York, NY, Manchester University Press.

Rees, W. E. (1995). "Achieving Sustainability: Reform or Transformation?" Journal of Planning Literature 9(4): 343-261.

Reinicke, W. H. (1998). Global Public Policy: Governing without Government? Washington, DC, Brookings Institution.

Reinicke, W. H., F. Deng, et al. (2000). Critical Choices: The United Nations, Networks, and the Future of Global Governance. Ottawa, ON, Canada, International Development Research Centre.

Resnick, M. (1995). Turtles, Termites and Traffic Jams. Cambridge, MA, MIT Press.

Resnick, M. (1996). "Beyond the Centralized Mindset." Journal of the Learning Sciences 5(1): 122. 
Richards, J. P. and J. Heard (2005). "European Environmental NGOs: Issues, Resources and Strategies in Marine Campaigns." Environmental Politics 14(1): 23-41.

Risse, T. (2003). "Transnational Actors and World Politics." Handbook of International Relations. W. Carlsnaes, T. Risse and B. A. Simmons. London, UK; Thousand Oaks, CA; New Delhi, India, Sage Publications.

Risse, T., C. Ropp, et al., Eds. (1999). The Power of Human Rights: International Norms and Domestic Change. Cambridge, UK, Cambridge University Press.

Roe, E. (1998). Taking Complexity Seriously: Policy Analysis, Triangulation and Sustainable Development. Norwell, MA and Dordrecht, The Netherlands, Kluwer Academic Publishers.

Rose, C. (1998). The Turning of the Spar. London, UK, Greenpeace.

Rosenbaum, W. A. (2003). Environmental Politics and Policy. Washington, D.C., CQ Press.

Rothschild, J. and J. A. Whitt (1986). The Cooperative Workplace: Potentials and dilemmas of organizational democracy and participation. Cambridge, UK, Cambridge University Press.

Rothschild-Whitt, J. (1979). "The collectivist organization: an alternative to rational-bureaucratic models." American Sociological Review 44: 509-527.

Rucht, D. (1995). "Ecological Protest as Calculated Law-breaking: Greenpeace and Earth First! in Comparative Perspective." Green Politics Three. W. Rüdig. Edinburgh, Scotland, Edinburgh University Press

Rucht, D. (1999). "The Transnationalization of Social Movements: Trends, Causes, Problems." Social Movements in a Globalizing World. D. della Porta, H. Kriesi and D. Rucht. London, UK, MacMillan Press.

Rumelt, R. P. (1995). "Inertia and transformation." Resource Based and Evolutionary Theories of the Firm: Towards a Synthesis. C. A. Montgomery. Boston, MA, Kluwer Academic Publishers.

Sachs, A. (1995). Eco-justice: Linking Human Rights and the Environment. Washington, DC, WorldWatch Institute.

Sawhill, J. C. and D. Williamson (2001a). "Mission Impossible? Measuring Success in Nonprofit Organizations." Nonprofit Management and Leadership 11(3): 371-383.

Sawhill, J. C. and D. Williamson (2001b). "Measuring what matters in nonprofits." The McKinsey Quarterly 2: 98-107.

Scarce, R. (1990). Eco-Warriors: Understanding the Radical Environmental Movement. Chicago, IL, The Noble Press Inc. 
Schein, E. H. (1985). Organizational Culture and Leadership. San Francisco, CA; London, UK, Jossey-Bass Publishers.

Scholte, J. A. (2004). Democratizing the Global Economy: The Role of Civil Society. Coventry, UK, Centre for the Study of Globalisation and Regionalisation, University of Warwick.

Scott, M. J. O. (2001). "Danger - Landmines! NGO-Government Collaboration in the Ottawa Process." Global Citizen Action. M. Edwards and J. Gaventa. Boulder, CO, Lynne Rienner Publishers, Inc.

Scott, R. W. (2003). Organizations: Rational, Natural and Open Systems. Upper Saddle River, NJ, Prentice Hall.

Scott, W. R. (2001). Institutions and Organizations. Sage Publications Inc, Thousand Oaks, CA; London UK; New Delhi, India.

Selin, H. and B. Linnér.(2005). The Quest for Global Sustainability: International Efforts on Linking Environment and Development. Cambridge, MA, Center for International Development, Kennedy School of Government, Harvard University.

Selznick, P. (1957). Leadership in Administration: A Sociological Interpretation. Evanston, IL; White Plains, NY, Row, Peterson and Company.

Shabecoff, P. (2003). A Fierce Green Fire: The American Environmental Movement. Washington, DC; London, UK, Island Press.

Shears, R. and I. Gidley (1986). The Rainbow Warrior Affair. London, UK, Unwin Paperbacks.

Sicicliano, J. I. (1997). "The Relationship Between Formal Planning and Performance in Nonprofit Organizations." Nonprofit Management and Leadership 7(4).

Sklair, L. (2001). The Transnational Capitalist Class. Cambridge, UK, Blackwell.

SLG, S. L. G.- (2001). Learning to Manage Global Environmental Risks: A Comparative History of Social Responses to Climate Change, Ozone Depletion and Acid Rain. Cambridge, MA, MIT Press.

Smillie, I. and J. Hailey (2001). Managing for Change: Leadership, Strategy and Management in Asian NGOs. London, UK; Sterling, VA, Earthscan Publications Ltd.

Smith, J. (2002). "Bridging Global Divides." International Sociology 17(4): 505-528.

Smith, J. (2005). "Globalization and Transnational Social Movement Organizations." Social Movements and Organization. Theory. G. F. Davis, D. McAdam, R. W. Scott and M. N. Zald. Cambridge, UK, Cambridge University Press.

Smith, J., C. Chatfield, et al., Eds. (1997). Transnational Social Movements and Global Politics. Syracuse, NY, Syracuse University Press. 
Snow, D. A. and R. D. Benford (1988). "Ideology, frame resonance, and participant mobilization." From Structure to Action: Comparing Social Movement Research Across Cultures. B. Klandermans, H. Kriesi and S. Tarrow. Greenwich, JAI Press.

Snow, D. A., J. Rochford, E.B., et al. (1986). "Frame alignment processes, micromobilization, and movement participation." American Sociological Review 51: 464-481.

Sowa, J. E., S. Coleman Selden, et al. (2004). "No longer unmeasurable? A Multidimensional Model of Nonprofit Organizational Effectiveness." Nonprofit and Voluntary Sector Quarterly 33: 711-728.

Staber, U. and J. Sydow (2002). "Organizational adaptive capacity: A structuration perspective." Journal of Management Inquiry 11(4): 408-424.

Staggenborg, S. (1988). "The consequences of professionalization and formalization in the prochoice movement." American Sociological Review 53(585-605).

Staggenborg, S. (1989). "Stability and Innovation in the Women's Movement: A Comparison of Two Movement Organizations." Social Problems 36(1): 75-92.

Sterman, J. D. (1994). "Learning In and About Complex Systems." System Dynamics Review 10(2-3): 291-330.

Sterman, J. D. (2000). Business Dynamics: Systems Thinking and Modeling for a Complex World. USA; McGraw-Hill Companies, Inc.

Stoett, P. J. (1997). The International Politics of Whaling. Vancouver, BC, UBC Press.

Sturmanis, K. and D. Sturmanis (1978). The Greenpeace Book. Vancouver, BC, Orca Sound Publications.

Suter, K. (2002/2003). "Friends of the Earth International." Green Globe Yearbook of International Co-operation on Environment and Development. T. F. N. Institute. Oxford, UK, Oxford University Press.

Sztompka, P. (1993). The Sociology of Change. Oxford, UK; Cambridge, MA, Blackwell Publishers.

Tarrow, S. (1995). "Cycles of Collective Action: Between moments of madness and the repertoires of contention." Repertoires and Cycles of Collective Action. M. Traugott. Durham, NC, Duke University Press.

Tarrow, S. (1996). "Fishnets, Internets, and Catnets: Globalization and Transnational Collective Action." Estudio / Working Paper 1996/78. New York, NY, Cornell University.

Tarrow, S. (1998). Power in Movement: Social Movements, Collective Action and Politics. Cambridge, Cambridge University Press.

Tilly, C. (1978). From Mobilization to Revolution. Reading, MA, Addison-Wesley. 
Tilly, C. (1984). "Social Movements and National Politics." Statemaking and Social Movements: Essays in History and Theory. C. Bright and S. Harding. Ann Arbor, Michigan, University of Michigan Press.

Tilly, C. and J. Rule (1965). Measuring Political Upheaval. Princeton, NJ, Center for International Studies, Princeton University.

Tilly, C., L. Tilly, et al. (1975). The Rebellious Century, 1830-1930. Cambridge, MA, Harvard University Press.

Turner II, B. L., R. E. Kasperson, et al. (2003). "A framework for vulnerability analysis in sustainability science." PNAS - Proceedings of the National Academy of Sciences of the United States of America 100(14): 8074-8079.

Turner II, B. L., W. C. Clark, et al., Eds. (1990). The Earth as transformed by human action: global and regional changes in the biosphere over the past 300 years. Cambridge, UK, Cambridge University Press.

Turner, R. (1970). "Determinants of social movement strategies." Collective Behavior. T. Shibutani. Englewood Cliffs, NJ, Prentice-Hall.

Turner, R. and R. Killian (1957). Collective Behavior. Englewood Cliffs, NJ, Prentice-Hall.

Tushmạ, M. L. and E. Romanelli (1985). "Organiżational revolution: a metamorphosis model of convergence and reorientation." Research in Organizational Behaviour(7): 171-222.

UIA (1993). Yearbook of International Organizations. Brussels, Belgium, UIA.

UN (2005). World Development Report. New York, NY, United Nations.

UNEP (2002). "Integrating Environment and Development: 1972-2002.” Global Environment Outlook. UNEP. London, UK: Sterling, VA, Earthscan Publications. 3: 1-27.

Useem, B. and M. N. Zald (1987). "From pressure group to social movement: Efforts to promote use of nuclear power." Social Movements in an Organizational Society. M. N. Zald and J. D. McCarthy. New Brunswick, NS, Transaction Books.

Uvin, P., P. Jain, et al. (2000). "Think Large and Act Small." World Development 28(8): 14091419.

Van de Ven, A. H. and M. S. Poole (1995). "Explaining Development and Change in Organizations." Academy of Management Review 20(3): 510-540.

Van der Heijden, H. A. (1997). "Political Opportunity Structures and the Institutionalization of the Environmental Movement." Environmental Politics 6(4): 25-50.

van Eijndhoven, J., W. C. Clark, et al. (2001). "The Long-term Development of Global Environmental Risk Management: Conclusions and Implications for the Future." Learning to Manage Global Environmental Risks: A Functional Analysis of Social Responses to Climate Change, Ozone Depletion, and Acid Rain. The Social Learning Group. Cambridge, MA, MIT Press. 2: 181-197. 
Vitousek, P. M., H. Mooney, et al. (1997). "Human Domination of Earth's Ecosystems." Science 277(5325).

Waltz, K. N. (1993). "The Emerging Structure of International Politics." International Security 18: 44-79.

Wapner, P. (1996). Environmental Activism and World Civic Politics. Albany, NY, State University of New York.

Wapner, P. (1997). "Governance in Global Civil Society." Global Governance: Drawing Insights from the Environmental Experience: O. R. Young. Cambridge, MA, MIT Press: 66-84.

Wapner, P. (2001). "Greenpeace." Encyclopedia of Global Change: Environmental Change and Human Society. A. S. Goudie and D. J. Cuff. Oxford, UK, Oxford University Press: 568569.

Warkentin, C. (2001). Reshaping World Politics: NGOs, the Internet, and Global Civil Society. Rowman and Littlefield Publishers, Inc., Lanham, ML; Oxford, UK.

Watson, P. (1993). Earthforce! An Earth Warrior's Guide to Strategy. Los Angeles, CA, Chaco Press.

WCED (1987). Our Common Future. Oxford, Oxford University Press.

Weber, M. (1958). From Max Weber: Essays in Sociology. New York, NY, Oxford University Press.

Weick, K. E. and R. E. Quinn (1999). "Organizational Change and Development." Annual Review of Psychology 50: 361-386.

Weyler, R. (2004). Greenpeace: How a Group of Ecologists, Journalists and Visionaries Changed the World. Vancouver, BC, Raincoast Books.

Wheatley, M. J. (1999). Leadership and the New Science: Discovering Order in a Chaotic World. San Francisco, USA, Berrett-Koehler Publishers.

Willetts, P., Ed. (1982). Pressure Groups in the Global System: The Transnational Relations of Issue-oriented Nongovernmental Organizations. London, UK, Frances Pinter Publishers Ltd.

Williamson, H. (2005). "Campaigners in a corporate mould." The Financial Times. London, UK: 10.

Wilson, D. C. (1992). A strategy of change: concepts and controversies in the management of change. London, UK; New York, NY, Routledge.

Wilson, D. C., Ed. (1984). The Environmental Crisis: A Handbook for All Friends of the Earth. London, UK, Heinemann Educational Books Ltd. 
Winston, M. (2002). "NGO Strategies for Promoting Corporate Social Responsibility." Ethics and International Affairs 16(1): 71-87.

Yanacopulos, H. (2005). "The strategies that bind: NGO coalitions and their influence." Global Networks 5(1): 93-109.

Yearley, S. (1996). Sociology, Environmentalism, Globalization: Reinventing the Globe. London, UK: Thousand Oaks, CA; New Dehli, India, Sage Publications.

Yearley, S. (2003). "Social Movements as Problematic Agents of Global Environmental Change." Globalization, Globalism, Environments, and Environmentalism:

Consciousness of Connections: The Linacre Lectures 2000. S. Vertovec and D. Posey. Oxford, UK, Oxford University Press.

Yin, R. K. (2003): Case Study Research: Design and Methods. Thousand Oaks, CA, Sage Publications.

Young, D. (1991). "The Structural Imperatives of International Advocacy Associations." Relations 44(9): 921-941.

Young, D. R., B. L. Koenig, et al. (1999). "Strategy and Structure in Managing Global Associations." Voluntas: International Journal of Voluntary and Nonprofit Organizations 10(4): 323-343.

Young, O. R., Ed. (1997). Global Governance: Drawing Insights from the Environmental Experience. Cambridge, MA, MIT Press.

Zald, M. N. and J. D. McCarthy (1987). Social Movements in an Organizational Society: Resource Mobilization, Conflict and Institutionalization. New Brunswick, NJ, Transaction Books.

Zald, M. N. and R. Ash (1966). "Social movement organizations: growth, decay and change." Social Forces 44: 327-341

Zelko, F. (2004). "Making Greenpeace: Direct Action Environmentalism in British Columbia." BC Studies (142/143): 197-239 


\section{APPENDIX A: FoEI Campaigns}

This chronology of FoE's campaigns is a record of some of their local, national and international activities and victories. Following a list of the successes presented in their $25^{\text {th }}$ anniversary booklet, there is a list of international campaign victories for 2003, 2004 and 2005.

Source:

"Friends Helping Friends: 25 Victories for the Earth" in Friends of the Earth: 25 Years for the Planet, For People

"Success is difficult to measure when the issues at stake are as enormous and as pervasive as nuclear energy, multilateral debt and ozone depletion. Nonetheless, the hundreds of thousands of local, national and international actions taken by FoE groups over the last 25 years have led to some tangible and inspirational victories on a wide range of issues; and the cumulative effects of many other actions will hopefully bear fruit in the future. The following is a sample of some FoE successes - each and every one stemming from international solidarity and co-operation within the federation. May the next 25 years bring many more such victories!"

\section{NUCLEAR ENERGY}

\section{Nuclear Referenda}

FoE groups have always reacted with a loud and unanimous NO when it comes to nuclear energy, and impressive results have been achieved by member groups pushing for referenda on nuclear power. In the 1970 s, for example, FoE Austria was active in a referendum that rejected the opening of the already-completed Zwentendorf power plant, thus killing their country's nuclear future. In later years, FoE Sweden and FoE Italy were both active in national referenda resulting in moratoria on the development of further nuclear capacity, and FoE Netherlands and FoE Poland played major roles in catalysing national energy debates which led to moratoria on nuclear energy.

Amici delta Terra's (FoE Italy) call for a referendum was catalysed by the 1986 Chernobyl disaster, and a broad majority of Italian voters rejected nuclear power in 1987 . The stunning victory was celebrated by FoE groups in Ireland, the Netherlands, the UK and the US - national Italian embassies were presented with flowers and cakes, and press releases congratulating the people of Italy were distributed.

FoE activists continue to commemorate annual Chernobyl anniversaries, albeit in a less joyous manner, with processions, silent vigils, 'die-ins', balloon releases and more. For example, the tenth anniversary in 1996 was marked by an international bike tour, organised by FoE Germany's youth branch, from Chernobyl to Berlin.

\section{Good Nukes in Slovakia!}

The resistance of FoE groups in many countries to the Mochovce nuclear power plant in Slovakia finally bore fruit in the spring of 1995, when the European Bank for Reconstruction and Development (EBRD) withdrew its crucial loan for this controversial project. Pressure came from the European Parliament, from several European governments, and from FoE groups all over Europe. 
FoE groups in Slovakia, the Czech Republic, Poland and Austria organised public hearings and lobbied local and national officials. FoE Austria sent information packs about Mochovce to 2300 Austrian mayors. FoE Sweden demonstrated outside its Finance Ministry, passed out leaflets, and lobbied until a debate was provoked in parliament. FoE Norway met several times with government officials. FoEI and FoE Germany ran advertisements in major German newspapers opposing the involvement of the Bayernwerke company, and FoE Europe drafted a protest letter which was signed by many countries. All in all, a powerful show of resistance against nuclear power, which should make future funders for Mochovce or other nuclear projects think twice.

\section{No Nukes for Uruguay}

During an anti-nuclear NGO meeting at the 1992 Earth Summit in Rio, Uruguayan environmentalists were shocked to learn that an agreement to transfer nuclear technology was being negotiated behind closed doors between their government and Canada. REDES (FoE Uruguay) swiftly drafted a letter which was signed by more than 100 groups present and handdelivered to the Uruguayan President in Rio. Meanwhile, FoEI sent a letter to all members of the Uruguayan Parliament.

Back in Montevideo, FoE Uruguay worked closely with FoE Canada to collect information about the deal. They visited every member of parliament, held press conferences, and organised demonstrations outside the parliament. The international outcry was also audible; one official asked REDES to stop the flood of faxes from all over the world. In August that year, the government rejected the agreement. "Our arguments, supported by the international federation, proved to be strong enough," said FoE Uruguay's Karin Nansen.

\section{WORLD BANK}

\section{Making Waves on the Xingu}

In the mid-1980s, FoE groups around the world collaborated with Amazonian forest peoples in a series of actions which ultimately forced the World Bank to cancel its proposed US\$500 million loan for a series of dams on the Xingu River. In 1988, a group of Kayapó Indians toured Europe and North America calling for a halt to funding for the dams. The tour, organised by FoE England, Wales and Northern Ireland (EWNI) in co-operation with FoE groups and other NGOs, generated extensive press coverage and public awareness. The following year, FoE EWNI and FoE Italy assisted in organising a large conference, attended by members of several indigenous tribes, in the Amazonian town of Altamira. Afterwards, hundreds of Amazonian tribal peoples demonstrated in Altamira for an entire month. The World Bank subsequently altered its plans, and the success was a global celebration. According to FoEI's Jim Barnes, "Tens of thousands of people have written letters to the World Bank, its member governments and commercial banks to oppose the original loan. This historic decision shows that environmentally concerned citizens working together in North and South can change the policies of the world's most powerful institutions."

\section{Saving the Narmada}

Opposition to the multi-million dollar system of dams planned for India's Narmada Valley has raged for years. The dams would submerge thousands of hectares of land and displace hundreds of thousands of indigenous peoples. FoE groups have long campaigned against the Sardar Sarovar dam in collaboration with Indian NGOs. FoE Japan's work on exposing the role of Japanese overseas development aid in Narmada catalysed the government's 1990 decision to halt funding 
for the project. And in 1992, over 20 FoE groups and affiliates joined hundreds of other NGOs in signing a letter (which appeared in The Financial Times, The Washington Post and The New York Times) to World Bank President Lewis Preston calling for the cancellation of funding for Sardar Sarovar. In 1993, after eight years of intense controversy, the Bank withdrew its US\$450 million loan for the project - succumbing to activist-generated environmental and social pressure for the first time!

\section{Arun III Damned}

Celebrations broke out in Nepal and reverberated around the globe with the World Bank's 1995 announcement of the cancellation of their US\$764 million loan for Arun III. The controversial hydro-electric dam planned for a remote part of the Himalayas had been the target of Nepalese and global environmental protests, and an issue of great concern to FoE groups.

Arun III was the first case for the World Bank's Inspection Panel, and the cancellation came just before the scheduled release of their report. Both Nepalese activist groups and the Bank now intend to advocate alternative energy sources for the country. "This is hopefully a sign of reality on the part of the Bank that large dams make no economic, environmental or social sense," said Patrick McCully of FoEI affiliate International Rivers Network.

\section{Planafloro Plan Flowers}

In June of 1995, 24 Brazilian NGOs, including the FoEI Amazonia Programme, submitted the first Latin American claim to the World Bank Inspection Panel for the Planafloro project under implementation in the Amazon state of Rondonia. Planafloro, which was intended to clean up the mess created by the Bank's disastrous Polonoroeste development project, has itself been full of problems. According to the claimants, the Bank violated several of its own rules during the implementation of the US\$160 million loan.

Ultimately, the Board of Directors asked the Panel only to monitor ongoing Bank improvements of the project rather than to perform a full inspection. Nonetheless, the request did lead to unprecedented and unexpected results, including the creation of dozens of extractive reserves, the reformulation of the project with the participation of local beneficiaries, and a new sense of urgency for the solution of other problems.

\section{Support for Sarawak}

Sarawak, home to the Penan and other tribal peoples, has been ravaged over the past two decades by the logging of ancient forests for short-term profits. Sahabat Alam Malaysia (FoE Malaysia) has long collaborated with these peoples in their battles to preserve their homelands, including participating in a series of non-violent blockades in an attempt to hinder logging activities.

In 1987, over 100 Malaysians, including the head of the FoE Sarawak office and two other FoE activists, were arrested under the Internal Security Act. At the same time, 42 blockading Penan and other tribes in Sarawak were arrested. FoE groups around the world reacted furiously to both waves of arrests, and lobbied their governments, pressured timber companies, and organised actions until all activists were finally released. Two of the FoE Malaysia activists were imprisoned for two years. The people of Sarawak acknowledged FoE support in a letter: "We thank everyone who thinks of us and helps us to solve our problems. We know there are many people in many countries who care for us even though they are far away. It is knowing that which keeps us alive." 


\section{FORESTS AND INDIGENOUS PEOPLE}

\section{Radio Amazonia}

"Hallo, hallo, this is the community of Agua Branca. Mr. Governor, could the state help us to sell our nuts next April?"

"Hallo, hallo, this is Governor João Capiberibe. Well, for sure, why don't you call us by radio in advance? Listen, my idea is that we could buy the nuts ourselves and improve school meals for the children."

Radio Amazonia, started by FoE Italy in 1991 as a project of FoEI's Amazonia programme, has installed a total of 93 radio stations in remote communities of the Amazon. In addition to providing forest inhabitants unprecedented opportunities to access local markets with their sustainable forest products, the radios also help the Council of Rubber Tappers and various indigenous associations to prevent invasions by illegal loggers and settlers. Local people have been trained to operate the solar-powered Radio Amazonia stations in what is now the largest non-governmental communications network in Latin America.

\section{Rubber Tappers to the Rescue in England}

In 1993 Chico Mendes' successor as President of the Brazilian Council of Rubber Tappers demonstrated 'empate' (meaning deadlock, a form of peaceful protest) thousands of kilometres from home. Atanagildo de Deus Matos and other rubber tappers, members of FoEI affiliate Grupo de Trabalho Amazônico, offered empate training to British citizens defending Oxleas Woods, a Site of Special Scientific Interest earmarked for a new road.

Giselda Castro of FoE Brazil helped the cause with her letter published in the British Daily Telegraph: "The struggle to save the rainforests in developing nations has certainly been assisted by campaigns in Western countries. But if Britain wrecks the last remnants of its natural heritage, why should we expect different behaviour from Brazil - a developing country with huge debts, whose efforts to protect its nature are often difficult to justify in the face of overwhelming human poverty?"

Thanks to a potent combination of local, national and global efforts, Oxleas Woods was saved from the bulldozers in 1993.

\section{Illegal Logging in Ghana}

During the 1980s, an enormous amount of deception, corruption, illegal practice and fraud was connected to Ghana's timber industry, resulting in the destruction of around 250 square kilometres of Ghana's tropical forest and the siphoning of millions of dollars from the country. Many of the involved companies were major recipients of aid and credit from multilateral and bilateral agencies. Since 1987, FoE Ghana has co-operated with FoE England, Wales and Northern Ireland (EWNI) and FoE Netherlands to investigate the damages and to implicate guilty European companies by generating negative publicity. These activities led to FoEI's current illegal logging project, which includes parallel cases in Cameroon, Paraguay and Brazil.

\section{Trees for Planes}

A coalition of Indonesian environmental groups, spearheaded by WALHI (FoE Indonesia) launched an unprecedented court challenge against President Suharto in 1994. The groups 
charged the Indonesian President of diverting funds allegedly intended for rainforest rehabilitation to the state-owned aircraft industry. Although the lawsuit failed, a FoE Indonesia spokesperson pointed out that "this was the first time that someone had the guts to sue the President." WALHI went on to sue the Ministry of Mining and Energy in 1995 for approving Freeport Indonesia's Environmental Impact Study for its enormous mines in Irian Jaya.

\section{AIR POLLUTION}

\section{Schiphol Campaign Goes Global}

Over the past few years, Milieudefensie (FoE Netherlands) has been battling the planned expansion of Amsterdam's Schiphol airport to accommodate millions of extra passengers. The campaign has catalysed a broad public debate which encompasses the environmental, social, economic and health effects of increased air traffic. 8,500 people have purchased plots of land in the path of the planned new runway, and a May 1995 demonstration at the airport drew approximately 10,000 people - the largest environmental protest in the Netherlands in over a decade.

The national momentum built up around Schiphol activities has blossomed into a pan-European campaign for the taxation of air traffic, in which many European FoE groups participate. And in 1995 , the campaign went global when FOE Netherlands filed a legal case on behalf of 28 Southern groups, including FOE organisations in Argentina, Benin, Brazil, Ghana, Togo, Sierra Leone and Uruguay. The claimants fear the environmental damage that a larger Schiphol will cause - specifically increased $\mathrm{C} 02$ outputs leading to global warming and the accelerated depletion of the ozone layer.

\section{Fixing the Ozone Hole}

Friends of the Earth has been trying to repair the ozone hole for over a decade. Following the adoption of the 1986 Montreal Protocol, which should lead to the phase-out of most ozonedepleting chemicals by 2000 , FoE groups used their international network to press for the ratification of the treaty worldwide. However, the Protocol's minimal cuts and relaxed timelines do not mean the end of our ozone worries, and FOE groups have continued to lobby for deeper, faster cuts and the ban of specific ozone-depleting substances such as methyl bromide.

For example, 11 European FoE groups took part in a day of action prior to the 1992 renegotiation of the Protocol in Copenhagen. Traditional FoE creativity ruled the day: for example FoE Denmark organised a parade of 50 people in penguin costumes; FoE Norway offered their Environment Minister a special suit that does not require drycleaning with CFCs; FoE Spain offered their Environment Secretary sunglasses and sun cream; and FoE Netherlands dropped banners with ozone-friendly text in several languages from a DuPont CFC production plant tower.

\section{Leaky Documents}

One contribution to the pressure which eventually led to the adoption of $\mathrm{CO}_{2}$ targets at the 1990 Bergen UNECE Ministerial Conference was a document leaked to FoEI Chair John Hontelez. The document, a message from the US State Department to its embassies, confirmed that the US would block progress on the adoption of a $\mathrm{CO}_{2}$ target in Bergen, and that Canada and the UK could also be counted on for resistance. The message, passed on to FoE England, Wales and Northern Ireland and then forwarded to FoE groups in Canada and the US, made front-page news 
in many countries. FoEl's prompt handling of the leak not only embarrassed the obstinate governments, but the resulting public scrutiny undoubtedly forced them into agreement as well.

\section{HEALTH AND TOXICS}

\section{Inspecting the Gulf}

A legacy of the Gulf War was one of the worst environmental crises ever to hit the planet. Millions of barrels of oil were spilled into the Gulf, and hundreds of oil wells were burned. In 1991, after groundwork had been laid by FoE US and FoE Italy, FoEI was officially invited to send a team of scientists - including specialists in air pollution, public health, desert ecology, oil pollution and wildlife protection - to Kuwait. Based on their report, FoEI prepared a set of environmental recommendations for the United Nations, the G-7, the European Commission and other governmental bodies. FoE US also used video footage from Kuwait to convince key members of the US Congress of the seriousness of the situation - effectively countering the Bush administration's claims of minor environmental impacts!

\section{Toxic Image Building}

In 1992, FoE US and FoE England, Wales and Northern Ireland released a survey on toxic releases from European and US chemical industries. Their research revealed that a few large European facilities were dumping greater quantities of some toxics into water than reported from the entire US industry put together. One culprit was the Dow Chemical plant in the Netherlands, which released 16,000 kilograms of benzene into the Westerschelde estuary in 1991 - compared with 11,300 kilograms from all 26,000 US facilities. These findings made headline news in the Netherlands, and according to Pim de Ruiter of FoE Netherlands, had a positive spin-off: "We had been working hard to emphasise the international character of Milieudefensie for some time, stressing the fact that environmental problems do not stop at our borders. At last our organisation was referred to in the media as the Dutch national member of FoEl. The bad news about the benzene release turned out to be a gigantic image-building operation for Milieudefensie!"

\section{Tracking the Karin B.}

In 1988, Andrew Lees (the late Campaigns Director of FoE England, Wales and Northern Ireland) and current EWNI Executive Director Charles Secrett travelled to Nigeria to expose the illegal dumping of 8,000 tonnes of European toxic waste in Koko, a tiny fishing port on the Niger Delta. The waste arrived on the Italian vessel Karin B., provoking FoE Italy's statement: "The Karin B. must return to Italy. Italian toxic wastes must be treated and disposed of in Italy." Lees continued to track the waste, however, and discovered that the toxic ship was heading towards Britain. According to journalist Geoffrey Lean, "The row that resulted from the revelation was probably the single most important turning point in Britain's policy on toxic waste." And, even more impressive, the resulting furore influenced the European Community's decision to ban the disposal of toxic waste in the Third World.

\section{SOS Clean Lomé}

When a general strike paralysed Togo at the end of 1992, garbage began to pile up all over the capital city of Lomé. FoE Togo, concerned about the spread of contagious disease, worked closely with FoEl and other NGOs to raise funds to clean up the city. The funds were used to purchase equipment ranging from sanitary gloves to wheelbarrows, and in June of 1993 
volunteers from FoE Togo, other environmental groups and local youth picked up 7025 tonnes of garbage. FoE Togo also collected something else - 150 new members from the Lomé area!

\section{INTERNATIONAL SOLIDARITY}

\section{Ecotopia Latinoamericana}

The Summer camp Ecotopia, organised by the youth branch of FoE Uruguay, has come to life every year since 1991. Young people active in Latin American environmental and social movements gather for two weeks for activities as far-ranging as peeling vegetables and creating solar-heated showers to discussing the effects of the North American Free Trade Agreement. At Ecotopia 1995, 40 young people from 14 countries gathered in Ecocomunidad, an ecological community outside of Montevideo. According to the late Ecotopia participant David Maradiaga Cruz of FoE Costa Rica, "The participants tend to think a lot and think alike, so we experience a better Ecotopia each year. We are talking about real structural change, and not just fixing holes."

\section{Sustainable Europe}

The Sustainable Europe Campaign unites 27 national FoE groups, 3 other NGOs and the German Wuppertal Institute in an unprecedented effort to identify strategies towards sustainability which take global equity into account. Dialogues with various sectors and national debates have been launched in 30 countries, and the European Union has shown its appreciation for the initiative by providing substantial financial support over a three-year period. A recent victory was the adoption of the 'environmental space' concept by the Danish government in 1995. Other groups have also enjoyed success: for example FoE Germany's national report sold thousands of copies when it first appeared, and FoE Italy's report can be found in Italian bookshops.

\section{CORPORATE ACCOUNTABILITY}

\section{Pineapple War}

Fields that once bore rice, corn, coffee, bananas, coconut and other fruit in South Cotabato, the Philippines, are now dry and barren. Once the source of livelihood for over 100 small farming families, they are now the site of Dole Philippines' large-scale pineapple plantations. In partnership with the affected farmers, the Legal Rights \& Natural Resources Centre (FoE Philippines) asked FoE groups for support in battling the pineapple giant, FoE Sweden included the Dole food corporation in its consumer awareness campaign Mudi Mums, and FoEI passed a resolution at its $1994 \mathrm{AGM}$ in support of the people of South Cotabato. FoE Philippines believes that "the international pressure generated has made Dole Philippines more cautious and perhaps sensitive to the effects of its operations."

\section{Freeing Nnimmo Bassey}

Actions, letters and faxes from all over the world were not enough to prevent the murder of Ken Saro-Wiwa and eight other environmental activists by the Nigerian government in November of 1995. Saro-Wiwa led the fight against Shell's operations in Ogoniland, and was demanding compensation for local populations and clean-up of the pollution caused by 30 years of oil operations in the region. FoE groups have campaigned against Shell for many years, for example demonstrating at Shell stations on international action days. 
When Nigerian environmentalist and human rights activist Nnimmo Bassey was arrested in June of 1996 as he was leaving the country to attend a West African FoE meeting in Ghana, many feared that he would meet with the same fate as Saro-Wiwa. FoE groups co-ordinated an urgent campaign to set Bassey free, and thankfully he was released after several weeks in prison. FoEI remains vigilant, however, and will continue to monitor the actions of Shell, other multinationals and governments closely.

\section{WATER}

\section{Horrors of Hidrovia}

Hidrovia, a plan by five Latin American Countries to deepen and straighten the Paraguay river for transport, is being contested by Rios Vivos, a coalition of 300 environmental groups in which FoE Paraguay, FoE Uruguay and FoEI affiliate International Rivers Network play a co-ordinating role. A multi-million dollar series of infrastructural projects, Hidrovia would allow cargocarrying ships to travel 3,300 kilometres up the Parana and Paraguay rivers. This would gravely affect the Pantanal, the world's largest wetland system, and could also instigate floods, drought and shrinking grasslands. Several indigenous peoples, some already close to extinction, would also be adversely affected by Hidrovia.

In late 1995, after several years of campaigning, the coalition met with limited success when its demands were met for public hearings, local participation and a delay in construction until the completion of an environmental impact assessment. Unfortunately, the first public participation meeting in mid-1996 was pronounced a failure by Rios Vivos. However, the coalition continues to take matters into its own hands, for example organising a 'Floating Seminar' on the Paraguay River for citizens of affected countries, North America and Europe. FoEI in the Ocean Waste dumped at sea appears to have had devastating effects upon marine life and upon human seafood consumers. Pressure over the years by environmental NGOs, including FoEI, has achieved a global moratorium on the dumping of radioactive waste, a ban on the incineration of industrial waste, and a possible ban on the dumping of industrial waste at sea. FoEI's suggestion to recover hazardous substances from the sea floor is still under discussion at the London Convention.

FoEl has also been very active against large-scale whaling, which in this century has destroyed most of the large species in the world's oceans. After more than a decade of work by FoEI and others, the International Whaling Commission (IWC) passed a historic moratorium on all commercial whaling in 1982.

"Next day we were sailing in slack winds through an ocean where the clear water was full of drifting black lumps of asphalt, seemingly never-ending... The Atlantic was no longer blue but grey-green and opaque, covered with dots of oil ranging from pin-head size to dimensions of the average sandwich. Plastic bottles floated among the waste. We might have been in a squalid city port... It became clear to all of us that mankind really was in the process of polluting its most vital well-spring, our planet's indispensable filtration plant, the ocean." From 'The Ra Expeditions' by Thor Heyerdahl, a FoEI Patron. 


\section{International Campaign Victories in 2003}

Source:

FoEI Annual Report 2003

\section{WTO Ministerial Collapses in Cancún}

Developing countries flexed their muscles at the September 2003 World Trade Organization talks in Cancún, standing up to rich countries and multinational corporations. Civil society, including social, environmental and peasant farmers' groups, celebrated when the meeting ground to a halt. Proposals on the table, which would have opened developing country markets to foreign investment and even more cheap agricultural imports, were overturned.

Some 40 Friends of the Earth campaigners from around the world were present in Cancun, working and demonstrating in coalition with other social movements including the Our World Is Not For Sale network and Vía Campesina. Friends of the Earth participated in memorial actions for Lee Kyung-Hae, the South Korean farmer who took his life in front of police barricades in Cancún in order to draw attention to the impact of neoliberal economic globalization on food production, livelihoods, and the environment.

\section{Another Trade Failure in the Americas}

Just eight weeks after the World Trade Organization's collapse in Cancun, trade ministers from most of the western hemisphere came to Miami for a key negotiating summit for the Free Trade Area of the Americas (FTAA/ALCA). A brutal police force - now accused of human rights violations by Amnesty International - tried to limit the free speech rights of thousands of protesters. But those same police could not prevent the negotiations inside, where Mercosur countries refused to make concessions on issues such as investment and services, from unraveling. Friends of the Earth activists from Latin America, the Caribbean and the United States came to Miami, but it was really the dozens of protests and citizen-sponsored plebiscites in Latin America during the run-up to the summit that led to today's shaky, watered-down FTAA. On the heels of Cancún, Miami was a reaffirmation of popular resistance to a biased and unsustainable trade agenda.

\section{Pushing the World Bank out of Oil and Mining}

In 2000, Friends of the Earth International Chair Ricardo Navarro publicly confronted World Bank President James Wolfensohn with the tragic impacts of the Bank's ongoing investments in oil, mining and gas. He spoke on behalf of Friends of the Earth International and the communities we work with that are impacted by Bank-funded projects like the ChadCameroon pipeline, the Yanacocha gold mine in Peru and the Baku-Ceyhan oil pipeline in the Caspian region. In response, the World Bank commissioned an independent review of its financing of oil, mining and gas projects. In November 2003, this Extractive Industries Review culminated in a report recommending that the Bank stop financing all coal and oil projects in developing countries, respect human rights, up its funding for renewable energy projects, and implement "free, prior and informed consent" for the communities and indigenous people that will be impacted by Bank projects. Although it remains to be seen whether these recommendations will be implemented, communities and campaigners now have increased leverage for halting destructive projects.

\section{Stopping up the Baku-Ceyhan Pipeline}


The planned Baku-Ceyhan pipeline is one of the most controversial projects in the world. When constructed, this US $\$ 3.5$ billion pipeline will carry oil from the Caspian Sea through Azerbaijan, Georgia and Turkey to the Mediterranean, wreaking environmental and social havoc along the way. Campaigning throughout 2003 resulted in severál stoppages to pipeline plans. Following a complaint by a coalition of human rights and environmental groups including Friends of the Earth, the European Union agreed to investigate alleged human rights abuses along the pipeline route. Furthermore, in early 2004 project consortium leader BP suffered an embarrassing setback with the postponement of the signing of a US\$150 million deal with the UK Export Credits Guarantee Department. And finally, a longstanding civil lawsuit against the company brought by Friends of the Earth Georgia and others to the courts alleging that BP pressured Georgia's environment minister to approve the pipeline route through a national park came to trial in early 2004 .

\section{Mangos over Mining in Tambogrande}

In December 2003, the Peruvian government terminated Manhattan Minerals' concession to develop the Tambogrande gold mine in Peru. In 2002, the people of Tambogrande had held a community-initiated referendum in which 98.65 percent voted against the mine. This destructive project, long a campaign focus of Friends of the Earth Peru and Friends of the Earth International, would have destroyed the sustainable agriculture, polluted the rivers, and displaced one-third of the population of the village of Tambogrande.

\section{Damning the Iceland Dam}

In July, following vigorous lobbying, cyberactions and a barrage of letters by a coalition including Friends of the Earth groups, the International Rivers Network and Icelandic groups, the European Investment Bank (EIB) announced that it would not finance the Kárahnjúkar Dam. The Icelandic government and Alcoa, the world's biggest aluminium company, plan to build a large dam and aluminum smelter in Europe's second-largest remaining wilderness area, damaging fish, seal, reindeer and pinkfooted goose habitats as well as rare vegetation and unique geological formations. Although the EIB will keep its hands off the dam, campaigners are now lobbying private banks not to fund this monstrosity.

\section{US Export-Import Bank Rejects Camisea Gas Project}

In August 2003, the US Export-Import Bank decided not to finance the Camisea gas project in Peru following intense local and international pressure from environmental and human rights groups including Friends of the Earth United States. Camisea is the most damaging project in the Amazon Basin, with gas extraction operations taking place in indigenous peoples' territories and a pipeline cutting through one of the world's most pristine rainforests. Campaigners hope that this rejection will send a signal to other funders that the project is financially, environmentally and socially risky.

\section{Dutch Bank Rejects EIB}

In July 2003, the socially responsible Dutch ASN Bank decided to withdraw its investments in European Investment Bank bonds in response to questions and information submitted by Friends of the Earth Netherlands, Friends of the Earth International and our affiliate members CEE Bankwatch and A SEED. In a press release announcing its decision, ASN stated: "It is inconceivable that a big financier like the EIB should lack an environmental policy, internal environmental expertise, or a mechanism of regulation. The projects it finances in areas such as 
infrastructure, oil production, mining, waste processing and dam building, have an enormously destructive impact. We reject the lack of sustainability."

\section{Bite Back: WTO Get Your Hands Off Our Food!}

More than 70 percent of EU citizens do not want genetically modified organisms (GMOs) in their food. However, George Bush and big biotech companies put consumer health and the environment at risk in 2003 by trying to use the World Trade Organization to force the EU and the rest of the world to accept genetically modified food and farming. In response, Friends of the Earth International and more than 350 other organizations - together representing 35 million citizen's worldwide - launched the "Bite Back" campaign. This initiative invites civil society around the world to submit Citizens' Objections to the WTO, demanding that the right to eat GMO-free food not be undermined and that the US complaint be dismissed. By the end of 2003 , more than 30,000 objections had been signed.

\section{Biosafety Protocol Becomes Law}

In September, Friends of the Earth International welcomed the Cartagena Protocol, the first treaty that seeks to protect the environment from the risks of genetically modified organisms (GMOs). Friends of the Earth, having lobbied for this important treaty for many years, celebrated the coming into force of the Protocol. Nonetheless, many issues are still pending, and we are calling for the immediate establishment of an effective liability mechanism under the Protocol to ensure that corporations are held financially responsible for damage they cause, for instance through contamination by genetically engineered crops.

\section{Socializing at the World Social Forum}

Friends of the Earth International strengthened existing alliances with Vía Campesina, the Our World is Not for Sale coalition, the World Rainforest Movement, Corporate Europe Observatory, the Water Justice campaign, and indigenous peoples' organizations at the January 2003 World Social Forum in Porto Alegre, Brazil. Together with other social movements and environmental NGOs, we co-organized seminars and workshops on water, forests, GMOs, food sovereignty, biodiversity and the impacts of trade and corporate misbehaviour on people and the environment.

\section{New Right-to-Know Pollution Treaty}

In January 2003, a new international law improving the public's right to know about the annual pollution output of individual industrial and intensive livestock sites was finalized. The United Nations treaty has so far been signed by 36 countries from Europe and Central Asia.

Environmental NGOs that took part in the two-year negotiations, including Friends of the Earth, welcomed the agreement. Although many toxic chemicals and radioactive pollutants are not covered by the protocol, the public nonetheless will have an important new pressure tool to reduce pollution levels. 
International Campaign Victories in 2004

Source:

FoEI Annual Report 2004

\section{GM-Free Europe Gathers Steam}

Friends of the Earth Europe's "GM Free Europe" campaign spread throughout 2004, with thousands of regions and subregions declaring themselves GMO-free (see www.foeeurope.org/GMOs/gmofree). Although Slovenia is the only entirely GM-free country, GMOs are not welcome in eight out of nine provinces in Austria and a huge chunk of Poland. Thanks to Friends of the Earth England, Wales and Northern Ireland's call for a GM- free Europe, more than 14 million people in the UK are now living in GM-free areas. In Germany, 12,000 farmers, most of them conventional, agreed not to grow GMOs on 430,000 hectares in more than 60 regions. In France, more than 1,000 mayors declared their municipalities GM-free; more than half of the 54 Greek prefectures banned GMOs; and over 500 Italian cities don't want genetically modified agriculture. Overall, seventy percent of European consumers have rejected genetically modified food, and many food retailers and manufacturers have pledged to source their products from GMO-free sources.

\section{Peruvian Mountain Can Keep its Gold}

In November, Minera Yanacocha, a unit of the US mining giant Newmont, cited local protests as the reason for its decision to stop exploring for gold on Peru's Mount Quilish. Friends of the Earth International and Friends of the Earth Peru have long supported local farmers struggling to protect their natural resources, particularly water, and pressured the World Bank's International Finance Corporation not to finance the mine.

\section{Climate Litigation Heating Up}

Friends of the Earth groups are involved in some of the world's hottest legal cases to combat climate change (see www.climatelaw.org). In Germany, for example, BUND/Friends of the Earth Germany launched a legal action in 2004 to force the German government to disclose its contributions towards fossil fuel projects through its export credit agency. Citing the 2003 floods in Argentina which killed more than 100 people and caused billions of dollars worth of damage, Friènds of the Earth Argentina successfully used Article 6 of the UN Framework Convention on Climate Change to reveal the failure of their government to adapt to climate change. Friends of the Earth Nepal petitioned the World Heritage Committee to place the Sagarmatha (Everest) National Park, where glaciers are threatened by the warming climate, on its World Heritage in Danger list. In the United States, Friends of the Earth and others launched a lawsuit against the US export credit agencies for funding fossil fuel projects without assessing their contribution to global warming, or their impact on the national environment as required under the National Environmental Policy Act.

\section{Biting Back: WTO Get Your Hands Off Our Food!}

In 2003, George Bush and big biotech companies put consumer health and the environment at risk by trying to use the World Trade Organization to force the EU and the rest of the world to accept genetically modified food and farming. In response, Friends of the Earth International and other organizations - together representing 48 million citizens worldwide - launched the "Bite Back" campaign, demanding that the US complaint be dismissed by gathering Citizens' objections. The first 100,000 Citizens' Objections, with signatories from 90 countries including 
Archbishop Desmond Tutu and French small farmers' leader Jose Bové, were handed over to the WTO in May 2004. Later in the year, the WTO panel decided to call in scientists, including several ecologists, to debate the safety of GM foods and crops. The move was a blow to the Bush Administration, which had attempted to stop any debate over scientific safety.

\section{New Targets for Sustainable Energy}

At the June intergovernmental conference on renewable energy in Germany, the World Bank Group, the European Bank for Reconstruction and Development and the European Investment Bank made new commitments to increase funding for renewable energy. The European Investment Bank announced an unexpected target for renewables lending of $50 \%$ of its financing for electricity generation in the EU - over 700 million Euro per year - by 2010 . Friends of the Earth groups advocated more financing for sustainable energy during the conference, handing out windmills to delegates.

\section{Russia Ratifies Kyoto Protocol}

In November 2004, the Russian parliament finally ratified the climate change treaty known as the Kyoto Protocol, paving the way for its entry into force in early 2005. Friends of the Earth and others had long campaigned for Russia's ratification, for example protesting outside Russian embassies around the world and sending e-cards to President Putin on his birthday asking him to take action.

\section{Recognizing Indigenous Rights}

In February 2004, our forest, trade and biodiversity campaigners teamed up at the Conference on Biological Diversity in Malaysia and fought successfully for the recognition of indigenous peoples' rights when protected areas are established, as well as indigenous rights in legal instruments dealing with biopiracy, the theft of genetic resources and traditional knowledge. Friends of the Earth International also generated attention by organizing a fake Biodiversity Auction to highlight the immoral sides of the increasing commercialization of biodiversity through biopiracy and biotrade. Items up for sale included Russian and Malaysian national parks, West African fish stocks, Peruvian potato varieties, the entire Colombian Amazon, a transgenic "tomato-fish", and even an indigenous person. Thanks to this and other campaigns, countries ultimately rejected the inclusion of ecological services in a tropical timber trade agreement that is currently being negotiated.

\section{EIB Drops Copper Mine in Laos}

Over the past years, Friends of the Earth groups have worked hard to stop public funding by the European Investment Bank (EIB) for a controversial copper mine in Laos. Although the EIB approved the loan in January 2004, it announced just a few months later that it was no longer involved in the problematic project as the mining company Oxiana had received a "better deal" somewhere else. This was an important victory in our campaign to phase out public funding for destructive large-scale mining projects.

\section{Quantifying Exxon's Climate Footprint}

In January, Friends of the Earth International released the landmark report "Exxon's Climate Footprint", which revealed that over the past 120 years the operations and burning of the products of oil giant Exxon Mobil and its predecessors have caused between 4.7 and $5.3 \%$ of all man-made 
carbon dioxide emissions across the globe. This is the first time a company's historic contribution to global climate change has ever been calculated, and should prove vital in paving the way for compensation claims against companies by victims of global warming.

\section{GMOs, Hunger and Food Aid}

Friends of the Earth International is working with groups in Latin America and Africa to detect the presence of GMOs in food aid, and supporting claims by citizens and NGOs that noncontaminated alternatives are available. In early 2004, FoE African groups together with over 50 African farmers' and environmental organizations criticized the pressure placed by the World Food Program and the US Administration upon Angola and Sudan for their refusal of GMOs as food aid, asserting that alternatives exist. Friends of the Earth was also a main organizer of the first international conference on hunger, food aid and GMOs, which took place in Mozambique in July and brought together over 100 people, mainly from the African continent.

\section{Shell Hit by Nigeria Spill Claim}

In August, the Nigerian parliament upheld a compensation claim of US $\$ 1.5$ billion against Shell made by the Ijaw tribe in the oil-rich Niger Delta. The company admitted that in 2002 alone there were 262 oil spill incidents in Nigeria, involving 2,700 tonnes of crude oil. Friends of the Earth Nigeria and Friends of the Earth International welcomed the ruling against Shell, which has long been the target of our campaigns in Nigeria and elsewhere. Shell, however, has thus far not accepted the compensation order, refusing to face up to its responsibilities to local communities.

\section{Monsanto Drops GM Wheat}

In May, Monsanto, the world's biggest seller of genetically modified (GM) seeds, quietly announced that it was stopping all further efforts to commercialize its controversial GM RoundUp Ready wheat. Monsanto had applied in the US and Canada to grow the GM wheat, but faced worldwide opposition from farmers, food manufacturers, consumers and environmental groups including Friends of the Earth. Friends of the Earth was particularly concerned that growing this GM wheat would increase the use of herbicides.

\section{Improved, More Transparent OPIC}

Following a sustained campaign by Friends of the Earth groups, the Board of Directors of the US Overseas Private Investment Corporation (OPIC) approved the creation of an Advisory and Accountability mechanism which will allow redress for all communities affected by its projects. Friends of the Earth International's campaign also resulted in a "no-go zone" policy in areas of high conservation value, and the integration of the World Commission on Dams' recommendations into OPIC's environmental standards.

\section{Global Law for GMOs}

Friends of the Earth GMO campaigners from many countries inflated an 8-meter high corn cob and launched a publication detailing a decade of failure in genetically modified crops at the February 2004 Biosafety Protocol meeting in Malaysia. The action and publication received worldwide media attention, and were part of a successful campaign to persuade governments to support strict GMO labelling laws and to launch negotiations for an international regime on liability for genetic contamination. 


\section{Reprieve for Sakhalin's Endangered Whales}

The Shell-led Sakhalin Energy company decided to postpone the construction of undersea pipelines in the Siberian Sakhalin II oil and gas project in mid-2004. Prior to the decision, the company had planned to lay the pipelines directly through the primary feeding habitat of the Western Grey Whale. Friends of the Earth groups and affiliate group CEE Bankwatch Network were part of a coalition generating pressure on the consortium and on potential international lenders, including the European Bank for Reconstruction and Development. Although the pipelines are only one part of a huge project, this was the first time that Shell acknowledged the impact of the project on the critically endangered whales.

\section{Pipeline Construction Stopped After Oil Company Violates Georgian Laws}

In July, the Georgian government suspended work on the Baku-Tbilisi-Ceyhan (BTC) pipeline after British oil giant BP decided to start construction in the ecologically vulnerable Borjomi region despite failing to obtain the necessary environmental permission. Furthermore, after continued pressure by Friends of the Earth groups and others, the World Bank Group and the European Bank for Reconstruction and Development agreed to a compensation scheme and monitoring plan for the project. The pipeline is a long-standing Friends of the Earth campaign due to its negative impacts on local communities and biodiversity, and its contribution to global climate change.

\section{World Bank Group Responds to NGO Boycott}

At the end of 2004, after months of civil society protest, the World Bank's International Finance Corporation (IFC) announced that it would significantly revise its consultation process on new social and environmental standards. The decision followed a three-month civil society boycott of IFC consultations in Brazil, Manila, London, Nairobi and Istanbul by Friends of the Earth and other groups from around the world.

\section{WTO Expansion Plans Scrapped}

In 1996, at the first ministerial meeting of the World Trade Organization, the European Union insisted that WTO member states begin discussions on liberalizing investment, competition, transparency in government procurement and trade facilitation. Since then, developing countries and civil society organizations around the world including Friends of the Earth International have staunchly opposed negotiations on these issues, which would greatly expand the WTO's power. In July 2004, following eight years of bitter wrangling, developing countries - with the full support of civil society networks such as Our World Is Not For Sale - finally succeeded in taking these issues off the WTO's negotiating agenda. 


\section{International Campaign Victories in $\mathbf{2 0 0 5}$}

Source:

FoEI Annual Report 2005

\section{GMO Opposition on the Rise in Central America}

Friends of the Earth groups and allies in Central America achieved a major victory in their campaign against the introduction of Genetically Modified Organisms (GMOs) in 2005. For over a year, activists in Nicaragua, Costa Rica, El Salvador, Guatemala and Honduras united within the Central American Biodiversity Alliance monitored the entrance of GMOs via food aid and commercial imports. They found Starlink, a GM maize variety unfit for human consumption, in food aid intended for children in Guatemala, as well as many other unauthorized GMOs elsewhere. Friends of the Earth International assisted in the public denunciation of these illegal GMOs, resulting in a resolution by the Central American Council of Human Rights calling the introduction of GMOs in the region a human rights violation. The Central American Parliament called for increasing controls over food aid and for biosafety legislation, and several biosafety laws were subsequently drafted in Honduras, Guatemala, Costa Rica, and Nicaragua in 2005. Guatemala also ratified the Cartagena Protocol after intensive lobbying by civil society. In addition, local opposition continued to grow in Costa Rica, and two municipalities were declared GMO free in 2005.

\section{No More Gas Flaring in Niger Delta Community}

On November 14th, the Federal High Court of Nigeria ordered that gas flaring must stop in the Niger Delta Iwherekan community as it violated guaranteed constitutional rights to life and dignity. This was the outcome of a lawsuit filed in June by communities from across the Niger Delta, with the support of Friends of the Earth Nigeria and the FoEI-based Climate Justice Program. In December, contempt of court proceedings were started against Shell and the Nigerian National Petroleum Corporation for failing to comply with the court order.

\section{Prying the WTO's Hands Off Our Natural Environment}

Following a Friends of the Earth Europe hearing in the European Parliament organized jointly with Women in Development Europe, Friends of the Earth succeeded in persuading the European Commission to change its position regarding the ongoing negotiations to completely liberalize the forests, fisheries, and gems and precious metals sectors. Shortly before December's World Trade Organization meeting in Hong Kong, the Commission explicitly stated that it does not support full liberalization in these sectors, as it would have devastating impacts on biodiversity and poverty in many areas of the world, and particularly for the 60 million indigenous people and 40 million smallscale fisherfolk who depend upon these resources for their survival.

\section{Loan for Papua New.Guinea Palm Oil Plantation Called Off}

An Asian Development Bank (ADB) loan to the government of Papua New Guinea for a largescale oil palm monoculture project was cancelled in 2005 thanks to campaigning by Friends of the Earth. The ADB has a reputation for funding large-scale monoculture cash crop projects under the guise of "poverty alleviation" that have had socially and environmentally damaging impacts. As a result, Friends of the Earth groups are campaigning with local communities and allies in Asia, and in increasingly in Latin America, against the use of public funds for these environmentally and socially destructive plantations. 


\section{Bringing the Climate Negotiations to Life}

The December UN climate negotiations in Montreal provided much-needed official impetus to the global effort to stop dangerous climate change, giving campaigners around the world something to celebrate. This was the first meeting since the Kyoto Protocol entered into force, and governments succeeded in launching a discussion on how to proceed when the first phase of the Protocol ends in 2012. Friends of the Earth has campaigned for this international climate treaty since initial discussions began in 1990. Friends of the Earth created a colorful 60-metre long mosaic called 'The World Can't Wait' outside the negotiation center. The mosaic was made up of 3,000 individual pictures and messages in different languages demanding action on climate change. It was the product of national painting sessions and actions by Friends of the Earth groups in 18 European countries.

\section{Big Noise at Shell Annual Shareḥolders Meetings}

At the June 2005 Shell annual meeting, simultaneously in London and the Hague, a number of fenceline communities and Friends of the Earth groups from the UK, the Netherlands, South Africa and Nigeria attended as shareholders and called upon Shell to clean up its act. In London, activists were expelled as they uncovered their (S)HELL t-shirts and shouted 'Shell is Hell!'. In the Hague, questions about the impact of Shell's operations on the environment and neighboring communities went on for two hours. Friends of the Earth South Africa offered the Corpse Award, which had recently been granted to Shell and BP's polluting refinery in Durban, South Africa, to Shell Chief Executive Jeroen van der Veer in person. Following the event, van der Veer agreed to a meeting with the communities to discuss their grievances.

\section{Pan-European Public Participation on GMO Decisions}

After four years of intense and polarized discussions, the Meeting of the Parties to the UN Aarhus Convention agreed in May to grant citizens in Europe, the Caucasus and Central Asia the right to participate on decisions related to Genetically Modified Organisms (GMOs). This will prevent the introduction of GMOs in these areas without public scrutiny and adequate information.

Friends of the Earth International, working with the Ecoforum coalition, had actively campaigned since 2001 to improve the rights of the citizens of the Pan-European region on this issue.

\section{Slowing Down Oil, Mining and Gas Investments}

Friends of the Earth International's campaign for a phase-out of public funding for destructive fossil fuel and mining projects was still going strong in 2005. West African groups are united in their stance against the West African Gas Pipeline, as it may worsen the Niger Delta crisis and will do little to stop gas flaring. This may have contributed to the European Investment Bank's hesitation to support the project. Similarly, campaigns on the Sakhalin II oil and gas project in the Russian Far East, which poses a grave threat to the last remaining grey whales, have forced the European Bank for Reconstruction and Development to put financing for the project on hold. These small victories mean a lot for the people on the ground!

\section{Million Tell WTO: Take Your Hands Off Our Food!}

Campaigners delivered a petition, signed by 135,000 citizens from 100 countries and over 740 organizations representing 60 million people, to WTO chief Pascal Lamy at the December Ministerial meeting in Hong Kong. The petition asks the WTO not to undermine the right of 
individual countries to take appropriate steps to protect their farmland, environment and consumers from the risks posed by genetically modified foods and crops. Friends of the Earth Chair Meena Raman, French Farmer José Bové and Indian ecologist Vandana Shiva were among those delivering the petition.

\section{Cutting Down Genetically-Modified Trees}

At the December meeting of the scientific advisory body of the Convention on Biodiversity in Montreal, Friends of the Earth International organized a successful campaign to raise awareness about the risks of genetically-modified trees, which are being promoted as potential carbon sinks. This led to the scientific body requesting an official report on the possible impacts of GM trees to be presented to the Biodiversity Convention meeting in March 2006.

\section{European Investment Bank Reacts to Exposure}

Friends of the Earth International and our allies continued to shine the light on the secretive European Investment Bank (EIB) in 2005. We launched a brand new web site revealing all EIB projects over the past ten years, www.eibprojects.org. After the launch of the site, the EIB announced that it was setting up an information disclosure policy, a success that can be chalked up to years of pressure by civil society.

\section{Saving the Himalayas}

In July, UNESCO established an expert working group to discuss the threat that climate change poses to some of the most important World Heritage Sites around the world. This unprecedented move resulted from the pressure applied by Friends of the Earth Nepal, Friends of the Earth International and others for the protection of World Heritage Sites including Mount Everest, the Peruvian Andes, and coral on the Belize and Great Barrier Reefs.

\section{Banning GM Foods and Crops in Europe}

Throughout Europe, 172 regions and over 4,500 local government and smaller areas have declared themselves GM-Free Zones. Opinion polls in the EU consistently show that $70-80 \%$ of citizens are opposed to GMOs. Throughout 2005, Friends of the Earth Europe called on EU Environment Ministers to allow European countries to ban GM foods and crops, similar to Switzerland's ban of November 2005 .

\section{Building Alliances to Protect Forest Ecosystems}

Friends of the Earth International believes that environmental issues are, in essence, social and political matters, and that we must build up common positions and make alliances in order to defend forests and the people that depend upon them. To this end, the main success of Friends of the Earth International's forest program in 2005 was the building and nurturing of the social movement that protects the cultural and biological diversity of forest ecosystems around the world. Throughout the year, we raised awareness and forged common positions on issues including community forest governance, market-based mechanisms, biofuels, destructive logging, expansion of monocoltures and land conversion, collective rights, and forests and climate change. Our partners include the World Rainforest Movement, Via Campesina, the Landless Rural Workers' Movement, the Global Forest Coalition, and indigenous and environmental organizations. 


\section{Exposing the True Face of the World Bank's IFC}

The World Bank's International Finance Corporation (IFC) decided to revise all of its social and environmental policies in 2005 , proposing to adopt non-binding weakened standards for corporations that receive funding. When it became clear that consultations with civil society would be extremely rushed and non-transparent, Friends of the Earth International launched a worldwide boycott of the official procedure and voiced concerns and proposals through alternative channels. Member groups around the world asked their governments to pressure the IFC to protect the rights of people and the environment rather than listening to industry. After the IFC was confronted with a walk out in Brazil, protests in Manila, an empty consultation room in London and various damning civil society statements, it was forced to improve its review process. Unfortunately, the results were still disappointing: the new lending standards are weak and pose a real threat to communities and the environment. 


\section{APPENDIX B: Greenpeace Campaigns}

This chronology of Greenpeace's campaigns is a record of protest actions Greenpeace carried out around the world to bring environmental problems to public attention. It shows important stages in the organization's international campaigning, but by no means all its many thousands of actions across the world. Nor does it include the countless tough negotiations with politicians and industrialists, the perseverance in political committees and at political conventions, and the costly research and publication of scientific studies that are an integral part of any Greenpeace campaign.

\section{Sources:}

1971 - 2001: Boettger, C. and F. Hamdan (2001). Greenpeace: Changing the World. Steinfurt, Germany, Druckhaus Tecklenbor

2002 - 2006: http://www.greenpeace.org/international/about/victories

$1969-1970$

A handful of anti-war protestors and environmentalists join forces in 1970 in the Don't Make a Wave Committee in Vancouver, Canada. Its aim is to prevent the nuclear testing the USA plans to carry out on the island of Amchitka off Alaska.

\section{1}

The Don't Make A Wave Committee charters the cutter Phyllis Cormack, which leaves port on 15 September under the name Greenpeace, headed for Alaska on a voyage of protest. On the way the ship is impounded by US coastguards. The activists nevertheless achieve their aim. Their protest draws the attention of the North American media to the resistance against the nuclear tests. Four months later, the US atomic energy commission announces the series of tests will be cancelled.

\section{2}

French nuclear tests in the South Pacific unleash protests across the world. After making preparations with Greenpeace people in Canada, a five-man crew led by David McTaggart sets out from New Zealand on his yacht Vega in May for the testing area at Mururoa atoll. A French minesweeper rams the Vega in international waters, ending the protest action.

\section{3}

In the summer the Vega, accompanied by other ships, sets off on its second voyage to Mururoa. The yacht is boarded by French military forces, and crew members David McTaggart and Nigel Ingram are beaten up. The incident causes outrage all over the world. In November the French government announces that it will only carry out further nuclear testing underground.

\section{4}

While McTaggart is suing for damages against the French navy in France, a group of people gather in Vancouver for "Project Ahab", a project to protect whales. They include Bob Hunter, one of those who went on the Amchitka expedition three years earlier, and whale expert Paul Spong. The group prepares an anti-whaling campaign.

\section{5}

Greenpeace launches its first campaign to protect whales with an expedition against the Soviet whaling fleet off the Californian coast. The activists aim to sail their dinghies into the harpoon firing lines. In April the Phyllis Cormack and the Vega set sail from Vancouver with a photographer and two professionals with cameras on board. The first confrontation with a Russian whaling vessel 
takes place in June. Films and photos of the encounter are published in numerous countries around the world.

\section{6}

Greenpeace begins a campaign to protect seals, with protest actions against the slaughtering of baby seals in Newfoundland. During the whaling season Greenpeace again goes into action against Soviet whalers with the James Bay. About 100 whales are saved directly from being killed, and at least another 1,300 saved because whalers are deterred from visiting their hunting grounds.

1977

The French actress Brigitte Bardot supports the seal campaign, which becomes a headline topic in the media throughout the world. Greenpeace goes into action against Soviet whaling vessels in the North Pacific during the summer whaling season. Greenpeace joins the protests of Australian anti-whaling demonstrators at the conference of the International Whaling Commission (IWC) in Canberra, Australia. Activists' inflatables obstruct the whalers on several occasions. Public opinion in Australia turns against whaling. Two years later the last Australian whaling station is closed down. Greenpeace is accorded observer status at the IWC.

\section{8}

Greenpeace becomes active in Europe with actions against Icelandic whalers, and the organisation starts a campaign against the dumping of nuclear waste in the Atlantic. In May the Rainbow Warrior, Greenpeace's new flagship, sails into Icelandic whaling areas. The crew successfully hinders whaling activities, and makes whaling a topic of discussion in Iceland. Late that summer the Rainbow Warrior goes into action against whalers off the Spanish coast. After its Iceland expedition Greenpeace hinders a British freighter from dumping 2,000 tonnes of radioactive waste into the Atlantic southwest of Britain's Cornish coast. In October the organisation takes action against seal hunters off the Orkney Islands, Britain. Public interest in Greenpeace's activities has meanwhile grown, and journalists accompany the Rainbow Warrior on its voyage. The British government calls off the seal hunt. Greenpeace in June takes part in mass protests in the USA against the construction of a nuclear power plant in Seabrook, New Hampshire.

\section{9}

Greenpeace protests against nuclear-powered submarines, shipments of nuclear waste and nuclear power plants in the USA and Canada. In June Greenpeace activists make a parachute jump above the Darlington nuclear power plant on Lake Ontario in Canada to protest against the construction of what at that time was the largest nuclear plant in the world. Using the Rainbow Warrior, Greenpeace again manages to protect whales from being killed by Icelandic whalers in April and August.

\section{0}

Greenpeace sets its sights on an environmental problem that will remain a major focus of its activities in years to come: the dumping of toxic waste at sea. In May Greenpeace prevents two freighters loaded with Bayer company chemical waste from leaving port in Rotterdam. The threeday-long blockade draws public attention to the dumping of acid waste at sea. Greenpeace's first protest in Germany takes place in October, as activists in Norderham hinder a ship aiming to dump waste. In Cherbourg, France, and then in Barrow-in-Furness in Britain, the Rainbow Warrior in February prevents nuclear shipments being made to the reprocessing plants at La Hague and Sellafield. The actions are a protest by Greenpeace against the transport of spent fuel rods from Japanese nuclear power plants. Greenpeace takes part in protests in the USA and. 
Canada against nuclear shipments and the construction of nuclear power plants. In Japan activists in February and November prevent the killing of hundreds of dolphins by taking down the nets in which they have been kept captive. In June the Rainbow Warrior obstructs Spanish whalers and is * impounded by the Spanish navy. It is detained at the navy base of El Ferreol. Five months later the Rainbow Warrior causes a stir as it manages to get away.

\section{1}

In March Greenpeace activists in Canada spray 200 baby seals with harmless green paint, making their fur worthless for seal hunters. Shortly afterwards the European Parliament recommends imports of seal products be banned. In June two Greenpeace activists scale the chimney of the Boehringer chemical factory in Hamburg, which was producing pesticides. In 1984 Boehringer is forced to close down its factory after a court ruling that it is discharging too much dioxin. Greenpeace becomes active against oil pollution of the world's seas and oceans. It protests off the northeast coast of the USA against oil drilling planned there, and in Puget Sound near Seattle against supertankers sailing on routes in waters near the coast. Greenpeace's new ship the Sirius prevents British nuclear waste being dumped in the Atlantic in July after a fierce confrontation with the freighter Gem. In October the Vega undertakes its third protest expedition to the Mururoa atoll because of renewed French nuclear testing.

\section{2}

Greenpeace turns acid rain into a campaign issue. In February activists climb factory and power plant chimneys in the USA to draw attention to sulphur dioxide emissions causing acid rain. At the beginning of the year, the Rainbow Warrior goes into action off the coast of New Jersey in the USA to protest against the dumping of chemical waste. In March the Sirius joins a demonstration by fishermen on the river Elbe outside a Dow Chemical factory near Hamburg. The fishermen had not been allowed to sell their catches because of pollution by mercury and chlorinated hydrocarbons. Late that summer actions are carried out on the high seas against ships intending to dump British, Dutch, Belgian and Swiss nuclear waste into the Atlantic off the northwest coast of Spain. The Dutch government backs down and announces it will stop dumping nuclear waste. In June the Sirius arrives in Kronstadt in the Soviet Union to protest against nuclear testing. The crew is expelled from the country after distributing leaflets. A protest action in March to save baby seals in Newfoundland is stopped by the Canadian police, and those participating are arrested. The European Community at the end of the year imposes a ban on imports of baby seal fur. At its July meeting in Brighton in England the International Whaling Commission adopts a moratorium on whaling that goes into force in 1986 and prohibits all commercial whaling - a historic success for the anti-whaling campaign.

\section{3}

Starting in March, Greenpeace carries out a whole series of actions in Britain, Germany, Belgium, Norway and the USA against dischargers of dilute sulphuric acid mixtures into rivers and seas. The Sirius and another 40 fishing boats are ready near La Havre in June when freighters carrying toxic waste are about to dump cadmium sludge off the French coast. Greenpeace inflatables in June disrupt the actions of a Japanese fishing fleet preparing to cast driftnets in US waters near the Aleutian Islands - a vast number of seabirds, seals and small whales have perished in the nets. In July the Rainbow Warrior enters Soviet waters to document illegal whaling. The members of the expedition enter Soviet territory and are arrested. The protest action draws more international attention than any other Greenpeace action hitherto. In April, four Greenpeace activists gain access to the US nuclear weapons testing range in Nevada to protest against continued testing there. Greenpeace activists in August make a flight in a hot-air balloon from West Berlin to protest against nuclear testing by the four superpowers; they land in East Germany. The London 
Dumping Convention in February decides on a Ten-year moratorium on the dumping of nuclear waste.

\section{4}

The Antarctic campaign begins. Its goal is a world park to protect Antarctica from being exploited for minerals or suffering environmental damage. In October a ship due to transport construction material for a French landing strip in Antarctica is occupied by Greenpeace activists, first in Le Havre, France, and later in Hobart, Tasmania. From February onwards Greenpeace carries out protest actions against the dumping of dilute acid in several countries including the USA, Canada and Germany In Nordenham in Germany the Sirius and over 50 German and Danish fishing trawlers block the Kronos Titan waste freighter. In North America Greenpeace activists block effluent pipes at several locations including the Monsanto works at Boston, Massachusetts, Chevron in Richmond, California, and the Tioxide of Canada works in Tracy, Quebec. In April Greenpeace occupies the chimneys of coal-fired power plants in several European countries to draw attention to the dangers of acid rain. Greenpeace activists in August scale the highest chimney in Europe, at the Buschhaus power plant in West Germany, demanding that the plant be not allowed to operate until desulphurization has been installed. There are demonstrations against nuclear testing before Big Ben in London in June, and at the Statue of Liberty in New York in August. In July Greenpeace activists joined before local environmentalists prevent the uranium freighter Clydebank from being loaded in Darwin harbor in Australia.

\section{5}

In May the Rainbow Warrior helps 300 inhabitants of the Pacific island of Rongelap to move to another island after their home is contaminated by French nuclear tests. Shortly before it is about to leave Auckland, New Zealand, to protest against French nuclear tests at the Mururoa atoll, the Rainbow Warrior is in July sunk by a bomb attack by the French secret service. Greenpeace photographer Fernando Pereira drowns in his cabin. In North America, Greenpeace starts its "Great Lakes Campaign" against Canadian and US companies discharging their chemical waste into the Great Lakes. "The rivers are drowning in filth" is the slogan of Greenpeace's rivers campaign in Europe, which starts up this year. During the summer the Beluga travels up the Rhine between Rotterdam and Basel, taking samples and blocking waste outlets. In Britain Greenpeace conducts actions against Tioxide UK Ltd, which is notorious for ignoring European Community environmental regulations. In March activists climb a chimney at the factory and seal a waste pipeline in the River Humber. Greenpeace activists in the French harbour of SaintNazaire in February block the Essi Flora, a ship transporting material for leaded petrol. The protest is part of a campaign for lead-free petrol and catalytic converters in motor vehicles begun by Greenpeace the year before. Working with local people and volunteers, Greenpeace starts a project to protect endangered leatherback turtles in French Guiana. Greenpeace had the previous year begun a campaign to stop the destruction of turtles' habitats and illegal trade in them in several Caribbean countries and the USA and Greece.

\section{6}

The worst accident to date in the history of the nuclear power industry occurs on 26 April 1986 at the nuclear power plant at Chernobyl in the Ukraine. People are killed and many suffer serious damage to their health. A huge area is radioactively contaminated for decades. The disaster leads Greenpeace to step up its activities against nuclear power in the years to follow. In support of its message "solar power, not plutonium", Greenpeace in November uses trucks to block access to the nuclear reprocessing plant planned at Wackersdorf in Germany Fourteen activists in April gain entry to the US testing site in Nevada, and for two days prevent a nuclear test from being conducted. Greenpeace's campaign against the pollution of rivers and lakes by chlorine bleach 
effluent from the pulp and paper industry begins in May and June with actions in Sweden and Austria. Several actions are carried out at the end of the year at companies polluting the river Rhine. In Basel, Switzerland, climbers occupy a Ciba-Geigy chimney, while at Leverkusen in Germany activists lower themselves from the Rhine bridge to protest against river pollution by the Bayer corporation. In September Greenpeace activists from West Germany, supported by numerous sympathisers from East Germany, dump a hundredweight of salt distilled from the Werra and Weser rivers in front of the East German Council of Ministers' building in East Berlin. The Sirius undertakes an extended tour of the Mediterranean from May to August, providing the public with information and performing actions. The actions are against freighters carrying nuclear and chemical waste, discharges of industrial effluent and illegal driftnetting. In the biggest ever Greenpeace action in the UK until that time, activists from several countries in November gain access to a coal-fired power plant at Ferrybridge in Yorkshire to protest against air pollution. In May Greenpeace's new campaign ship, the Moby Dick, leaves Hamburg for Norway Until mid July the crew successfully disrupt several Norwegian whaling operations. The IWC moratorium on commercial whaling comes into force.

\section{7}

On the second anniversary of the French secret service sinking of the Rainbow Warrior, Greenpeace starts a campaign in July for nuclear-free seas. In Sydney Greenpeace members climb the highest tower in the city, and in Auckland activists descend on ropes from the harbour bridge. In January over a thousand demonstrators protest at the Nevada testing site against a US nuclear test. Greenpeace penetrates the testing zone in a balloon. In January the MV Greenpeace sets out from New Zealand on an expedition to Antarctica. The crew sets up the first non-government Antarctic station. Greenpeace in April starts up a reforestation project in the canton of Graubunden in the Swiss mountains. Using the Trinity hot-air balloon, in summer Greenpeace documents damage done in Britain to forests, lakes and historic buildings by acid rain. In the spring the Beluga travels along the coast of southern Sweden and across Swedish lakes to point to the damage caused by untreated industrial effluent. In a series of actions beginning in August, the Sirius prevents the Vesta and Vulcanus II from burning toxic waste in the North Sea. Over 30 Danish fishing trawlers take part in the confrontation in October. Using the slogan, "No more Chernobyls - We want a nuclear-free future", Greenpeace in April demonstrates against nuclear power plants in Czechoslovakia in Wenceslas Square in Prague. 50,000 schoolchildren in the Netherlands take part in a schools campaign organised by Greenpeace and television for schools. The campaign works on local environmental projects.

\section{8}

The Beluga sets off in May on a six-month tour of North American rivers and the Great Lakes. Dischargers and corporations responsible are publicly exposed by protest actions and water samples taken. Greenpeace's "laboratory bus" starts a 3,000-mile tour along the Baltic coast at the beginning of May to draw attention to marine pollution. In the German harbour of Nordenham Greenpeace blocks the freighter Kronos and its load of dilute acid at the end of May On 31 December 1988 the firms involved stop dumping dilute acid in the North Sea. In the Baltic, Greenpeace's nuclear-free seas campaign as of April draws attention to British and Soviet warships with nuclear weapons on board. In July. Greenpeace frogmen holding on to buoys prevent the US guided missile destroyer Conyngham from entering port at Alborg in Denmark. The Sirius and its inflatables in June hinder the nuclear-powered, nuclear-armed US aircraft carrier Dwight D Eisenhower as it tries to enter the "nuclear-weapon-free zone" at Palma-de Mallorca in the Mediterranean. A boycott of Icelandic fish products in several countries moves the Icelandic government to abandon whaling. 


\section{9}

Greenpeace in January carries out protest actions in Antarctica against the construction of a French landing strip. The United Nations passes a majority vote in November in favour of the Antarctic World Park called for by Greenpeace. In March the supertanker Exxon Valdez collides with a reef off the coast of Alaska, and over 40 million litres of crude oil escape. Greenpeace helps with the clean-up operation and documents the disaster. In May activists penetrate the factory premises of the DuPont chemical giant in Luxembourg to protest against the use of carcinogenic chlorinated hydrocarbons. In July, 250 Greenpeace activists demanding an end to CFC production occupy Hoechst factory premises in Frankfurt. In September Greenpeace demonstrates in Argentina against planned waste incineration plants in which toxic waste imported from the USA and Europe was to be burned. Greenpeace in November blocks the Council of Ministers building in Brussels to protest against the planned authorisation of pesticides hazardous to groundwater. In Germany, Greenpeace carries out actions against ships carrying nuclear weapons and powered by nuclear fuel. In September the Sirius goes into action against the Soviet nuclear fleet in the Mediterranean.

\section{0}

In January, the Rainbow Warrior prevents Japanese and Taiwanese fishing vessels in the Tasman Sea from setting out their driftnets, which are miles in length. Japan announces during the year that it will end driftnet fishing in the South Pacific. In a series of actions against chlorine bleaching, activists block delivery of chlorine to paper factories and plug effluent pipelines in the Baltic Sea, along the Canadian west coast, and in Belgium and Spain. Greenpeace in April blocks the entrance to three DuPont factories in the USA, DuPont being the world's largest producer of CFC gases, which damage the earth's ozone layers. Actions in Britain are directed at ICI, the largest CFC manufacturer there. In Germany, Greenpeace puts up 1,700 billboard posters that display the message "Everyone is talking about the climate. We are ruining it" above the photos of chemical industry bosses. A year later Hoechst announces it will phase out its CFC production. Supported by local environment groups, Greenpeace in the first six months of the year runs a campaign against the discharge of industrial effluent into the sea along Australia's southern and eastern coasts. The Beluga leaves Hamburg in April to start a tour along the Elbe river to the Czech border. The tour, which lasts several weeks, protests against river polluters in East and West. Greenpeace carries out a series of actions against nuclear shipments to the reprocessing facilities in La Hague and Sellafield. Actions take place in the French harbour of Dunkirk and at nuclear power plants in Switzerland and Germany. During the summer Greenpeace conducts actions for nuclear free seas. Actions take place at many ports around the world, including Yokosuka in Japan, Gothenborg in Sweden, and Portland, Oregon, in the USA. The MV Greenpeace in October sails to the Arctic Ocean to protest against Russian nuclear testing on Novaya Zemlya. Crew members are able to land and measure high levels of radioactivity A Greenpeace action, its slogan "Life is not patentable", is carried out in October when 20 activists demonstrate against patents on animal and plant life at a GATT (General Agreement on Tariffs and Trade) conference in Geneva.

\section{1}

Greenpeace expands its international campaign against the chlorine chemical industry Highlights of the campaign are actions against PVC manufacturers in Belgium, Switzerland, Italy, Spain and Germany. The Moby Dick tours the Great Lakes of North America from July until September. The tour begins after activists in Cornwall, Canada, block the entrance to a paper factory discharging effluent contaminated with dioxins. "Das Plagiat", or "plagiarism", closely modeled on the German weekly "Der Spiegel", is published in March. "Das Plagiat" is the first magazine in the world to be printed on chlorine-free printing paper. Greenpeace's first "International Waste Trade" dossier is published in February and is followed by many reports on different countries. 
These are a source of information for police, authorities and journalists in exposing international trade in toxic wastes. Activists occupy an oil shipping facility near Thessalonika, Greece, in protest against pollution of the Saronic Gulf by oil refineries. Greenpeace staff in many countries including the USA, Britain and Germany in January participate in demonstrations against the threatening war in the Gulf. After the conflict ends, Greenpeace documents the ecological effects of the war on the region. In October, the 26 voting members of the Antarctic Treaty sign an agreement to protect Antarctica. This agreement goes into force in 1998 and bans mining for 50 years. Mission accomplished: Greenpeace dismantles its Antarctic station.

\section{2}

Greenpeace actions in March target oil exploration off Australia's southeast coast to protect the natural habitat of whales. The United Nations conference on environment and development is held in Rio de Janeiro in June. Greenpeace calls for measures to ensure the conference produces more than just statements of intent. A few days before the summit, the Rainbow Warrior blocks the Rio harbour facilities of Aracruz, a Brazilian pulp producer that has destroyed large sections of rainforest. Greenfreeze, the world's first refrigerator that does not use ozone-depleting CFCs or climate-damaging HFCs, is ready for mass production. Environmentally-friendly gas technology, co-developed and promoted by Greenpeace, will be adopted in many countries in years to come. Sailing to protest against French nuclear testing, the Rainbow Warrior is in March seized by the French navy off Mururoa in the Pacific. Shortly afterward, the French government declares a moratorium on the nuclear testing. Greenpeace in. June carries out a series of protests against the nuclear waste factory at Sellafield, Britain. A solidarity concert against Sellafield takes place in Manchester with the rock band U2. Greenpeace's ship the Solo in October sails on a documenting expedition to the Kara Sea, where the Soviet navy has dumped several nuclear reactors from decommissioned submarines off the island of Novaya Zemlya. The Russian navy impounds the Solo and tows it to Murmansk. In October over 100 activists chain themselves to the iron gates of the La Hague reprocessing plant in protest against the shipment of 1.7 tonnes of plutonium to Japan. The Solo subsequently pursues the freighter Akatsuki Maru on its way to Japan, and draws attention to the dangers of transporting nuclear waste.

\section{3}

The London Dumping Convention permanently bans the disposal of industrial and radioactive waste at sea. It transforms the moratorium on nuclear waste dumping, valid since 1983, into a definitive ban. This does not affect the discharge of radioactive waste from land-based sites into the sea. A number of Greenpeace actions and publications continue to draw attention to the radioactive contamination of the Irish Sea near Sellafield and the English Channel near La Hague. Greenpeace finds leaking barrels and boxes of outdated pesticides that German companies have disposed of illegally in Romania. Activists secure and then return large amounts of the toxic waste to Germany in March. Greenpeace carries out a series of protests against the chlorine chemicals industry from March to November. Actions are directed at PVC producers in several European countries, among them Solvay in Belgium and Switzerland, and EniChem in Italy. Greenpeace begins to promote the CFC-free and HFC-free Greenfreeze refrigerator in China and Japan, notably at the household goods trade fair in Beijing in November. From June until November, Greenpeace protests and erects blockades against clearcutting in the ancient forests of Clayoquot Sound in British Columbia, Canada, after the provincial government opens two-thirds of the area for logging. Two hundred Greenpeace activists in November occupy a former salt mine near Morsleben in Germany in which the federal government intends to store nuclear waste although the site is blatantly unsafe. 


\section{4}

Greenpeace discovers in February that toxic waste has been exported to the Philippines. In March, activists secure German toxic waste in Albania and later ship it back to Germany in trucks. Member states of the Basel Convention agree in March to ban all toxic waste exports from OECD countries to eastern Europe or the Third World. This is a great success for Greenpeace's international toxic trade campaign, which has been waged for five years. At its meeting in Mexico in May, the International Whaling Commission resolves to set up a whale sanctuary in Antarctic waters. In June, Greenpeace and the city forestry office in Lubeck in Germany present a joint plan for viable natural forest management. An oil disaster occurs in September near Usinsk in the Komi region of northern Russia. Greenpeace investigates on site and discovers further pipeline leaks. The MV Greenpeace tours the Amazon region to document and draw attention to destructive logging practices in the Brazilian rainforest and toxic discharges into rivers. Greenpeace's bus equipped to monitor air pollution measures smog concentrations in Mexico City, putting the city's high atmospheric contamination on the front page of Mexican newspapers. The German Institute for Economic Research, the DIW, publishes a study commissioned by Greenpeace substantiating the positive effects of an ecological tax reform on jobs and the environment.

\section{5}

On 30 April, Greenpeace activists occupy the Brent Spar oil platform in the northeast Atlantic to prevent its being dumped at sea by the Shell multinational oil corporation. A storm of public indignation forces the oil giant to abandon its dumping plans in June. At the end of June the Ospar conference for the Protection of the Marine Environment of the North-East Atlantic agrees by a majority vote to generally ban the dumping of oil rigs. President Chirac of France in June announces the resumption of nuclear testing in the South Pacific in a series of eight tests. Greenpeace sends ships to the Mururoa atoll test site. Shortly before testing begins in September, the MV Greenpeace and Rainbow Warrior II are impounded by the French navy. In August, Greenpeace activists from Europe and the USA hold up a banner in Beijing's Tiananmen Square reading: "Stop all nuclear testing. Stop nuclear testing in China." All the activists are immediately detained and then expelled from China. In April, Greenpeace blockades the Sellafield reprocessing plant and the Aldermaston nuclear weapons lab in Britain in order to draw attention to the connection between civil and military uses of nuclear energy. From February to April, Greenpeace's Solo pursues the Pacific Pintail, freighter carrying plutonium, on its route between the French port of Cherbourg and Japan. Thirty-five countries refuse the Pintail passage through their waters. Greenpeace introduces the SmILE, a low-consumption car, at the International Automobile Show in Frankfurt in September. The SmILE technology (Small, Intelligent, Light, Efficient) has been developed to put pressure on the automobile industry to manufacture cars that consume considerably less petrol than present models. In November, Greenpeace in Germany introduces Cyrus, a standardised solar system, in launching a campaign for electricity using solar power.

\section{6}

Greenpeace launches an international campaign against genetically modified food. Actions take place in Switzerland, Austria, Germany, Britain, the USA, and elsewhere. German and Czech activists hinder the departure of a freight train from the port of Hamburg in December. The train is loaded with genetically modified maize from the USA intended for the Czech Republic. In November, Greenpeace reveals that genetically manipulated soybeans have been shipped to Antwerp and Ghent in Belgium. The MV Greenpeace visits Shanghai in June to protest against Chinese nuclear testing. The United Nations in September agrees on the Comprehensive Test Ban Treaty, a goal Greenpeace has worked to bring about for 25 years. Near Kristiansand, a Norwegian port, Greenpeace hinders the departure of four whaling ships in June. The ships were 
on their way to hunt minke whales. The Sirius encounters ten Danish and one Scottish industrial fishing vessel off Scotland's Wee Bankie in June. Activists place floating barriers around one ship to protest against the overfishing of the seas. In a four-week expedition during the summer, the Arctic Sunrise documents the oil industry's continuous pollution of the North Sea by oil production. Activists from seven countries in August chain themselves to logging machines near the Russian city of Kostamus, protesting against the destruction of ancient forests in order to supply the Finnish company, Enso, with wood for paper production. Enso in October declares a one-year moratorium on logging in Karelian forests. In October, Greenpeace discovers that 36 containers with contaminated plastic waste have been illegally exported from Germany to Lebanon. They are all returned to Germany seven months later.

\section{7}

In January, Greenpeace blockades the European headquarters of Unilever, Nestle and Danone, to prevent them from importing genetically modified food. Greenpeace Germany in March launches the Shopping Net, a consumer campaign against genetically manipulated food. Other Greenpeace. offices follow, launching projects like the True Food Campaign in Britain and the Supermercato virtuale in Italy. In Austria, 1.2 million people vote against GM organisms in April in the most successful non-party petition for a referendum in the country to date. Greenpeace steps up its activities against nuclear shipments in Germany Large-scale protests require the German government to deploy a huge police force to enable a "Castor" flask of spent fuel shipment to be made to the Gorleben. interim storage site in February. Greenpeace conducts a successful campaign against the transport of radioactive waste from Taiwan to North Korea. During the summer, Greenpeace occupies the island of Rockall and the Stena Dee BP oil rig in the northeastern Atlantic to protest against the planned exploitation of new oil fields. The action's slogan is "No New Oil. Stop Climate Change!" Thirty-eight industrial nations adopt the Kyoto Protocol to protect the climate. Greenpeace and other environmental organisations criticise the protocol's low carbon dioxide reduction goals as being insufficient. Greenpeace discovers rusted drums of dioxin left by the chemical company, Union Carbide, near the grounds of the Sydney Olympic Games to be held in 2000. Greenpeace develops guidelines for the Olympics to be carried out ecologically. Greenpeace is active in India, Indonesia and the Philippines against imports of toxic waste from industrial nations. It is successful in getting a freighter loaded with computer scrap sent back to Australia from Hong Kong in April. Greenpeace conducts a campaign against toxic discharges into the Mediterranean and carries out supporting actions in Greece, Turkey, Italy, Spain and Israel.. In Lebanon, activists in an inflatable sample the main sources of industrial pollution along the whole coast in October. Test results name all the firms. A campaign against soft-PVC toys at the end of the year meets with success in several European countries, toys made with this toxic softener are removed from the market. To encourage the ecological development of local economies, Greenpeace supports indigenous groups in Papua New Guinea and the Solomon Islands who are resisting the clearcutting of their ancient forests.

\section{8}

The Ospar conference to protect the North Sea and the north Atlantic, held in Lisbon in July, agrees to place a compulsory ban on dumping obsolete oil and natural-gas rigs at sea and to reduce discharges of radioactive and highly toxic substances from land-based sources. Greenpeace in October documents how basic labour and environmental protection standards are disregarded when European ocean-going ships contaminated with toxins are scrapped in India. Together with consumers' and doctors' organisations, Greenpeace in Germany protests against the cultivation of genetically manipulated plants. In September, activists harvest fields in France and Germany where Novartis GM maize has been planted. The activists tip out the crops in front of Novartis' hazardous waste incinerator in Basel. Greenpeace activists in April hinder freighters from Canada in docking at ports in Britain, the Netherlands and Germany. The ships are loaded 
with old-growth wood pulp. Activists in Long Beach, California, in October chain themselves to a freighter's loading crane and succeed in stopping the ship's entry into port for several days. Greenpeace cooperates with local environmentalists in Ecuador to reforest mangrove forests destroyed by illegal clearcutting. By the end of 2000 the Ecuadorian government will ban logging mangroves for shrimp farms. In June, the European Union votes for driftnet fishing in European waters to be banned as of 2002 .

\section{9}

The Arctic Sunrise sails to the Southern Ocean early in the year to draw attention to overfishing in Antarctic waters. A Greenpeace campaign in Norway against whaling succeeds in making it a public issue early in the summer. Leading European supermarket chains declare in March that they will no longer permit the use of basic foodstuffs which have been genetically modified in their own brand products. In July, activists harvest a field of GM maize in Lyng in England, and are arrested. They are however acquitted before court in September a year later. Greenpeace supports projects to introduce more protective methods for harvesting rubber in the Amazon region. The organisation exposes illegal trade in lumber and contributes to the introduction of more effective penalties for environmental crimes in Brazil. In Bhopal, India, where 16,000 people died in 1984 after a large chemical accident occurred at the US-owned Union Carbide plant, Greenpeace supports survivors calling for the plant grounds to be cleaned up. Japan. experiences its worst nuclear accident early in October. Greenpeace publishes data on radiation measured near the Tokaimura fuel rod factory.

\section{0}

Ninety activists in February brick up the entrances to the European Patent Office in Munich. Greenpeace discovered shortly before this action that the office had issued a patent on the breeding of human embryos. Greenpeace repeatedly stops freighters carrying genetically modified soybeans from the USA, for example in actions off the coast of Anglesey in Wales in February, and in Bordeaux in France in December. Following a Greenpeace campaign that lasted several years, plans to construct the world's largest salt production facility in the Baja California biosphere reservation in Mexico are finally laid to rest in March. Following years of campaigning and dozens of actions by Greenpeace and local environmentalist groups, the Turkish government in July decides not to build its first nuclear power plant, planned to be at Akkuyu on the Mediterranean coast. Starting in February, Greenpeace actions protest against the construction of BP's North Star oil production project in the Beaufort Sea off the northern coast of Alaska. Saying that Russia is drowning in oil - while multinational oil corporations are watching it happen, Greenpeace conducts activities against TotalFinaElf and other Western oil corporations, pressuring them to take responsibility for disastrous oil pollution in Siberia. After an accident in the English Channel involving a tanker carrying chemicals, the levoli Sun, Greenpeace demands that the European Union at last introduce stricter guidelines and inspection regulations for the shipment of hazardous goods at sea. Early in the year, the Rainbow Warrior goes on its "ToxicFree Asia" tour to several several countries, including India, Thailand and the Philippines. The Arctic Sunrise begins a five-month tour of South America to raise awareness of water contamination by persistent toxic pollutants. The crew directs protest actions against industrial effluent discharges in Santiago, Buenos Aires and other cities. Late in the summer, the Rainbow Warrior tours the Mediterranean to draw public attention to toxin discharges and their consequences, such as the contamination of Israel's Kishon River and tributyl tin pollution in Greek ports.

\section{1}

Greenpeace goes into action against companies whose activities in poorer countries far from comply with European environmental standards. These include Bayer's waste incineration in 
Brazil and the waste disposal practices of a Unilever subsidiary in India. Greenpeace in May begins a series of actions against the release of dioxins and other persistent toxins. Activists blockade incineration facilities in Turkey, Lebanon and England. Greenpeace protests against nuclear shipments in France and Germany. In March, Greenpeace Germany protests in several actions against the first nuclear shipment to the Gorleben interim storage site to take place under the Social Democrat/Greens coalition government. These actions are part of a large protest movement. Greenpeace activists from ten countries enter a freighter delivering Canadian oldgrowth lumber to the French port of La Pallice. More actions follow in other European ports. Leading Canadian lumber companies in April promise to stop logging in large parts of the Great Bear rainforest in British Columbia. Greenpeace focuses on opposing Washington's satellitesupported missile defence system. "Stop Star Wars" is the Rainbow Warrior's Motto in May when activists warn of the danger of a new nuclear arms race and protest at the US army's missile test area on the Kwajalein atoll in the north Pacific. In July, activists from different countries enter the Vandenburg test site in California and delay the start of a launch. They are arrested and charges are brought against them.

\section{2}

The EU, Japan, New. Zealand and Canada ratify the Kyoto Protocol on climate change, further isolating USA and Australia who continue to resist the global agreement on cutting greenhouse gases.

Following years of campaigning by Greenpeace and other environmental groups, oil giant BP announces it is dropping plans for the controversial 'Liberty' oil field in Alaska.

Numerous port actions are carried out by three Greenpeace vessels - the Rainbow Warrior, Arctic Sunrise, and Esperanza - to highlight the continued importation of illegal and destructively extracted timber into Europe, America and Asia-Pacific.

Greenpeace helps defeat a major drive by pro-whaling nation Japan and its supporters toreintroduce commercial whaling through the International Whaling Commission. The reintroduction would have been disastrous for whales, which are now protected under the 1982 commercial whaling ban. Despite mounting a vigorous campaign, Japan fails to win any concessions in favor of whaling at the $54^{\text {th }}$ meeting of the International Commission in the whaler's home port of Shimonoseki.

On the final day of Greenpeace's Choose Positive Energy Tour in the Philippines, authorities announce that a proposed 50 megawatt coal-fired power station in Negros will not be built and that renewable energy is the solution to the province's power needs.

The publication of Greenpeace images showing how climate change is melting glaciers in the USA, Peru, New Zealand, Nepal, Austria, Uganda and Norway generates tremendous international interest and media coverage.

The work of world-renowned photographer, Raghu Rai, features in a Greenpeace exhibition which opens in Mumbai, India. 'Exposure' tells the human and environmental tragedy of Bhopal, where tens of thousands were killed and maimed by an explosion at a pesticide plant in December 1984, and where thousands are still suffering.

Using a ship and a light aircraft, Greenpeace tracks a shipment of plutonium mixed oxide from Japan to the UK. This highly dangerous material was being returned by the Japanese government after the UK nuclear energy company involved admitted to falsifying vital safety data.

"Nukes out of Africa!" During the Earth Summit in Johannesburg, six Greenpeace climbers enter the grounds of South Africa's Koeberg nuclear facility and hang banners from the roof of a building in front of the reactor domes.

More than 600 Greenpeace volunteers from 31 countries peacefully blockade every ESSO petrol station in Luxembourg in a protest against the oil giant's continued sabotage of international efforts to protect the climate. 
The Convention of the International Trade in Endangered Species (CITES) votes to protect mahogany.

In the wake of the Prestige oil disaster, Greenpeace activists highlight the threat to our oceans by a series of actions around the Byzantio, a 26-year-old single-hulled oil tanker.

Brazil declares a moratorium on export of Mahogany following revelations of the extent of illegal logging and timber trade. Greenpeace actions around the world help enforce the ban.

The European Union, followed by Japan, ratifies the Kyoto Protocol on climate change. Intensive Greenpeace lobbying must continue because, for the protocol to enter into force, 55 parties to the convention must ratify it.

\section{3}

Extensive Greenpeace actions in European countries keep the pressure on the EU to act against imports of logs illegally extracted from ancient forests.

No War! Greenpeace activists around the world undertake dozens of dramatic and peaceful actions against the build-up to the US-led attack on Iraq. 30 million people worldwide create the largest anti-war protest in the history of humankind.

Embarrassed ExxonMobil executives attempt to explain how, on the eve of their annual general meeting, Greenpeace activists are able to penetrate tight security at their international HQ in Texas, mingle with office staff, and bring the world's most powerful company to a halt! Greenpeace activists in Iraq present US occupying forces with radioactive material collected near Tuwaitha nuclear complex south of Baghdad, and call for de-contamination of villages surrounding the plant.

Palau becomes the 50the country to ratify the Cartagena Protocol on Biosafety - the first legally binding global agreement that reaffirms the right of states to reject GMOs; a defeat for the aggressive US-led campaign to force worldwide acceptance of genetically engineered food and seeds.

The European Parliament adopts the world's most comprehensive rules on the labeling of genetically modified organisms (GMOs); victory for the many organizations - including Greenpeace - who campaigned for this measure.

McDonalds in Denmark bows to pressure and takes a leadership position in opening its first restaurants that use no climate-killing chemicals for refrigeration. A campaign by Greenpeace cyberactivists three years ago had led to a similar decision by Coca Cola to phase out HFC/HCFCs and adopt Greenpeace's innovative "Greenfreeze" technology.

A French court agrees to lift an injunction against Greenpeace for creating a parody version of the Esso logo. In July Greenpeace was ordered to remove the logo from its website. On appeal, the court agreed the depiction on a website branding the oil giant Environmental Enemy Number One was protected speech.

Intense lobbying efforts by Greenpeace and Global Witness results in UN Sanctions on Liberia for illegal logging.

The Deni, indigenous peoples of the Amazon, celebrate the end of an 18-year campaign to mark their land as protected from logging. 13 Greenpeace volunteers, including a member of the cyberactivist community, used GPS technology and a helicopter for a month to create an "ecocorridor" around 3.6 million hectares of land.

Thanks to intensive lobbying by cyberactivists around the world, Greenpeace prevails against and attempt by Flag of Convenience States to remove the organisation from the International Maritime Organisation, the UN body charged with regulating shipping worldwide. Greenpeace action against unsafe oil tankers, such as the Prestige, handed to the ouster attempt on purported "safety" grounds. 
Esso loses its court case against Greenpeace in France. As part of our. "Don't buy Esso, Don't buy Exxon/Mobil" campaign, we developed a parody of Esso's logo with a double dollar sign: E\$\$O, which the oil giant (which trades under the name Exxon/Mobil in other parts of the world) attempted to censor. In a victory for freedom of expression on the web and for our campaign against the world's \#1 environmental criminal, the French court defended the logo as an exercise in free speech. Greenpeace culture jammed the Esso logo at the entrance to a large station near the Germany-Luxembourg border in Wasserbillig.

The Stockholm Convention comes into force following years of lobbying by Greenpeace and other environmental organisations. A key feature of the Convention calls for the elimination of all Persistent Organic Pollutants. They include intentionally produced chemicals, such as pesticides . and PCBs, as well as by-products such as cancer-causing dioxins that are released from industries that use chlorine and from waste incinerators:

Following the controversial UK government approval of genetically engineered (GE) maize for commercial planting, the only company authorized to grow GE maize withdraws its application. In a victory for activists and consumers across Europe who lobbied for tougher legislation and boycotted GE products, Bayer CropScience, a German company authorised to plant an herbicideresistant variety of maize known as Chardon LL, said regulations on how and where the crop could be planted would make it "economically non-viable." Chardon LL was the crop pulled up by Greenpeace UK activists in 1999. The activists were acquitted of charges of criminal damage when the court agreed they were acting in the interest of protecting the environment.

The UN International Maritime Organisation (IMO) designate the Baltic sea as a "Particularly Sensitive Sea Area," a decision which Greenpeace advocated for years. The IMO regulates shipping worldwide, and the new designation means tougher restrictions on oil tankers and other dangerous cargo vessels. The move was vehemently opposed by the shipping and oil industries. Thanks to years of pressure from environmental groups, the consumers, our cyberactivists and Greenpeace, we can celebrate a victory for the environment following the announcement by Monsanto that it would suspend further development or open field trials of its genetically engineered, Roundup Ready wheat. Monsanto stated that it was deferring all further efforts to introduce the crop and that it was discontinuing breeding and field-level research of the wheat. This follows a similar announcement in 2003 when the company announced its withdrawal from the development of pharmaceutical crops.

Iceland steps back from plans to kill 500 minke, sei, and fin whales over two years, announcing a quota of only 25 minkes for the year. Greenpeace web activists fueled domestic opposition by gathering 50,000 worldwide signatures to a pledge to visit Iceland if the government would stop whaling. With a potential value of more than US\$ 60 million in tourist spend, against a whaling programme which generated 3-4million in profits, the pledge dramatically illustrated that whales are worth more to Iceland alive than dead.

Publishers of 34 Canadian magazines pledged to shift away from paper containing tree fibre from Canada's ancient forests thanks to ongoing pressure from the Markets Initiative coalition, of which Greenpeace Canada has a key role. The coalition has similar commitments from 71 Canadian book publishers including the Canadian publisher of Harry Potter, which printed the Order of the Phoenix on AFF paper in June2003. Greenpeace Canada's work to protect its forests also encouraged Cascades, as the second largest producer of tissue products in Canada to commit to an Ancient Forest-Friendly purchasing policy.

Consumer power scored a victory following the announcement from electronics giant Samsung that it plans to phase out hazardous chemicals in its products. Seeing its brand-name products graded red -as containing hazardous chemicals - on the Greenpeace database, prompted the company to do the right thing on dangerous chemicals.

Unilever, Coca Cola and McDonalds promise to phase out climate-killing chemicals in their refrigeration equipment. In 1992 Greenpeace launched Greenfreeze with the help of two scientists 
who pointed out how to avoid HFC's altogether. We found an old fridge factory, appealed to our supporters to pre-order enough units to finance a refit, helped build the market and Greenfreeze was born. Today there are over 100 million Greenfreeze refrigerators in the world, produced by all the major European, Chinese, Japanese and Indian manufacturers.

Samsung announces phase out of hazardous chemicals.

Queensland Energy Resources announce an end to the Stuart Shale Oil Project in Australia.

Greenpeace campaigned against the project, which would have produced oil with four times the greenhouse impact as oil from the ground, since 1998. The project cost millions of dollars in government subsidies which should have been spent on renewable energy.

Ford Europe announce a reversal of the decision to scrap its fleet of fuel efficient electric Th!nK City cars, and instead investigate sending them to eager customers in Norway. Pressure applied by Greenpeace and web-based cyberactivists convinced Ford to Th!nk Again. When charged by electricity from renewable sources, these cars help fight the biggest threat to our planet: climate change.

Cyberactivists in Japan halt introduction of recycling-unfriendly and unreturnable plastic bottles when beer manufacture Asahi bows to citizen pressure.

A decade of lobbying, scientific research, and direct non-violent action by Greenpeace and environmental groups around the world comes to fruition as Russia ratifies the Kyoto Protocol, bringing to force the world's sole global effort to address the dangers of global warming.

Greenpeace efforts to achieve tighter controls on the notorious ship breaking industry result in an international agreement to treat obsolete ships as waste. Treaty commitments by 163 nations can be expected to increase demands for decontamination of ships prior to export to the principle ship breaking countries of India, Bangladesh, and Turkey. It will also create new demand for the development of "green" ship recycling capacity in developed countries.

Bayer conceded to Greenpeace India that ALL its projects on genetically engineered (GE) crops have been "discontinued" in a letter sent by Aloke V. Pradhan, head of Bayer's Corporate Communications in India. This announcement followed earlier actions by Greenpeace outside Bayer's head office in Mumbai.

Following years of campaigning in the Amazon by Greenpeace and other environmental organisations the Brazilian government stood up to the powerful forces of illegal loggers and greedy soya and beef barons by creating two massive protective reserves. The presidential decree has protected 2 million hectares of the Amazon forest by creating the Verde Para Sempre and Riozinho do Anfrisio extractive reserves.

\section{5}

Photocopy giant X'erox agrees to stop buying timber pulp from StoraEnso, the Finnish national logging company which is cutting down one of Europe's last remaining ancient forests. Following pressure by Greenpeace cyberactivists, the company agrees a new procurement policy, ensuring that suppliers do not source timber from 'old-growth forests, conservation areas or other areas designated for protection.'

Sony Ericsson announces that it will be phasing toxic chemicals out of its products. This is the result of the thousands of participants in our online action to pressure electronics companies to come clean. Sony Ericsson joins Samsung, Nokia and Sony as electronics companies who are phasing toxic chemicals out of all their products. Electronics giant LG announces that it is committing to eliminating toxic chemicals from their entire consumer 'electronics range. Electronics giant Motorola and health and body care companies L'Occitane, Melvitacosm and Alqvimia are the latest companies to drop the most toxic chemicals from their products.

Bad Barbies, toxic Teletubbies and rotten rubber ducks could have been slowly poisoning small children. The very chemicals that made these toys so soft and tempting to teething toddlers have been shown to damage organs in animals. But the European Parliament has banned manufacturers from using six of these toxic chemicals, freeing Europe from many toxic toys for good. 
The intervention of some home-grown celebrities to finally tips the balance in favour of protecting the forests of northern Argentina after a long fight by Greenpeace and the indigenous Wichi people.

The city of Buenos Aires announces plans to implement a zero waste policy after a campaign by Greenpeace in Argentina. The plan aims to reduce dramatically the 4-5000 tonnes of waste the city dumps every day. Buenos Aires is the largest city so far to announce a zero waste plan. Swiss voters vote no in a referendum to determine whether genetically engineered (GE) crops and animals can be grown in the alpine nation during the next five years. Their verdict in each and every one of the three main languages was the same, nein, non, no, to GE.

\section{6}

In January, our Argentine Ocean Defenders hit Nissui in their pockets. Nissui own about one third of Kyodo Senpaku - the people who run the Japanese whaling fleet. Our cyberactivists convinced a major Nissui client in Argentina not to buy from a corporation involved in the killing of whales. After months of pressure, consumer actions, online activism and more than 100,000 emails from Ocean Defenders everywhere, seafood suppliers Gorton's, Sealord and parent company Nissui withdraw their active support for Japanese whaling. Whalers announce that the 32 percent share in whaling operations owned by these commercial corporations will be transferred to a "public interest entity." The retreat isolates whaling economically and probably scuppers plans to find new markets for whale products.

An area twice the size of Belgium has been given greater protection in the Amazon after a Presidential decree. The decree by President Lula of Brazil to create the 6.4 million hectare (around 16 million acres) conservation area is a great victory for the people of the Amazon battling land grabbers, cattle ranchers and loggers. The decree calls for around 1.6 million hectares to be permanently protected and totally off limits to logging and deforestation. French President Chirac announced the dramatic recall of the asbestos-laden warship Clemenceau - it will be turning around and going back to France. Our actions, emails to Chirac and an embarrassing international scandal left France with little choice but to abandon the misguided attempt to dump its own toxic mess on India.

Take ten years of difficult, dangerous, and at times, heart breaking work. Add thousands of activists from around the world - some who sent emails, some who stood on the blockades, some who voted against destruction with their wallets. Some who were beaten, some who were sued, some who were arrested. But eventually commonsense has prevailed and one of the world's treasures, the Great Bear Rainforest, is saved from destruction.

Thanks to enormous pressure from the 30,000 emails and letters sent to their European headquarters, McDonald's has agreed to stop selling chicken fed on soya grown in newly deforested areas of the Amazon rainforest. By committing to the stop buying soya from Amazon destruction, the companies' massive buying power has created a huge demand for soya that hasn't been grown in the ashes of the rainforest.

Despite heavy lobbying by the nuclear power industry, Spain has confirmed that the country's 8 operating plants will be phased out in favour of clean, renewable energy. Spain joins Sweden, Germany, Italy and Belgium as the fifth European country to abandon nuclear power. Electronics giant Hewlett Packard commits to a phase out plan for a range of hazardous chemicals in its products. Dell becomes the latest company to promise to remove the worst toxic chemicals from its products, closely following the move of its rival HP. Both companies have been pressured by us to make their products greener and help tackle the growing mountain of toxic e-waste. 


\section{APPENDIX C: The Evolution of FoEI Mission Statements}

\section{1}

FoEI's founding mission - to promote...the conservation, restoration and rational use of the natural resources and beauty of the Earth

Source: Burke 1982: 107

\section{4-1985}

Friends of the Earth is rooted in a powerful idea: that the Earth needs friends... Underlying FoEl are several fundamental concepts:

- Commitment to the preservation, restoration and rational use of the environment is FoEl's bonding philosophy. An underlying respect for the Earth's natural wealth and diversity, and a common understanding of the need to sustain its ecological systems, hold together FoE organizations and their actions. Essentially non-ideological, FoE looks continually for new ways to promote the protection of the earth's people and the environment on which they depend.

- Citizen participation is critical in effective international work. FoEI promotes new. ideas for international citizen action, and works to empower and inform citizen organizations on a wide range of environmental issues. Decentralization, democratic values, and effective control of changes by those most directly affected by them, must accompany work to create change.

- Environmental problems cannot be approached in isolation from social, economic and cultural factors that influence them. Poverty and environmental degradation often go hand in hand. Inequality and militarism have a direct impact on the human and financial resources allocated to environmental issues. Land reform may be the key change necessary to protect valuable tropical forests from intrusion by marginal farmers.

- Through cooperation with other organizations, FoE works to build networks of people approaching the same problem from differing perspectives. In addition to FoE National groups, we are linked directly or indirectly with dozens of other environmental, consumer, human rights and peace organizations worldwide.

- FoEI stresses the importance of positive alternatives in approaching environmental degradation. For example, FoE promotes "soft energy paths" while attacking nuclear energy, and sustainable agricultural systems.

Source: FoEI (1984-1985) Annual Report, FoEI, Amsterdam, The Netherlands, p.5.

\section{2}

Mission Statement:

Friends of the Earth International is a worldwide federation of national environmental organizations. This federation aims to:

- Protect the earth against further deterioration and restore damage inflicted upon the environment by human activities and negligence;

- Preserve the earth's ecological, cultural and ethnic diversity; 
- Increase public participation and democratic decision-making. Greater democracy is both an end in itself and is vital to the protection of the environment and the sound management of natural resources;

- Achieve social, economic and political justice and equal access to resources and opportunities for men and women on the local, national, regional and international levels;

- Promote environmentally sustainable development on local, national, regional and global levels.

Friends of the Earth International has a democratic structure with autonomous national groups which comply with the guidelines established by the federation.

Friends of the Earth member groups are united by a common conviction that these aims require both strong grassroots activism and effective national and international campaigning and coordination. They see Friends of the Earth International as a unique and diverse forum to pursue international initiatives, taking advantage of the variety of backgrounds and perspectives of its members.

By sharing information, knowledge, skills and resources on both a bilateral and multilateral level, Friends of the Earth groups support each other's development and strengthen their international campaigns.

Source: FoEI (1992) Annual Report, FoEI, Amsterdam, The Netherlands, p.5.

\section{2}

Friends of the Earth International is a global federation of national environmental organizations that aims to:

- Protect the earth against further deterioration and repair damage inflicted upon the environment by human activities and negligence

- Preserve the earth's ecological, cultural and ethnic diversity;

- Increase public participation and democratic decision-making, both of which are vital to the protection of the environment and the sound management of natural resources;

- Achieve social, economic and political justice and equal access to resources and opportunities for men and women on the local, national, regional and international levels;

- Promote environmentally sustainable development on the local, national, regional and global levels.

Friends of the Earth has a democratic structure with autonomous national groups which comply with the guidelines established by the federation.

Friends of the Earth member groups are united by a common conviction that these aims require both strong grassroots activism and effective national and international campaigning and coordination. They see Friends of the Earth International as a unique and diverse forum in which to pursue international initiatives, taking advantage of the varied backgrounds and perspectives of the members.

By sharing information, knowledge, skills, and resources both bilaterally and multilaterally, Friends of the Earth groups support each other's development and strengthen their international campaigns.

Source: FoEI (2002) Annual Report, FoEI, Amsterdam, The Netherlands, p.2. 
2003

Friends of the Earth International is a global federation of national environmental organizations that aims to:

- Protect the earth against further deterioration and repair damage inflicted upon the environment by human activities and negligence

- Preserve the earth's ecological, cultural and ethnic diversity;

- Increase public participation and democratic decision-making, both of which are vital to the protection of the environment and the sound management of natural resources;

- Achieve social, economic and political justice and equal access to resources and opportunities for men and women on the local, national, regional and international levels;

- Promote environmentally sustainable development on the local, national, regional and global levels.

Friends of the Earth International is the world's largest grassroots environmental network, uniting 71 diverse national member groups and some 5,000 local activist groups on every continent. With approximately 1.5 million members and supporters around the world, we campaign on today's most urgent environmental and social issues. We challenge the current model of economic and corporate globalization, and promote solutions that will help to create environmentally sustainable and socially just societies. Our decentralized and democratic structure allows all member groups to participate in decision-making. Our international positions are informed and strengthened by our work with communities, and our alliances with indigenous peoples, farmers' movements, trade unions, human rights groups and others.

Source: FoEI (2003) Annual Report, FoĖI, Amsterdam, The Netherlands, p.2.

\section{5}

\section{Core Values}

- Ecological and cultural diversity

- Peoples' sovereignty, human and peoples' rights

- Equity and environmental, social, economic and gender justice;

- The intrinsic value of nature and the inextricable link between nature and people;

- Participatory democracy and other forms of participatory decision-making processes;

- Solidarity, responsibility and human dignity

\section{Vision of the World}

Our vision is of a peaceful and sustainable world based on societies living in harmony with nature. We envision a society of interdependent people living in dignity, wholeness and fulfilment in which equity and human and peoples' rights are realized.

This will be a society built upon peoples' sovereignty and participation. It will be founded on social, economic, gender and environmental justice and free from all forms of domination and exploitation, such as neoliberalism, corporate globalization, neocolonialism and militarism.

\section{Vision of the Network}

Friends of the Earth International is a worldwide grassroots environmental network campaigning for an ecologically sustainable, just and peaceful world. We are a vibrant, 
credible, effective federation, driving social transformation and securing sustainable, gender just and equitable societies.

Our strength comes from our solidarity, passion and shared beliefs. We respect each other and value our diversity. We inspire and bring about change by living according to our values, and we learn from our experiences. In turn, we are inspired by successful campaigns and strengthened by the friendships and alliances we forge.

We believe that our children's future will be better because of what we do.

\section{Mission}

1. To collectively ensure environmental and social justice, human dignity, and respect for human rights and peoples' rights so as to secure sustainable societies.

2. To halt and reverse environmental degradation and depletion of natural resources, nurture the earth's ecological and cultural diversity, and secure sustainable livelihoods.

3. To secure the empowerment of indigenous peoples, local communities, women, groups and individuals, and to ensure public participation in decision making.

4. To bring about transformation towards sustainability and equity between and within societies with creative approaches and solutions.

5. To engage in vibrant campaigns, raise awareness, mobilize people and build alliances with diverse movements, linking grassroots, national and global struggles.

6. To inspire one another and to harness, strengthen and complement each other's capacities, living the change we wish to see and working together in solidarity.

Source: FoEI (2005) Outcomes of the Penang Visioning Workshop, FoEI, Amsterdam, The Netherlands, October; FoEI (2005) Annual Report, FoEI, Amsterdam, The Netherlands 


\section{APPENDIX D: FoEI and Greenpeace Empirical Data}

\section{FoEI and Greenpeace Interviews Conducted for this Dissertation}

\begin{tabular}{|l|l|}
\hline \multicolumn{2}{|c|}{ Friends of the Earth International } \\
\hline Mike Childs & Head of Campaigns, FoE England, Wales and Northern Ireland (EWNI) \\
\hline Ann Doherty & Communications Coordinator, FoEI \\
\hline Kevin Dunion & FoEI Chair (1996-2003), Executive Director, FoE Scotland (1991-1996) \\
\hline John Hontelez & FoEI Chair (1986-1996) \\
\hline Tony Juniper & FoEI Vice-Chair (2000-present); Executive Director, FoE EWNI \\
\hline Daniel Mittler & FoE Germany 1996-2004; Greenpeace International 2004 - present \\
\hline Mae Ocampo & International Membership Development Coordinator \\
\hline Beatrice Olivastri & Co-founder and CEO, FoE Canada \\
\hline Meena Raman & FoEI Chair (2004- present), Sahabat Alam Malaysia (FoE Malaysia) \\
\hline Marijke Torfs & FoEI International Coordinator (1998 - present) \\
\hline \multicolumn{2}{|l|}{ Greenpeace } \\
\hline Gerd Leipold & Executive Director, Greenpeace International \\
\hline Brian Fitzgerald & New Media Director, Greenpeace International \\
\hline Marcelo Furtado & Campaigner, Greenpeace Brazil \\
\hline Josselien Janssens & Campaign Direction Officer, Greenpeace International \\
\hline Michael M'Gonigle & Greenpeace campaigner (1976-1982) \\
\hline T. Mohan & Board, Greenpeace India \\
\hline Rémi Parmentier & $\begin{array}{l}\text { Co-founder of Greenpeace France (1974), Greenpeace campaigner } \\
\text { including Political Director, Greenpeace International (1974- 2005) }\end{array}$ \\
\hline Steve Sawyer & $\begin{array}{l}\text { Climate and Energy Policy Advisor, Greenpeace International; Past } \\
\text { Executive Director of Greenpeace USA (1986-88); Past Executive } \\
\text { Director of Greenpeace International (1988-1993) }\end{array}$ \\
\hline Jenny Stannard & $\begin{array}{l}\text { Manager, Greenpeace Governance and Board Relations, Greenpeace } \\
\text { International }\end{array}$ \\
\hline Guido Verbist & $\begin{array}{l}\text { Actions Coordinator, Greenpeace International } \\
\text { Group of Ecologists, Journalists and Visionaries Changed the World } \\
\text { (2004) }\end{array}$ \\
\hline Rex Weyler & \\
\hline
\end{tabular}

\section{Friends of the Earth International - Empirical Data}

Burke, Tom (1981) A History of Friends of the Earth. FoEI historical archive, Amsterdam, The Netherlands, February.

Executive Committee (2004) Making FoEI Strategy Focused: Strategic Planning for Friends of the Earth International. FoEI, Amsterdam, The Netherlands

Executive Committee (1994) Discussion Paper about the Need for an International Agenda for FoEI. FoEI, Amsterdam, The Netherlands, 10 August.

Executive Committee (1988) Annual General Meeting paper about the future of Friends of the Earth International. Amsterdam, The Netherlands, $25^{\text {th }}$ August

FoEI (2005) Outcomes of the Penang Visioning Workshop, FoEI, Amsterdam, The Netherlands, October

FoEI (2004) Our Environment, Our Rights: standing up for people and the planet. FoEI, Amsterdam, The Netherlands.

FoEI (2001) Sparks of Hope, Fires of Resistance: FoEI Celebrates the Sustainable Path Forward: $30^{\text {th }}$ Anniversary Publication. FoEI, Amsterdam, The Netherlands.

FoEI (2000) Friends of the Earth International Handbook, FoEI, Amsterdam, The Netherlands. 
FoEI (1997) Rules of Engagement with TNCs. in FoEI Handbook, May 2000, FoEI, Amsterdam,

The Netherlands.

FoEI (1996) Friends of the Earth: 26 Years for the Planet, for People. FoEI, Amsterdam, The Netherlands.

FoEI (1992/1993) LINK. FoEI, Amsterdam, The Netherlands, December - January, Issue 52, p.17

FoE (1992) Friends of the Earth 1971-1992: 21 Years of Friends of the Earth. Friends of the Earth Ltd. London, UK.

FoEI (1991) Friends of the Earth International. Brochure, FoEI historical archive, Amsterdam, The Netherlands.

FoEI (1991) International Activity Report. FoEI, Amsterdam, The Netherlands

Innis, Stuart (1993) "Friends of the Earth: Earth Gets a New Friend" Senior Thesis. FoEI historical archives, Amsterdam, The Netherlands.

MacArthur, Mairi (1989) The Growth of FoEI: A Personal View. July. FoEI historical archives, Amsterdam, The Netherlands.

MacArthur, Mairi (1991) Mairi MacArthur takes a personal look back at her memories of FoE International as the network enters its third decade. FoEI historical archive, Amsterdam, The Netherlands.

MacArthur, Mairi (1993) Location of FoEI Annual Meetings, Location of Secretariat. FoEI historical archives, Amsterdam, The Netherlands.

Samuel, Pierre (1992) Remembrance of Things Past. In FoEI LINK: $25^{\text {th }}$ Anniversary Special. July/August. Issue 73, p.8.

Turner, Tom (1986) Friends of the Earth: The First Sixteen Years. San Francisco, USA, Earth Island Institute.

Friends of the Earth quarterly publication LINK: $1985-2001$

Friends of the Earth International Annual Reports: 1984/1985, 1992, 1993, 1994, 1995, 1996, 1997, 1998, 1999, 2000, 2001, 2002, 2003, 2004, and 2005

\section{Greenpeace - Empirical Data}

Bode, T. and Upsall, D. (2000) The Role of Greenpeace in Society. In Greenpeace International Organizational Development Plan.

Bode, T. (1999) A Perspective on Technological Innovations. Discussion paper submitted to the Executive Directors of Greenpeace, August.

Bode, T. (1999) Greenpeace Global Presence. Submitted to Executive Directors Meeting of Sept/October of 1999 by Greenpeace International for discussion.

Bode, T. (1998) "Driving Technology towards Sustainable Development" published in Time Magazine, 23 March.

Bode, T. (1998) "People of the World Practicing Moves to Democracy" in Frankfurter Allgemeine Zeitung. $31^{\text {st }}$ December.

Bode, T. (1998) International Executive Director's Report to the Board, 1998: Review of 19951998 and the Challenges Ahead. Greenpeace International, Amsterdam, The Netherlands.

Bode, T. (1996) Thoughts on the Role of Greenpeace International in the World. discussion paper submitted to the February 1996 Executive Director's Meeting.

Bode, T. (1997) Greenpeace International Long Term Strategic Plan. Greenpeace International, Amsterdam, The Netherlands, September.

Bode, T. (1995) The Future of Greenpeace. Internal strategy document. Greenpeace International, Amsterdam, The Netherlands

Bode, T. (1995) Confrontation and Solutions. Discussion Paper for the Solutions Conference, Dublin, June. 
Bode, T. (1995) Greenpeace and International Conferences. Discussion paper, Greenpeace International, Amsterdam, The Netherlands, May.

Durrant, C. (1999) One Greenpeace. Discussion paper submitted to the Board and the 1999 Stichting Greenpeace Council Annual General Meeting.

Greenpeace (2004) Board Manual. Greenpeace International, Amsterdam, The Netherlands, Greenpeace (1998) Summary of Mature Offices' Meeting, March 16 and 17, Greenpeace, Amsterdam, The Netherlands.

Greenpeace (1998) "Prioritizing the Core Functions of Greenpeace International" extracted from . the 1998 Long Term Strategic Plan as agreed at the March 1998 Executive Directors Meeting and submitted by the Strategic Management Team to the Stichting Greenpeace Council Annual General Meeting and agreed by Council.

Greenpeace (1996) Twenty-five Years as a Catalyst for Change. Greenpeace International, Amsterdam, The Netherlands.

Greenpeace International (2000) Extract from Approved International Policies, Guidelines and Procedures. Compiled from formal Board, Council, and Executive Director Meeting Agreements from 1979 to the present.

Haerlin, B. (1995) The Seven No-No's of Industry Cooperation. Discussion document submitted to the Greenpeace Solutions Conference, Dublin, June.

Hinck, J. (1996) Effective Campaigning, An internal discussion document distributed at the Executive Directors Meeting, 18 October.

Lawrence, E., C. Rose, K. Rigg (1999) Some thoughts on what has come to be called 'Blue Skies' submitted to the 1999 Executive Directors Meeting as a discussion document, 29 July.

Lawrence, E. (1997) Comparison of International Strategic Plans of 1987, 1993, 1994 and 1997. Research paper by Elaine Lawrence. Annex 2 of the 1997 Long Term Strategic Plan, Greenpeace International, Amsterdam, The Netherlands.

Lawrence, E. (1995) Extract from the Evaluation of Actions at Moruroa. Greenpeace International, Amsterdam, The Netherlands.

LeCoyte, R. (1998) Greenpeace Campaign Guide. Greenpeace UK, London.

Leipold, G. (2000) "Campaigning: a fashion or the best way to change the global agenda? In Development in Practice. Vol. 10, No. 3 \&4, August.

Leipold, G. and Eleanor O'Hanlon (Gem Partners Ltd) (1998) Quality in Campaigning: A Study for Greenpeace, Phase I: Standard Quality Systems and Other Organizations. Greenpeace International and Gem Partners Ltd, October.

McTaggart, David (1992) Letter to the organization from David McTaggart, Greenpeace International Honorary Chair, $18^{\text {th }}$ August

Mulvaney, K. (1996) in Greenpeace Witness: Twenty-Five Years on the Environmental Frontline. London, UK: André Deutsch Limited, p. 33.

Ostertag, B. "Greenpeace Takes over the World" in Mother Jones. March / April 1991.

Rose, C. (1999) Mature Offices or Campaign Environments and the Case to Change Campaigning - Some Factors Relevant to the 1999 Program. Greenpeace UK.

Sawyer, S. (1994) Organizational Objectives for Greenpeace. Submitted to the Stichting Greenpeace Council Board, July

Sawyer, Steve (1991) Saving the World the Greenpeace Way. Introduction to the International Executive Director's Report to the 1991 Stichting Greenpeace Council Annual General Meeting

Stichting Greenpeace Council Meeting Minutes: 2000, 2001, 2002

Greenpeace Annual Reports: 1990, 1991, 1992, 1993, 1994, 1995, 1996, 1997, 1998, 1999 , 2000, 2001, 2002, 2003, 2004, 2005 


\section{APPENDIX E: List of Dissertation Related Publications and Presentations}

\section{Publications:}

Vanessa Timmer (forthcoming) "Agility and Resilience: Designing for Adaptive Capacity in Friends of the Earth International and Greenpeace" - book chapter in F. Bièrrmann, A. Schreyögg, and B. Siebenhüner (eds.) International Organizations and Global Environmental Governance.

L. David Brown and Vanessa Timmer (2006) Civil Society Actors as Catalysts for Transnational Social Learning. Voluntas: International Journal of Voluntary and Nonprofit Organizations, March.

Vanessa Timmer (2003) "Protest, Propose, Partner: The Diverse Roles of Non-governmental Organizations in Addressing Global Environmental Change" in International Human Dimensions Program Conference Proceedings. IHDP.

Vanessa Timmer (2002) "Dynamic Social Change Agents: A Systems Thinking Approach to Assessing the Effectiveness of the Strategies of Non-governmental Organizations in Advancing Sustainability" in World Forum on Sustainable Development 2002: Economy, Environment and Society Conference Proceedings. The International Research Foundation for Development, World Summit on Sustainable Development, Johannesburg, South Africa.

\section{Presentations:}

2 December 2005: Presentation on "Greenpeace be Nimble, Friends of the Earth be Quick: The Influence of Agility in the Organizational Effectiveness of International Nongovernmental Organizations" at the 2005 Berlin Conference on the Human Dimensions of Global Environmental Change "International Organizations and Global Environmental Governance," Potsdam, Germany.

12 July 2004: Presentation on "Organizational Form as a Strategic Choice: A Case Study Comparison of Greenpeace International and Friends of the Earth International" at The $6^{\text {th }}$ International Conference of the International Society for Third Sector Research "Contesting Citizenship and Civil Society in a Divided World," Ryerson University, Toronto, ON, Canada. 